\title{
SATURATED POOL AND FLOW BOILING STUDIES WITH FREON-113 AND WATER AT ATMOSPHERIC PRESSURE
}

R H. Chapman
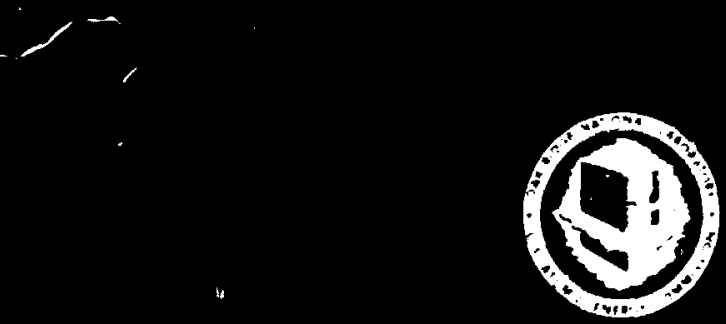

OAK RIDGE NATIONAL LABORATORY

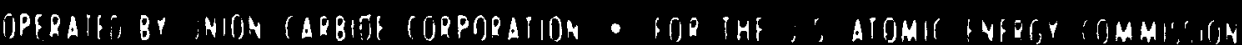
$\int$. 

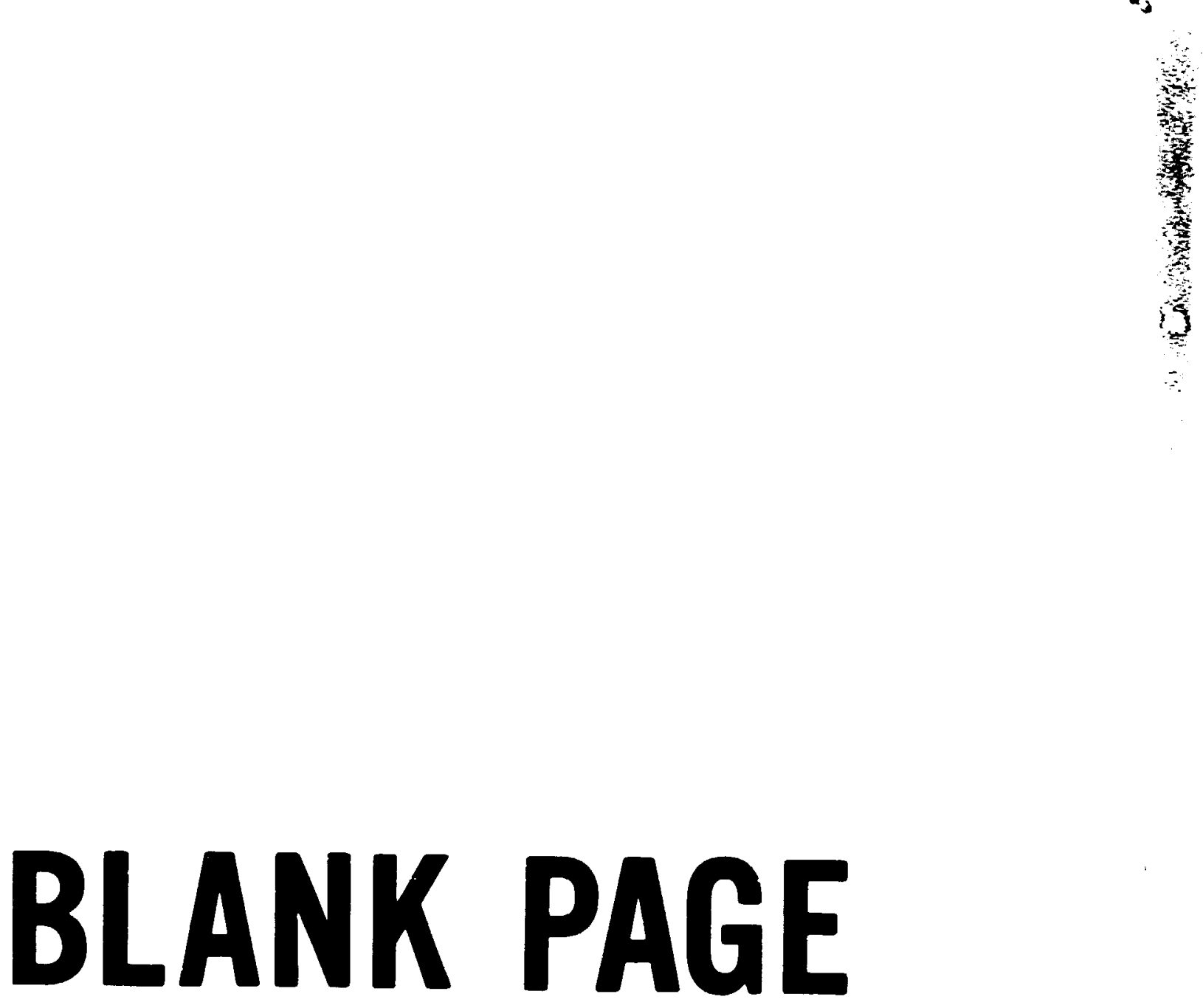
Printer - ine United Stutes of America. Availate from Alationa Tectrics information Service

US Deoriment of C smmerce

5285 Port Royal Rad. Siringfield. Virgenia 22151

Price Printed Cocy \$7.60. Microfiche \$1.45

Thrs report nos prepared as an account ef nurix sponsored by the United States Governireal. Neither the United States nor the United States Atomic Energy Commiss:on. not any of their employen. nor any of their contractors. subcontractors, or the:r molo, ses. makes any waeranly. express or implied, or axs:imes any teol tiability or responsibility for the acciuracy. completeness or icefisiness of any information. apparatus, preduct or process disclosed. or represents that its use woibld not inf:irge privately mared rigits 


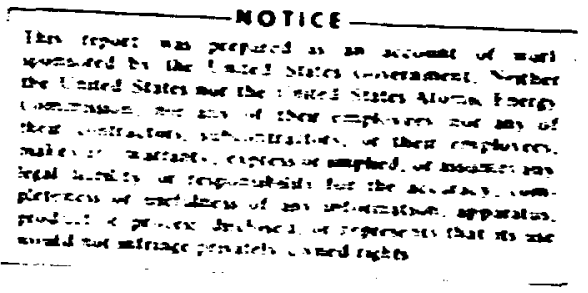

\author{
ORTI-498? \\ V-38 - Engineering ard Equipment
}

Contra.t \$o. 1 -7 $1+05$-eng-26

Peactor Divisicn

SATUEATED PSOL AWD FLOW BOILING STUEIES WITH FREON-113

AWD YATER AT ATMOSPHERIC PRESSURE

R. H. Chaparan

NOVEMBER 1974

Submitted as a dissertation to the Graduate Council of The University of Tennessee in partial fulfillient of the requirements for the degree Doctor of Philosophy.

OAK RIDGE NATIOHAL LABOPATOPY

Oak Ríage, Tennessee 37830

operated by

UHION CARBIDE COPPORATIOH

for the

IJ.S. ATOMIC ENERGY COMUSSIOI 
Page

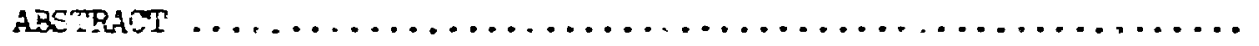

v

LST CF SMMECLS $\ldots \ldots \ldots \ldots \ldots \ldots \ldots \ldots \ldots \ldots \ldots \ldots \ldots \ldots \ldots \ldots \ldots \ldots \ldots$ vii

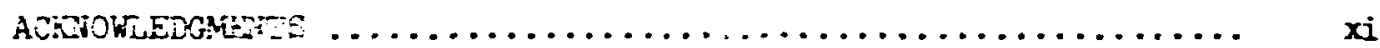

I. IUTROSj Ior $\ldots \ldots \ldots \ldots \ldots \ldots \ldots \ldots \ldots \ldots \ldots \ldots \ldots \ldots \ldots \ldots$

II. LITERATE E R.VEW . . . . . . . . . . . . . . . . . . .

Introduc ion $\ldots \ldots \ldots \ldots \ldots \ldots \ldots \ldots \ldots \ldots \ldots \ldots \ldots \ldots \ldots$

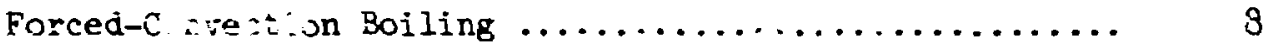

Dengle ard didacms $\ldots \ldots \ldots \ldots \ldots \ldots \ldots \ldots \ldots \ldots \ldots$

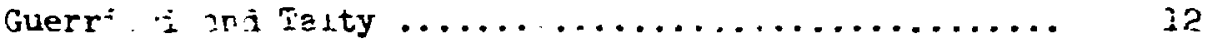

Schrock, consmail, et $21 . \ldots \ldots \ldots \ldots \ldots \ldots \ldots \ldots \ldots . \ldots \ldots$

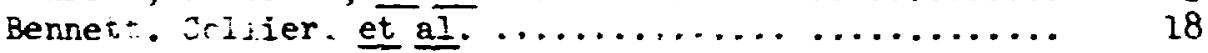

Chen .. . . . . . . . . . . . . . . . . . . . . .

Huehrert. ............................ 29

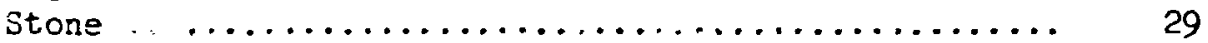

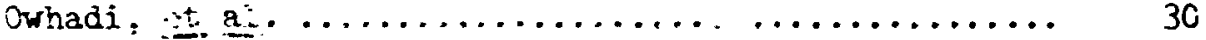

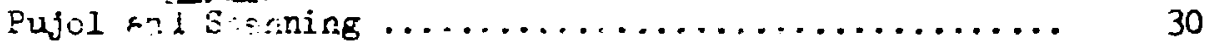

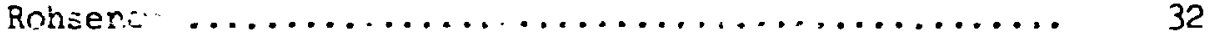

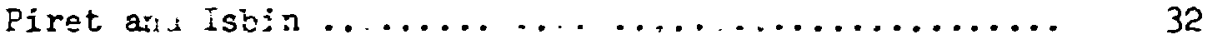

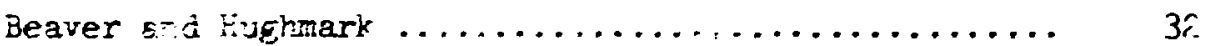

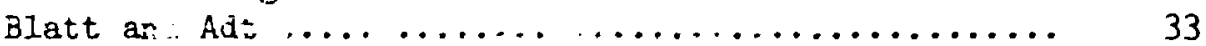

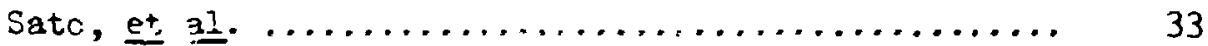

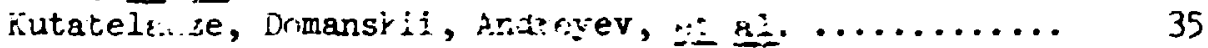

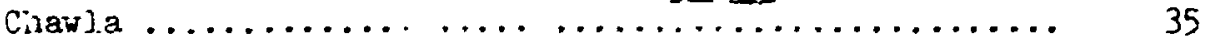

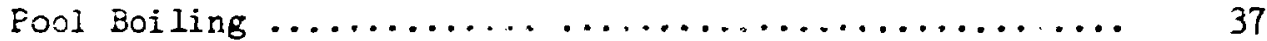

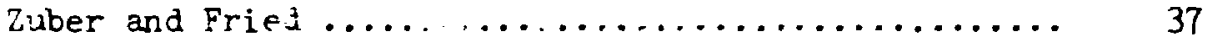

iishikawa and Yamagat:. ................... 38

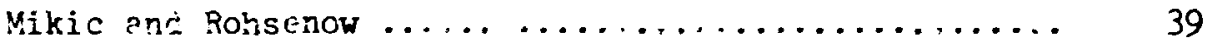

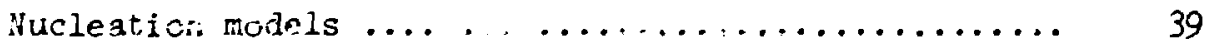

reat trensport models ..................... 40

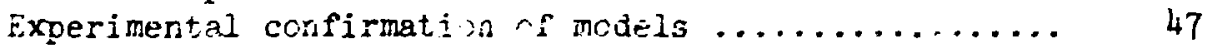

II. EXPERIMENTAL PROTRAM ...................... 53

IV. EQUIPMENT ANI PRDCEDURES ..................... 59

Flow Test Facility ........................ 59

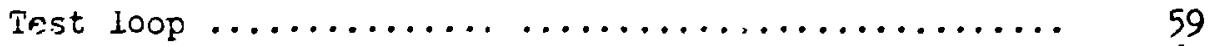

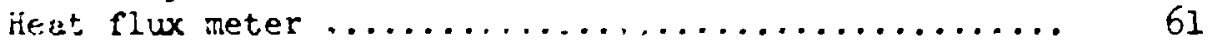

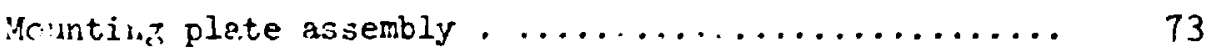

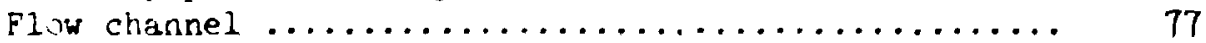

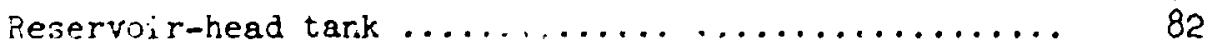

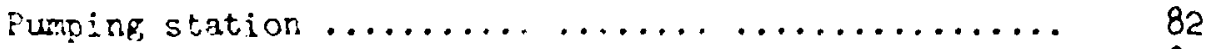

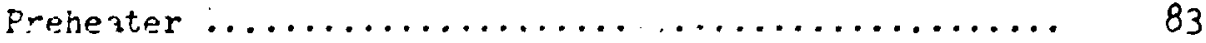

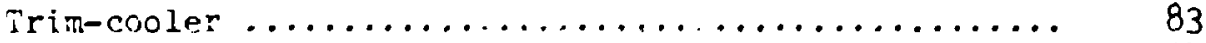

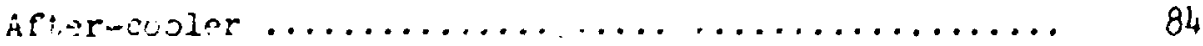




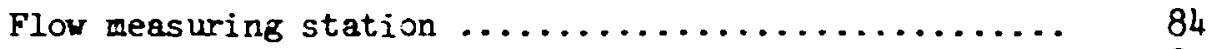

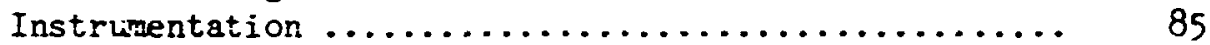

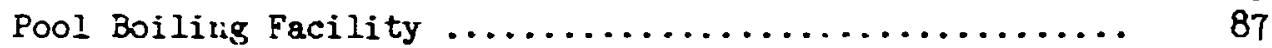

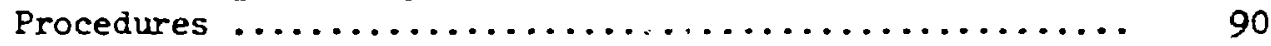

Flow tests ....................................... 90

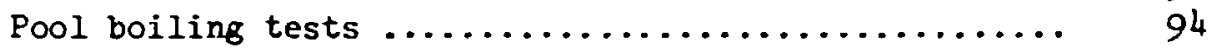

Boiling surface preparation ................... 95

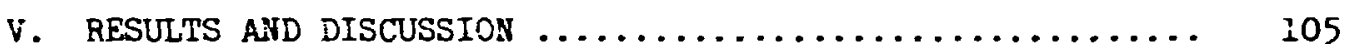

heat Flux Meter Thermal Performance .............. 105

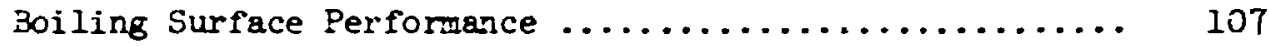

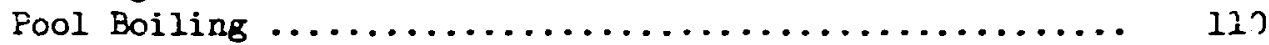

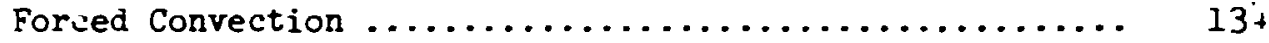

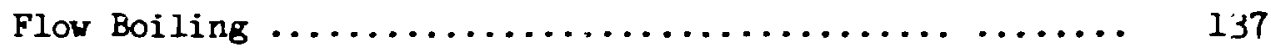

VI. SUMMARY, CONCEUSIONS, AND RECOMENDATIONS .......... 163

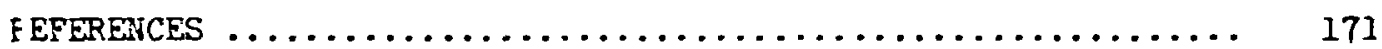

APPEIIIX A. CALIBRATIGI DATA ................... 283

A-1. Current Meesuring Shunts ............. 183

A-z. Calibration of 'iurb ine Flowmeters ......... 185

A-3. Thermocouple Calibrations ............ 189

A. -4 . System Heat Losses ................ 200

A-5. Heat Fiux Meter heat Loss Calibration ..... 201

APPIUDIX B. COMPUPER ALALYSIS OF HEAT METER DESIGN ......... 209

APPEIDIX C. THERMODYMAMIC AND PHYSICAL PROPERTIES OF TEST

FLUTDS $\ldots \ldots \ldots \ldots \ldots \ldots \ldots \ldots \ldots \ldots \ldots \ldots \ldots \ldots \ldots \ldots \ldots \ldots \ldots$

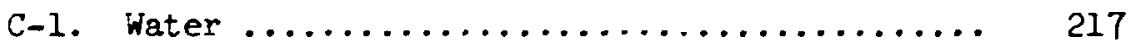

C-2. Freon-113 ..................... 217

ADPEND $* X$ D. DATA SHEETS, REDUCED DATA TALULATIONS, AND
CROSS REFEREICE LISTING OF EXPERTMENTS ........ 221

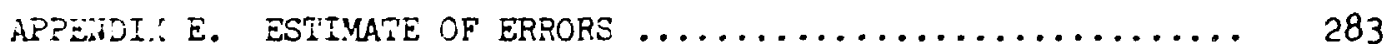

APPEADIX F. ALTERNAIIVE ROHSEIOW CORRELATION OF BOILING

DATA .......................... 287 


\section{ABSTRAC:}

Research was undertaken to obtain an internally consistent data set from which convective flow boiling could be separated into its constituent pooi boiling and forced-conrection components and which could be used to test the adequacy of two commonly use, correlations for predicting boiling heat transfer. Pool and $f l o v$ toiling under saturation conditions at atmospheric pressure were stujied using Freon-113 anci demineraijzed water as test fluids. The same copper test surfaces, prepared by lapping with a 400-grit compound, were ised for all the tests. Horizontal and vertical criencaisuns were studied in the pool boiling fecility; whereas the flow test facility was operated in the upflow mode. For the flow boiling tests, the mass flux was varied from 106,000 to $1,325,000 \mathrm{lb} / \mathrm{hr} \cdot \mathrm{ft}^{2}$ with Freon and from 106,000 to $852,000 \mathrm{lb} / \mathrm{hr} \cdot \mathrm{ft}^{2}$ with water. Convective boiling with Freon under annular flow conditions was investigated for a thermodymamic quality range of 2 to $8 \%$, corresponding to a range of 4.1 to 0.94 for the Martinelli parameter. Most of the data were characterized as nucleate bolling; relatively few data were obtained under suppressed nucleation csiditions.

$\mathrm{Ali}$ the Freon flow bolling data were well correlated by the Rohsenow additive method. The annular flow boiling data were not predicted by the relation proposed by Chen. This was attributed to failure of the Zuber expression, on which Chen's relation is based, to describe the pool bolling results adequately.

Afing effects of the copper boiling surface in the plow boiling tests with water (and to some extent in the horizontal pool boiling tests) caused excessive scatter and poor reproducibility in the data, negating correlation of the results with the Rohsenow additive technique. The data exhibited, however, the same general trends as observed with Freon.

Measured boiling coefficients and photography provided sone evidence that steam bubbles in the water stream flowir: past the test surface interfere slightly with the bolling performance; this effect was not observed in the Freon tests. Degradation in performance appeared related to bubble size; the stean buobles were observed qualitatively to be two to three factors greater in diameter than the Freon bubbles. 
Nic detectable surface orientation effeet was found in the pool boiling studies with Freon. The results were well correlated by the Rohsenow pool boiling relation; the expression proposed by Zuber was inadequate. Measured coefficients for water boiling or: vertical surfaces were found to be about 10\% greater than those determined for horizontal surfaces. The results for pool boiling of water were reasonably well correlated with the Rohsenow expression but again the Zuber relation was deficient.

Based on the resuits of this study, the Rohsenow additive mathod is recommended for use with Freori-113 cver the investigated range of mass flux anà thermodynamic quality. Its use for higher mass fluxes and qualities is probably justified. Although the formulation of Chen's correlation facilitates its use, $i \therefore$ is not recommended for application with Freor:-113 in the mass 1 lux and quality range studied. The results of this study suggest that modifications to improve the nucleate boiling formulation are needed.

Metallographic examination of specimens prepired identically to the boiling test surfaces revealed a highly irregular surface (on a microscopic scale). High magnification micrographs obtained by ordinary optical techniques and by use of an electron scanning microscope are included.

Recommendations for further investigations are given. 


\section{LISI OF SYMBOLS}

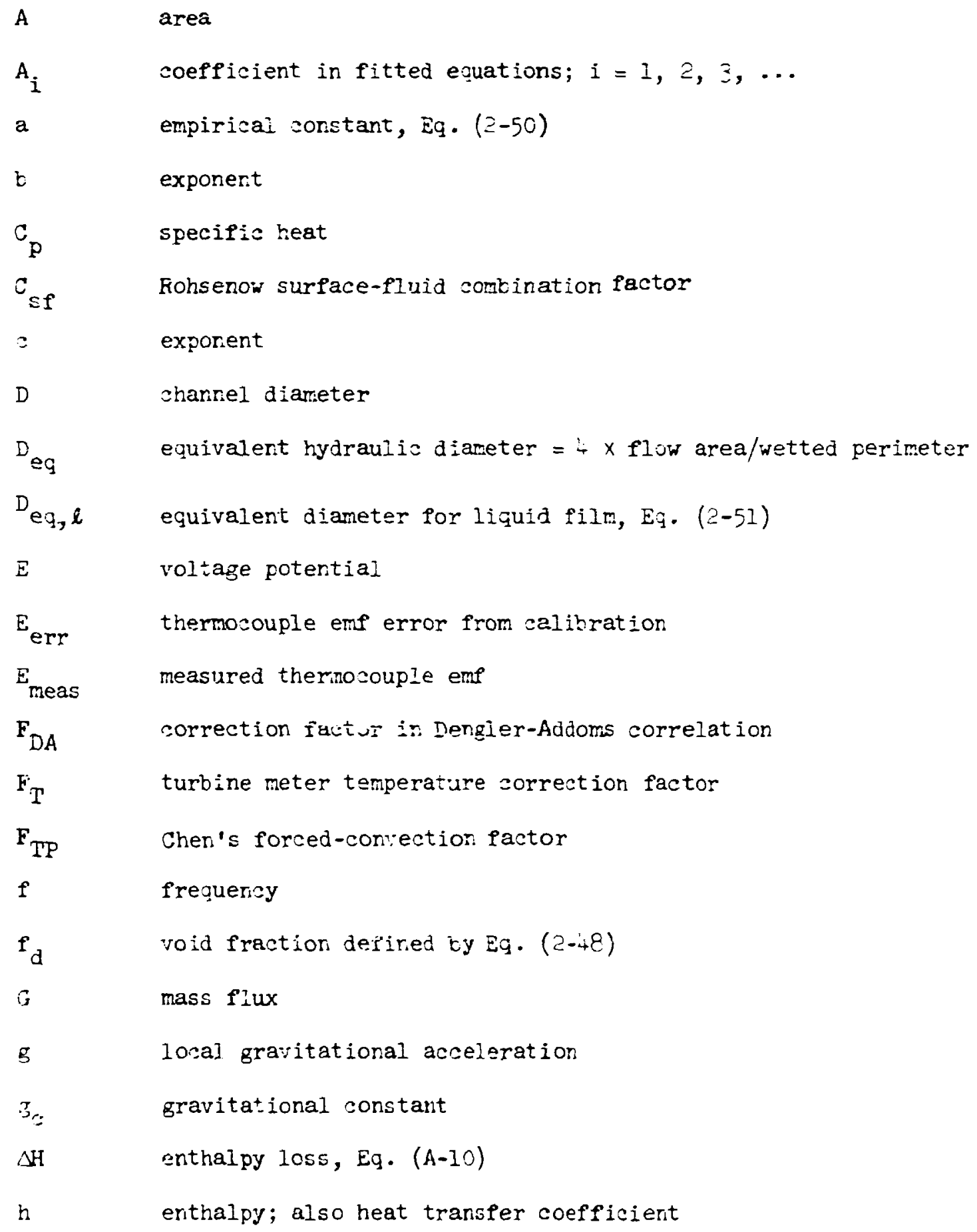




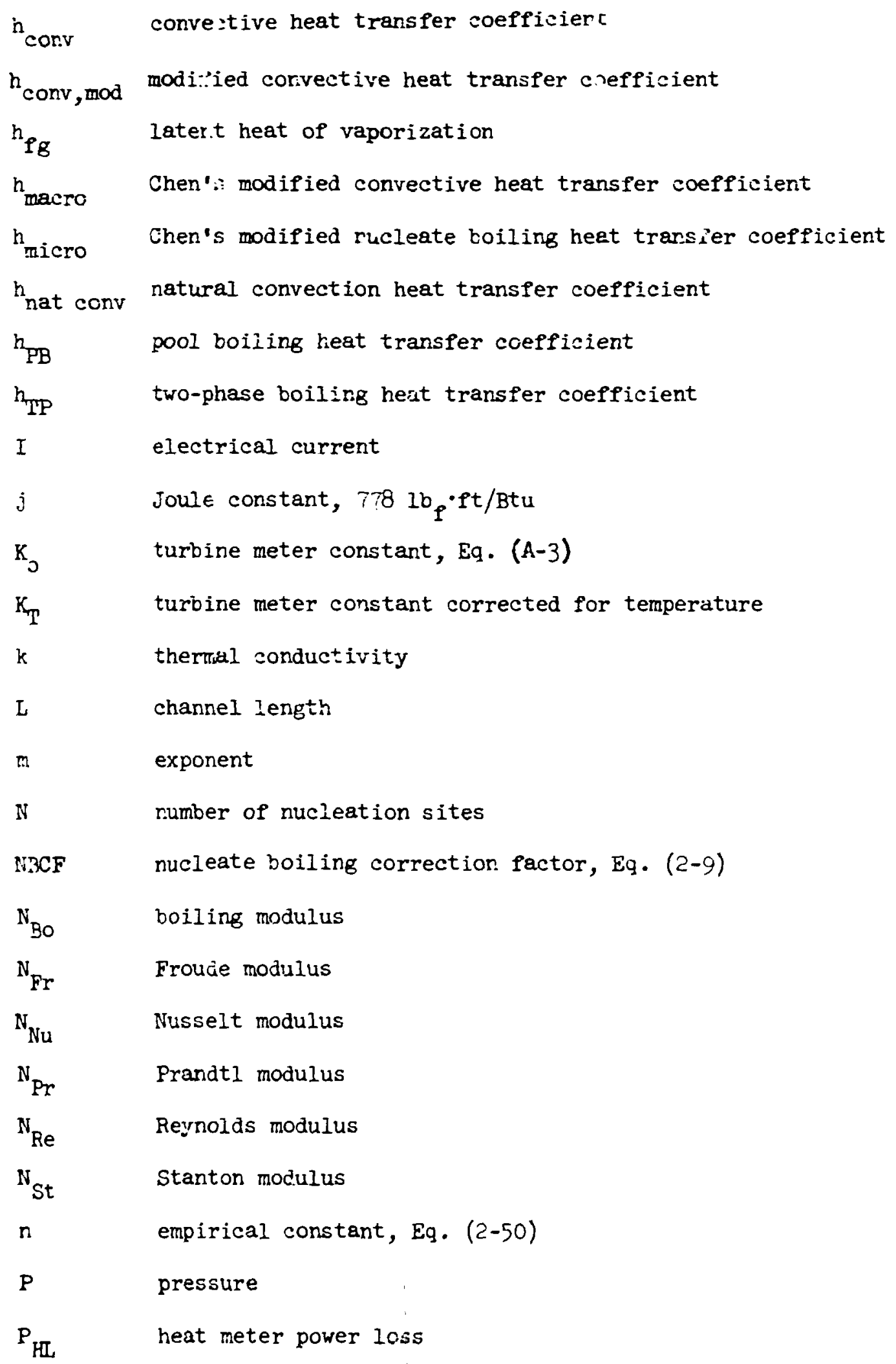




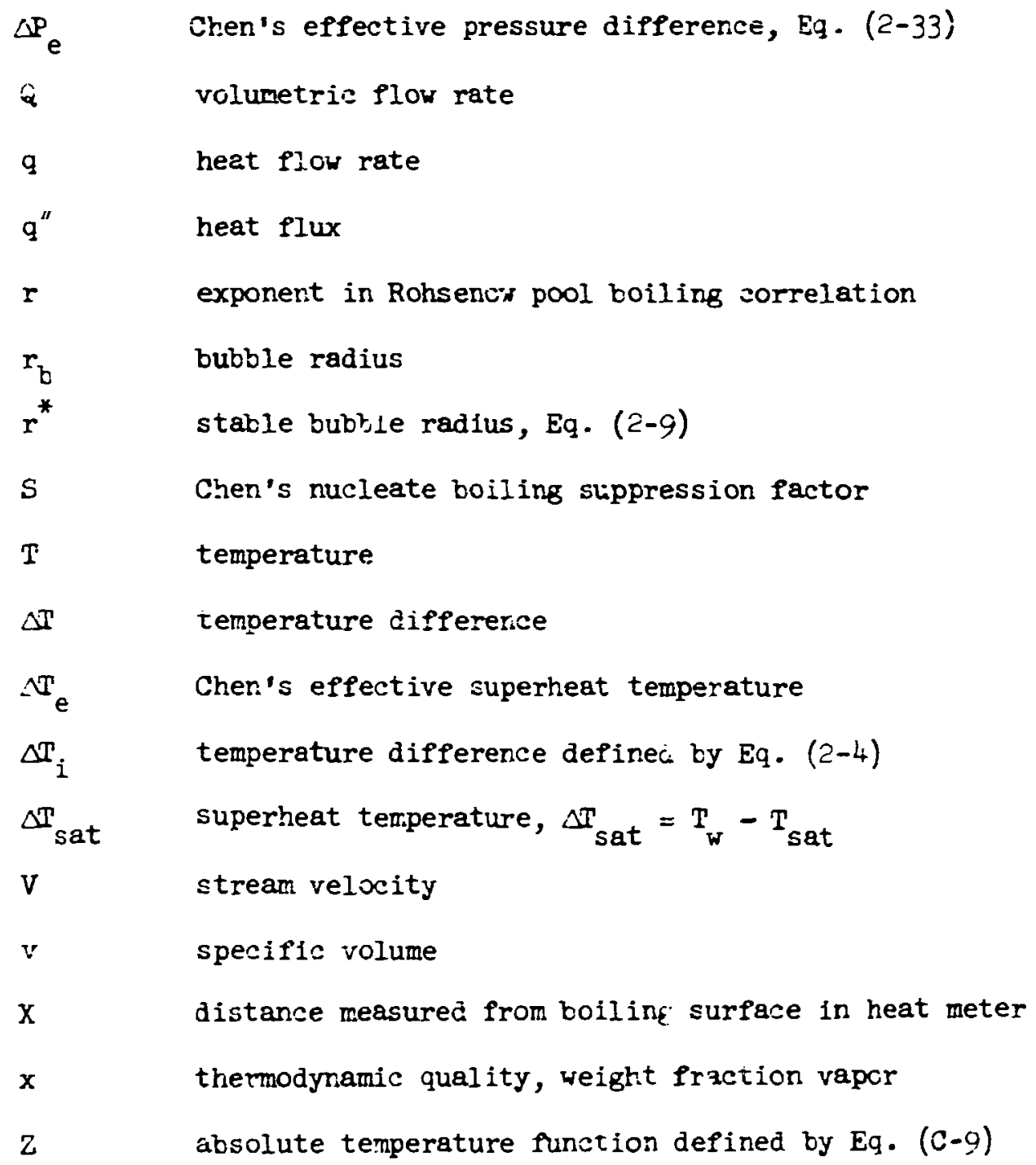

\section{Greek: Symbols}

$\delta$

$\Delta$

$\epsilon$

$\mu$

$\nu$

$\rho$

$\sigma$ laminar sublayer thickness; also finite aifferential

finite difference

Chawla's two-phase flow parameter

mölecular viscosity

kinematic viscosity

density

surface tension 


$x_{t t}$ Martireili parameter defined cy Eq. $(2-3)$
function

\section{Subscripi:}

$\begin{array}{ll}\text { sonv } & \text { oubble; bulk; boiling } \\ f & \text { film; fluid } \\ \text { g } & \text { vapor } \\ \text { H } & \text { horizon } \doteqdot \text { al } \\ 2 & \text { liquid } \\ \text { meas } & \text { moesurea } \\ \text { NE } & \text { nucleate boiling } \\ \text { PB } & \text { pool boiling } \\ \text { Sat } & \text { saturation. } \\ \text { TP } & \text { iwo-phase } \\ \text { W } & \text { wall; surface }\end{array}$




\section{ACKNOWTEDGMENTS}

This investigation was performed at the Oak Ridz; National Laboratory operated by tine Union Caride Corvoration for the U. S. Atomic Energy Comaission. The author wishes to express his appreciaticr for the use of the facilities and equipment of the Laboratory and fror the assistance of many of its sioff mecibers. The author is particularly grateful for the contricutions of the followirg persons: Dr. H. W. Hoffuar who serred as Research Comittee Chairman and offered many helpful suggestions throughout the program; Dr. D. M. Eissenberg for suggesting the probiem area and with whom many helpful discussions were held; Dr. D. L. McEiroy for thermal conductivity measurenents; $\mathrm{L}$. J. O. Griess for water chemistry and corrosion sonsuitation; Dr. T. L. Hebtle for consutation on statistical matters; A. I. Hoorhead for developing the special brazing techrique; B. C. Leslie for netallographic assistance; R. S. Cruuse for the very interesting ESM micrographs; D. C. Davis for instrumentation assistance; T. C. Tucker for deve'uping a computer program for presentation of the tabular data; I. I. Simon-rov for assistance with the HEATING computer program; R. E. Dial, project techniciar, whuse ingenuity and careful attention to details helped inmeasurably; Frances Burkhalter for preparatior of the figures that appeai's in this report; and Dolores Eder. for typing the manuscript.

Finally, I wish to thank my wife, Jeannine, for her encouragement, understanding, and forbearance throughout my period of graduate study; she cheerfully deferred many fanily activities these last months that I migh: devote full attention to completion of this dissertation. 


\section{CHAPTER I}

\section{INTRODUCTION}

It has long been re:ejnized that the boiling mode of heat :ransfer can sustain very high heat fluxes with modest temperature differences. For single-phase, forced-con rection heat transfer, the heat flux varies approximately with the first jower of the temperature difference; whereas for boiling, the dependence is to about the fourth power. Using heat removal per unit coc!ant vojume as a figure of merit, forsed-convection boiling has the greatest potentiai for application in systems characterized by high volumetric heat generation. Notable examples employing convestive boiling as the primary mechanism for heat removal include nuclear reactor cores, rocket engines, and once-through evaporators.

For fully developed nucleate boiling, the temperature differerce, which is the driving force for the transfer of heat, is nearly constant over a wide range of conditions. This attribute, coupled with the heat removal capability per unit coolant volume, has led recent ly to a new area of gereral application for boiling heat transier; namely, the cooling of solid-state electronic devices. Proper functioning of these devices is highly dependent on the temperature level, and, in order to fully exploit minjaturization, convective boiling is considered a necessity.

Heat transfer to boiling liquids has ceen studied extensively, both experimentally and theoretically; and the literature on the subject is overwhelming. Although there appears to be general acceptance of the mechanistis involved with simple pool boiling systems, there remains a diversity of opinion on the manrer best suited for correlating t.le derived 
knowledge of an admittediy somelex phenomerion. A ₹ one departi fror the simpie pool boizing system to syctems of more interest in industria: appisations, the somplexities inarease and the areas of agreement desreaze. This is not unexceted sinse there are many poorly understood fastors that influence the koiling prozese to baryine de jrees.

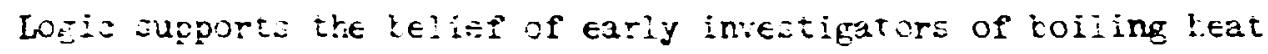
iransier tinat an underetandire of sonvestive coilizg zould bezt be obtained by $\epsilon$ liminating the effest of flow and stuying the phenomena in stagrant :iquids first. This led, iteraily, to thusands of pool kcii-

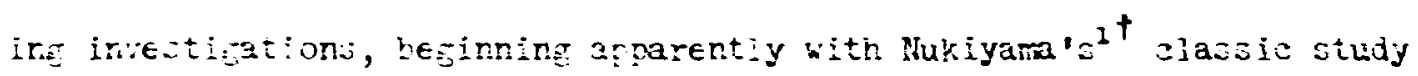
in : it. Based on and/or ouided by these studies, investigators then urres their attention to fior-boilinf sytem Collier publishej an Exe: $\in$ ent re:iei of the world literature on the wejent furing the periud

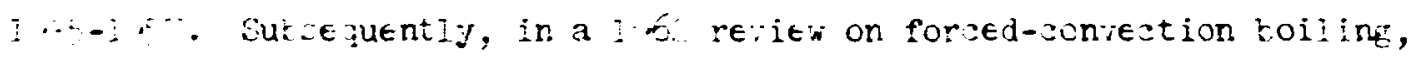

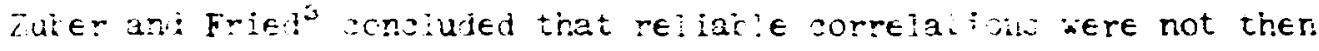
3a: a: : :

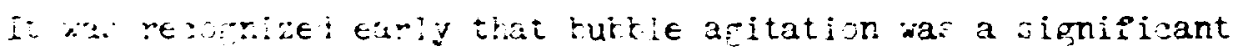

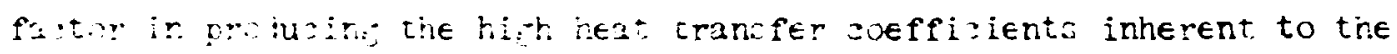

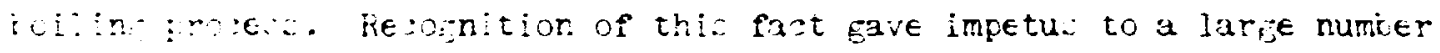

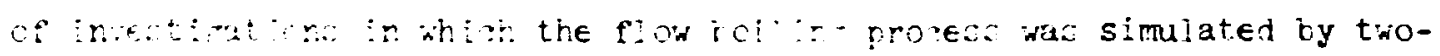

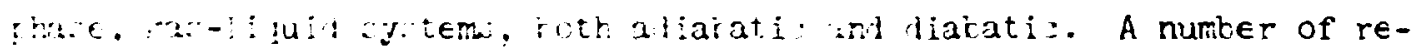

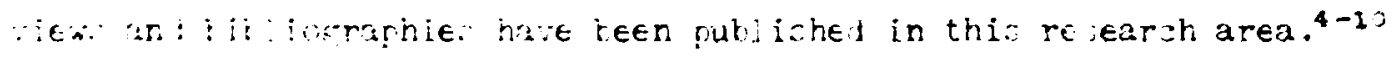

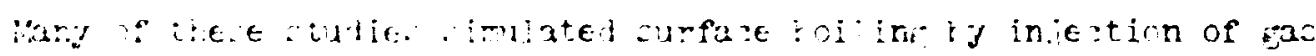

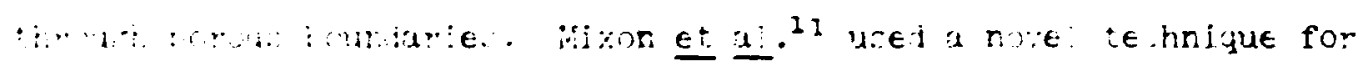

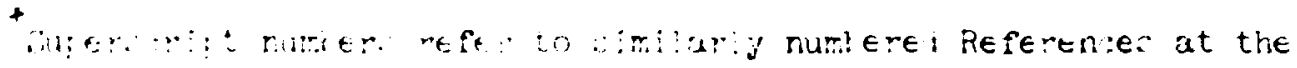

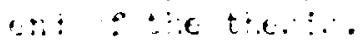


Etudyirg a z: rę:te: surfaze.

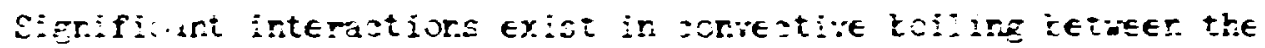

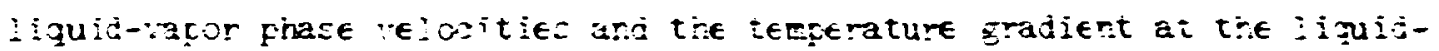
zoidd interfaze; theze factors must not ie regieziej if meaningfu: in-

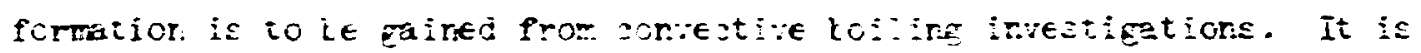

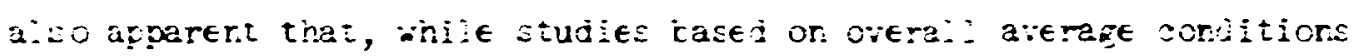

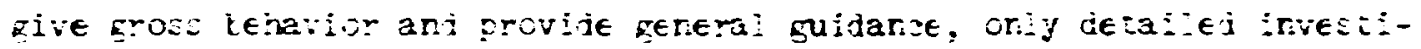
Eution of locel vorditionz car. lead to definitite information. Mris is, of zource, the rescor. for the many studies uniertaren to se ineate the

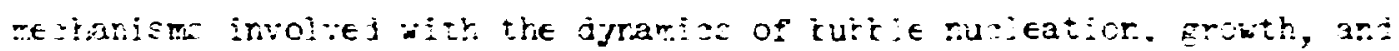

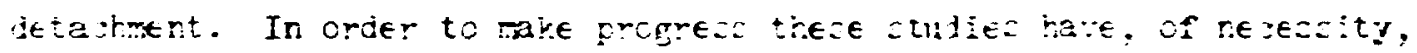

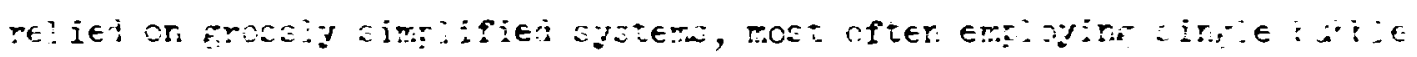

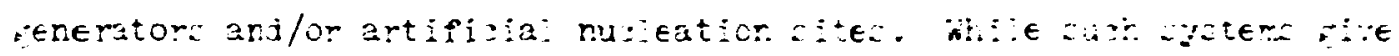
important information - ir. fast, if it iere rot for the , cur troifeje

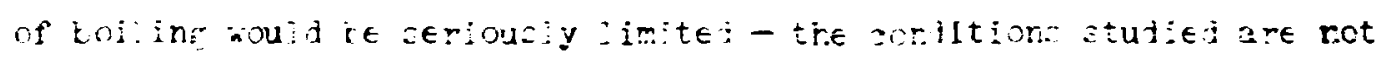

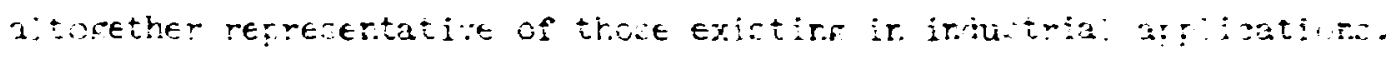

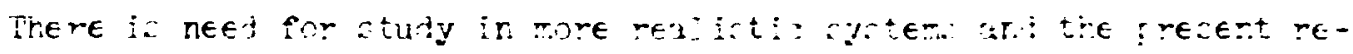

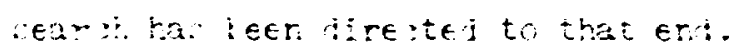

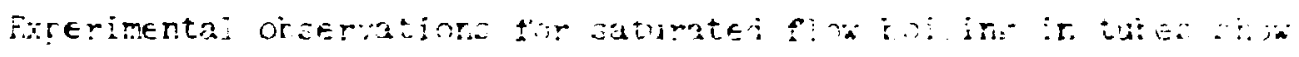

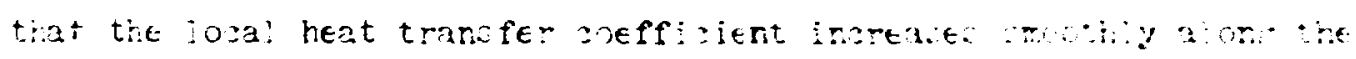

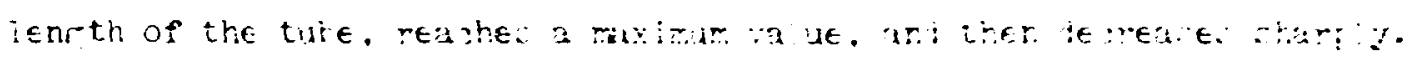

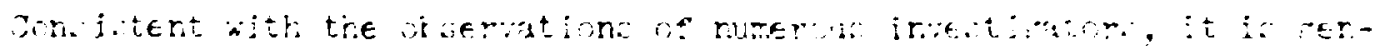

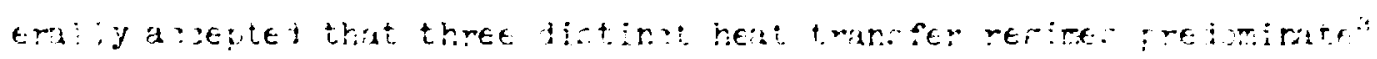


a: ong the tube in the direstion of Pior. Intese are:

․ A "muieate so:ing" region in which the heat transfer methanist is characteristic of nucieate coiling. Obseried coffiaients for this region refiect the infuence of forced convection by increasing with heat Ilux and wass f:or; hosever, they do not appear to ke strongiy infiuenced by the vapor fraction (i.e., bulk strear quality). This fechanism appears to be dowinant in the $0-15 \%$ quality range.

2. A "mucleate boiling suppressed" region, in which the heat trans$f \in r$ mechanism is characteristic of turbulent forced convection. Observed coefficients in this region exhitit an 0.8 power dependence on mass velocity and an independenes of heat flux on temperature difference (wall minus buik), both distinetive features of forced corvection. There appears to be a strong dependence on quality, with the cofficient increasing with increasing quality. This manism appears to be dominant in t!e 15-70\% guality range. Annular flow (with a liquid film on the wall and a central rapor scre) erists in this region. Evaporation from the liquid film to the vapor core is most ikely the dominant heat transfer mechanism.

$\because$ A "liquid deficient" region in which the wall is no longer completeiy sovered by a lizuid fiim. (Liquid may be present as a mist or fog dispersed in the contimuous vapor phase.) Observed coefficlents in this region are sharazteristis of forsed convection to a vapor. Obviously this regime extende to the limiting case of sing:e-phase (Ell vapor) heat transiter regime.

Distinat roundaries zannot he identified por each region, since they noma! !y c:er:an eash other ac evidenced by the obsemed smooth variation of the heat transfer seffizient as a function of lenfth (i.e., quallty). The research reporter herein ic soncerned only :'ith the "nucleate boli ing" 
and " suppressed mucleate boiling" regions (i.e., regimes 1 and 2 as discusseà above).

Most ettempts at correlating turbulent forced-convectire bciling heat transfer ${ }^{12-26}$ in the regions of interest (saturation conditions) to this research have been based on the addition of two terms, one related to the mechanism of nucleate pool boiling and the other related to the mechanism of turbulent forced-convection in closed conduits. There appears to be general agreenent among previous investigators ${ }^{2-25}$ that the term related to the forced-convection mechanism can be well correlated as a function of the Martinelli parameter, ${ }^{27}$ which is strongly dependent on vapor quality. On the other hand, there is less aqreement on treatment of the macleate boiling region. Some investigators ${ }^{23-27,24-26}$ have used modifications of pool betifing correlations, while others ${ }^{28-a}$ have used correlations besed on the boil ing mumber concept introducea by Davidson et $a 1 .{ }^{28}$ The boiling muioer, $\mathrm{H}_{\mathrm{BO}}$, is defined as the ratic or the perpendicular mass flux away from the wall due to bolling to the total axial mass flux. This ratio way be interpreted as a measure of the suppression of mucleate bolling; macleate bolling is more likely at high values of $\mathrm{H}_{\mathrm{BO}}$

It thus seems apparent that a more basic investigation is reeded to delineate the mechanisms involved in forced-convection bolling of saturated fluids. One gets the impression that most investigations have pursued the empirical correlation of extensive test data. While this in itself is not objectionable (from a practical viewpoint, it does make avallable information userul to the designer), such an approach is not likely to lead to better correlations until supplemented by an increased 
understanding of the interactions of the various wechanisas involved in the conrective-bolling process.

The present research initiated to study bubble enhancenent and to elucidate and clarify the mechanisis involved in turbulent, forcedconvection boiling of saturated Iuids at atwospheric pressure. The approach chosen was to separate the mechanisus involved by a series of experiments (in a given geowetry) that examine successively the various modes of heat transfer from forced-convection nonboiline through suppressed nucleate bolling. Although significant progress has bee. achleved, no claim is made that ail the questions iave been answered. Indeed, my facets of this complicated problen rewin to be studied; because to paraphrase an obscure quotaticn, "In boiling heat transfer, unlike buman codes, de minimis surat lex - the law is concerned with trivia." 
CHAPIIR II

\section{LITERATURE REVTIW}

\section{Introduction}

Introduction of high power density systems during the ear-ly $1950^{\circ}$ s created a need to predict with reasonable accuracy the rate of heat transfer in flow bolling systems and provlced the impetus for extensive research in bolling heat transfer and two-phase flow. While the effort expended in the subsequent years was great, the results were not altogether satisfactory. Even the basic question of the doninant mechanism of bolling heat transfer, f.e., whether the high heat transfer rates associated with bolling are caused by the agitacion and stirring action of bubbles in the leninar sublayer adjacent to the heated surface or whether it is due to latent epergy tr-ansport, has not been completely settled. The former mechanism is belleved to be dominant at low heat flux densities, whereas the latter is most likely important at high flux densities. This situation is leas than desirable, eince no relfable metho' exists by which tise designer can predict witin confidence and reasonable accuracy the bciling heat flux for a given surface temerature. Correlations are avellable, but their accuracies range from about 254 upwards to, is some situaticns, hundreds of percent.

In single-phase corvective systems, knowledge of the pressure and temperature ifstributions as well as of the flow regime (laminar or turbulent) is suff:cient to analyze system performance. Additionally needed in:ormation on the volumetric vapor fraction and the two-phase regime (buibly, slug, anrular, etc.) is required for detalled analysis of 
two-phase convective systems. Where nucleate koiling is present in the two-phase system, the nucieating qualities of the heated surface can become of major importance. Ooviously, an extraordinary amount of detailed inforwation is needed to make a complete analysis of a typical two-phase system. As a rule this information is unavailable; and as noted the analyst must resort to avaiiable correlations, wany of which are of gauestionable validity.

The studies undertaken to gain the necessary undeistarding of the mechanisms involved and/or to improve the predictive techniques are waititudinous. In addition to the many journals currently reporting boiling heat transfer research, a number of $t \in x t s^{29-31}$ and bibliographies ${ }^{5-9}$ devoted to tro-phase flow and heat transfer have been pucIished. The reader interested in a more complete discussion and/or extensi:e itiographies is referred to these sources; only those refsrences havirg a firect reiationship to the present research will ce re:ie:ejej.

\section{Forseu-Convectior. soling}

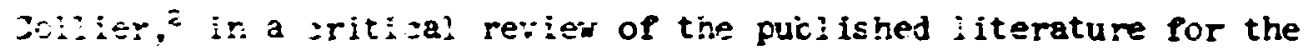

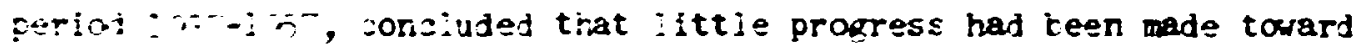
an uristztanitn of tre frosesses taking piace in progressive vaporiza-

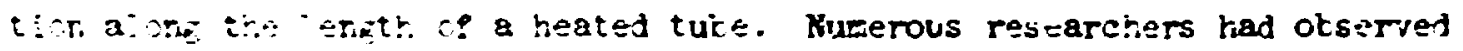

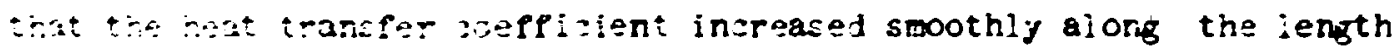

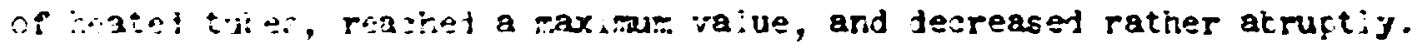

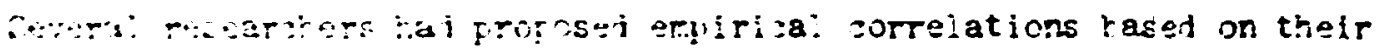

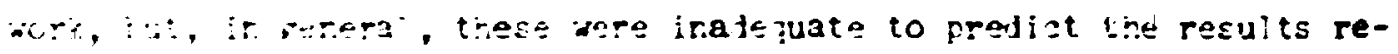

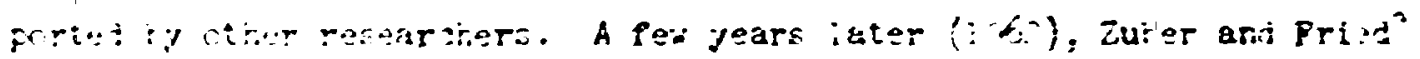


agair revieved the forced-convection boiling literature and concluded that the situation had not changed significantly in that reliakle correlations still vere not availatle.

\section{Dengler and Addous}

Dengler and Addomsto.15 were anong the first to postuiate the existence of ?.1fferent heat transfer mecharisus to expiain the otserved tehavior. In analyzing their forced-conection zolling data, they sonsludes that vaporization in tuces is governed ty the somined erferts of forsed convection and nucleate tolling and that nusleate toilirs is dorinant only under conditions of low lfguid plow reiceities. As the reiosity of the liguij-vapcr aixture increases (ircused if in:reased ripor produstion along the ieneth of the tuise), waieatior is suppresisi: anj

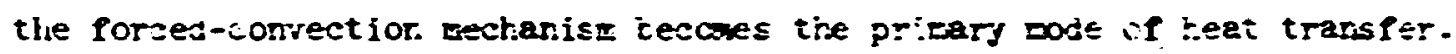

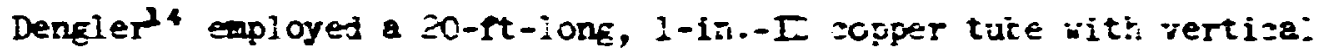
upfion of water under forsed eirculation to ar guire the jeta arsijzed $y$

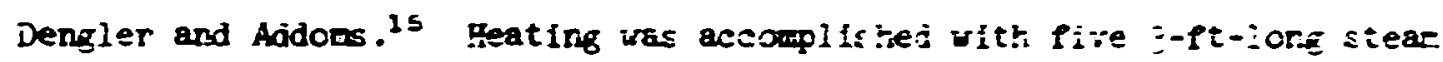
jacikets equally speced along the length of the sotper tuie. Iosa: (averaged over the :-ft sestior) heat ruxes were chtained iy zeasurement of the condensate collected frow each jacinet. Provialor. fo: grassure drof and void fraction measurements, usine e rasioastion tracer te:hnique, were made tetween eaci. steam saiket. Wail temperatures wsts measurad with thermocoiples exiceddad in longitudina: eiots al one ti.e length of the tuke. The pressure range tested was $\varepsilon$ to $\rightarrow$ psia. Saturated fiuid entered the test sestion, whth exit juai:ties ranging up

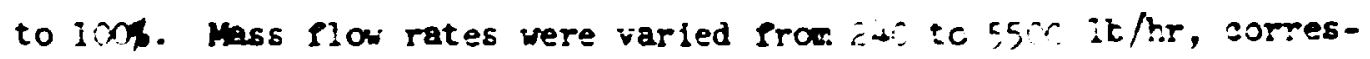
ponting to fnlet relocities or $0 . \bar{c}$ to $4 . \overline{\mathrm{rt}} / \mathrm{sec}$. 
In the range of suppressed musieation, they yere atie to ecrraist: 854 of their data within \pm 20, wits the eguation:

$$
\frac{h_{i p}}{i_{\text {sotv }}}=j .5\left(\frac{i}{x_{t t}}\right)^{2.5} .
$$

They found, for the conditions of their investigatior, ihat rusieaticr.

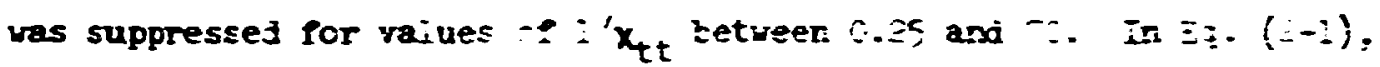

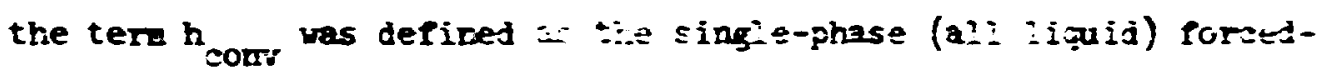
comeetioz soefficient as given $k y$ tre Żttus-Bositer zuation:

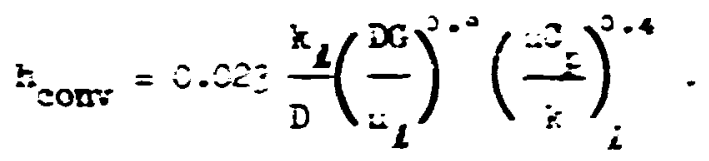

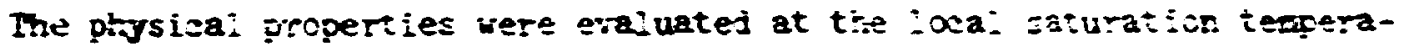

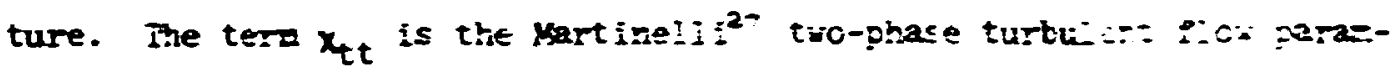
eter as giver. ij:

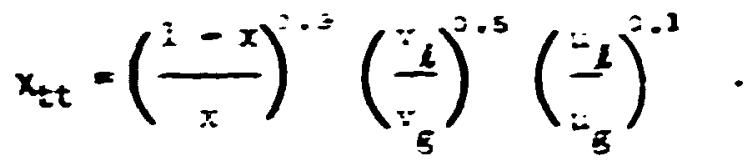

The reciprocal of $x_{t t}$ is a strong furetion of the rapor weigrt irastion (stean guality) and also, iy zeans of tie riszosity and spesifi:

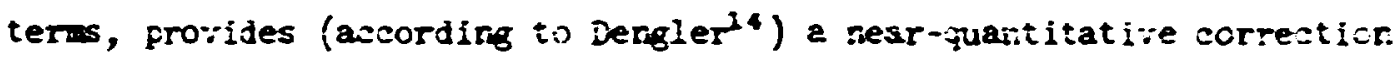
for pressure cr. the two-phase soeffizient.

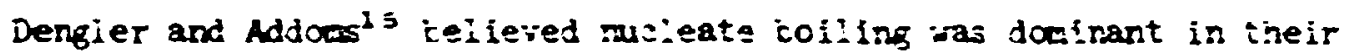
Inrestigation at raiues of $1 / x_{t}$ less than 0.25 . in though they wera of the opinion that the effest of sucieate coiling was adaitlye :c irat of convection, they susgested an explizi:ai sorrection pactor in the ror: cl

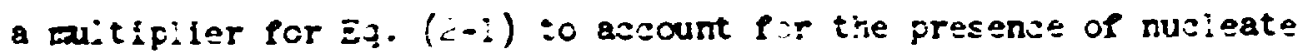
tolling. The shoize of a mutipiler instead of an addition sorrs:tion. 
was strictly for conrenience. They octkined the sorrection factor ty postulating that the teqperature difference, $\Delta r_{i}$, nesessary to initiate nueleation was a runition of the arerage streas rejosity. Fros the zarured roid fraction data, they deduced for $\mathrm{si}_{i}$ :

$$
\Delta \mathbb{r}_{i}=\text { if }\left(v_{\text {are }}\right)^{=.3} \text {. }
$$

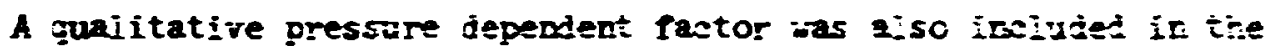
find fork of the correstion; tius:

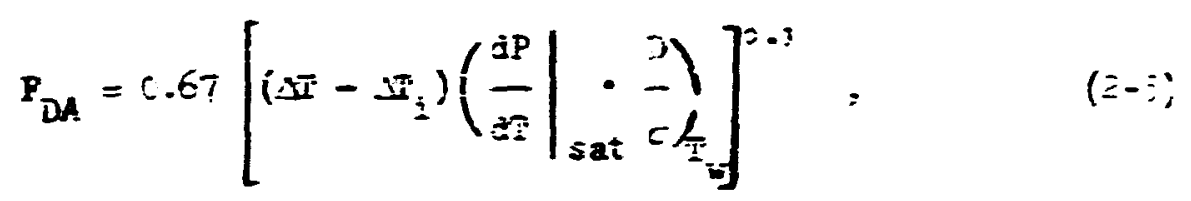

were $\left.\frac{d P}{d r}\right|_{\text {sat }}$ and $=$ are evaiuated at the rail tesoerature. Frus, ite finei for of the generai sorrejation is given ig:

$$
\frac{n \cdot T}{n_{c o n v}}=3.5\left(\frac{i}{x_{t t}}\right)^{2.5} \cdot P_{D A}, \quad \text { ic-i }
$$

with $P_{D A}$ teing used only wher it ex:eeas unity.

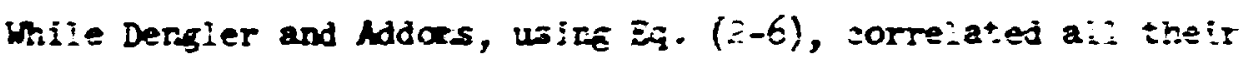

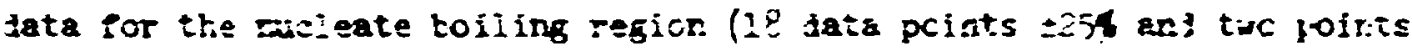

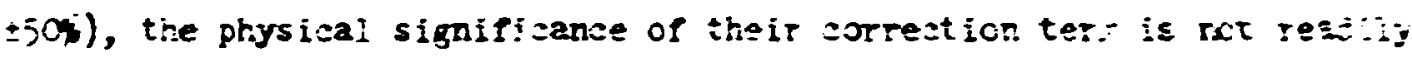
apparent. Ho attempt was zade to sorrelate their data cite:upd for cryweli or ilquid deficient conditions. It was motec that dy-wei: ecri:tions, sharacterized by a sudcen and sharp redustion in feat iransfor coeficient with increas ing vaporization, vert erachintered at raines ot $1 / x_{t t}$ as iow as $25\left(x \approx 0.4^{-}\right)$with gerera: occurrese ai raiues of $I / x_{t}$ around $: 0(x \approx 0 . \cdots)$ 
Gierrieri and Talty

Guerrieri anc Talty ${ }^{26}$ investigated boiling with a number of organic liquids under natural-convection conditions in single, vertical tube bollers. The test fluids were cyclchexane, methanol, benzene, pentane, and heptane. Brass tubes, $0.75-$ in. ID $\times 6.0$-tt long and 1.00-in. ID $x$ 6.5-ft long, were heated exterrally by oil flowing thrcugh a concentric jacket. Thermocouples were used to measure the tube wall temperature at 6-in. intervals. Subcooled liquid entered the test section and exited with qualities in the range of 2.8 to $16 \%$. The range of mass fluxes tested was $28.8 \times 10^{4}$ to $35.8 \times 10^{4} \mathrm{lb} / \mathrm{hr} \cdot \mathrm{ft}^{2}$.

In the region of suppressed mucleation, Guerrieri and Talty represented their data by the relation:

$$
\frac{h_{\mathrm{TP}}}{h_{\text {conv, mod }}}=3.4\left(\frac{1}{x_{t:}}\right)^{0.45} .
$$

This agrees fairly closely with the Dengler-Addcms correlation, Eq.

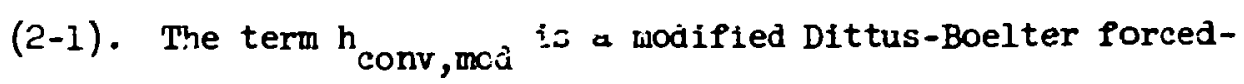
convection correlation:

$$
h_{\text {conv, mod }}=0.023 \frac{k_{l}}{D}\left(\frac{D G(1-x)}{H_{l}}\right)^{0.8}\left(\frac{\mu C p}{k}\right)_{l}^{0.4} .
$$

Comparing Eqs. $(2-8)$ and (2-2), the modification consists only of basing the coefficient on the liquid fraction of the stream. The lower limi $i^{+}$of $1 / x_{t t}$ in Eq. (2-7) was stated by the authors to be about 0.3 .

To account for bubble agitation in the region of nucleation, Guerrieri and Telty deduced from their data a nucleate boiling correction factor (designated NBCF) irvolving the ratio of the radius of the animum size of a thermodyramically stable bubble to the thickness of 
the laminar sublayer. This correction factor, used as a multiplier for Eq. (2-8), was expressed as:

$$
\text { NBCF }=0.187\left(r^{*} / 8\right)^{-5 / 9},
$$

and is to be applied only if it exceeds unity. Thus, Guerrieri and Talty's general correlation becomes:

$$
\frac{h_{\mathrm{TF}}}{h_{\text {conv, mod }}}=3.4\left(\frac{1}{x_{t t}}\right)^{0.45} \cdot \mathrm{NBCF} \text {, }
$$

again not too different from that proposed by Dengler and Addoms. Equation (2-10) suscesstully correlated $88 \%$ of Gerrieri and Talty's data to within $\pm 20 \%$.

The restriction on Eq. (2-10) that NBCF $\geq 1.0$ implies that $r^{*} / \delta 2$ 0.049. This is interpreted physically to mean that mucleation is suppressed when the radius of the minimum thermodynamically stable bubble exceeds about $5 \%$ of the laminar sublayer.

Schrock, Grossman, et al.

Schrock and Grossmen,,$^{18}$ in the Pirst of a series of two-phase boiling research investigations at the University of California at Berkeley, studied bulk boilifig of upward flowing water under forced circulation in electrically heated round tubes having diameters of 0.1162 to 0.4317 in. and heated lengths of 15 to $40 \mathrm{in.}$ Inlet pressures ranged from 42 to $505 \mathrm{psia}$, and exit qualities varied from 5 to $57 \%$. Mass fluxes $:$ varied over the range of $1.76 \times 10^{5}$ to $3.28 \times 10^{6}$ $\mathrm{lb} / \mathrm{hr} \cdot \mathrm{ft} \mathrm{t}^{2}$.

These authors postulated for the range of variables tested in their investigation that the local forced-convection boiling heat iransfer 
coefficient (defined in terms of $\Delta T=T_{i r}-T_{\text {sat }}$ ) could be expressed as:

$$
N_{\text {Ku }}=\left(H_{R e}, N_{P}, N_{B O}, x_{t t}\right) \text {, }
$$

where the toiling modulus, as used $b$ y ${ }^{19}$ is fiven as:

$$
\mathrm{N}_{\mathrm{DO}^{\circ}}=q^{\prime \prime} / \mathrm{G} \mathrm{n}_{\hat{\mathrm{I}}_{\overline{5}}} \text {, }
$$

and the other dizensionless moduli have their usuai definitions. The boiling modulus can te interpreted physically as the ratio of the mass flux dir eted away from (perpendicular to) the wall due to boiling to the total wass flux directed aiong the axis of the tube. They were able to correlate their full range of data to within $\$ 356$ by the expression:

$$
\frac{N_{\mathrm{Nu}}}{\mathbb{R}_{\mathrm{Re}}^{0.8} \mathrm{~N}_{\mathrm{Pr}}^{2 / 3}}=170\left(\mathrm{~N}_{\mathrm{Bo}}+1.5 \times 10^{-4} \mathrm{x}_{\mathrm{tt}}^{-2 / 3}\right),
$$

where the dimensionless moduli were eviluated usinf saturated liquid properties at the local pressure. Since the correiating equation is expressed in terms of dimensioniess moduli, the authors were of the opinion that it would apply to liquids other than water. The correlation was recommerided for the quality range of 0 to $50 \%$; that is, for both the mucleate toiling region and the suppressed macleation region. Equation $(2-1 \hat{j})$ can be rearranged to give:

$$
\frac{h_{\mathrm{TP}}}{\mathrm{h}_{\text {conv }}}=2.739\left[\mathrm{~N}_{\mathrm{BO}} \times 10^{4}+1.5\left(1 / \mathrm{x}_{\mathrm{tt}}\right)^{2 / 3}\right] \text {, }
$$

with the minor modification that in Eq. (2-2) $h_{\text {conv }}$ is written in terms of $\mathrm{N}_{\mathrm{Pr}}$ to the one-third power rather than the usual 0.4 power. Written in this form a structural comparison of schrock and Grossman's equation is conveniently made with those proposea by Dengler and Addoms [Eq. $(2.6)]$ and by Guerrieri ard Talty [Eq. $(2-10)]$. 
Bxamination of Eq. (2-14) reveals that for large heat flux to mass ratios (i.e., large values of $n_{E O}$ ) micieats boiling predominates; and the neat transfer becomes virtually independent of the lartineili parameter, $x_{t t}$, the only paraceter in the eguation containing the stean quality. on the other hand, for low values of $\mathrm{N}_{E .0}$, the sonvestive mechanisms as reflected by the MartineiIi parameter predominates.

Sani, ${ }^{20}$ using Schrock and Grossman's experimental facility, investigated downsard flow of water under forced-circulation conditions. An electrically reated stainless steel tuce, $0.99+-i n$. D $\times 68$-in. long, sas empioyed. Mass fiuxes were raried over the range $1.84 \times 10^{5}$ to $5.94 \times 10^{5} \mathrm{ic} / \mathrm{hr} \cdot \mathrm{ft}^{2}$, wile the pressure ranged between 15.8 and 30.9 pisa. Exit qualities up to $1 \div \%$ were oitained.

Sani correlated $95 \%$ of his data to within $\pm 15 \%$ by an equation of the Schrock and Grossman frrm:

$$
\frac{\mathrm{Nu}_{\mathrm{Nu}}}{\mathrm{Re}_{\mathrm{Re}}^{\mathrm{O} .8} \mathrm{~N}_{\mathrm{Pr}}^{1 / 3}}=3 i c 0\left(\mathrm{~N}_{\mathrm{BO}}+1.5 \times 10^{-4} x_{\mathrm{tt}}^{-2 / 3}\right) \text {. }
$$

This is identical with Eq. (2-1i) except that the numerical coeffisient in Sani's equation is twice that found to give the tet fit to Schrock and Grossman's data. Sani speculated that the difference in ecefficlents could not be wholly attributed to the $\mathrm{flcw}$ petterns (1.e., upflow versus downflow) and that other factors (possibly pressure) not specifically included in the correlation had an effect.

In a third investigation performed with the same test facility at the Berkeley campus, Wright ${ }^{21}$ reexamined forced-convection boilins of water in electrically heated, stain?ess steel tibes in the downflow mode. The tubes were $0.719-$ and $0.472-\mathrm{in}$. $D$, with heated lengths of 5.67 and 
$4.69 \ell^{2}$, espectively. The wass pluxes vere varled over the range $3.96 \times 10^{6}$ to $2.52 \times 10^{6} 1 \mathrm{t} / \mathrm{hr} \cdot \mathrm{ft}^{2}$, with exit qualities of 0 to $19 \%$. Pressure was varied from 15.8 to $68.2 \mathrm{psia}$, while the bolling modulus ranged $\operatorname{Tran} 0.24 \times 10^{-4}$ to $1.9 \times 10^{-4}$.

Wright correlated his data in a mober of ways, with average errors ranging from 10.8 to $16.1 \%$. One correlating equation vas:

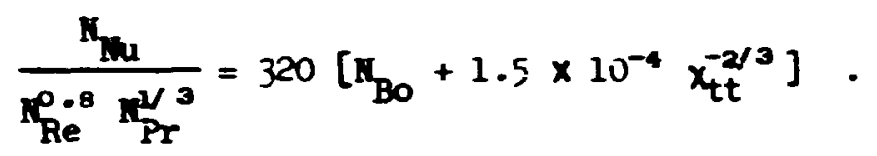

This equation is essentially the sase as that obtained by Sani [Eq. (2-15)] and, hence, yields (for a given $\mathbb{R}_{\text {Re }}$ and $N_{P r}$ ) a $K_{\text {th }}$ almost tulce that obtained by Schrock and Grosswan. Wright attrikuted most of the difference to pressure effect.s. He recast the bolling modulus in terms of volumetric ratios, which indeed have a large pressure dependence. Wright's modified boiling wotulus is simply the modulus as defined by Eq. (2-12) waltiplied by $\rho_{\mathcal{L}} / \rho_{B}$ or, in wathematical form,

$$
\mathrm{N}_{\mathrm{BO}, \bmod }=\mathrm{N}_{\mathrm{BO}}\left(\rho_{\ell} / \rho_{\mathrm{B}}\right) \text {. }
$$

Wris,ht used this parameter to correlate his data with the least error $( \pm 10.8 \%)$; thas:

$$
N_{S t}=0.003377\left[K_{R e}^{0.106} \mathbb{R}_{\mathrm{Pr}}^{0.4} \mathrm{~F}_{\mathrm{Bo}, \bmod }^{.02} x_{t t}^{-0.457}\right] .
$$

Using the usual bolling motulus in a similar type correlation, he obtained:

$$
\mathrm{N}_{\mathrm{St}}=1.7310\left[\mathrm{~N}_{\mathrm{Re}}^{-.258} \mathrm{RPr}_{\mathrm{Pr}}^{0.4} \mathrm{~N}_{\mathrm{BO}}^{0.138} \mathrm{x}^{0.382}\right] .
$$

Although this equation correlated his data almost as well $( \pm 13.4 \%)$ as Eq. $(2-18)$, the dependence on Reynolds modulus was opposite to that in 
Eq. (2-15). [Note that the reciprocal of $x_{t t}$ is a strong function of x.]

The fourth investigation performed yith the same facility was that of Somerville $e^{22}$ for dowmard forced-convection koiling of n-tutanol. Electrically hzated, stainless steel tuices (c.6--in. D) vith heated lengths of $5.60, f$ and $+.10 \mathrm{ft}$ vere used. hass piures varied from $4.90 \times 10^{5}$ to $1.58 \times 10^{6} i \mathrm{c} / \mathrm{hr} \cdot \mathrm{ft}^{2}$, with exit qualities up to 314 . The range of pressure investigated was 16.9 to 50.0 psia.

Somerville correlated his data in several ways. Thus, his correlation in tie form suggested by Dengler and Addous was:

$$
\frac{h_{\mathrm{TP}}}{n_{\text {conv }}}=-.5\left(\frac{1}{x_{t t}}\right)^{0.322}
$$

and in the Schrock and Jrossmar for:

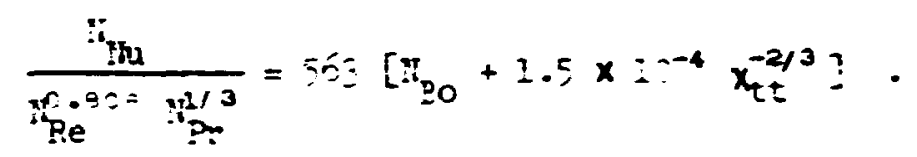

The leading coeffizient of Somerifie's equation is almost a factor of - Ereater thar that for schrock and jrossman. This tends to contradiat Schrock and Grossman's ielief that their sorrejation, belng vasej on dimenzionless moduif, would also apply to orgarife fluids.

Since Somer:ilie had used the sare eguipment as utilized by Wright, he seiected an equa: numer of Wright's water data points arid deduced a correlatior. for the tio data sets:

$$
N_{S t}=0.205\left[R_{R e}^{s .296} N_{P r}^{0.253} x_{E 0}^{0.19_{1}} x_{t t}^{-0.292}\right]
$$

This correlation was then stown to predict the data of a number of other investfgators within reasoraicle limits (no error ind was given). 
Bennet, Collier, et al.

Bennett et al..$^{13}$ perforwed an extensive series of tiro-phase bolling heat transfer experiments with upard now of steam-water nixtures at essentially atmospheric pressure. An elcarricaliy heated stainless stee: tuke located concentricaly within a glass tute formed an annular test gecmetry that was $z ;$ in. in le ugth. Tro difierent anmuli vere used: me employed a heater of $6.575-1 n$ - Jlam instde a $0.51-i n .-I D$ Glass tuke; and the other, a heater of $0.62 \%-i n .-$ dam insije a $0.866-i n .-$ D glass tube. The range of mass fiuxes tested was $1.12 \times 10^{5}$ to $2.1^{-} \times 10^{5} \mathrm{lt} / \mathrm{hr} \cdot \mathrm{rt}^{2}$. Sxit steam quaiities ranged from $c$ to $100 \%$, depending on $\Gamma$ w rate and power :eve:.

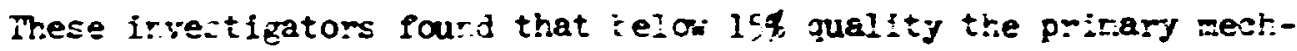

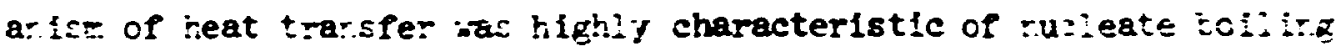

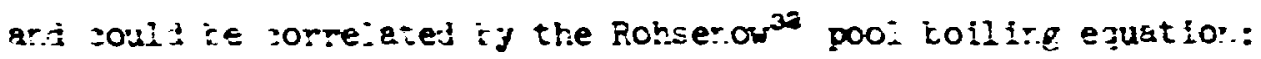

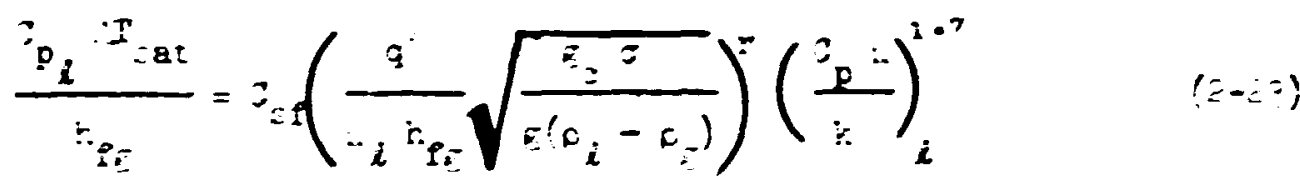

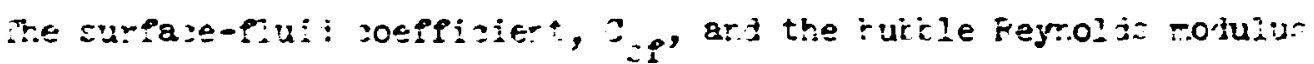

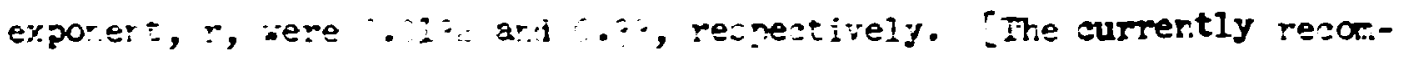

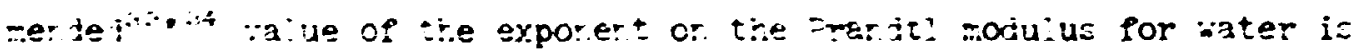
i. , ard remairs i." for other fludje.j

it righer stear: guaities (up to 55 to $65 \%$ ), they found the mechanfs:- staracteristil of forsed soriestion (i.e., the redion of sup-

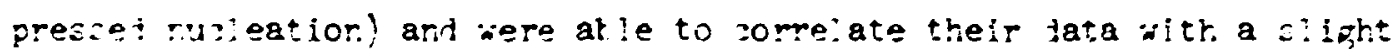
mo: ifizat:on to the typo of equation prcposei ty inerrieri and Taity. ${ }^{1}$

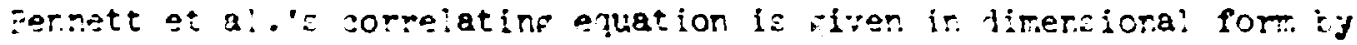




$$
\frac{h_{\mathrm{TP}}}{h_{\text {com }, \mathrm{mod}}}=0.6-\left(\frac{i}{x_{t t}}\right)^{0.7}\left(\xi^{-1}\right)^{2 . i 1},
$$

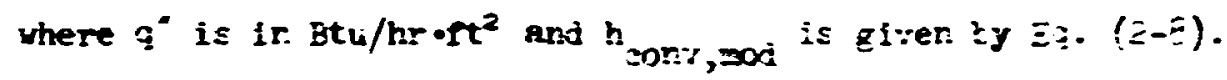

For gualities atove 55t, the rete of heat transfer desteasei and

In the lind approates the ralue set iy the iny stean soeficient.

Cullier and Puliirg't used the save experimertai equipuent to ex-

tend the wrrk of bennett et $a^{1.13}$ to kigher pressures and zass ${ }^{1}$ iures.

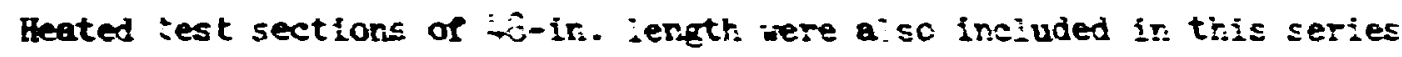

of experibents. The range of test pressures ias 15.5 to 5. Fs

with wass fluxes in the range of $2.87 \times 10$ to $.5 \times 2.5 \mathrm{ig} / \mathrm{hr} \cdot \mathrm{ft}^{2}$.

Bit quality ranged as higi as 65.3 .

These authors curfirmed the existence of the three regions of heat transfer found by the previous researshers. Further they zere at:s to elfminate the slight heat $f$ iw dependence reported iy sennett et al. for the suppressed mucieation region. Some lisic data points, inciudirg the 54: data points reported by Bennett et ai..$^{3}$ in the suppressed rivieasion region were correlated by the expression:

$$
\frac{h_{\text {TP }}}{h_{\text {sonv }, \operatorname{Lod}}}=2.15^{-}\left(\frac{I}{x_{t t}}\right)^{2.639}
$$

with a standard deviation of $26 . \not 3$. In this equation tine is guid-only coefficient is given ty $\Xi q$. $(2-8)$ with the properties of the ifigud evaluated at the $\mathrm{film}$ temperature, $\mathrm{T}_{f}$, as defined $i y$ :

$$
T_{p}=T_{\text {sat }}+0.32\left(T_{* i}-T_{s a t}\right) \text {. }
$$

Their data for the nucleate collirs region were not sorre:ated, although the pattern of the fata followed that obsersed ry Pennett et al. 
and is discussed above. Sinlarly, no attept was ade to correlate the data obtained under liquid deficient conditions.

In addition to a thorough discussion or both Bennett et al.'s and tiseir an extensive data, Collier and Pulling ${ }^{7}$ gave an excellent revies of a wber of proposed correlations pablished prior to 1963. These investigators testei the correlation of Schrock and Grossman or a representative frectios of their date and found that that correlation underpredicted the neasured coefficients in the suppressed nacleation region by ants up to 100, and overpredicted the ceesured coefficients in the meleate boling region by about 25\%. Collier and Pulling cor:ented that their data, unlike those of Schrock and Grossian, indicated a sharp transition from the nucleate bolling to the convective or suppressed macleation region and that an equation in which the two processes are wade additive cannot be expected to represent the data accurately in the vicinity of the transition. Since the two aechanisms of heat transfer are guite different in character, they considered it most unlikeiy that a simpie aditive-type equation can be wade to span the transition region with the desired accuracy.

Collfer and Puling tested their data against the Dukler-Hewitt ${ }^{35}$ analytical model for annular flow ard found that the calculated heat transfer coefficlents averaged about $50 \%$ (with considerable scatter) above the measured values.

Ten well-defined data points were used to estimate the transition from r.cleate tolling to forced convection based on the method proposed by $\mathrm{Hsu}^{36}$ for predicting the onset of nucleation in the boundary layer. Very good agreement was found between calculated and experimental results . 
Chen

Chen'" presented a correiatior at the : Conference that has recelred sonsideratle attention in: the susceeding years. [Although Chen's correiation bas arailatie at the Sonference as ASE Paper 6:-Er-34, it was gereraily urarailakle in the ijterature

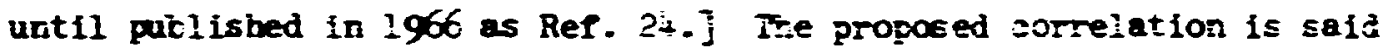
to te applicable to saturated, tro-phase, sonrectire tosing of nonnetallic nuids in the upflor aode. It is assuned that starle flow sonditions exist, with the heat flux being less than the critica: nwx. Slug flow and liquid deficient conditions are excluded. According to Chen, ${ }^{24}$ these conditions usually occur with anmuiar or annular-eist flow in the guality range of approximately 1 to 70 . In othe: words, the range of applicability is the nucleate toiling and suppressed macleation regions observed in the previously discussed investigations. In deveioping his correlation, Cher ${ }^{24}$ relied altogether on the date of Dengler and Addoms,,$^{15}$ Guerrieri and Palty, ${ }^{15}$ Bennett et al., ${ }^{13}$ Schrock and Grosswan, ${ }^{10}$ Sani, ${ }^{20}$ and Wright.$^{-1} P^{\prime}$ rst, a thorough comparison was rade of the correiations proposed by these investigators, using 665 reported data points covering the range of coniftions tabulated in Table II-1. The results of the comparisons as reported ty Chen ${ }^{24}$ are sumarized in Table II- 2 . He concluded the correlations were unsatisfactory for general use and turned his attention to developing a new correlation, using the above-mentioned data sources. The last column in Table II- $\hat{c}$ shows how well his results n:edicted the various data. Chen ${ }^{24}$ postulated that two mechanisms aro :molved in convective flow boiling of saturated, nonmetalli: pluids: the o,dinary macroconvection mechanism normally operative with fiowing fluids, and the 
'CABLE' II-I

RANGE OF CONDITIONS FOR DATA USED IN 'TEETING CORRKLATION"

\begin{tabular}{|c|c|c|c|c|c|c|c|}
\hline $\operatorname{Res} .^{b}$ & Fluta & Geometry & Flow & $\begin{array}{c}\text { Preseure, } \\
\text { pola }\end{array}$ & $\begin{array}{l}\text { Flow Velocity } \\
\text { It/oeo(Llyuld) }\end{array}$ & $\begin{array}{l}\text { Quall ity, } \\
\text { wt of }\end{array}$ & $\begin{array}{l}q^{\prime \prime} \times 10^{-4} \\
B t w / h r \cdot f t\end{array}$ \\
\hline 15 & Water & Tube & $U_{p}$ & 8.40 & $0.2-4.8$ & $15-11$ & $\therefore .8-50$ \\
\hline 18 & Water & Tulse & Up & $40-50 \%$ & $0.8-14.7$ & $3-50$ & $6.5-16$ \\
\hline $2 n$ & Water & Tube & Down & 16.31 & $0.8=\ldots . ?$ & $\therefore-j h$ & $.1 .4-5.0$ \\
\hline 12 & Water & Annulus & Up & $15-35$ & $0.2-0.11$ & $1-51)$ & $3.2-1.6$ \\
\hline 16 & Methano] & 'nube & Up & 1.5 & $1.0-2.5$ & ]-4 & $0.1-1.1$ \\
\hline 16 & L'yojohexane & Tube & Up & .5 & $1.3-2.88$ & $2-10$ & $0.3-1.3$ \\
\hline 16 & Pentane & 'Tube & Up & 15 & $0.4-6.0$ & $\because-1 \therefore$ & $0.3-1 . \therefore$ \\
\hline 16 & Heprane & Tube & $U_{p}$ & 15 & $1.0-2.4$ & $\therefore-10$ & $0.2-0.11$ \\
\hline 10 & Benzene & 'Tube & Up & 13 & $1.0-2.4$ & $a-?$ & $0.4-1.3$ \\
\hline 21 & Water & Tubs & Down & $16-6+3$ & $1.89-1] .2$ ? & $1-11$ & $2.3-13.8$ \\
\hline
\end{tabular}


TABLE II-:2

COMPARISON OF CORRELATIONS ${ }^{a}$

\begin{tabular}{|c|c|c|c|c|c|}
\hline \multirow[b]{2}{*}{ Data } & \multicolumn{5}{|c|}{ Average Percent Deviations for Correlatione } \\
\hline & $\begin{array}{l}\text { Dengler and } \\
\text { Addoms }\end{array}$ & $\begin{array}{l}\text { Guerriert and } \\
\text { Talty }\end{array}$ & $\begin{array}{l}\text { Bennett } \\
\text { et a.l. }\end{array}$ & $\begin{array}{l}\text { schrock and } \\
\text { Grossman }\end{array}$ & Chen \\
\hline $\begin{array}{l}\text { Dengle: and Addoms } \\
\text { (water) }\end{array}$ & 30.5 & $6 i \cdot 3$ & 20.0 & 20.3 & .14 .7 \\
\hline $\begin{array}{l}\text { Schrock and Grossman } \\
\text { (water) }\end{array}$ & 84.5 & 26.4 & 24.2 & 20.0 & 35.1 \\
\hline San1 (water) & 26.9 & 70.3 & 26.5 & 48.6 & 8.5 \\
\hline$\underset{(\text { water }}{\text { onnett }}$ et & 17.4 & 61.8 & 11.4 & 34.6 & 10.8 \\
\hline $\begin{array}{l}\text { Guerrierl and Talty } \\
\text { (methanol }\end{array}$ & $4: .5$ & 9.5 & 64.8 & 62.5 & 11.3 \\
\hline $\begin{array}{c}\text { Guerrierl and Talty } \\
\text { (cyclohexane) }\end{array}$ & 39.8 & 31.1 & 65.4 & 50.7 & 13.6 \\
\hline $\begin{array}{l}\text { Guerrierl and Talty } \\
\text { (benzene) }\end{array}$ & 65.1 & 8.6 & 56.4 & 40.1 & 6.3 \\
\hline $\begin{array}{l}\text { Guerrierl and Talty } \\
\text { (heptane) }\end{array}$ & 61.2 & 12.3 & 58.0 & 31.83 & 11.0 \\
\hline $\begin{array}{l}\text { Guerrierl and Talty } \\
\text { (pentane) }\end{array}$ & 66.6 & 9.4 & 59.2 & 35.8 & 1.1 .9 \\
\hline $\begin{array}{l}\text { Wrlght } \\
\text { (water) }\end{array}$ & 24.0 & 75.8 & 30.4 & 51.7 & 35.4 \\
\hline $\begin{array}{c}\text { Combined average for } \\
\text { all data }\end{array}$ & 36.0 & 47.5 & 32.3 & 34.7 & 6 \\
\hline
\end{tabular}


aferocourective nechanisin normally associated with nucleation and bubble grouth. He further postulated that these two mechenises were additive in their contribution to the total heat transfer, citing the sogges:ion of Rohsenowl that heat transfez $k y$ coarection and bolling can be added

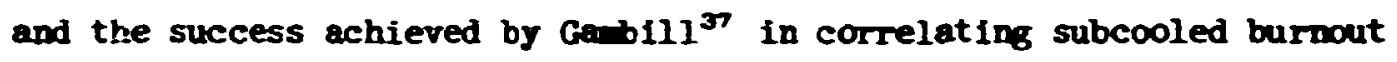
data with an additive-type equation. Chen reasoned that while the two mechanisas would be operative, their normal effects would be nodified by the presence of quality and by mitual interactions.

Since the Dittus-Boelter correlation would be appilcable in the limits of 0 and 100, quality, it was postulated that in the tro-phase region a modified version of this correlation should be used to deseribe the macroconvection contrłbution, Phus,

$$
h_{\text {macro }}=0.023(x / D) R_{R e}^{P .8} F_{P r}^{0.4} \text {, }
$$

where the chysical properties and the mass flw. ( $\mathrm{R}_{\mathrm{Re}}$ ) are effective values for tice two-phase fluid. For ordinary fluids (excluding liquid metals), the Prandtl moduli of the liquid and rapor phases are cormally of the same magnitude; the two-phase Prandtl modulus should therefore also be of the same magaitude. Furthermore, since the heat is transferred through an annular film at the wall, the liquid properties should be dominant. Chen assuned as a first approximation that the effective values could be replaced by the liquid-only values and that the racroconvection contribution souid be expressed as:

$$
r_{\text {macro }}=0.023\left(k_{\ell} / D\right) N_{R e, l}^{P .8} \mathbb{R}_{\mathrm{Pr}, l}^{0.4} \mathrm{~F}_{\mathrm{TP}} \text {, }
$$

where $F_{T P}$ is defined as:

$$
F_{T P} \equiv\left(N_{R e, T P} / r_{R e, \ell}\right)^{0 . A}=\left[N_{R e} \cdot \frac{\mu_{\ell}}{D G(1-x)}\right]^{0.8} \cdot(2-23)
$$


In priniple the on 7 unknown in $\mathrm{Eq} .(2-23)$ is $\mathrm{F}_{\mathrm{TP}}$; this ratio is stricily fow parameter and is related to the kartinelli parameter, $x_{t t}$

The araigsis of Porster and Zuber ${ }^{30}$ vas =hosian as the jasis for formalacing the microconvection contribution to the total hea: transfer. These investigators derived for the case oi pcol boiiing from horizontal surfaces the following equations for the bciling Muss slt modulus:

$$
\mathrm{H}_{\mathrm{Tu}}=0 . \operatorname{col} 5 \mathrm{~K}_{\mathrm{Re}}^{0.62} \mathrm{R}_{\mathrm{Pr}}^{0.32}=\mathrm{hr}_{\mathrm{r}} / \mathrm{k}_{\ell} \text {, }
$$

where

$$
I_{b}=\frac{\Delta r}{n_{I_{B}} \rho_{B}}\left(\frac{2 \pi k_{i} \rho_{\ell} C_{D_{l}} \sigma}{\Delta P}\right)^{0.5}\left(\frac{\rho_{\ell}}{\varepsilon_{c} \Delta P}\right)^{0.25},
$$

and

$$
N_{\mathrm{Re}}=\left(\frac{\pi k_{l} C_{\rho_{\ell} l}}{\mu_{l}}\right)\left(\frac{\rho_{l} \Delta r}{\rho_{8} r_{f_{\ell}}}\right)^{2} \text {. }
$$

One of the basic premises of Eq. $(2-30)$ is that the Reynolds modulus for coiling is determined by the bubble growth rate as alescribed by the Kayleigh equation. Forster and zuber were able to solve the Rayleigh equation to show that the product of the blibbie radius and the bubble growth rate is a constant for a specific superfieat. Cher reasoned that the superheat across the boundary layer (through which bubble growth and detachment takes place) was not constent and, therefore, that the Reynolds modulus wust be representat: ve on some man, effective superheat. According to Chen, the difference between the wall superheat and the effective superheat is smail for foci boliting and could be neglected in the Forster-Zuber analysis. However, Ifi flow bolling this difference cannot be neglected, since the radial temperature gradient is a function 
of flow rate and vapor quality and is in general wuch steeper than for the case of pool toiling sith the same degree of wall superheat.

Rased on this postulate, $\mathrm{Eq} .(\Sigma-30)$ was then written by Cren in termi of pizsicai properties and effective vaiues of $\mathrm{I}_{\mathrm{e}}$ and $\mathcal{P}_{\equiv}$ as:

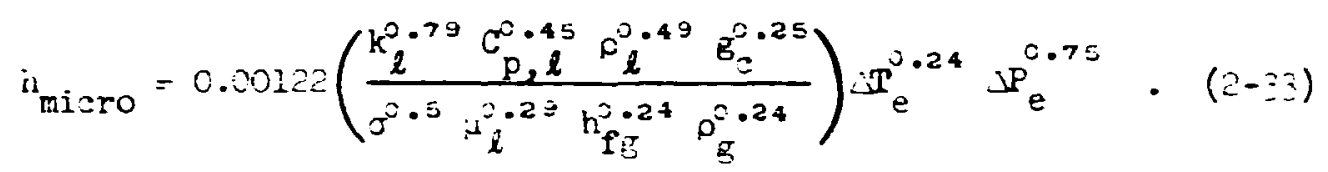

A suppression factor, $s$, was iefined as the 0.00 power of the ratio of the efrective superheat to the cot:l superheat of the wall; namely:

$$
S \equiv\left(\frac{\Delta \Gamma_{\epsilon}}{\Delta T}\right)^{-\cdots}
$$

The choice of the power in $5 q .(2-34)$ was arbitra.iy taken as 0.99 , so that $S$ would appear to the first power in the final equrtion.

Writing the Clausius-Clapeyron equation in turms of t:e effective and the wall superheats:

$$
S_{e}^{2 . j 3}=\left(\frac{T_{e}}{h_{f_{g} \rho_{g} j}}\right)^{0.75} \Delta T_{e}^{0.24} \Delta P_{e}^{2.75}
$$

and

$$
\Delta \Gamma^{\circ .99}=\left(\frac{T}{h_{f g} \rho_{g} j}\right)^{0.75} \Delta T^{0.24} \Delta P^{0.75} .
$$

For amal: tempereture differences:

$$
\left(\frac{T_{e}}{h_{f g} \rho_{g} j}\right)_{T_{e}}=\left(\frac{T}{h_{f g} \rho_{g} j}\right)_{T},
$$

inin:

$$
S=\left(\frac{I_{e}}{\Delta P}\right)^{0.24}\left(\frac{\Delta P_{e}}{\Delta P}\right)^{0.75}
$$




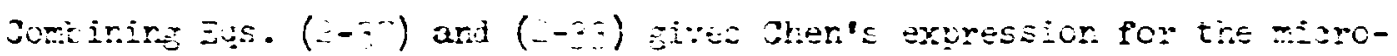

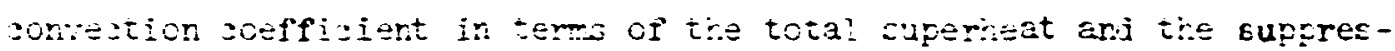
zion fastor:

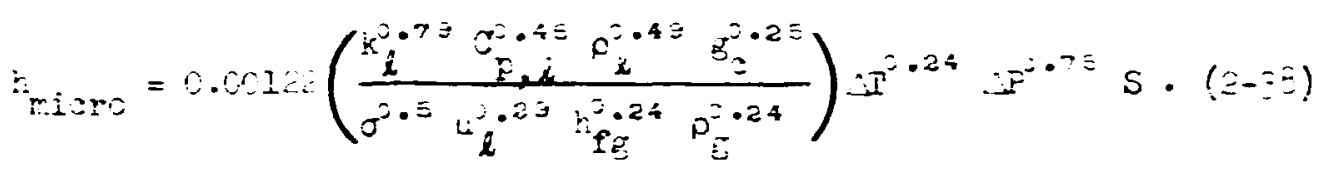

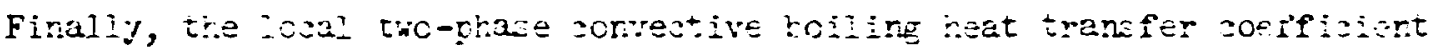
is giver: ty:

$$
h_{T E}=h_{\text {masro }}+h_{\text {misro }} \text {, }
$$

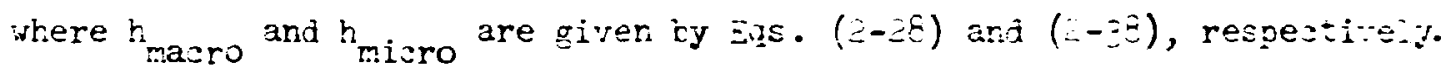

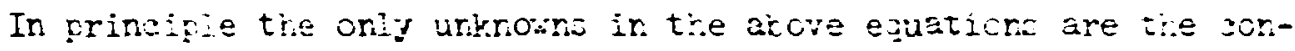
vective enharzement factor, $F_{T P}$, and the rusleate toiling suppression factor, S. These rere determined empirisaliy ty chen from the data sourzes mentioned atove ty an iterative prozedurs ard are preserted in Figs. II-I and II-E. The shaded area in the pieures resrecent the data satter arouni the two correiatins funstions. The zorvesi:e erhaneel:ont factor, $F_{T P}$, increases smoothly with insreasine veiues of the reciproca? Martinelli parameter, indicatins the effect of insreaced turkulence with increasing vapor fraction. The nueleaticn suppression factor, S, tends to unity at loir values of the tro-phase Reyolds roduIus and to zero at high values of the modulus. Acsording to chen, these trends appear reasonal 1 e in that at low flows and jow vapor fraction the toiling contribution is relatively important: whereas at hish fiows and high vapor fractions, nucleation is suppressed and the conveative mechanism becomes increasingly important. These trends are also consistent with experimental ofservations. 


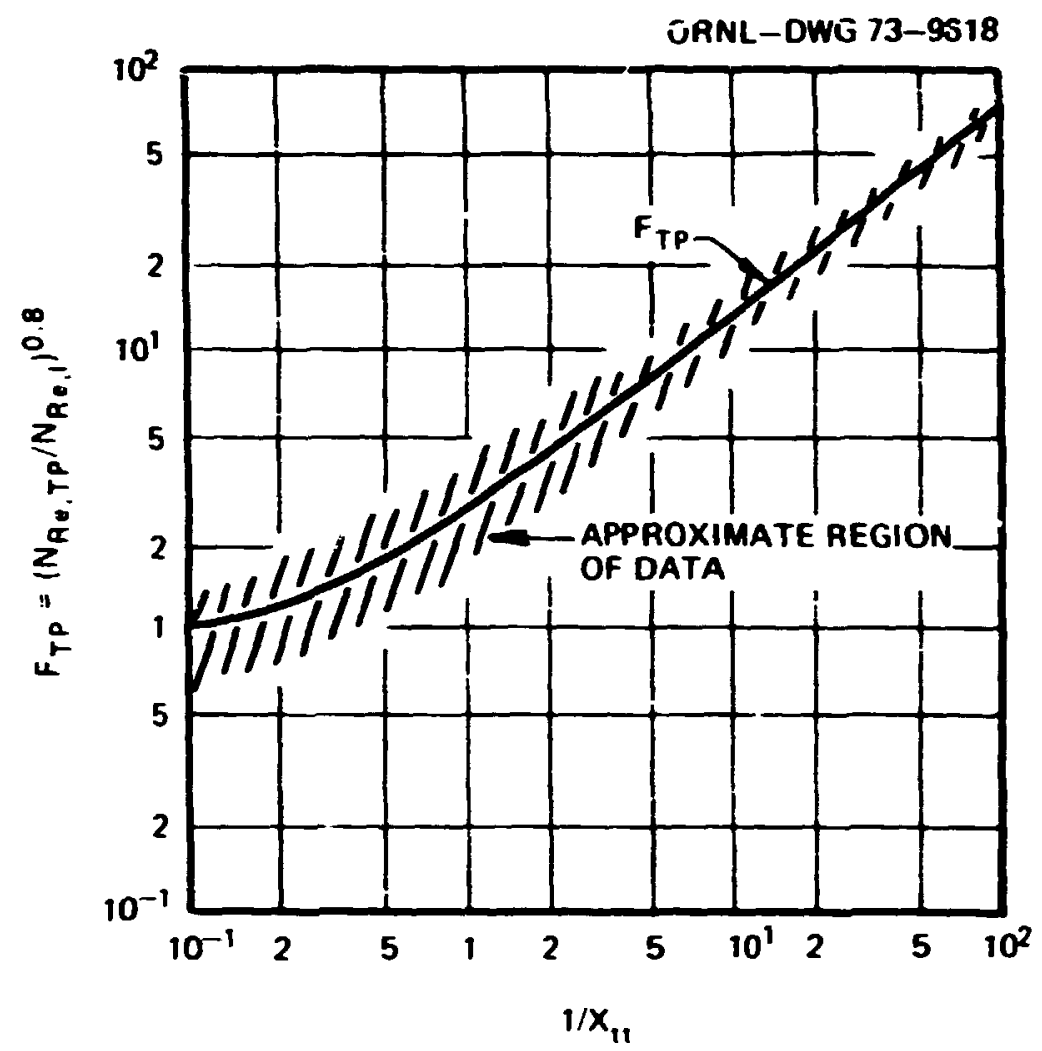

Fig. II-1. Chen's flow enhancement factor.

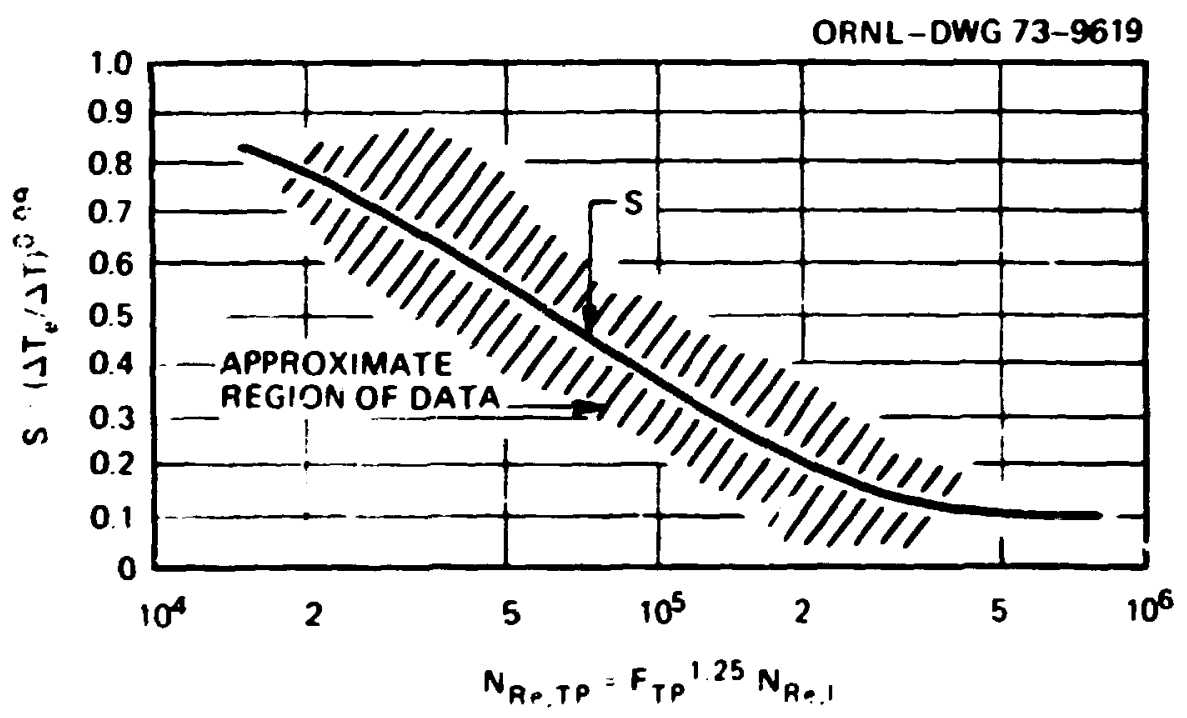

Fig. II-. Chen'z nucleation suppression factor. 
As indicated in Table II- $\hat{2}$, Chen's sorreiation shows a definite improvement over those proposed by the cther investigatcrs. Based on this suscess, standard references ${ }^{29-31}$ on two-phase flow and boiling heat transfer recomend the use of Iher's sorrelation for sonvective boiling situations. Hore recently $(19-2)$, Tong ${ }^{39}$ resomended the correlation for application to the thermal-hydrauliz design of muciear reactor sores.

\section{Shghmark}

A] though Chen's correiation is accepted as being the best availatle, Hughmark ${ }^{4}$ was unakle to correlate his data with it. In particular, it appeared that a value of $S=0.25$ ketter fit his data where nueieation apparently occurred. This seems to imply that $s$ is independent of $\mathrm{N}_{\mathrm{Re}, \mathrm{TP}}$. Hughtark also points out that Chen's microconvection expression neglests the effest of metal surface-fluid coukination on nucieate boiling. This factor is $\mathrm{known}^{33,34,4 b-46}$ to te an important variable.

Stone

Stcne, ${ }^{47}$ in a thorough investigation of convective bolling of water over a wide range of conditions, tested his extensive data against the correlations of Dengier and Aädoms, ${ }^{1} \equiv$ Schrock and Grossman, ${ }^{2}$ Wright, ${ }^{23}$ Collier and Pulling, ${ }^{17}$ and Chen $^{24}$ and found that all were Iradequate in that $x_{t t}$ did not appear to be the proper correlating paraneter. In particular, for constant heat flux, mass velocity, and quality, the data showed that $h_{\text {Tp }} / h_{\text {conv }}$ increased with increasing pressure; whereas the correlations predict the opposite, due to the effect of pressure on the physical properties in $x_{t t}$. Stone ${ }^{47}$ did not propose a correlatins 
technique, but he did speculate that a nonequilibrium model sight te more successful.

Owhadi et al.

Orhadi et $\underline{\text { el }} .,^{40}$ in a study of forced-convection boiling of water at atmospheric pressure in electrically heated, helically soiled tubes, found reasonably good agreement of their data with Chen's ${ }^{24}$ correlation. The predicted soefficients were about $15 \%$ high at lor quelities and about 158 low at high qualities. On the other hand, the correlintion of Dengier and Addons ${ }^{15}$ predicted values, on the average, mly lop less than the experimental values in the low and medium quality ranges. Both correlations predicted coefficients several times to high for the very high (200\%) guality range. This is to be expested since neither is applisatle under liguld deficient conditions.

\section{Pu,jol and Stenning}

Pujols studied the effect of flow directioia on convective boiling heat transfer in an electrically heated, stainless steel pipe, using Freon-11:. The test section was $0.522-1 n$. nominal inside diameter pipe, having a totai heated length of 1 ? $\mathrm{ft}$, tent to a serpentine form to provide two upfiow and two downflow seztions of equal length. The mass flux was varied orer the range $1.49 \times 10^{6}$ to $1.4 \mathrm{C} \times 10^{6} \mathrm{lt} / \mathrm{hr} \cdot \mathrm{ft}^{2}$, with qualities in the range of 0 to 70 ; pressures ranged from $1^{\text {- }}$ to 64.2 ps 1a. The derived Martinelli parameter, $x_{t t}$, showed a spread of 0.065 to 8, ; whlle the bolling modulus, $\mathrm{Bd}_{\mathrm{Bd}}$ varied between $1.09 \times 10^{4}$ and $5.5 \times 10^{-4}$. 
Pujol and Steming ${ }^{3}$ anaiyzed Pujol 's data and found that the difPerence betueen upflow and domfiow bolling heat transfer coefficients vas small in the suppressed nucleation region tut was sutstantial in t'le nucleate boiling region; higher coefficients vere otserved in the upflow mode.

The equation that best correlated $( \pm 15 \%)$ the suppresse: nucieation: data ior toth upplow and downflow modes was found to ke of tine tyge suggested ty Dengler and Addoms: $:^{15}$

$$
\frac{h_{\text {TP }}}{h_{\text {conv }}}=4.0\left(\frac{1}{x_{t t}}\right)^{0.37} \text {, }
$$

where $h_{\text {eonv }}$ is as given ky Eq. $(2-2)$.

Correlations of the tjpe suggested cy Schrock and Grosiman, ${ }^{1}$ applicable to both the nucleate bolling and the suppressed nuclestion regions, were also developed. For upflow, Pujol and stenning's test equation was:

$$
\frac{h_{\mathrm{TP}}}{h_{\text {conv }}}=0.90\left[H_{\mathrm{BO}} \times 10^{4}+4.45\left(\frac{1}{x_{t t}}\right)^{0.37}\right] ;
$$

and for downelow:

$$
\frac{h_{\mathrm{TP}}}{h_{\text {conv }}}=0.53\left[\mathrm{~B}_{\mathrm{BC}} \times 10^{4}+7.55\left(\frac{1}{x_{t t}}\right)^{0.37}\right]
$$

In the limit, as $\mathbb{F}_{B o}$ tends to zero, both Egs. (2-4.1) and (2-42) degenerate to give Eg. $(2-40)$. The accuracy of Eqs. $(2-41)$ and $(2-42)$ is not as good as that of Eq. $(2-40)$ in the suppressed nucleation region, since this region is not necessarily restricted to low values of $\mathrm{N}_{B O}$. The equations predict values about 10 to $20 \%$ high in this region. 
In the discussion of Pajol and Steming's paper, ${ }^{23}$ these wthors point out that they coparnd their suppressed nucleation data vith Chen's $s^{24}$ acroconvection tern and found good agreenent. Although the slope of Chen's Emhancenent factor (Fig. II-I) was larger than the authors, this was attributed to $\mathrm{a}$ slight difference in the definition of the single-phase forced-convection coefficient.

Rohsenor

Historieally, Rohsenow ${ }^{2}$ aade one of the first attempts to correlate forced-convection boiling. He suggested a simple additive-type equation for the total heat transfer rate:

$$
q_{\text {IP }}^{\prime \prime}=q_{\text {boll }}^{\prime \prime}+q_{\text {corrv }}^{\prime \prime} \text {, }
$$

where $q_{\text {conv }}^{\prime \prime}$ was computed from a wodified Dittus-Boelter equation in which a coefricient of 0.019 (rather than 0.023 ) was used, and $q_{\text {boil }}^{\prime \prime}$ could be correlated with the Rohsenow pool bolling cirrelation, Eq. $(2-23)$.

Piret and Istin

A number of investigators have followed the Rohsenow method for correlating forced-convection bolling heat transfer data. Piret and Isbin ${ }^{50}$ correlated natural-circulation bolling heat transfer data (at atmospheric pressure) for water, isopropyl and n-butyl alcohols, carbon tetrachloride, and potassium carbonate solutions in this manner with good results.

Beaver and Hughmark

Beaver and Hughmark ${ }^{61}$ also used this method to correlate the mucleate bolling region in a single tube thermosiphon investigation 
under sub- and atmospheric pressure conditions for 12 organic fluids. Their data for the suppressed nacleation region did not correlate vell vith the correlation of Dengler and Addars, 15 but showed ilproved agreewent when plotted against the reciprocal of the liquid voluse fraction to the 0.8 porer in place of the reciprocal martinelii paraneter.

\section{Blatt and Adt}

Rlatt and Adt ${ }^{52}$ invest $i_{\text {fated }}$ forced-convection toiling beat transfer to Preon-11 and Preon-113 in horizcntal tubes and correlated their results by the Rolssenow whod. Usiog values of $\mathrm{f}_{\text {sf }}$ (the rurface-fluid factor is Rohsenow's pool boiling correlation) determined experimentally, all their nucleate bolling data vere correlated with an average deviation of about $30 \%$.

\section{Sato et al.}

Sato et a‥ ${ }^{26}$ recently (1972) reported on an extensive investigacion of flos patterns and heat transfer in the (saturated) mucleate boiling region for upflowing water in a rectangular flow channel (15 x $10 \mathrm{~mm}$ ), having a heated length of $1000 \mathrm{~km}$. As observed by many investigators, the transition between the various flow patterns was found to be complex and jependent on flow rate, heat flux, heated length, and channel diameter. In the bubbly flow regime, bubble diameter decreased wh increased flow rate; the bubbles had a tendency to collect mainly near the wall. They observed that the liquid film on the wall adjacent to slugs of vapor was rather thick when noticeable mucleate bolling occurred. In the slug-to-anmular transition flow regime, bubbles were observed to mucleate and grow to large diameters in the liquid film. Slug flow was 
not observed in the higher f.ou range, instead the bubbly annuler regine appeared. The transition between the flow patterns occurred at lower quality as the heat flux, the flow rate, of the heated length was increased and as the flow chamel dianeter decreased.

Based on the observed flor patterns, Satn et al. ${ }^{25}$ correlated their saturated bolling heat transfer data for the mucleate boiling region (bubble flow range) by an additive correlation of the form suggested by Rohsenor ${ }^{22}$ as:

$$
q_{\text {IP }}^{\prime \prime}=q_{\text {boil }}^{\prime \prime}+q_{\text {conv }}^{\prime \prime},
$$

where

$$
\begin{aligned}
& q_{\text {boil }}^{\prime \prime}=4.5 \mathrm{e}^{\mathrm{P} / 20}\left(G_{\ell} \times 10^{-6}\right)^{-1 / 3} \Delta \pi_{\text {sat }}^{3.6},
\end{aligned}
$$

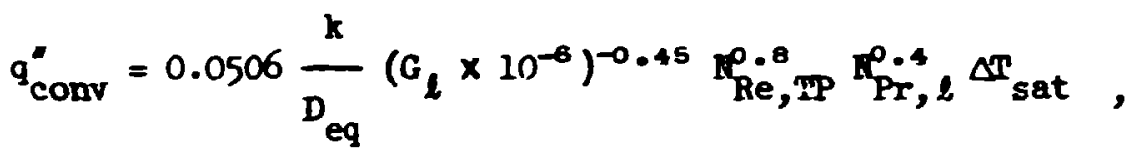

$$
\begin{aligned}
& G_{l}=\frac{1-x}{1-t_{d}} G \text {, } \\
& f_{d}=1-\left(\frac{(1-x) \rho_{g}}{x \rho_{l}+(1-x) \rho_{g}}\right)^{0.5} \text {, }
\end{aligned}
$$

and

$$
N_{R e, T P}=\frac{G_{l} D_{e}}{\mu_{l}}
$$

Metric units are employed in the above equations; in particular, the preseure normalization factor in ES. $(2-45)$ is in $\mathrm{kg} / \mathrm{cm}^{2}$ and is applicable over the range 1 to $150 \mathrm{~kg} / \mathrm{cm}^{2}$ (Rer. 53). The pressure and twophase flow dependencies given in the above equations were derived specifically from these authors' work and are not necessarily general. 
Howerer, they speculate that their method of correlating the flow patterns witn the heat transfer equations ay have general applicability.

Xutateladze, Domansil, Andreyev, et al.

The Russian literature generaily correiates forced-convection boiling heat transfer by an expression of the type:

$$
\frac{h_{\text {IP }}}{h_{\text {conv }}}=\left[1+\left(\frac{a h_{P B}}{h_{\text {conv }}}\right)^{n}\right]^{y / n},
$$

where $a$ and $n$ are empirically deterwined constants. Kutateladze recomends $a=0.7$ to 0.8 and $n=2$. Domanskif ${ }^{55}$ suggests $a=C .5$ and $n=3$. Araireyer et $\underline{a} .{ }^{26}$ indicate $n=3$ and give a modifled pool boiling expression for the term "ah $\mathrm{PB}^{n}$

Chawla

Cramla ${ }^{56,57}$ proposed a parameter different from the Martinell1 parameter for correlating the forced-convection boiling heat transfer coeffictent. He defines a two-phase flow parameter, e, as the ratio of the mean liquid velocity to the mean vapor velocity, witich ne correlates 58.59 (using measured two-phase flow pressure drop data) as a function of $x, \mathbb{N}_{\mathrm{Re}, \ell}, \mathrm{K}_{\mathrm{Fr}, \ell}, \rho_{\ell} / \rho_{\mathrm{B}}, \mu_{\ell} / \mu_{\mathrm{B}}$, and reiative tube :rall surface roughness, $e / D$. The results of this correlation are presented in Fig. II-3. Since the jor portion of the heat is transferred to the liquid film on the wall, Chawla defines an equivalent hydraul ic diameter for the liquid film as:

$$
D_{e q, l}=D\left[1-\left(1+\frac{1-x}{x \in \rho_{l} / D_{g}}\right)^{-0.8}\right] \text {, }
$$

for use in the definition of the so-phase Nusselt modulus, N $N_{\text {MU, TP }}$ 


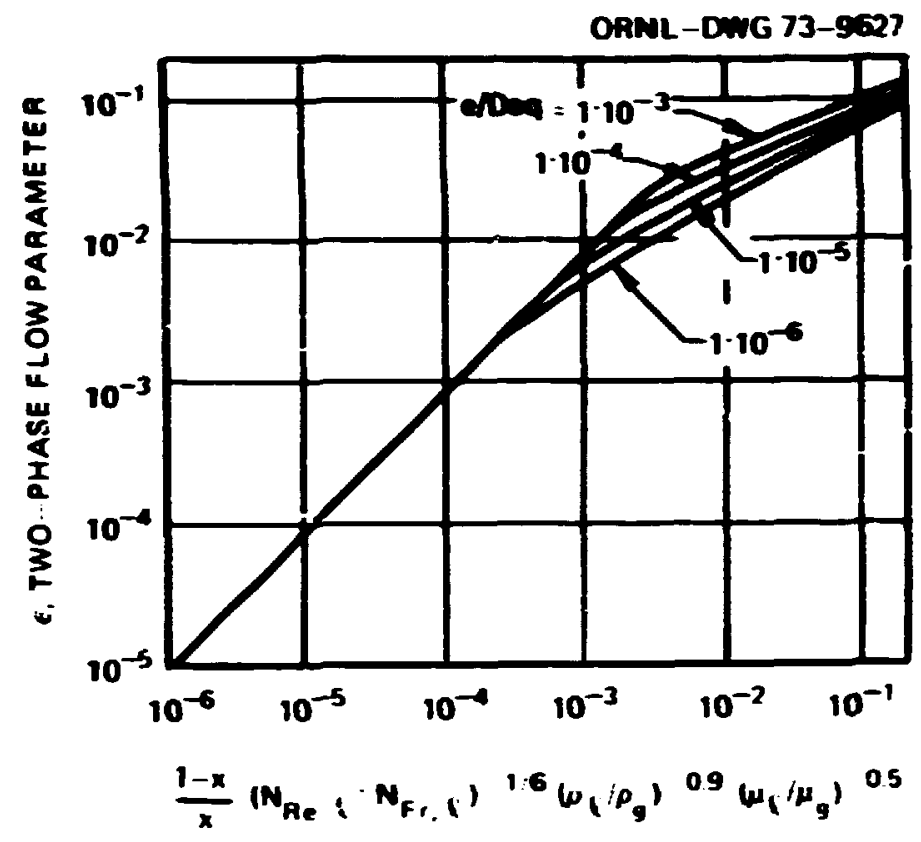

Fig. II-3. Chawla's two-phase flow parameter, c.

Using the two-phase heat transfer data of Penman and $\mathrm{Taft}^{60}$ for vater, methanol, ethanol, 2-prupanol, and chloroform, of Lavin and Young ${ }^{61}$ for Preor-12 and Freon-22, and of Charla $a^{57}$ for Freon-11, he was able to correlate the entire data set to within 30\%. Chawla's set of recommended 66.57 dimension' ess equations for the forced-conveetion boiling heat transfer in the quality range $0<x<1.0$ is:

Por $\mathrm{N}_{\mathrm{Re}, \ell} \cdot \mathrm{N}_{\mathrm{Fr}, \ell}<109$ :

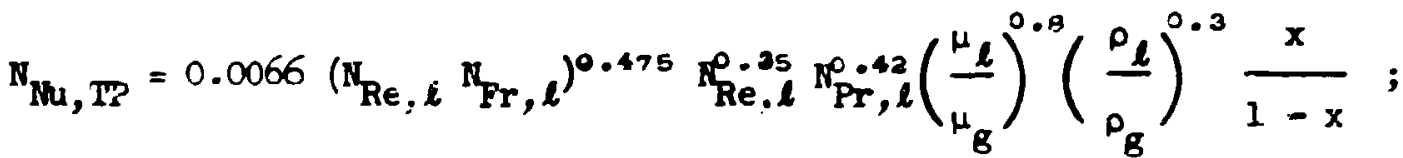

and for $\mathrm{N}_{\mathrm{Re}, \ell} \cdot \mathrm{N}_{\mathrm{Fr}, \ell}>109$ :

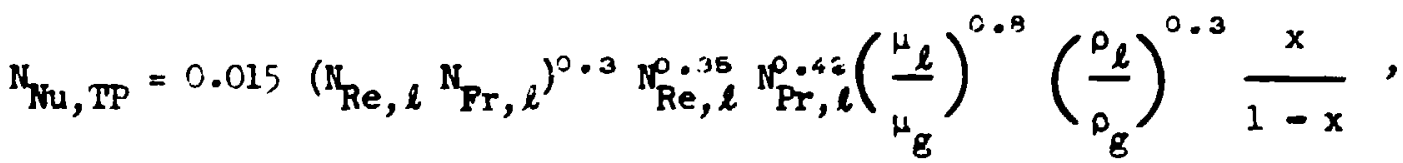


where

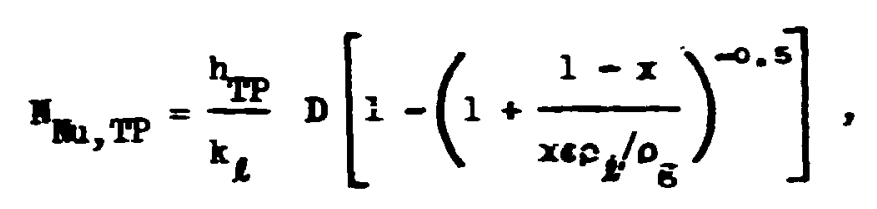

and $c$ is as presented graphically in Fig. II-3.

\section{Pool Boiling}

\section{Zuber and Fried}

Zuber and Fried ${ }^{3}$ discussed nucleate pool bolling and compared in detall a nuber of proposed correlations with particular exphas is on their application to cryogenic liquids. In addition to a lucid discussion of the dimensionless moduli used to correlate pool bo:11.78 heat transfer, tinis revier (published in 1962) provides a list of 61 references. In 1964 zuber $^{62}$ critically reviewed the state of the art for mucleate pool bolling (101 references are included). These two reviews are strongly recowmended for an overview and detalled discussion of the world literature avallable at that time. According to Zuber, 62 more than three dozen equations had been proposed for correlating nucleate pool bolling; a number of additional ones have been suggested since 1964. Some of the more widely known are given in Refs. 34, 38, 46 , and 63 through 80 .

Since the high heat transfer rates associated with micleate boiling are attributed to bulb]es tinat induce a strong localized agitation in the thermal boundary layer, most of the correlations are formulated in terms of a bubble Reynolds moduius and a bubble Musselt modulus. The significance of these 18 discussed hy Zuber and Fried. ${ }^{3}$ Nost of the correlations result in an expression for the heat transfer coefficient of 
the form:

$$
h_{\mathrm{PB}}=\operatorname{consi}\left(\mathrm{T}_{\mathbf{w}}-\mathrm{T}_{\text {sat }}\right)^{\mathrm{b}}
$$

where $b$ varies between 1 and 3 , and the constant depends on the therwodynamic properties of the fluid. Rohsenow ${ }^{32}$ fnciuded a surface-fluidcombination factor in the constant to account for some of the properties thought to be importent but not included in the correlation. Munerous investigations (e.g., Refs. 41 through 45, 70) have shown that different meleating surface characteristics affect not only the constant in Eq. (2-55) but also the power of the temperature difference factor.

Nishikgure sin iamagata

Nishfikawa and Yamagata ${ }^{69}$ were among the first to propose that pcol bolling data correlated well with a two parameter eqaation of the type:

$$
q^{\prime \prime}{ }_{P B}=\text { const }\left(T_{w}-T_{s a t}\right)^{b}(N / A)^{c},
$$

where $N / A$ is the bubble population (or nucleating site) density. Subsequently, a number of investigations (e.g., Refs. 70 through 73, 75, 76) confirmed this observation; and several of the proposed correlations include this parameter. A difticulty lies in the fact that reliable nethods are not avallable to predict the site density.

\section{Mikic and Rohsenow}

Mikic and Rohsenow ${ }^{75}$ assumed that the experimental results of Brown ${ }^{81}$ on site density could be generalized to sroride a reiationship for the site density for use in their prcposed correlation; insufficien: evidence exists to substantiate this assumptior.. Thus, in the absence of a reliable method for quantifylng the site density, the designer has 
few cholces $c$ aslable for predicting the performance of a given pool boiling system. Since the Rohsenow correlation ${ }^{30}$ purports to do this and has been showr to correlate experimentel results yith reasonable accuracy, wide use is mde of $1 t$. In consequence, monerous investigetions $33.50 .82^{-04}$ have been undertaken to broaden the range of siarfacenuid factors for this correlation.

\section{Fucleation Models}

Zuber $^{62}$ comented that there was no completely satisfactory theory of bubble macleation from a heated surface. Bxperimental obe'srvations show that bubbles macleate at superheat temperatures considerably belor values predicted by classical theories. Clark et aㅡ. ${ }^{85}$ and Griffith and Wall18 ${ }^{86}$ shored conclusively that bubbles meleate from surface irregularities, such as pits, cavities, and scratches. The interaction of the boundary layer, the diameter of pits, and the heat flux density has been analyzed by a riumber of investigators, based on the assumption that the temperature prifile is Iinear near the heated wall. This assumption appesrs yil substantiated by the temperature measurements of $\mathrm{JIJ1}$ and Clark, ${ }^{87}$ Narcus and Drcipkin, ${ }^{88}$ and Bobst and Colver. ${ }^{99} \mathrm{Hsu}^{36}$ proposed a criterion that has froved reasonably successful for determining the size ranze of effective cavities. Collier and Pulling ${ }^{7}$ were able, using Hou's method, to estimate the transition from nucleate boiling to forced convection with very good agreement between pridicted and measured values.

Rohsenow roviewed macleation phenomena and, using Brown's results, ${ }^{\theta 1}$ suggested that the position of the bolling clirve for pool 
boiling should be a strong function of the heating surface characteristics but that for forced-convection boiling the influence would be mach less.

\section{Heat Transport Models}

Earlier fundamental nucleate boiling studies were based on the behavior of separate bubbles; $1 . e .$, the xigime of isolated bubbles. ${ }^{62}$ In this regime, which is restricted to low heat flux densities and hence to low vapor flow rates, liquid is set in motion by giowing and rising bubbles. Source flow (11quid displacement) accompanies bujble growth in the thermal boundary layer, and liquid entrainment takes place in the wake of rising bubbles. This source and wake flow induces liquid circulation in the boundary layer. It appears that heat transfer in this regime is primarily by localized convection, or microconvection as it is often referred to in the boiling literature.

As the heat flux increases, bubbles begin to interact to form vapor columns and large vapor patches: this has been termed the regime of interference. ${ }^{62}$ The transition from the first regime to the second takes place when the space between the two adjacent bubbles is about 1.5 to 2 times the bubble diameter. ${ }^{92.92}$ Gaertner ${ }^{92}$ noted that the change in flow regime corresponded to the inflection point on the bolling curve. He showed further that the transition was not only marked by a change in the flow in the vicinity of the heating surface but also by a change in the shermal boundary layer thickness and, therefore, in the heat transfer mechanism. The heat transfer mechanism in this regime is thought to be microlayer evaporation and latent heat transport. 
Several models have been hypothesized to explain nucleate pool boiling, some of which are undoubtedly valid in part. Hovever, experimental jerification of the various hypotheses has been difficult to obtain due to the complexities of the boiling phenomena. A brief overview will bs given of some of the more promirent models; more detail is fourd in the referenced sources.

Microconvection model. This mociel, depicted schematically in Fig. II-4a, assumes that rardom miczoconvection is induced in the superheated layer by bubble action. Heat transfer is considered to take place from the heated suriace to the superheated liquid; augmentation results from the action of the induced microcurrents. Heat transport by vapor bubbles is considered negligible. This concept is generally dis"sarded in the current boiling licerature.

Latent heat transport model. This concept (show schematically in Fig. II-4b) assumes that each bubble as it nucleates, grows, and departs transports heat from the heated surface and deposits in the bulk fluid (by condensation and/or bubble collapse) an equivalent bubble vilume of latent heat. The model is only concerned with the mechanism by which heat is removed from the superheated layer and does not consider the transfer of heat from the surface to the superheated layer. This model was highly regarded by early bolling researchere but fell into disfavor as other models were proposed. In 1964, Kollis and Jawurek ${ }^{93}$ reintroduced it by reporting an experiment in which it could be shown that latent heat transfer and natural convection together accounted for the total heat transfer for saturated water boiling on a 


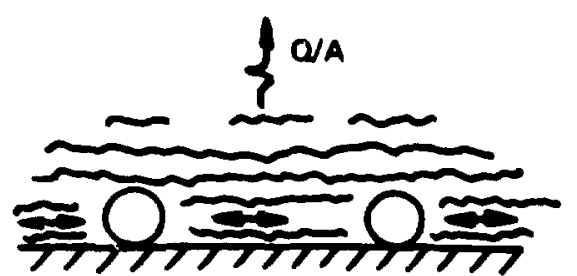

(a) MICROCONVECTION MODEL

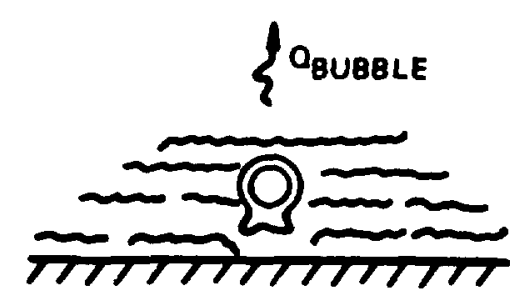

(d) ENTHALPY TRANSPORT MODEL

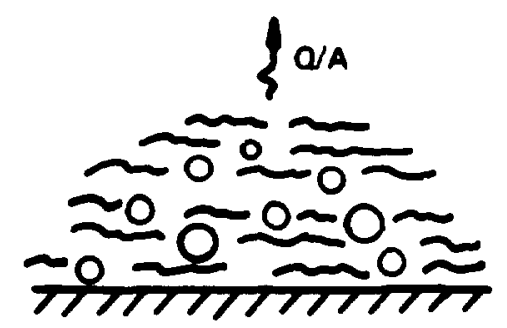

(g) ENHANCEO NATURAL CONVECTION MODEL

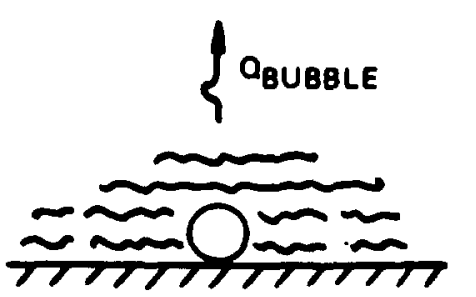

(b) LATENT HEAT TRANSPORT MODEL

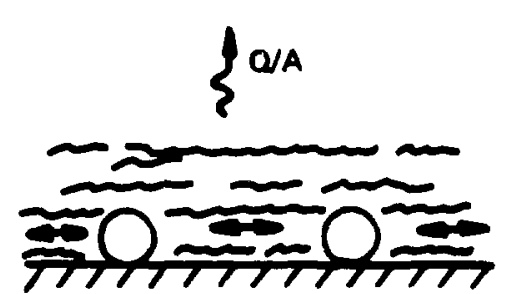

(1) SOURCE FLOW MODEL.

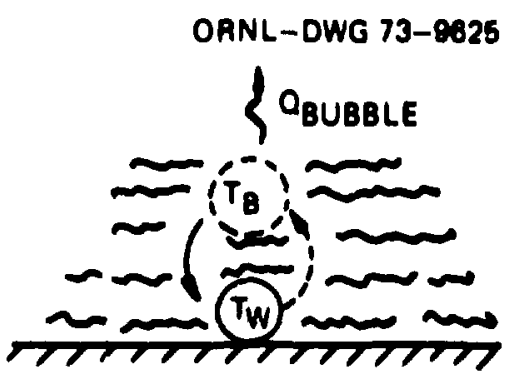

(c) VAPOR-LIOUID EXCHANGE MODEL

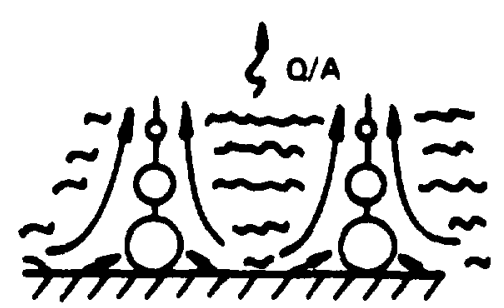

(8) WAKE FLOW MODEL

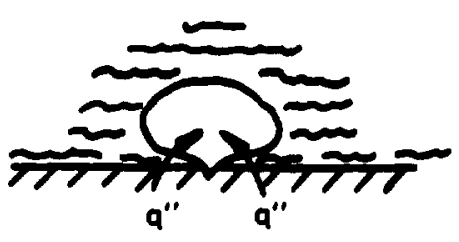

(h) MICROLAYER VAPORIZATION MODEL

F1g. II-4. Bolling heat transfer models. 
horizortal wire. Once again, the latent heat transport oodel is considered a possible mechanism in the isolated bubble regine.

Vapor-11quid exchange model. This concept (see Fib. II-4c) assures the vapor bubbles act as a piston pum. As the bubbles grou and depart from the heated surface, hot fluid is displaced from the ouperhented layer to the bulk liquid. Cooler fluid (from the bulk liquid) is drarn in to replace the vold created by the departing bubbles. Latent heat transport is assumed negilgible. The doatinant mechanism in this wodel, as proposed by Forster and Grief, ${ }^{68}$ is the transport of sensible heat associated with the volume of the vapor bubbles.

Enthalpy transport model. This concept, proposed by Han and Griffith, is illustrated in $\mathrm{FI}$. II-4d; the transport of enthalpy from the superheated layer to the bulk liguld is accomplished by departing bubbles, soweshat like the vapor-ilguid exchariger wodel of Forster and Grief. The quantity of heat transpciced by each bubble is assumed to equal the enerty content of the boundary layer within the region of influence stout a iven nucleetion site. inis region is taken to be an app:oximately cylindrical volume of twice the bubble departure diameter and of helght equal to the boundary layer thickness at the instant of departure. Transient conduction is considered to be the mechanism by which heat is transferred from the heated surface to the superheated layer. Although the model predicted Han and Griffith's experir ental data with good accuracy, these investigators conceded that an extraordinary amount of data about the surface was required. Such detailed descriptions are not usually avallable for systems of practical interest. 


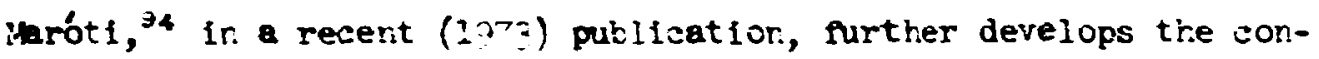
sept of enthalpy transport as the dominart meshanism for fully developed nucleate pool coiling of saturated fluids. He slaims good agreement for infs sorrelatio: ith pullished experimertal results. He also dismisses micrclayer evaporation (see kelow) as ceirg irsignificant in most cases.

Scurce floi model. This modei, shown schematisaily ir. Fig. II-ie, attributes the hligh boflirg heat transfer rates to the combired action of microcorvection irdused by growth, detachmert, and collapse of kutEles (kuble agitation) and transient zorduction to the liquid flowing ir. to replace tive coilapsed butkles (surface querching). This model serres as the basis of Roheenow's correlation. ${ }^{32}$ 3arkoff's was able to express the more? mathematically (without resorting to dimensional analysis) :iti: a single arbitrary constant which mast be obtained from experimen:al data.

Wake Plon model. This concept, pictured ir. Fig. II-4f, was proposed ky Tier ${ }^{71}$ and is hased or. the similarity of axisymetric stagration flo: It is assumed that the periodis detachment and rise of butbles in tr.o isolated kubble regime can be replased with a continuous columr: morirg upward through the boundery layer. The resultant upward flow patterr induced fr. the adjacent lifuid in the wake of the vapor column is approximated by an inverted stagna-ion flow model. Boehm and Lienhara ${ }^{25}$ modified Tien's model to include an additional term to acccurt for heat transfer associated with the transient wake flow induced ky departure of individual bubbles. According to Tien, this model can also be used for the region of bubble interference. 
Erreraed ratura!-zoryestion model. Tria rode? (Fig. II--g) was proposed zy Zuker for the isclated tuikie regime. It is kased or the similarity ket:asr. rusieate toilire ard turiulert ratural corvestion With respest to the irdusea zirculation that gorerrs teat trarsfer ir. toth zases. Ihe molel assumes that thermally induced kuojarey ir. the Iigid is augmented ing rapor kutkle kuoyarsy ir: the visinity of the hcatci surfaze, erfarairg tre corrective reat transfer meshariso much tiss sams as turbulent eddies. Zuier ${ }^{73}$ was aicle to shor that the same predistive equation for the heat trarsfer coefficiert under turbulent ratural coryection zould also ze used for the isolated cuikle regime, proyided the volumetric vapor frastior. was taken into account. [Peference $":$ also scrtains an exceilent discussion of rucleate pool tciling and a list of $"$ refererses.]

Yicrolayar vaporizatior. rodel. This model, depicted in. Fig. II--h, ia first sugirested hy Enyder and Edwards ${ }^{37}$ with loore and yesler ${ }^{30}$ boing the first to present evidence in support of the model. Since this model appears promising, it is rezeiving wide-spreac attention; and much of the current boiling literature is deroted to it (e.g., see Refs. 29 through 105).

The model assumes, based on the "ro-slip hypothesis, "that a kubble cannot iipe the curface dry of liquid as bubble growth takes place. Thus, a very thin subla;er (hence, the name misrolayer; of liquid should be established between the growirg cubtle and the heated surface. Burble growth takes place hy evaporation of the thin layer (beneath the tutble) with simu!taneous iocalized cooling of the heated surface. A significant consequence of this model is the hypothesis that the heating 
surface area between bubbles plays a passive role in the process. In effect, the rising buoble column acts as a shunt through which most of the heat is transferred; and the problem of explainirg the high surfaceto-liquid heat transfer rate characteristic of nucleate boiling is eliminated. Optical techniques ${ }^{103,204}$ and surface temperature measurements (using fast response thermometry) have shown conclusively that a thin iiquid film does, indeed, exist teneath a growing bubble. ${ }^{98-105}$ Analyses $^{206}$ based on these obserrations confirm the importance of this mechar:ism. However, Maróti ${ }^{94}$ discounts the importance of this mechanism. Tr.ermocapillarity model. Brown ${ }^{81}$ suggested that thermocapillarity (resulting from surface tersion gradients) was possibly the most important mechanism, overshadowing the others. Marangoni ${ }^{107}$ was the first to report that motica can be sritruduced by a variation in surface tension at a liquid-vapor interface. This variation produces a force imoalance that tends to accelerate the interfacial liquid film. As a result of viscous forces, motion is irduced in the adjacent fluid. Since temperature gradients exist rear the heater, surface tension gradients will ke present. These act to cause bubtles in nonuniform temperature fields to ejest hot liquid ir the cold direction. This phenomenon, kiown as "jetting," has beer. otserved ${ }^{81,108}$ from electrically heated wires and surfaces. Based on his work, Brown concluded that latent heat transport ard misroiayer evaporation were not important heat removal mechanisms in pool hoiling but that thermocapillarity might be the dominant mecharism. Ir gereral, thermocapillarity will remove more heat in flow koiling than ir pool boiling. 
Experimental Confirmation of Models

Pigure II-5 is a plot of the heat transfer coefficient for nucleate pool bolling at atwospheric pressure versus the superheated film thickness as given by Bobst and Colver. 89 The data of Marcus ${ }^{109}$ are also shown. Although the curves are disflaced (attributed to different chemisal and physical properties of the bolling surface), there is great similarity in the two data sets. The bolling coefficient is observed to increase as the fil. thickness decreases, with three distinct regions

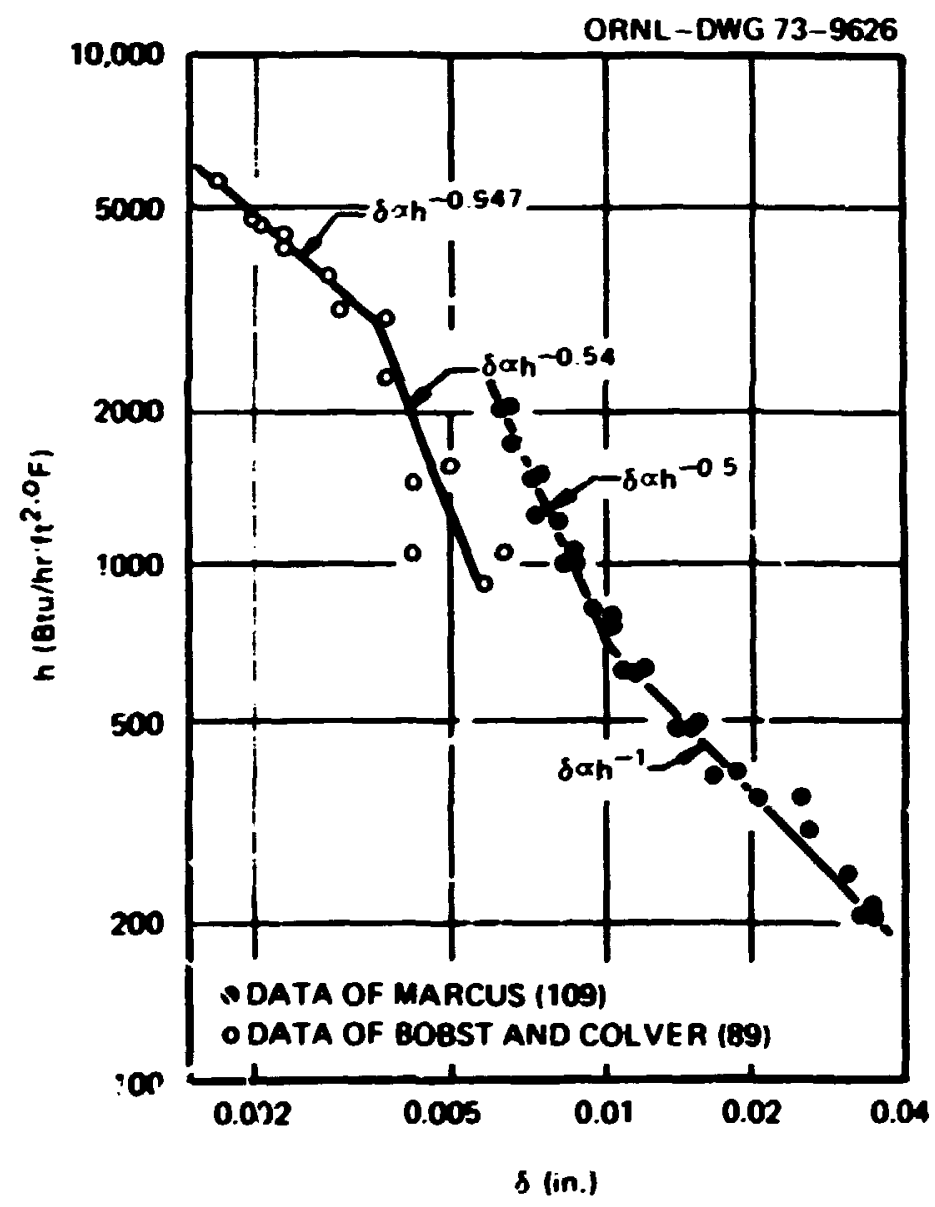

Fig. II.5. Nucleate poui toliling heat transfar coefticient vo f1lw thickness according to Bobst and Colver. 
being indicated. The break in Marcus' data occurs at $h_{\mathrm{PB}}=700 \mathrm{Btu} /$ $\mathrm{hr} \cdot \mathrm{ft} \mathrm{t}^{\circ} \cdot{ }^{\circ} \mathrm{F}\left(\mathrm{q}^{\prime \prime} \approx 10,000 \mathrm{Btu} / \mathrm{hr} \cdot \mathrm{ft}^{2}\right)$. Above this value $\mathrm{h}_{\mathrm{PB}}$ increases faster with decreasing film thickness. Bobst and Colver postulate that the break corresponds to the laminar-turbulent flow transition in the boundary layer. They also observed another sharp break at $h_{\mathrm{PB}}=2000$ $\mathrm{Btu} / \mathrm{hr} \cdot \mathrm{ft}^{2} \cdot{ }^{\circ} \mathrm{F}$, corresponding to a heat flux of $80,000 \mathrm{Btu} / \mathrm{hr} \cdot \mathrm{f}^{2}$. Above this break point, the coefficient increases at a lower rate than belos the transition. They attribute this change to bubble interference, based on Geertner and Westwater's findings ${ }^{120}$ that bubbles grow and depart with a constant diameter in the isolated bubble regime and that they depart with swaller diameters in the regime of interference. (Koumoutsos et al ${ }^{111}$ observed that the bubble departure diameter for saturated flow boiling was considerably less than for similar conditions of pool bofling and that the diameter decreased with increasing flow velocity.) Bobst and Colver ${ }^{\theta 9}$ conclude that the effect of this change places a limitation on the fraction of heat that can be transferred by mechanisms other than those solely ralated to the liquid. They speculate that at the point where bubble interference begins, the boundary layer develops a condition that might be characterized as "saturated with turbulence." With further increases in the heat flux, bubble generation and agitation are not as effective and contribute less significantly to a reduction in the thermal resistance of the boundary layer. In other words, a condition of diminishing returns develops with respect to increastd bubble gerieration. ${ }^{89}$

Mention was made above to reviews and comparisons by Zuber and Pried ${ }^{3}$ and by Zuber 62 of correlations proposed by a mumber of investigators; other reviews are also available. Koskg and Lyon ${ }^{45}$ tested 
several correlations against experimental pool bolling heat transfer data for a number of cryogenic liquids. They found that the correlations of MeNelly 57 and Borishanskii at al. ${ }^{77}$ vere superior to those of Rohsenow, ${ }^{32}$ Forster and Grief, ${ }^{68}$ Forster and Zuber, ${ }^{36}$ Gilmour, $^{66}$ and Kutateladze. ${ }^{3}$ It is noted that the equations having the strongest theoretical basis were found to give poorest agreement with their data. Using their own data for water and alcohol, Borishanskif et al. ${ }^{77}$ compared five Russian correlations over a pressure range of 1 to $60 \mathrm{~atm}$. They also included the data of Cichelli and Bonilla $a^{212}$ for heptane, benzene, propane, and pentane. They found poor agreement with the data and concluded that the correlations are only approximately valid for the conditions for which they were developed.

Rice and Calus ${ }^{46}$ obtained pool boiling data for a number of hydrocarbons, water, and water-isopropanol azetrope at atmospheric pressure. They tested their data against the correlations mentfoned above; however, they omitted those involving nucleation site density. These investigators found that the Borishanskif et al. correlation gave the best agreement for each fluid although each curve was displaced from the others. However, by introducing an additional correlating factor relating the boiling points of the fluids, all the data could be correlaxed by a single line. The Cichelll and Bonilla and the Borishanski et al. dsca were also correlated by this modified correlation. This does snow quite clearly, based on the three independent data sets, that (1) the nature and structure of the heat transfer surface constitute the dominant component of the surface-fluid combination factor and (i) the modified correlation responds well to variations in pressure over the range of ? to 60 atm. 
Another noteworthy comperison of pool boiling correla:ions was published recently (19:2) by Judd and Merte. ${ }^{13}$ They compared the heat flux predictiors of six diffarent correlating models to heat flux measurements of Freon-113 at the same subcooling and acceleration levels. The models tested (discussed above) are identified as:

1. latent heat transport model proposed by RaJ lis and Jawurek, ${ }^{93}$

2. vapor-1iquid exchange model proposed by Forster and Grief ${ }^{68}$ (identicai to the Forster-Zuber correlation ${ }^{39}$ ),

$\because$ enthalpy transport model proposed by Han and Griffith, ${ }^{74}$

4. source flow model proposed by Bankoff ${ }^{95}$ (this model is coneeptualiy identical to the model of Rohsenow ${ }^{32}$ ),

5. wake fiow model proposed by $\mathrm{Tien}^{71}$ and modified by Boehm and Lienhard, 98 and

5. enhanced natural-corveztion model proposed by Zuber. ${ }^{73}$ Judd and yert $\underbrace{\mathbf{1 1} 3}$ found that only Tien's wake flow model (as modified $: y$ Eoshe and Lienhard) was capable of predieting koiling heat transfor resuit: for caturated Freon-i13 on an oxide-coated glass heater arfion at ztandard grayty. AII the modsls overpredicted the measured rsults with inseroseing subcooling and acesleration level. A slightly rod:fict rerzion of Zurer's enhanced natur: -convection model showed improvament at the himing lovels of sukscc. irg. They suggest that the teztej mofeiz urit some mechaniom that is inoperative (or insignificant) unisy zaturatej roi::nr conjitione hut that is very sensitive to the

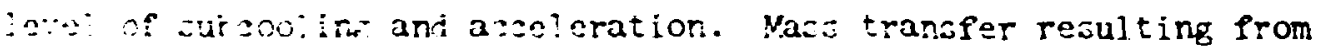
-: :ro:arer gunoration at the lutrin base with sursequent condensation

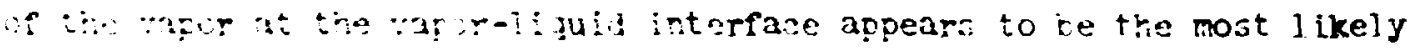
pro:s: $:$ : 
Kenning and $\operatorname{KaO}^{214}$ tested Brown's $\mathrm{s}^{\theta 2}$ hypothes's under simulated flow boiling conditions by injecting gas butt?es into the therma: toundary layer of a heated chanrel with upplow of water. They argue that thermocapillary effects should be stronger for gas butbles with a nearadiabatic boundary :ondition than for vapor bubkles for which interna: evaporation-condensation processes reduce the interfacial temperature (and therefore surface tension gran'ients). The effects should also be more pronounced at high heat flux lev 's than at low flux levels. It was found that significant (up to 50\%) improviment in the heat transfer coefficient was obtained with small quantitles of injected gas ( umetric flow ratios up to 9.07 ) and that the improvement was indepenent of heat flux levei over the range of 20 to $300 \mathrm{~kW} / \mathrm{m}^{2}$. Wo evidense of a direct contribution to heat transfer ty thermocapiliarity was fourd in their investigation. They concede that this mechanism might exert an indirect efrect iy modifying the bubble distribution in the vicinity of the heated wall. In a related investigation, Kao and Kenning ${ }^{116}$ point out that thermocapillary flow, being dependent on surface tension effects, is very sensitive to surfactants (surface-active contaminarts). Numerical aralyses and experimental observations both indicate for water that thermocapillary motion may be suppressed by contamination that $r \geqslant-$ duces the surface tension by as little as $0.1 \%$. In the latter study, ${ }^{11 s}$ considerable difficulty was encountered in keeping the siperimental equipment "clean" so that thermocapillary motion could be otserved. Thus, it appears from these investigations that thermocapillarity effects are not likely to be encountered in practica? systems. Larkin ${ }^{216}$ a] so performed a numerical analyzis of thermorapillary flom around a 
hemispherical bubble and concluded that the ispmrement in heat transfer was modest. These results tend to disprove Brown's hypothes is that thermocapillarity is an important mechanism in both pocl and flor boiling. 
CHAPTER III

\section{EXPER DTERTAI PROGRAM}

An experimental program was developed to investigats taiil soneefts believed to be sienificant in explaining the "nucleate coiline" and the "suppressed nucleate boiling" regions obserred cy many investigators in forced-convection boiling of saturated fuicis. The experiments rere designed to eiucidate and to e:arify the mechanisms invol:ed in turtulent, forsed-convection boiling of saturated fluids at atrospheric pressure.

The following experiments with water and Freor-11? 3t atmospheris pressure were conceived as important tc a solplete investigation in this area:

1. saturated gool boiling frox horizontai surfacts facing ucward,

$\therefore$ saturated pcol roiling from yertiza: surpaes,

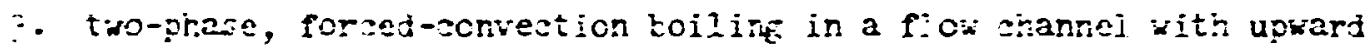
fIDi,

$\therefore$ sirfi-e-phase, forsaj-sonvestion heat tranefer in a flow shanne! with upiarj fick,

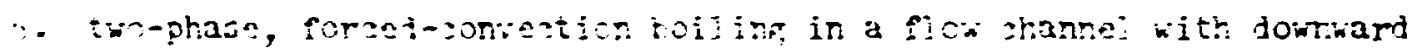
flow, ard

$\therefore$ sinfle-phaso, for:nt-sonestion heat transfor in a fiom shanned with downar: f: $\mathrm{xi}$.

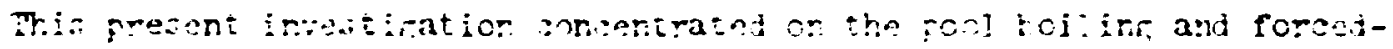

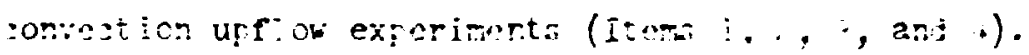


The experiments were built around tre us:e of a heat flux meter to measure the heat-transfer coefficients under carefully controlled conditions. The heat flux meter, described in detail in Chapter IV, is quite simple in principle and permits a simultaneous determination of the test surface heat flux and temperature. A small electric heater supplies heat to the boiling surface via conduction thiough a copper cylinder having a number of thermrcouples located along its axis at known distances from the boilirg surface. From the thermal conductivity of the copper and the temperature as a functicn of position as indicated by the thermocouples, the heat flux through the boiling surface can be calculated. The boiling surface temperature can be determined simultaneously by extrapolation of the internal temperacures. Measurement of bulk fluid temperature provides the additional information needed to calculate heat-tranifer ccefficients. Two identical heat flux meters were installed in a mount:ng plate with the voiling suriaces smooth with the surface of the plate.

The following sories of experinents were carried out with water:

Serjes HPBWC. This test series provided saturated pool boiling data from a horizontal coppel. sirface for heat fluxes in the range of $1 r^{3}$ to $\times 10^{4} \mathrm{Btu} / \mathrm{hr} \cdot \mathrm{ft} \mathrm{t}^{2}$. The mounting plate with the two meters installed was plazed in a large Pyrex glass cuntainer with the boiling iurfaces facing upward. A busisle level was used to glve assurance that the rounting plate was horizontal. Demineralized and deaerated water was used as the fluid. These data are considered the base for comparisor. witi data reported in the literature and with other data obtained Is: this stidy. 
Series VPBLC. This series of experiments providea saturated pool boiling data from vertical copper surfaces for tha same lange of heat fluxes used in the HPBLC series. The wounting plate with installed meters was positions in the glass container as before. The plete was oriented so that the meters were one above the other with the copper boiling surfaces in the same vertical plane. A bubble ievel was used to give assurarin that the plane of the boiling surfaces was vertical. Demineralized and deaerated water was used as the fluid. These tata were collected to compare with Serie: HPBWC data (from horizontal surfaces). In addition, with the meters located one above the other as described, the lower meter could generate bubbles that $f_{i} \mathrm{jw}=\mathrm{J}$ (by natural convection) past the upper boiling surface. In this manner, any enhancement of the heat transfer on the upper meter by bubbles in the boundary layer could be determined.

Series TPBWN and TPBHC. These experiments provided two-phase, forced-convection boiling heat transfer data for vertical upflow of demineralized and deaerated water or nickel and copper surfaces. The mounting plate (with heat flux meters installed) was inserted in a specially constructed, rectangular flow channel (described in Chapter IV). Metered flow to the channel produced flow velocities past the heat flux meters at nominal values of 0.5 to $4 \mathrm{ft} / \mathrm{sec}$, corresponding to Reynolds moduli of $1.1 \times 10^{4} \leqslant N_{\mathrm{Re}} \leqslant 9.2 \times 10^{5}$. Similar to series VPBW the upstream heat flux meter could be used to generate bubbles in the boundary layer flowing past the downstream meter. In this manner, the upstream meter could be used to measure the effect of bubble enhancement in forced-convection boiling. The range of heat fluxes was the same as In the previous series o: experiments. 
Series SPCWI and SPCW. These experimental sets provided forcedcorvection: heat transfer data (roncoiling) for vertical upflaw of dezinerelized and deaerated water on nickel ard copper surfaces. Under sertair. flow ard coilirg conditions, the pressure at the heat flux meters could be increased sufficiertly to supp:ess nucleation and ths Fiv: lde forced-cor:restion heat trarsfer data at essentially the same corditions as the previous tiu-phase toilirig datı. The ackievemert of these corditiors was distated ty structurel strurgth requirements on the glass ard Plexiglas nemkers (:over plates) of the sow shanrel. The p:eszure could te ircreased cy either of two $i:$ iques:

(1) slight? y ciosirg a ralve ir the exit ine of $t^{\prime}$ it: fiom charrel or (2) by slightly jesreacing the coolirg water flow ir. the exit lire socle: (ascumirg the covier was ir operation) to ircrease the two-phase prescure jrop ir. the exit lire. Forsed-comectio! heat transfer data iere cojiestej for represertative rangss of the ir sependent parameters ' $\because$ loojty ard heat fiur! as us d ir: the previous series.

Freor-l1: was selested as a second workire fluid to provide experire: tal data cimilar to that r,taired for water but for a fluid haring ong:iza? propertie: quite differert from those of water. A comparison cf :cme of the simpifizart properties of Freor-113 ard water is given i. Tails III-!. Felevart differerses to be roted are (1) the thermal coriusi:jty of Freor-1: 13 atout ore-eishth that of water, frdicating

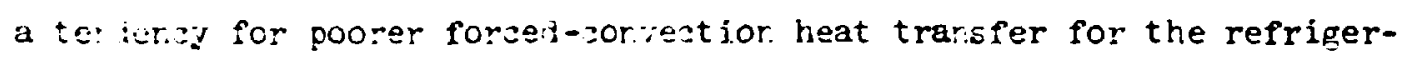
a:t relative to water, and (.) the latert heat of varpo-ization and the

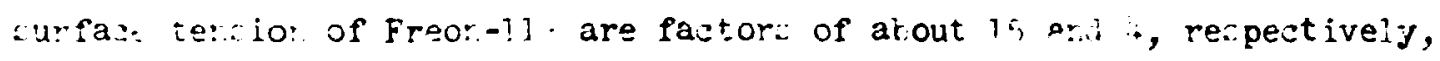

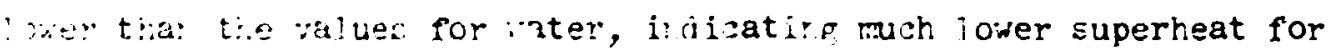


TRELE III-1

COMPARISON OF PAYSICAL PROPERTIES OF WATER AND FREON-11:

\begin{tabular}{|c|c|c|}
\hline & water & Freon-1: : \\
\hline Chemi val formula & $\mathrm{H}_{8} \mathrm{O}$ & $\left(C l_{2} F\right) C-C\left(C 1 F_{a}\right)$ \\
\hline Mclesuizr weight & $1 \hat{e}$ & $29 \cdot \therefore$ \\
\hline Eoiling vint at $: a t-m,{ }^{\circ} \mathrm{F}$ & 210 & $11-.6$ \\
\hline Freezing poir.t, ${ }^{\circ} \mathrm{F}$ & $\because$ & $-\because$ \\
\hline Dritisa: temperature, ${ }^{\circ} \mathrm{F}$ & $70:$. & $\therefore \because \therefore$ \\
\hline Nritled! prezsure, psia & $\because C \bar{c}$. & $\therefore=$ \\
\hline Liquid derity $\left(-r^{\circ} \mathrm{F}\right), 1 \mathrm{k} / \mathrm{ft}^{3}$ & $6 \ldots=$ & 2.66 \\
\hline Vapor density (boiling point), $1 \mathrm{k} / \mathrm{ft}^{3}$ & $0.9: 7=$ & $\therefore \therefore \sigma_{2}=$ \\
\hline Iiquid $\leqslant$ peiff: hat $\left(\bigcirc^{\circ} \mathrm{F}\right)$, Etu/ $/ \mathrm{b}_{\mathrm{m}}{ }^{\circ} \mathrm{F}$ & $\therefore=$ & . . : \\
\hline Vapor zpe:ifi= heat $\left(\varepsilon, 6^{\circ} \mathrm{F}\right)$, Etu $/: r_{\mathrm{m}}{ }^{\circ} \mathrm{F}$ & $\therefore \ldots$ & $\therefore \approx$ \\
\hline $\begin{array}{l}\text { Liment nezt of aronization (atmostheris } \\
\text { pre:oure), Btu/it }\end{array}$ & $\because \therefore$ & $\therefore \therefore$ \\
\hline I.iguid viccosity $\left(86^{\circ} \mathrm{F}\right), \mathrm{cP}$ & $\therefore 9=$ & $\therefore \therefore$. \\
\hline 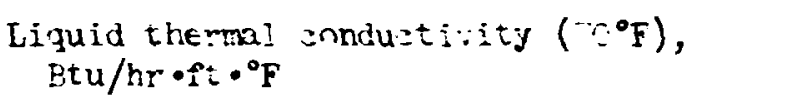 & $\therefore=: \vdots$ & $\therefore \therefore$ \\
\hline Surfaze tenzion $\left({ }^{*} \mathrm{~F}\right)$, dynez/=m & $\because z \cdot i$ & $\therefore-:$ \\
\hline
\end{tabular}

kultie rucleatior. and larger sized tukt les for the refricerat for the same roiling surface characteriztiss.

The arore descriked set of water experimerts was repeated witr. Freor-11? as the tert fluid, except that the riskel-plated surface ras rot avaijatle. The same rar.je of flows were tested; however, the marimum heat flux was limited to approximately $4,0,003 t u / h r$ oft ${ }^{2}$ to avoij fi?m boiling. Since cortamination of the sopper surface was not a proiIem with the freor, these data pro:ed to be more consistert and renroducible thar 'hose obtaired with water. Correquertly, the freor deca 
form the kasis for the testing of analytical models in Chapter $v$, with the water data serving to support the results of the freon tests.

A descriptive nowenclature, consisting of five letters and numeral followed by a serial number (e.g., ABCDE2-001), was employed to ident ify the individual experiments. The first thrce letters characterize the ger.eral experimental arrar.zement, the fourth letter iajentifies the fiuid, the fifth letter denctes the surface metal, and the numeral indicates on which heat flux weter the data were taken. Thus, for the first three letters $\mathrm{HPB}=$ horizontal pool boiling, VPB $=$ vertical pool bolling, TPB = two-phase convective bojilinf. SPC = single-phase forced convection, and $\mathrm{TPX}=$ two-phase convective boilirs with "high" void fraction flow. These descriptors will become apparent in the discussion of the results in Chapter $V$. As for the Pluid jaentification, $F=$ Preca, $W=$ water, while the surface is denoted by $\mathbf{N}$ for $n i c k e l$ and $C$ for sopper. The heat flux meters are denoted by 1 (upotream) or: 2 (downstream). For example, HPBWC?-09 identifies test run No. 9 with heat flux meter No. 2 for pool boiling of water on a horizontal copper surface. 


\section{CHAPTER IV}

\section{EQUIPHEIT AND TROCEDURES}

The equipment vas designed to permit direct calculation of heat transfer coefficients from the experimental data obtained with the test configurations described in the previous chapter (Experimental Progras). Central to the experiments was a heat flux weter that enabled simultareous deternination of the test surface heat flux and temperature. Detalls of this heat flux meter and of other test equipment are discussed in following sections; an outline of the procedures used in the experimental program foliars the description of the equipment.

\section{Flow Test Pacility}

\section{Test Loop}

A test $100 p$ was assembled from available components to provide a facility in which heat flux meters (described below) could be operated to obtain forced-conrection and two-phase, convective bolling heat transfer coefficients in the upflow mode. Initially constructed of stainless steel, brass, and copper, the loop was subsequently modified on evidence of corrosion to eliminate all brass and copper surfaces exposed to the circulating hot water. A schematic nowsheet of the facility is show in Pig. IV-1.

Major components in the system included a reservoir-head tank, a small reflux condenser (vented to the atmosphere), two centrifugal pumps conrected in parallel, a preheater (In three sections), a trim-cooler, two turbine flow meters in parallel flow lines, a test flow channel with 


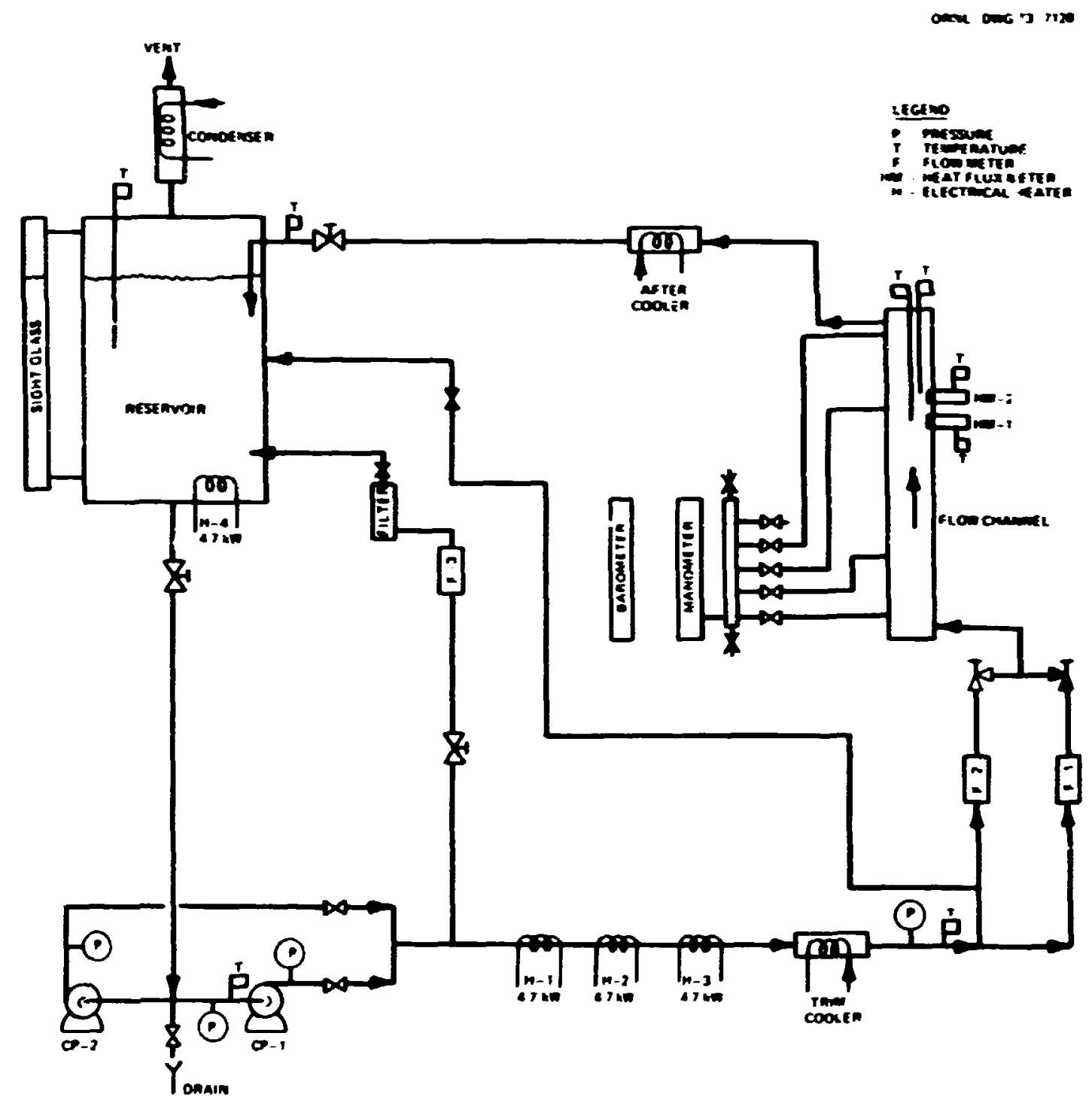

Fig. IV-1. Schematic florsheet of test loop.

two heat flux meters, an after-cooler, a pump bjpass (with filter), and associated instrumentation. Valves permitted controllcd variability in operating conditions at the test section. The piping system was designed for test Plows up to $25 \mathrm{gpm}$; maximum systen pressure was about $23 \mathrm{psig}$ at 
the pump aischarge header. Individual components are described in detail in later sections.

The experimental system prior to application of theral insulation is pictured in Pig. TV-2. Prouinent features, as noted in the photograph, include (1) a pup control and knitoring sabinet to the extrese left, (2) the reservoir-head tank with reflux conderser on the framework in tine center, (3) the two punps and interconnecting piping located beneath the reservoir, (4) the test siand wih now chamel installea for upflow, and (5) an instrument panel on the extrese right containing a potentioneter, thermocauple switches, flow measuring readout equipment, ets. Other control and readout instrumentation are not visible in this photograph.

\section{Heat Pux Meter}

The heat flux meters were constructed similar to thase used by a number of investigators (Refs. $74,84,88,117$ througri 120). Based on reported difficulties74,117,118 and experience gained from a nuber of earlfer models fabricated at this Laboratory, the design selected for the current research was as shown in $\mathrm{Fig} . \mathrm{IV}-3$.

In principle, the heat flux meter is guite simple and permits simaltaneous determination of the boiling surface heat flux and temperature. A small electric heater supplies heat to the bolling surface via conducticn through a copper body having a number of thermoccuples located along its axis at known pasitions relative to the bolling surface. From the known therwal conductivity of the copper and the temperature gradient indicated by the thermocouples, the heat flux is calculated. The 


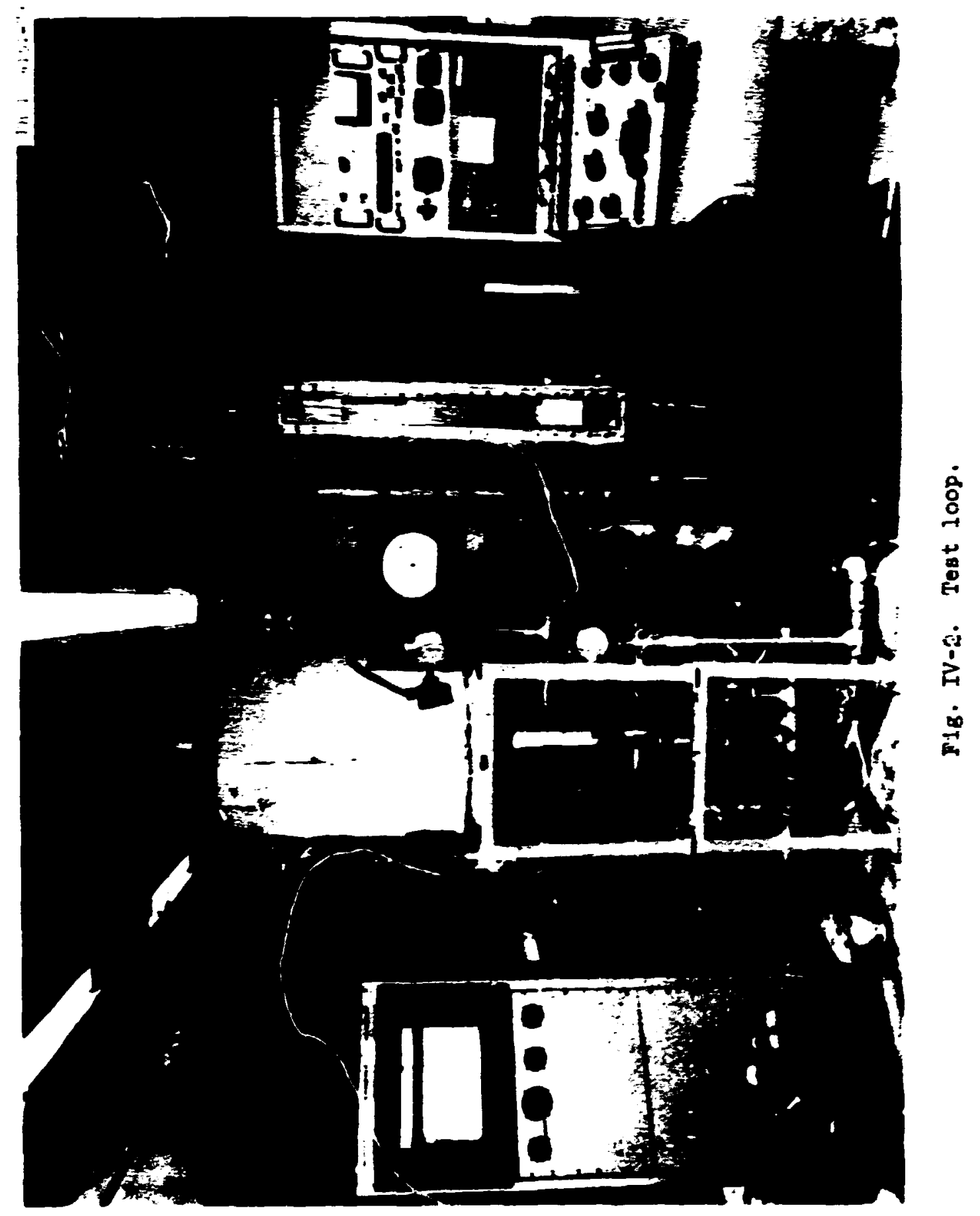




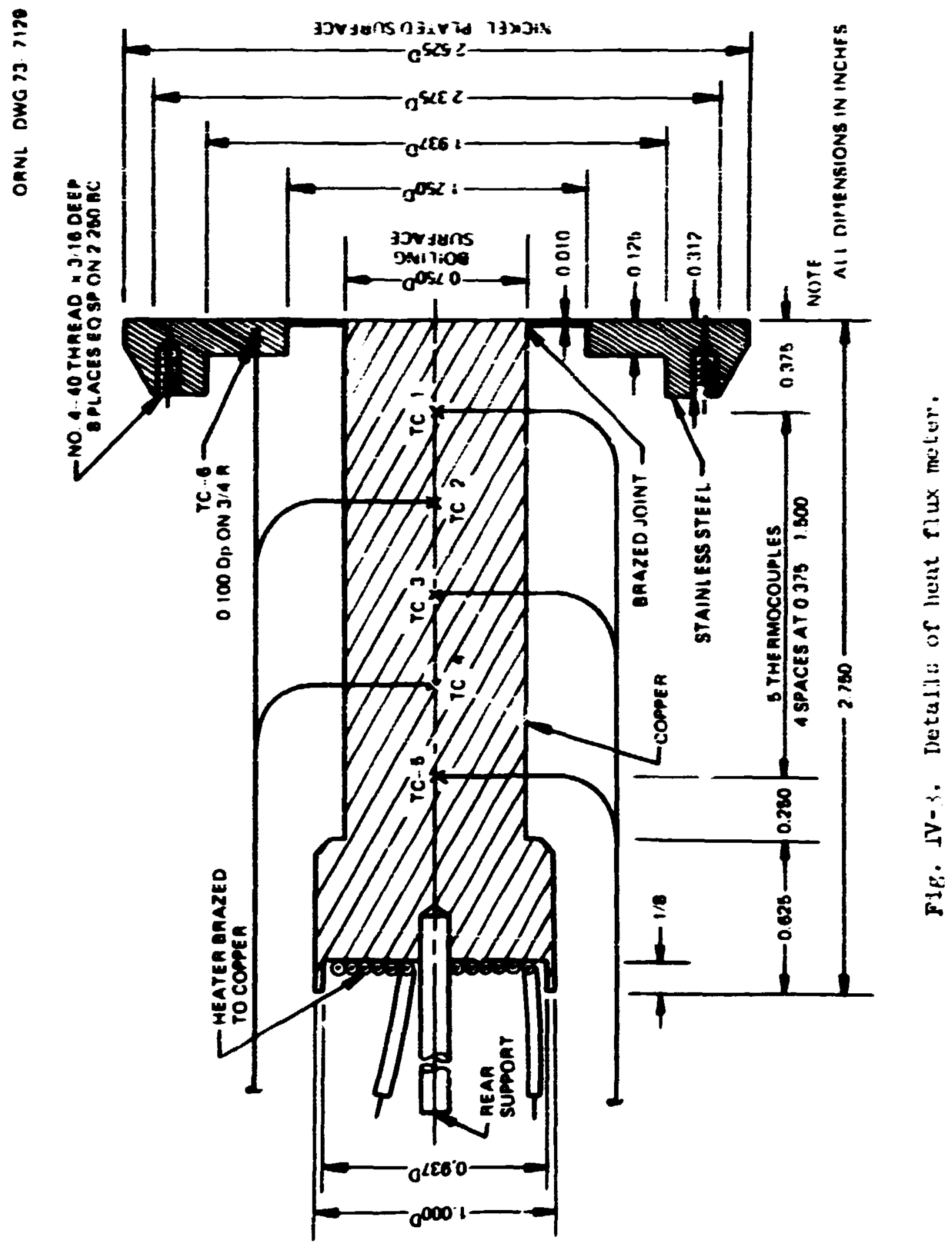


toiling-surface cemperature is ditaibed iy extracoiation of this sare texperature gradie:t.

Recusing the sonieptue? design of the heat aeter te practise us

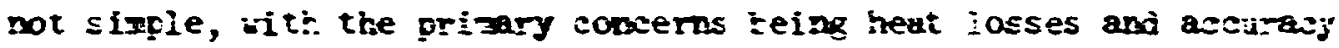
of the iepperaturs neesurements. Ej sarefui attentior: to ine jisigr and sonstriction details and to tise seitrations, the seters jessriced hereir furztioned exzeptionaily iel!

The ineory of the heat $\mathrm{f}$ iux neter cesuess a higinly conductive sateriai $\equiv 0$ that the isotherts are normai to the aris of the conductor ard lozi: perturiaticre in the heat flow path are fulsily snoothed out. A zrod sondustor aiso -inimizes the influerse of heat losses to the

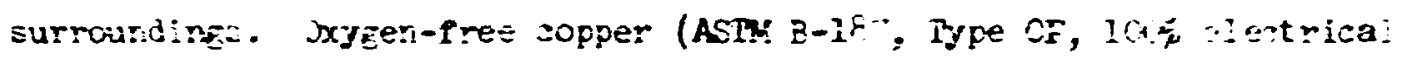
sonduzt:-ity) was selected for tinis use. Sufficiant stocir from the sane 1-in.-diar tar aid oitaired to fakrisats the four neters prepared for this etudy. A coiled roatire elenert was trazed into a machinei recess in one end of the sopper sody. A thin-ialled stairlesz steel turs ias trazed (zimultaneously with tre neater irazing operation; to the heater end cf tre suppe: iar ty serve as a rear guide and support to minimize bending stresses on the thin stainless steel flange at the coll ing ond. The lengtn of this tube was initially a few inches longer than necessary Eoth ic fasilitate herrling and to serve as an anchor for the small dfameter sheated thermocciples during final fabrication; the tuite was out to proper lengti prior to installation of the meter in the mounting. plate. Tukinf was selected ir prefererce to a solid rod for this function io reduce heat losses by ariai conduction. 
Agproxizatoly it ir. of someraialiy arailatie single-sontuctor,

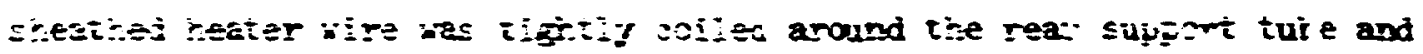

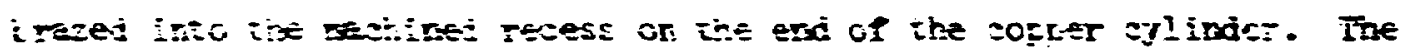

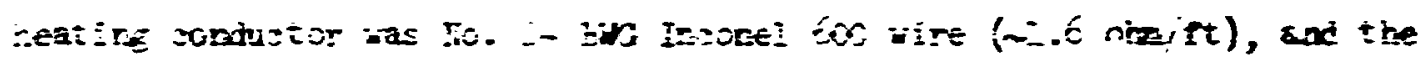

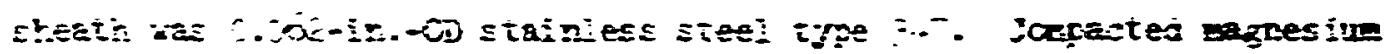

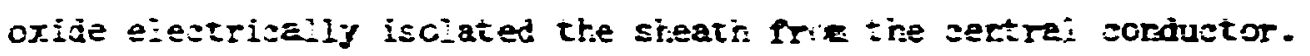

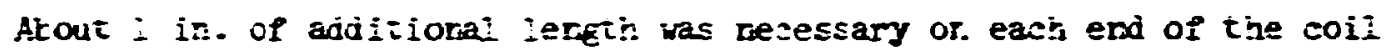
io sonstruct reliatle elestrizal connestions. Glosely fitting copper tutirs ias trazed over the sheath of these free (connector) ends of the coil: to sondiet heat back to the sopper sylinder and, thus, to prevenx crerheating and premature failure of the heater extensions. Small nicirei connectors were used to join (by soldering) the Inconel heater wire to tine electrical lead and the voltage tap wires. The coint was potted in a small machined sleeve iftted over the end of the sheath, using a seranis cenent, to provide mechanical strengtr and eiectrical isolation for the fragi'e connection.

Initially, ac electrical power was supplied independently to each heat meter, using tiro Variacs in series for cortrol. The first Variac reduced the $120 \mathrm{~V}$ supply to about $12 \mathrm{~V}$, and the second varias provided fine adjustment of the heater voltage over the operating range of $\sim$ to $10 \mathrm{v}$. After preliminary operation disciosed inadequate control and undesirable voltage fluctuations, this method was discarued in favor of Individually reglated de power supplies for each meter. Two Kepco power supplies (Model SM-75-6xM, 0-75 Vdc, O-d A) were used for the high flux $\left(q^{\prime \prime} \chi 10,000 \mathrm{Btu} / \mathrm{hr} \cdot \mathrm{ft}^{2}\right)$ range. Since these units would not control 
at roltage levels below about $4.5 \mathrm{~g}$, two UE porer supplies (model

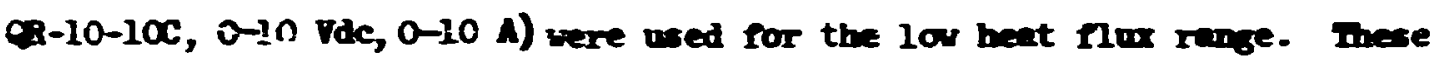
units successfouly elinineted the opesetional difficalties with roltage sootrol and stability.

The copper eylinder wes redreed in dimeter to 0.750 in. nowinl in the temerature casuring region to increase the heat nux, and thas, provide sufficient te-perature differences for accurate neasurenent at low heat flux levels. Sased on the minu design beat nux of 50,000 $\mathrm{Btu} / \mathrm{hr} \cdot \mathrm{ft}^{2}$ in the copper cylincer, the temperature gradieric vas $\sim 18.5^{\circ} \mathrm{P} /$ in. With the thernocouples spaced noninally at 0.375 in., the difference between adjace:rt therioncouples was about $6.9^{\circ} \mathrm{F}$, corresponding to an ex of $160 \mu \mathrm{V}$ for Chromel-Alumel therwocouples. Sinilarly, at the ninim desigr heat $\mathrm{flux}$ of $1000 \mathrm{Btu} / \mathrm{hr} \cdot \mathrm{ft}^{2}$, the temperature gradient vas about $0.37^{\circ} \mathrm{F} /$ in. $\left(0.14^{\circ} \mathrm{F}\right.$ between adjacent thermocouples). This latter difference corresponded to an exf of about $3.2 \mu \mathrm{V}$, which was considered acceptable for calibrated thermocouples in conjunction with use of a Leeds and Northrup $K-3$ potentiometer as a readout instrument $(0.5 \mu \mathrm{V}$ scale subdivistions).

Five 0.040-in.-OD stainless steel shenthed, Chromel-Alumel Erounded junction thermocouples were soldered in holes arilled to the center line of the copper cylinder. [While most investigators have used on'y three therwocouples to determine the gradient in similar devicer, j.t. was decided that the improved statisties derived from five t'iermocouples justifled their use.] The thermocouples were nominally spased 0.375 in. apart; however, their exact location reiative to the boiling surface 


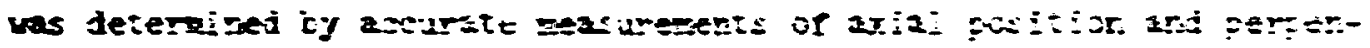

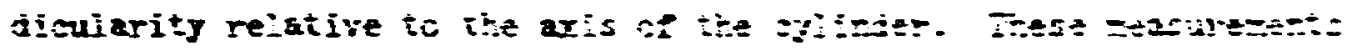

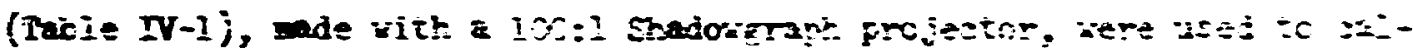

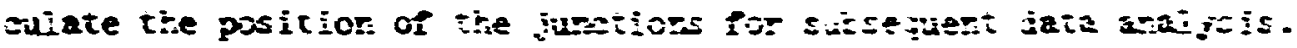

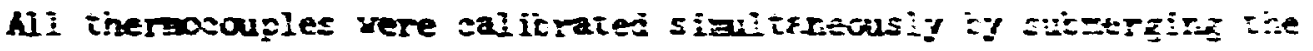

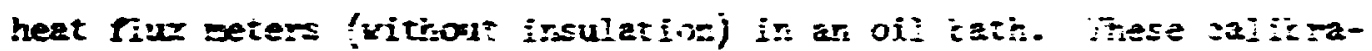
tions vere perioned ig the Cak Ridze lationai iabcratorg's Staviari Intoratory ageirst standards traceaile to the Matiorei Eureas of Etani-

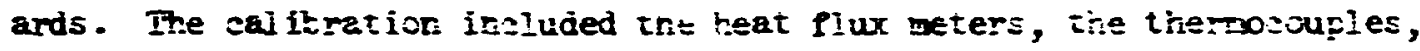
the selector switsh, the ice cath reference, and the soper isads ig to the point where they were connected to the rea'out potentioneter. Re-

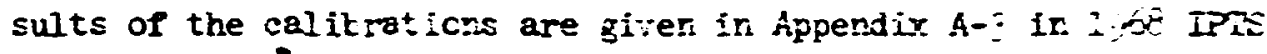
unit.5. 121

A section of the copper tar stock from risis the heet fur eeters were machived was used to determine the thermai sonductivity at roo: temperatlu:a, usinf very accurate measurements of electrieal properties and appropriate lattice corrections. This determination was performed

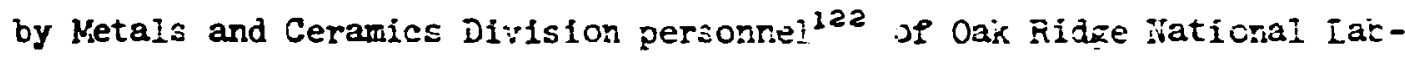
oratory. From the data cotained at room temperatule, a iest-esimate curve was produced for the temperature range of $80 \leq I \leq L 50^{\circ} \vec{F}$, based on accurate $( \pm 0.7 \%)$ thermal conductivity data reported $d^{123}$ for vers pure copper. The best-estimate curve ${ }^{2: 2}$ for the copper used in the heat $f$ l:x meters is:

$$
\mathbf{k}=230.1755-0.01862 . \mathbf{T} .
$$

The estimated accuracy ${ }^{122}$ of the above equation is $\pm \alpha .0 \%$ orer the full temperature range. 
TABLE IV-I

AXIAL POSITION OF THERMOCOUPIE JUNCTIONS RET ITIVE TO BOILING SURFACE

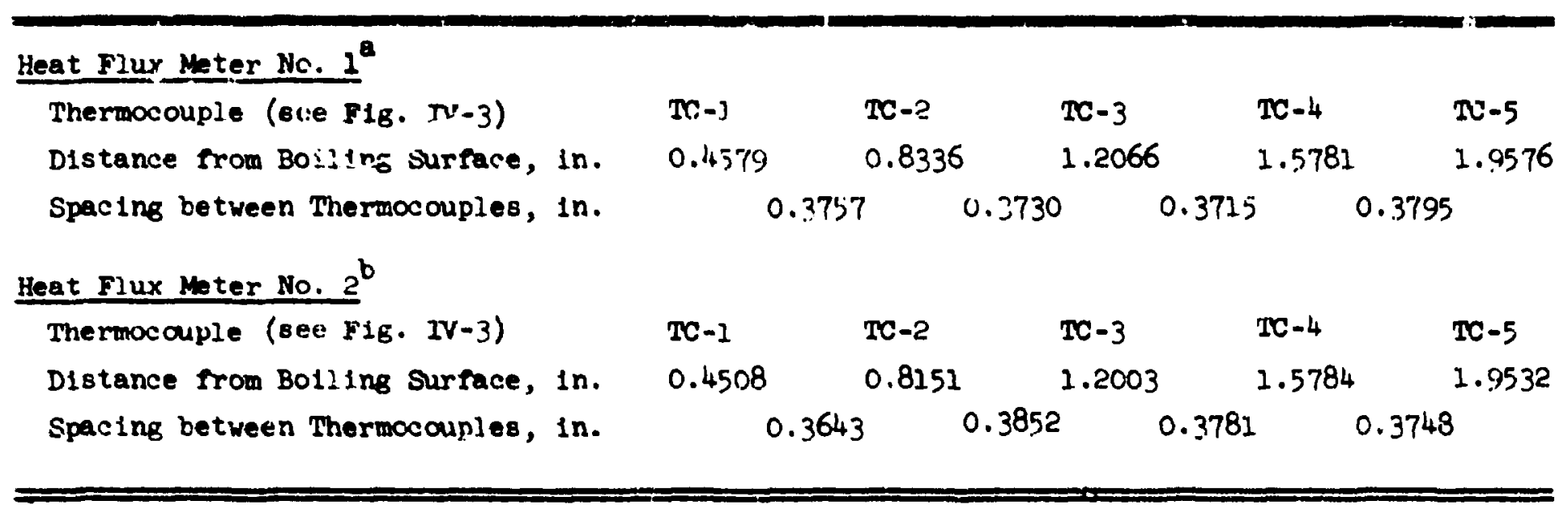

"Diaweter of heat meter body $=0.7493$ in. (weter cerlal No. 2).

biameter of heat weter body $=0.7495 \mathrm{in}$. (meter cerial No. 3). 
Dubble nucleation at the periphery of the bolling surface and/or on the flange surface has been reported by a numer of lavestigators; 74.117 .118 this was also \& problem with earlier designs at this laboratory. As shown in PIg. IV-3, a thin stainless steel flange vas trazed to the end of the copper cyllnder to alleviate this problem. Pabrication proved difficult (from both brazing and finish wachining vieupoints) but was successnuly accomplished by special brazing and machining techniques. The thickness of the flange wes raigh sachined to $0.125 \mathrm{in}$. For the vacuum rurnace braziag operation. A gold-nickel alloy (82 w/0 Au, 18 w/0 $\mathrm{K}$, welting point: 1742\%) was used without flux to eliminate objectionable volds and/or inclusions and to provide a ductile transition alloy in the solnt. Following the trazing opera$\because$ Ion, the stainless steel Nlange and copper cylinder vere Platsh machined to a final thickness of 0.010 in. The surface was then hand lapped unt il flat wth $400-g r i t$ aluminum axide compound. This was followed by a fintsh lap, using 1200-grit eluaimum oxide compound to produce a bright alrror-like surface with a 3 to 4 RMS PInlsh. The surfaces erjosed to the test fluids ware then nickel plated b- a sputtering process to provide thickness $; 0.0001$ in. of nickel or. meter No. 1 and 0.0003 in. on meter No. 2. Since this plating process falthrully reproduces the surface finish of the substrate for the finished surface, no surther treatment (other thas, cleaning ith alcoholl and air drying) was given tc the bolling surface. Pigure IV-4 is a photograph of the completed weters; the bright surface finisin and the thin section (made epparent by slightly diffisent reflective characteristics) are evident. Nickel plating was selected for the surface exposed to the test fiuid, sfine it is known 


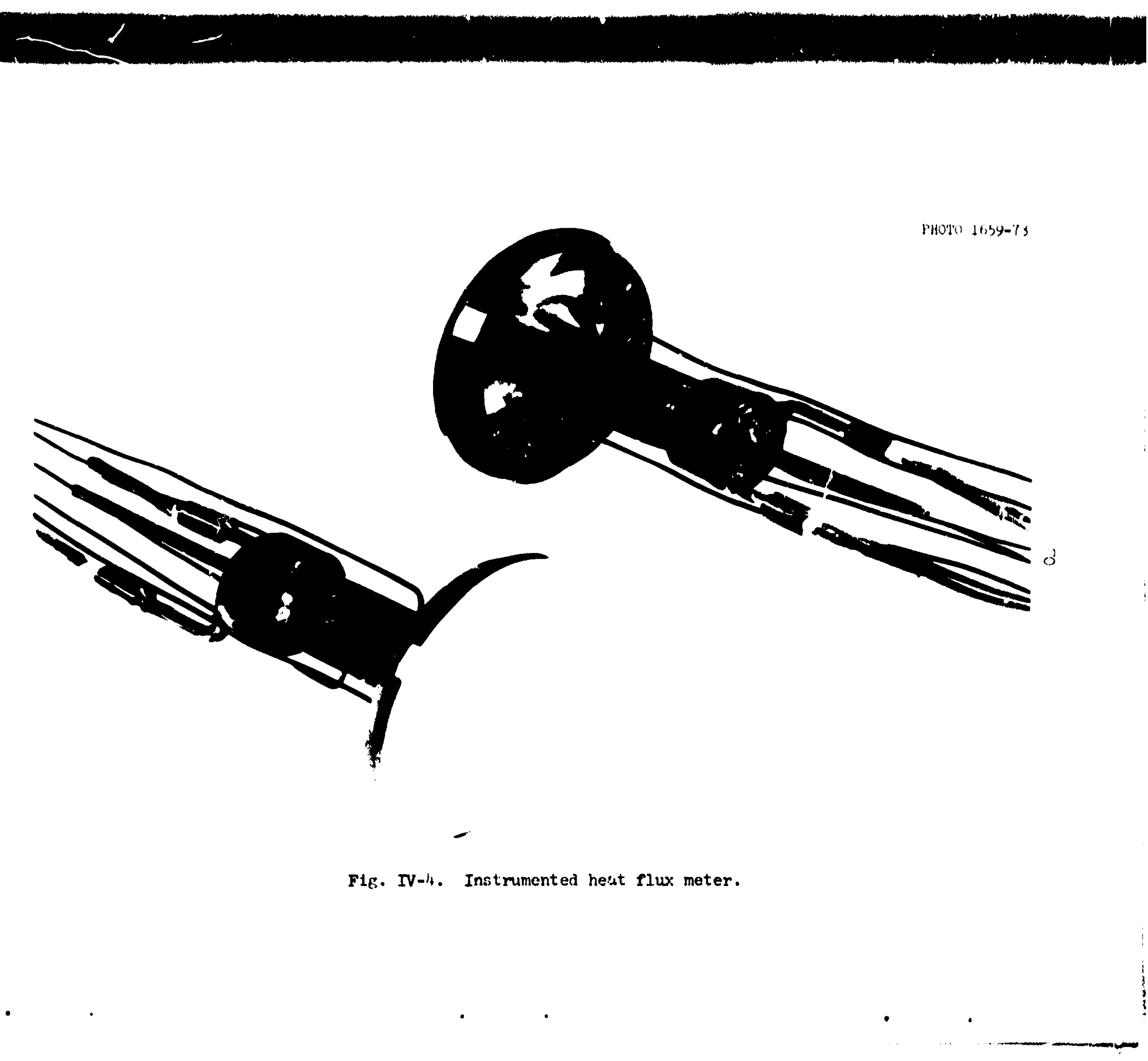


to be less prone to oxidation and, hence, gives reproducible results, particularly after an initial "aging" period. Also, data reported for pool bolling on nickel ${ }^{119}$ and nickel-plated ${ }^{109,124,125}$ surfaces under sinflar conditions could be used as a check against the data generated in this research. Surface aging and nonreproducible mucleation behevior dur ing operation made necessary suhsecuent surface treatment; this is considsred in detail in Chapter $V$, Discussion of Results.

Extensive calculations were perforned, using the HEATIN-3 computer program, ${ }^{126}$ to assess the sultability of the final design for alleviating the bothersome nucleating problews resulting from heat 1088 es through the stainless steel flange to the test fluid. The rery thin nickel plating was ignored in the computer studies.

Hearnig-3, ${ }^{128}$ a modified version of the Hearnig progran, ${ }^{127}$ is designed to solve a wide variety of steady-state and/or transient beat conduction problem at oxe-, two-, or three-dimensional cartesian or cylindr:-al coorinates. Input values of thermal conductivity, density, and specific heat may be depesdent on temperature at each lattice point. Specified heat generation raties way be tiwe dependent. The boundary cnnditions may be fixed temperatures or an combination of ccostant heat Nux, forced convection, natural convection, and radiation and can be from-surface-to-boundary, from-surface-to-surface, or from-surface-tosurface plus conduction. The mesh ripacing can vary along each axis, with 28 my 1750 lattice points, 100 regions, 50 waterials, and 50 boundary conditions beling accounodated.

Pigure IV-5 presents the results of a typical design calculation for the meter ascembly submerged in $212^{\circ} \mathrm{F}$ water with pool boling taking place on the bolling surface and natural convection on all other exposed 
ORNL-DWG 73-11432

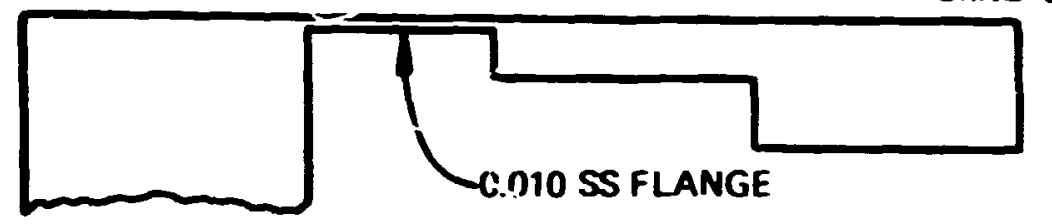

G HEAT FLUX METER

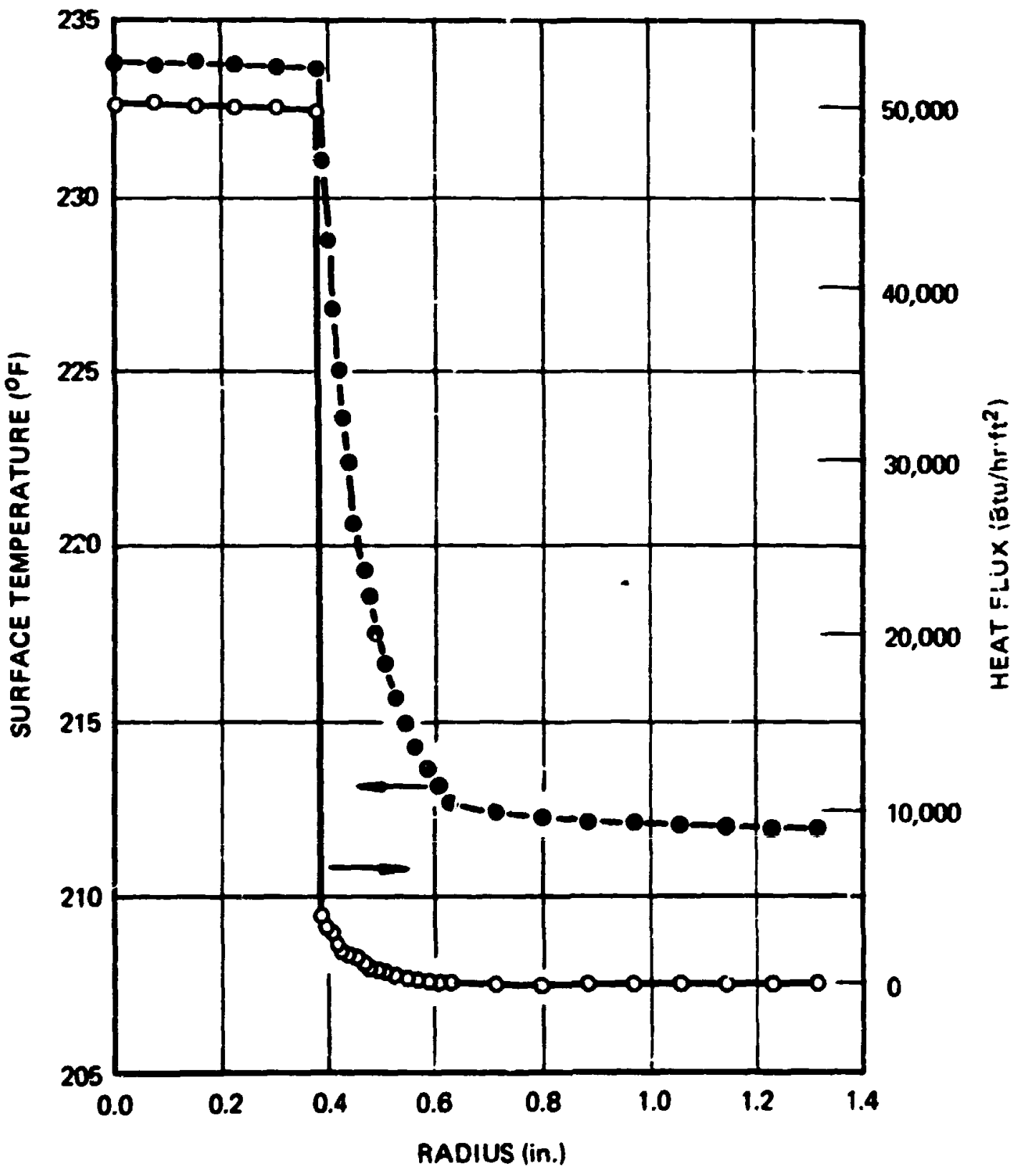

Fig. IV-5. Flot of temperature and heat flux distribution on bolling surface based on computer calculat ons. 
surfaces. This figure show the conputed radial districution in the heat flux to the pluid and the surface temperature. As indicated, the heat flux and temperature are suite unifore cyer the central boiling region and decrease sharply at the inner edge of the stainitss stee: plange. For the example, the heat flux is $50,000 \mathrm{Btu}$ 'hr.ft over the boiling surface $\left(h_{\mathrm{PB}}=2300 \mathrm{Btu} / \mathrm{hr} \cdot \mathrm{ft}^{2} \cdot{ }^{\circ} \mathrm{F}\right)$ and desreases precipitously to about $4000 \mathrm{btu} / \mathrm{hr} \cdot \mathrm{ft}^{2}$ in $0.010 \mathrm{in}$, while the temperature decreases from $233.75^{\circ} \mathrm{P}$ to about $230.90^{\circ} \mathrm{F}$ in the same radial distance. At $0.050-$ in. radial distance, the temperatlure is decreased to $223.68^{\circ} \mathrm{F}$. If higher coefficients (enhanied natural convection) had been specified for the stainless steel flange, the abrupt decrease at the inner edge of the Plange would be more pronounced. Based on these results and others discussed in Appendix B, it was concluded that the design selected would eliminate nucleation on the stainless steel flange.

A thermocouple, identical to those instalied in the copper cylinder, was soldered into the stainless steel plange as finiliated in Fig. $\mathrm{N}-3$ to measure the plange temperature for comparison with the ccmputed distribution. This thermocouple was calibrated simultanecusly with the ones in the copper; the results are rerorted in Appendix A-3.

The heat meters were calibrated for heat losses prior to use in the pool bofling and the flow experiments; the results are given in Appendix in-4.

\section{Mounting Plate Assembly}

A brass mounting plate was designed to retain the two heat slux meters in fixed relative posttions as shown in Fig. IV-6. The mounting plate could be inserted through an opening in the back side of the flow 


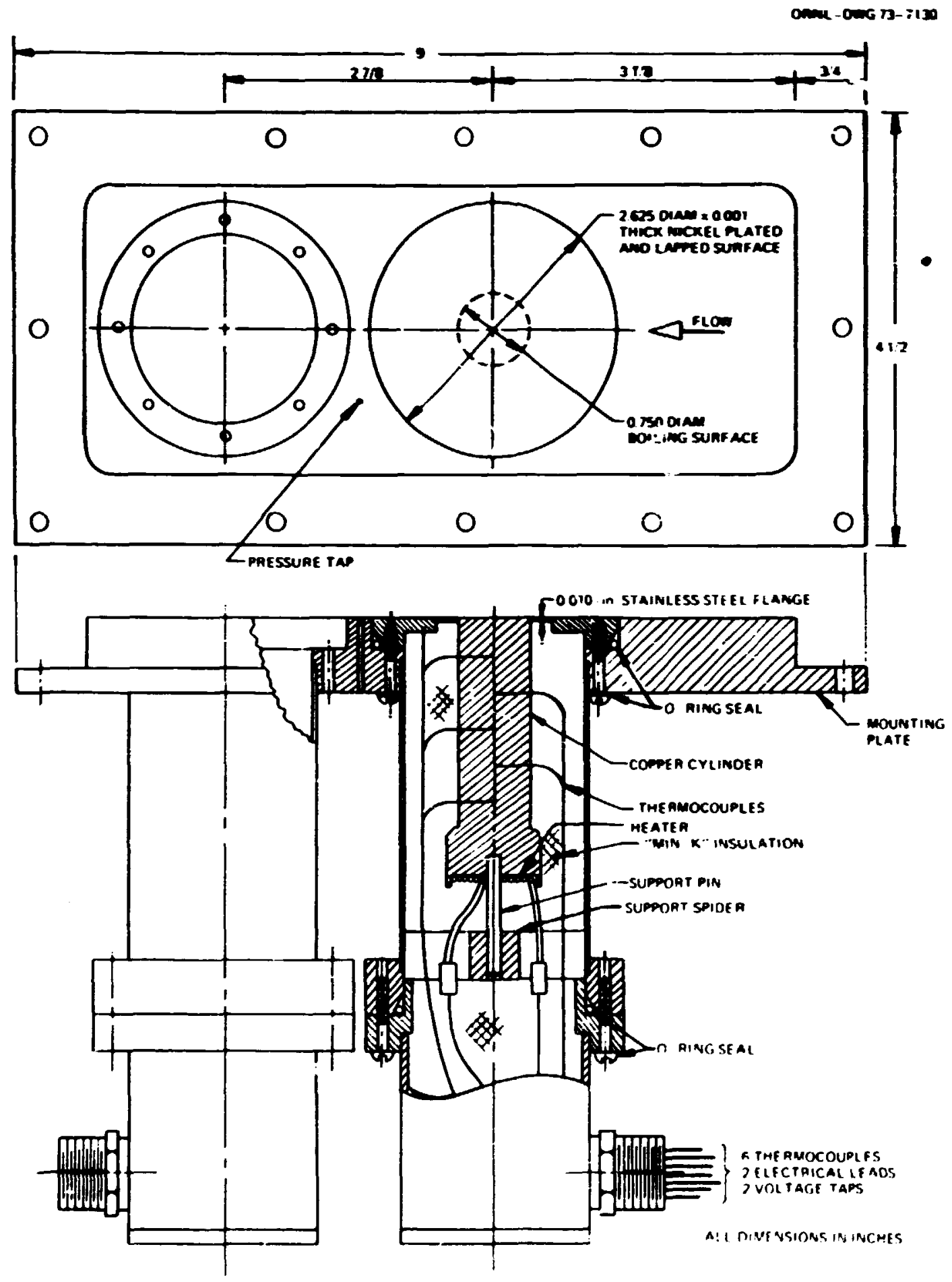

Fig. IV-6. Mounting plate and heat flux meter assembly construction details. 
chanrel so that the fiow toundary was se:ooth and zortinuous (the two surfaces were wachired and polished sizuitareousiy to zinizize scundary layer disturtanees). A neoprene o-ring was used to sezi the mountine plate to the flow channel. The nountiris plate assembiy was also used as a fixture for positioning the heat flux meters in the pool toiling experiments .

The stainiess steel planges on the metars were tightiy fitted into mashired recesses in the mounting plate. Special tachining prosau iors were taksn to give assurance of minimum toundary iayer disturkance. The meters were staled io the mounting plate as indisated in $\mathrm{Fig}$. $\mathrm{T}-6$, using Runa-N O-rings. Small Buna-N O-rings with retainers were used under the head of the mounting screws to prevent inleakage when the assembly was sutmerged in the pool boiling experiments. Flanged zylinders were soldered on the back side of the monnting plate to provide a learproof protective housing for the meters. A Planged cover, witr: Buna-rf O-ring seal and a tube fitting for egress of the thermccouples and $\in$ lectrical leads, compieted the water-tight enclosure.

Tho layers of "Min-K" flexitle, thermal insulating tape $(1 / 4-i n$. thisk, $k=0.20 \mathrm{Btu} \cdot 1 \mathrm{r} . / \mathrm{hr} \cdot \mathrm{ft}^{2} \cdot{ }^{\circ} \mathrm{F}$ ) filled the space zerwesh the heat meteis and the cylindrical housing. A rear support spider, machined from "Mykroy-1100" ( $\left.k=2.8 \mathrm{Btu} \cdot \mathrm{in} \cdot / \mathrm{hr} \cdot \mathrm{ft}^{2} \cdot{ }^{\circ} \mathrm{F}\right)$, was centered on the thinwalled stainless steel tube to minimize heat losses from the heater via axial conduction.

Figure $I \vec{r}-\because$ is a photograph of the mounting plate and heat flux meters in the final slise of assembly. One meter is shown in place on the upstream end of the plate. In the compieted assemty, the leads exit from the cylindrical houling through the side tublng connection of 
$-5$

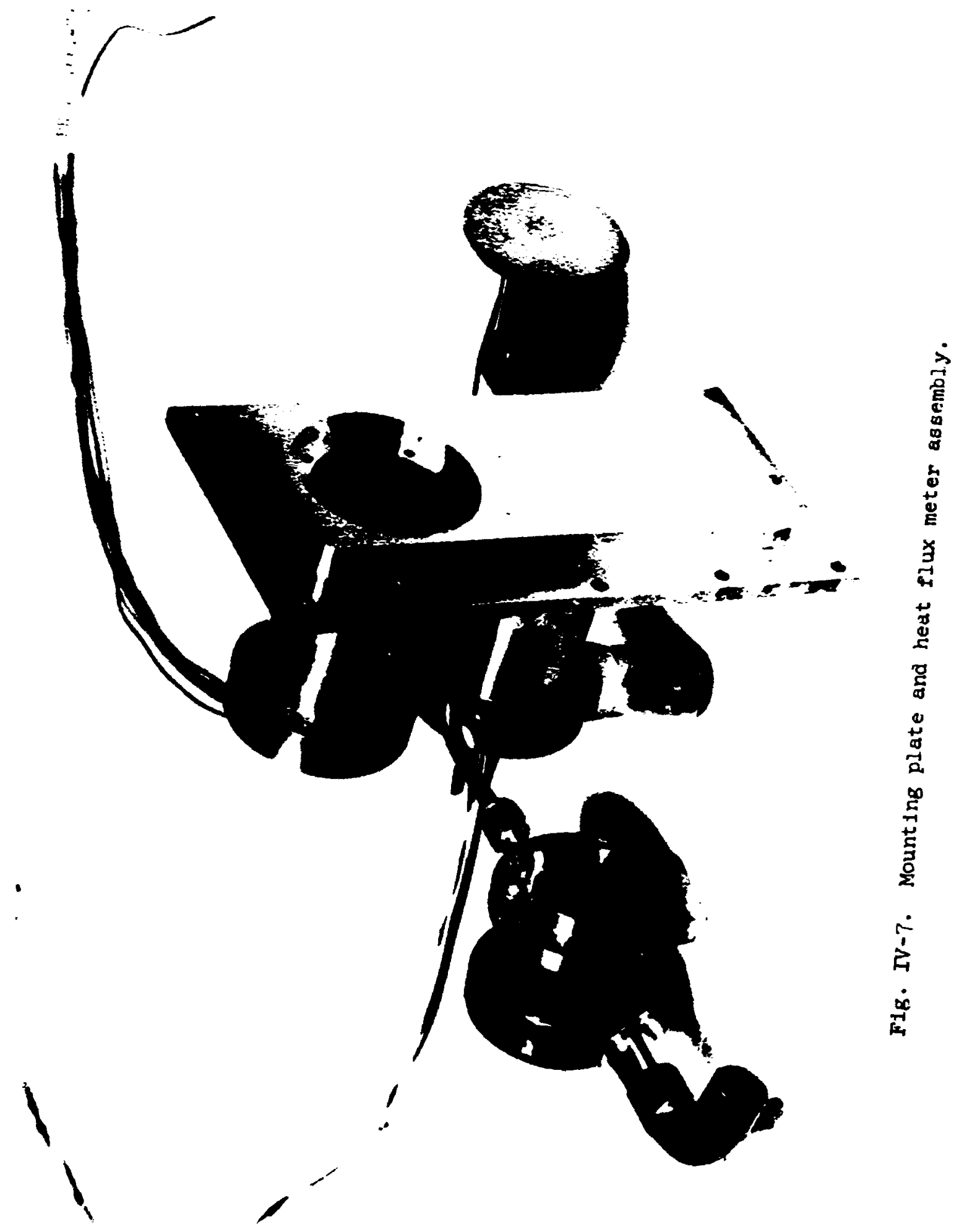


the end closure flange. This tubing (not show) extends a sufficient distance to terainate above the top closure of the pool boiling apparatus. The leads are sealed to the open end of the protective tube, using an epoxy sealant to permit operation with a slight buffer gas pressure.

A sharp-edged pressure tap (0.032-in. drilled hole) for local pressure measurements is located midray between the heat flux meters and slightly to one side of the center line (tc avcid flow disturbances) sf: seen in the photograph. Locating dimensions of the tap are indicated in F1g. IV-6.

Shakedown operation of the flow facility revealed significant corInsion of the brass surfaces exposed to the hot $\left(215^{\circ} \mathrm{F}\right)$ demineralized and deacrated water. This raised the possfillity that, if not corrected, corrosion products might be plated out on the hot surface of the heat flux meters. Consequently, the exposed brass surfaces vere nickel plated to preclude this possibility.

\section{Flow Channel}

A rectangular flow channel was machlned from brass stock. Pert.1nent dimensions of the cinannel are given in Fig. IV-8. To provide the actual flow chamel, a cavity 3.000 in. In width by 0.500 in. in depth $\left(D_{\text {eq }}=0.857\right.$ in.) was milled in the brass stock with the heat flux meter mounting plate (witl. excess thickness at this stage) bolted in position. This technique gave assurance that the mounting plate inlohed surface was precisely the same as the flow channel. The channelmounting plate assembly was polished after wachining to give a surface Iinish better than 32 rms. Brass couplings, 1 1/2-1n. nominal pipe size, 


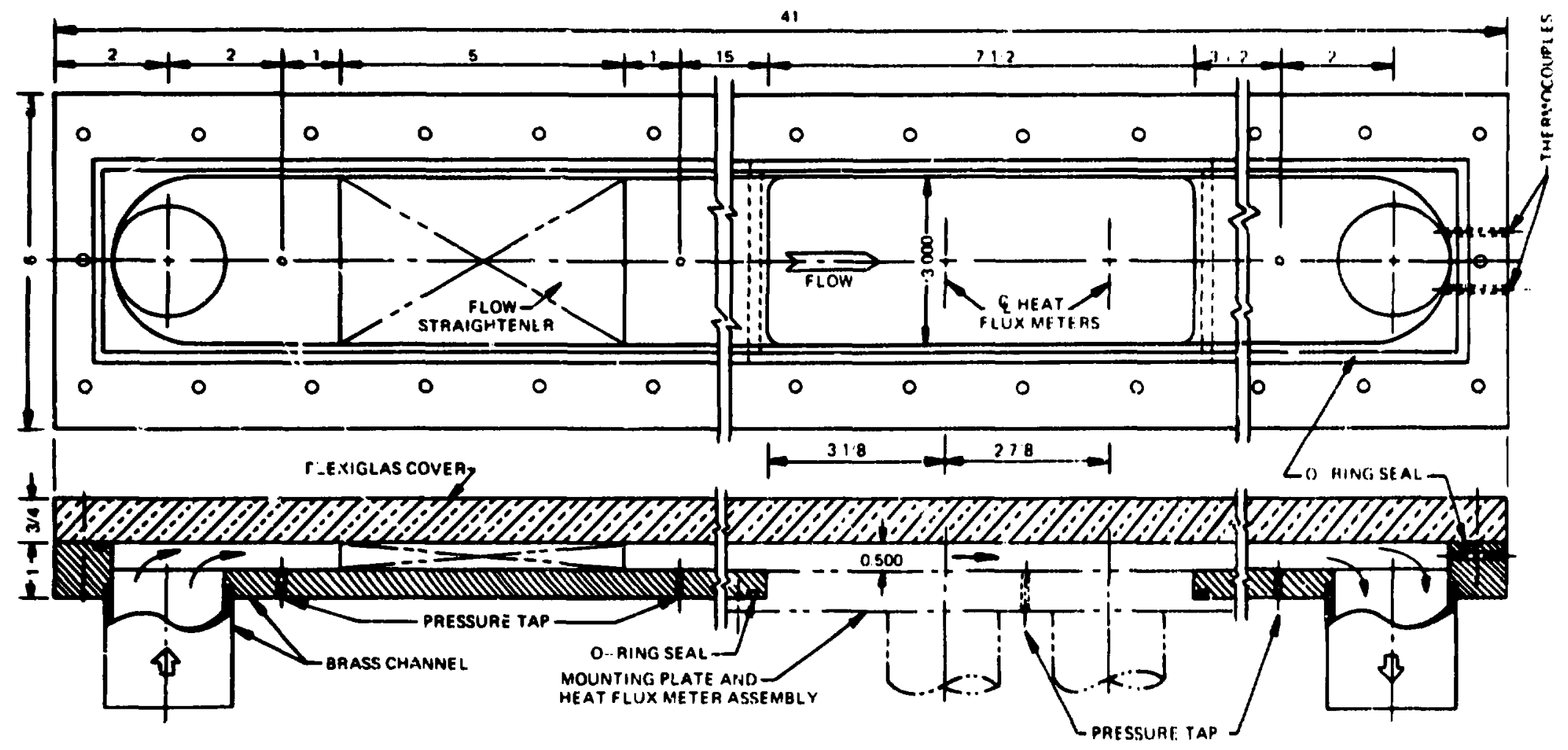

Fig. IV-8. Flow channel construction detalls. 
were soldered on the back side of the channel at each end tc provide inlet and exit connections.

Originally, a 5-in.-long section of "honeycomb" aluminum was machined to fit the flow charnel and pinned in place near the inlet to serve as a flow straightener as show in Fig. IV-8. Fevere galvanic corrofion of the alumimum and bress flow channel occurred curing the shakedown operation; the brass fiow channel was nickel figied and the aluininum Plow straightener was replaced with a 5-in.-long section of stairless steel "mist separator" ("Yorkmesh"; similar to steel wool). filthcugh the mesh introduced consfderably higher pressure drop relative to tine "honeycomb" section, it was very effective in dispersing the large turbulent eddie: generated by the inlet design.

The center ?ine of tiie first heat flux meter was J.ocated 19.125 in. $\left(L / D_{e q} \approx C c\right)$ downstream of the flow stralbitenfi. The ceriser line of the second meter was $2.875 \mathrm{in}$. $\left(L / D_{e q}=3.4\right)$ downstream of the first. Sharp-edged pressure taps were located 1 in. upstream and downstream of the flow stralghtener, midway between the meters, and I in. upstream of the exit. The pressure tape were made by drilling a $0.032-$ in. hole through the backside of the chanrel and then counterdrilling to 0.250-in. diameter to a depth of 0.375 in. A short section of copper tubling was soldered in the counterdrilied hole to facilitate external tubing convections.

Compression-type seals were provided at the exit end to permit insertion of two calibrated thermocouples for measuring the bulk fluid temperature in the vicinity of each heat flux meter. The thermocouples were $0.04 C-1 n .-d i a m$ stainiess steel sheathed, Chromel-Alumel, with grounded junctions. 
Since visual visemtatinn was the oniy technique available in this investigation for detection of nueieation on the toiling surface, the flos channel was fitted with 20.75 -in.-thick by $6.0-i n$-wide piece of Plexiglas. This also had ine adrantage that ti.e entire flow field was visible. A groove was machized in the brass chennel for a necprene O-ring seal between the cover ant the channel. Prolonged exposure of tile PlExiglas to the hot $\left(-215^{\circ} \mathrm{F}\right)$ demineraized wats raused the Plexiglas to become opaque. This wes rirsequently circumented by inserting a 5-mm-thick section of temperei pyrex glass tetween the Plexiglas and the coolant. Careful cortrol ci the seal tolting and of the rate of heatup orevented breakage of the Pyrex insert. The insert also served (in the tests with refrigerart) to prevent Freon from contacting the Plexiglas. It has been reported ${ }^{123}$ that long-term expcsure of Plexiglas to Freon-11z cacses "crazing" and ioss of optical qualities. [Our preliminary compatibility tests of Plexiglas in Freon-113 did not confirm the reported obsemations.] Figure $\Gamma \gamma-g$ is a photograph of the flow channel assembly and the mounting plate (before machining the holes for the heat flux meters). The "honeycomo" aluminum flow straightener (repiaced latur with stainless steel 'mist separator" to overcome a severe corrosion protlem) and the bulk stream thermocouples are also show in place.

The f] on chanrel was mulnted in a section of 8 -in. structural steel channel to prevent thermul distort;on. A l-1n.-thick layer of Fiberglas insulation was placed cotween the rackup structure and the flow channel. Provisions were made tc permit mounting the channel upside down for future downflow experiments. 


$$
21
$$




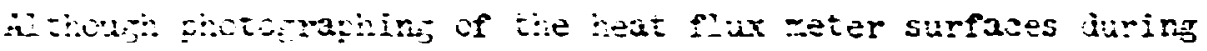

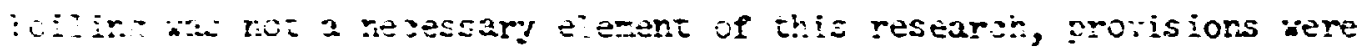

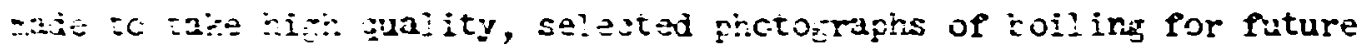

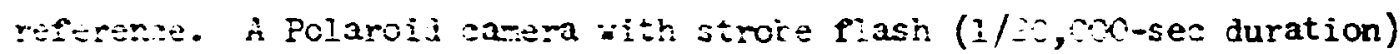
ias uivd for sinis purpose.

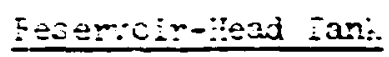

The rezer:oir-head tanir, made from a 5氵-ga! stainless steel drur,

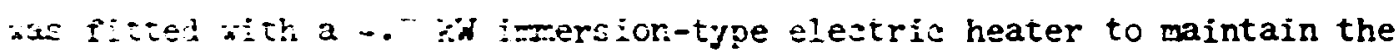
Iidii at saturation terperature. The tank was vented to atmosphere Lrou:ti a sma: reflux zonienser, connested to the top of the reserrolr y a zextion of -iasz pips. Azsurance that saturated conditions were Eein mantaired was ortained from visual observation of the reflux scr-

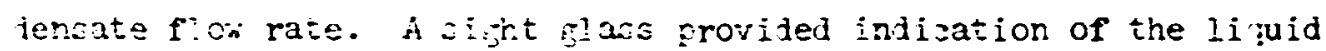
levs. A sal itrated ihermocouple imersed in the reserroir measured the fluif temperature.

The recorroir-read tanir was el evated .. ft to provide suificient net socit:ye sustion heai (iFGH) tc aroid saritation in the pumps. A i-in. pipe ras used for the pump sustion line to minimize friction losses.

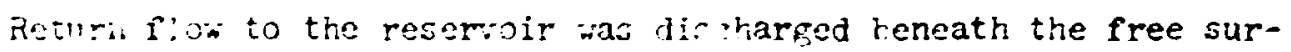
face to siminte entrainment of ronsond. Inle gases. The pump lypass cntorni the reveroir tangentially to promote mixing and to eliminate thom:a. zt atifjcation in the tank.

Pumpin: Etation

Tro amal! sontrifura! numpe were piped in a parallel flow conflgu-

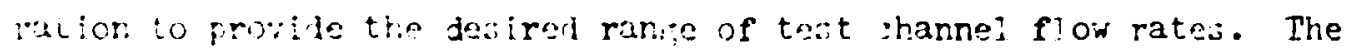

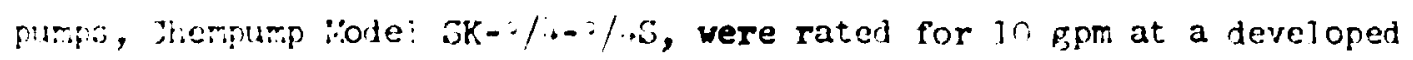




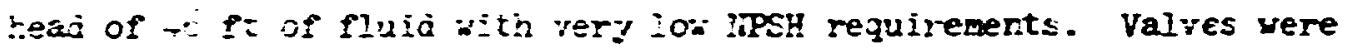
irstailed in the pu=p ais sharge ines to grevert resirouiation when the isct f:or rarue reulired oniy one of the pumps to ke operated. Bourdon pressure zages wers aiso sonrezied to tie purp dissharge lines to pro-

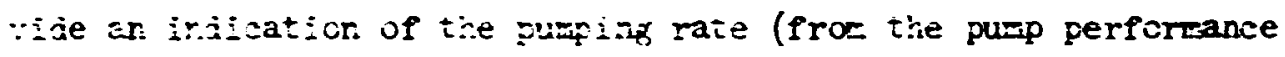
surves). Sustion pressure anci terperature indisators were installed to zaintain a shesis or incipient savitatior.

A sypass ine was connezted froc the plup discharge header to the reserroir to divert the excess flow and to inprove flow staility. The Ejpass line sontained a turine pion zeter and a lo-zicron filter station to zssure particie-free coolant.

\section{$\underline{\text { Preneater }}$}

A preneater section, consisting of three separately controlled, i.sersion-type eiestric heaters (each rated at ..- kW) inserted in sactions of i $1 /$ :-ir. nominal pipe, provided sufficient heat input to maintain saturation conditions at the heat flux meters. By locating the major flow restrietion (the flow control valves) dowstream of the preheater, the aisoiute pressure in the preheater was supficient to prevent toiling.

The reaters ere manualiy controlled to provide saturated, buik fluid conditions at the heat plur meters.

\section{Irim-Cooler}

A trim-scoler was located downstrear of the preheater in the event that starle conditions could not be maintainsd' $v$ manusi suntrol of the preheater. This trowed not to be the case, however, over the range of test conditions. 
Since Preon-113 boiis at $11^{-} \cdot 6^{\circ} \mathrm{F}$ at atmospheris pressure and the Fums supp?ied core than adequate heat to the circulatine refrigerant to maintain saturation conditions, this cooler was availacle to resove the excess purph heat and, thus, minimize ro:lorf and loss of the rePrigerant from the reservoir.

The sooler scnsisted of 10 ft of $i / 4-i n .-O D$ copper tubing (nickel plated) coiled inside a section of $11 / 2-i n$. pipe. Connestions for a Heise pressure gage and a calikrated thermoccuple were located near the exit of the cooler to determine the thermodynamic state conditions of the coolant at that point.

\section{After-Cooler}

At the higher $l^{2}$.ow rates, the two-phase pressure drop in the return line prom the flow shannel to the reservoir was such that pluctuatiog pressures were encountered at the heat flux meters. An after-cooler, consisting of is ft of ?/9-in.-OD copper tubing (nickel plated) coiled inside the 2-in. pipe, aircumrented this operating difficulty. A calibrated thermocouple was located downstream of the cooler to monitor the return plow so that subcooled contitions could be avoided.

\section{Flow Measuring Station}

The desired range of flow velocities past the heat flux meters ( 1 to $5 \mathrm{ft} / \mathrm{sec})$ and the dimensions of the rectangular flow shannel $(0.500$ in. $x=.000$ in.) dictated a flow measuring capability over the range of about 5 to $25 \mathrm{gpm}$. Since a single flow measuring device capabie of accurate measurement over this range was not readily available, two suitakly zized turbine flow meters were installed in a parallel flow 
configuration. The tlow control yas :es vere lasated domstrear of the weters to avoid flasing fiow as a resuit of nead losses in the seters.

The weters seiested for use vere an In-Vaj-so Hade: Wj/75: $\left(K_{n}=\right.$ $-5,35$ pulces per ga:ion) covering a $n \alpha$ range of 1.8 to $1 E \mathrm{bFs}$, and ar:

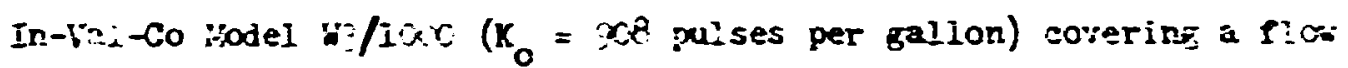
ranie of $i s$ to $6 C$ efa. The zeters have an accuracy of to. 51 in their P:ow rangez and $\pm C .16$ repeatalility. Recal itraticr runs vere performid

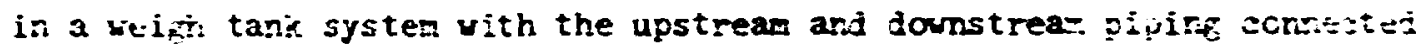
to inslude the ertrance-exit effects in the saitration. The resuits of

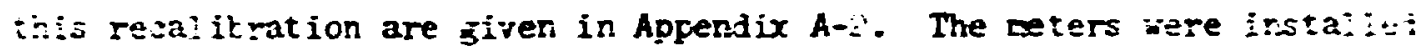
(ard saiitrated) in vertical runs of pipe to minimize graritatiorai efreztz at ica flow rates.

\section{In:trimeritatior.}

Fressuro. Pressure meacurement were ade with rourdon-type Eage at ine purp sustion, on the disatarge lines of the two purps, ant dowetrsam of the trir-govior. Since the pressure downtrean of the sooier was use' to estall ssh the tinermodyramis state of the coolant, ar to 10 .

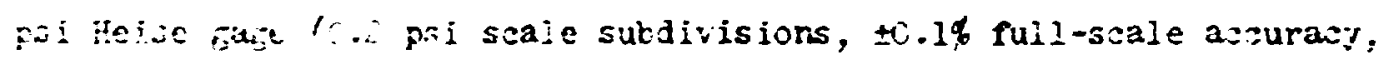
tempcrature compensated over the range $-25^{2}$ to $125^{\circ} \mathrm{F}$ ) was used at this position. The gaxe was certified for accuracy prior to use. Fressure can conreztions were located at four places alone the flow channel (Fir. IV-A): these zere valved to a manifold which was connected to a li-ir.

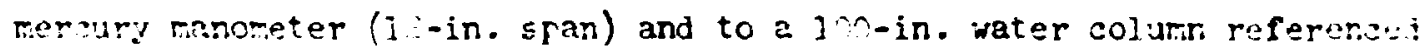
to atmoiptere. By proper manipulation of the vaives, the frescure sull is reat at the dosired loation in either inches of water or mervey, 
depending on range. A texperature compensated baraeter sas used tc measure atzospheris pressure.

Temperature- Tenptrature measurezents used in the data aralysis vere ottained from O. O-in-in-OD stainless steel sheathed, Chronel-Alumel, grounded iusction, thersocouples referensed to the se poiri. A Leeds

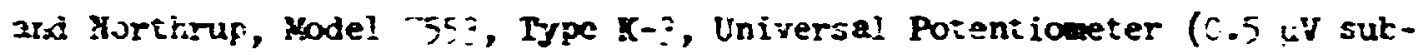
dizision, $\pm(.0154$ at 0.5 uV accuracy) vas used as the reatcut device. Tre potentioneter war sertified for accuracy prior to use. A selestor sitith was used to sorinest the individua: thermosorples in sequence to the potentioneter. Calitration of the therwasouples sas performei ajairet staniards traceat is to the kationai Bureau of Standarde. Results of the cailtration are gi:en in hprendix A-Z. The saitraticn ins:uge: a:l elemerts of the temperature set:ing instrumentation de to the zermaje of tide jotertiometer. The salitration data wore fitted to auki a suatiors, ning the CRDEAI prograr, i2 2 to fasilitate data redi:ticr.

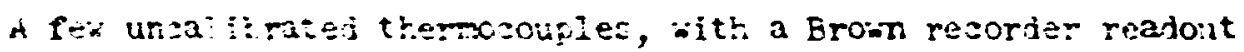
soiertickster, iere usei for monitcrine loor oraration.

Foi fate. Jalimed turtin: reters rers uest to mearur: the tect sharre: f cor rate. This was asomplishes ly counting the pulses generatej fer unit time irterraj ty the reter. A Iransiator sposialtino,

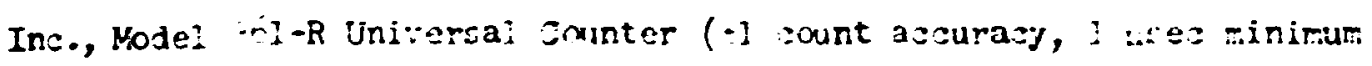
time intara! intwar gusez) war sogt to sourt tho pujses. It.e rolu-

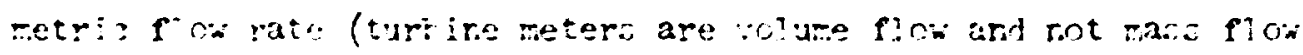

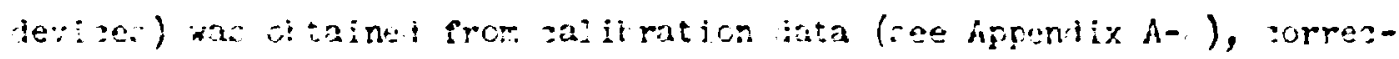

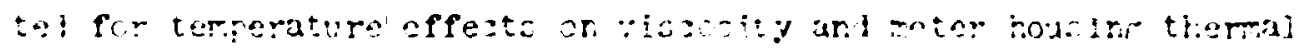


expansion. ${ }^{30}$ mas flow rates vere ealculated frow the cesured roiu. net-ic nows.

A continucus readout nor fndicator ves also used for soaitoring now trends turing startup and stabilization of conditions pricr to each test run.

Liguid Level. An ordinary sight glass was used to indieate tice coolant ievel in reservoir-head tank.

Heat Plux Meter Power. Input power to the heat Nlux meters vas conguted from voltage and current measurements. A Dan yodel ia300 difital voltweter [10 jV to $1000 \mathrm{~V}$ dc rull-scale input rages, accuracj $\pm(0.00$ sf of reading +0.005 f of null seale $)]$ was used to ceasure the de voltage drop across the heater. [Voltage taps were attached $2_{6}$ the exis of the heater.] With the aid of a selector switch, the digital roltneter could be switched to measure the voltage drop across a cailibrated shunt (10 0 to $100 \mathrm{mv}, \pm 0.5 \%$ accuracy on current) in the de pover lead to the heater. The voltweter and shunt vere certified for accuracy by the Standards Laboratory prior to use. The results of the calibration are reported in Appendix $A-1$.

Electrical power measurements, corrected for heat losses, were usec as a check on power measurements oktained by the temperature gradient method.

\section{Pool Bciling Pacility}

The pcol boiling tests vere performed in a Pyrex biass holler (11.5 in. ID by $18 \mathrm{in.} \mathrm{high)} \mathrm{fitted} \mathrm{with} \mathrm{a} \mathrm{Plexiglas} \mathrm{cover.} \mathrm{A} \mathrm{2.5} \mathrm{kW} \mathrm{heating}$ element was incorporated in the support structure and served as the 
primary :'eat source. The rest fluid was zintained at seturation teaperktire by proper adjustment of a variar. contrc s soupled to the heating elewert. Additions? heating capacity (for faster hextup) was provided s; a variac-conirolled, imersion beater. Fiter dess insulation airi$=$ : zed heat losses throufa the vall of the eyindrical boiler. The Plexiglas sorer war construsted in three layers (vith insulation jetireen the laver two iaysers) to retuce reat losses through the to?. A refliux condenser, fatricated in the forz of a "parcake" from copper tubing, vas suspended beneath the cover to condense the vapor and to prevent loss of the test fluid. Aceess we s provided through the cover for four caliirated therwocouples; two were iockted approximately $i / 2$ in. beios the vapur-ligufd interface and the other two were iacated 0.18 in. atove and slightly to the side of the test surfaces.

FOr the horizontal bofling surface tests, the mcuntirg plate assemily (see Fig. $\mathrm{NV}^{-}$) was supported and carerully leveled ir: the boiier. P18ure IV-10 shors a photograph of the setup. Pyrex glass skirts (2.3 in. If by 5.5 in. high) sere positioned concentric with the $0.5-i n .-d i a n$ test zurfaces to minimice the effect of external corivestion currents generated if the hot plate. In addition to the internal details, the photograph shows the manner by which access was gained for the heat weter insirumertatior. and power through the cover plate assendy. A slight overpressure of cuffer gas (nitrogen) was applied to the housings iat all times to preiert inieakage of test fluid. The Brid level was maintaired 5 to ir. atore the test surfaces.

A Jari glass tacigground was placea tehind the test surfaces to aid photoryphis. The strote light was positioned to the left for side 


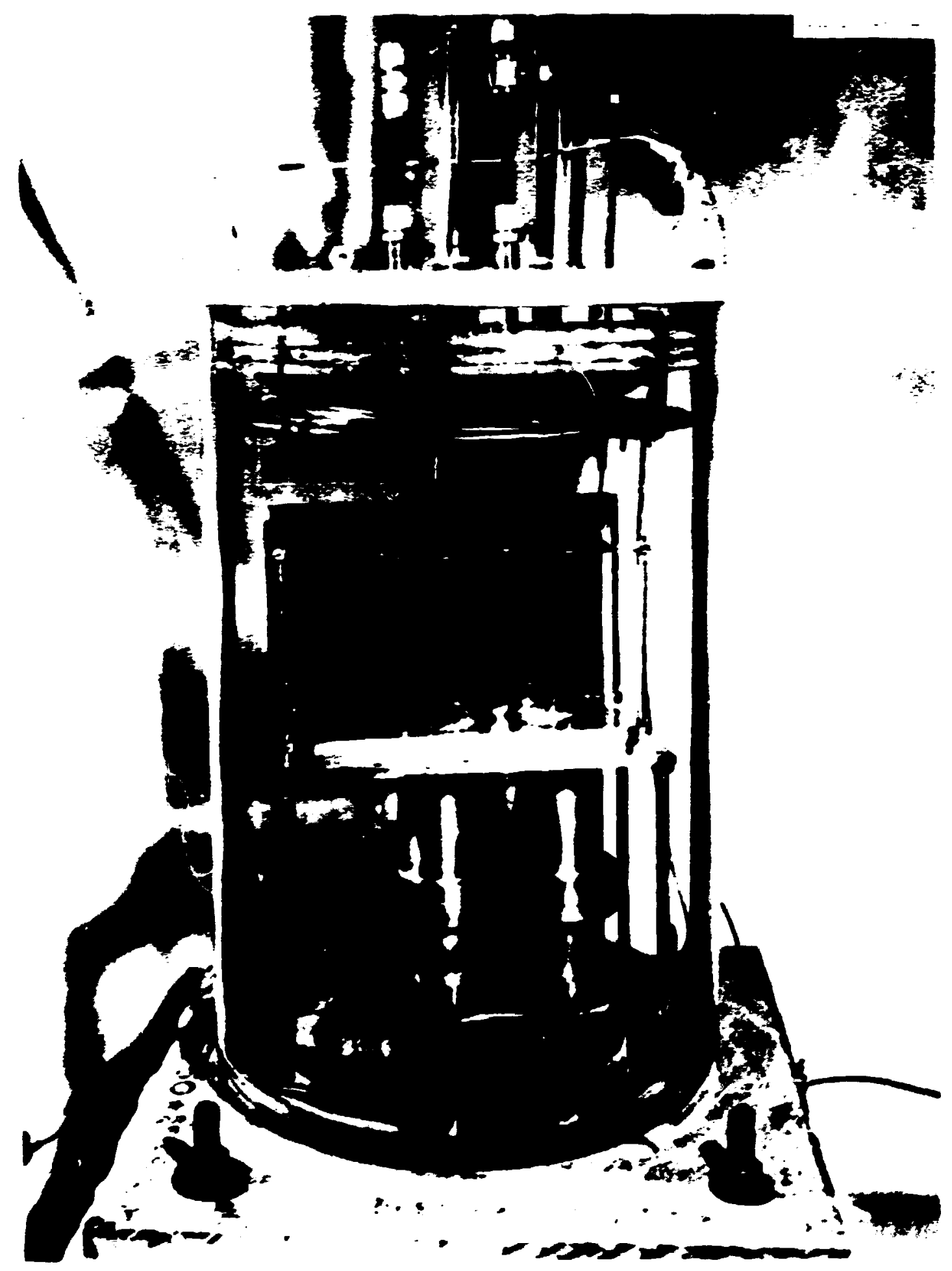

Fig. IV-10. Horizontal pool boiling arrangement. 
iighting. [Back lighting was impractical due to the access tubes and optical distortion.]

For the vertical surface boiling tests, the mounting plate assembly was carefully aligned (in the same relative position as was used in the flow test facility) by means of a support frame as showr. by the photograph in Fig. IV-1l. A rectangular isolation chamber was attached to the front of the mounting plete co minimize the influence of external convection currents. The chamber, clearly show in the photograph, had a cross section of $3 \mathrm{in.} \mathrm{by} 1.5 \mathrm{ir}$. and was closed at the botton. Thermocouples for local fluid temperature measurements were located at the center line of the heat meters; the center line distance between the two meters was $2.875 \mathrm{in}$. The fluid level was maintained 5 to 6 in. above the center line of the upper heat flux meter.

\section{Procedures}

Flow Tests

The flow tests (bolling and forced convection) were performed before the pool bolling experiments; water data collection preceded the Freon-113 experiments. The following discussion is primarily related to the water tests; the tests with Freon-113 deviated slightly due to the peculiarities associated with the use of a low vapor pressure (and expensive) fluid.

The reservoir was maintained at sufficient level ( $\sim_{40} \mathrm{gal}$ total loop inventory) to pert.it oreration for several days without addition of makeup. Bolling conditions were maintained in the reservoir continuously (except during prolonged shutdoms) by the reservoir heater 


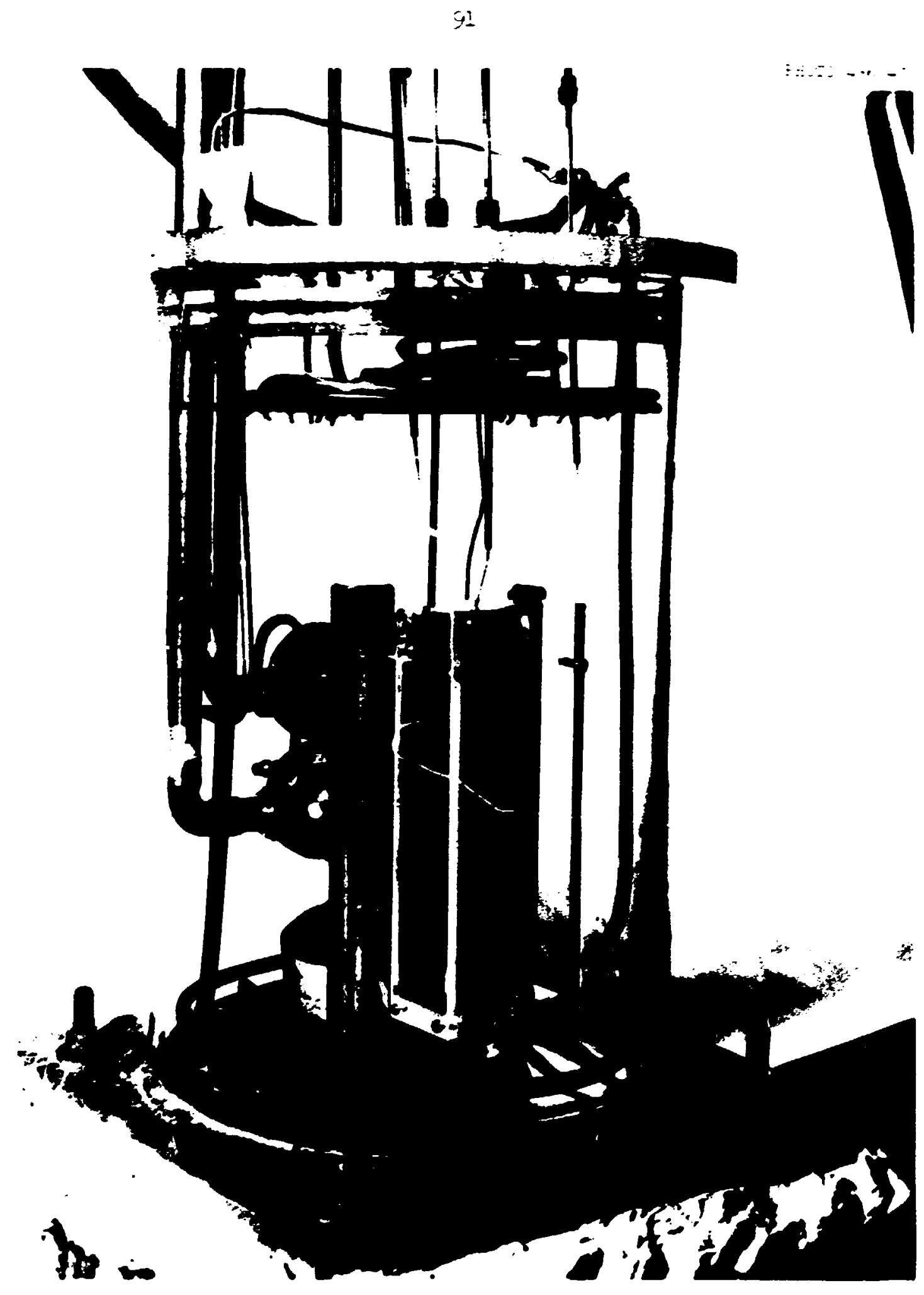

Fig. IV-11. Vertical pool bolling arrangement. 
to provide deaeration. Heat input was adjusted to the poirt that a sligint amount of condensate was refluxed from the vent cordenser. The pressure was set at the upstrean heat flux meter (EMi-1) to correspond to a specific saturation temperature $\left(215^{\circ} \mathrm{F}\right.$ for water, for Freon-113) by adjusting the throttling valve downstream of the tes: channel and/or by controlling the coolant fiow to the aftersooler. The Earcmeter was read every 3 or it hr (corrected for temoerature arij loval gravity) prior to making adjustments. The coolant flor rate was zair:taired corstant (indicated by a frequeney meter monitoring the turicine cutput sigrs?) throughout a given series of tests. Iocal pressure at the heat metars was indicated on 100-in. water (or Freon) manomiters cr by a 12-in. mercury manometer, depending on pressure range. The suppressed coiling tests required that the mercury manometer be used. The voltage to the line heaters was adjusted as required to maintain the saturation temperature corresponding to the specified pressir.e. The kulk stream thermocouple (TC-37) was used to indicate that the temperature was at the desired value. Occasional generation of bubbles sit local flow disturbances providea a second indication of saturatior. conditions at the heat flux meters.

The taps for measuring the local pressure before and aiter the channel flow straightener and at the channel exit were unfortunately located in regions of hydrodynamic disturbances, thus negating their usefulness. Since these measurements were superfluous to the oh.jective of this research, no attempt was made to relocate the taps; neither was any use made of these data. The tap at the heat meters, being in a hydrodynamically "smooth" region, provided data consistent with the measured temperztures. 


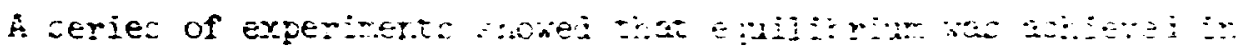

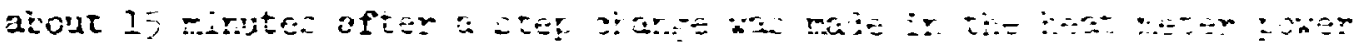

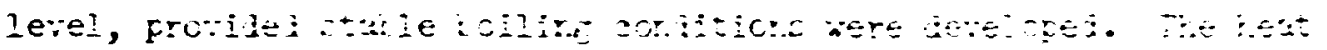

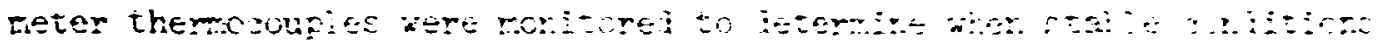

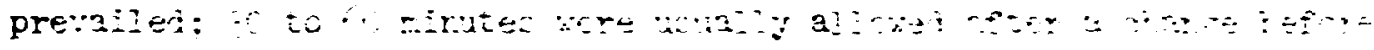

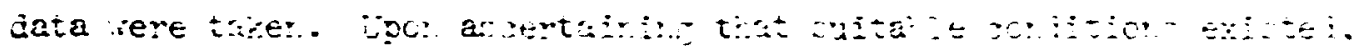

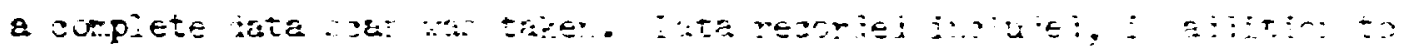

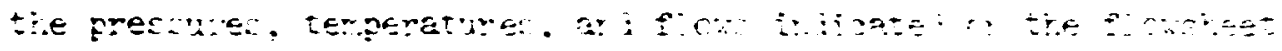

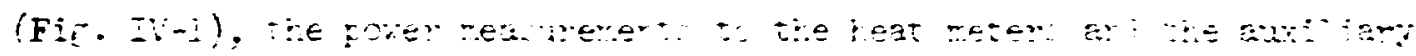

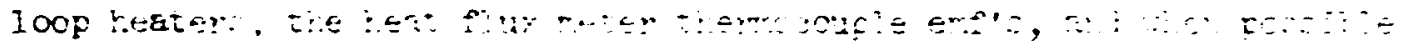

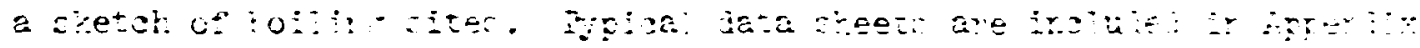

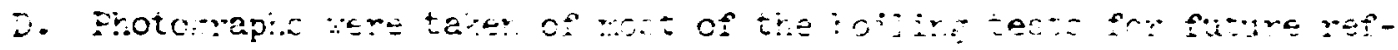

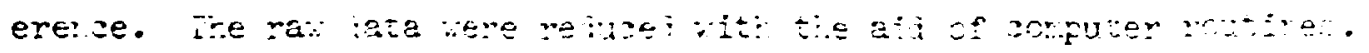

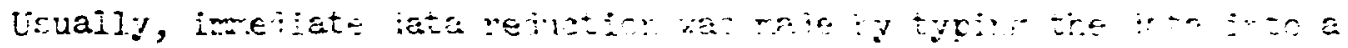

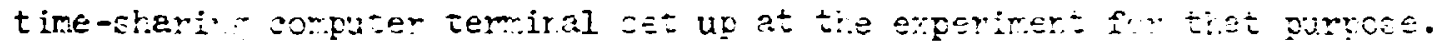

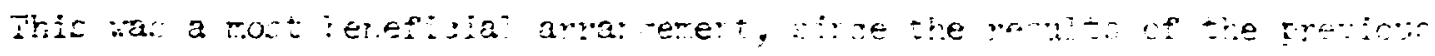

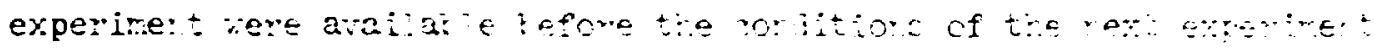
nas zet.

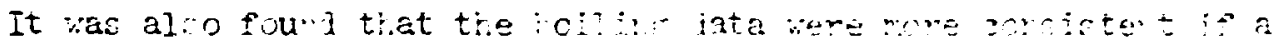

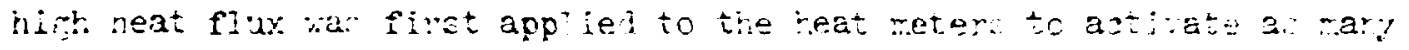

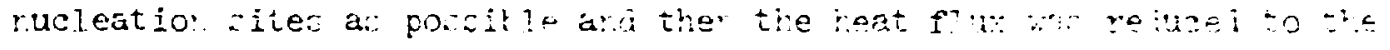

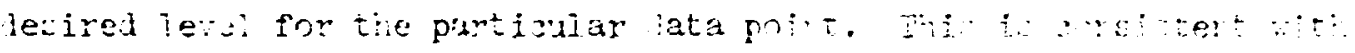

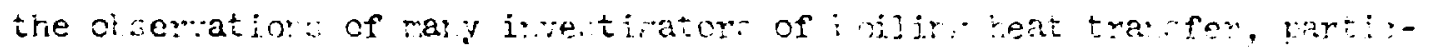

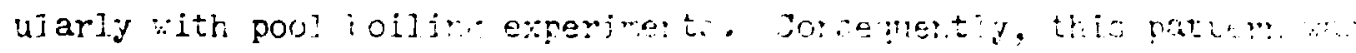

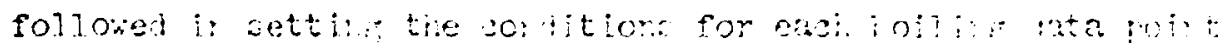


The ligh roid fractior. Freon flow koiling tests were conducted by initiating tulk or homgereous koilirg (as the result of the pressure drop asross the mist separator) at the charnel inlet. This techrique provided staile, two-plase-flow conditions and produced uniform cubrles ir: the stream. This as accomplished at a predetermired floi rate by adiusting the inlet fiuid terperature to the desired level and ther. momertarily desmasing the fro rate to initiate rueleation followed Ey restoratic: of the flc: nate. The rane of thermodyramic quality ottainal le (2 to sy a limited by tic raximum heat flux or the lire heaters to arcis film boiling.

After estai 1 shir the stream conditions, tise same procedures were followed ts of tair. heat transfer data outlired arcve for the zero-guality tects.

\section{I.PI Boiliririests}

The pool ioilne teste with both horizontal za? vertical surfaces were muh eacier to perform. Usirs the arranemert previousl: descrited, the boiler mo filled to the proper lavei, neated to saturation temperature, ar maintuined at this temperature urtil the series was complete 'wo or thres dege). Prelinirary testo showed that 30 mirutes was alequate to ouilin rate after a charge ir heat meter power leve?. Thus, the loildre te:te were ronducted by starting at the maximum powar level and redu:is: in atepr to the next lowest lerel. Data oi tained at each power settir. inruter sarometric pressure (with corrections for lural Gravity aid temperature), ponj cepth (to permit calculation of the joca!

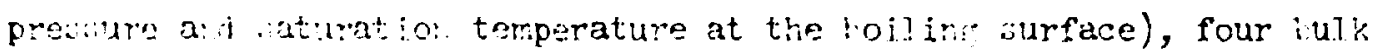
fluid tempentums: a the beat neter tenperatures ari power parameters. 
The recural-convection data points were obtained by setting the desires power level in tine evering and recording the data the next morning; thus 12 to $16 \mathrm{hr}$ were aveijable for the meters to equilibrate unde:- these low heat flux conditions.

\section{Boiling zurface Preparation}

Originally, the test surfaces were plated with a $0.0001-i r$. thickness of pure nickel to prevent oxidation (often referred to as "aging" in the boilirg literature) of the copper surface during the water tests. This nickel surface was then finished, by lapping with 1-ricron (1200g.j.t) aluminum oxide compounc, to give a mirror finish. (Photographs of the surfaces wfre shown in Figs. $T V-4$ and $I V-T_{\cdot}$ ) Since a moderately large number of nucleation sites was essential to insure stable and reproducible boiling, it appeared that the nickel-plated surface would be ideally suited. However, difficulties with surface contamination (caused ty corrosion of brass fittings in the system piping) and nonreproducible nucleation in the water flow boiling tests necessitated further surface treatments to improve the nucleating characteristics. Accordingly, the surfaces were successtvely lapped with a 600 - and 400grit corundum (natlirally occurring alumirum oxide) lapping compound in an effort to reactivate and to improve the performance of the nickelplated surfaces; this was only marginally successful. [Lapping was selected over the use of emery peper to provide a more uniform surface finish.] In a final resort, the nickel p?ating was removed completely by polishirig with 300-grit silicon carbide paper, followed by 600 -grit paper, to expose the copper as the bolling surface. The copper surface was then lapped with 400 -grit corundura to remove all scratches. This 
preparation gave a surface that performed admiratly; results are discussed in the next shapter. Thus, the final sorvective flow tests with water, all the Freon flo: tests, ard all the pool boiling tasts (bcth water and Frecr) were earried out with this surface preparitior.

Frior to eash series of tests, the copper surfa: was relapped (using a smail sast iron lapping disk arad toj-grit corundua sompcu.j), :ashei with Freon, ard air dried. Erarination of the iapged surfaces under a miscosope ( $4 K$ ) shored that the mat firish ras reprojusitie. As will be Jiscussed later, the iapped sopger surface yielded pool roilirg jata indisative of a fairiy rough surface wher refeicrzed to ti.e iulk of the data reourted fur corcer firished with dry $4 / 0$ amery paper. Fossible explanstions for this some-hat surprising firding iryolve the type of surface produced or the relatively soft copper by the lapping cperation and the possibility that aluminum oxide purticles (from the lapping comfourd) remaired embedded in the copcer. This prompted soxe further examination of surfases finfshed with dry emery paper and sith LOri-grit lappir.g somcourd.

One of the prototype meters used in ferfecting tile fabrication procejures (the copper care from tise same bar as that used in the test meters) was given the same surface finishing treatment as used for the boiling test surfaces. Examiration of this surface under the microscope indicated the same surface finish as had ineen produced numerous times on the test meters. The surface was ther submitted for metallographic examination and surface roughness mosurements. Fo:lowing this, the si::Pace wa: Japped and (reexamired) with 600-grit compound, and then succersively with 40 -grit si]icor carbide paper (wet), 2/0, 3/0, 4/0 
dry emery paper and 600-grit silizor zaridide faf face being examined between each treatmert. This proceaure is in orjer of decreasing particle size, with vet (aatcy ; uorisated) paper produzirg smoother surfaces than dry emery paper. ¿Water cannot te used as a lutricant with emery paper as it dissol:es the adhesive conding the partizles to the support paper.] The surface firish was gererated iy placing the paper on a surfize plate and riting the prototype reter over the paper in parallel strokes. About io strokes were suffisient to remove completely the marks from the previcus polishing (perperdisular to the direction of the strokes); each stroke was aje or. a new area of the paper, since worn paper turnishes the surface and projuses a smontiner Pinish. The above is the itandard tecn:ique for preparing metallograpin= specimens for examination.

Photomicrr; uphs were taken of the surfaces; full-sized photographi= reproductions (100X) are shown in Fig. IV-12 for the $400-g r i t$ lapped surPace, $r .: 2,0$ and 3,0 dry em. y finish $2 d$ surface, ard the $60 \mathrm{C}$-grit wet silicon arbide finishat surface. The phctomicrograph of the 40 -grit lapped surfact confirins the arisence of saratches in tha prototype meter and, by inference, from the meters used in the boiling tests. The surface exhivits a mat-1:ke finish with no confirmed erbedded al uminum oxide particles within the area of view.

After the pinotomicrographs were taken, the arithmetic average surface roughness was measured a number of times (perpendicular and parallel to the direction of polishing) for each surface finisin with a calibrated Brush Gurfindicator, Model B-110 (0.006-in. radius dianond stylus). The arithme $t$ ic average roughness in microinches (RMS values wouid te $11 \%$ 
PHOTO 0258-74

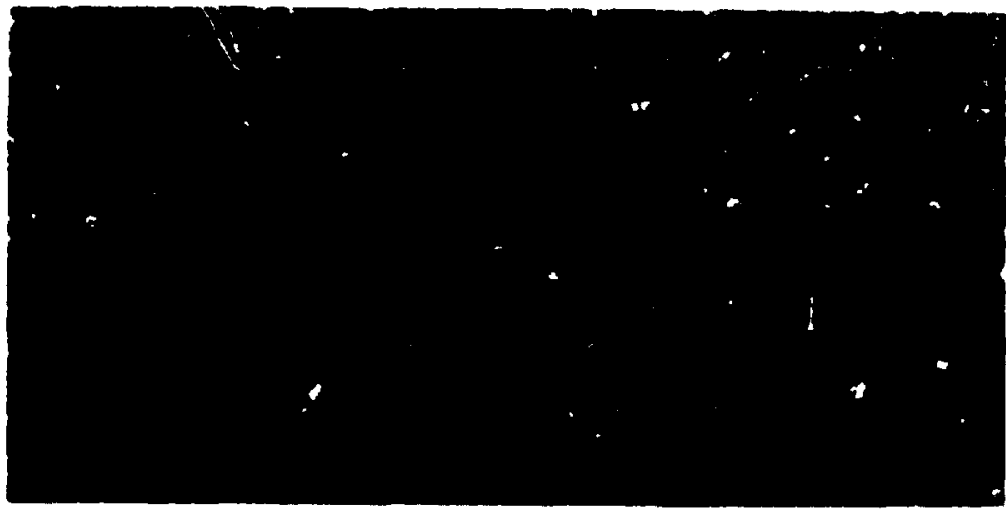

$\frac{100200}{1}, \begin{aligned} & \text { MICRONS } \\ & 0.000\end{aligned}$

(a) 400-grit iapped
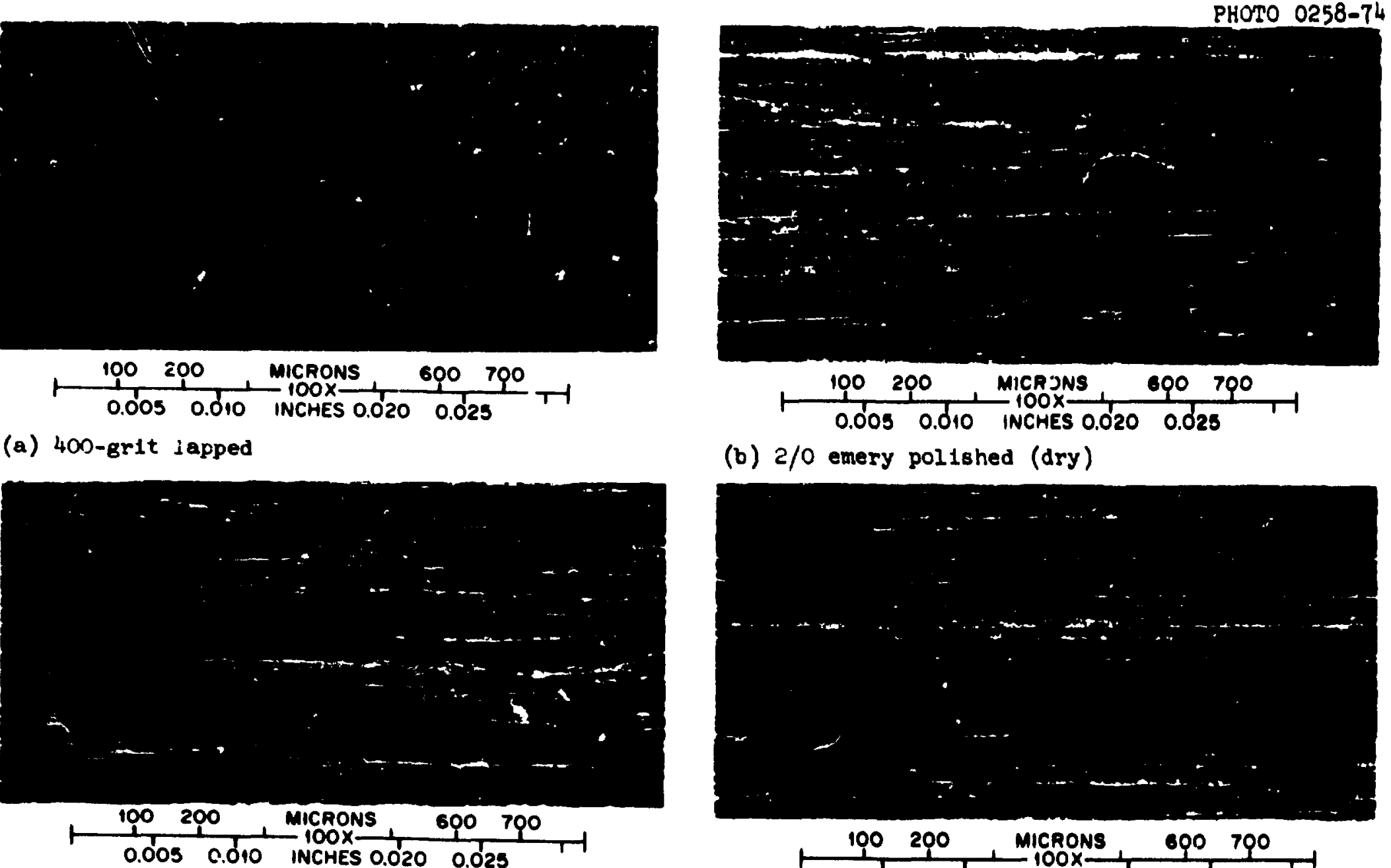

(c) $3 / 0$ emery polished (dry)

(b) $2 / 0$ emery pollshed (dry)

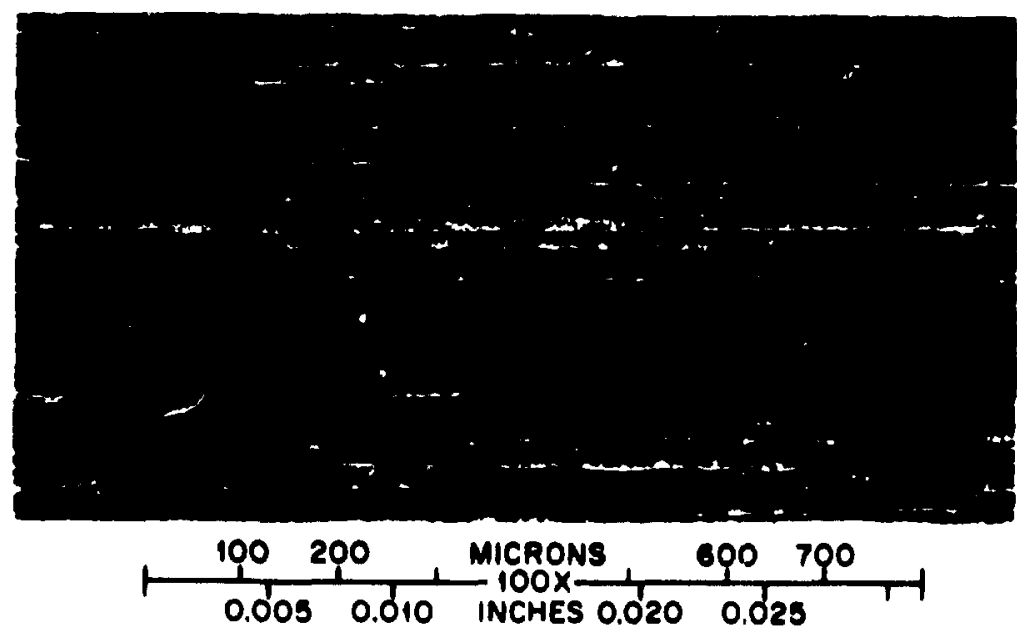

(d) 600-8rit silicon carbide polished (wet)

Fig. IV-12. Photomlcrographs of lapped and pollshed surfaces (100X). 
greater) were:

$\begin{array}{lllll}\frac{\text { Lapped Surfaces }}{400 \text { grit }} & \frac{650 \text { grit }}{20} & \frac{2 / 0}{13} & \frac{3}{110} & 5\end{array}$

The surface rcughress masurements were highly reprojucitle and essentially irdependent of polishing direstion. Al though the roughress cf the $i / 0$ and $i / 2$ finishes anpear reversed, toth were reskecked and $c 0$. firmed. It is noted that the $\angle / 6,3 / C, \rightarrow / 0$ paper each sam fium a oifferent manufasturer; this probably accounts for the inversion in stardings for the last two listings.

Tho specimens of the same copcer tar were prepared as tefore (one by lapping with on-grit compound; the other by polishir.g with dry $2 / C$ emery) and cast in epoxy for sectionirg to cttain profiles of the surface finish. The apecimens were handled in accord with standard metalWureine techniques tc preserve the surface contour. Fuli-sized reprojueticrs of phctomicrographs (500x) of the sirface crntours are show in Fig. I. j; the dart area is the epoxy and the iight area is the copfer.

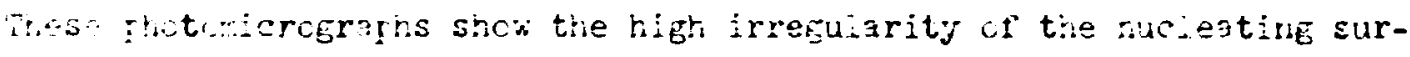
r": e rite nuerous cavities within shich vapor can be traped.

To prove the possibility that aluminum oxide particles embedded in the relatively soft copper might be the cause of the outstanding nucleating performance of the test meters, another specimen was lapped with the $00-$ grit compound as before and examined by an electron scanning micros zope (ESM). This devi ze has a very large range of magnification and depth of field for focusing compared to an ordinary optical microsope. The specimen surface was scanned acrose two diameters in a 


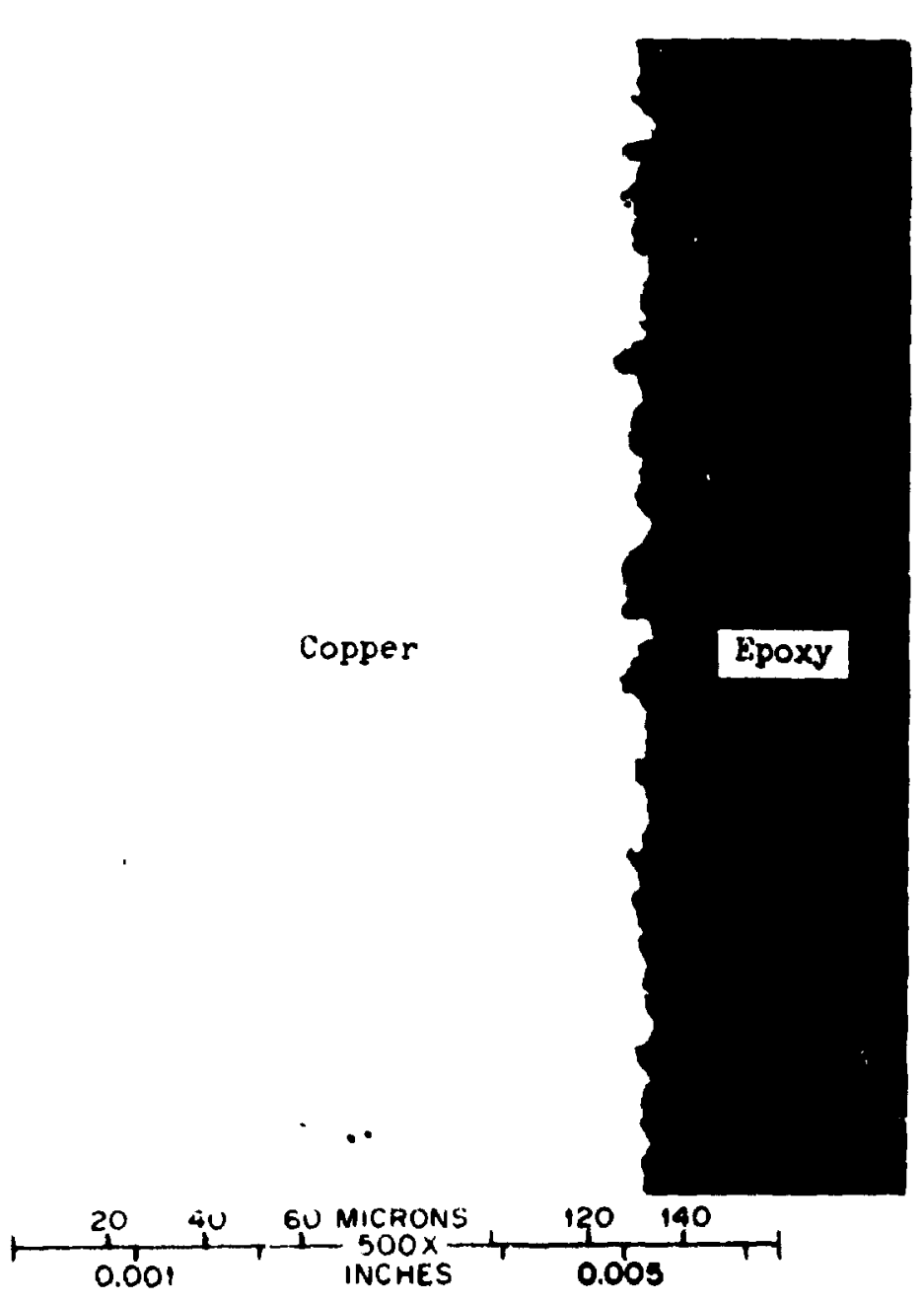

(a) 4 -o-grit lapped surface
PHOTO 0256-74

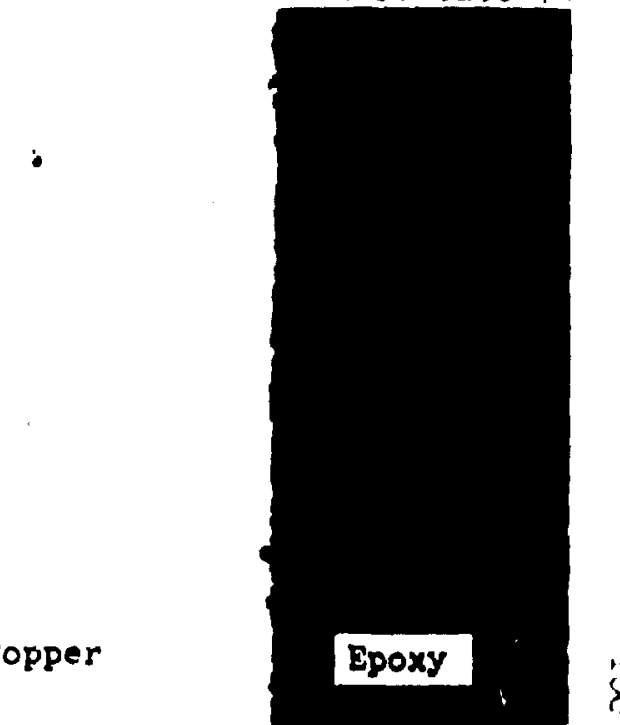

s',

F1B. TV-13. Profiles of lapped and pollahed surfaces (500X). 
0.035 -in.-wide band (123 of the total area) to deternine if particles vere presect and, if so, the approximate muter per unit area. Several particles (about 50 in each scan) vere found and identified by spectral analysis to be alunimu oxide. The particles vere wostly on one side of the copper area, possibly where the lapping stone vas first placed or where it vas renoved. Pull-size reproductions of the vicrographs of one interesting cluster of perticles are show in Pig. $\mathrm{N}-14$. The aree shown in PIg. IV-14a is approximately $0.03 \times 0.03$ in.; this micrograph can be contrasted to the one shown in $\mathrm{FIg}$. IV-12a, since they are or identically prepared surfaces. The depth of field vithin focus in the 1000 manification of the ESM scan clearly shows the presence of four alunima oxide particles. Figures IV-14b, $c$, and d, showing enlarged views of the "large" sentral particle of Fig. IV-12a, also clearly exhibit the character of the surface rougmess. Pigure $I V-14 \mathrm{~b}$ (at $300 x$ ) is consistent with the surface profile shown (at 500x) in P1g. IV-12a. The particle show is Fig. IV-14c appears to be about $0.2017 \mathrm{in}$. acrass the longest dimension.

Pigure IV-15 shows full-size reproductions of a set of ESM inages of the 400-grit lapped copper surface. The two traversing scans (each covering a strip $0.035 \mathrm{in}$. wide by $0.750 \mathrm{ir}$. 1003) Indicated these areas to be far more representative of the general surface condition than that shown in P18. IV-14a. Thus, it was concluded that embedded alumimm oxide particies had an insignificas c effect on the bolifing performance relative to the effect of surface roughness produced by the lapping. By way of comparison, the ESM Image of Pig. IV-15a (IOCX) shows far more detail of the surface than that given by opt lcal means (see 


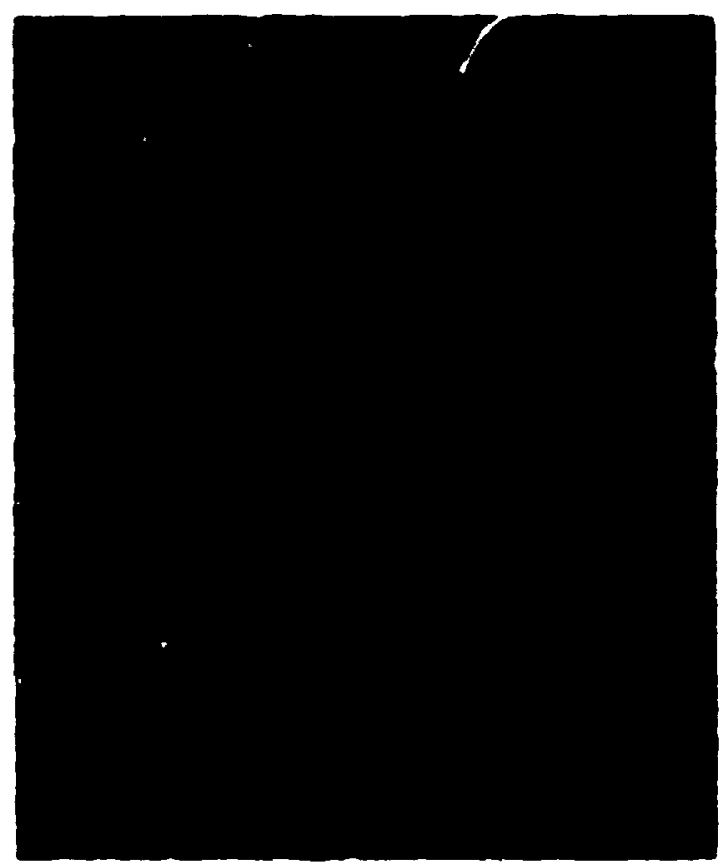

(a) $100 x$

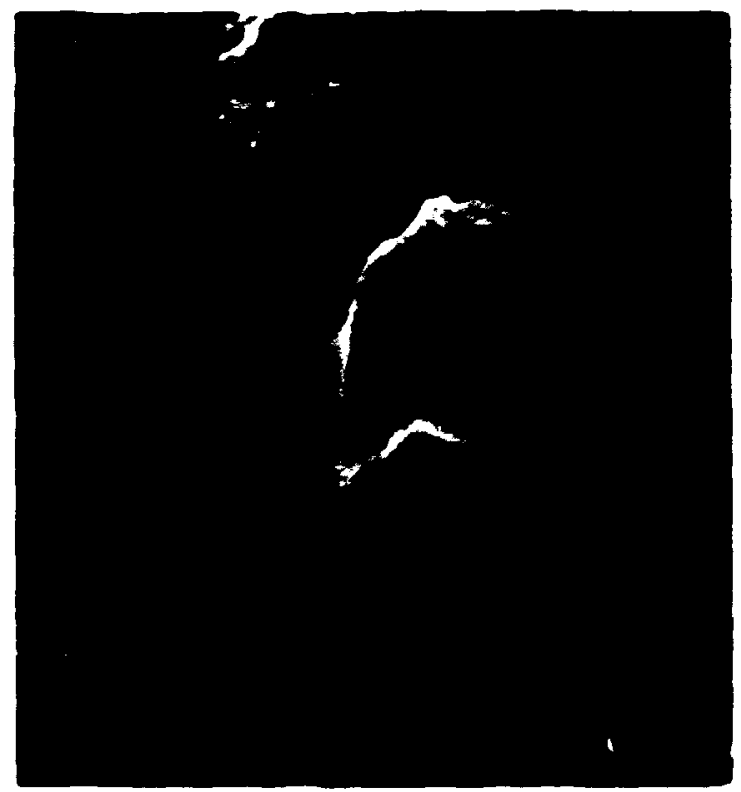

(c) $1000 x$

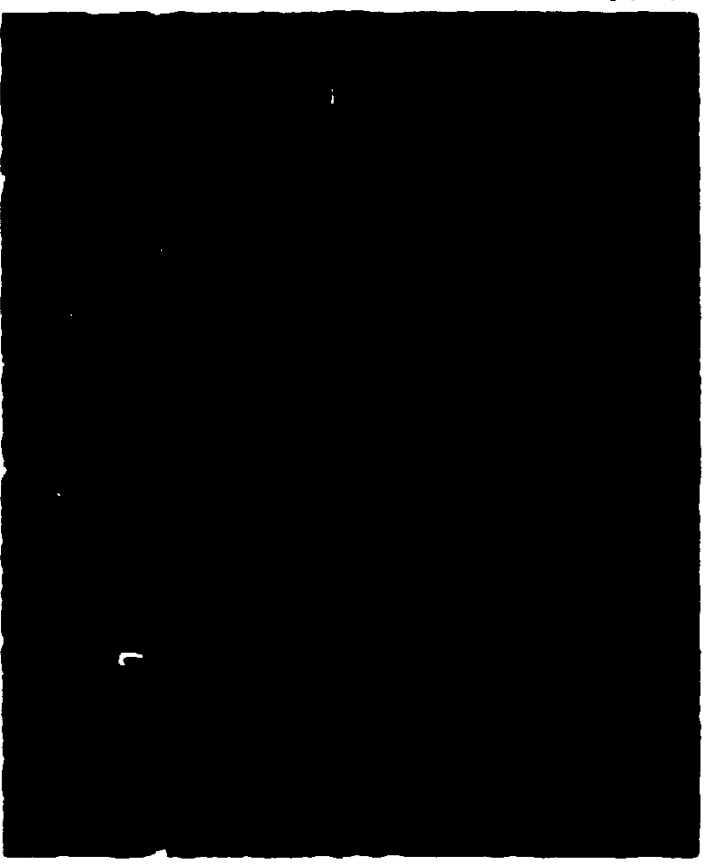

(b) $300 x$

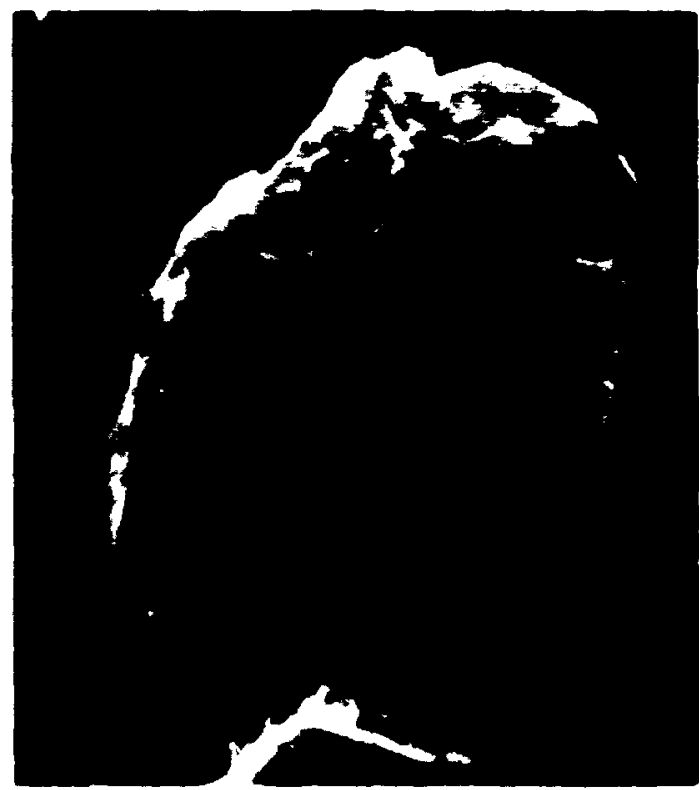

(d) $3000 x$

FIE. IV-!4. EsW mierographs showing alumirum oxide particles on lapped zurface. 


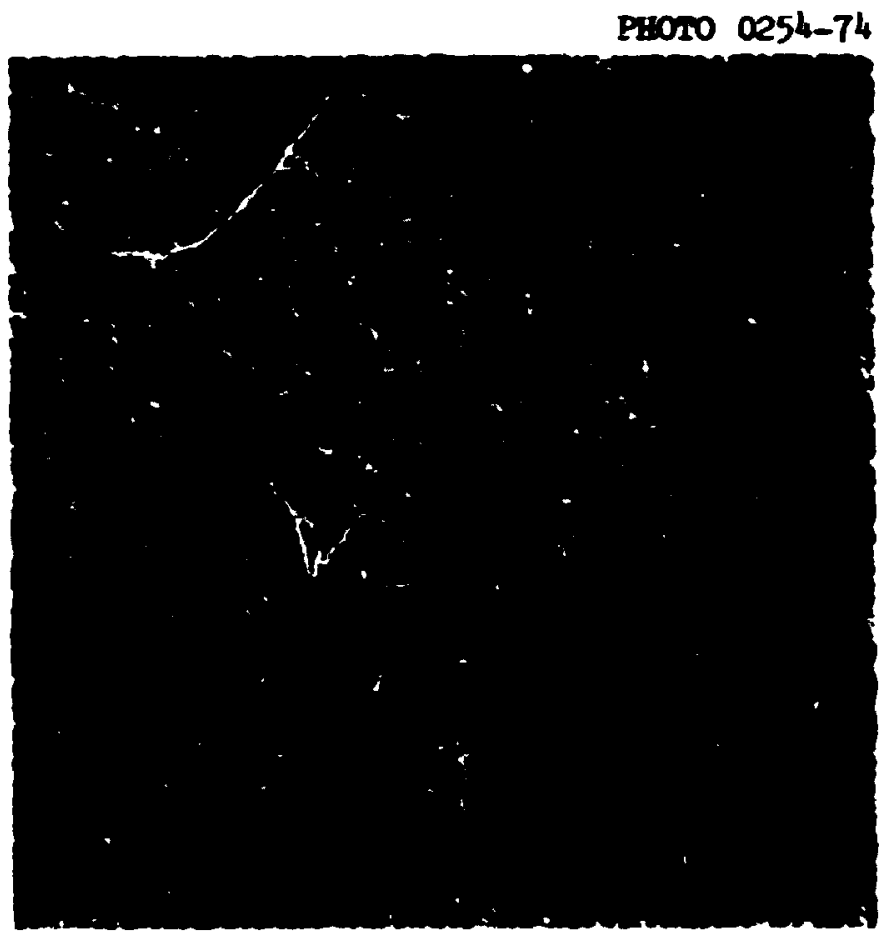

(a) $100 x$

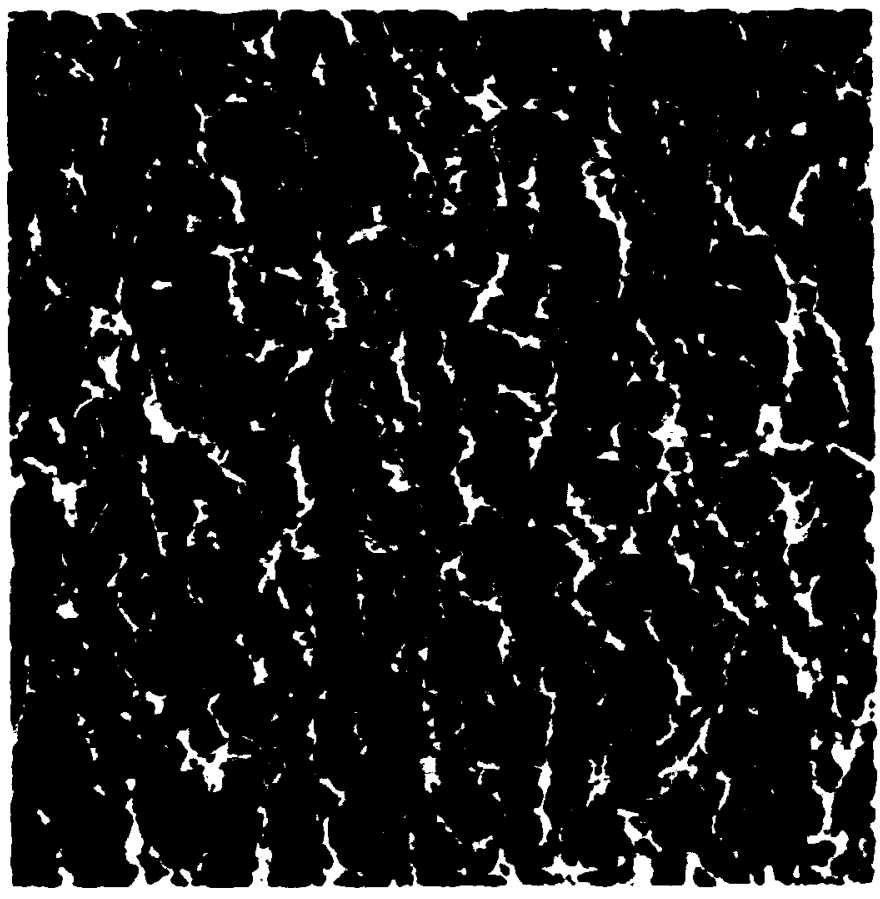

(b) $500 x$

Fig. IV-15. ESM micrographs of 400-grit lapped copper surface. 
Fig. IV-12a); the sirface is vividly portrayed at 500X in P18. IV-15b. The profile viess shown at $500 \mathrm{x}$ in Fig. IV-13a can be compared to the surface inge (at $500 x$ ) in PIG. IV-150.

These findings strongly suggest that the use of a surface roughness measurement to characterize a boiling surface finish is somewhat questionable. This undoubtedly partially explains the cause of differences is: koilirg performance as reported by various investigators on surfaces ostersikly prepargd al ike. Views of a surface by the electron scanning micruscops clearly display the character of the surface. The use of this inctrument may thus provide an improved technique for studying the relationship between the boiling surface and the bollfing performance. 


\section{CHAPTER V}

RESULTS AND DISCUSSIO:

\section{Heat Fiux Meter Thermal Performarce}

It is of interest to compare the thermel performarce of the heat flux weter with th: expected cehavior on which the aesigr. was based (see Chapter IV and Appendix B). The results of a typical Plow kollfre experimert were used as input parameters to the HEATDNG-3 computer programi27 to determine how well the computationsi model zould predist the experimental data. Run TPBLC2-01- (upflowirg water kollirg on a copper surface; was selected from the flow tolling experinerts for this purpose, since the heat $\mathrm{N} w \mathrm{w}$ and the boflir.g heat trarsfer coefficier.t were comparable to those used ir. the desigr. analysis (Appendix B).

The measured electrical power and stream temperature and the tolling coefficient calculated from the noat flux ard the temperature difference measuremerts were input to the HEATDNG-3 computer program ${ }^{127}$ to describe the experiment in terms of the calculational model. Naturalcorvectior heat transfer to water [Eq. (B-1) of Apperdix B with $\mathrm{T}_{\mathrm{f}}=$ $21^{4} .81 \mathrm{~T}$ ] and to air [Eq. (B-2) of Apperdfx B with $T_{k}=80^{\circ} \mathrm{P}$ ] was specified for the stainless steel plange surroundirif the copper surface area and the exposed surface area of the meter housing, respectively. The resulting calculated center-Iine temperature within the meter is compared in Pig. V-l with the five experimertally deternined temperatures and a least-squares linear fit to these experimertal ralues. The agreement between the predicted and measured temperature profties is extraordinarily good. 


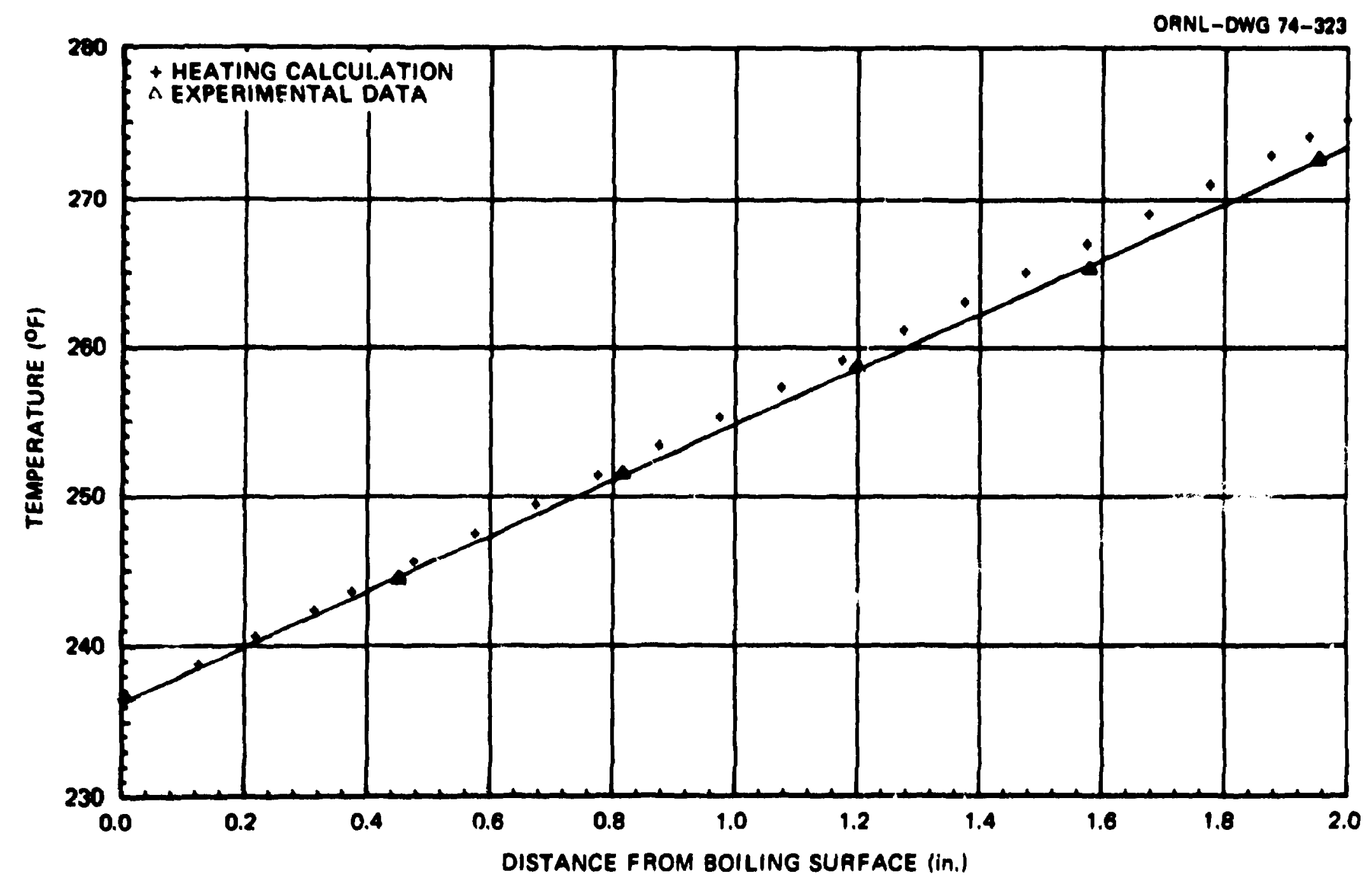

Fig. V-1. Comparison of HM-L performance with predicted behavior. 
A further comparisor. of ths IEAFLis sal aulatior ard tist soperimertal date is given ir. Fále $v-1$. Az roted frot the tatie, the caisulated roiline surface temperature is ir remarial le aereenert atr. the extrapolitei temperature oitairsd fror. a lirear leart-zuares fit of tie reacured temperatures (corrected for themocoup:- sai: ination): tise fittirs function is:

$$
\bar{I}=-\because i^{2}+\because \therefore x,
$$

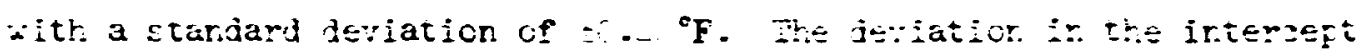

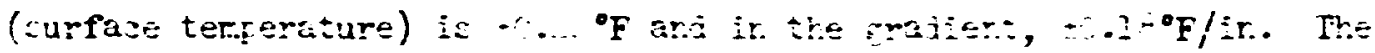

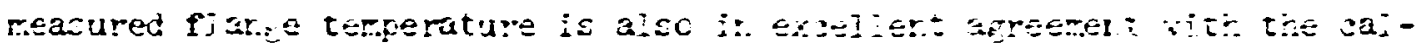

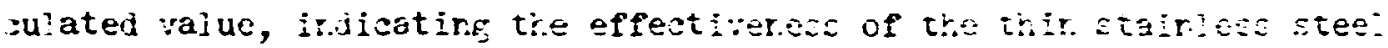

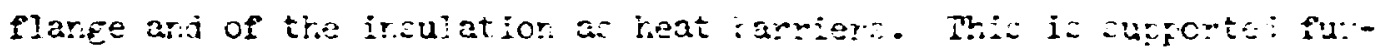

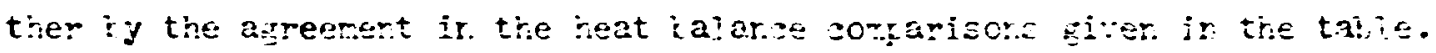

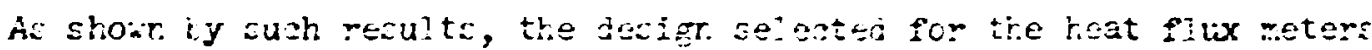

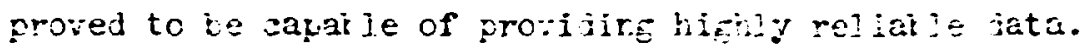

\section{EciIiris Surfaze Ferformar.z}

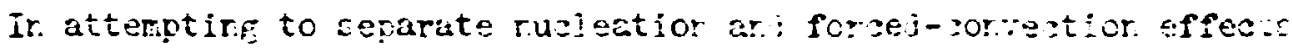
ir. flow boiling, the sorvective ztudis: jere to $i \in$ made cr. a zuriace havire krowr pol koiling haracteristise. It was resonizoj that eoni nucleating performance with a roroxidizine curface wovid te moli ing it

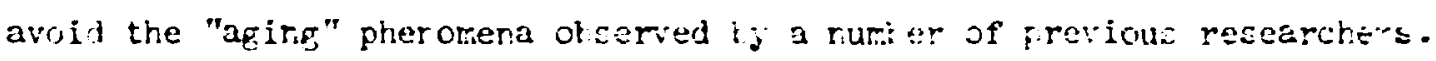

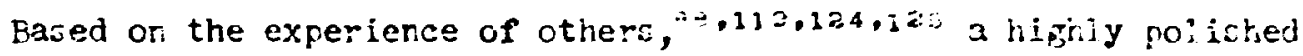
niskel-plated surface was iritialy estested to andit ve the desires reculte. Howerer, eorrocior of a few zrass nipe sitticus ir ecritant with caturated water ir the eary fion roiling tecti sauced sortaminarion 
TABLE V-1

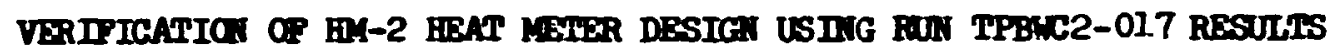

\begin{tabular}{|c|c|c|}
\hline Paraneter & $\begin{array}{l}\text { HEATITG } \\
\text { Results }\end{array}$ & $\begin{array}{l}\text { Bxperimental } \\
\text { Results }\end{array}$ \\
\hline Electrical power $(\mathrm{W})$ & $49.4^{8}$ & 49.399 \\
\hline $\begin{array}{l}\text { Boiling heat transier coefficient } \\
\left(\mathrm{Btu} / \mathrm{hr} \cdot \mathrm{Pt}^{2} \cdot \mathrm{T}\right)\end{array}$ & $2361^{a}$ & 2361 \\
\hline Stream temperature $\left({ }^{\circ} \boldsymbol{F}\right)$ & $214.81^{8}$ & 214.81 \\
\hline Average bolling heat $\mathrm{flux}\left(\mathrm{Btu} / \mathrm{hr} \cdot \mathrm{ft}^{2}\right.$ ) & 50,755 & 50,451 \\
\hline Test surface temperature ( $P$ ) & 236.38 & $236.18^{b}$ \\
\hline Temperature at $\mathrm{TC}-1\left({ }^{\circ} \mathrm{F}\right)^{\mathrm{C}}$ & 245.07 & $244.42(244.57)^{d}$ \\
\hline Temperature at $\mathrm{TC}-2\left({ }^{\circ} \mathrm{F}\right)^{\mathrm{C}}$ & 252.17 & $251.51(251.36)^{d}$ \\
\hline Temperature at $\mathrm{TC}-3\left({ }^{\circ} \mathrm{F}\right)^{\mathrm{C}}$ & $259 \cdot 70$ & $258.72(258.53)^{d}$ \\
\hline Temperature at $\mathrm{TC}-4\left({ }^{\circ} \mathrm{P}\right)^{\mathrm{C}}$ & 267.10 & $265.33(265.57)^{d}$ \\
\hline Temperature at $\mathrm{TC}-5\left({ }^{\circ} \mathrm{F}\right)^{\mathrm{C}}$ & $274 \cdot 36$ & $272.60(272.55)^{\mathrm{d}}$ \\
\hline Flange temperature at $\mathrm{LC}-6\left({ }^{\circ} \mathrm{F}\right)^{\mathrm{C}}$ & $2] 5.15$ & 215.09 \\
\hline Fraction of heat through test surface ( $(\phi)$ & 92.38 & 91.71 \\
\hline Fraction of heat through SS flange (\$) & 2.78 & $\mathbf{e}$ \\
\hline ieat loss to surroundings ( $\$$ ) & 4.84 & $4.75^{1}$ \\
\hline Uraccounted heat loss (\$) & 0.0 & 3.54 \\
\hline 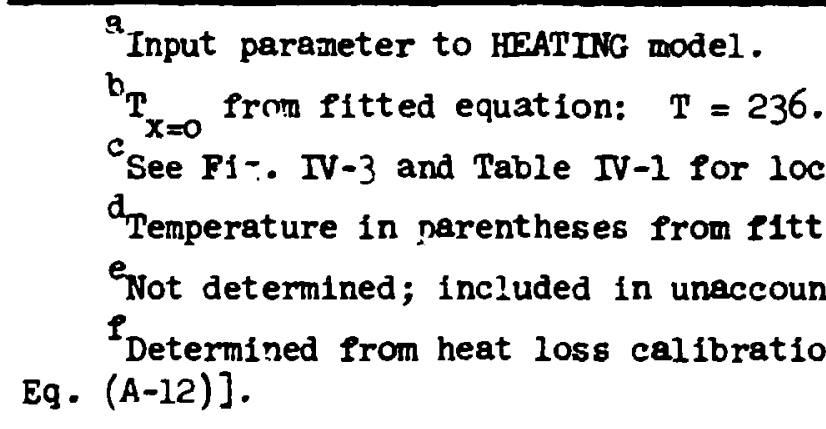 & $\begin{array}{l}93+18 . \\
\text { lon. } \\
\text { equat 10 } \\
\text { d heat } 1\end{array}$ & see Appendix A, \\
\hline
\end{tabular}


of the nickel-plated boiling surface; and efforts to overcome the effects of this corrosion were insurficient to produce a surface with the requisite nucleating characteristics. As discussed in detail in Chapter IV, the nickel plating was removed to reexpose the underly:ng copper surface. The copper was then finished by lapping with 450 -grit corundum, yielding a surface with excellent meleating characteristics (as discussed later).

The nickel-plated surface (after treatment to overcome the contanination prölem) performed erratically in water with no wore than 10 to 12 nucleating sites even at the highest heat fluxes and, consequently, showed considerable scatter and poor reproducibility in the data. In contrast the cocper surfare provided copious sites (at wach lower heet fluxes) and very good data reproducibility. With copper it was difficult to count the active toiling sites, except from photographs taken under stroboscopic lighting conditions during boiling operation. Although the copper surface thus prepared fulfilled the requirement for a surfese of good tucleation characteristics for investigating convestive boiling, perforwance during pool bolling indicated that a smoother surface would have produced data in better agreement with the bulk of the published literature. Even so, the data were consistent and agreed we? 1 with published data for surfaces of comparable finish. [Metallographic examination of identically prenared surfaces after completion of the boiling experiments provided exact details of the surfase finish. See discussion and Figs. IV-13, IV-14, and IV-15 in Chapter IV.] 
Pool Bollirg

Data vere taken with Freon-113 and with denineralized, deaerated vater for pool bolling on both horizontal and vertical copper surfaces at atwospheric pressure, using the apparatus described earlier. Heat transfer regimes ranged from natural convection to rully developed nucleate boiling. The reduced data are tabulated in Tables D-1 through D-16 in Appendix D. In retucing the data, the geasured (and corrected for alibration) temperatures were fitted with a linear least-squares routine from which the boiling surface temperature was obtained by extrapolation. A typical example was shown in Fig. V-1. The botling heat flux was computed from the gradient of the fitted runction. In general, the bolling flux accounted for about 90 to $96 \%$ of the wensured electrical pcwer input; at the very low heat fluxes, the bolling heat flux decreased to about 75 to $80 \%$ of the input. Fucleation was never observed on the stainless steel flarge surrounding the copper boiling surfare.

Typical photographs of vertical pool bolling at very low heat fluxes ar3 shown in Fig. V-2a for Freon-113 (experimen: vPBrc2-15, $q^{\prime \prime}=2359$ $B t u / h r \cdot f t^{2}, \Delta r=17.31^{\circ} \mathrm{F}$ ) and $\mathrm{Pig} \cdot \mathrm{V}-2 \mathrm{~b}$ for water (experiment VPBLC2-10, $\left.q^{\prime \prime}=11,3453 t u / h r \cdot \mathrm{ft}^{2}, \Delta r=10.71^{\circ} \mathrm{P}\right)$. The heat now through the boilIng surface for Pig. V-2a was $80.0 \%$ of the total input and for $\mathrm{Pig} \cdot \mathrm{V}-2 \mathrm{~b}$, 90.8\%. The bubble colum to the right side of the meters in Fig. V-2b arises from in-leakage of buffer gas (nitrogen) through the 0-ring seal at the periphery of the lower meter. Note that the spherical shape and bubble diameter remain nearly constant for this stream while rising 


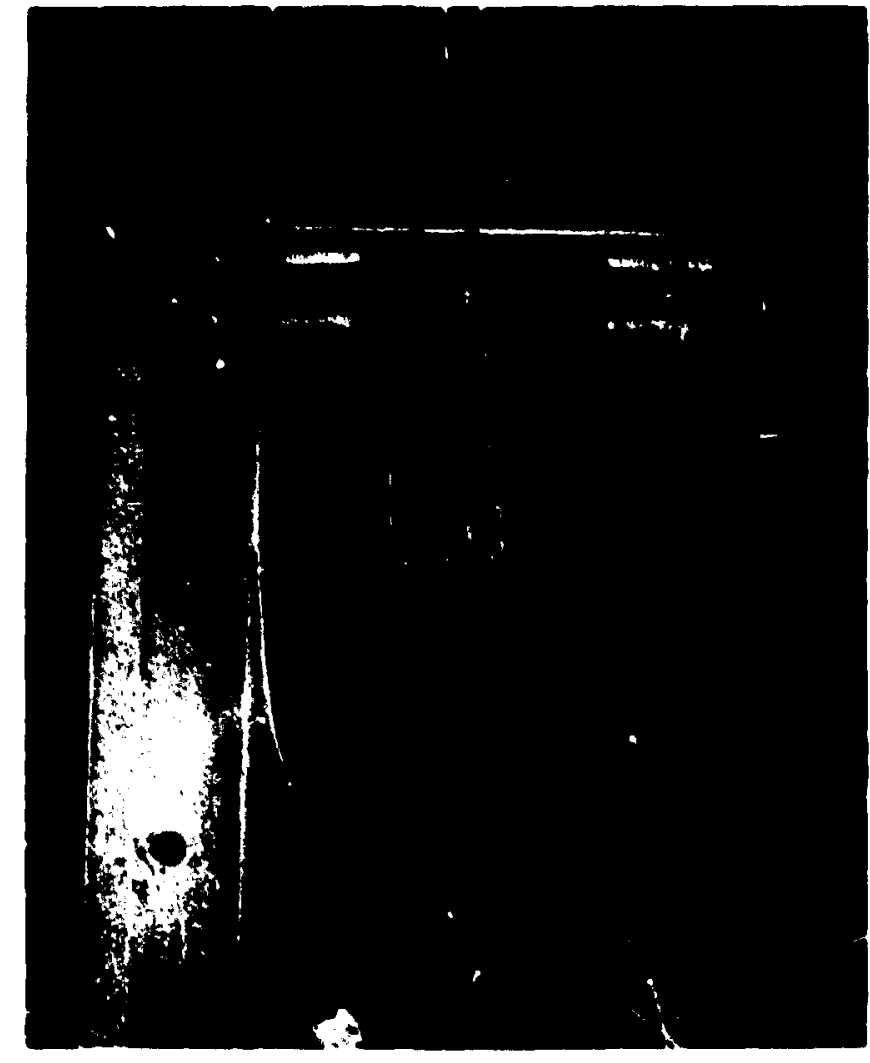

(a) Preon-123, q" $=2359, \Delta r=17.32$

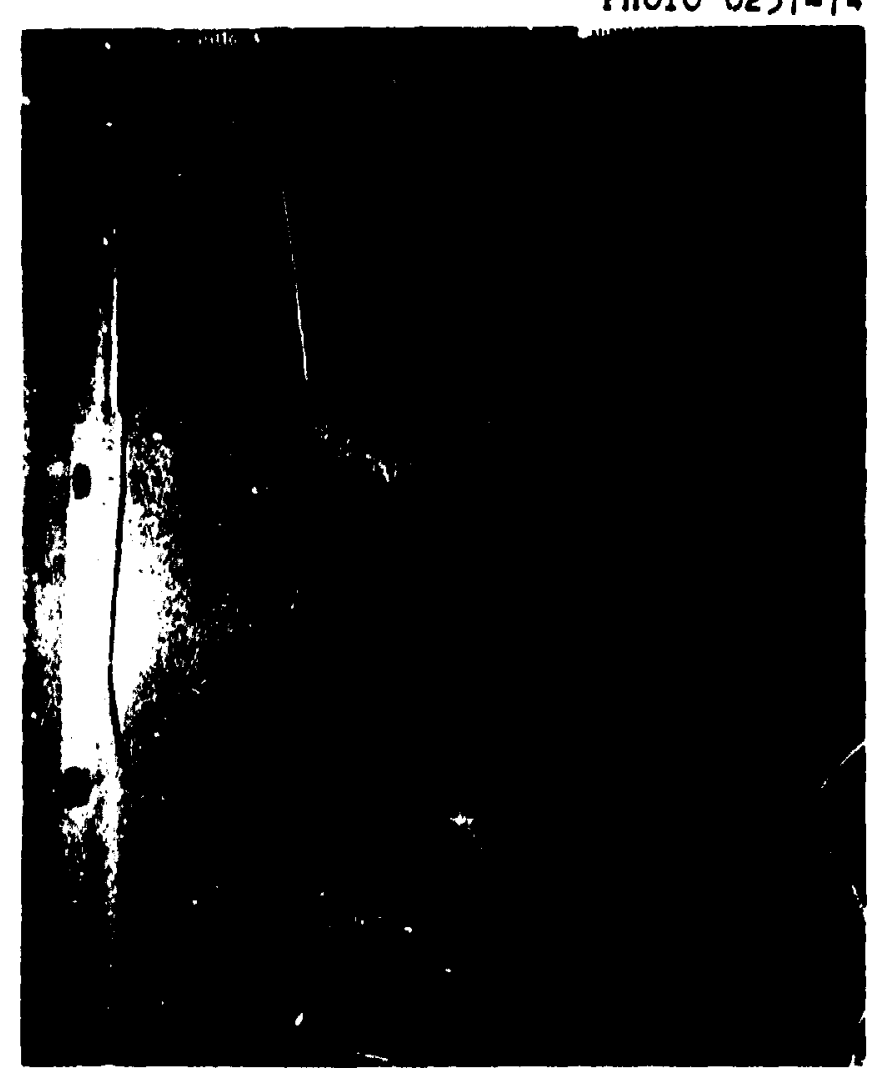

(b) Water, $q^{\prime \prime}=12,345, N=10.71$

Fig. V.2. Tyjtcal vertical pool bolling photographs.

(Note: Reference dlameter of thermocouples $180.040 \mathrm{in.}$ ) 
through the saturated $\mathrm{fluid}$; in contrast, the steam bubtles rising from the upper boiling surface grow in size and become rather distorted.

Results for pool boiling of Freon-11 at atmospheric pressure are shown in Fig. V-3 for bolling on vertical copper surfaces, and in Fig. $\mathrm{V}-4$ for the same surfaces in horizontal orientation. In the vertical arrarbement, the data for the upper mete: (BM-2) were taken with no power on the lower meter (HM-1). The figures indicate little, if any, difference in the characteristics of the two meters. Purther, Figs. V-5 asd $v-6$, depicting the boiling coefficient as a function of the heat flux, frdicate for this study insignificant effects of surface oriertation. Lirear least-squares regression analysis ${ }^{25}$ of the fully developed nucleate boiling data (on a $\log -\log$ plot) gave ralues tabulated below for $\underline{\text { I }}$ in the relationship $q^{*} \propto \Delta \mathrm{r}_{\text {sat }}^{\mathrm{m}}$.

Values of m for pool bolling of Freon-11

\begin{tabular}{|c|c|c|c|}
\hline Orientation & EM-1 Deta & EM-2 Data & Comb ined Data \\
\hline Vertical & -.43 & 10.20 & $\because .73$ \\
\hline Iorizontal & 9.06 & 9.20 & $9.0^{\circ}$ \\
\hline
\end{tabular}

These values are consideratly higher than normally associated with pooi boiling of ordinary fluids tut are in apparent agreement with putlished data; $;^{25}$ it is known that $m$ can be altered from 3 to $2+$ by increasing the surface roughness.

Relatively few data were found in the literature for pool koiling of Freor.-1I ; the oft referenced data of Corty 4.125 being the exception. By way if comparison, the data of $F i g_{3}$. V-is are replotted in Pig. V-with the three data sete Corty ortaired for a horizortal copper toiling 


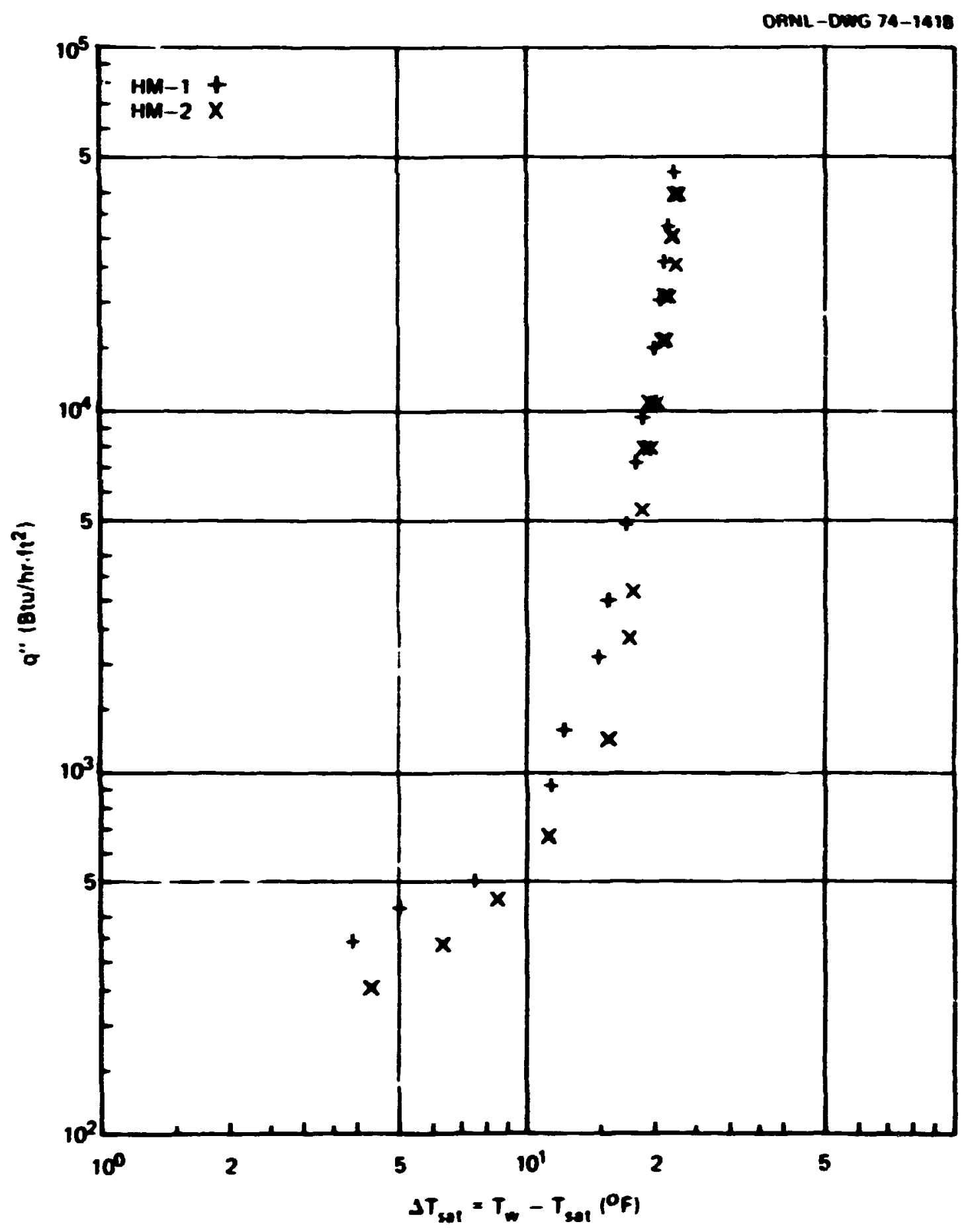

Fig. V-?. Pool tolling with Preon-113 on vertical surfaces. 


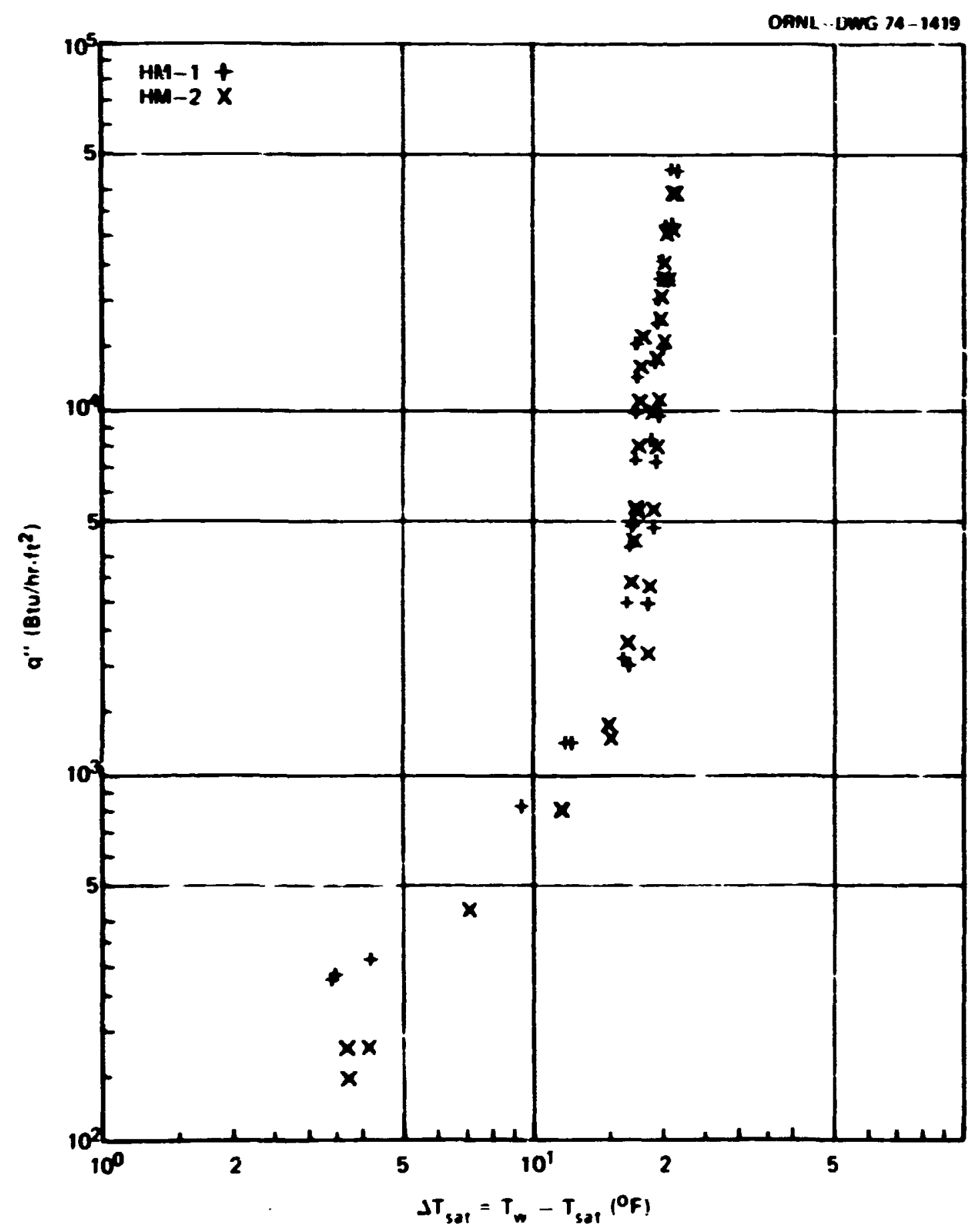

Fig. V-4. Pool hoiling with Freon-1] = or horizortal curfaces. 


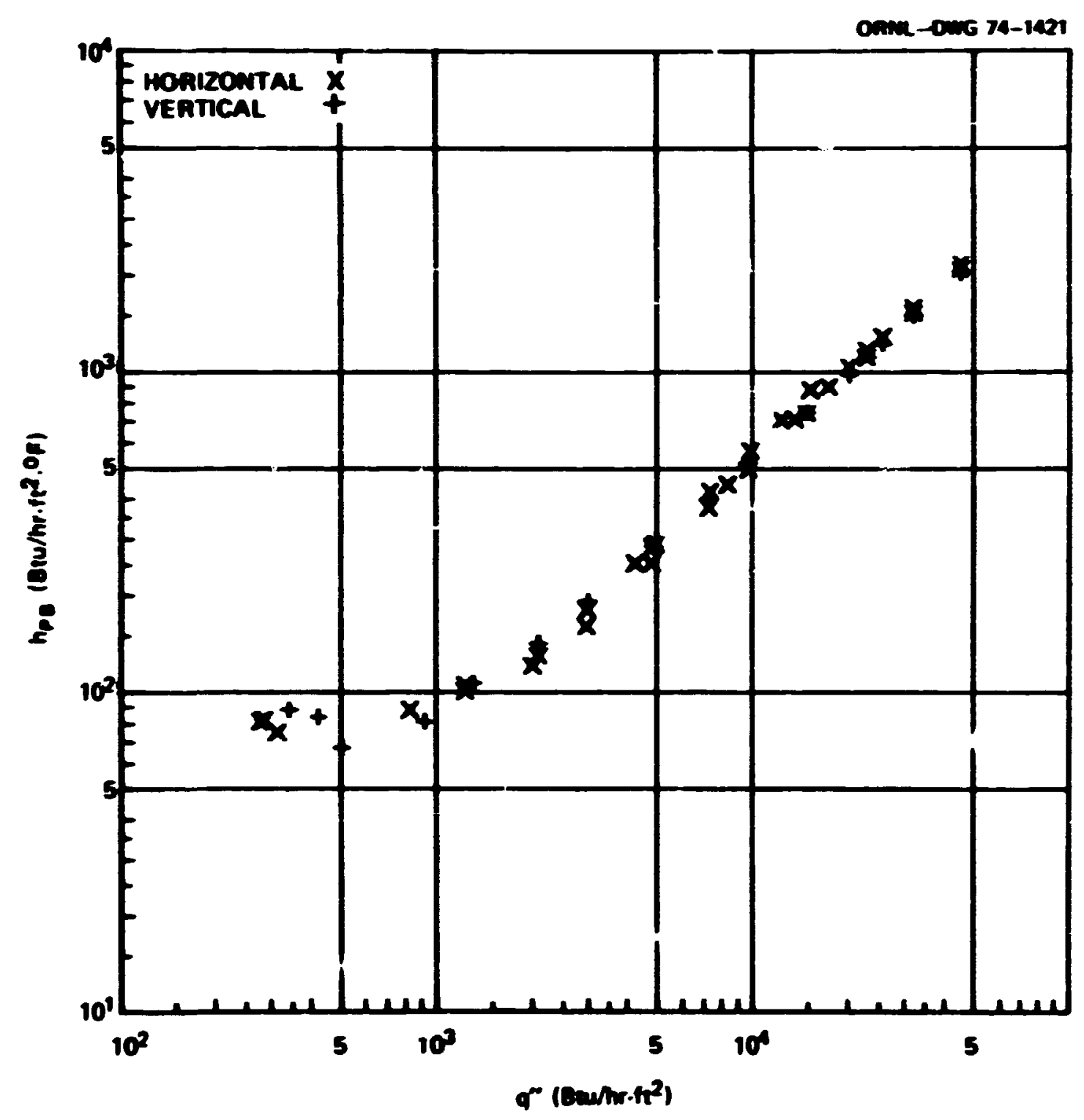

P18. V-5. Preon-113 pool bolling coefficients for bx-1 in horizuntal and vertical plenes.

surface finished with $4 / 0$ emory. Clearly, the functional relationship between $q^{\prime \prime}$ and $\Delta r_{\text {gat }}$ is neariy the same for the two sets of data. The noticeable. difference is the displacement of the present data toward lower values of $\Delta r_{\text {gat }}$ This is a direct manifestation of the "rough" 


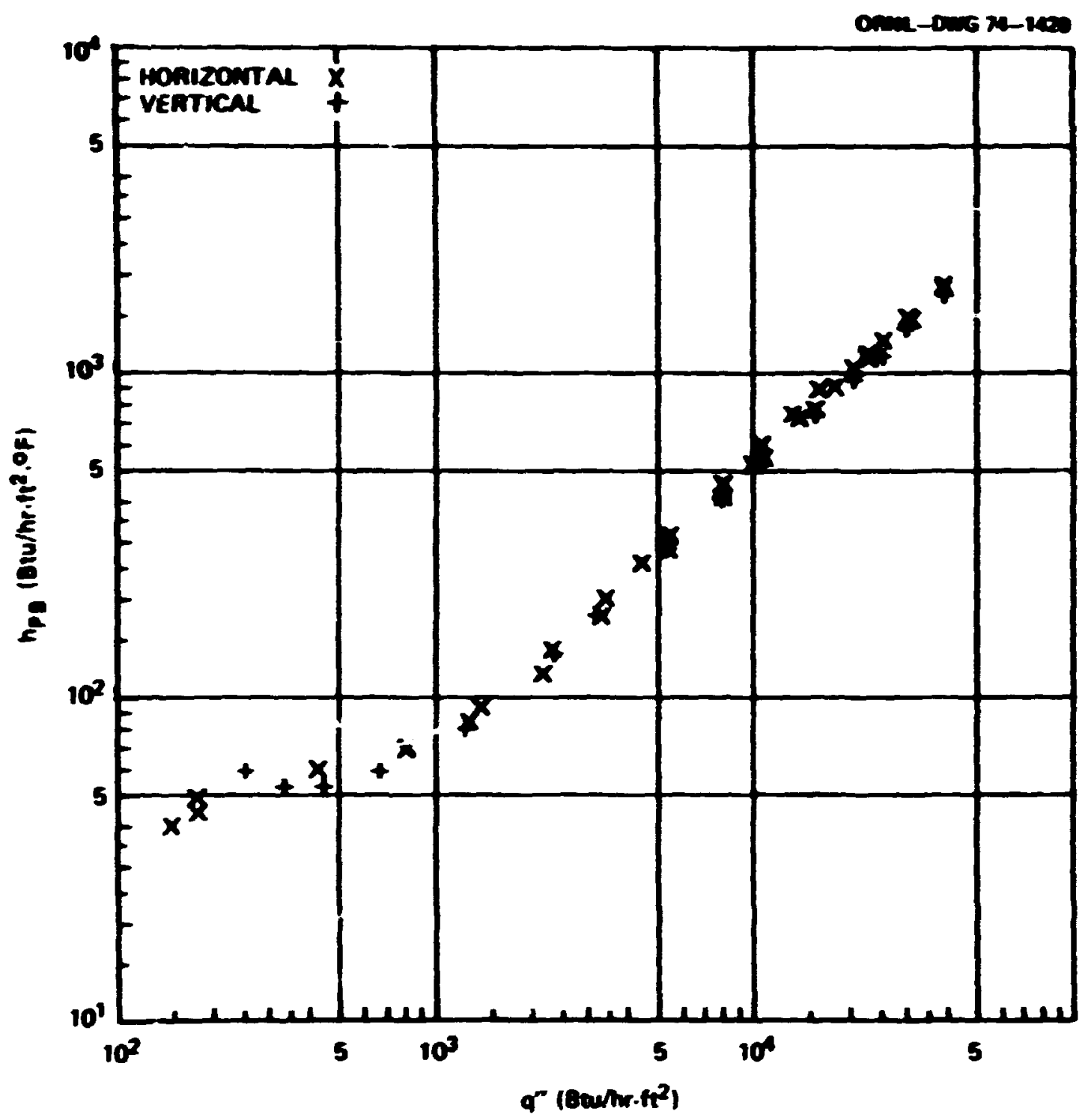

Pig- V-6. Freon-113 pool boiling coefricients for Bd-2 in horizontal and vertical planes.

(relatively speaing) surface produced by the 400-grit lapping compound used to finish the heat neter boiling surfaces.

The horizontal pool data, shown in Pig. V-4, vere collected on three consecutive days with the system remaining at saturation throughout the series. Data taken on the first day were limited to a heat flux 


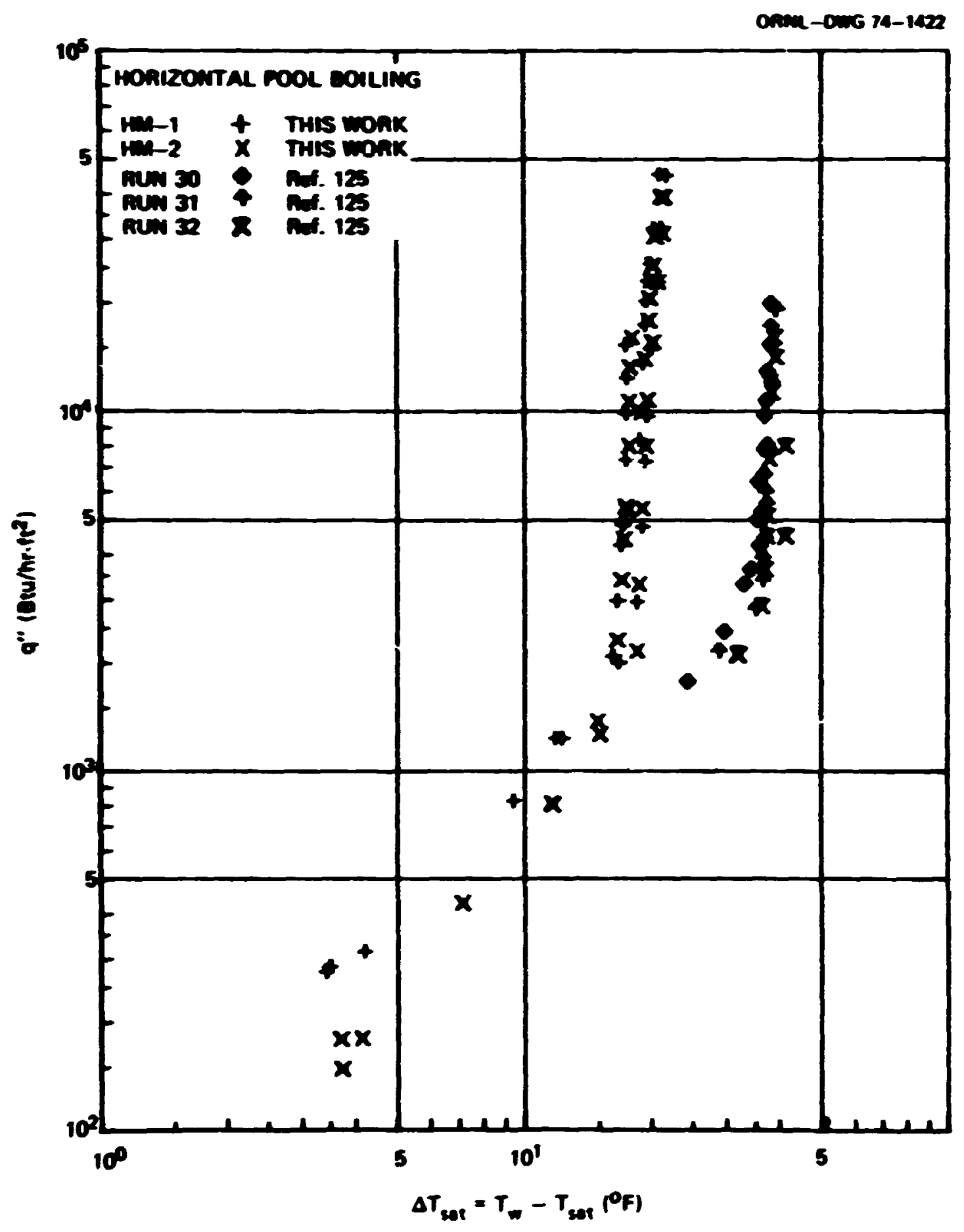

P18. V-7. Comparison of Corty's Preon-113 data with data obtained in this work. 
of acout $i \equiv, 000 \mathrm{Bt} u / \mathrm{hr}-\mathrm{ft}^{2}$; the levels were inereased or: the second ard thini days to the wimm peraitted iy the availarle porter supplies. The data acquired on the first day yere at slightly lower temperature differences thar: the sutsequent data. ikile "aging" is a comeon occurrer:se witr. zary fiuid-zetal sominations, tinis lizited data was the orly e:iderce of such fouris in this work with Preor:-1ij. The neters hod teer.

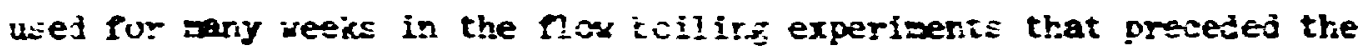
pool s0ilir.j tests without any indisatior: of surrece aging. Purther, the se:ere: days of operation fr. the rertfeal pccl toiling arrangenent pro-

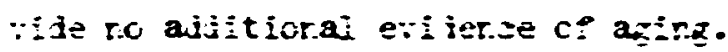

Excep: for ine sirele ir.jtarce diszused atore, the pocl coilire

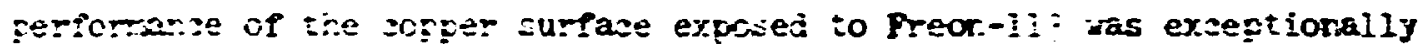

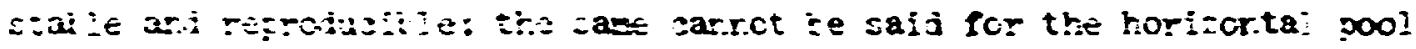

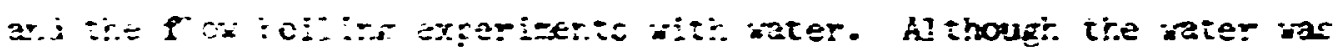

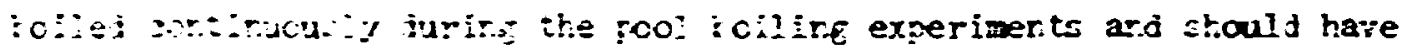

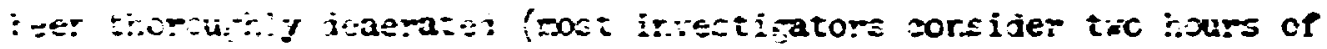

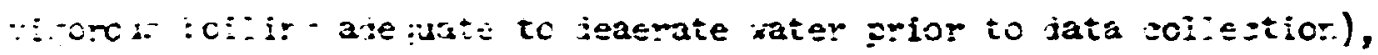

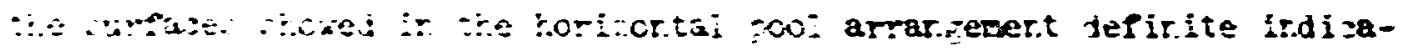

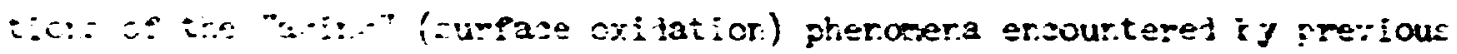
rasion.

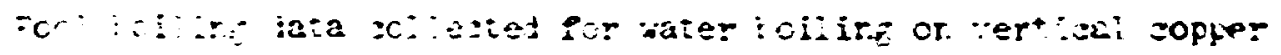

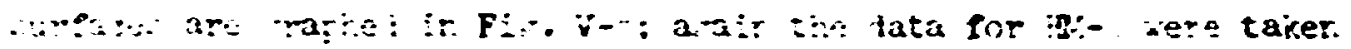

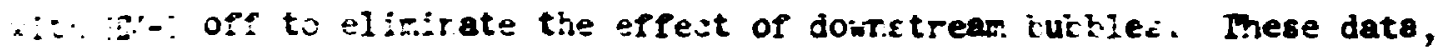

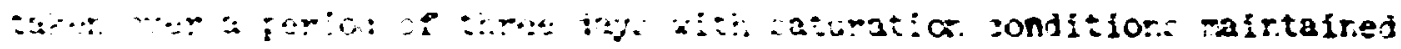

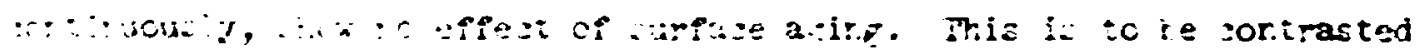

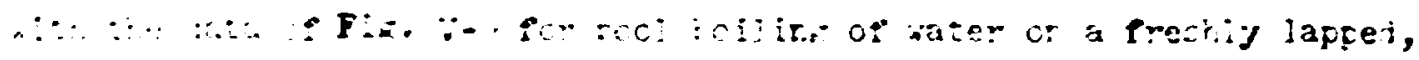




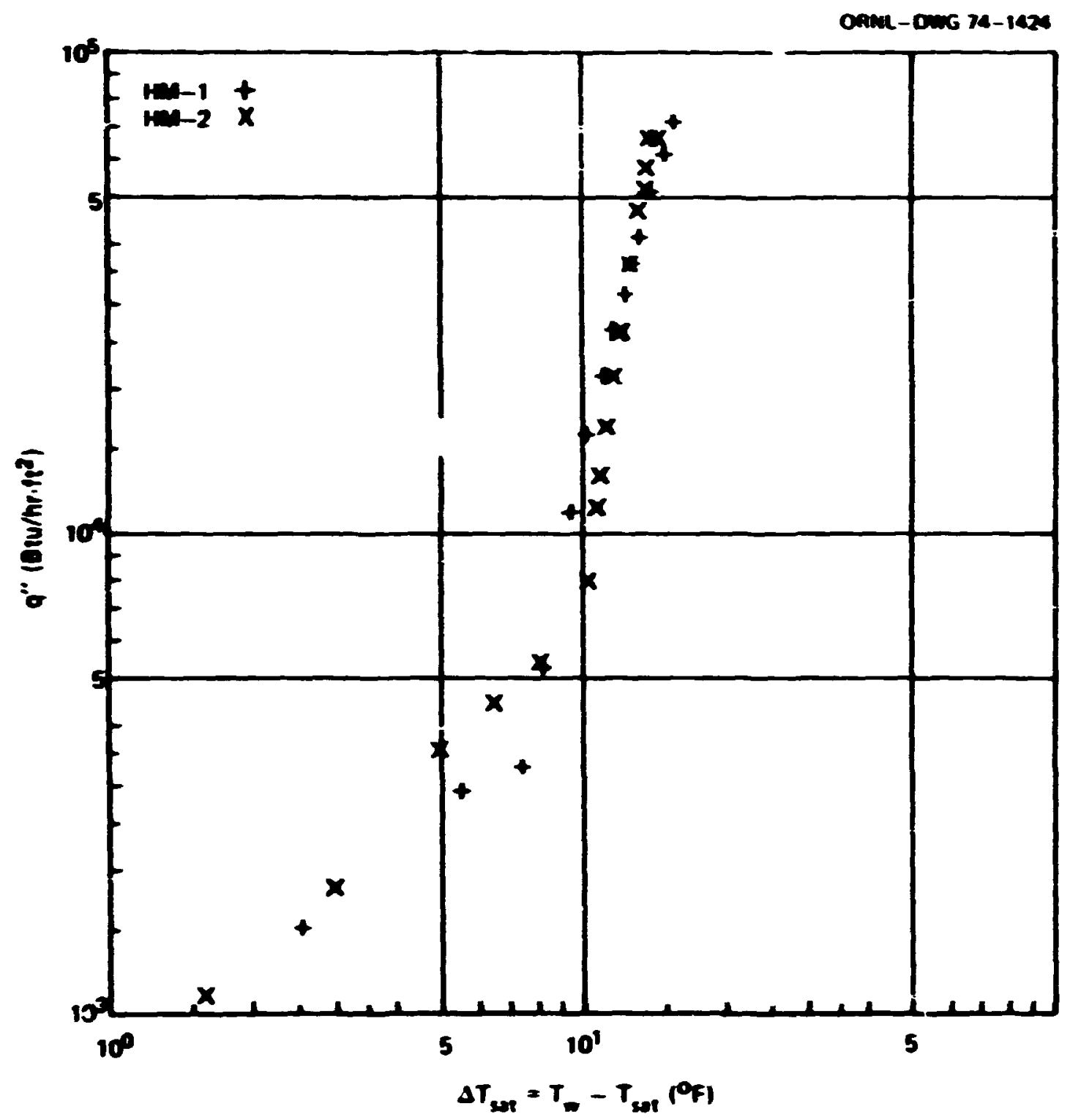

PIg. v-e. Pool holling with sater cn vertical surfaces.

horizortal copper surface taken over a two-day inter:ai where a definite agirg effect appears jisient. (note the definite displazement to the right in Pig. V-? for the second day's data.]

The data for the vertiaal orientation wore taicer after scmpletior. of the Preon tests (wth rertical surfacss) without rolapping the zurfaces. Thus, the surfaces may have been "conditiored" suffiziert: to 


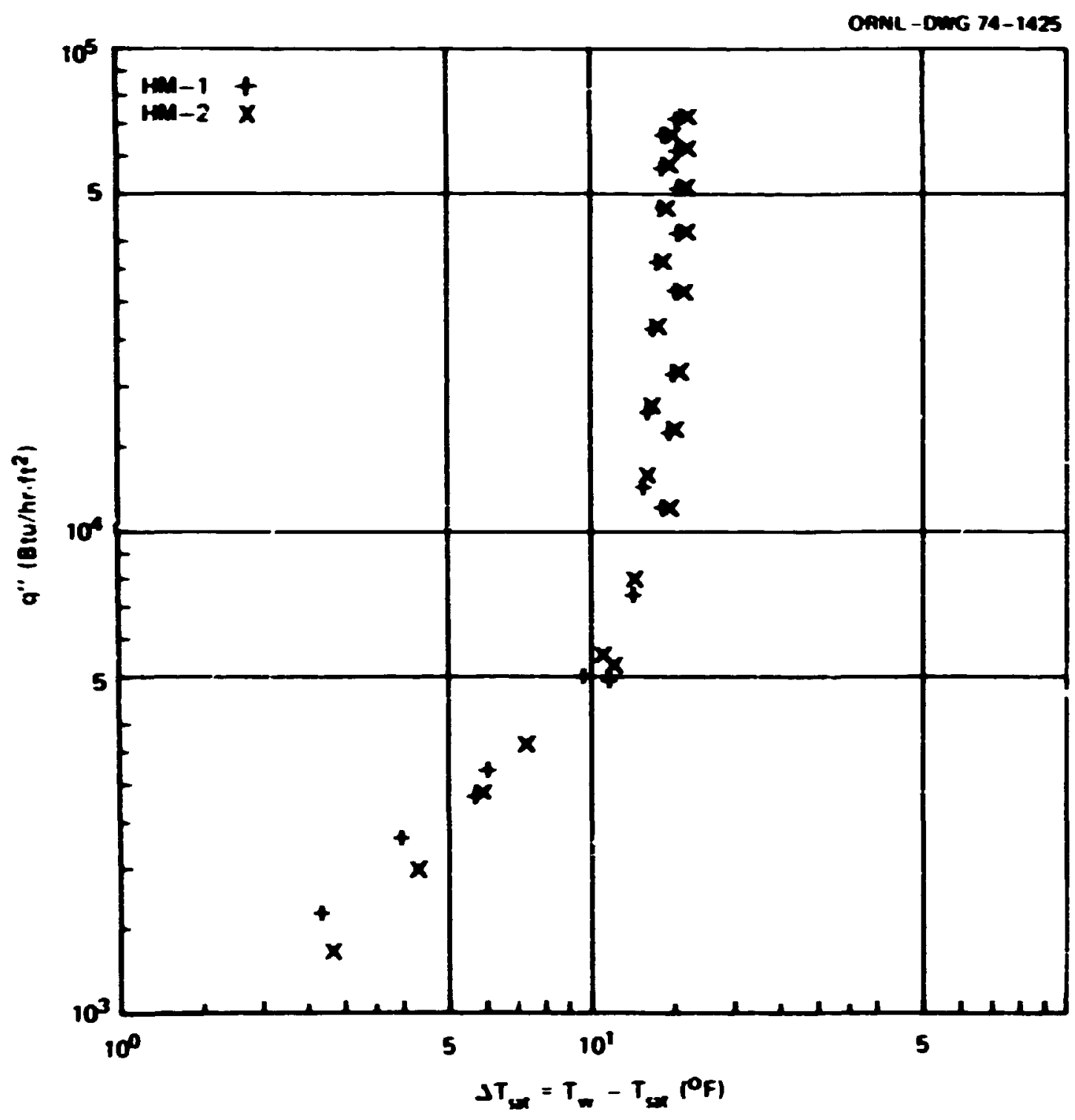

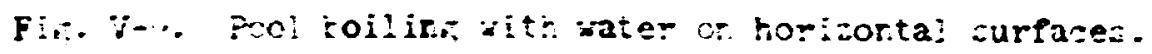

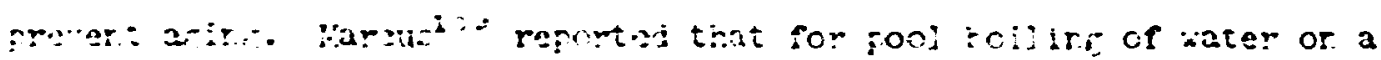

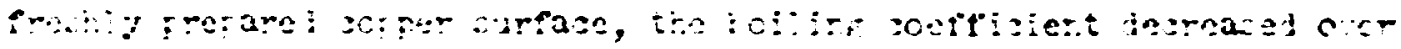

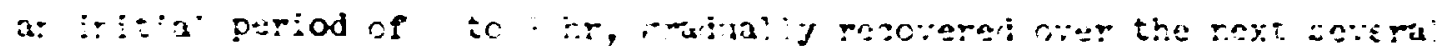

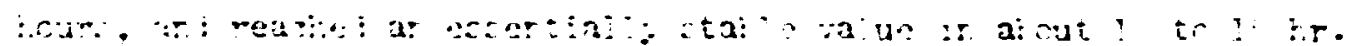

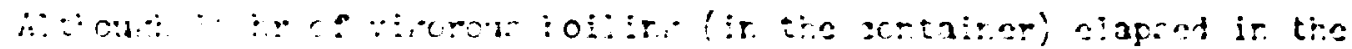


present study before che first data point was taken in the norizontal orientation, this was spparently irsufficient for stable conditions to be established.

As indicated with Preon, there is evidently :-ittle difference in tie performance of the two meters. Slopes obtained by licear regressicr analysis of the horizortal pool boiling data takez cn the first day vere tested to deternine if a statistically significant difference existed (at the 95\% confidence level) between the data sets. This test shored that the data collected from the two neters could be considered the aame. Sintlarly to the enalysis of the Preon data, least squares fits to the fully developed meleate pool boiling date for vater gave the ralues tabulated belor for $E$ in the relastion $q^{*} \propto$ sr $_{\text {sat }}$.

\section{Velues of t for pool bollins of water}

$\begin{array}{lcccc}\text { Orientation } & \text { Bu-1 Date } & \text { By-2 Date } & \text { Contingd Data } \\ \text { Vertical } & 3.65 & 6.34 & 4.69 \\ \text { Horizontal } & 5.88 & 6.16 & 6.14\end{array}$

These values are somexhat high, cappared to the uiually reported values of 3.5 to 4.5 for pocl tolling of vater. Purther discussfor of this is deferred until a fes paragraphs later.

Figures $v-10$ and $v-11$, showing bolling heat transfer crefficients for water as a runction of hest flux for the two aeters, indicate somewhat higher $(\approx 10,4)$ boiling coefficients on the versinal surfaces than cn the horizontel surfaces; this contrasts wit. the results for Preon-113. Marcus 109 reported pool boiling coefficients on a vertical surface to be 


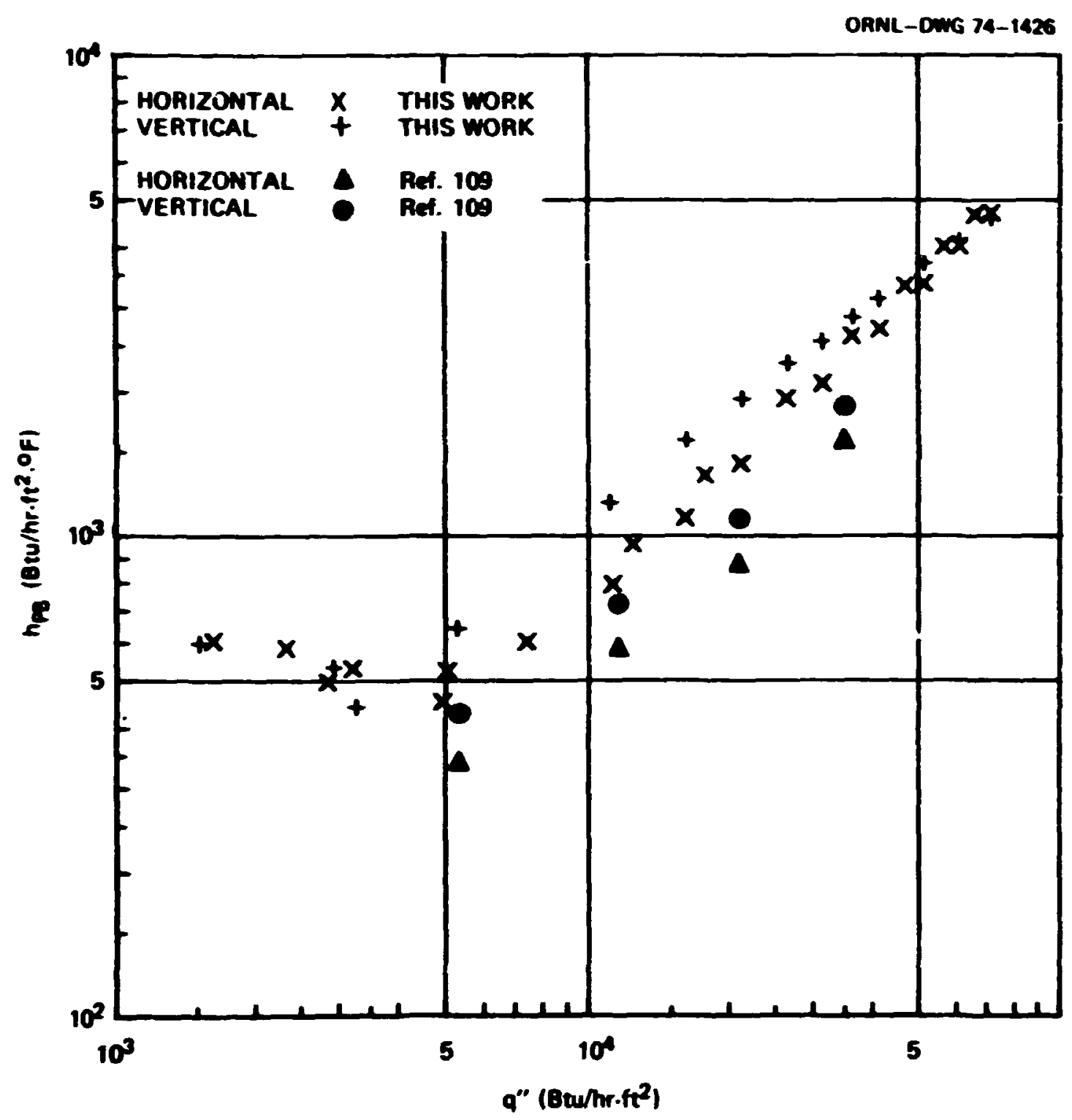

Pig. V-10. Water pool bolling coefficients for lif-l in horizontal and vertical planes.

about 20 to $25 \%$ higher than the corresponding coefficient for water bolling on a horizontal copper ourfare; his data, shom in the figures for comparison, are lower than those determinel in this research. Marcusios did not report detalls of his surface prepiration other than "... freshly lapped, polished, and cleaned, ...." and "... the bolling surface was 


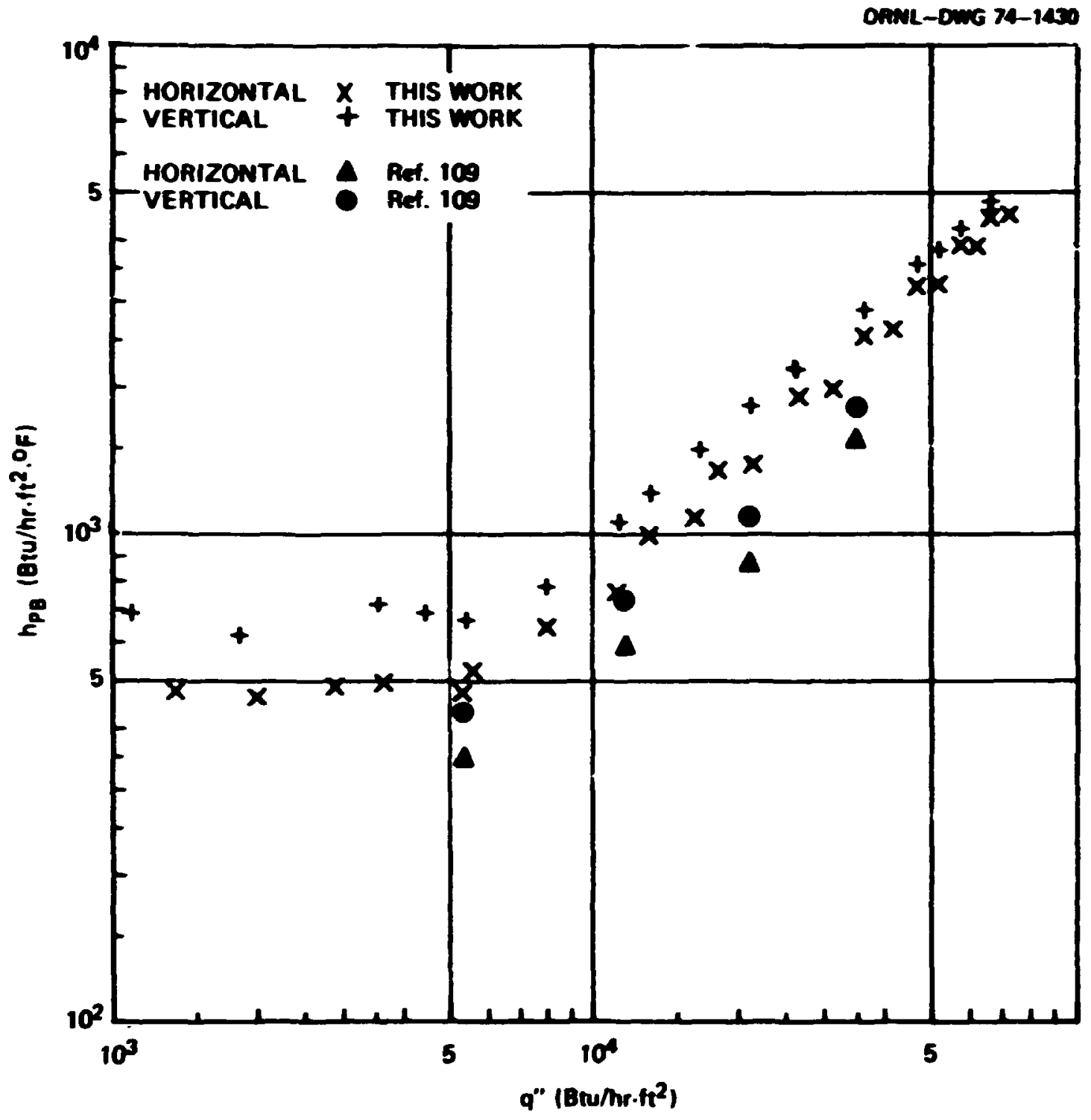

Fig. V-11. Water pool bolling coefficients for bin-2 in horlzontal and vertical planes.

polished and cleaned with acetone, wethyl alcohol, and distilled water." However, his data indicate a smoother surface than used for the experiments reported herein.

Kurihara70.131 carried out a thorough investigation of the effects of surface finish with water (and other Fuids) in saturated pool boilIng at atmospheric pressure on a horizontal copper surface for a rull 
range of surface finishes $(4 / 0,3 / 0,2 / 0,1 / 0$, Ko. 1 and Ko. 2 enery, and 140-mesh carborundun, in order of increasing roughness). The hor:zontal pool boiling data for water collected in this work can be compared with Kurihara's data to establish a relationship between the $400-$ grit-lapped and emery-polished surfaces, since both experiments empioyed the same general design concepts. To perfcrm this comparison, equations were fitted (usiag a least-squares routine) to Kurihara's fully developed nucleate boiling data; plots of the fitted equations are given in Pig. V-12, with the comparable data of this research. By inspection the data acquired on the second day (presumably after stable conditions were estaiclished) compare favorably with Kurihara's data for a $2 / 0$ emery finish; for this reason the $2 / 0$ emery finish was compared to the 400 -grit lapped finish in 0 rail in the metallographic investigation discussed in the preceding chapter. Further data comparizons are also repeated in the Pigure: Marcus 2109 ho:izontal data of uncertain surface finish are shown along with the data of Nagarajan ${ }^{84.124}$ for a surface polished with 600 grit silicon carbile paper and buffed. [600-grit is approximately equivalent to 4/0 emery particle size and for this reason Nagarajan's data are in good agreement with Kurlinara's 4/0 data.]

From the pool boiling data 1 is is concluded that the steep $q^{\prime \prime}$ vs $\Delta r_{\text {sat }}$ curves (indicated by the previously tarulated values of $\underline{m}$ ) result directly from the roughness of the bolling surface. This conclusion is also supported by the metallographic investigation of the bolling surface discussed in Chapter $I V$ with the rough surface (on a microscopic scale) providing superior nucleating characteristics for both Freon and vater. 
OANL-OWG 74-1927

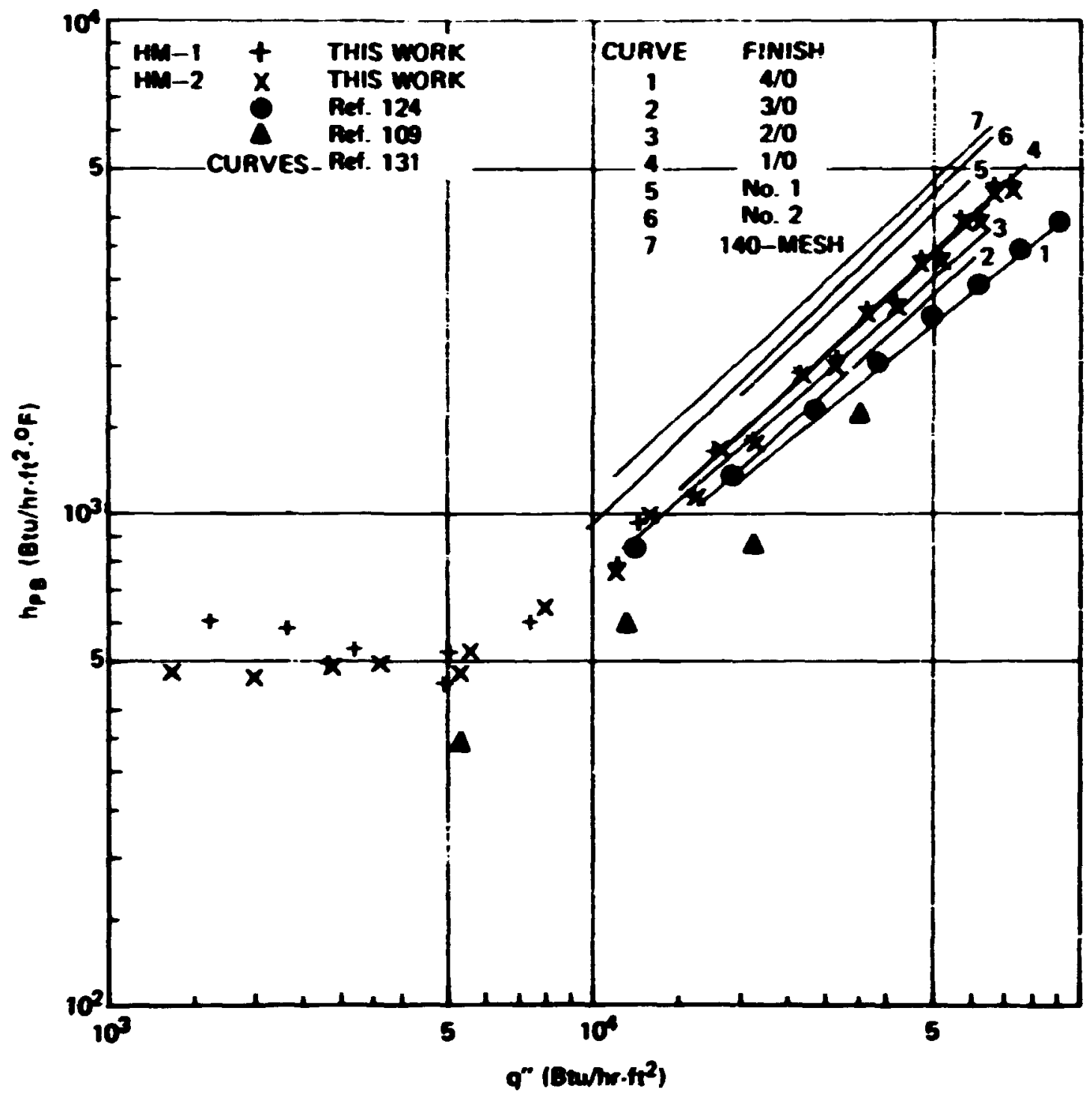

P18. - -2?. Comparison of data obtained by several investigators with pool bolling of water on horizontal copper surfares.

The experinental bolling surfaces vere arranged to pernit the lower heat flux woter (In the vertical orientation tests) to be used a a bubble generator while measuring on the upper neter the effect of downtrean bubbles on the upper sursace's bolling performance. It was thought that this would provide insight into the manism of convective hor bolling. 
The results of such an experinent are graphed in Fig. V-1j, wherein the vertical surfece data of Mg. V-3 for Freon bolling on B!-2 (with Bi-1 orf) are replotted for conparison vith data obtained for Bi-i? with constant bX-1 Mux levels of 14,850 and 32,100 Btu/hr-ft. [The bubble now rate, or vold frection, is a direct punction of BM-Z nux.] the Pigure indicates a slight increase in the teperature difference (decrease in bolling coefficient) at the higier heat nuxes to sustain a given heat Mux on BM-2 in the presence of bubbles generated upstrean and an appreciable decrease (increase in coeffieient) at the lover flux levels as a result of enhanced conrection.

Related date are given in PIg. V-14, wherein constant Nux performance of BM-2 is graphed as a runction BH-1 flux, or, in other words, as a sunction of upstrean bubble generation rate. Tro nux levels are show for each of the fluids tested. For Freon, there appears to be no effect or: the easured BH-2 bolling coefficient of bubbles (generated upstrean) in the nuld lavers near the wall. On the other hand, there Is a sall but discernable decr zase in the measured coefficient for vater. This difference in behevior is believed to be directly related to the size of the bubbles. Although measuresarc of bubble dianeters was outside the scope of this investigation, qualitative observations indicated the water vapor bubble diemeters vere two to three times larger than the Preon vapor bubbles (see P18. V-2). It appears plausible that the larger bubbles passing the bolling surface tend to sweep the growing bubbles may before they conplete their growth cycle and, thus, rectuce the mount of heat renoved by each bubble. This will be discussed rurther with the flow bolling results. 


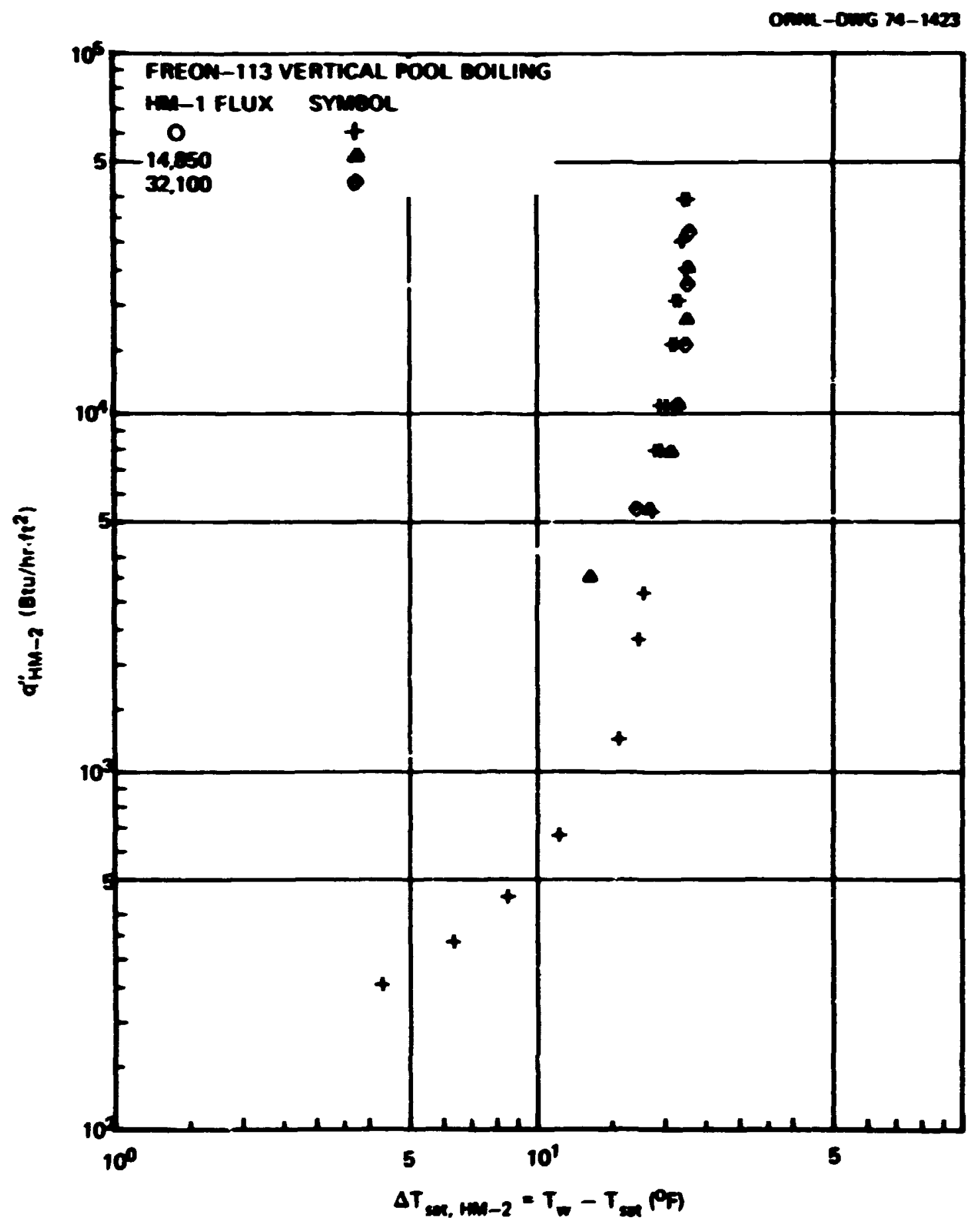

Pig. V-13. Effect on HM-2 performance of bubbles generated upstreqm with constant flux on Bu-1 in vertical pool boiling. 


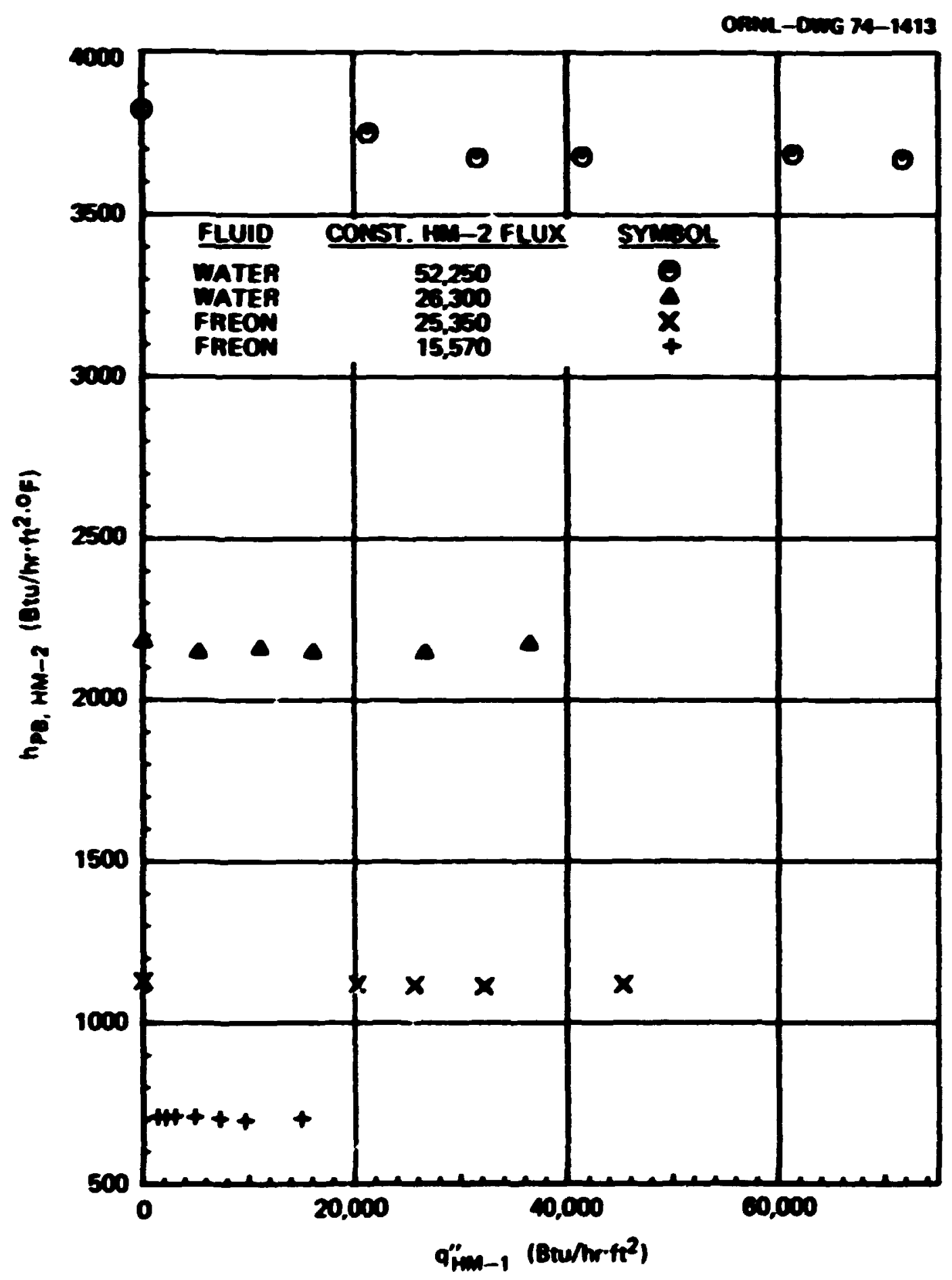

P18. V-14. Effect of Fi-1 flux level on the constant flux performance of BH-2 in vertical pool bolling. 
Since the Dohsenor and the Porster-2nber 30 pool bolling correletions [Eq5. (2-23) and (2-30), respectively] are videly used in aditive correletions 12.24 for convective bolling, the muly developed maleate bouling data vere exanined to deternine the applicabilsty of these correlations. Plomres V-15 and V-16 show the results (Foles D-9 throngh D-16 in Appendix $D$ tabulate the data) for the Bohsenos correlation for Preon and vater, respectively. Values deternined by least-squares analys is for the two correlating rectors in Eq. (2-23), the surrece-fluid combintion ractor, $\mathrm{C}_{\text {sf }}$, and the bubble Bespolds wodulus exponent, $r$, are tabalated In the figures. Nil cine Freob date are vell correlated in the leastsquares sense (13.8p wite error) with a $C_{\text {sf }}$ of 0.00272 and an $I$ value of 0.092; values for pool boiling of Preon were not fourd ir. the literature for comparison. The data for water exhibit considerably wore seatter, reflecting differences between the two neters arising from surfoce finish, orientation (horizontal vs vertical), and aging. Considering all the water data 28 one set, a least-8quares analysis gave values of 0.00898 for $C_{s f}$ and 0.11 for $I$ wth a maxim error of $29.3 \%$. The above values of $C_{s f}$ and $I$ were obtained by the procedure customilly followed in the bolling literature; alternative values obtained using the technically rect statistical procedures are discussed and compared in Appendix $P$. Although it was originally suggested ${ }^{20}$ that I nigit have a value of 0.33 for wost fluids, Vachon et al.$^{33}$ perforned an extens ive evaluation of reported values of these two paraneters; they susgest uetter results ight be obtained if $I$ is pernitted to take on different values. By way of comparison, Vachon et $\underline{\text { al }}$. ousgest $C_{s f}=0.0097$ and $x=0.10$ for water bolling on a copper surface finiohed with $2 / 0$ enery. The line cbtained 


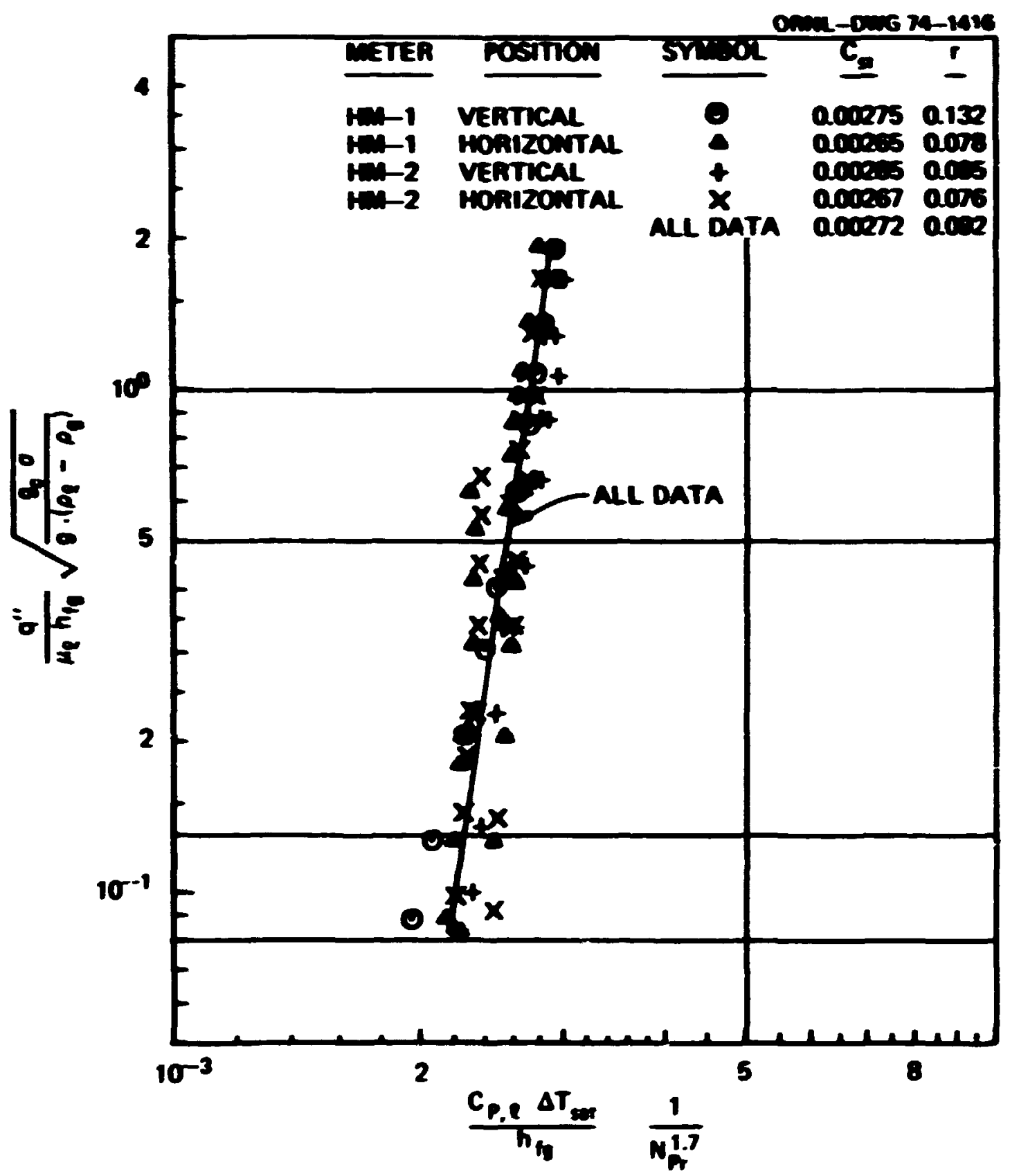

Pig. V-15. Rohsenow pool bolling correlation for Preon-11?.

using these values is seen in Fig. V-16 to sorrelate the horizontal pool bolling data quite well also.

While the data collected in this research were correlated by the Rohsenow correlation, ${ }^{22}$ the Porster-Zuber relation ${ }^{30}$ falled; this is 


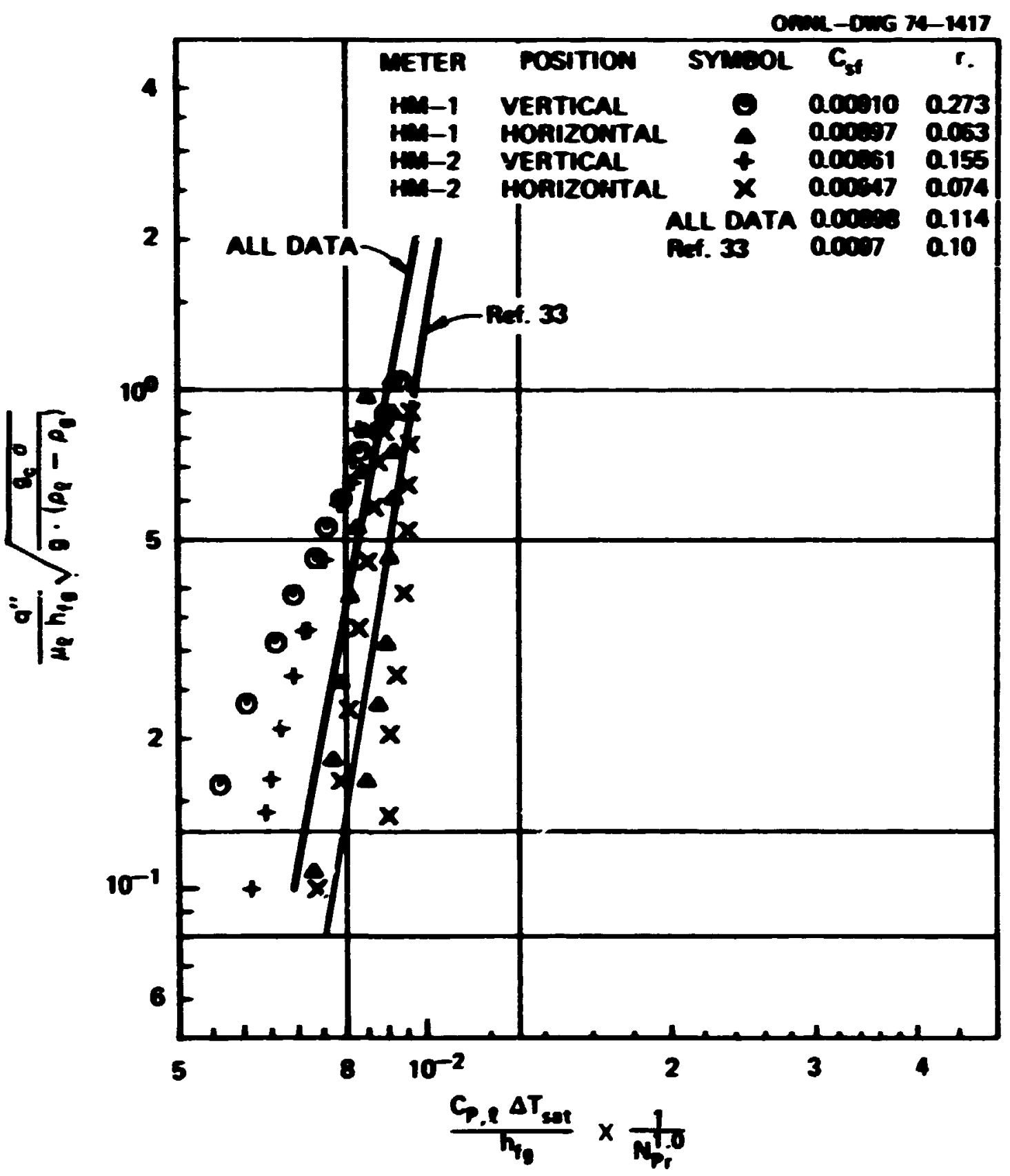

P18. V-16. Rohsenow pool bolling correlation for water.

Indicated by the graphed runctions in P10. V-17 ard V-18 for Frean and vater, respectively. Robsenow et $2.1 .{ }^{120}$ in the discussion of a paper authored by $2 u b e^{2} 3$ gave a lucid explanation of certaln inherent shortconingo rif tie Inrster-Zuber correlation and questioned its applicability. 


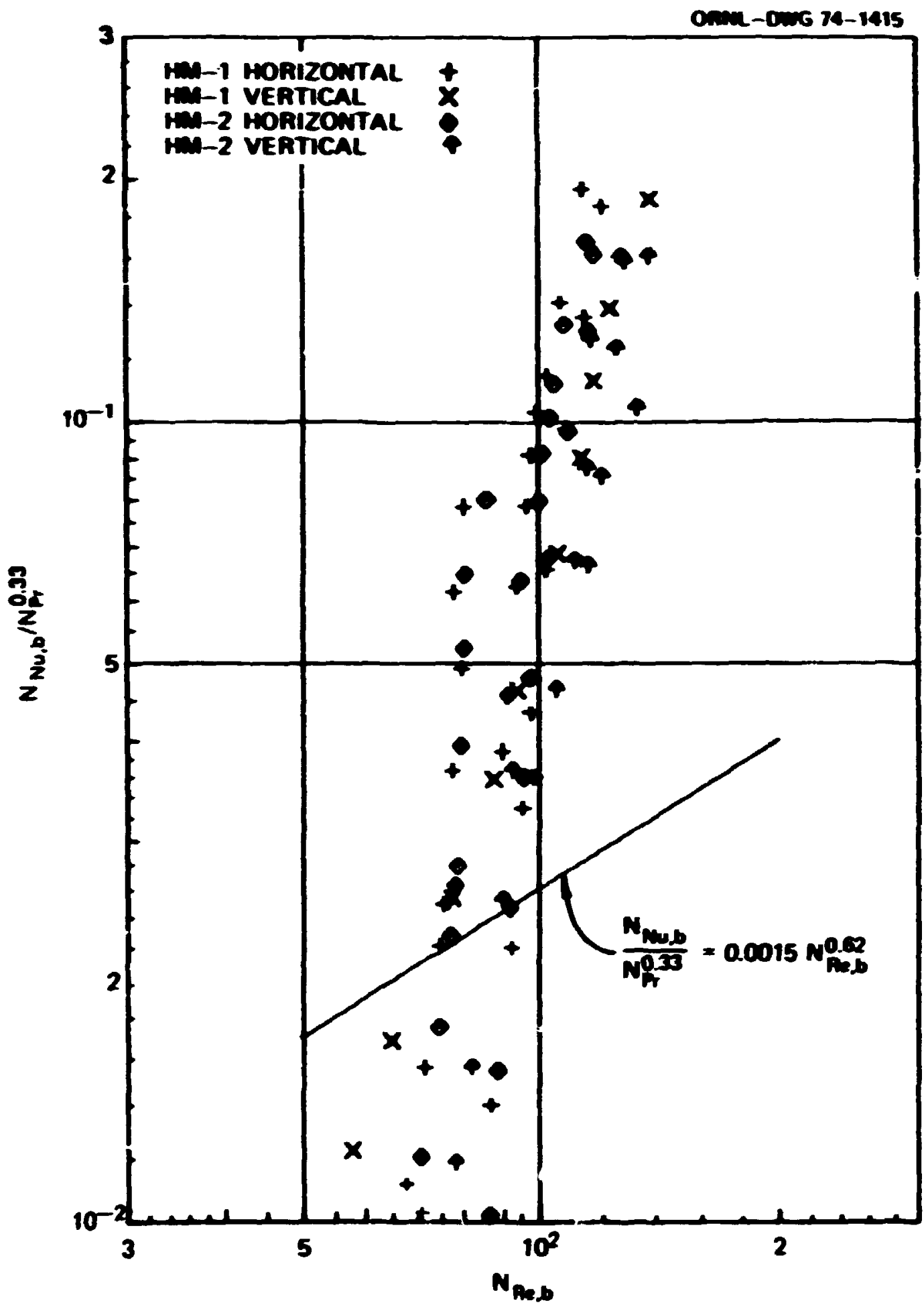

F18. V-17. Forster-Zuber pool bolling cor lation for Freon-113. 


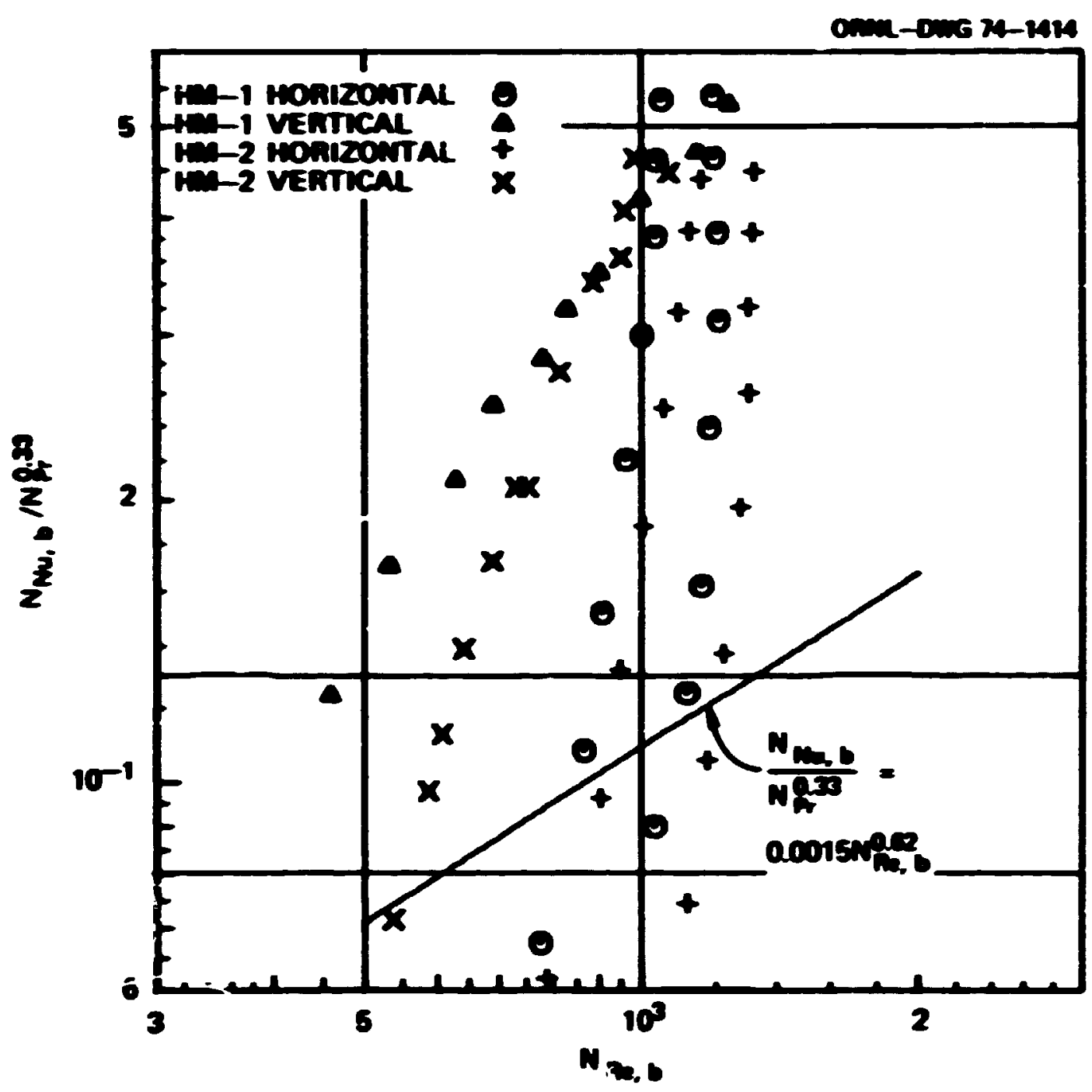

F8. V-18. Porsior-2aber pool bolling correlat ion for water.

2uber deterifined the leading coefficient and the exponents in Bg. (2-30) fros experinental data at wim beat nlux (near or at burnout) conditiose; use of the parneters over the full ringe of maleate bolling is therefore subject to question. Secondly, Rohsenow et al .120 pointed out that $q^{*} \propto T_{\text {sat }}^{2}$ is 1mplicit in $\mathrm{Eq} .(2-23)$, whereas the exponent $\mathrm{Cn}$ ${ }_{\text {seat }}$ in Bq. (2-30) 1s approxinately 2. Then, wing the date on which 
Eq. (2-23) was originally besed, they proceeded to deternine new constants (depeodent on surfuce-fluid cabintion) for B. (2-30). Te equation with the nes constants was show to correlate nonpolar fluids but epparently would not correlate water and other polar fiufis.

With this beckeround and the rect that the exponent $n$ in $q^{\prime \prime}=\Delta \Delta_{\text {set }}^{p}$ was round te be of the order 4 to 6 fos the boiling date collected in this investigation, it is not surprising that the Zuber expression rafled to correlate the Freon data or, particuiarly, the uster date.

\section{Porced convection}

Host correlations of codrective boiling beat trassicr dats recuire a inowledge of the single-phese foreed-courective beat transer coefricient. The experimental plan for this imrestigation (outlined in Chapter III) envisioned experinental deternination of this coefricient for subsequent use in the data analjsis. A considerable anount of such data, collected for various flor rates and heat nux levels with Freon-113 and rater, are tabulated in Tables $D-17$ and $D-18$ or Appendix $D$. The Reyrolds codulus ranged in the interval $1.1 \times 10^{*} \leqslant H_{\text {Re }} \leqslant 9 \times 10^{*}$, and the heat Rux was varied from 1000 to $35,000 \mathrm{Btu} / \mathrm{hr} \cdot \mathrm{It}^{\mathrm{2}}$. The data at the ingher heat nuxes vere taken under suppressed bolling conditiocs to preclude mucleation. Flots of the data in terms of beat transfer coefficient rersus heat flux are deferred for convenience until the discussion of now boll1r, (see belor).

The hisated lexath of the heat flux weters was short in tern of $\mathrm{L} / \mathrm{D}_{\mathrm{eq}}(\sim 1.5)$, resulting in the forced-convection data being in the therwal entrance region rather than the fully developed region. Irous, the local Nusselt wodulus was consideraily ereater than that predicted 
by the Dittus-Boelter correlation [Eq. (2.2)]; this is in agreenent rith published data. 33 Eissenbert 으 al ${ }^{23}$ studied the Rejnolds and Prandtl noduli dependence of the courective heat trousfer coefricient in the turbalert therial entrace region, wing heat neters alsost identical to those eplosed in this study. [The design of the exters used herein are secont gaverefion developments derived from the Bissenberg weters.] Iney studied defineralized sater and eqreous-glveerol solutions up to $30 \mathrm{v} / 0$ elveerol, difing a range for the Prandt wodulus of 1.9 to 11.4 and a Reyolds codulu range of $10^{4}$ to $2 \times 10^{5}$. It was coceluded that, in agreenat with porvious stodies, 120 the exponent on the Resnolds

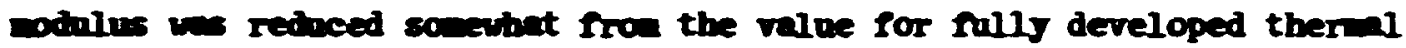
couditions for heat trunsfer in the thernal entrance region and the exposent on the Prandi nodulus was essentially the sese. The significant difference spense in the leading constent, beling weh grenter for therial eatrabe region effects. The Bissenberg correlating equation is given as:

$$
T_{\text {La }}=0.122 T_{\mathrm{Re}}^{0.70} \mathrm{Fr}_{\mathrm{Pr}}^{0.26}
$$

The unenhasced forced-sourection data collected in this study are Graphed in Fig. V-19; the correlating equation of BLssenberg et al. Is shown for comparison. Wote that the Pranitl wodulus for vater at the terperatures teeted was about 1.7 and for Freon-113 about 6.9 , well within the rase investigated by Biseenberg et al. The individual surface-riuid data and the entire data set (excluding tra enhanced conrection data) vere fitted with least-squares equations to disternine the best-fit constents for use in equations of the forn of $\mathrm{Eq}$. (5-1): the constrnts deterined are; soted in the figure. The fitted equation for 


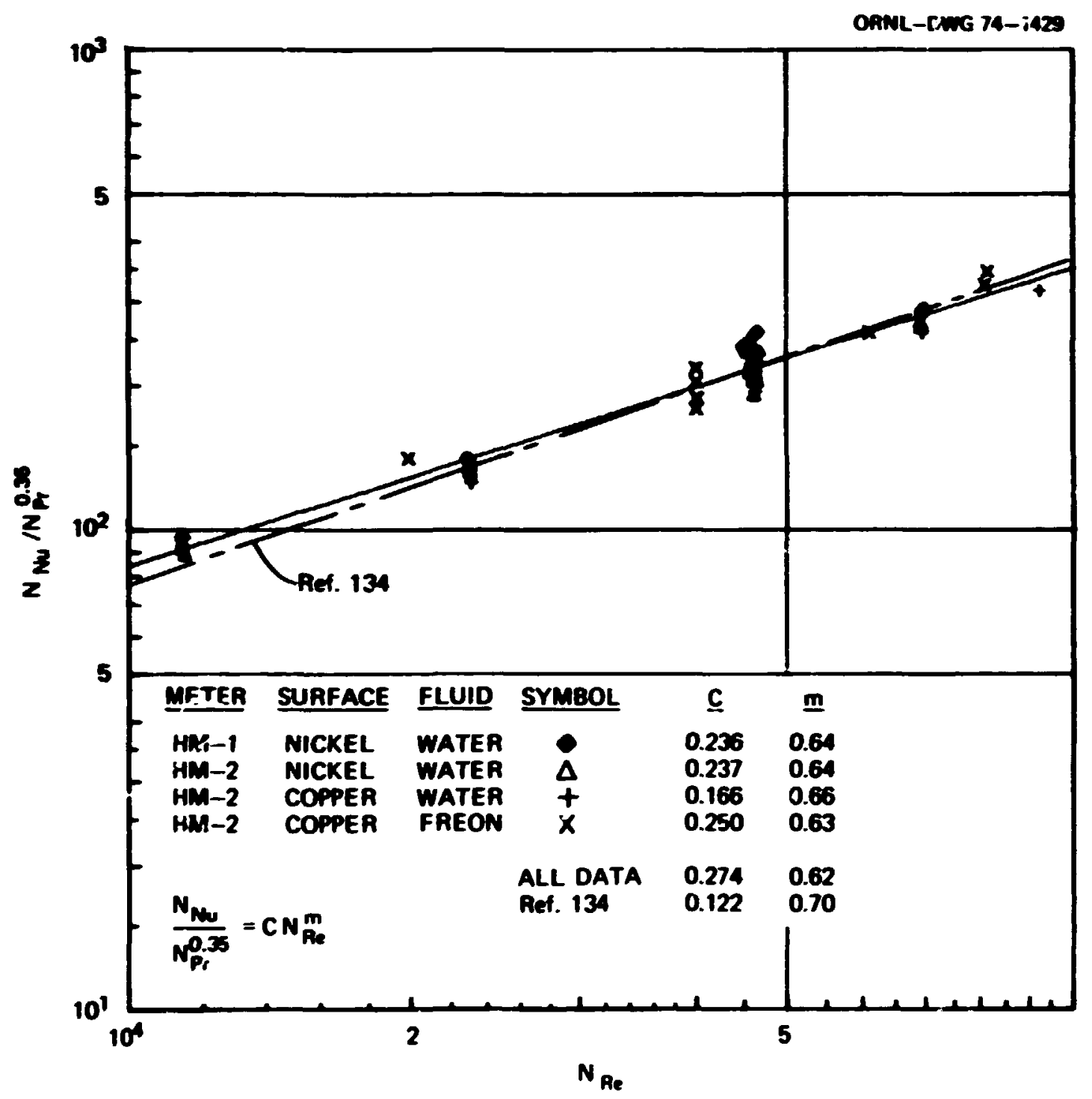

Fi6. V-19. Effect of ?eynolds modilus on forced-convection heat transfer.

the total data set is also graphed in the figure. Although the experimentally determined constants diff ər slightly from Eissenberg's constants, 1t was concluded that an equation of the form (5-1) represented the data adequately for the intended use. Thus, in subsequent data analysis the forced-convection heat transfer coefficient was computed from the 
expression ( $\pm 16 \%$ maximum error; 85\% of data $\leqslant \pm 10 \%$ error):

$$
\mathrm{K}_{\mathrm{Nu}, \mathrm{conv}}=0.274 \mathrm{~N}_{\mathrm{Re}}^{0.62} \mathrm{~K}_{\mathrm{Fr}}^{0.35}
$$

\section{Fle Boiling}

Convective flow boiling data were collected with both Freon-113 and demineralized (and deaerated) water under saturation conditions at atmospheric pressure. The heat meters were used with the flow test facility described earlier (Chapter IV) to obtain lxcal two-phase boiling heat transfer coefficienis in the vertical upflow mode over a range of flow and heat flux conditions. Ail the data reported and discussed herein were taken with the copper boiling surface prepared by lapping with 400-grit compound. Most of the data were collected under conditions of essentially zero percent thermodynamic quality; thus, the value of the reciprocal Martinelli parameter, $1 / x_{t t}$, approached zero for these tests. A limited number of annular flow boiling tests were carried out with Freon over a range in the thermodynamic quality of 2 to $8 \%(0.25$ $\left.1 / x_{t t} \leq 1.06\right)$. Thermodynamic quality is defined as:

$$
x=\frac{h-h_{f}}{h_{\rho g}},
$$

where $h$ is the local two-phase enthalpy, assuming thermodynamic equilibrium exists.

The reduced flow bolling data are tabulated in Tables D-19 through D-24 in Appendix D. Two-phase flow bolling data for Freon-113 are shown in Fig. V-20, where the local boiling coefficient for heat meter HM-2 is graphed as a function of the heat flux with flow velocity as a parameter. The data presented in the figure were obtained with zero 


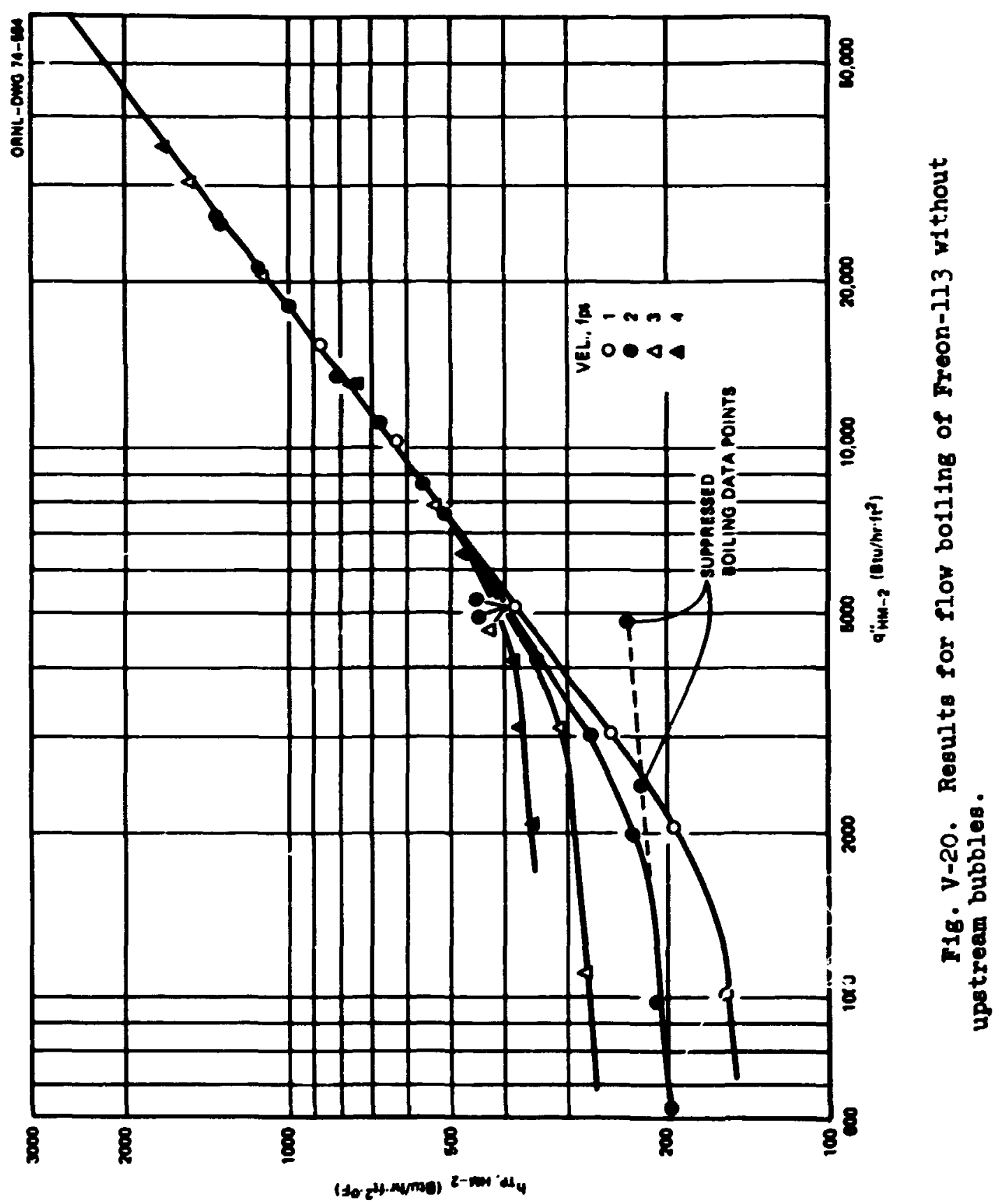


heat ninx on the lower meter (hil) to preclude the effect of upstrean tubbles. It can be seen that, for heat pluxes greater than 8 coc Btu/ $\mathrm{hr} \cdot \mathrm{ft}^{2}$, coefriclents for the four velocities tested (note: I fps $\approx$ $325,000 \mathrm{lb} / \mathrm{hr} \cdot \mathrm{rt}^{2}$ ) all $\mathrm{l}$ ie along the same line. At nuxes belo. $800 \mathrm{C}$ Btu/hr-ft, incipient bolline and foreed-convection prevall; ard in this region, a minor dependense of the corvestive coefficient or. hnat $n u x$ was obse:r ed. Sufficient conventive data were ottained at $\sum$ and - fos. to estailish sloper for the curves in this region; sirce these were the same, surface roughness can be ruled out as the cense of the observed flux deperdence. If roughness vere the cause, the slope for the $\rightarrow$ fus data should have been greater than for the 2 fps data. Curves having the same slope as the 2 fps data were drawr. through the 1 and $=f t s$ date in the convective region.

Data taken on the upper meter (HM-2) dith kuktles in the stream. (generaied by constant flux operation of HM-I) are graphed ir. Fig. V-2I; the enhanced convection data are included in the data takulation of Table D-18 and the fully developed nucieatior data are included ir. Table D-20 of Appendix D. The curves (without data points) Prom Fig. V-20 are shown also for raference in Fig. $V-a 1$ by the dashed Ines. For heat flux values above $8000 \mathrm{Btu} / \mathrm{hr} \cdot \mathrm{ft}^{2}$, the presence of butbles in the stream has little, if any, effect on the local bolling coefficien:; at lower heat flux values, the bubbles enhance apprectably (as expected) the convective heat transfer coefficient. These observations ar. con. sistent with the results obtained in the Freon pool bolling experiments with vertical orientation (see $\mathrm{PIg}, \mathrm{V}-\mathrm{I}_{4}$ ).

Since the data graphed in Figs. V-20 and V-21 are for essentially zero thermudynamic quality, Chen's correlation ${ }^{24}$ is not applicable; on 


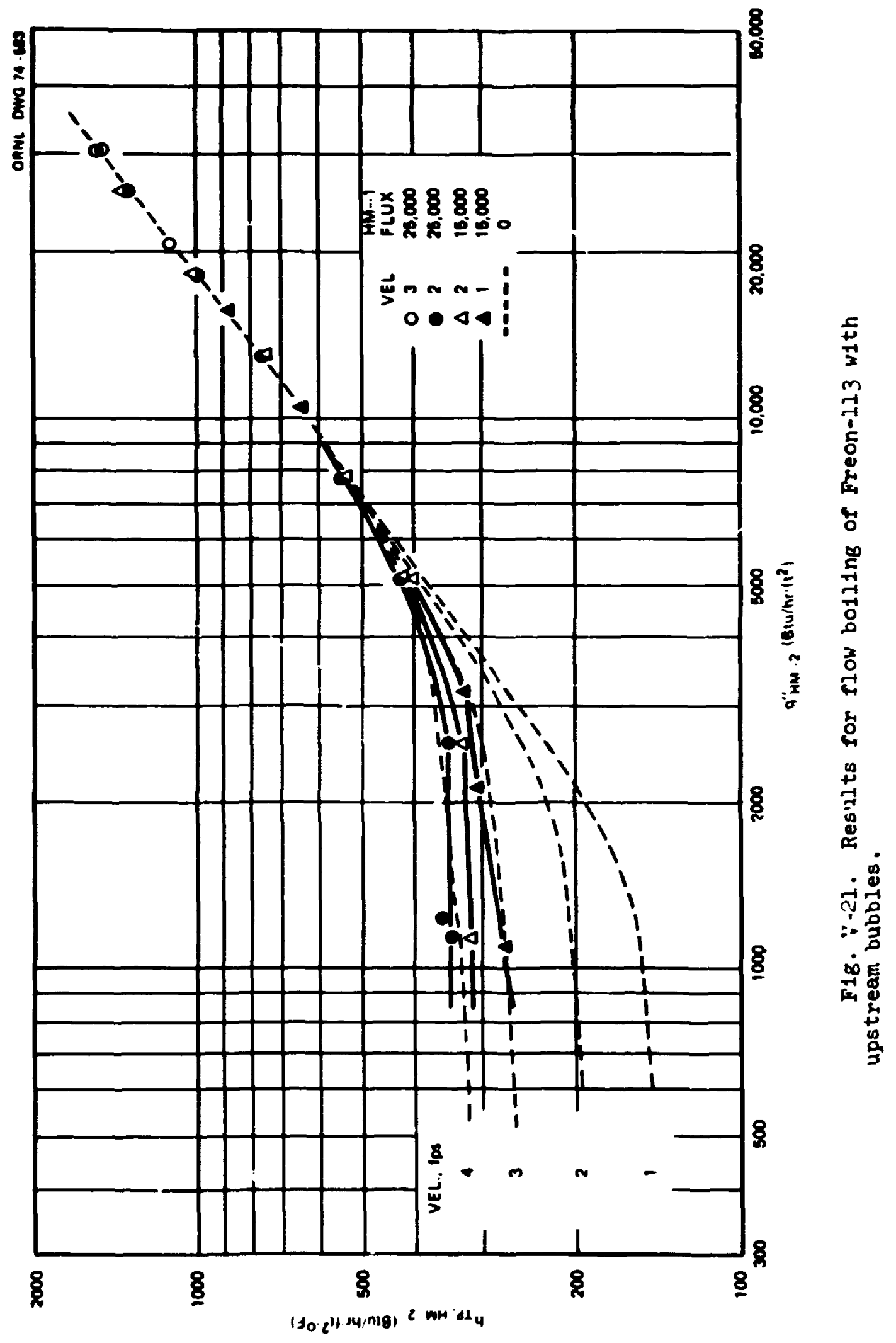


the other hard, hohsenow's additive technique ${ }^{12}$ has no such restriction. This correlation is given as:

$$
q_{\text {IP }}^{\prime \prime}=q_{\text {NB }}^{\prime \prime}+q_{\text {conv }}^{\prime \prime} \text {, }
$$

where $q_{\text {corv }}$ is given by the Dittus-Boelter expression [Eq. $\left.(z-\hat{c})\right]$, and $\mathrm{q}_{\text {IB }}^{\text {Is }}$ is correlated with the Rohsenow pool boiling reiation [Eq. (2.23)].

In analyzing the fully developed nucleate boiling data, an appropriate convection coefficient was calculated using Eq. (5-2). [The enhanced convection data points were not included in that correlation.] Next, the quantity of heat attributed to forced convection $\left(q_{\text {conv }}^{\alpha}\right)$ was evaluated, based on $\Delta \mathrm{r}_{\text {sat, meas }}$. Following this, Eq. $(5-4)$ was used to obtain the nucleate boiling heat $\mathrm{flux}, \mathrm{q}_{\mathrm{NB}}$. The results of this analysis are graphej in Fig. V-22 (and tabulated in Table D-2l of Appenaix D); clearly a high degree of correlation exists. Figure V-23 presents the data in terws of the Rohsenow pool boiling correlation. Using a linear regression routine, values of $c_{s f}=0.00262$ and $r=0.144$ were found to correlate the entire data set with $10.5 \%$ maximum error (2.7.7\% if the one point for not fully developed nucleate boiling is included); these are to be coupared with $C_{s f}=0.00272$ and $r=0.092$ (Fig. $V-15$ ) obtained for then entire Freon pool boiling data set. Blatt and Adt, ${ }^{52}$ using the Rohsenow additive method, correlated their Freon-113 flow boiling data (horizontal flow in $0.25-$ in.-ID copper tube, exit quality in the range 2 to $90 \%$, mass flux in the range 28,800 to $54,000 \mathrm{lb} / \mathrm{hr} \cdot \mathrm{ft}^{2}$ ) with $\mathrm{C}_{\text {sf }}=$ 0.007 and $r=0.33$. [See Append $i x F$ for alternative $C_{s f}$ and $\underline{r}$ values.]

Flow system design permitted operation with Freon under limited conditions of annular flow as described in the Proceciures Section of Chapter IV. A series of such tests were perfomed in which the local (calculated) thermodynamic quality at HM-2 ranged from 2 to $8 \%$ vapor by weight; 


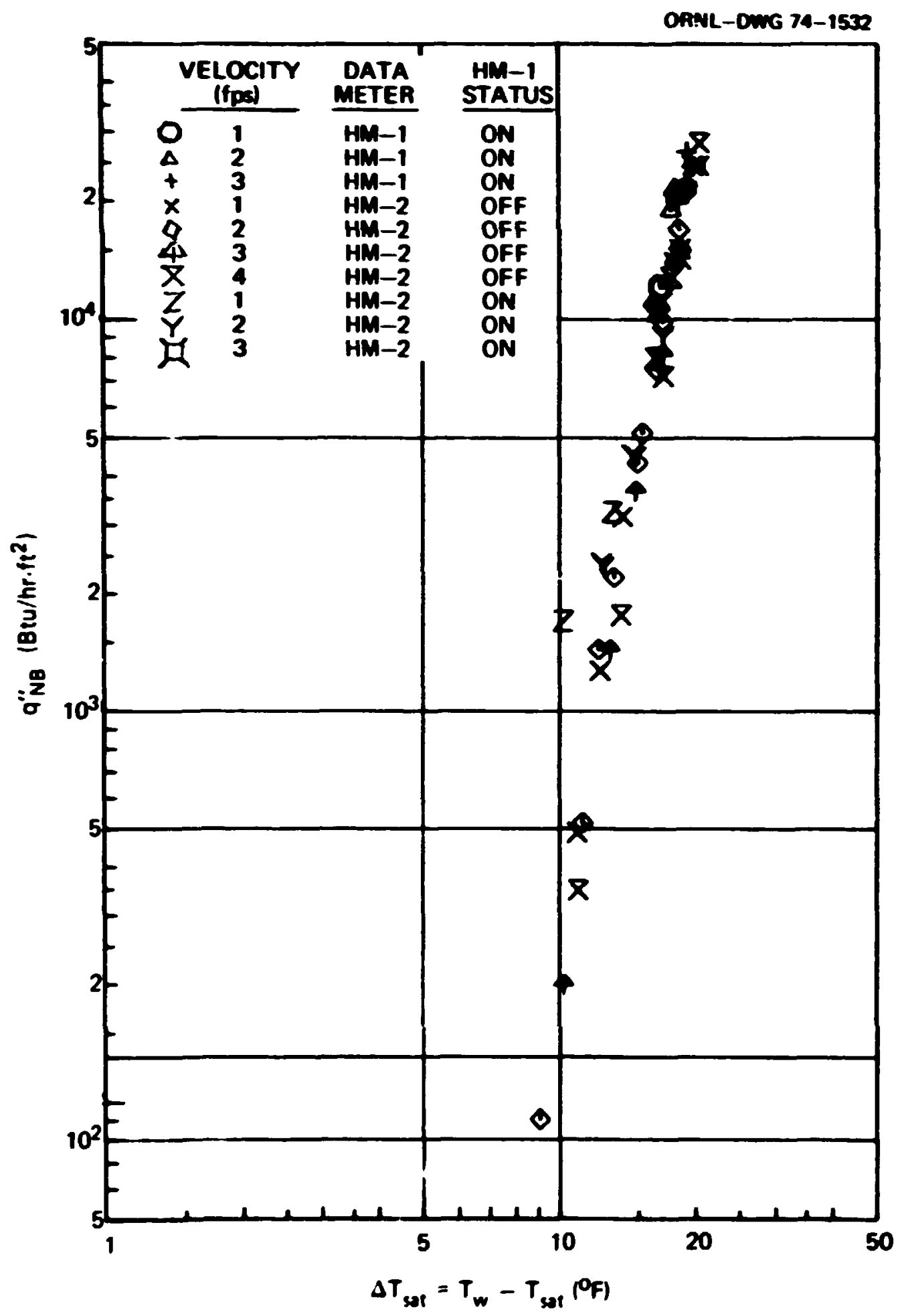

Fig. V-2á. Nucleate boiling heat flux contribution in Freon flow bolling. 


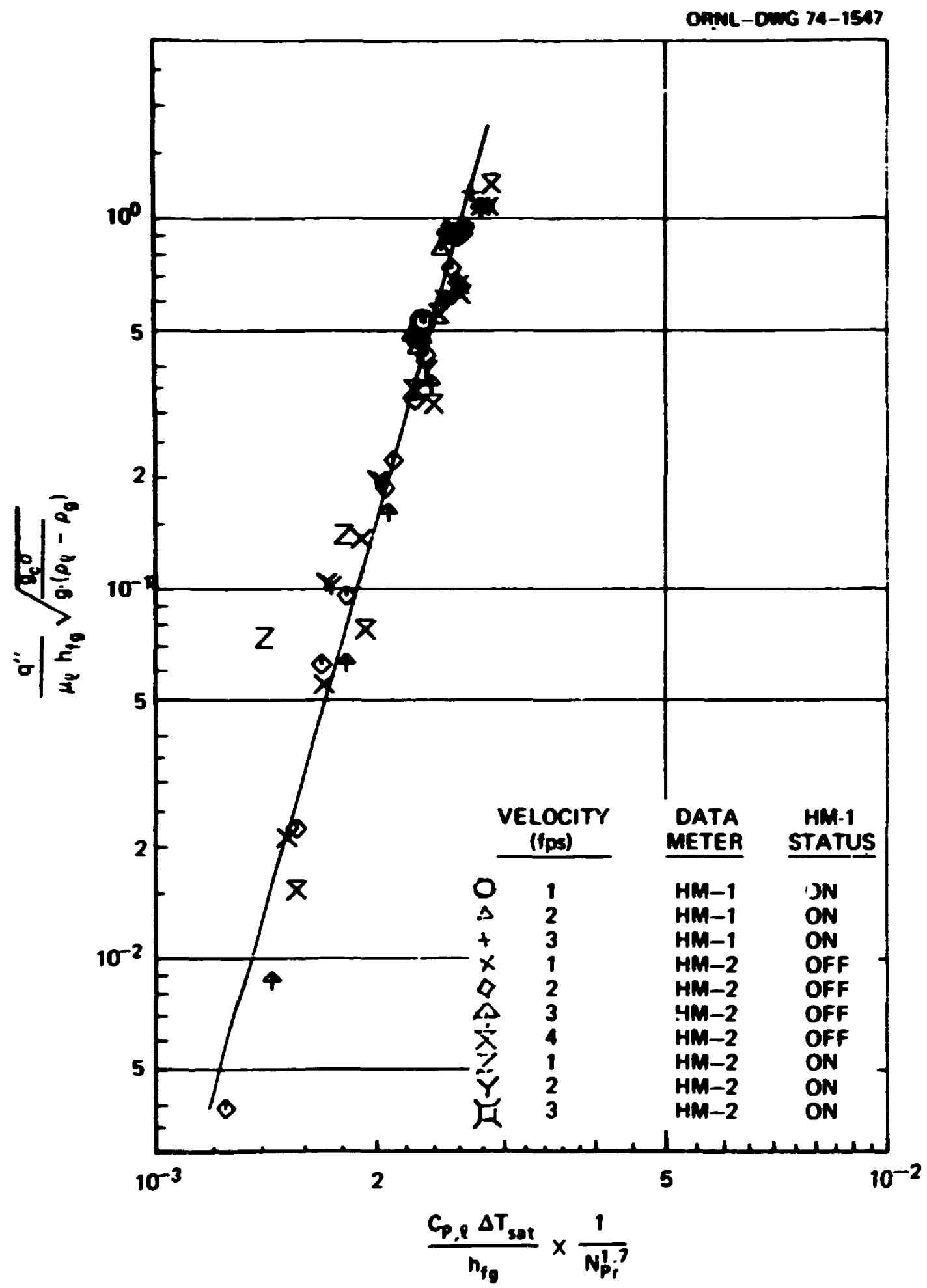

Fig. V-23. Rohsenow correlation of Preon flow bolling results. 
corresponding values of $x_{t t}$ ranged from 4.1 to 0.94 . In reducing the data, the Reynolds modulus was based on the liquid phase only; the results are tabulated in Table D-2l of Appendix D and graphed in Pig. V- 24 . Separation of the individual points in the plot according to the local quality did not appear jusified, since the weasu:ed coefficient was not sensitive to this parameter in the range tested.

Chen's correlation ${ }^{24}$ sho'ld be applicable under the conditions of this series of tests. Accordingly, the data ere analyzed to determine if this method adequately predicted the experimental data. In applyinf the method of Chen, use was made of Eq. $(2-30)$ and Figs. II-I and II-2; the equation is repeated here for convenience:

$$
h_{\mathrm{TP}}=h_{\text {macro }}+h_{\text {micro }} \text {, }
$$

where $h_{\text {macro }}$ is related to the Dittus-Boelter expression $\left.\left[E_{1} \cdot 2-2\right)\right]$ and $h_{\text {micro }}$ is based on the Zuber pool boiling correlation, ${ }^{38}$ as discussed in Chapter II. As before, a convective heat transfer coefficient was computed, using Eq. (5-2), and multiplied by the proper $\mathbf{P}_{\mathrm{TP}}$ value from Fig. II-1. The value for $h_{\text {mirro }}$ was obtained from the Zuber expression [Eq. (2-30)] and the appropriate suppression factor from Fig. II-2. The sum of these two coefficients, according to Eq. $(2-39)$, is the local two-phase boiling coefficient as given ty Chen's correlation and should compare ravorably with the experimental values. Coeficients thus alculated are graphed in Fig. V-24 for comparison with the experimental data. In these caiculations, qualities weie varied at four levels between 2 and $8 \%$ (to correspond with the measured levels) at the lowest flow rate; at the highest mass flow, system limitations prevented operation with quality above the single value (2.1\%) shown. Clearly, the correlation of Chen does not represent the data. This could have 


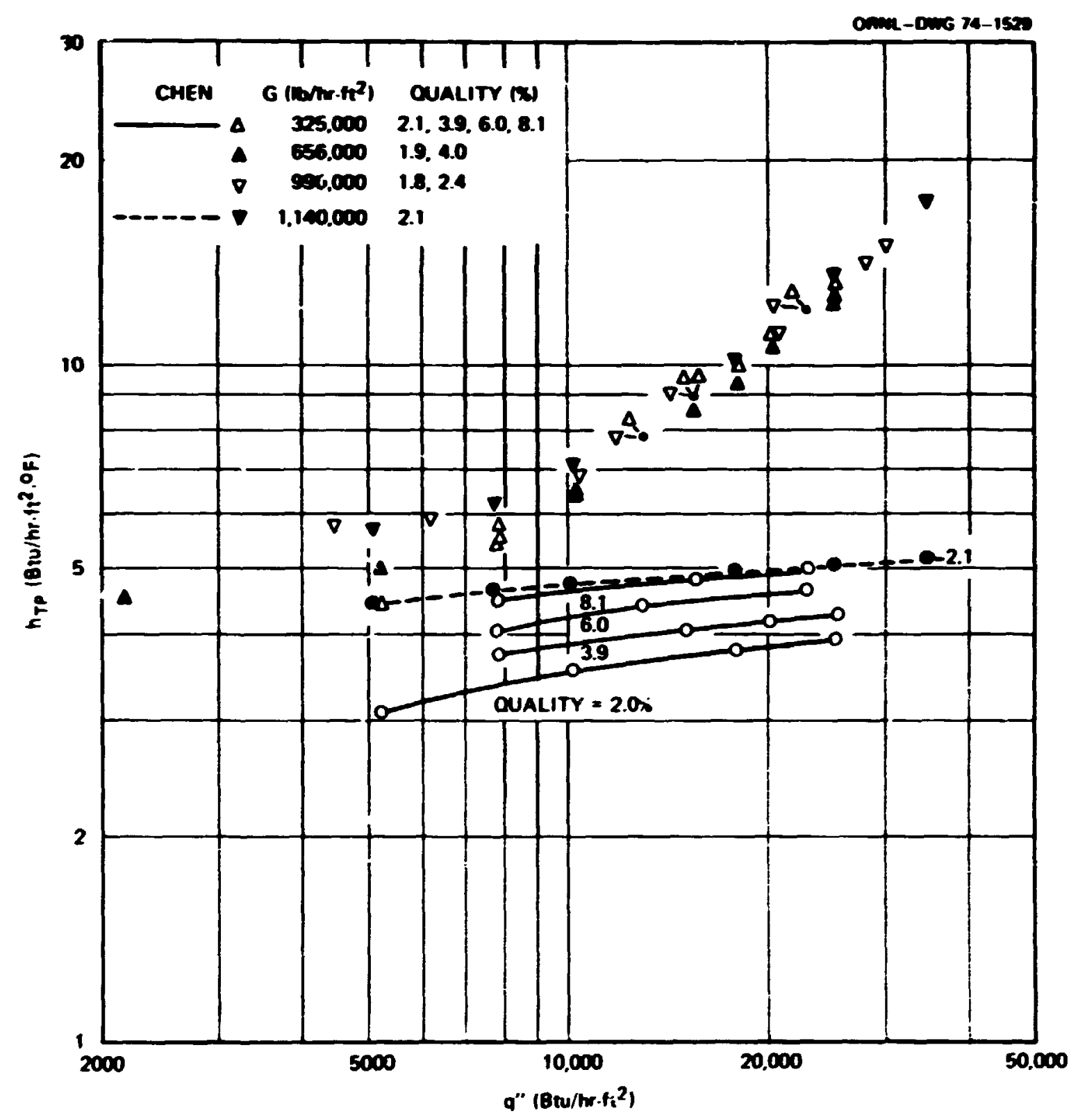

Fif. V-24. Results for two-phase bolling of Freon in annuler flow. 
been anticipated, since the Zuber pool bolling expression did xo: correlate the Freon (and water) pool boiling data obtained in this research (see $F$ igs, V-i7 and $V-18$ ). This result suggests the need for a modification of the Chen correlation to include a more suitable mucleate bolling formulation.

As discussed in Chapter II, a number of investigators have divided flow boiling into two regimes: the nucleate bolling and the suppressed nucleation regimes, depending on the general behavior. That is to say, if the heat transfer phenomena is primarily characteristic of forced convection, it is referred to as suppressed nucleation; whereas if the heat transfer coefficient increases with flux (as in pool boiling), it is classified as nucleate boiling. These regimes can be recognized conveniently in a dimensionless plot of $h_{\text {IIP }} / h$ conv versus the boiling modulus $N_{\mathrm{BO}}[\mathrm{Eq} \cdot(2-12)]$. On such a plot, in the region where the coefficient is independent of $\mathrm{N}_{\mathrm{BO}}$, nucleation is suppressed. Since the heat transfer process in this regime is charasteristic of forced convection, the dimensionless plot is quite similar to an ordinary plot of h versus $q^{\prime \prime}$. In the region for which the coefficient shows a dependence on $\mathrm{N}_{\mathrm{BO}}$, the heat trarsfer process is characteristic of nucleate botling and appears so in the dimensionless plot. For cunstant flow, $N_{B O}$ varies approximately linearly with $q^{\prime \prime}$, and the similarit; of the dimensionless plot with the ordinary plot reflects the behavior of nucleate bolling. The annular flow data are graphed in tnis manrer in Fig. $v-25$, where $h_{\text {conv }}$ wes calculated by Eq. $(5-2)$. For $\mathrm{I}_{\text {Bo }}$ less than $1.6 \times 10^{-4}$, the dimensionless coefficient is insensitive to $N_{B O}$ (or $f(u x$ ), and nucleatior was suppressed; atove this value the coefficient depends strongly on flux 


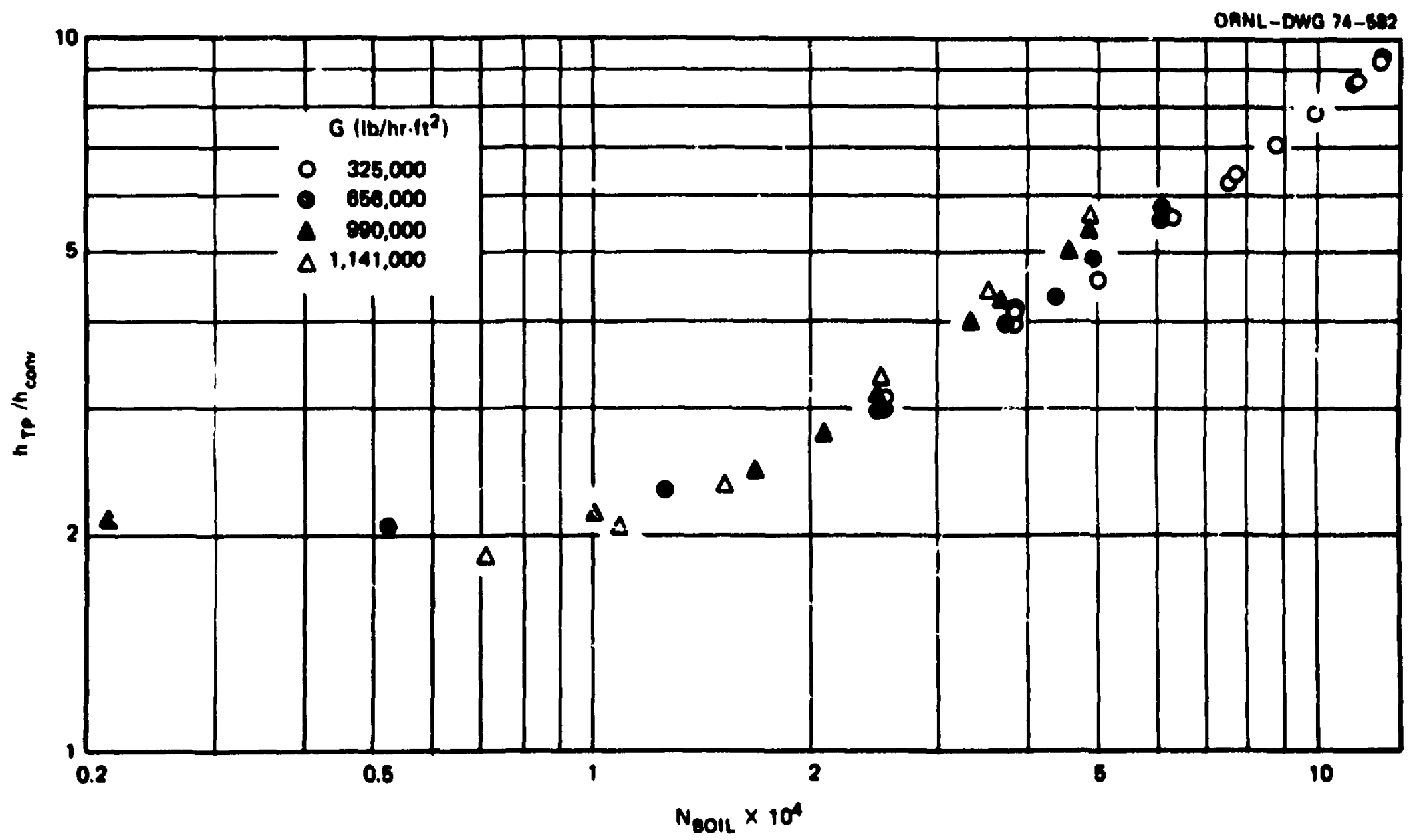

Fig. V-25. Bolling modulus vs $h_{\text {IP }} / h_{\text {conv }}$ for Freon-113 in 
and, hence, is presuned to correspond to the nucleate coiling regine. Trus, the figure shows that wost of the data of this study vere collected under nucleate boiling conditions and that very few data points were in the suppressed nucleation region. This may provide an alternative reason for failure of Chen's correlation to predict the measured coefricient.

Pujol ${ }^{45}$ investigated flow boiling of Preon-113 in the upflow wode (discussed in Chapter II) and correlated his results in terms of the Martinelli parameter, $x_{t t}$, and $\mathrm{N}_{B O}$ [defined in Eqs. $(2-3)$ and (2-12), respectively]. The results of this study are given in Fig. V-26 in a form similar to Fig. 19 of Ref. 49; the suppressed nucleation correlation of Pujol is shown also for reference. Plotted in this manner, the nucleate boiling regine is independent of $x_{t t}$ (as indicated by the horizontal $l$ ines) and if extended to lower values of $x_{t t}$ (higher qualities), would fair into the suppressed nucleation line. Except for the data at the lowest values of $\mathrm{N}_{\mathrm{BO}}$, this figure also demonstrated that the annular Now results were obtained in the nucleate boiling ragime. Too few data were collected under suppressed nucleation conditions to attempt a correlation; it is noted, however, that che group of data points with the lowest boiling moduli apree with Pujol's sorrelation.

The annular flow data were also araly. us irs, the Rohsenow additive technique in the same manner as described acove for the very low $\leqslant 0.2 \%$ quality) flow boiling data; the results are takulated in Tabje D-24 of Appendix D. The contribution to the total heat flux attributed to

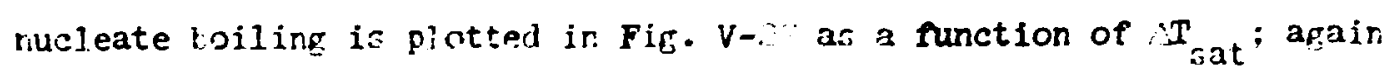
the sorrelation is good. Correlation of the fully develoned nucleate 


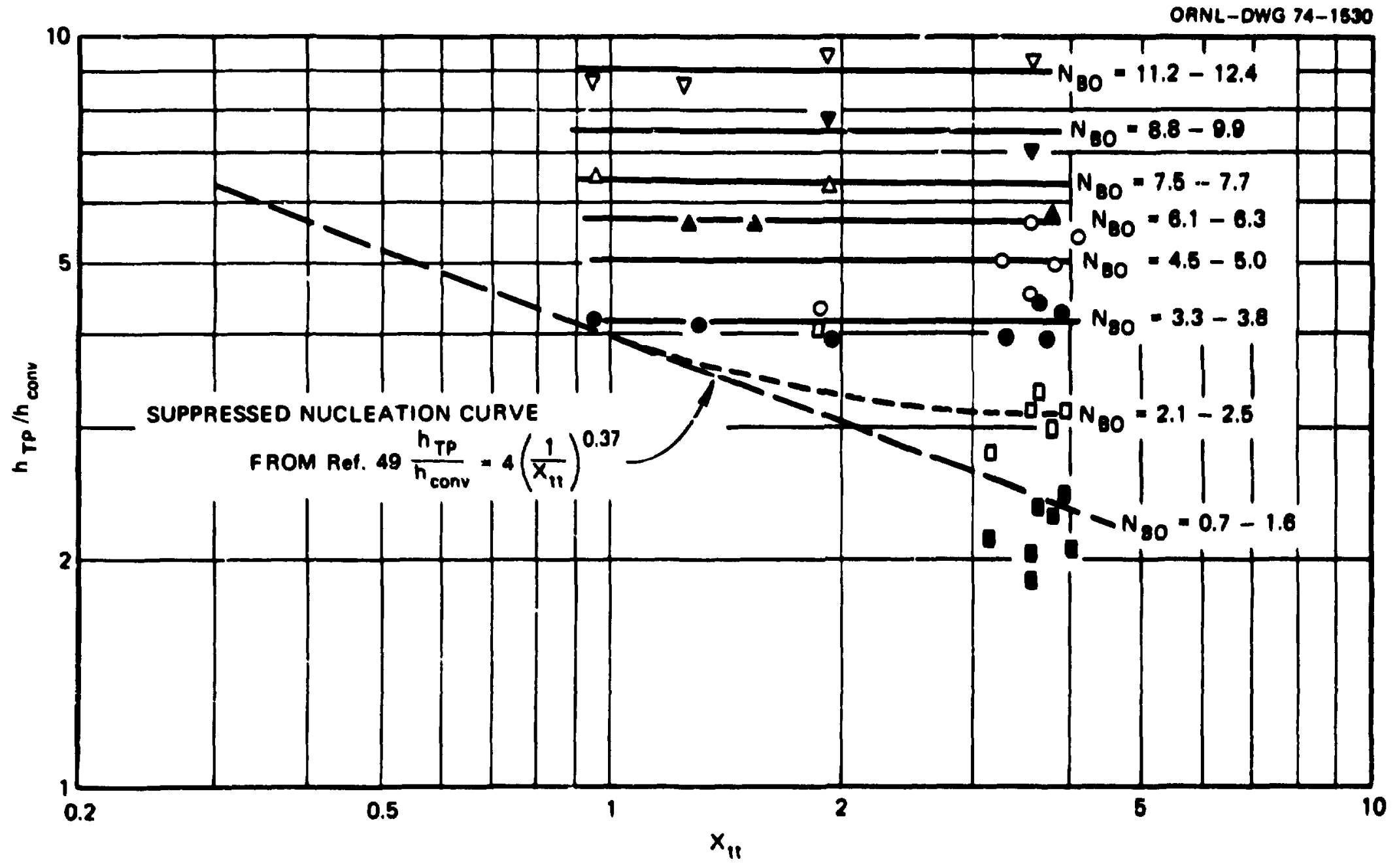

FiB. V-26. Rat1o of $h_{\mathrm{TP}} / h_{\text {conv }}$ vo Martinelli parameter. 


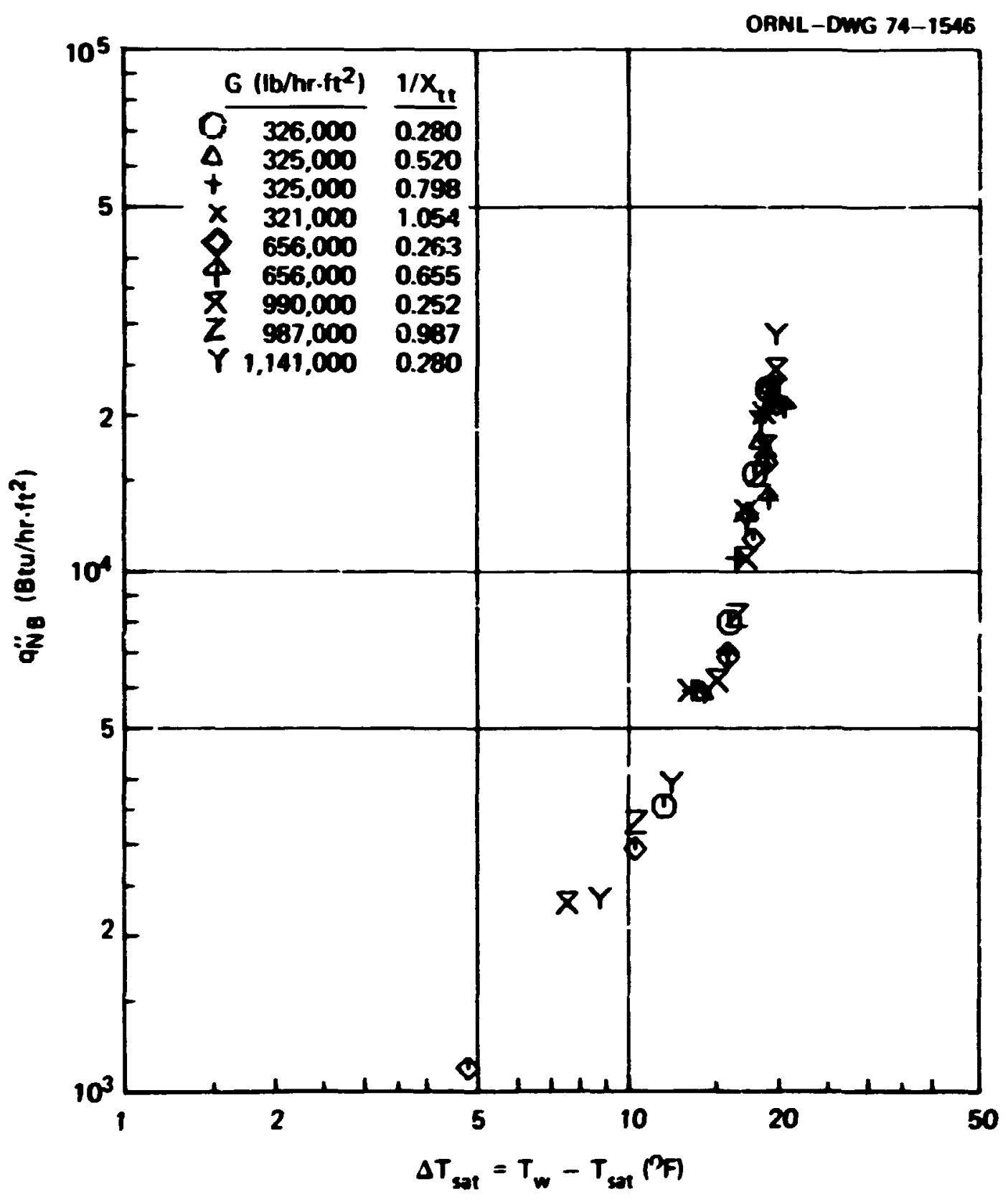

Fig. V-2\% Nucleate boiling heat flux contribution for boiling Freon in annular flow. 
boiling data of Fig. V-2? $\left(q^{\prime \prime} \geq 6000\right)$ in terms of the Rohsenow pool boiling expression is indicated in Fig. V-28. The data were correlated (5.8\% maximum error) with $\sigma_{s f}=0.00276$ and $r=0.192$ (see Appendix $\mathbf{F}$ ), compared to values of 0.00262 and 0.144 , respectively, for the very low quality flow boiling results. It was concluded that the Rohsenor addftive technique also best described the annulir flow boiling results.

The preceding discussion of Freon flow bolling was marked by the consistency and reproducibility of the data; tice same was not the case with the water flow boiling experitrents. While considerable effort was expended in deaerating the circulating system and mairiating it in that condition by continuous bolling in the large reserviry, the data still showed evidence of aging similar to that observed in the pool bolling experiments with water.

The reduced data for the vatrr flow bolling experiments are tabulated in Tables D-20 and D-23 of Appendix D; the enhanced conrection results are tabulated with the forced-convection data in Tables $D-1^{\top}$ and D-18. The flow bolling data collected with weter HM-2 under conditions of very low local thermodynamic quality $(\leqslant 0.2 \%$ vapor) and without upstream bubbles are graphed in Fig. V-29; when compared with a similar plot for Freon (see Fig. V-20), the data show the same general behavior but are lf:ss consistent. Thus, in the nucleate boiling region, significant separation of the data with velocity exists. While this contrasts with the Freon results, no consistent trend is observed. Deta at 2 fps (corresponding to $2+30,000 \mathrm{lb} / \mathrm{hr}^{2} \cdot \mathrm{ft}^{2}$ ) and $4 \mathrm{fpe}$ Iie below and to the right of the values for 1 and $3 \mathrm{fps}$; : imited data at $0.5 \mathrm{fps}$ fall intermediate to the higher results. These Alscrepancies appear to be assoclated with surface aging. Indeed, it was difficult to operate for 


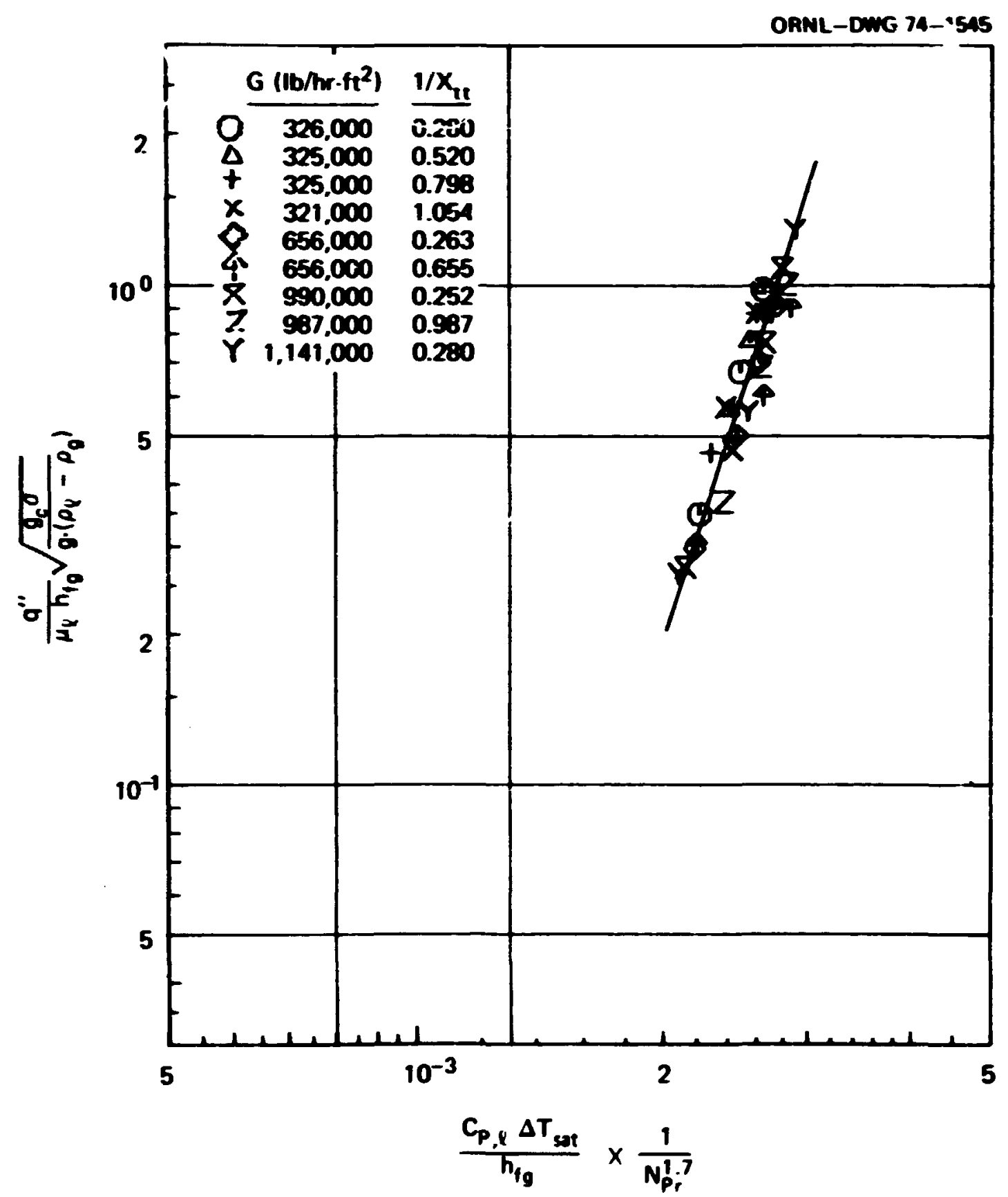

Fig. V-28. Rohsenow correlation of Freon annular flow bolling. 


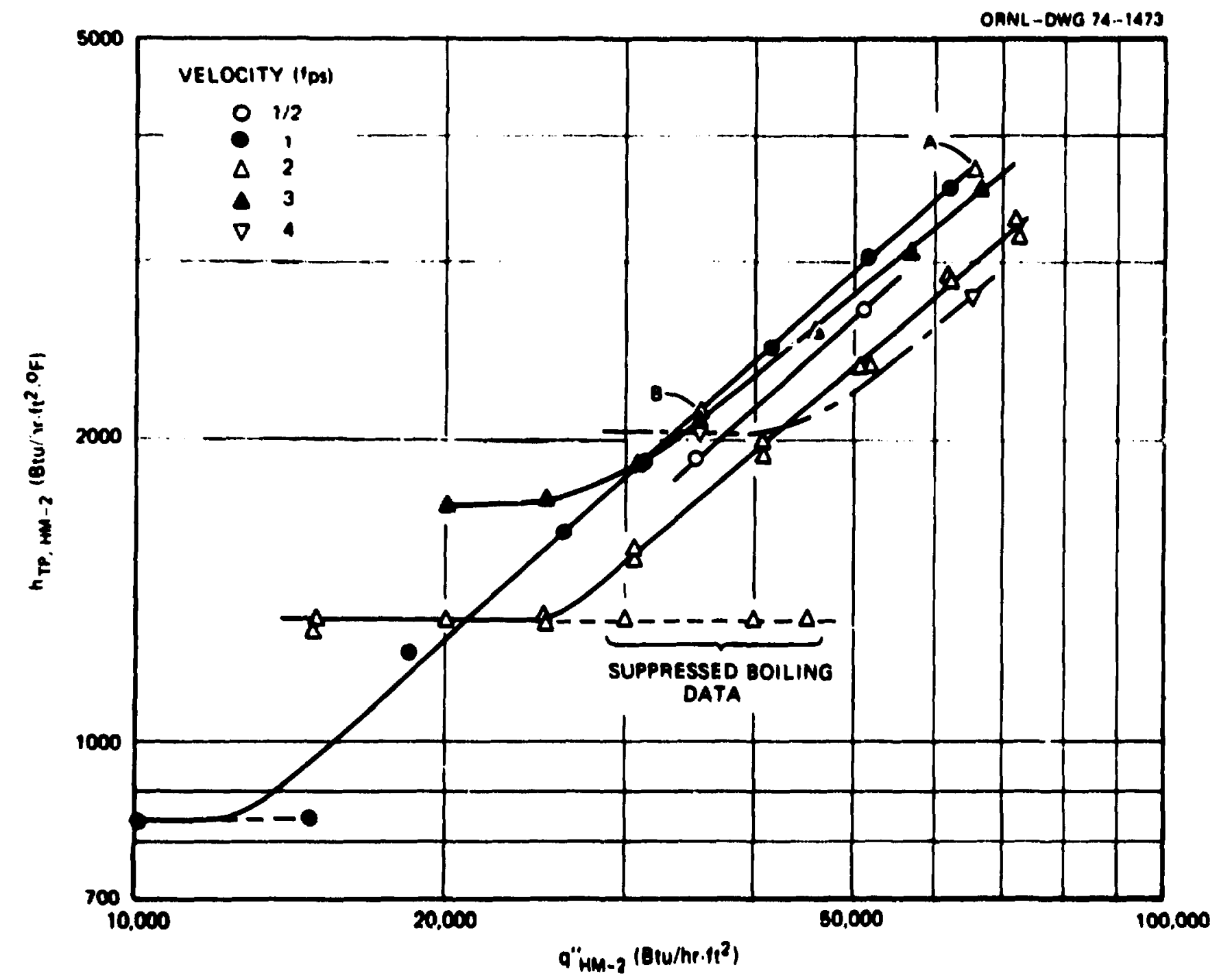

w.

F18. V-29. Results for slow bolling of water without upstream bubbles. 
wre than three successive days before severe degradation of the boiling performance necessitated reconditioning of the surface. In fact, the two groups of data points shown for the 2 fps line (distirguished in Pig. V-29 only by the two data points at each nux level) were actually obtained on successive days, wth the higher values being recorded on the second day. After collecting these particular data, the surfaces were relapped, and the data points warked as "A" and "B" (at 2 fps) vere recorded snortly after operation resumed. These values aqree reasorably with the $1 / 2,1,2$, 3 fps data collected subsequently.

Data taken with HM-I operating at constant heat fiux levels of 75,000 and $50,000 \mathrm{Btu} / \mathrm{hr} \cdot \mathrm{ft}^{2}$ to produce bubbles in the stream flowing (at 2 fps) past HM-2 are graphed in Fig. V-30; the dashed curves are reproduced from Fig. V-29 for refererse. With the exception of tine points ncted by " $\mathrm{C}$ " and "D", these data were taker a!.ternately with the 2 fps data of Fig. V-2g; i.e., a run with thi-i at zero flux was followed immediately by runs with BM-1 at the higher fluxes. This should have minimized the effects of aging. Points " $\mathrm{C}$ " and "D" followed points "A" and " $\mathrm{B}$ " of the preceding figure. The data suggest for heat flux values above $40,000 \mathrm{Btu} / \mathrm{hr} \cdot \mathrm{ft}^{2}$ that the butkles canse a slight degradation in the local two-phase boiling coefficient; this result is consistent with the findings of the vertical pool boiling experiments (see Fig. V-14). of particular interest are the three data points recorded for a velosity of $1 / 2$ fps with HM-2 operating at a constant flux level of $35,000 \mathrm{Btu} / \mathrm{hr} \cdot \mathrm{ft}^{2}$ and $\mathrm{HM}-1$ at three different $\mathrm{flux}$ levels. The sequence of this series of experiments was as follows: (1) a flux of $35,000 \mathrm{Btu} /$ $\mathrm{hr} \cdot \mathrm{ft}^{2}$ was established on $H M-?$ with zero $\mathrm{flux}$ on $\mathrm{HM}-1$ to obtain a reference value, and (2) subsequent data were taken with HM-1 at successive 


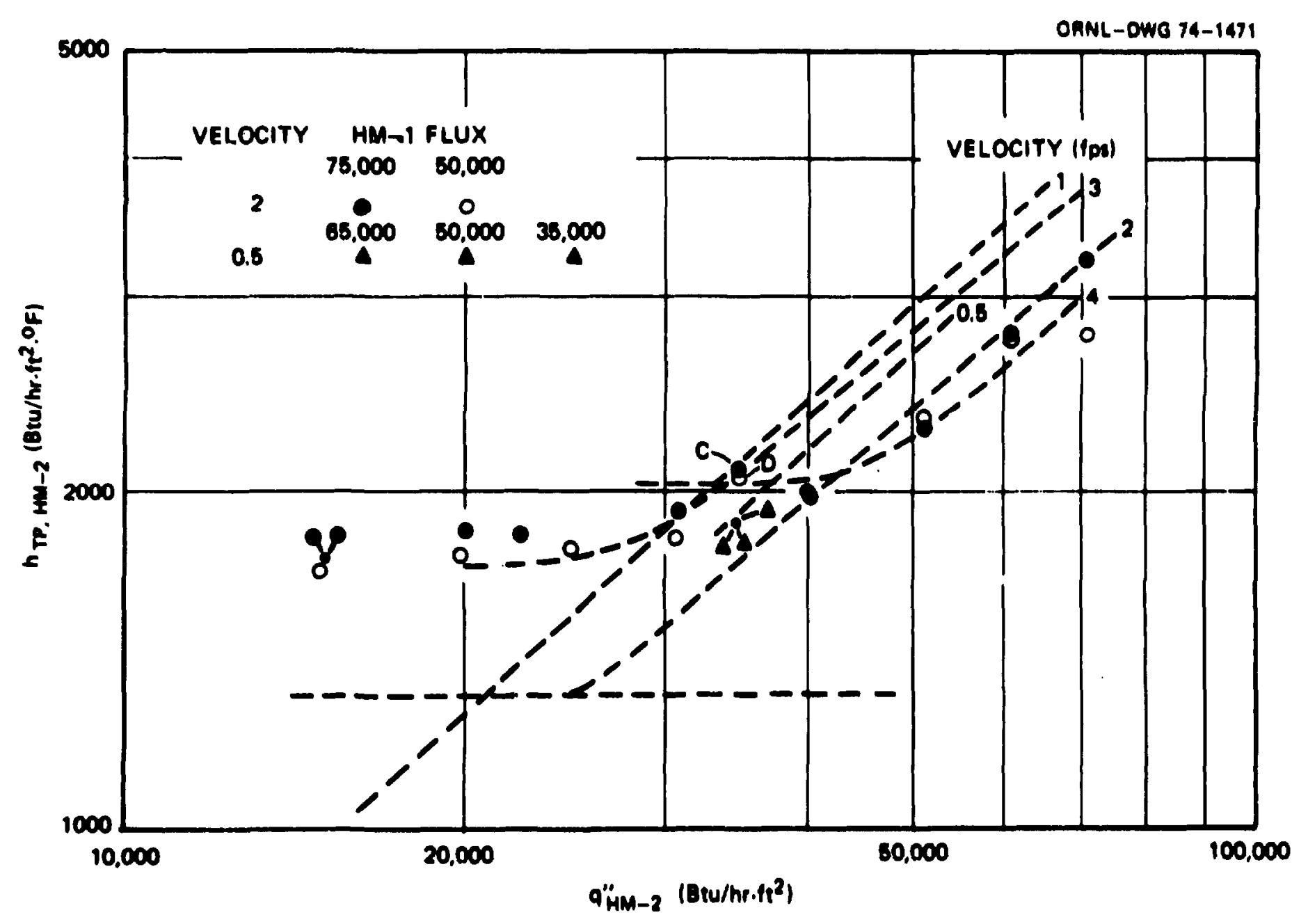

F1g. V-30. Results for flow bolling of water with upstream bubbles. 
nux levels of $50,000,35,000$, and $65,000 \mathrm{Btu} / \mathrm{hr} \cdot \mathrm{ft}^{2}$ to determine the effect of bubbles in the strean ( $1.0 \mathrm{~m} \mathrm{BM-1)}$ fioring past HM-2 on the bolling perforwance of this (upper) meter. As noted in Tabie v-2 and graphed in Fig. V-31, the boiilng heat transfer coefsicient degraded as the number of bubbles in the stream increased. Photographs of the boilInf during this sequence are presented in Pig. V-32. As observed in the photozraphs, moderate maleation exists on HII-2 in the absence of upstrean bubbles; then as the flux level on BM-I increases, the number of nucleation sites on BM-2 decreases and essentially disappears at the highest nux value. These data are consistent with the pool boiling results for water on vertical surfaces discussed earifer (see Fig. V-14). Based on the observed coefficients, this series cf photographs might be interpreted as evidence that the contribution to the tota! heat removal process by bubble growth was relatively small; since the fractional lass

TABIE V-2

EHTDCT OP UPSTREAM BCBBLES OI HA-2 BOIIIIG PERPORMANCE

\begin{tabular}{|c|c|c|c|c|}
\hline $\begin{array}{c}\text { HA-2 } \\
\text { Experiment No. }\end{array}$ & $\begin{array}{c}\text { BM-1 Plux } \\
(\text { Btu/hr·ft })\end{array}$ & $\begin{array}{c}\text { Fu-2 Plux } \\
\left(\mathrm{Btu} / \mathrm{hr} \cdot \mathrm{ft} \mathrm{t}^{2}\right)\end{array}$ & $\begin{array}{l}\text { BH-2 Coefficient } \\
\left(\text { Btu/hr.ft }{ }^{2} \cdot \mathrm{P}\right)\end{array}$ & $\begin{array}{l}\text { Heat }^{\mathbf{a}} \\
\text { Balance }\end{array}$ \\
\hline TPBIC2-0C2 & 0 & 34,905 & 1902 & 0.904 \\
\hline TPBLC2-032 & 34,984 & 34,880 & 1856 & 0.904 \\
\hline TPBLC2-037 & 50,209 & 34,767 & 1864 & 0.902 \\
\hline TPBLC2-033 & 65,228 & 34,332 & 1867 & 0.903 \\
\hline
\end{tabular}

Priction of heat input ascounted for by the kM-2 heat flux. 


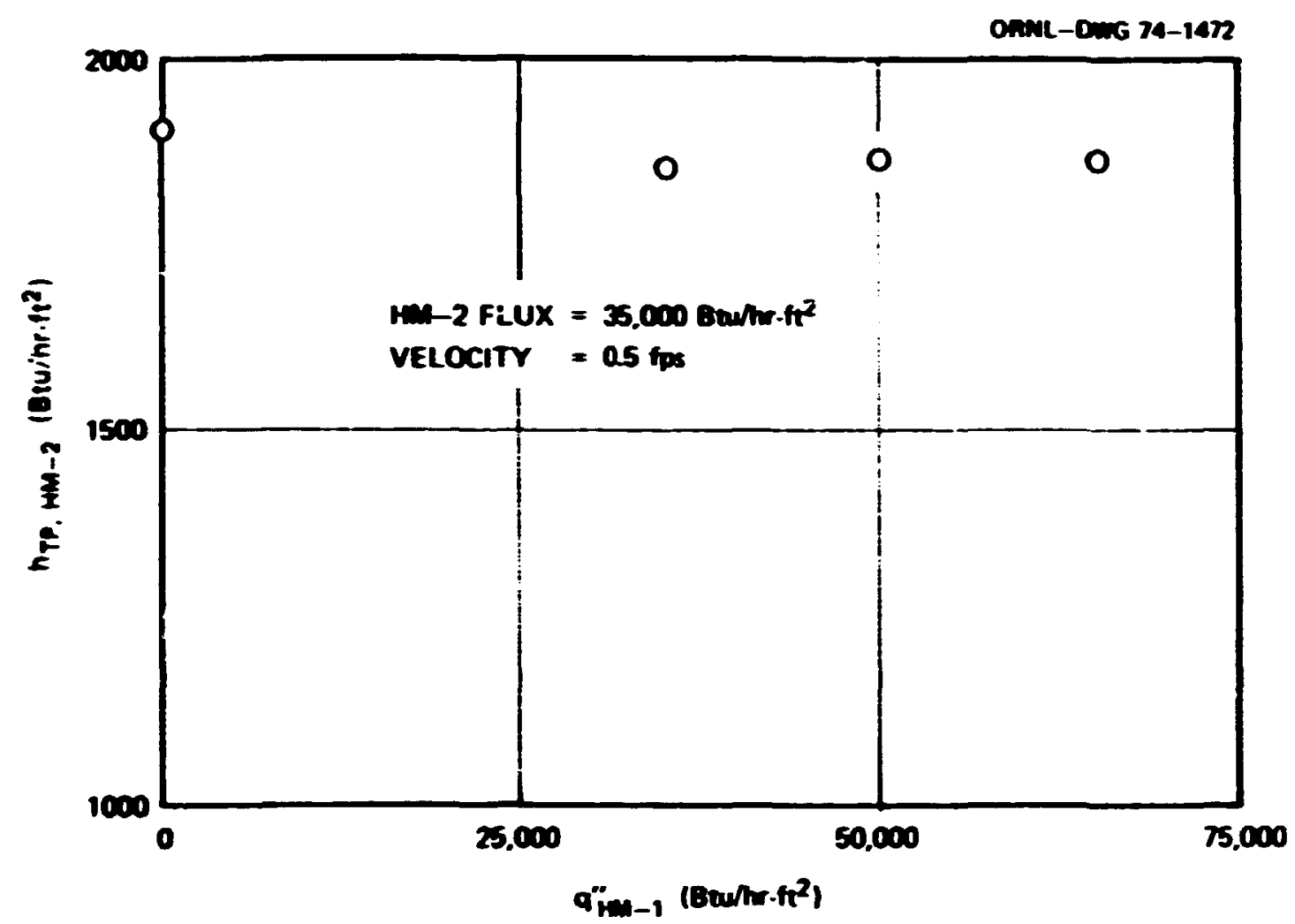
on int-2.

Fig. V-31. Effect of upstream bubbles on constant flux performance

in coericient was small. However, alternatively, the loss in heat rewoval due to bubble growth (while evading the question of how wuch) wight be taken to be compensated by enhanced convection associated with the bubbles in the flowing stream. Since the study of bubble dynamics was outside the scope of this investigacion, the inforwation necessary to establish the correct interpretation is not now available.

Since the Rohsenow additive techns gue was shown to correlate the Freon flor boiling data well, the water flow bolling data were treated in a similar manner. Pigure V-33 graphs the contribution of the total 

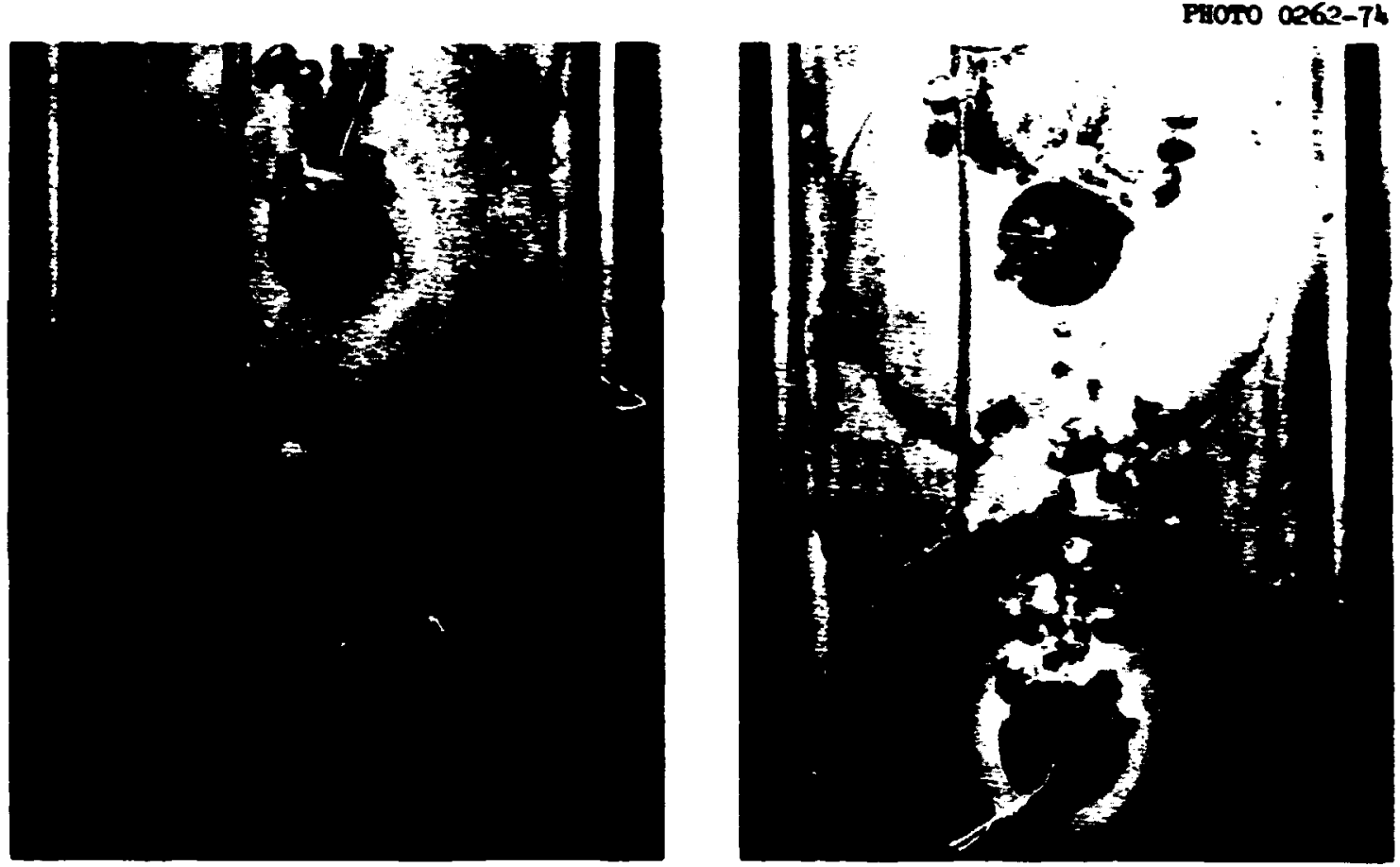

(a) $\mathrm{q}_{\mathrm{BH}-1}^{*}=0 ; \mathrm{h}_{\mathrm{IP}, \mathrm{BL}-2}=190 \mathrm{e}$

(b)
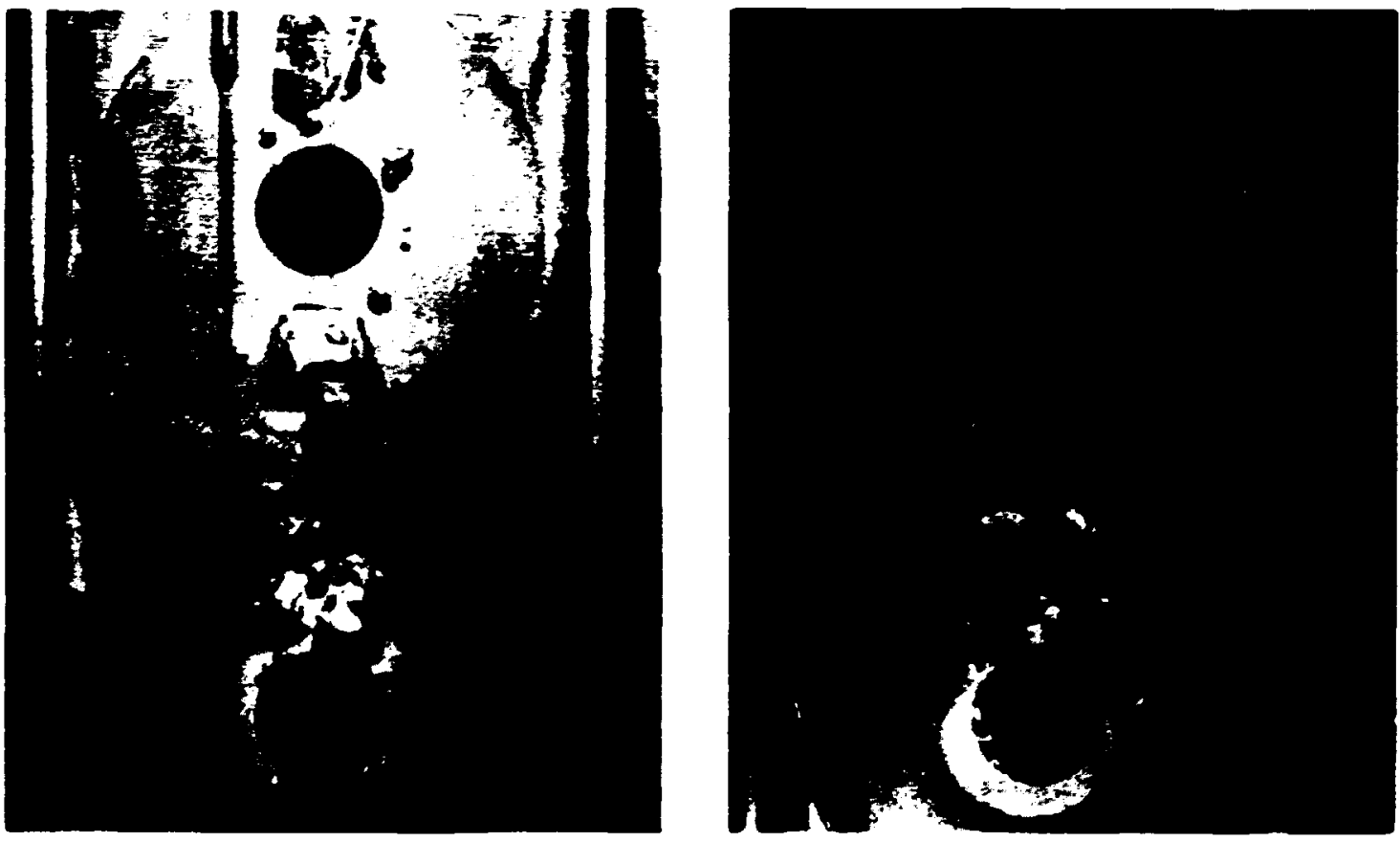

(c) $q_{\text {FM-1 }}^{*}=50,200 ; h_{\text {IP, }, \text { IN-2 }}=1864$

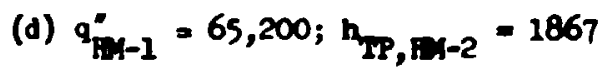

Fig. V-32. Boiling on $\mathrm{HM}-2$ at 35,000 flux in the presence of upstream bubbles. 


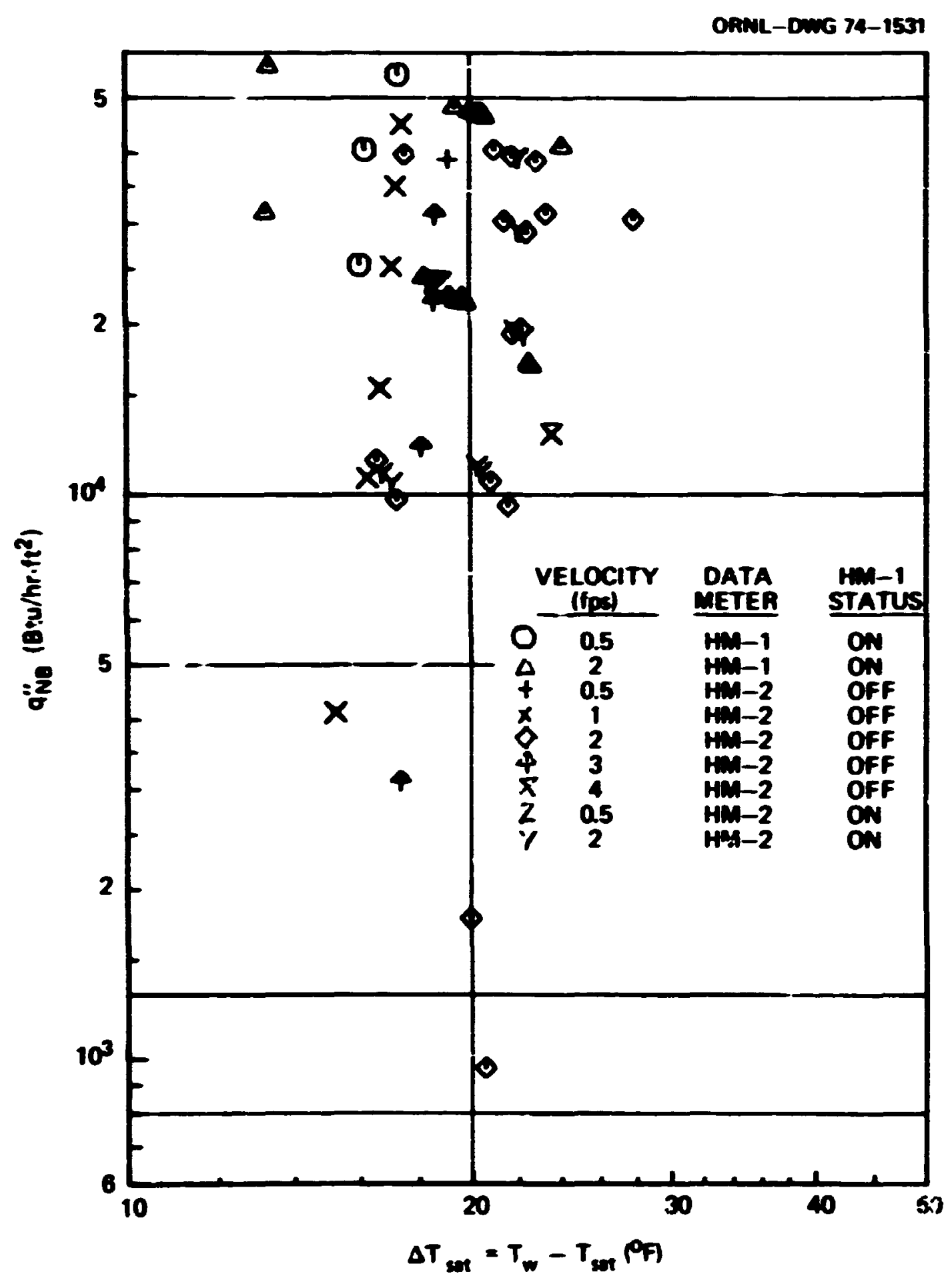

P18. V-33. Nucleate boiling heat flux contribution in water now boiling. 


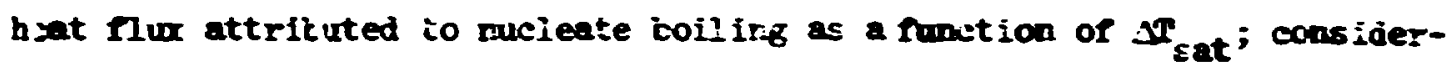
atle scatter exists in the plot, inilike tinat ottaired for Fres. (see Fig. V-22). Carenul study of the figure reveals fair sorsister.cy for

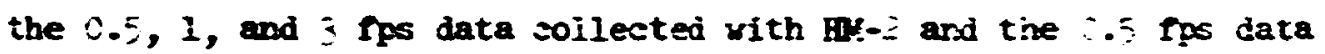

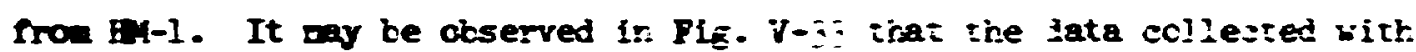
We- for $0.5,1$, and $\equiv$ fps and the. .5 fpe date troe met-i are fairis

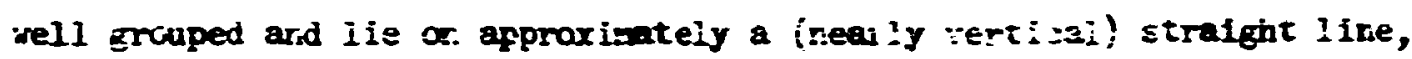
indicatirf a degree of sorreiatior: cetrees. these partivular jata. Feferecte to $P$ ig. V-2; shows that inese jate lie or soproximately the sace line in that figure, indiestire a segree of scrolatior: should te expested. Purther, refererce to the data for pool rolling of water on vertival surfaces (see Pig. V-E) shows good agreenert ketireer: the data ottained fras the two weters and a weli-defined tolifis surie. These data (Pif $\cdot V-\bar{C}$ ) did rot indicate en aging erfest and were found tc te represented rather well by the Rchsenow pocl roflinf correlatior. Thus,

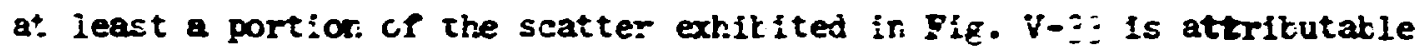
co tise lack of a good correiation (with now rate) in Figs. V-zj, and v-î, presumahly a direct resuit of agirg.

in sumary, failure of the Rohsenow additive method to correlate the water flow tciling data ariaustely is attrikuted to the oxidation of the boiling surface, more commily known as agfrg, under long-term operation. It is belfeved, based on the success of the additive technique with the Freor data and the ability of the Rohs,enow pool toiling expression to correlate ine water pooi bricing data, that the additive sechnique rould also be shown applicable to flow bolling of water provided consistent data were available. 
Systen linitations precloded ancular ifi: tests vith vater.

Careful attertior. was giver. to design, contruction asd :istration of the heat flu weters so that re: iatle data, having cot! precision and accuracy, would be obtained. As discussed in the first seetion of this shapter, the aeters perfonei exceptionsily well; the guartity of heat that passed through the test surfoce, as determined froe the cradsent (evaluated at the wail) of the lirear least-s suares egation fitted is the fire irterior tew erature beasurestents, fr. generai, anounted to $\$ C$ to $26, p$ of the mesured input at the higtier fiuxes ard 5,5 to 80, at the lover fluxes. The staniard deviation for the slope of the ritted terperature distritution ras generail; ir. the rarfe \pm 0.00 ic $0.05{ }^{\circ} \mathrm{F} / \mathrm{L}=$. for

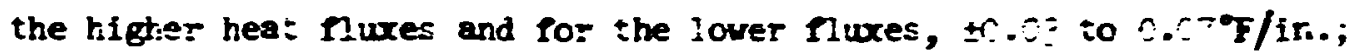

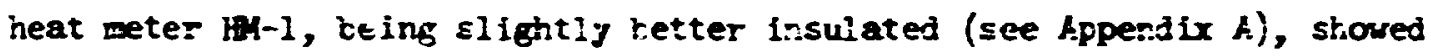
slightly loser stariard deviatiors. Si=ilarly, standari deriatiors for the kolitir: surface temperature (oitaired qlso from the fitted teaperature distributior.) were ir. the rarge \pm 0.05 to 0.050 and \pm 0.03 to $2.10 \%$ for the sigher and lower firx experiments, respectiveiy.

f.. error analysis (see Appenoix $\equiv$ ) was performed to estimate the range of the maximan percentage error expected for the seat Nux, the temperature differerce, and the heat trarsier coefricisnt for high and low fiux operation with hoth water and Fresn. The results (taiculated in Tates E-1 and E-2 of Appendix $\equiv$ ) indicate that the $\Gamma_{2}:$ r could te ir. error as much as $15.1 \%$ at the lower fluxes, decreasing to $\equiv . \%$ at the higher fluxes. Upper and lower linits of the errors ir $\Delta T_{\text {sat }}$ were est:mated to he 0.49 and $0.12^{\circ} F$, respectively, jepending on flux levei ard temperature difference. Correspondingly, errors in the soefficient could 
be 17.3 for the lower nux range, decreasing to $6.7 \%$ for the higher range. These estimates assumed aximum errors in all the pareneters occurred simultaneously and vere sucin to produce waxim errors in flux, temperature difference, and coefficient. Certainly, this is an unlikely situatior: the nost probsble erroi is expected to be lover. 
CHAPIER VI

SUMARY, CONCLUSIOKS, ADD RECOAMENDATIOAS

To well-known correlations are widely used to predict convective boiling heat transfer results: (1) the wethod of Chen based on the Zuber pool toiling expression, and (2) an additive technique suggested by Rohsenou that wakes use of the pool boiling reletion proposed alsc by hin. Since these two methods differ rather sigrificantly, this research was undertaken to obtain an internally consistent set of data from which nov boiling could be separated into its constituent pool boiling and forced-convection componer.ts and wich soulc te used to test the experimental results against the commoniy used predictive techniques. To this end pool and flos boiling tests were performed wth saturated Preori-11? and water at atwospheric pressure, using s copper tolling surface prepared by lapping with 400-grit compound. Based on the experiwental findings and study of the published literature, the following conslusions may be dram:

1. Corivective flow bolling at atmospheric pressure with saturated Freon-1ij was correlated with the Rohseriow additive method orer a mass flux range of 325,000 to $1,325,000 \mathrm{lt} / \mathrm{hr} \cdot \mathrm{ft}^{2}$ and a thermodymamic quelity range of $c$ to $8 \%\left(0 \lesssim 1 / x_{t t} \lesssim 1.06\right)$. The experimentai results were not predicted by the reiationship suggested by Chen. Failure of the iacter method was attributed primarily to the irability of the Zuber expression. to provide adequate correlation of the pool bofling resilts. A possible contrituting factor may be the fact that most of the flow bolling tests 
in this investigation were performed in the nucleate boiling region and very $\mathrm{few}$ in the suppressed nucleation region.

2. Convective flow toiling with saturated water at essentially zero percent quality, spanning a mass flux range or 106,000 to 852,000 lh/hr $\cdot f t^{2}$, was not correlated adequately by the Rohsenow additive technique, presumabiy due to excessive scatter in the data as a result of surface aying. However, the same general trends were exhibited by the water boiling data as observed for the Freon data; and the water pool boiling results were correlated reasonably well by the Rohsenow pool boiling relation. Based on these and other observations discussed, it is beilieved that the additive technique would be shom also applicable to flow bolling with water, provided consistent and reproducible data were available. Chen's sethod is not applicabie to the quailty range used (due to systen limitations) in the water flow boilini tests.

3. Too few Freon flow boiling data were coliected under suppressed rucleation conditions to attempt correlation; however, the: data were shom to be in agreement with the resuits of Pujol.

4. Tie rresence of thermally ger:erated buibles (produced $k y$ the lower heat meter) in the stream flowing past the upper test surface did not altar the lofling performarce in the "..'ly developed nucleate boiling regicn using Freon as the test fluid tat seared to degrade slightly the performance with water as the test fluid. Tn both cases, considerable enhancemert was otserved (as expected) for the convective and inciplent boiling regions. These observetions are consictent with the pool bolling results. Degradation of the bolling performance with wacer appears to be related to hublle size. Photographz of the water holling procesz ztuwed 
that as the number of bubbles in the strean increased, the numer of nucleation sites on the upper test surface decreased. It was conjectured that the free streen bubbles sweep the growing bubbles off the bolling surface before their grouth cycle is completed, thus lovering the contribution of heat rewoval by bubbie growth. Simultaneously, the free streen bubbles enhance the convective coefficient to partially compensate the loss surfered as a result of decreased (or eliminated) bubble mucleation. Since study of bubble dyranics was outside the scope of this research, sufficient information is presentiy unavailable to resolve the observation.

5. Saturated pool bolling with Preon was investigated with the same test surfaces in both inorizontal and vertical orientations; the results showed no effect of surface orfentation and were well correlated by the Roksenow relation. Linear least-squares analysis of the fully developed nucleate bolling data gave a value cf 0.00272 for the surface-fluid parameter $\left(c_{s f}\right)$ and 0.092 for the bubble Reynolds modulus exponent (r). Pubilshed valkes for pool bolling with Freen were not found for compariscn. The data were not correlated with the expassion recomended by Zuber. The bolling heat $n w x$ was determined to be proportional to $\Delta T_{\text {sat }}$ raised to the seventh to the ninth power, higher than ordinarily encountered, but consistent with the nft-referenced data of Corty. Vapor bubbles generated $n$ the lower miter asi rising by natural convection (buoyancy) past the test surface produced little, if any, effect on the uppe: meter bolling performance in the rully developed nucleate boiling region but appreciably enhanced performance in the convective and incipient boiling regions. 
6. Saturated pool boiling vith vater vas investigated also with the same test surfaces in both horizontal and vertical orientation; in contrast with the Freon results, crefficients for vertical surfaces were about 10 , greater than those observed for horizontai surfaces. This finding is in agreenent with marus' nzitis. The data vera reasonably vell correlated by the Rohsenow relationsh1.., although surface aging erfects in the horizontal pool bolling dat:s cansed some scatter. In least-squares analysis of the combinex, nilly developed mucleate boiling, data set gave a value of 0.0898 for the surface-nuid combination factor and 0.114 for the bubble Reyrolds moduius exponent; these are in good agreement with surrently recomended values for comparabie surfaces. Zuber's recommended expression failed to descrice the results. The bolling haat flux dependence on $\Delta T_{\text {sat }}$ was determined to be proportional to the 4.? to 6.1 power; this range is somewhat higher than norwally reported for very smooth surfaces but is in agreement with published data for comparable surface characteristics. Vapor bubbles buoyantly streaming past the test surface caused a slight degradation in boiling performance of the upper meter; this same effect was observed in the water flow boiling tests, in contrast with the Preon pool and flow bolling obsemations. Qualitative ciservation of kubble size indicated that the diameter of the water vapor cuttles was a factor of 2 or 3 greater than the diameter of the Freon vapor bubbles. [The Zuber pool bolling expression indicated a fuctor of 6 to $\%$.] This difference in bubble size is belleved to be related to the deleterious effect on bolling performance observed in the water tests. $\because$ Based on the above results, the Rohsenow additive technique is recomnended for use with Freon-113 under convective flcw holling conditions in the mass flux and the:modynamic quality ranges tested. Its use 
at higher mass fluxes and quallites is probably justified. Although application of the Chen correlation is scmerhat adrantageous beceuse of its direct calculational approech, chs results discussed above suggest modification is needed to provide a wre suitable meleate bolling formlation. It appears particularly appropriate to include a surface-fluid combination effect, since this paraneter has been shom by namerous inrestigators to be a significant factor in pool bolling. Another, perhaps less objectiosable, deficiency reiates to the ract that $q^{\prime}$ is proportional to approximately the second power of $\Delta r_{\text {sat }}$ in the Zuber nucleate bolling formalation, whereas experience has shown that the third to fourth powrer is more comonly observed.

8. Due to the small relative heated length $\left(L / D_{\mathrm{eq}} \approx 1.5\right)$ of the heat meters, single-phase convective heat transfer was show to be in the thermal entrance region. Measured (unenhanced) convective coefficients were in gcod agreenent with published results for sinllar heat flux weters; however, they were represented slightly better by the relation:

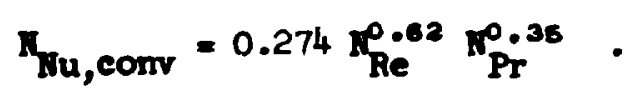

9. The surface finish produced by lapping with the 400-grit compound provided excellent nucleating characteristics. Although this was considered a necessary requisite to permit separation of nucleate boiling effects from convective heat transfer effects, in retrospect, a smoother surface would have produced pool bolling date in better agreement with the bulk of the published 1iterature. Boiling perforwance measurements Indicated the surface Iinish to be comparable to a $2 / 0$ emery polished surface. Notallographic examination completed after conclusion of the bolling tests confirmed the surface characteristics and raised the guestion that surface roughness may not be the best indicator of boiling 
performece. Micrographs obtained wth an electron scanning nicroscope showed rivid details of the bolling surface; this device an offer an inproved technique for detailed study of eavity size, shepe, and distribution. To the lnouledge of this investigator, this is the first tive the electron scanning nicroscope has been used to chnracterize bolling surfaces.

Based on the experience gained and the findings of this resenrch, ti:e following recomendations are suggested for future research:

1. Athough Chen's correlation has been recomended by a wiber of investigators as bring the best available for convective boiling, it is based strongly on a pool bolling correlation of questionable applicability. The results of this research suggest that modification should be inltiated to resolve certain inherent deficiencies.

2. The:e appears to be evidence that vater vapor bubbles in the stream flowing past the bolling test surface affect the bolling yerformance deleteriously. This investigation should be expended, perhaps in connection with the previous recomendation, since it could alter the present concepts of convective bolling.

3. It now appears posslii.e to study cavity size, shape and statistical distribution on typical bc!ling surfaces, using the electron scanning microscrope and suriace profiles obtained by ordinr ry metallographic techniques. A rundewental study of these parameters in conjunction with measured bolling performance of surfaces of specified preparation should lead to a better undersianaing of the boiling phenomena as related to surface finish. 
4. Wth regard to the equipant used and the data generated in this research, those data coliected with water as the test fluid were more scattered than desired, due to aging effects. It is believed that the nickel-plated boiling surface offers the best opporcunity for inproved date collection vith vater. An iproved flow systen, peraitting operation over a vide range of quality and incorporating techniques for ascertaining the locel rold fraction, would pernit a wore thorough evaluation of the existing correlations over the rull range of two-phase boiling conditions, or alternatively, provide definitive data on which wore realistic correlations could be based.

5. The heat flux meter used in this study has keen demonstrated to be a well developed and highly rellahle device for measuring local heat transfer coefficients. The conceptual design offers many opportunities for use in unusual situations. While this study used the same meters in both pool and How test facilities, the design was somewhat complicated by the need for interchangeability. Experience suggests the use of separate meters for the different purposes. This would lead to simplification and eliminate sowe of the bothersome detalls required for maltipurpose installations. 
1. Shiro Makijan, The Moim and Minima Values of the Beat Q Transatted fro Netal to Boiling Vter Under Atwospheric Pressure," J. Jap. Soc. Fech. Bors., 37: 367 (1934); Bnplish tranolation avallable in int. J. ist mas Irenafer, 9: 1419 (1966).

2. J. G. Collier, "A Revies of Two-Phase Beat Transer (1935-195?)," British Report AESB-CE/R-2496, 1958.

3. Novak Zuber and Erwin Fried, No-Phase Mow and Boiling Beat Transfer to Crjogenic Liquids," … Rocket Soc. J., 32: 1332 (1962).

4. J. A. R. Benpett, Mro-Phase Flow in Ges-Liquid Systew - A Literature Survey," Brit:sh Report IERE-CE/R-2497, 1958.

5. P. A. Lottes et al., Boiling Wter Reactor Technology - Status of the Art Report - Vol. I, Beat Tre csfer and Hydrwalies," usnix Report All-6561, Argonne lationai Laboretory, 1962.

6. Robert R. Kepple and Thones V. Tuns, Two-Phase (Gas-Iiquid) System: Heat Th ansfer and Eydramlics, Ar Annotated Bibliography," USABC Report Ar,-6734, Argonne lational isaborstory, 1963.

7. E. H. Burr et al., "A Bitliography on Heat Transfer and Fluid Mechanics Aspects of melear Reactors," USAEC Report WAPD-315, Vol. I, Bett is Atcaic Power Laboratory, 1967.

8. S. H. Gouse, Jr., "An Index to the Tru-Phase Gas-Liquid Flow LIterature," Part I, AD-411512 (MIT Report DSR 8734-1), 1963; Part II, AD-607180 (NII Report DSR 8734-4), 1964; and Part III, AD-630295 (MII Report DSR 8734-6), 1966.

9. G. E. Kleeman III, "Critical heat Plux in Tro-Phase Plow," PhD Thesis, University of Minnesota, 1966.

10. A. A. Kudirka, "Two-Phase Heat Transfer with Gas Injection Through a Porous Boundary Surface," USABC Report AII-6862, Argonne Tational Laboratory, 1964.

11. F. 0. Mixon et al., "The Effect of Electrolytic Gac Evolution on Heat Transfer," Chem. Eng. Prosr., 55: 49 (1953).

12. Warren M. Rohsenow, "Heat Transfer with Evaporation," in Proceedings of 1952 Heat Transfer Sycjposium at the University of Michigan, 1953.

12. J. A. R. Bennett et al., "Heat Transfer to Two-Phase Ges-Iiquid Systems," British Report AEPS-R-3159, 1959.

14. Carl Eugene Dengler, "Heat Transfer and Pressure Drop for Evaporation of Water in a Vertical Tube," PhD Thesis, Massachusetts Institute of Technology, 1952. 
BLANK PAGE 
15. C. B. Dengler and J. M. Addons, "Teat Transfer Nechaniso for Vaporization of water in Vertical Tubes," Chea. Bag. Progr. SLposive Series, 52: 95 (1956).

16. S. A. Guerrieri and R. D. Talty, "A Study of Heat Transfer to Organic Liquids in Sirgle Tube, Natural circulation, Vertical Tube Bollers," Chea. Eng. Progr. Sylposion Series, 52: 69 (1956).

17. J. G. Collier and D. J. Pulling, "Heat Transfer to Two-Phase casLiquid Systems - Part II. Purther Data on Steed/Water Mixtures in the Liquid Dispersed Region in an Anmalus," British Report AERB-R-3809, 1962.

18. V. E. Schrock and L. M. Grossman, Foreed Convection Boiling in Tubes," nucl. Sc1. Bag., 12: 474 (1962).

19. J. F. Mun, "Heat Transfer to Boiling Water Foreed Through a Uniforvily Heated Tube," USABC Report AL-5276, Argonne Rational Laborat ory, 19:4.

20. R. L. Sani, "Downflor Bolling and Fonbolling Heat Transier in a Uniformly Beated Tube," UCRL-9023, University of Calffors.a Radiation Laboratory, 1960.

21. R. M. Wright, Downflow Forced Convection Bolling of water in Uniformly Heated Tubes," UCRL-9744, University of California Radiation Laboratory, 1961.

22. G. F. Scmerville, "Downflow Bolling of n-Butanol in a Unifornly Heated Tube," UCRL-1C527, University of Callfornia Radiation Laboratory, 1962.

23. L. Pujol and A. H. Stenning, "Brfect of Flow Direction on the Boiling Heat Transfer Coefficient in Vertical Tubes," Symposiu Series of Can. Soc. Chem. Eng., 10. 1, 1968.

24. John C. Chen, "Correlation for Boiling Heat Transfer to Saturated Fluids in Convective Flow," Ind. Eng. Ches. Proc. Des. Dev., 5: $322(1966)$.

25. Takashi Sato et al., "Study of Heat Transfer in Bolling Two-Phase Channel Far = Part I: Fow Patterns in a Bolling Channel, and Part II: Heat I insfer in the lucleate Boiling Region," Beat Transfer - Japanese Research, 1: 1 and 15 (1972).

26. P. A. Andreyev et al., Porced Convecticn Heat Transfer to Bolling Hater in P1pes and Channels," Beat Transfer - Boviet Research, 1: 22 (1969).

27. R. W. Lockhart and R. C. Martine111, Proposed Correlation of Data for Isothermal Two-Phase, Two-Component How in Pipes," Chem. Ens Progr., 45: $39^{\text {'(1949). }}$ 
28. W. F. Davidson et al., "Studies of Heat Transnission Through Boiler Tubing at Pressures from 500 to 3300 Pounds," Trans. Asez, 65: 553 (1943).

29. L. S. Tong, Boiling Heat Transfer and Two Phase Plow, John Wiley and Sons, Inc., Mer York, 1966.

3'). G. F. Hewitt and K. S. Ball-Taylor, Anmular Two-Phase Flor, Pergamon Press, Oxford, 1970.

31. John G. Colıler and Graham B. Wallis, Two-Phase Flow and Heat Tr asfer Notes, Stanford University Press, Stanford, California, 1967.

32. W. M. Rohsenow, "A Hethod of Correlating Heat Transfer Data for Surface Boiling of Liquids," Trans. ASire, 74: 969 (1952).

33. R. I. Vachon et al., "Evaluation of Constants for the Rohsenou Pool Bolling Correlation," J. Heat Transfer, 90: 239 (1968).

34. W. M. Rohsanow, "Some Recent Results in Boiling and Condensing Research," in Proceedings of Second Southeastern Seminar on Thermal sciences, July 25-26, 1966, Oak Ridge, Tennessee, USAEC Report CRIL-TI-1975, Oak Ridge lational Laboratory, 1967.

35. G. F. Hewitt, "Analys is of Anmular Two-Phase Plow: Application of the Dukler Analysis to Vertical Upwara Flow in a Tube," British Report AFRE-R-3680, 1061 .

36. Y. Y. Bsu, "On the Size Range of Active Mucleation Cevities on a Heating surface," J. Heat Transfer, 84: 207 (1962).

37. H. R. Gambill, "Generalized Prediction of Burnout Heat Flux for Flowing Subcooled Wetting Iiquids," Chem. Eng. Progr. Symposium Series, 59: 71 (1963).

38. H. K. Forster and H. Zuker, "Dynamics of Vapor Bubbles and Bolling Heat Transfer," AIChE J., 1: 531 (1955).

39. L. S. Tong, "Heat Transfer Mechanisms in Mucleate and Pilm Boilin3", macl. Eng. Design, 21: 1 (1972).

40. G. A. Bughwark, "Designing Therwosiphon Reboilers," Chea. Eng. Proge., 65: 67 (1969).

41. I. R. Juloor and V. I. Radhakrishnan, "Effect of Surface Roughness on Mucleate Bolling," Chem. Proc. Eng., 47: 276 (1966).

42. Cleude Corty and Nan 8. Poust, "Surface Variables in Mucieate Bollirg," Chem. Eng. Prorr. Bymposi im series, 51: 1 (1955).

43. P. J. Berenoon, "Bxperimedt on Pool Pu1ling Heat Transfer," Int. J. Heat vase Transfer, 5: 985 (1962). 
44. David I. Lyon, Peak Mucleate Bolling Heat Fluxes and llucleate Boiling Heat Transfer Coefficients for Liquid $\mathrm{H}_{\mathrm{a}}$, Liquid $\mathrm{O}_{2}$, and their Mixtures in Pool Boiling at Atmospheric Pressure," Int. J. Heat yass Transfer, 7: 1097 (1964).

45. P. G. Kosky and D. K. Lyon, "Pool Boiling Heet Transfer to Cryogenic Liquids; 1 . Mucleate Regime Data and a Test of Some Pucleate Bolling Correlations," AIChE J., 14: 372 (1968).

46. P. Rice and H. F. Calus, "Pool Boiling - Single Component Liquids," Chem. Eng. Sc1., 27: 1677 (1972).

47. James R. Stone, "Subcooled-and Net-Boiling Heat Transfer to LowPressure Hater in Electrically Beated Tubes," MASA-TM-D-5402, Lewis Research Center, Cleveland, Ohio, $19 i 1$.

48. Ali Orhadi et al., "Torced Convection Boiling Inside Yelically c :led Tibes," Int. J. Heat Mass Transfer, 11: 1779 (j.968).

49. Luis Pujol, "Bolling Heat Transfer in Vertical Upflo. and Downflor Tubes," PhD Thesis, Lehigh University, 1968.

50. Edgar L. Pilec anä H. S. Isbin, "Tatural Circulecion Evaporation; Two-P'aase Heat Transfer," Chem. Eng. Progr., 50: 305 (1954).

51. P. R. Beaver and G. A. Hughwark, "Heat Transfer Coefficients and Circulation Rates for Thermos iphon Rebofiers," AIChE J., 14: 746 (1968).

52. T. A. Blatt and R. R. Adt, Jr., "An Experimental Investigation of Boiling Heat Tranefer and Pressure Drop Characteristics of Freon-11 and Freon-113 Refrigerants," AIChE J., 10: 369 (1964).

53. Professor Takashi Sato, Faculty of Engineering, Kyoto University, Kyoto, Japan, personal comminication to R. H. Chapman, Oak Ridge Rational Laboratory, June 1973.

54. S. S. Kutateladze, "Boiling Heat Transfer," Int. J. Heat Mass Transfer, 4: 31 (19ól).

55. I. V. Domanskil, "Heat Thansfer in Fucleate Boiling of a Freely Palling Liquid P1lm," Inzhenerno-fizicheski zhurnal, 21: 368 (1971); unpiblished English translation by J. Lewin, Dak Ridge Rational Iabc:atory, 1972.

56. J. M. Chawla, "Correlation of Convective Heat Transfer Coefficient Por Tro-Phase Liquid-Vapour Flow," Paper B5.7 in Heat Transfer 3970, Vol. v, Ulrich Grigull and Erich Hahne, Eds., Elsevier Pubishing Company, Amsterdam, 1970. 
57. Jogindar Whan Chawla, Mirmeibergang und Druckell in Vangerechter Rohren bel der Ströming von Verder pfenden filtenitteln," IDIPorschungsheft, 523: 5 (1967); usABC Translat ion 0all-Tr-2695, onk Ridge iational Laboratory, 1973.

58. Jogindar Mohan Chaula, "Reibungsaruckebrall bel der Strönung voa Pisssigkeits-Gas-Gemischen in Wagerechten Rohren," Porsch. Ins.Wes., 34: 47 (1968); USADC Trenslation CRLL-Tr-2696, Oat Ridge Wat Ional Iaboratory, 1973.

59. J. M. Charla, Müssigkeitsiobalt in Rohren fïr Füssigkeits-rasGewische bei der Zweiphasenströiang," Chene. Ing. Techn., 41: 328 (1969); USABC Trans?at ion CRIL-Tr-2697, Oal Ridge Tational Laboratory, 1973.

60. T. O. Penan and R. W. P. Tait, "Heat Transfer in Liguid Ful = Flow," Ind. Eng. Chem. Fund., 4: 407 (1965).

61. J. Gerard Lavin and Bdwin H. Young, "Heat Transfer to Braporating Refrigerants in Two-Phere Flow," AIChE J., 11: 1124 (1965).

62. Novak Zuber, "Recent Trends in Bojling Heat Transfer Research Part 1: Mucleate Ponl Boiling," Appl1. Nech. Ret., 17: 663 (1964).

63. S. S. Kutateladze, "Heat Trawsier in Cordensation and Boiling," 2nd ed., Mashgiz, Moscow, 1952; ISABC Translation 3770, Technical Information Service, Oak Rićge, Tennessee, $196:$.

64. Yan-Po Chang and I. W. Snyder, "Heat Irar' fer in Saturated Boiling;" Chere. Eng. Prorr. Sroosion Series, 56: 25 (1960).

65. S. Levy, "Generalized Correlation of Bolling Heat Transfer," J. Heat Transfer, 81: 37 (1959).

66. C. H. Gilmour, "Mucleate Boiling - A Correlation," Ches. Eng. Progs., 54: 77 (1958).

6́ . M. J. McNelly, "A Correlation of the Rates of Heat Transer to Nucleate Boiling Liquids," J. Inp. Coll. Che. Eng. soc., 7: 18 (1953).

68. H. K. Porster and R. Greif, "Heat Tranefer to a Bolling I1quid -Wechanism anci Correlations," J. Heat Transfer, 81: 43 (1959).

69. K. Nishikawa and K. Yemagata, "On the Correlation of Fucleate Bolling Heat Pransfer," Int. J. Beat kass Pranefer, 1: 219 (1960).

70. H. M. Kurihara and J. E. Myers, "The Effects of Buperhear and Surface Roughness on Bolling Coefficients," AIChE J., 6: 83 (1960).

71. C. I. Tien, "A Hyurodynmic Model for Mucleate Pool Bolling," Int. J. Heat Yass Transfer, 5: 533 (1962). 
72. T. Bara, The flechanisen or kncleate Bolling Heat Transfer," Int. J. Beat pass iranser, 6: 959 (1953).

73. Fovak Zuber, Tucleate Bolling - The Region of Isolated Bubbles and the Sidilarity with Iatural Conrection," Int. J. Heat Hess Transfer, 6: 53 (1963).

74. Chi-Teh Ban ard Peter Griffith, The Mechanion of Heat Transfer in Ducleate Pool Bolling - Part I. Bubble Inftiation, Grorth and Departure; Part II. The Heat Mux-Temperature Difference Relation," Int. J. Heat yass Transfer, 8: 887 and 905 (1965).

75. B. B. Kilfic and W. M. Rohsenor, "A Hew Correlation of Pool Bolling Date Including the Bffect of Heating Surface Charaiteristics," J. Heat Transer, 91: 245 (1969).

75. J. J. Lorenz, B. B. Mikic, and U. H. Rohsenow, "The Erfests of Surface Conditions on Bot ing Mtaracteristics," MIT Report DSR73413-79, =s8achussets Institnie of Technolc8y, 19?2.

77. V. M. Borishanikil, G. I. Bobrovich, and F. P. Minchenko, "Hsat Transfer fron a 'iube to Water and to Ethanol in Mucleate Ponl Bolling," in A Syuposium on Problems of Heat Transper and Hydremulics of Mro-Phase Fedia, S. S. Kutateladze, Ed., Pergamon Press, Oxford, 1969.

78. I. V. Domansty, "Seniepirical Hethod for solving Nucleate Boliing Heat Transfer Froblem," Heat Transfer - Sovlet Research, 3: 52 (1971).

79. Terubatsu Miyeuchi and Morihide Yolura, "Ihe Mechanism of Iucleate Bolling Heat Transfer," Heat Transfer - Japanese Research, 1: 109 (1972).

80. S. J. D. van Stralen, The Nechanise of Jucleate Boiling in Pure Liguids and in Binary Mixtures - Parts I, II, III, and IV. Surface Bolling," Int. J. Heat yass Transfer, 9: 995 and 1 vel (1966), 10: 1469 and $1485(1367)$.

81. Walter Tarleton Frown, Jr., "A Study of Flow surface bulling," PhD Thes 18, Masachussetts Institute of Technology, 1967.

82. C. W. Frost and K. W. II, "On the Rohsenor Pool Bolling Correlation," J. Heat Transier, 93.232 (1971).

83. W. ห. Rohsenur, "On the Rohsenow Pwo Bolling Correlation," J. Heat Transfer, 94: 255 (1972).

84. R. Nagarajan and Maurise Alelman, "An Experimental Investigation of the Influence of the Grain size of the Metal surface on Pool Boiling Heat Transfer," Can. J. Chew. Eng., 48: 39 (1970). 
85. H. B. Clark, P. H. Strenge, and J. U. Westwater, "Active sites for Mucleate Boiling," Chem. Bng. Progr. Syeposiun Series, 55: 103 (1959).

86. P. Griffith and J. D. Wallis, The Role of Surface Conditions in mucleate Boiling," Chem. Bng. Progr. Sycoosiun Series, 56: 49 (1960).

87. L. M. Jiji and J. A. Clark, "Bubble Boundary Layer and Teaperature Profiles for Forced Convection Boiling in C'sannel Flow," J. Heet Transfer, 86: 50 (1964).

88. B. D. Marcus and D. Dropkin, Measured Temperature Profiles Within the Superheated Bourdary Layer Above a Horizontal Surface in Saturated Tucleate Pool Boiling of Water," J. Heat Transfer, 87: 333 (1965).

89. Robert H. Bobst and C. Philip Colver, "Temperature Profiles up to Burnout Adjacent to a Horizontal Heat ing Surface in Nucieate Pool Boiling Water," Chen. Eng. Progr. Symposium Series, 64: 26 (1970).

90. Warteב M. Rohsenow, "Tucleation with Boiling Heat Transfer," ASTE Paper 70-Brl-18, Bngintering, Heat Transfer, and Lubrication ConSerence, Detroit, Mcbigan, 1970.

91. Y. Y. Hsu and R. H. Graham, "An Analytical and Experimental Study of the Thermal Bountary Layer and the Ebullition Cycle in Furlea: ? Bolling," MASA Report TW-D-594, Lewis Research Center, Cleveland, Ohio, 1961.

92. R. F. Geertner, "Photographic Study of fucleate Pool Bolling on a Horizontal Surface," J. Heat Transfer, 87:17 (1965).

93. C. J. Rallis and H. H. Janurek, "Latent Heat Trarisport in Saturated Nucleate Bolling," Int. J. Heat Mass Transfer, 7: 1051 (1964).

94. I. Marót1, "Pool Boiling Heat Transfer," Hungarian Report KTKI$73-11,1973$.

95. S. G. Bankoif, "On the Mechanism of Subcooled Hucleate Bo: Iing," Chem. Eng. Progr. Symposium Series, 57: 156 (1961).

96. R. F. Boehm and J. H. Ilenhard, Mransient Effects in Tien's Mucleate Bolling Nodel, ASME Paper 64-WA/HT-34, 1964.

97. H. H. Snyder and D. K. Edwards, "Post Conference Comments: Summary of Conference on Bubble Dynamics and Bolling Heat Transfer, "Jet Propulsion Laboratory Mewo 20-137, 1956.

S.8. Franklin D. Noore and Russel B. Mes].er, "The Measurement of Rapid Surface Temperature Fluctuations During Fucleate Bolling of Water," AIChR J., 7: 620 (1961). 
99. L. A. Bule, "Surface Teperature Fluctuation in Pool Bniling of Refrigerant 11," 1553 Paper 67-12-68, 1367.

100. Richard S. Dougall and Thons B. Lippert, "An Investigation into the Role of Thernal Fluctuntions on Bubble Nucleation in Pool Boiling," ASr Paper 67-W//Er-31, 1967.

101. H. B. Hospeti and R. B. Mesler, Vaporization at the Base of Butbles of Difierent Shape During kucleate Boiling of Water," AIChE J., 15: 214 (1969).

102. Robert B. Roener, "Surface Teperature Fluctuntion During Steedy State Boiling," Int. J. Heet mass Transfer, 13: 985 (1970).

103. Robert B. Sharp, The Nature of Liquid PIl E Braporation Daring Hucleate Boiling," IASA Report TI-D-1997, Lewis Research Center, Cleveland, Onio, 1964.

104. R. C. Hendricks and R. B. Sharp, "Initiation of Cooling due to Bubble Growth on a Heating Surface," IASA Report IT-D-2290, Lewis Research Center, Cleveland, Onio, 1964.

105. M. G. Cooper and A. J. P. Lloyd, "The Merolayer in Mucleate itool Bolling," Int. J. Heat Mass Transfer, 12: 895 (1969).

106. G. S. Dzakowic and W. Frost, Yapor Bubble Grorth in Saturated Pool Bofling by Microlayer Eiqporecion of Liquid at the Heated Surface," Paper B2.2. In Heat Transfer i070, Vol. V, Ulrich Grigull and Erich Hahne, Eds., Elsevier Publishing Company, Ansterdam, 1970 .

107. C. S. M. Marangoni, Muovo Cimento, Seri=s 2.156, 239-273, 1872.

108. M. Behar et al., "Fundamental Aspects of subcooled Boiling with and without $\overline{D i s s o l v e d ~ G a s e s, " ~ P p . ~ 1-11 ~ i n ~ P r o c e e d i n g s ~ o f ~ t h e ~ T h i r d ~}$ AIChE-ASME International Heat Transfer Conference, V01. IV, 1966.

109. B. D. Marcus, "Experiment.s on the Mechanism of Saturated Nucleate Pool Boiling Heat Transfer," PhD mesis, Cornell University, 1963.

110. R. F. Gaertner and J. W. Westwater, "Pcpulation of Active Sites in Mucleate Boiling Heat Trans:er," Chem. Eng. Progr. Symposium Series, 56: 39 (1960).

1i1. N. Koutmoutsos, R. Moissi, and A. Spyridonos, "A Study of Bubble Departure in Forsed Convection Boliing," J. Heat Transfer, 90: 223 (1968).

112. M. T. Cichelli and U. F. Bonilla, "Heat Transfer to Liquids Bolling under Pressure," Trans. Am. Inst. Chem. Engrs., 41: 155 (1945). 
113. R. L. Jodd and H. Merte, Jr., Braluation of Dncleate Boiling Beat Flux Prediction at Varying Ievels of subcooling and Acceleration," Int. J. Beat mas Trensfer, 15: 1075 (1972).

114. D. B. R. Kenning and Y. S. Kao, Convective Heat Transfer to Water Containing Bubbles: Bnhancenent not Dependent on Therwocapillarity," Int. J. Heat Mess Trensfer, 15: 1709 (1972).

115. Y. S. Koo and D. B. R. Kennipg, Therwoeapillary Flour near a Hemispherical Bubble on a Beated Wall," J. Muid Hech., 53: 75 (1972).

116. Bert K. Larkin, Thermocepillary Flow Around Henisphericai Bubble," AIChE J., 16: 10I (1970).

117. P. J. Marto, J. A. Moulson, and H. D. Mannard, Mucleate Pool Bofling of Hitrogen with Different Surface Conditions," J. Heet Transfer, 90: 437 (1968).

118. Duane Stewart Duncan, Jr., "Watural Convection Heat Transfer from a Horizontal Disk in a Cylindrical Exclosure," M.S. Thesis, Haval Postgraduate School, 1971.

119. Donal 1 Kenneth Makenzie, "Vaporization of Thin Liquid Pilmo," M.S. Thes is, Maval Postgraduate School, 1972.

120. D. M. Fontana, "Simultaneous Neasurement of Bubble Growth Rate and Therwal Flux from the Heating Wall to the Bolling Fluid near the Fucleation Site," Int. J. Heat Mass Transfer, 15: 707 (1972).

121. Robert L. Powell et al., "Thermocouple Reference Tables Based on the IPIS-68," Rat Ional Bureau of Staudards Monograph 125, 1972.

122. D. L. MeElroy ard R. K. Williams, Oak Ridge Kational Laboratory, personal comminication to R. H. Chapman, Oak Ridge Kational Laboratory, March and June 1973.

123. J. P. Moore, D. L. McElroy, and R. S. Graves, MThermal Conductivity and Electrical Resistivity of High-Purity Copper from 78 to $400^{\circ} \mathrm{K}$," Canadian J. of Phys., 45: 3849 (1967).

124. Ramanathan Nagarajan, "An Experimental Investigation of the InPlience of the Surface Grain size of the Metal on the value of $\mathrm{C}_{\mathrm{GP}}$ in the Rohsenow Equation for Bofling Heat Transfer," PhD Thesis, University of Hindsor, 1968.

125. Claude Corty, "Surface Variables in Boiling," PhD Thesis, University of Michigan, 1951 .

126. W. D. Turner and J. S. Crovell, Wotes on HEATIIG - an IBM-360 Heat Conduction Program," USADC Report CTC-IIP-980 and Addendum 1, Computing Technology Center, Dak Ridge, Tennessee, 1969. 
127. W. D. Turner and M. Siman-Tov, MRATI 3 - an IEY-360 Heat Conduction Code," USADC Report CRIL-TH-3208, Oak Ridge Fational Laboratory, 197 .

128. R. W. Murphy and A. E. Bergles, Mubcooled Fion Boiling if Fluorocarbons," MIT Report DSR 71903-72, 1971.

129. M. Feliciano et al., Mak Ridge Deta Evaluation and Analysis Language," USABC Report Ciall-4506, Oak Ridge Fational Laboratory, 1970.

130. H. M. Hochreiter, "Dimensionless Correlation of Coefficients of Turbine-Type Flowmeters," Trans. AST, 80: 1363 (1958).

131. H. M. Kurihara, Tundanental Factors Affecting Boiling Coefficients," PhD Thes is, Purdue University, 1956.

132. Novak Zuber, "On the Stability of Boiling Heat Transfer," and Discussion by M. H. Rohsenow et al., Trans. Asy, 80: 711 (1956).

133. P. H. Abbrecht and S. H. Churchill, "The Thermal Entrance Region in Fully Developed Turbulent Flow," AIChR J., 6: 268 (1960).

134. D. M. Eissenberg et al., "Ine Prandt Number Dependense of the Convective Heat Transfer Coefficient in a Turbulent Therwal Entrance Region," AIChE J., 19: 393 (1973).

135. "Thermodyriemic Properties of Freon-115," I. E. Dupont de Nemours and Company, Technical Bülletin T-113A (1938).

136. R. C. Downing, I. E. Dupont de Hemours and Company, personal communication to R. H. Chapman, Oak Ridge National Laboratory, June 1973.

137. Ye. N. Sinitsyn et al., "The SurPace Tension of $F-11,21$ and 113," Hea.t Transfer-foviet Research, 4: 79 (1972). 
181

APPENDDDES 


\section{AFFiDI A}

\section{chlnarion Dara}

\section{A-1. Current Mensurin Shonts}

Calibration of the 0 to $100 \mathrm{w}$ shunts used to measure carrent to the heat flux weters was performed in the I-12 Plant Standards Iaboratory. The shunts vere combected to a standard test conole, and the de current ves set to knom $( \pm 0.5 \%)$ vines. A difital voltweter (certified for accuracy) was used to indiciate the potential across the shunt. The data for shunt 10. 1 are shown in P18. A-1 and were fitted, using a least-squares routine, to the equation:

$$
I=0.097624 \mathrm{E},
$$

with a standard deviation of 0.00475 aperes.

Simflarly, the data for shust Ho. 2, shown in Pig. A-2, were fitted to the equation:

$$
I=0.099759 \mathrm{E} \text {, }
$$

with a standard deviation of 0.00377 amperes. In spite ct the good fit obtained, the accuracy of the fitted equations can be no better than that for the input current. Thus, the accuracy on current was taken as 10.54. These equations were used to compute the heater current from the measured voltage drop across the calibrated shunts.

The DARA Model 4800 digital voltmeter used to measure (to the nearest $10 \mu \mathrm{V}$ ) the voltage drop across the meter heaters and the calibrated shunts was certified to conform to the manufacturer's specifications $[ \pm(0.0054$ of the reading +0.005 , of cull scale $)$ on $a$ ?. Five voltage 
BLANK PAGE 


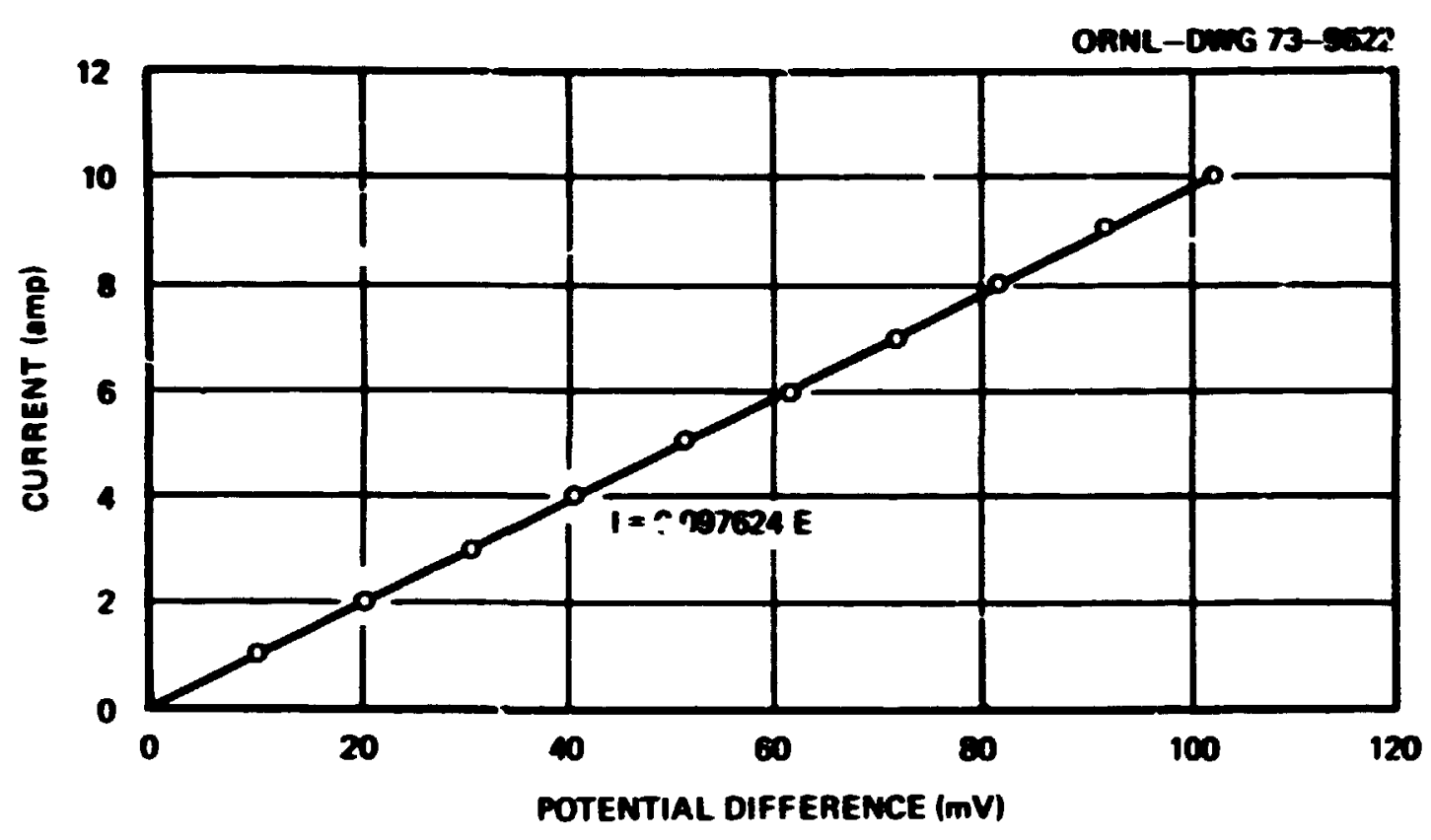

Fig. A-1. Shant No. 1 calibration.

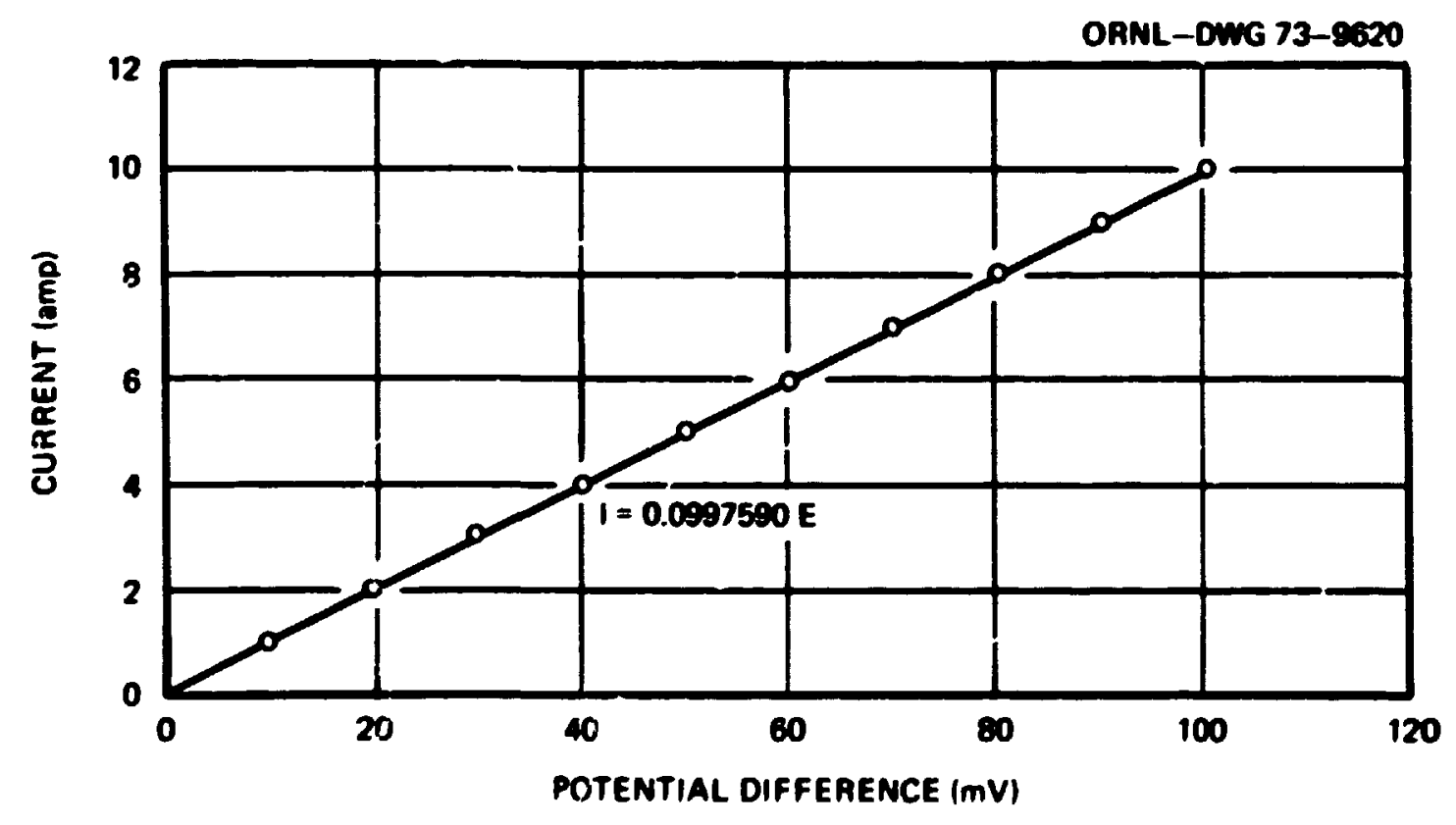

Fig. A-ż. Shunt No. 2 callibration. 


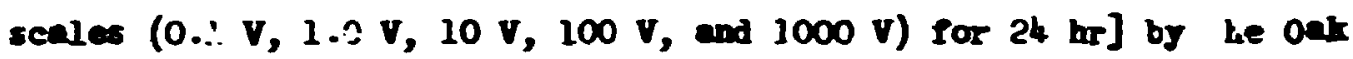
Ridge Eationel Iaboratory Instrument Standards Iaboratory.

\section{A-2. Calibration of Turbine Flaneters}

Two turbice floneters, installed in a parallel flow path configuration, were used to neasuze the flow rate throusth the test chamel. An In-Val-Co, Mode: W3/75C, meter (nominal frequency renge of 100 to $1000 \mathrm{H} 2$ ) was used for the lower range of flcirs, and a Model W/ino (noninal frequency range of 100 to $1000 \mathrm{~Hz}$ ) was usea for the higher flow range. Manufacturer's data indicate 50\% overranging is acceptable. They were installed in vertical sections of pipe vith 20 pipe diameters of straight pipe upstrean to smooth the velocity profile entering the meters. The meters vere guaranteed by the mampacturer to be sccurate within $\pm 0.5 \%$ in the "linear" flow range with $\pm 0.1 \%$ repeatability. Since the meters had experiessed considerable use prifur to this research, they were refurbished and recalibrated, using a weigh tank system ( $\pm 0.5 \%$ accuracy) with the upstream and downstream piping attached. In this manner, the effects of the piping was included in the calibration.

Turbine meters measure velocity rather than mass nlow. The output signal (roltage pulses) is proportional to flow velocity regardless of fluid, and for a given weter this proportionality is expressed as $\mathrm{K}_{0}$ in pulses/gal. The coefficient wast be determined by calibration. The data are usually plotted as $K_{0}$ in pulses/gal versus the logarithm of the ratio of measured frequency in Hertz to the viscosity in centistokes. Plotted this way the coefficient is universal (with respect to fluid) over the "linear" range. The "Iinear" range is defined as that range 
over utich the mensured curve can be represented ( $\pm 0.5 \%$ ) by a constant value of $\mathrm{K}_{0}$. For grenter eccurecy, one can we the plotted curve to detenine $K_{0}$ at the appropriate value of $\mathrm{f} / \mathrm{v}$. Fitting the calibration curve with a suitable function facilitate date redection by conputer. This approach wes followed in this research.

The calibrations vere perforned with water at $52 \%(v=1.239 \mathrm{cst})$. The reduced dxta were fitted with linear nuction, using a least-sguares routine. Figure A-3 shows the calibration data for the $13 / 1000$ neter, plotted on rectangular coordinates. For the "Iinear" range deternined in this investigation, $150 \leq f / v \leq 600$ (210 $\leq f \leq 765)$, the data fit the equation:

$$
K_{0}=912.855-0.00978185 \mathrm{r} / \mathrm{v} \text {, }
$$

wth a standard deviation of $1.282 \mathrm{pulses} / \mathrm{gal}$. Since the frequency covered by the calibration is less than the nominal maximin guaranteed by the eamufactuer $\left(765 \mathrm{vs} 1000 \mathrm{~Hz}\right.$ ) and since the value of $\mathrm{K}_{0}$ is nearly independent of $\mathrm{f} / \mathrm{v}$ over the "IInear" range, it was assumed that $\mathrm{Bq} .(\mathrm{A}-\mathrm{B})$ was applicable over the full range of frequencies. This is consistent with the wamfacturer's data furnished with the weter.

Pigure A-4 is a similar plot for the W3/750 neter. The "linear" range for this meter was determined from calibration data to be $120 \leqslant f / v \leq 1265(150 \leq f \leq 1600)$. The data were fitted over the range $120 \leq \mathrm{f} / \mathrm{v} \leqslant 485$ with the equation:

$$
x_{0}=4650.33-0.179528 \mathrm{r} / \mathrm{v},
$$

with a standard deviation of $10.79 \mathrm{pulses} / \mathrm{gal}$, and for the range 


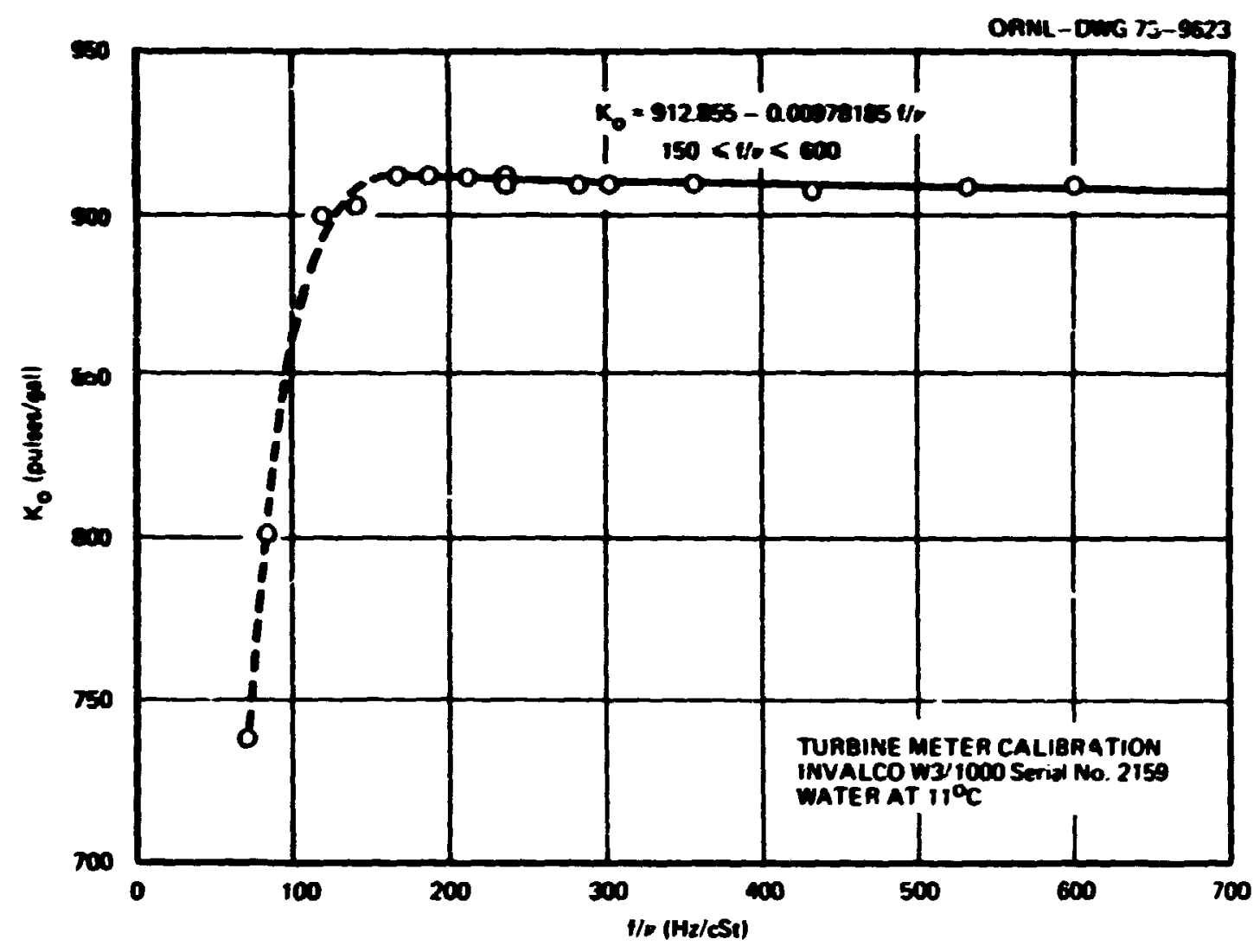

Fig. A-3. Calibration data for plowmeter F-1.

$485 \leq \mathrm{f} / \mathrm{v} \leq 1265$ with the equation:

$$
K_{0}=4576.40-0.0258513 \mathrm{f} / \mathrm{v},
$$

with a standard deviation of $7.40 \mathrm{pulses} / \mathrm{gal}$. The frequency range covered in this salibration confirmed the manufacturer's data that the meter is "Iinear" over the nominal frequency range $(100 \mathrm{i} ; 1000 \mathrm{~Hz})$. In fact, it was demonstrated to be "linear" at $60 \%$ overrange.

In order to use the above equations at temperatures other than that at wich the calibration is made, the viscosity (in centistckes) at the temperature of the fluid wast be used to form the frequency-to-viscosity ratio. This autcmatically corrects for drag effects in the meter. A 


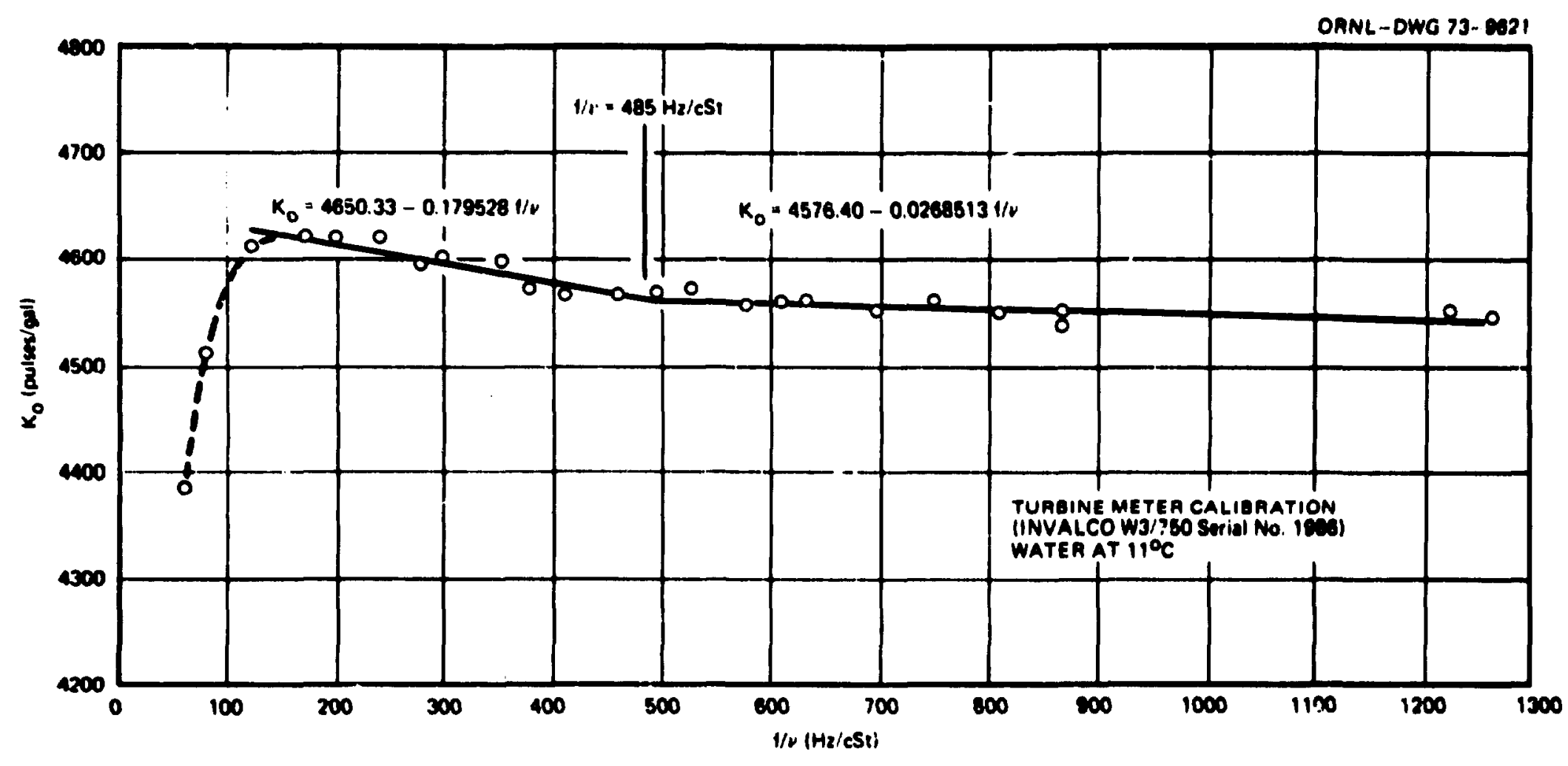

Fig. A-4. Calibration data for flowmeter F-2. 
geosetric correction wust be made also to account for the thermal expansion of the weter housing. This is simply a volunetric correction ${ }^{200}$ and is given as:

$$
F_{T}=\frac{1}{1+3 \alpha\left(T-T_{0}\right)}
$$

Substituting the appropriate values. Eq. (A-6) becomes for the temperature range $52 \leq \mathrm{T} \leq 300^{\circ} \mathrm{T}$ :

$$
F_{\mathrm{T}}=\frac{1}{1+2.48: 6 \times 2 n^{-5}(2-52)} \text {. }
$$

Using this correstion, the oppropriate turbine meter coefficient at operating temperature is given as:

$$
\mathbf{K}_{\mathbf{T}}=\mathbf{F}_{\mathbf{T}} \mathbf{K}_{\mathrm{O}}
$$

where $K_{0}$ is obtained from $E q .(A-3),(A-4)$, or $(A-5)$, using the temperature-corrected $v\{s \cos i t y$ in the $f / v$ rat:o. An accuracy of 0.58 was assigned to the meters.

\section{A-3. Thermocouple Calibrat ions}

The thermocouples used for data analysts vere caltbrated, using standard techniques, by the Cak Ridge National Laboraciory's Instrument Standards Laboratory. All 18 thermocouples (6 each installed in the finished heat flux meters and 6 individual thermocouples for use in various loop locations) were cal fbrated simultaneously against a reperence standard traceable to the National Bureau of Standards. The entire circuit (i.e., thermocouple, ice-point reference junction, switches, and leags up to the potentiometer) were included in the calibration. The daia are tabulated in Tables A-1, A-2, and A-3. Column 1 
TABTE A-]

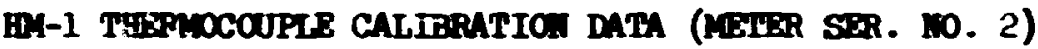

\begin{tabular}{|c|c|c|c|c|c|}
\hline $\begin{array}{l}\text { TC } \\
\text { Ho. }\end{array}$ & $\begin{array}{l}\text { Meter } \\
\text { Position }\end{array}$ & $\begin{array}{c}\text { Actual } \\
\text { Temperature } \\
(\top)^{\mathrm{a}}\end{array}$ & $\begin{array}{c}\text { 'bulated } \\
\text { EF } \\
\text { (IN) }\end{array}$ & $\begin{array}{l}\text { Measured } \\
\text { ERF } \\
\text { (MV) }\end{array}$ & $\begin{array}{l}\text { Er? } \\
\text { Brror } \\
\text { (MV) }\end{array}$ \\
\hline 7 & $T C-1$ & $\begin{array}{r}99.0061 \\
149.7695 \\
200.8239 \\
251.3638 \\
301.9554\end{array}$ & $\begin{array}{l}1.497807 \\
2.660598 \\
3.838130 \\
4.995476 \\
6.136223\end{array}$ & $\begin{array}{l}1.4948 \\
2.6700 \\
3.8657 \\
5.0426 \\
6.2018\end{array}$ & $\begin{array}{r}0.003007 \\
-0.009402 \\
-0.087570 \\
-0.047124 \\
-0.065577\end{array}$ \\
\hline 8 & TC-2 & $\begin{array}{r}99.006 i \\
149.7695 \\
200.8239 \\
251.3638 \\
301.9554\end{array}$ & $\begin{array}{l}1.497807 \\
2.660598 \\
3.838130 \\
4.995476 \\
0.136223\end{array}$ & $\begin{array}{l}1.4952 \\
2.6694 \\
3.8636 \\
5.0406 \\
6.1985\end{array}$ & $\begin{array}{r}0.002607 \\
-0.008802 \\
-0.025470 \\
-0.045124 \\
-0.062277\end{array}$ \\
\hline 9 & $T C-3$ & $\begin{array}{r}99.0061 \\
149.7695 \\
200.8239 \\
251.3638 \\
301.9554\end{array}$ & $\begin{array}{l}1.49780 i \\
2.660598 \\
3.838130 \\
4.995476 \\
6.136223\end{array}$ & $\begin{array}{l}1.4957 \\
2.6695 \\
3.8632 \\
5.0406 \\
6.1991\end{array}$ & $\begin{array}{r}0.002107 \\
-0.008702 \\
-0.025070 \\
-0.045124 \\
-0.051877\end{array}$ \\
\hline 10 & TC-4 & $\begin{array}{r}99.0061 \\
149.7695 \\
200.8239 \\
251.36 .38 \\
301.9554\end{array}$ & $\begin{array}{l}1.497807 \\
2.660598 \\
3.838130 \\
4.99 \times 476 \\
6.135223\end{array}$ & $\begin{array}{l}1.5001 \\
2.6745 \\
3.8680 \\
5.0456 \\
6.2029\end{array}$ & $\begin{array}{l}-0.002293 \\
-0.01 .3902 \\
-0.029870 \\
-0.050124 \\
-0.066677\end{array}$ \\
\hline 11 & $T-5$ & $\begin{array}{r}99.0061 \\
149.7695 \\
200.8239 \\
251.3638 \\
301.9554\end{array}$ & $\begin{array}{l}1.497807 \\
2.660598 \\
3.838130 \\
4.995476 \\
5.136223\end{array}$ & $\begin{array}{l}1.4956 \\
2.6694 \\
3.8631 \\
5.0393 \\
6.1983\end{array}$ & $\begin{array}{r}0.002207 \\
-0.008802 \\
-0.024970 \\
-0.043824 \\
-0.062077\end{array}$ \\
\hline 19 & $\mathrm{xc}-6$ & $\begin{array}{r}99.0061 \\
149.7695 \\
200.8239 \\
251.3638 \\
301 . .9554\end{array}$ & $\begin{array}{l}1.197807 \\
2.660598 \\
3.838130 \\
4.995476 \\
6.136223\end{array}$ & $\begin{array}{l}i .4(194 \\
2.671+9 \\
3.8699 \\
5.0475 \\
6.2057\end{array}$ & $\begin{array}{l}-0.001593 \\
-0.014302 \\
-0.031770 \\
-0.052024 \\
-0.069477\end{array}$ \\
\hline
\end{tabular}

a 1,68 IPTS:

${ }^{b}$ NBS smoothed data for type $K$ thermosouples. ${ }^{121}$ 
TABTE A-2

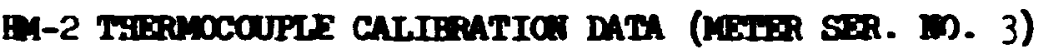

\begin{tabular}{|c|c|c|c|c|c|}
\hline $\begin{array}{l}\text { TC } \\
\text { No. }\end{array}$ & $\begin{array}{c}\text { Meter } \\
\text { Position }\end{array}$ & $\begin{array}{c}\text { Actual } \\
\text { Teqerature } \\
(\mathrm{P})^{\mathrm{a}}\end{array}$ & $\begin{array}{c}\text { Tabulated } \\
\text { ErF } \\
\text { (HV) }\end{array}$ & $\begin{array}{l}\text { Measured } \\
\text { BrF } \\
\text { (MV) }\end{array}$ & $\begin{array}{l}\text { Ere } \\
\text { Error } \\
\text { (MV) }\end{array}$ \\
\hline 21 & TC-1 & $\begin{array}{r}99.0061 \\
149.7695 \\
200.8239 \\
251.3638 \\
301.9554\end{array}$ & $\begin{array}{l}1.497607 \\
2.650558 \\
3.838130 \\
. .995476 \\
1.130223\end{array}$ & $\begin{array}{l}1.5001 \\
2.6741 \\
3.8676 \\
5.0448 \\
6.2017\end{array}$ & $\begin{array}{l}-0.002293 \\
-0.013502 \\
-0.029470 \\
-0.049324 \\
-0.065477\end{array}$ \\
\hline 22 & TC-2 & $\begin{array}{r}99.0061 \\
149.7095 \\
200.8239 \\
251.3638 \\
301.9554\end{array}$ & $\begin{array}{l}1.497807 \\
2.660598 \\
3.838130 \\
4.995476 \\
6.136223\end{array}$ & $\begin{array}{l}1.5: 007 \\
2.6761 \\
3.8709 \\
5.0491 \\
6.2070\end{array}$ & $\begin{array}{l}-0.002893 \\
-0.015502 \\
-0.032770 \\
-0.053624 \\
-0.070777\end{array}$ \\
\hline 23 & $\mathrm{TC}-3$ & $\begin{array}{r}99.0061 \\
149.7695 \\
200.8239 \\
251.3638 \\
301.9554\end{array}$ & $\begin{array}{l}1.497807 \\
2.660599 \\
3.839130 \\
4.995476 \\
6.136223\end{array}$ & $\begin{array}{l}1.5011 \\
2.6755 \\
3.8692 \\
5.0467 \\
6.2041\end{array}$ & $\begin{array}{l}-0.003293 \\
-0.014902 \\
-0.031070 \\
-0.051224 \\
-0.067877\end{array}$ \\
\hline 24 & TC-4 & $\begin{array}{r}99.0061 \\
149.7695 \\
200.8239 \\
251.3638 \\
301.9554\end{array}$ & $\begin{array}{l}1.497807 \\
2.660598 \\
3.839130 \\
4.995476 \\
6.136223\end{array}$ & $\begin{array}{l}1.5016 \\
2.6774 \\
3.8725 \\
5.0512 \\
6.2096\end{array}$ & $\begin{array}{l}-0.003793 \\
-0.016802 \\
-0.034370 \\
-0.055724 \\
-0.073377\end{array}$ \\
\hline 25 & $T C-j$ & $\begin{array}{r}99.0061 \\
149.7695 \\
200.8239 \\
251.3638 \\
301.9554\end{array}$ & $\begin{array}{l}1.497807 \\
2.660598 \\
3.838130 \\
4.995476 \\
6.136223\end{array}$ & $\begin{array}{l}1.4960 \\
2.6715 \\
3.8660 \\
5.0442 \\
6.2021\end{array}$ & $\begin{array}{r}0.001807 \\
-0.010902 \\
-0.027870 \\
-0.048724 \\
-0.065877\end{array}$ \\
\hline 33 & TC-6 & $\begin{array}{r}99.006 i \\
149.7695 \\
200.8239 \\
251.3638 \\
301.9554\end{array}$ & $\begin{array}{l}3.497807 \\
2.660598 \\
3.938130 \\
4.995476 \\
6.136223\end{array}$ & $\begin{array}{l}1.4973 \\
2.6728 \\
3.8674 \\
5.0456 \\
6.2035\end{array}$ & $\begin{array}{r}0.000507 \\
-0.012202 \\
-0.029270 \\
-0.050124 \\
-0.067277\end{array}$ \\
\hline
\end{tabular}


TABTE A-3

MUSCETIAIEOUS THERDCOUPL CALIBRATIOA DATR

\begin{tabular}{|c|c|c|c|c|c|}
\hline $\begin{array}{l}\text { TC } \\
\text { Ho. }\end{array}$ & $\begin{array}{c}\text { Loop } \\
\text { Locat ion }\end{array}$ & $\begin{array}{c}\text { Actual } \\
\text { Teqpereture } \\
(\cdot \mathrm{P})^{\mathrm{e}}\end{array}$ & $\begin{array}{c}\text { Tabulated } \\
\text { Di? } \\
\text { (IN) }\end{array}$ & $\begin{array}{l}\text { Measured } \\
\text { ER } \\
\text { (HV) }\end{array}$ & $\begin{array}{c}\text { EPP } \\
\text { Error } \\
(\mathbf{M V})\end{array}$ \\
\hline 34 & Reservoir & $\begin{array}{r}99.0061 \\
149.7695 \\
200.8239 \\
251.3638 \\
.36 .1 .9554\end{array}$ & $\begin{array}{l}1.497307 \\
2.600598 \\
3.838130 \\
4.995476 \\
6.136223\end{array}$ & $\begin{array}{l}1.4959 \\
2.6696 \\
3.8617 \\
5.0393 \\
6.1973\end{array}$ & $\begin{array}{l}0.001907 \\
-0.009002 \\
-0.023570 \\
-0.043824 \\
-0.061077\end{array}$ \\
\hline 35 & $\begin{array}{l}\text { Pump } \\
\text { Suction }\end{array}$ & $\begin{array}{r}99.0061 \\
149.7695 \\
200.8239 \\
251.3638 \\
301.9554\end{array}$ & $\begin{array}{l}1.497807 \\
2.660598 \\
3.838130 \\
4.995476 \\
6.136223\end{array}$ & $\begin{array}{l}1.4992 \\
2.6708 \\
3.8614 \\
5.0375 \\
6.1067\end{array}$ & $\begin{array}{l}-0.00193 \\
-0.010202 \\
-0.023270 \\
-0.042024 \\
-0.060+77\end{array}$ \\
\hline 36 & $\begin{array}{l}\text { Upstream } \\
\text { of Plow } \\
\text { Neters }\end{array}$ & $\begin{array}{r}99.0061 \\
149.7695 \\
200.8239 \\
251.3638 \\
301.9554\end{array}$ & $\begin{array}{l}1.497807 \\
2.660598 \\
3.836130 \\
4.995476 \\
6.136223\end{array}$ & $\begin{array}{l}1.4792 \\
: .671 ? \\
3.8618 \\
5.0375 \\
6.19=0\end{array}$ & $\begin{array}{l}-0.001393 \\
-0.010502 \\
-0.023670 \\
-0.042024 \\
-0.062777\end{array}$ \\
\hline $3 ?$ & $\begin{array}{l}\text { HM-1 Bulk } \\
\text { Stream }\end{array}$ & $\begin{array}{r}99.0069 \\
149.7695 \\
200.9239 \\
251.3638 \\
301.9554\end{array}$ & $\begin{array}{l}1.497807 \\
2.560598 \\
3.838130 \\
4.995476 \\
6.136223\end{array}$ & $\begin{array}{l}1.5026 \\
2.6805 \\
3.8770 \\
5.0578 \\
6.2191\end{array}$ & $\begin{array}{l}-0.004793 \\
-0.019902 \\
-0.038870 \\
-0.062324 \\
-0.082877\end{array}$ \\
\hline 38 & $\begin{array}{l}\text { IM-2 Bulk } \\
\text { Stream }\end{array}$ & $\begin{array}{r}99.0061 \\
14: .7695 \\
200.8239 \\
251.3638 \\
301.9554\end{array}$ & $\begin{array}{l}1.497807 \\
2.600598 \\
3.838130 \\
4.995476 \\
6.136223\end{array}$ & $\begin{array}{l}1.5003 \\
2.6753 \\
3.8703 \\
5.0500 \\
6.2104\end{array}$ & $\begin{array}{l}-0.002493 \\
-0.014702 \\
-0.032170 \\
-0.054524 \\
-0.074177\end{array}$ \\
\hline 39 & $\begin{array}{l}\text { Downstream } \\
\text { of After. } \\
\text { Cooler }\end{array}$ & $\begin{array}{r}99.0061 \\
149.7695 \\
20 . .8239 \\
251.3638 \\
301.9554\end{array}$ & $\begin{array}{l}1.497807 \\
2.660596 \\
3.838130 \\
4.995476 \\
6.136223\end{array}$ & $\begin{array}{l}1.5005 \\
2.6765 \\
3.8723 \\
5.0533 \\
6.2162\end{array}$ & $\begin{array}{l}-0.002693 \\
-0.015902 \\
-0.034170 \\
-0.05782 \\
-0.079477\end{array}$ \\
\hline
\end{tabular}

${ }^{2} 1968$ IPRS.

WIS smorsthed data fir type $K$ thermocouples. 121 
gives a unique identification nuber, whereas Colum 2 gives an identification related to the heat $\mathrm{Iux}$ neter geanetry (see Pig. IV-3) or the loop flow schere (see Pig. IV-1). Ccling 3 tabulates the known (determined independently) temperature ( $\pm 0.006 \%)$ at which the calibrations vere perforned. Coluen tabulates the thermal ex corresponding to the known tesperature as deternined fron the soothed date of wBS for Iype $\mathrm{K}$ therwoccupies, ${ }^{221}$ wherees the eif neasured $( \pm 0.1 \mu \mathrm{p})$ at that terperature

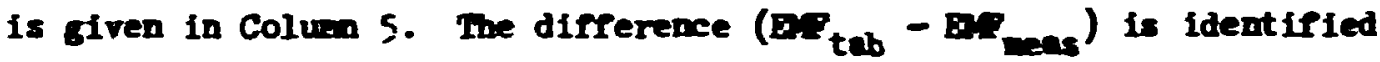
as the error and is tabulated in colwen 6.

For purposes of analysis, the srrors for the individual thernocouples were fitted to a cubir, equation using a leist-squares fitting

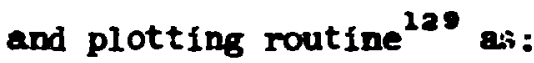

$$
E_{\text {err }}=A_{1}+A_{\text {en }} E_{\text {ineas }}+A_{3} \vec{E}_{\text {meas }}+A_{4} E_{\text {meas }}^{3}
$$

Coefficients of the fitted equations are tabuiated in Table A-4, along with standard errors and P-ratio coefficients. Figure A-5 shows a plot of the fitted error equation for therwocouple No. 7, which is typical of the plots of all the pitted functions. As indicated in the figure, the fitted function is "well behaved" over the callbration range. The fitted error functions and the NBS runctional representation ${ }^{222}$ for Tyre $K$ thermocouples were used in a couputer routine to obtain corrected temperatures from the measured emp values.

Upon completion of assembly and inftial heat flux meter performance (exploratory) tests in the flow loop, a rellability check was made on the meter and bulk stream thermocouples. Since the loop had been drained for severa] days, it was assumed that equilibrium existed (except for the 
TABLE $A-4$

RESULIS OF IEAST-SQUARES CUBIC FIT TO THORMOCOUPLE CALIBRATION DATA

\begin{tabular}{|c|c|c|c|c|c|}
\hline Thermoccuple & Coefricients & Fltted Value & Standard Drror & Fat1o & \\
\hline $\mathrm{TC}-7$ & $\begin{array}{l}A_{2} \\
A_{6} \\
A_{9} \\
A_{6}\end{array}$ & $\begin{array}{r}0.31888451 D-03 \\
0.441983590-02 \\
0.351343260-02 \\
0.658404930-02\end{array}$ & $\begin{array}{l}0.245662960-04 \\
0.285218700-03 \\
0.100328350-02 \\
0.103373060-02\end{array}$ & $3 \cdot 326125520$ & O4 \\
\hline$T C-8$ & $\begin{array}{l}A_{2} \\
A_{0} \\
A_{3} \\
A_{4}\end{array}$ & $\begin{array}{r}0.36542548 D-03 \\
0.50066705 \mathrm{D}-02 \\
0.64801467 \mathrm{D}-02 \\
0.28360161 \mathrm{D}-02\end{array}$ & $\begin{array}{l}0.721564870-04 \\
0.837400560-03 \\
0.294464430-02 \\
0.303347290-02\end{array}$ & $3.49974102 D$ & 03 \\
\hline IC-9 & $\begin{array}{l}A_{6} \\
A_{6}\end{array}$ & $\begin{array}{r}0.40072468 \mathrm{D}-03 \\
-0.54604958 \mathrm{D}-02 \\
0.83988491 \mathrm{D}-02 \\
0.32829870 \mathrm{D}-03\end{array}$ & $\begin{array}{l}0.123631300-03 \\
0.143477230-02 \\
0.504541770-02 \\
0.519823280-02\end{array}$ & 1.167835040 & 03 \\
\hline$T C-10$ & $\begin{array}{l}A_{3} \\
A_{0} \\
A_{3} \\
A_{4}\end{array}$ & $\begin{array}{r}0.38005063 \mathrm{D}-03 \\
0.51659302 \mathrm{D}-02 \\
0.70873204 \mathrm{D}-02 \\
-0.27024748 \mathrm{D}-02\end{array}$ & $\begin{array}{l}0.161933480-03 \\
0.18814765 \mathrm{D}-02 \\
0.66253804 \mathrm{D}-02 \\
0.9977 .784 \mathrm{D}-02\end{array}$ & 6.861685420 & 02 \\
\hline$T C-11$ & $\begin{array}{l}A_{2} \\
A_{3} \\
A_{3}\end{array}$ & $\begin{array}{r}0.26516578 \mathrm{D}-03 \\
-0.39859718 \mathrm{D}-02 \\
0.37593063 \mathrm{D}-02 \\
0.45949266 \mathrm{D}-02\end{array}$ & $\begin{array}{l}0.249723090-04 \\
0.289823390-03 \\
0.101919770-02 \\
0.105005390-02\end{array}$ & 2.841324980 & 04 \\
\hline TC-19 & $\begin{array}{l}A_{1} \\
A_{0} \\
A_{3} \\
A_{6}\end{array}$ & $\begin{array}{r}0.35360131 D-03 \\
-0.47647814 \mathrm{D}-02 \\
0.45859994 \mathrm{D}-02 \\
0.99136766 \mathrm{D}-03\end{array}$ & $\begin{array}{l}0.804677110-04 \\
0.935227380-03 \\
0.329400090-02 \\
0.33997765 D-02\end{array}$ & $3.05232032 D$ & 03 \\
\hline
\end{tabular}


TABRE A-l, (Contimad)

\begin{tabular}{|c|c|c|c|c|}
\hline Thermocouple & Coerficient & Fitted value & Standard Irror & Rat10 \\
\hline$T C-21$ & $\begin{array}{l}A_{2} \\
A_{6} \\
A_{3} \\
A_{6}\end{array}$ & $\begin{array}{r}0.40129563 \mathrm{D}-03 \\
-0.53901503 \mathrm{D}-02 \\
0.80036580 \mathrm{D}-02 \\
-0.36273872 \mathrm{D}-02\end{array}$ & $\begin{array}{l}0.13925294 \mathrm{D}-03 \\
0.16177157 \mathrm{D}-02 \\
0.56958646 \mathrm{D}-02 \\
0.58779754 \mathrm{D}-02\end{array}$ & $8.98208216 \mathrm{D} 02$ \\
\hline TC-22 & $\begin{array}{l}A_{2} \\
A_{3} \\
A_{3} \\
A_{4}\end{array}$ & $\begin{array}{r}0.39327840 D-03 \\
-0.52459603 \mathrm{D}-02 \\
0.63086933 \mathrm{D}-02 \\
-0.19716181 \mathrm{D}-02\end{array}$ & $\begin{array}{l}0.23013268 D-03 \\
0.25129314 D-02 \\
0.533079730-02 \\
0.55047721 D-0.2\end{array}$ & 2.17324885003 \\
\hline$T C-23$ & $\begin{array}{l}A_{2} \\
A_{0} \\
A_{3} \\
A_{6}\end{array}$ & $\begin{array}{r}0.38010758 \mathrm{D}-03 \\
-0.51626983 \mathrm{D}-02 \\
0.70192506 \mathrm{D}-02 \\
-0.35878542 \mathrm{D}-02\end{array}$ & $\begin{array}{l}0.142891790-0 ? \\
0.16607156 \mathrm{D}-\mathrm{C} 2 \\
0.58499686 \mathrm{D}-12 \\
0.60400851 \mathrm{D}-1,2\end{array}$ & 8.86249225002 \\
\hline$T C-24$ & $\begin{array}{l}A_{2} \\
A_{6} \\
A_{6} \\
A_{4}\end{array}$ & $\begin{array}{r}0.38697072 D-03 \\
-0.51958200 D-02 \\
0.58832508 D-02 \\
-0.23254753 D-02\end{array}$ & $\begin{array}{l}0.13956218 \mathrm{D}-03 \\
0.1623288 \mathrm{TD} \cdot 02 \\
0.57223067 \mathrm{D} .02 \\
0.59120096 \mathrm{r}-02\end{array}$ & 1.06742230003 \\
\hline$T C-25$ & $\begin{array}{l}A_{2} \\
A_{3} \\
A_{3} \\
A_{1}\end{array}$ & $\begin{array}{r}0.3731: 3 j 2 D-0.3 \\
-0.50123376 \mathrm{D}-02 \\
0.55532920 \mathrm{D}-02 \\
0.33574024 \mathrm{D}-02\end{array}$ & $\begin{array}{l}0.148962590-03 \\
0.172970230-02 \\
0.60856156 \mathrm{D}-02 \\
0.62725358 \mathrm{D}-02\end{array}$ & $8.8826 n j 28 \mathrm{D} 02$ \\
\hline$T C-33$ & $\begin{array}{l}A_{2} \\
A_{6} \\
A_{3} \\
A_{4}\end{array}$ & $\begin{array}{r}0.37814021 D-03 \\
-0.50668759 D-02 \\
0.57028416 D-02 \\
0.19520930 D-02\end{array}$ & $\begin{array}{l}0.14332256 \mathrm{D}-13 \\
0.16647936 \mathrm{~L}-02 \\
0.58596656 \mathrm{~L}-02 \\
0.60427822 \mathrm{0}-02\end{array}$ & $9.6271881 .8 \mathrm{D} 02$ \\
\hline
\end{tabular}


TABLE A-4 (Cont Inued)

\begin{tabular}{|c|c|c|c|c|}
\hline Phermu:ouple & Coerfialent & Fitted value & standiurd Error & IRat10 \\
\hline IC -3. & $\begin{array}{l}A_{2} \\
A_{2} \\
A_{3} \\
A_{4}\end{array}$ & 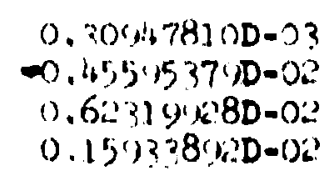 & $\begin{array}{l}0.2139413100-03 \\
0.248255650-02 \\
0.8729071,20-02 \\
0.899313390-02\end{array}$ & $2.75 ? 01796002$ \\
\hline IC-35 & $\begin{array}{l}A_{3} \\
A_{2} \\
A_{3} \\
A_{4}\end{array}$ & 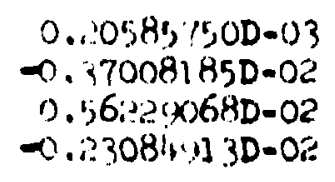 & $\begin{array}{l}0.14882 B 145 D-03 \\
0.17276131 . D-02 \\
0.6078060 " \mathrm{D}-02 \\
0.6268028 .2 \mathrm{D}-02\end{array}$ & 6.34781477002 \\
\hline rc -36 & $\begin{array}{l}A_{2} \\
A_{2} \\
A_{3} \\
A_{4}\end{array}$ & 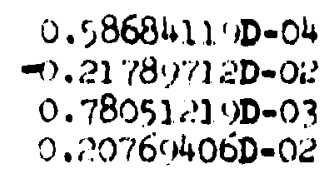 & $\begin{array}{l}0.806] 03 \% 00-04 \\
0.936032970-0.3 \\
0.3291402650-02 \\
0.33976703 D-02\end{array}$ & $3.4720 \% 39403$ \\
\hline $\mathrm{rC}-3 ?$ & $\begin{array}{l}A_{1} \\
A_{b} \\
A_{3} \\
A_{4}\end{array}$ & $\begin{array}{r}0.106082224 D-03 \\
0.4+38261308 D-02 \\
0.18450134 D-02 \\
0.101443230-02\end{array}$ & $\begin{array}{l}0.167281300-03 \\
0.190174400-02 \\
0.6712314730-02 \\
0.614269310-02\end{array}$ & $1.587906 \% 00$ \\
\hline $1 c-38$ & $\begin{array}{l}A_{1} \\
A_{0} \\
A_{3} \\
A_{4}\end{array}$ & $\begin{array}{r}0.36 \times 88775 D-03 \\
0.533853 \% 0 D-0.2 \\
0.73 \times 873222 D-02 \\
-0.29356793 D-02\end{array}$ & $\begin{array}{l}0.1474253150-03 \\
0.171461 .500-0.2 \\
0.604335160-02 \\
0.624192130-02\end{array}$ & 1.01360322003 \\
\hline $\mathrm{cc}-3 \mathrm{~s}$ & $\begin{array}{l}A_{1} \\
A_{b} \\
A_{3} \\
A_{6}\end{array}$ & $\begin{array}{r}0.29631852 D-03 \\
-0.46667777 D-02 \\
0.461427048 D-02 \\
-0.41119370 D-03\end{array}$ & $\begin{array}{l}0.14633847 \mathrm{D}-0.3 \\
0.17040242 \mathrm{D}-02 \\
0.6010028 \mathrm{D}-02 \\
0.62111318 \mathrm{D}-02\end{array}$ & 1.27542667003 \\
\hline
\end{tabular}

acoefflctents for use in Eq. (A-9). 


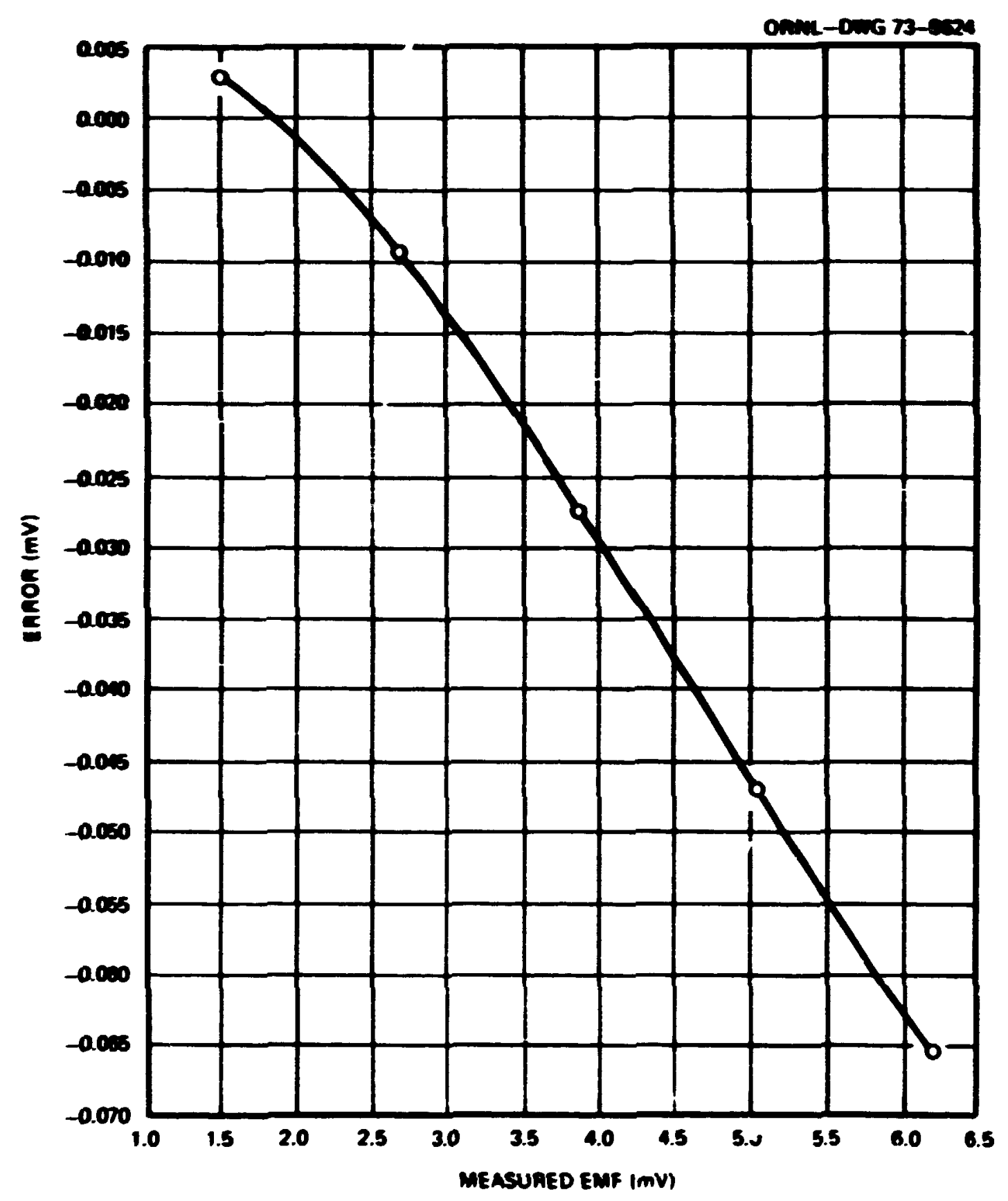

P1B. A-5. Calibration data for TC-7. 
norval diuranl teperature nuctuat:ans present in the laboratory area). Table A-5 shows the reoults of the check. [The wuber of significant Figures indicated in the table are reported for con istency and are not Intended to reflect the abolute accuracy.] The excellent agreanen betreen the temperatures calculated from the ritted equations and the neasured ralves gave essurance that the thernocouples vere relibble. It is woted that the dowstreen bulk nald thermacouple (re-38 at E-2) indiceted about 0.029 higher then that indiceted by the upstreen therwocouple (x-27 at al-1). Sinilarly, the extrapolated surface temperature

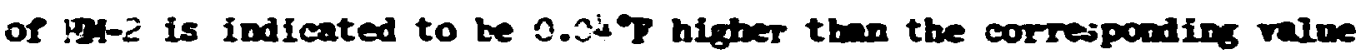
Sor at-1. Although agreenent between these ralnes is excel'ent, ibe discrepancies are attributed to the fitted ealibretion error functions and the fitted tenperature distributions within the ieat flux meters. Periodic rechecks of the above test continued to give assurance of thernocouple reliabl]1ty.

Another auparison was made between the bulk strean therwocouples ( $T C-27$ and $T-38$ ) by meacuring the toliting temperature in an open beaker of demineralized water at a barometris pressure of $29.10 \mathrm{in}$. of $\mathrm{HB}$. The average of stren determinations gave the following results:

\begin{tabular}{|c|c|c|}
\hline Thermocouple & $\begin{array}{c}\text { Temperature } \\
\left({ }^{\circ} \mathrm{P}\right) \\
\end{array}$ & $\begin{array}{l}\text { Standard Deviat 1or } \\
(\mathrm{P}) \\
\end{array}$ \\
\hline$T C-37$ & 210.66 & 0.029 \\
\hline TC- -38 & 210.76 & 0.015 \\
\hline
\end{tabular}

These are in exsellent agreement with the interpolated value of $210.60^{\circ} \mathrm{P}$ Jitained from the 1.6. ASME Steam Tables at $29.10 \mathrm{ln}$. of Hg. 
Tane A-s

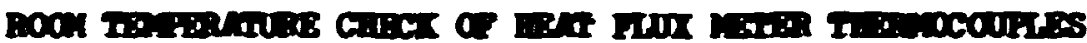

\section{Deente}

Leat-Square Bqution: $T=81.9681-0.0151097 x$

std. Der. $=0.0321$, Dev. of slope $=0.227$, Dev. of $\mathbf{T}_{\mathrm{I}=0}=0.033$

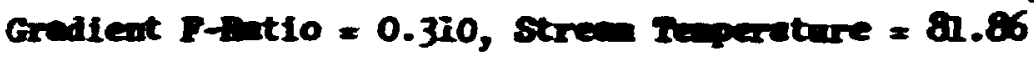

\begin{tabular}{|c|c|c|c|c|}
\hline E. & $\begin{array}{l}\text { Fosition } \\
\text { (in.) }\end{array}$ & $(T)^{T-1}$ & $\begin{array}{l}\text { Cale } T \text { - } \\
(T)\end{array}$ & $(P)$ \\
\hline$?$ & 0.4579 & 81.9904 & 81.9612 & 0.0092 \\
\hline 8 & .0 .8336 & 81.9452 & 91.9555 & -0.0103 \\
\hline 9 & 1.2066 & 81.9056 & 81.9499 & -0.0443 \\
\hline 10 & 1.5781 & 81.947 & 81.9443 & 0.0028 \\
\hline $\mathbf{1 1}$ & 1.9576 & 81.9611 & 81.9365 & 0.0226 \\
\hline
\end{tabular}

\section{Ei-2 Reoults}

Least-Squares Bquation: $T=82.0143-0.0299858 x$ std. Dev. $=0.015$, Dev. of slope $=0.013$, Dev. of $T_{x=0}=0.015$ Gradient P-Rat10 $=5.66$, strean Teaperature $=81.88$

\begin{tabular}{|c|c|c|c|c|}
\hline $\begin{array}{l}\text { TC } \\
\text { No. }\end{array}$ & $\begin{array}{c}\text { Position } \\
\text { (in.) }\end{array}$ & $\begin{array}{l}\text { Meas Tenp } \\
(P)\end{array}$ & $\begin{array}{l}\text { Cale Teap } \\
(\mathrm{P}) \\
\end{array}$ & $\begin{array}{c}\text { Meas-Cale } \\
(\mathrm{P})\end{array}$ \\
\hline 21 & 0.4508 & 82.0022 & 82.0007 & 0.0015 \\
\hline 22 & 0.8151 & 81.9773 & 81.9898 & -0.0125 \\
\hline 23 & 1.2003 & 81.9887 & 81.9783 & 0.0104 \\
\hline 24 & 1.5784 & 81.9783 & 81.9669 & 0.0113 \\
\hline 25 & $1.9,332$ & 81.9450 & 81.9557 & -0.0107 \\
\hline
\end{tabular}
in.

$a_{\text {f }}=$ degrees Pahrenhelt,$X=$ distance from bolling surface, 
It wes observed in the experineatal portion of this researeh that IC-38 aewly aluy indicated a slifutly hidher (0.05 to 0.25\%) temper

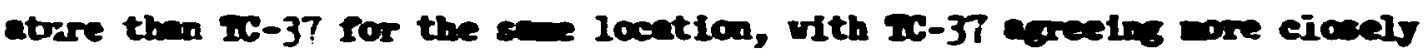

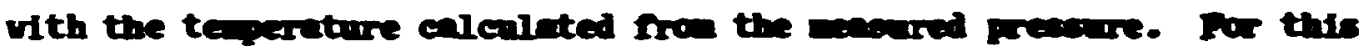

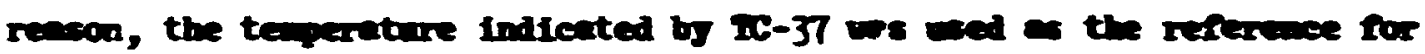

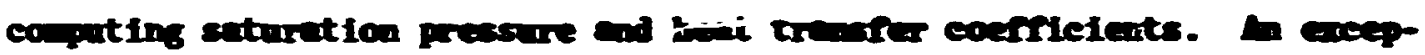

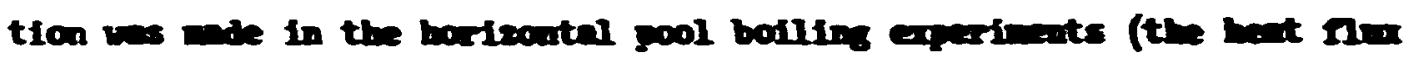

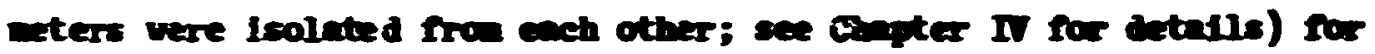

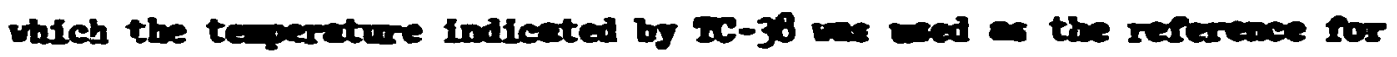
conpting the E-1 beat truisfer conficient.

\section{A-4. Sister Deat Iosses}

Since the flow boiling tests vith Freon under high vold frection conditions depended on a calculated heat balance between the state point station lipstreen of the nor neters and the beat nux ecters, a series of tests were ade to ascertain the enthalpy lose per pound of noulns Nuid for use in the ancilysis. Although the system wes well inoulated and the experimertally deterained losses were all (probably negligible), they were taken into account in the beat balance.

The systen was operated at saturation coniltions in the reservoir to provide a stable temperature distribution (none of the ine heaters were on for these tests) throughout the 100p, while the now rate was varied over the range of interest. The two thermocsuples at the beat meters were positioned at the same stream point to provide duplicate temperature measurements from which the temperature 1008 experienced by 
the fluid between the state point station and the neter condd be deter-

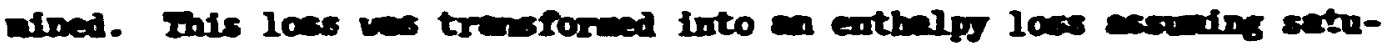
reted lighid conition existed. IIn reality the nuils vere slight]

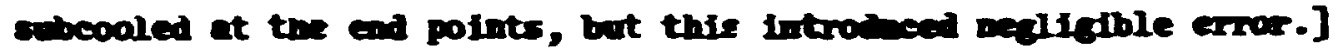
Pive nar velocities $(0.5,1,2,3$, ad $4 I / \mathrm{Isec})$ were eplosed for this pappose. The rediced ate conit be represented reasoubly vell with a upertolie nuction as shom in Fis. A-6, wherein the euthalp 108 (Bta/1b) is plocted a a nuction of the reeiproen of the was flos

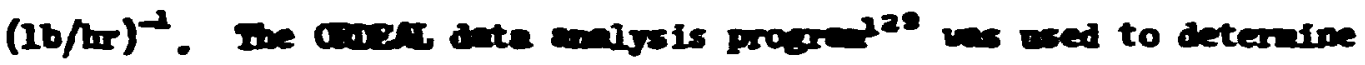
- least-agnares rit to the duta es:

$$
\Delta=4 / N+42
$$

The exerficient $h_{1}=214.851$ with a standerd error of \pm 6.413 , and $4=$ $0.236 \times 10^{-3}$ with a standard error of $\pm 0.185 \times 10^{-2}$. The fitted equation has a stadard deriation of $\pm 0.0037 \mathrm{Btu} / 1 \mathrm{~b}$.

Since the Freon temperature was varied over a narrou range (i18 :0 $138^{\circ} \mathrm{P}$ ) in the high void fraction tests, it was judged acceptable to use Bq. (A-10) for the entire range without including a temperature erfect.

\section{A-5. Heat Mux Noter Heat Ioss Calibrat Ion}

\section{Mow Test Calibration}

A number of tests were made to ascertain the equilibrium heat 1085 of the individual heat flux meters as installed in the flow 100p. Three tismperature levels, spanning the range of fluid temperatures expected in the experimental program, wore used with water flowing at $2 \mathrm{ft} / \mathrm{sec}$.

The condition of zero texperature gradient (within the weter) at the bofling surface indicates no transfer of heat across the surface. 


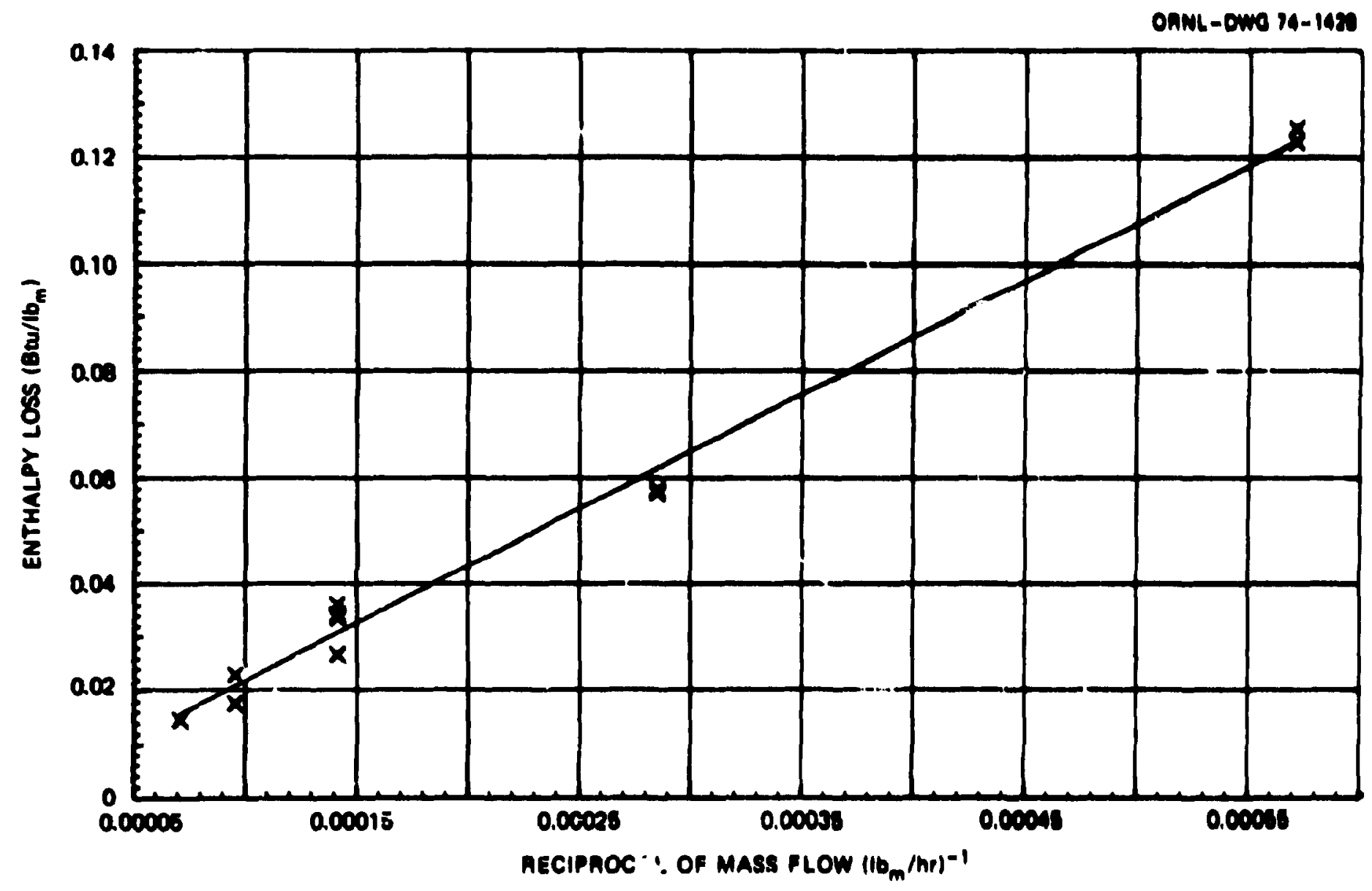

F1g. A-6. Syatem heat lose as anotion of mase slow rate. 
The electrical ingest poier required to achieve this soriition. has jetermined indireetly at the three tempe ature lerels ir the foliosirs marrer.

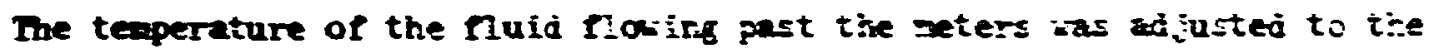
desired value and a series of russ ade at various lor lereis of netser

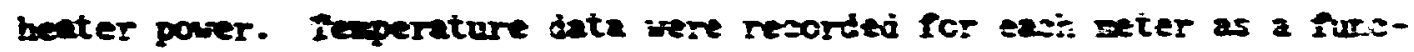
tion of mensured electrienl poser. The texpertive izte yere fitiej ic a lirear least-squares equation to provide the grailect as a furetioc of

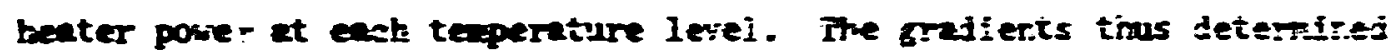
for a tuber ci power ierels vere then fittec (usirg a incar ieastsquares soutire) to an equation reiating the gradiest to tise pcrer level at that particalar temperature lerel. The root of the resuiting 6 jat:s. is the power level reguired to produce a zero t=mperat.ite gredient ct tin: boiling surface for that temoerature level. The zero-grailiest-foverIevels were then fitted to a linear least-squares nunction uf tre s.srperature for each of the tests. Urder these conditicns the injicate 3 temperature, as well as the arerage of the indicated values, w.thin tias heat flux meter is the came as tice surface temperature, at liast sit:in a standard deviation of the fittea temperature distri intion.

Pigure A-7 shows the results of the calsulated gritient versis tise measured input electricai power for east, of the heat fiux meters soy Pluld temperatures in the range of 213 to $216{ }^{\circ} \mathrm{F}$. Similar rewilts Nere obtained for fluid temperature values of 1.25 and $180^{\circ} \mathrm{F}$. Figire A-8: shows the roots of the equations, i.e., the input elestrica! pcirar sequired to produce zero temperature gradient within the meters, ess $e$ function of surface temperature fersentially the same as trie average of the indicated values). 


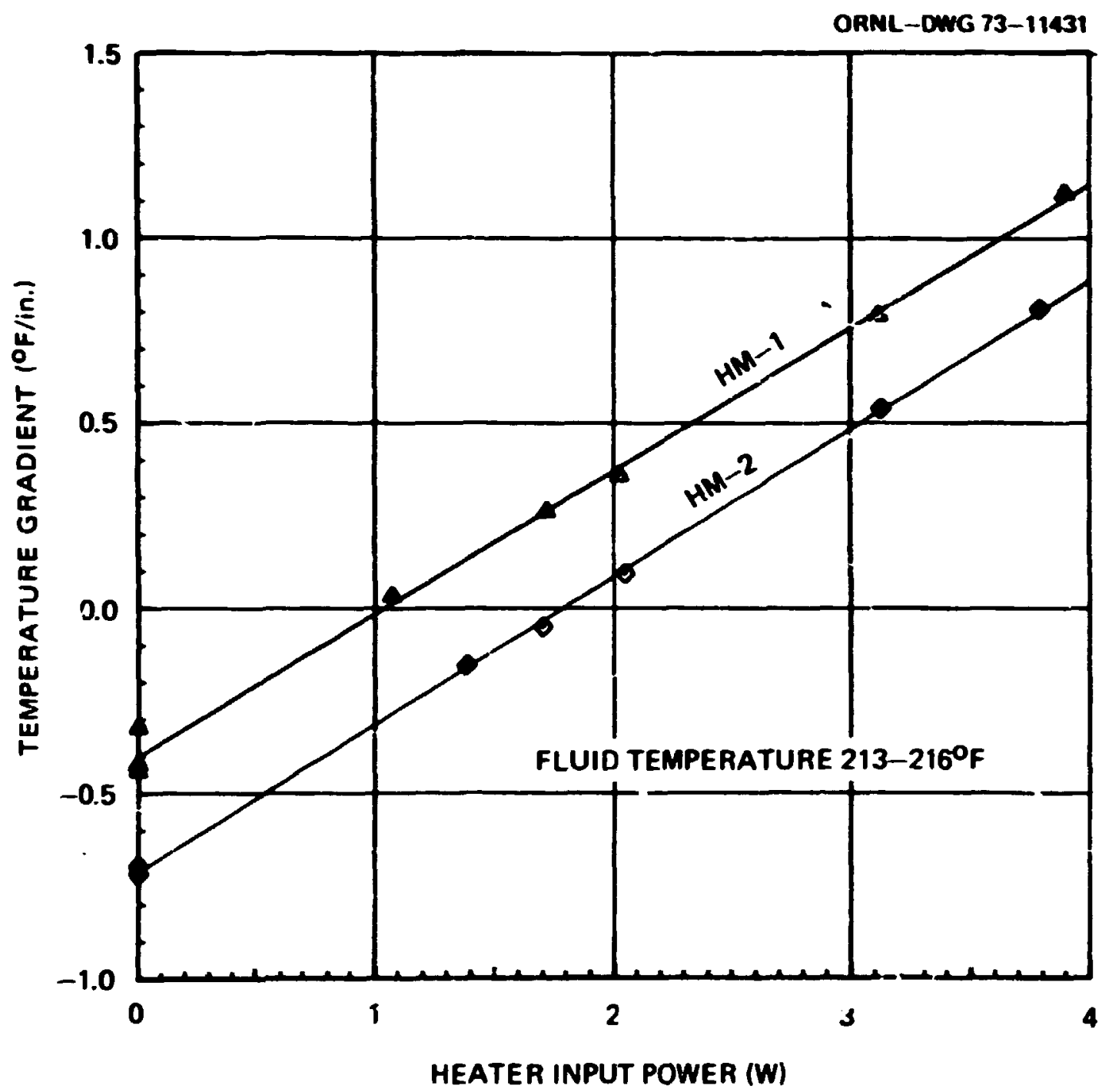

Fig. A-? Heter temperature gradient vs input power.

The equilibrium heat loss functions were determined to be linear over the range of interest and are given for HW-1 as:

$$
P_{\mathrm{HL}-1}=-0.614404+0.00781815 \overline{\mathrm{T}},
$$

with a standard deviation of $0 . n 01145$; watt; and for HM-? as:

$$
P_{\text {IIL-? }}=-0.815 \% 20+0.0122395 \ddot{T},
$$

with a standard deviation of 0.04276 watt. 


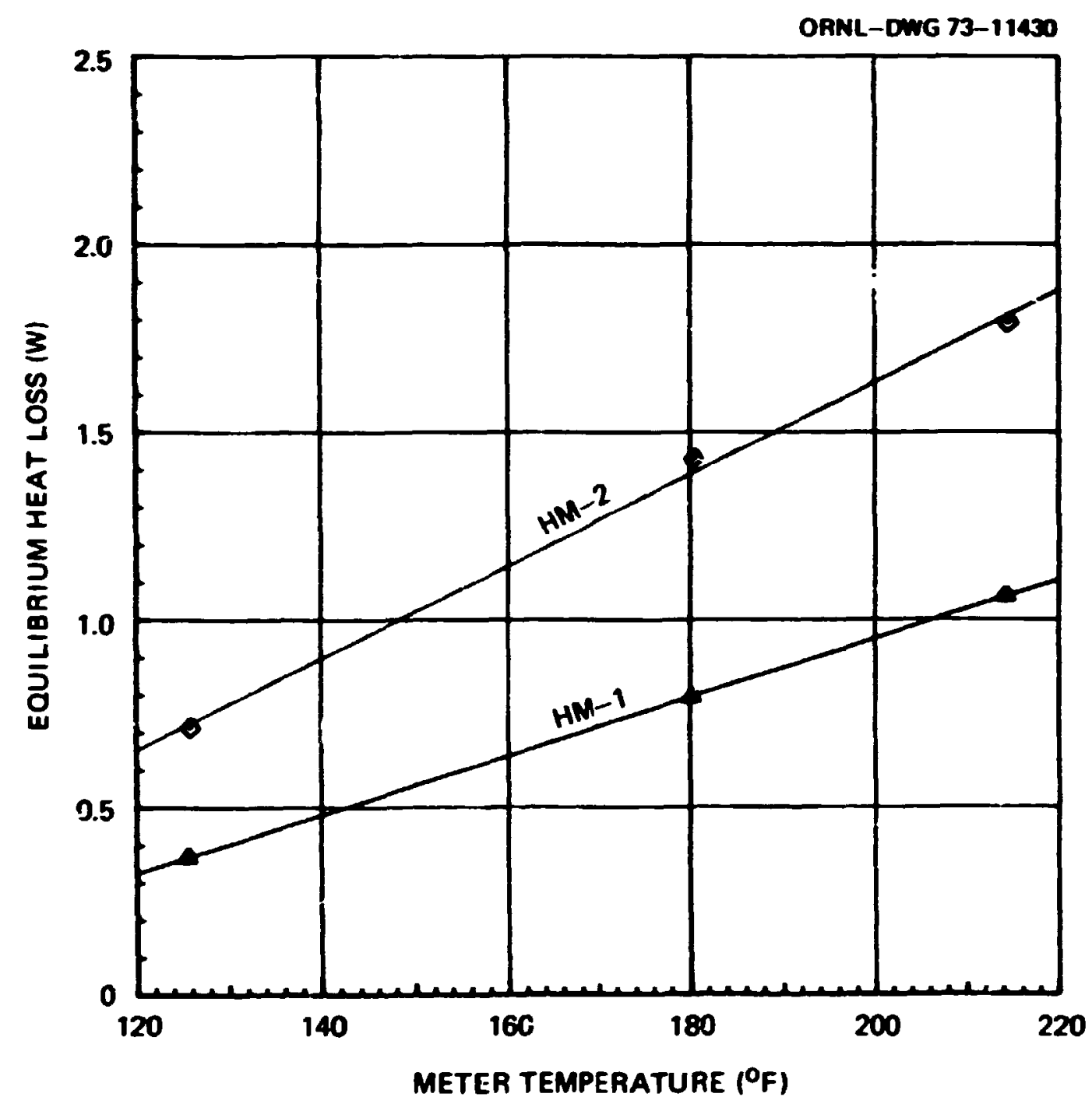

Fig. A-8. Input power required to produce zero temperature gradient.

These equations were used to estimate the equilibrium heat loss for the flow tests, using the average of the measured temperatures within the heat flux meters. Thy is known to be a conservative estimate of the minimum equilibrium heat loss for two reasons:

1. The average value of the fudicated temperature is less than the average temperature of the entire copper bod: of the meter. Reference 
to $\mathrm{Mg}$. IV-3 shows that considerable surface ar $\$ 2$ will be at a temperature higirer than the highest value inciuded in the averaging process. Since no estimate was availabie for the true average temperature, the average of the measured values was used to calculate the equilibrium hert loss associated with each data point.

2. The wanner by which the electrical leads were joined to the meter heater (as described in Chapter IV) necessiteted about 1 in. of heater on each end not being brazed to the copper body. (About 10 in. of heater was brazed to the body.) Copper s!eeves were brazed over the heater extensions to condust heat to the body, but no estimate of this heat flow could be wade. At the low power levels used to determine the heat loss functions, this loss was included in the orerall Ioss; however, at the higher power levels associated with the aata runs, this contribution to the total would be underestimated by the fitted heat loss equations. Thus, an unestimable fraction of the electrical power input never reaches the useful portion of the heat flux meter.

The heat loss calculated from the above equations will not inslude the heat transferred to the test fluid through the stainless steel elango surrounding the boiling surface of the meter. Based on design calculations discussed in Appencix B, this is shown to be a small fraction of the total heat input and is incluaed as unaccounted heat losses. Therefore, the calculated heat balance, consisting of the heat flow through the boiling surface (determined from the Pourier heat condustion equation evaluated at the boiling surface) and the loss calsulate.? from 
Eq. $(A-12)$ or Eo. $(A-12)$, does not include the small heat losses discussed abcre; for tnese reasons, the calculated heat tillance should re less than unity.

Checks were made prior to the Freon-I1j flow boiling tests to determine if the meter heat loss calibrations made with water flowing at $2 \mathrm{ft} / \mathrm{sec}$ vere applicable (as expected) under similar sonditions to the refrigerant. For an averaze meter temperature of $118.5^{\circ} \mathrm{F}$, the experimentally determined heat loss for meter $\mathrm{BM}-?$ was $0.5 \% \mathrm{~W}$, whereas Eq. (A-12) Fredicted $0.635 \mathrm{H}$. Similarly for HM-1 at an arerage terperature of $121.9^{\circ} \mathrm{F}$, the neat loss was determined to ke $0.375 \mathrm{~W}$, which is to be ccmparea to a value of $0.312 \mathrm{~W}$ computed from Eq. (A-II). Since these checks afreed vell with the predictive expressions, the equations were also used to calculate the meter heat losses ir the Freon-113 tests. It may be noted from these resuits that meter HM-1 was somewhat better insuiated against heat losses. This was also apparerit in the pool boiling experiments in which the entire assembly was submerged in: the boiling fluid isee Chapter i for a description of the physical arrangement). 


\section{AT FEIDIX B}

\section{COAPUIER ARALYSIS OP HBAT METER DESIGA}

It was recognized at the outset of this research that wuch would depend on successful elinina'ion of bubble nucleation at the periphery of the bofling surface and/or on the flange surface surrounding the test surface. This bothersone problem plagued a muber of investigators 74.217 .128 both at this laboratory and =-3ewhere. Aside from the annoyance, definition of the boiling area was uncertain and varied with the heat flux level. As a result heat loss corrections, generally based on the fin equations, were necessary.

Based on physical considerations of thermal corductivity, therwal expansion, and material compatibility (for brazingi, it was concluded that w thin stainless steel nange brazed to the end of a copper cylinder would most likely be the best meter design concept. Ooviously the thinner the stainless steel nange, the better the performance. However, increasingly wore difficult fabrication problems accompany the increased performance; and a srmponise unst be made between these two conflicting aspects.

Conceptual designs based on a nange thickness in the range of 0.010 to $0.015 \mathrm{in}$. was judged feasible by shop personnel. A number of design calculations were $p$ cormed, using the Hexrng-3 conputer program, ${ }^{26}$ to determine the expected performance characteristics.

HEATDIG-3 (Rep. 126), a modified version of the HEATIic program,i27 is designed to solve $A$ uide variety of steady-state and/or transient heat conduction problems in one-, two-, or three-dimenstional Cartesian or 
BLANK PAGE 
cylindrical coondinates. Input values of thermal conductivity, density, and specific heat way be dependent on teaperature at each lattice point. Specified heat generation rates way be tine dependent. The boundary conditions wy be fixed terperatures or any combination of constant heat flux, forced convection, natural convection, and radiation and can be from-surface-to-boundary, from-surface-to-surface, or from-surface-tosurface plus cosduction. The wesh spacing can vary along eacn axis, with as any as 1750 lattins points, 100 reglons, 50 waterials, and 50 boundary conditions being acsommodated.

Por purposes of analysis, the desion shown earlier (see PIg. IV-3) was modeled conceptually as depicted in PIg. B-1. Fourteen regions (for a total of 1073 node points) vere necersary to avoid muerical instabiiities in the calculation. The thin plating of nickel on the surface exposed to the fluid was neglected. The calculations vere perforwed for R-Z geometry under steady-state conditions.

In order to use the HENTIIG progran, boundary conditions, a volumetric heat generation runction, and an initial temperature distribution must be specified. A relaxation technique is used to calculate a new Lemperature distribution; the calculation continues until the specified cc.uvergence criterion is satisfied $\left(10^{-\%}\right.$ is generally used) or the specified computing time limit is reached. After the final tempereture iteration, the heat fluxes across all the external boundaries and the temperature at each node $16 \mathrm{printed.} \mathrm{Thus,} \mathrm{since} \mathrm{the} \mathrm{bolling} \mathrm{heat} \mathrm{flux}$ is a derived result, it is necessar; to repeat the calculation, making an adjustment in the input heat generation runction, a number of times to mat.ch the bolling reat nux to the specified bolling heat transfer 


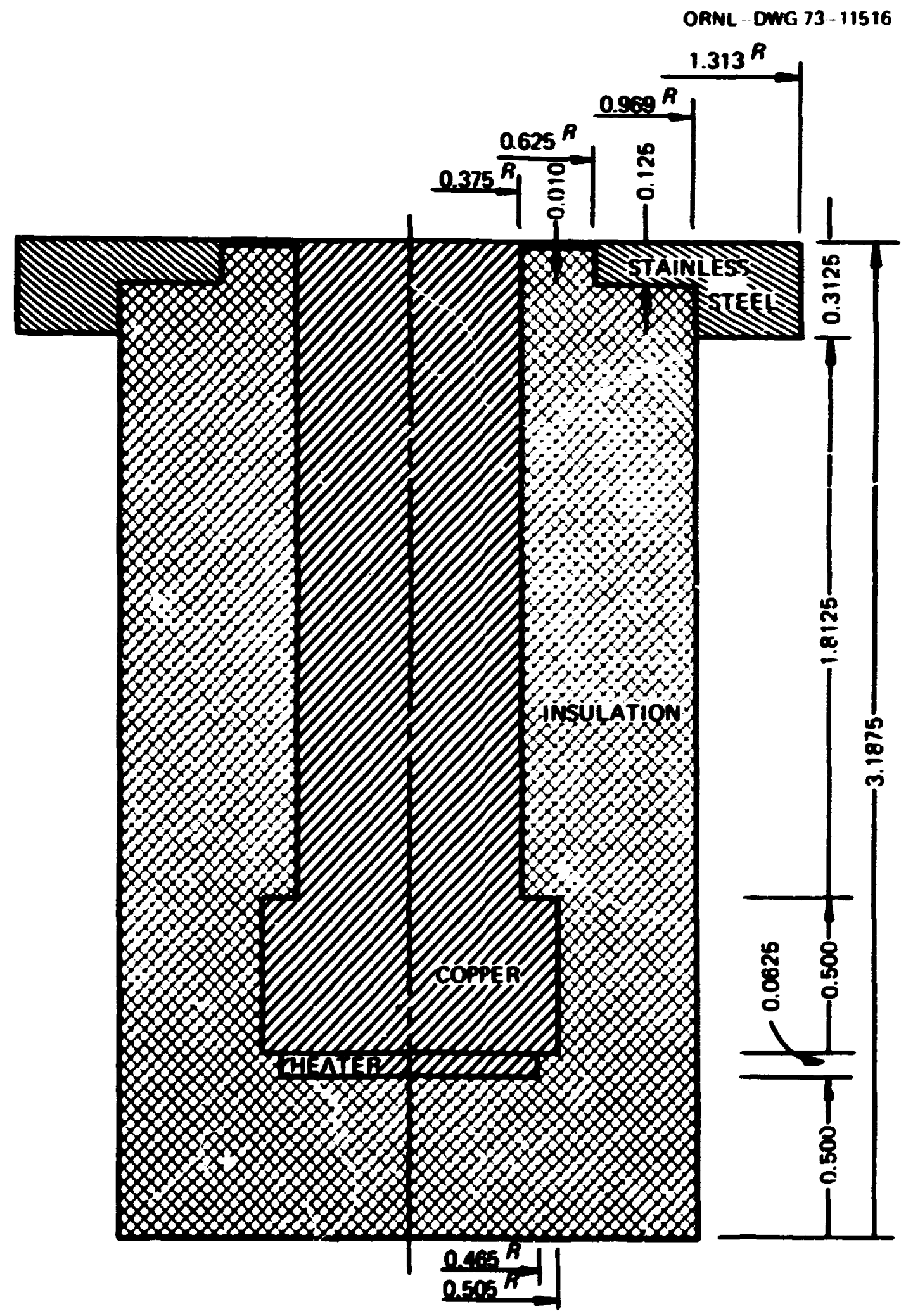

P1g. B-1. Calculational wodel of heat flux meter. 
coefficient. This, of course, is costly in computing time and should be avolded. This wes accomplished by making survey calculations on a simplified model.

With the exception of natural-convection heat transfer coefficients, temperature independent input parameters were used. In the cuse where the meter was considered subwerged in $212^{\circ} \mathrm{T}$ water (to simulate the pool oolling test setup), natural-convection coefficients vere specified as:

$$
h_{\text {nat corv }}=0.46 \Delta \mathrm{u}^{2 / 3}
$$

for all the external boundaries eircept the boiling surface. A constant value for the jool boiling coefficient was specified to match the desired boiling heat flux. The data of Marcus ${ }^{109}$ were used for this purpose. In those cases where the model simulated the flow bolling test setup, the surfaces exposed to air at $80^{\circ} \mathrm{T}$ were specified to have a naturalconvection coefficient given by:

$$
h_{\text {nat conv }}=0.002319 \Delta T^{1 / 3}
$$

Calculations were pezformed for $l o t h i \bar{i}-m i l$ and $15-m i l$ flange thicknesses. As would be expected, the temperature and heat flux distribution on the face of the 15-mil nange was not as flat as those for the $10-\mathrm{mil}$ nange.

The surface temperature and heat nwx distributions calculated for the meter $\left(0,010-\right.$ in.-in1ck $\rho$ ange) submerged in water at $212^{\circ} \mathrm{P}$ were shown earlier in Fig. IV-5. A pool bolling coefficient of 2304 Btu/ $h r \cdot f t^{2} \cdot{ }^{\circ}$ (at $50,000 \mathrm{Btu} / \mathrm{hr} \cdot \mathrm{ft}^{2}$ heat $\mathrm{flux}$ ) was used for the bolling surface, and Eq. (B-1) was spesified for the remainder of the external surfases. Floure B-.. shows the corresponding calculated axial (center 


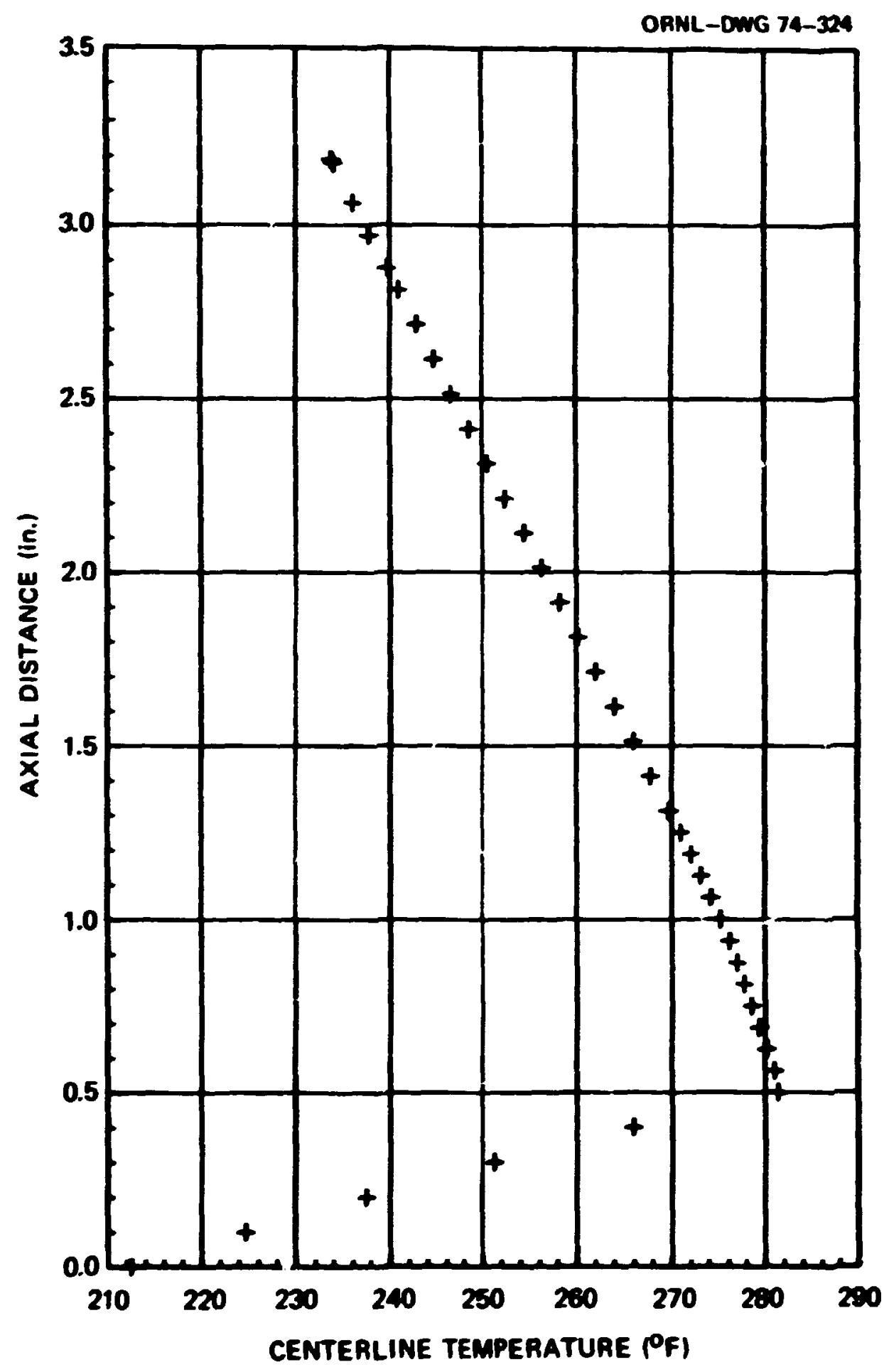

Pig. B-2. Calculated axial temperature distribution. 
Iine) temperature for the model. Bxcellent Iinearity in the reduced diameter portion of the meter is readily apparent in the figure. The corresponding radial temperature proflle at the middle thermoccuple is depicted in FIg. B-3. The calcuated distribution indicates negligible radial heat loss.

For this case, the analysis shows that 89.91 of the electrical power input is transferred to the fluid by bolling on the test surface, 2.8p is transti-rred by natural convection frow the stainless steel flange, and $7.3 \%$ by natural convection from the reaining exposed surraces. It was concluded from these results that the stainless steel nange thiciness should be specifled as $0.010 \mathrm{in}$. 


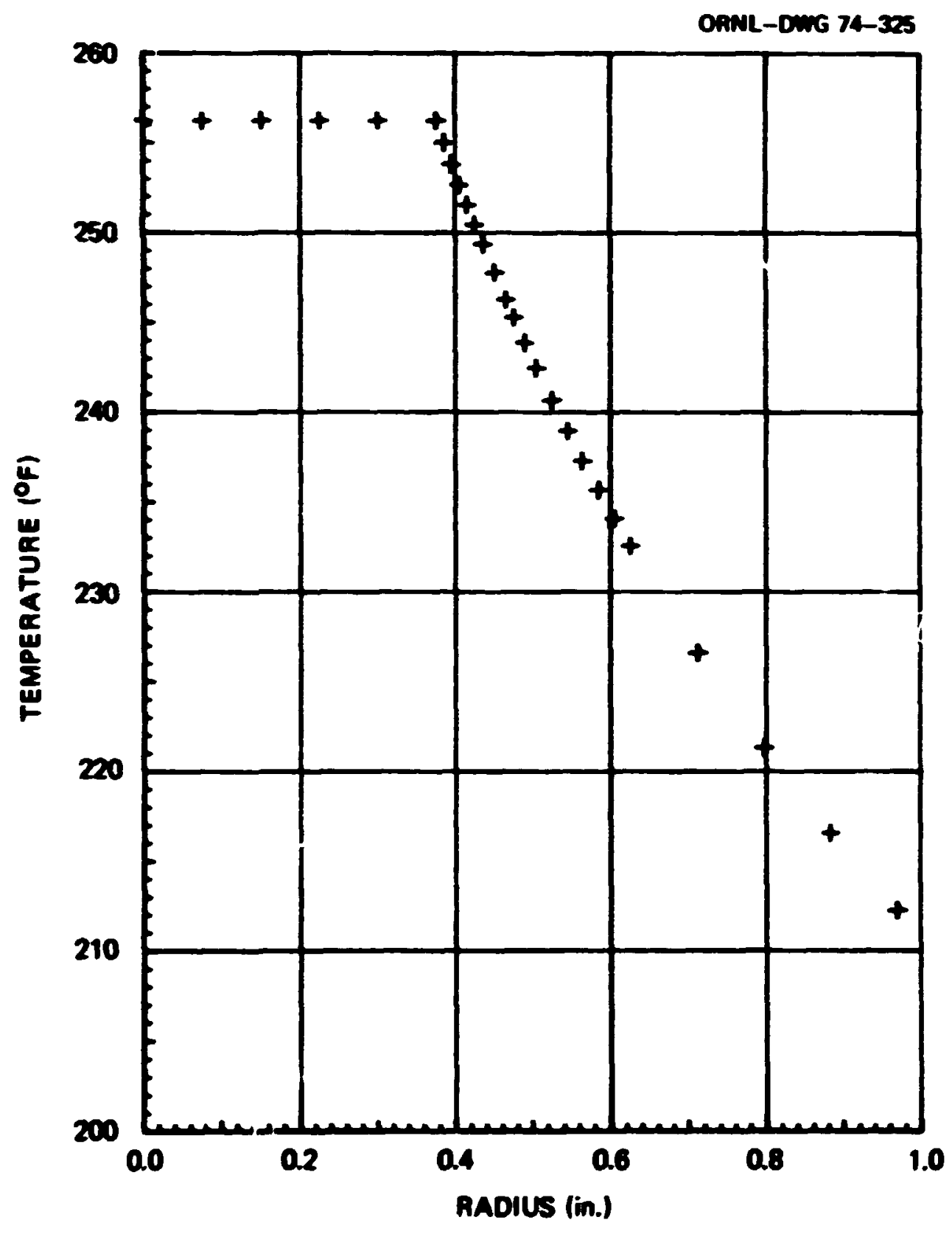

F13. B-3. Calculated radial terperature distribution. 


\section{APPEIDIX C}

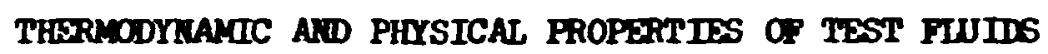

\section{C-1. Nater}

The thermodynami= and transport properties of water were calculated with a computer rourine written (unpublished) at Oak Ridge National Laboratory, using the equations and constants available in the 1967 ASEE Stean Tables.

\section{C-2. Fieon-113}

The thermodynamic and physical propertias of Freon-113 are not known :0 the same accuracy and are not as readily available as for water. For the purposes of this research, yubl sshed $^{135}$ and unpablished ${ }^{136}$ data vere fitt@d over the range of interest to facilitate data reduction and analysis by computer roitines. The ORDEAL ${ }^{129}$ least-squares fitting and plottiig routines were used fo: this purpose. It was determined for the limited temperature range that first, second, or third degree polynomials (depending on the property) gave lower standard errors for the coefficients than did fourth, fifth, or sixth degree fits.

The fitted equations, used for data reduction, are given below in skeletal format; Tablo C-1 1 ists the coefficients and pertinent statistical parameters.

1. Saturation temperatire ac a function of absolute pressure. $T_{\text {sat }}=P(F) ; 100 \leq T_{\text {sat }}\left({ }^{\circ} P\right) \leq 160,10.48 \leq P($ psia $) \leq 30.44$. $T_{\text {sat }}=A_{1} P^{3}+A_{2} P^{2}+A_{3} P+A_{4}$.

Data zource: Bulletin T-113A (Rer. 135). 
 \\ BLANK PAGE}

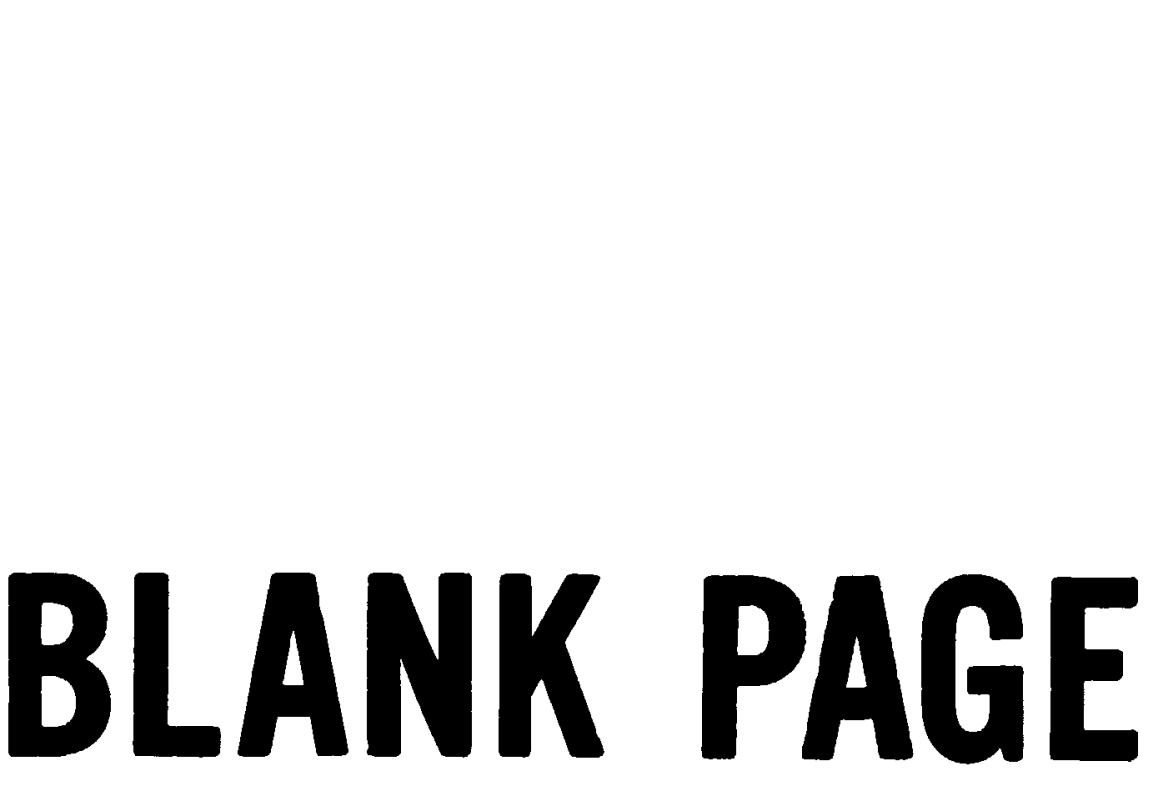


TABLE C-1

RESULTS OP LEAST-SQUARES FIHYED EQUATIOTS FOR FREOA - 113 PROPERTIES

\begin{tabular}{|c|c|c|c|c|}
\hline Equation & Coeffisient & Fitted Value & Standard Error & P Ratio \\
\hline$c-1$ & $\begin{array}{l}A_{1} \\
A_{2} \\
A_{3}\end{array}$ & $\begin{array}{r}0.1897151 \& D-02 \\
-0.1754251 \div D 00 \\
0.761272211 \mathrm{Di} \\
0.3742+943 \mathrm{D} 02\end{array}$ & $\begin{array}{l}0.66927096 \mathrm{D}-04 \\
0.40739514 \mathrm{D}-02 \\
0.79013288 \mathrm{D}-01 \\
0.48532009 \mathrm{D} 00\end{array}$ & $6.63460074 \mathrm{D}$ o5 \\
\hline$c-2$ & $\begin{array}{l}A_{1} \\
A_{2} \\
A_{3} \\
A_{4}\end{array}$ & 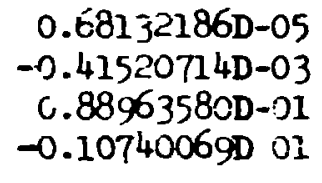 & $\begin{array}{l}0.22817187 \mathrm{D}-06 \\
0.89058609 \mathrm{D}-04 \\
0.11474814 \mathrm{D}-01 \\
0.48789346 \mathrm{D} 00\end{array}$ & 8.48753553006 \\
\hline$c-3$ & $\begin{array}{l}A_{1} \\
A_{2} \\
A_{3}\end{array}$ & $\begin{array}{l}0.12910952 \mathrm{D}-03 \\
0.19566733 \mathrm{D} 00 \\
0.81494590 \mathrm{D} 01\end{array}$ & $\begin{array}{l}0.23385419 \mathrm{D}-05 \\
0.60916762 \mathrm{D}-03 \\
0.39001 ? \mathrm{D}-01\end{array}$ & $1.25233786 \mathrm{D} 07$ \\
\hline$c-4$ & $\begin{array}{l}A_{1} \\
A_{3} \\
A_{3}\end{array}$ & $\begin{array}{r}-0.14631156 \mathrm{D}-03 \\
-0.43684801 \mathrm{D}-01 \\
0.70286251 \mathrm{D} 02\end{array}$ & $\begin{array}{l}0.238240050-05 \\
0.620592390-03 \\
0.39814685 \mathrm{D}-01\end{array}$ & $1.53830295 D \mathrm{Co}$ \\
\hline$c-7$ & $\begin{array}{l}A_{1} \\
A_{2} \\
A_{3} \\
A_{4}\end{array}$ & $\begin{array}{r}-0.24791887 \mathrm{D}-05 \\
0.12765348 \mathrm{D}-02 \\
-0.23531746 \mathrm{D} 00 \\
0.16217747 \mathrm{D} 02\end{array}$ & $\begin{array}{l}0.66920961 \mathrm{D}-07 \\
0.26120164 \mathrm{D}-04 \\
0.33654689 \mathrm{D}-02 \\
0.1430951 .4 \mathrm{D} 00\end{array}$ & $8.55586863 \mathrm{D} 05$ \\
\hline$c-8$ & $\begin{array}{l}A_{1} \\
A_{2}\end{array}$ & $\begin{array}{r}0.213263640 .04 \\
-0.34891142 D 01\end{array}$ & $\begin{array}{l}0.71259749000 \\
0.11847024 D-02\end{array}$ & 4.47831942006 \\
\hline$c-1 C$ & $\begin{array}{l}A_{2} \\
A_{3} \\
A_{4}\end{array}$ & $\begin{array}{r}0.13888889 \mathrm{D}-0 \mathrm{~B} \\
-0.86507143 \mathrm{D}-06 \\
0.21093254 \mathrm{D}-03 \\
0.10450 \mathrm{C} 00 \mathrm{D}-01\end{array}$ & $\begin{array}{l}0.28350566 \mathrm{D}-09 \\
0.15336286 \mathrm{D}-06 \\
0.26964204 \mathrm{D}-04 \\
0.15373565 \mathrm{D}-02\end{array}$ & 3.69246429003 \\
\hline$c-11$ & $\begin{array}{l}A_{1} \\
A_{2}\end{array}$ & $\begin{array}{r}-0.65774286 D-04 \\
0.48461905 D-01\end{array}$ & $\begin{array}{l}C .41239304 D-06 \\
0.47499852 D-04\end{array}$ & $1.26960000 \mathrm{D} 04$ \\
\hline$c-12$ & $\hat{A_{2}}$ & $\begin{array}{l}0.13857143 \mathrm{D}-03 \\
0.21792381 \mathrm{D} \mathrm{CO}\end{array}$ & $\begin{array}{l}0.38685876 \mathrm{D}-05 \\
0.44558803 \mathrm{D}-03\end{array}$ & $6.4 \div 522727 \mathrm{D}$ oc \\
\hline$c-13$ & $\begin{array}{l}A_{1} \\
A_{2}\end{array}$ & $\begin{array}{c}-0.6001984 \mathrm{ID}-01 \\
0.21901349 \mathrm{D} 0 ?\end{array}$ & $\begin{array}{l}0.34436025 \mathrm{D}-03 \\
0.4729^{\prime} 084 \mathrm{D}-01\end{array}$ & 1.51891599004 \\
\hline
\end{tabular}


2. Saturation pressure (absolute) as a function of temperature. $P_{\text {sat }}=P(T) ; 10.48 \leq P_{\text {sat }}($ psia $) \leq 30.44,100 \leq T\left({ }^{\circ} \mathrm{F}\right) \leq 160$. $P_{\text {sat }}=A_{2} T^{3}+A_{2} T^{2}+A_{3} T+A_{6}$.

Data source: Bulletin T-113A (Rer. 135).

3. Saturated liquid enthalpy as a function of temperature.

$h_{f}=f\left(T_{s a t}\right) ; 28.99 \leq h_{f}\left(B^{B t} / / 2 b_{m}\right) \leq 42.74,100 \leq T_{\text {sat }}\left({ }^{\circ} \mathrm{F}\right) \leq 160$.

$h_{f}=A_{1} T_{\text {sat }}^{3}+s_{2} T_{\text {sat }}^{2}+A_{3} T_{\text {sat }}+A_{s}$.

Data source: Bulleitin T-113A (Ref. 135).

4. Latent heat of vaporization as a function temperature.

$h_{f g}=f\left(T_{\text {sat }}\right): 54.46 \leq h_{f g}\left(B t u / 1 b_{m}\right) \leq 59.55,100 \leq T_{s a t}\left({ }^{\circ} F\right) \leq 160$.

$h_{\text {fg }}=A_{1} T_{\text {sat }}^{2}+A_{2} T_{\text {sat }}+A_{3}$.

Data source: Bulletin T-113A (Kef. 135).

5. Saturated liquid density as a function of temperature.

$\mathcal{c}_{\ell}=\mathrm{f}\left(\mathrm{T}_{\text {sat }}\right) ;-30 \leq \mathrm{T}_{\text {sat }}\left({ }^{\circ} \mathrm{F}\right) \leq 220,105.64 \leq \rho_{\ell}\left(1 \mathrm{~b}_{\mathrm{m}} / \mathrm{ft}^{3}\right) \leq 84.80$.

$p_{\ell}=103.555-0.07126 \mathrm{~T}_{\text {sat }}-0.0000636 \mathrm{~T}_{\text {sat }}^{\mathrm{e}}$.

Equation given in Bulletin T-113A (Ref. 135).

6. Saturated liquid specific volume as a function of temperature. $v_{l}=f\left({ }^{\prime}{ }_{s a t}\right) ; 0.00947 \leq v_{l}\left(\mathrm{ft}^{3} / \mathrm{Ib}_{\mathrm{m}}\right) \leq 0.01179,-30 \leq \mathrm{T}_{\text {sat }}\left({ }^{\circ} \mathrm{F}\right) \leq 220$.

$v_{\ell}=1 / \rho_{\ell}$,

where $\rho_{\ell}$ is given by Eq. $(C-5)$.

\%. Saturated vapor specific vclume as a function of temperature.

$v_{B}=f\left(T_{\text {sat }}\right) ; 2.076 \leq\left(\mathrm{ft}^{3} / 1 b_{m}\right) \leq 1.094,100 \leq T_{\text {sat }}\left({ }^{\circ} \mathrm{F}\right) \leq 160$.

$v_{B}=A_{1} T_{\text {sat }}^{3}+A_{2} T_{\text {sat }}^{2}+A_{3} T_{\text {sat }}+A_{4}$.

Data source: Bulletin T-113A (Ref. 135). 
8. Saturated liquid viscosity as a function of temperature. $\mu_{\ell}=I\left(T_{\text {sat }}\right) ; 1.849 \leq \mu_{\ell}\left(1 b_{m} / \mathrm{ft} \cdot \mathrm{hr}\right) \leq 0.643,60 \leq T\left({ }^{T}\right) \leq 2^{4}+0$. $\ln \mu_{l}=A_{2} Z+A_{2}$,

where $\mathrm{Z} \equiv\left(\mathrm{T}_{\text {sat }}+459.67\right)^{-1}$.

Data source: DuPont Company. 136

9. Saturated vapor viscosity as a function of terperature. $\mu_{\mathrm{g}}=f\left(T_{\text {sat }}\right) ; 0.0257 \leq \mu_{\mathrm{g}}\left(1 \mathrm{o}_{\mathrm{w}} / \mathrm{ft} \cdot \mathrm{hr}\right) \leq 0.0304,120 \leq \mathrm{T}_{\text {sat }}\left({ }^{\circ} \mathrm{F}\right) \leq 240$. $\mu_{B}=A_{1} T_{s a t}^{3}+A_{2} T_{s a t}^{2}+A_{3} T_{\text {sat }}+A_{4}$.

Data source: DuPont Company.$^{136}$

10. Saturated liquid thermal conductivity as a function of temperature.

$k_{l}=f\left(T_{\text {sat }}\right) ; 0.0445 \leq k_{l}\left(B t u / h r \cdot f t \cdot{ }^{\circ} F\right) \leq 0.0379,100 \leq T_{s a t}\left({ }^{\circ} F\right) \leq 160$. $k_{l}=A_{1} T_{3 a t}+A_{2}$.

Dis source: DuPont Company. ${ }^{36}$

11. Saturated liquid specteic heat as a function of temperature. $C_{p}=P\left(T_{\text {sat }}\right) ; 0.226 \leq C_{p}\left(B t u / 1 b_{m} \cdot{ }^{\circ} \mathrm{Z}\right) \leq 0.240,60 \leq T_{\text {sat }}\left({ }^{\circ} \mathrm{P}\right) \leq 160$. $C_{p}=A_{1} T_{\text {sat }}+A_{2}$.

Data source: Dupont Company. 130

12. Saturated liquid surface tension as a function of temperature. $\sigma=\mathcal{I}\left(T_{\text {sat }}\right) ; 17.87 \leq \sigma($ dynes $/ \mathrm{cm}) \leq 10.31,68 \leq T_{\text {sat }}\left({ }^{\circ} \mathrm{T}\right) \leq 194$. $\sigma=A_{1} T_{\text {sat }}+A_{0}$.

Dats source: Sinitsyn et aㅡ. ${ }^{37}$ 
APPSTDIX D

DATA SHEETS, REDUCED DATA TABULATIOIS, AND

CROSS RETERERICE LISTIIG OP EXPERDARTIS 


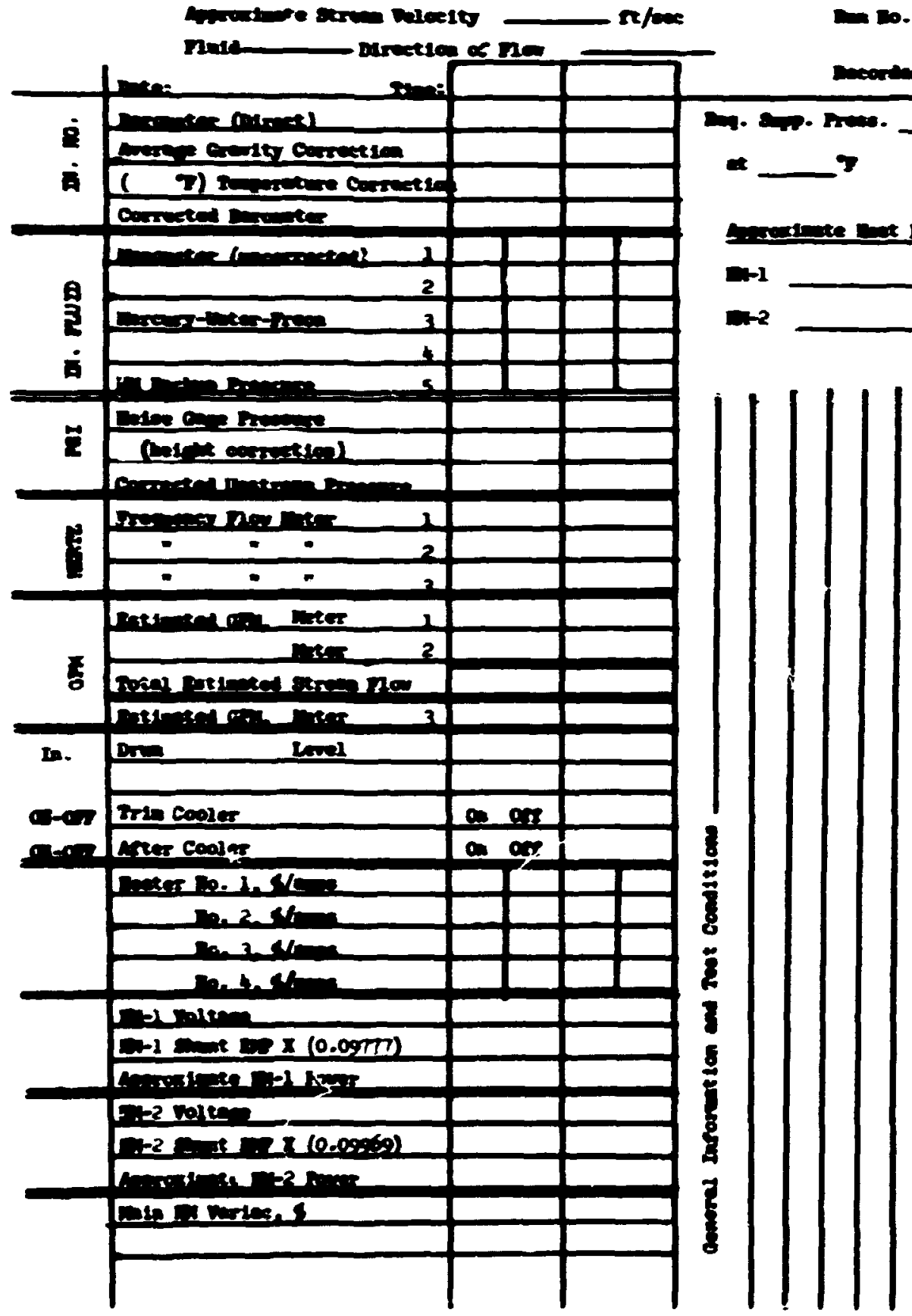

PIg. D-1. Data sheet 1 for flon tests. 


\section{BLANK PAGE}




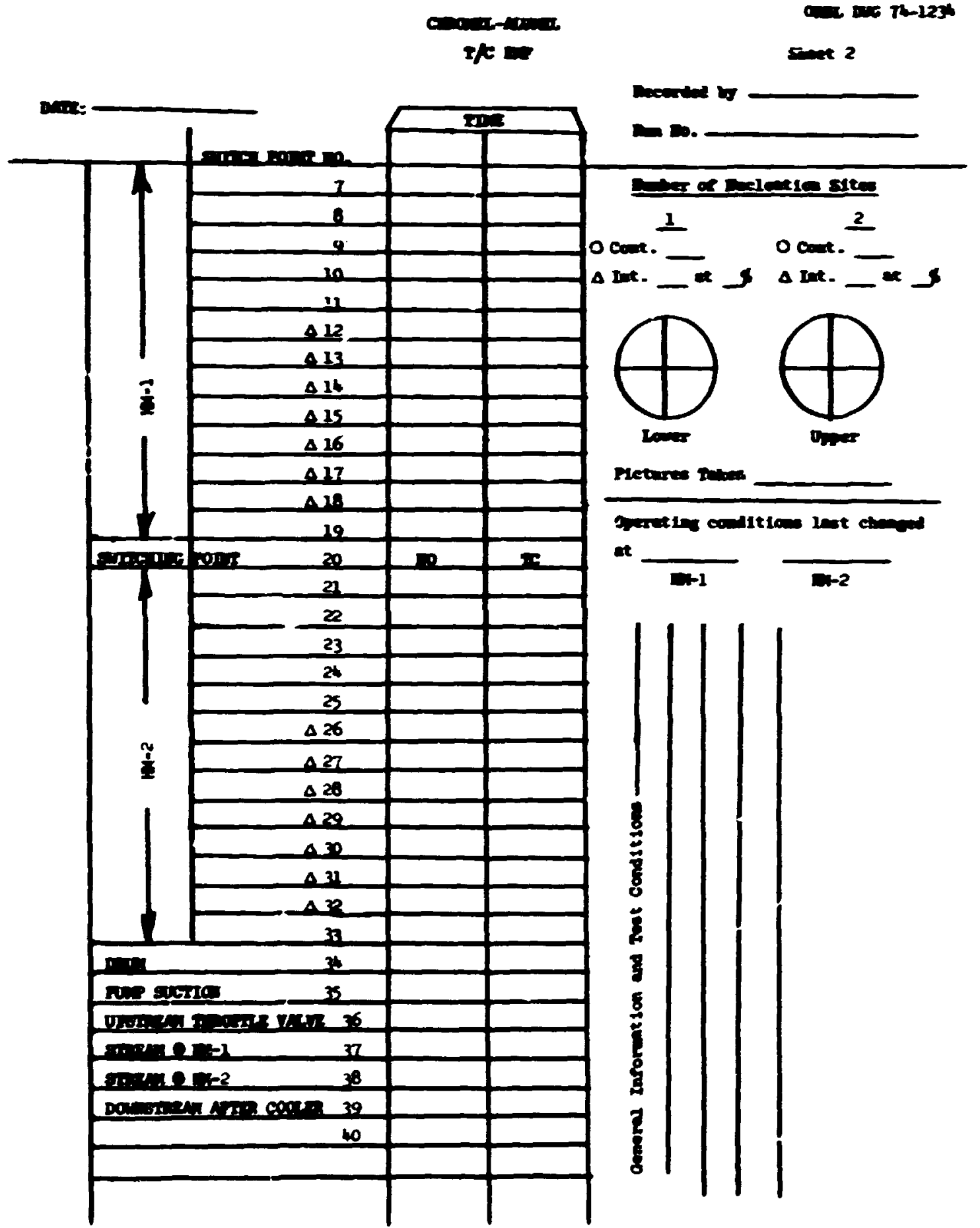

Fig. D-2. Data sheet 2 for flow tests. 


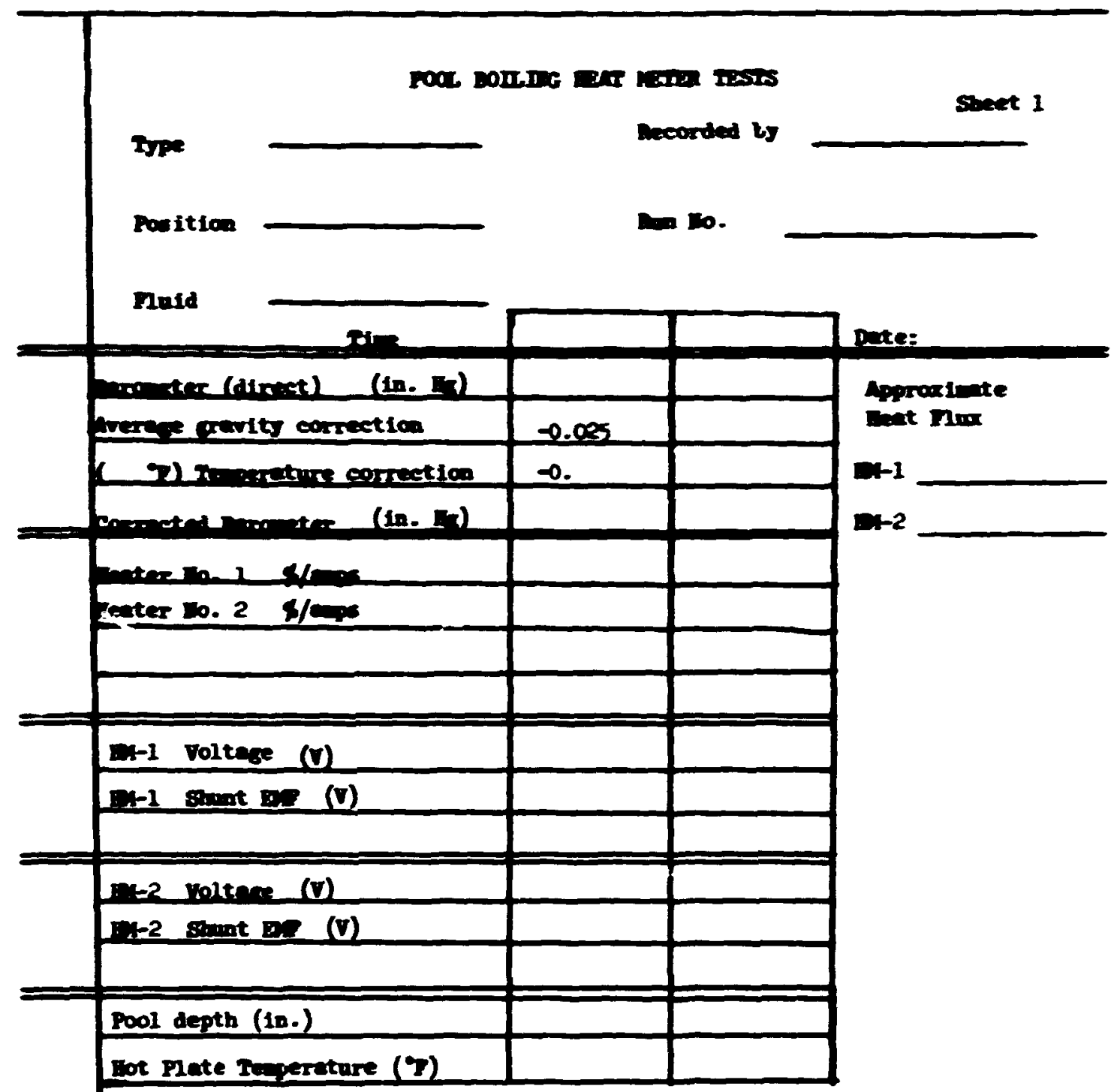

ceocinal Incountion

F1g. D-3. Data sheet 1 for pool bolling tests. 
$0+14-123$

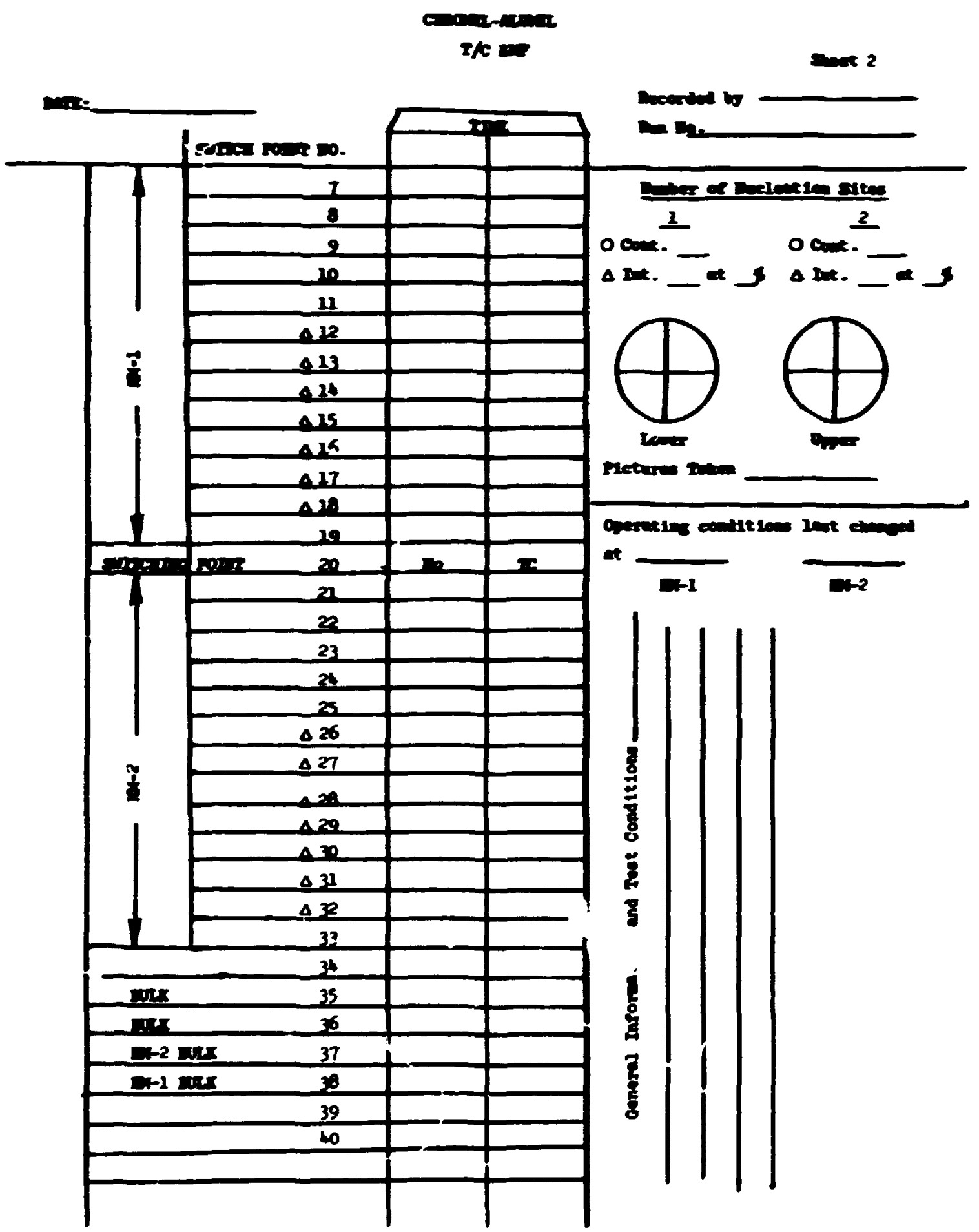

Fig. D-4. Data sheet $z$ for pool bolling tests. 
PAL2: D-1

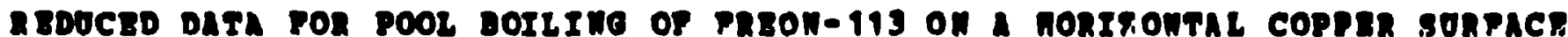
OSIno MaAT hETER GH-1

\begin{tabular}{|c|c|c|c|c|c|c|c|c|}
\hline In Ideat. & Date & nove & $\begin{array}{l}g_{n+n}^{n}(n n-1) \\
n+r-p t s\end{array}$ & $\begin{array}{l}\text { meas. } \\
\text { preas. } \\
\text { pela }\end{array}$ & $\underset{0 p}{\operatorname{Ta}}$ & 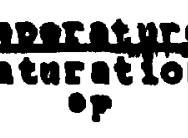 & & 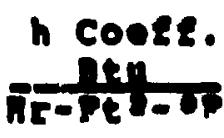 \\
\hline 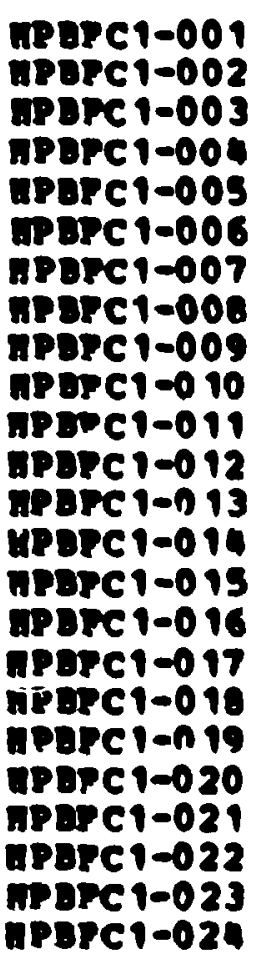 & $\begin{array}{l}12-04-73 \\
12-05-73 \\
12-05-73 \\
12-05-73 \\
12-05-73 \\
12-05-73 \\
12-05-73 \\
12-05-73 \\
12-06-73 \\
12-06-73 \\
12-06-73 \\
12-06-73 \\
12-06-73 \\
12-06-73 \\
12-06-73 \\
12-06-73 \\
12-06-73 \\
12-06-73 \\
12-06-73 \\
12-06-73 \\
12-06-73 \\
12-07-73 \\
12-07-73 \\
12-07-73\end{array}$ & $\begin{array}{l}1245 \\
1045 \\
1605 \\
1710 \\
1810 \\
1915 \\
2025 \\
2130 \\
1015 \\
1115 \\
1220 \\
1320 \\
1115 \\
1500 \\
1535 \\
1620 \\
1700 \\
1740 \\
1030 \\
1910 \\
2000 \\
0830 \\
1015 \\
1050\end{array}$ & $\begin{array}{r}314 \\
15271 \\
1842 \\
1254 \\
2985 \\
2092 \\
1234 \\
826 \\
205 \\
12398 \\
9859 \\
7340 \\
4946 \\
19408 \\
32162 \\
25657 \\
22947 \\
20207 \\
17396 \\
13626 \\
8336 \\
277 \\
45132 \\
32222\end{array}$ & 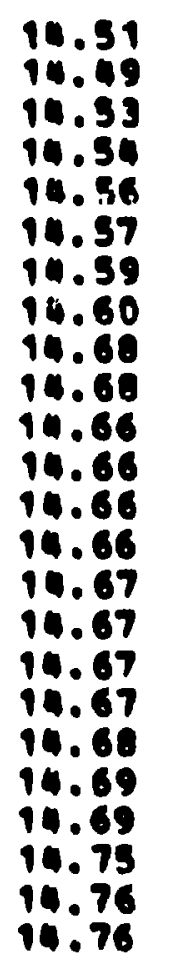 & $\begin{array}{l}120.69 \\
133.45 \\
133.42 \\
133.40 \\
133.47 \\
133.20 \\
129.30 \\
126.54 \\
120.49 \\
134.73 \\
134.56 \\
134.55 \\
134.36 \\
137.90 \\
137.43 \\
137.08 \\
136.92 \\
136.78 \\
136.70 \\
136.45 \\
136.18 \\
121.11 \\
199.19\end{array}$ & $\begin{array}{l}116.51 \\
116.10 \\
119.44 \\
116.59 \\
116.94 \\
117.08 \\
117.07 \\
117.28 \\
117.31 \\
117.32 \\
117.21 \\
117.23 \\
117.26 \\
116.99 \\
117.14 \\
117.18 \\
117.29 \\
117.30 \\
117.33 \\
117.35 \\
117.47 \\
117.70 \\
117.41 \\
117.49\end{array}$ & 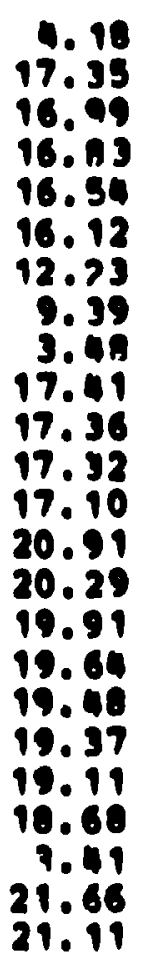 & $\begin{array}{r}75 \\
890 \\
285 \\
253 \\
181 \\
130 \\
101 \\
88 \\
12 \\
711 \\
561 \\
124 \\
289 \\
2171 \\
1585 \\
1289 \\
1119 \\
1037 \\
894 \\
713 \\
146 \\
81 \\
20194 \\
1526\end{array}$ \\
\hline
\end{tabular}




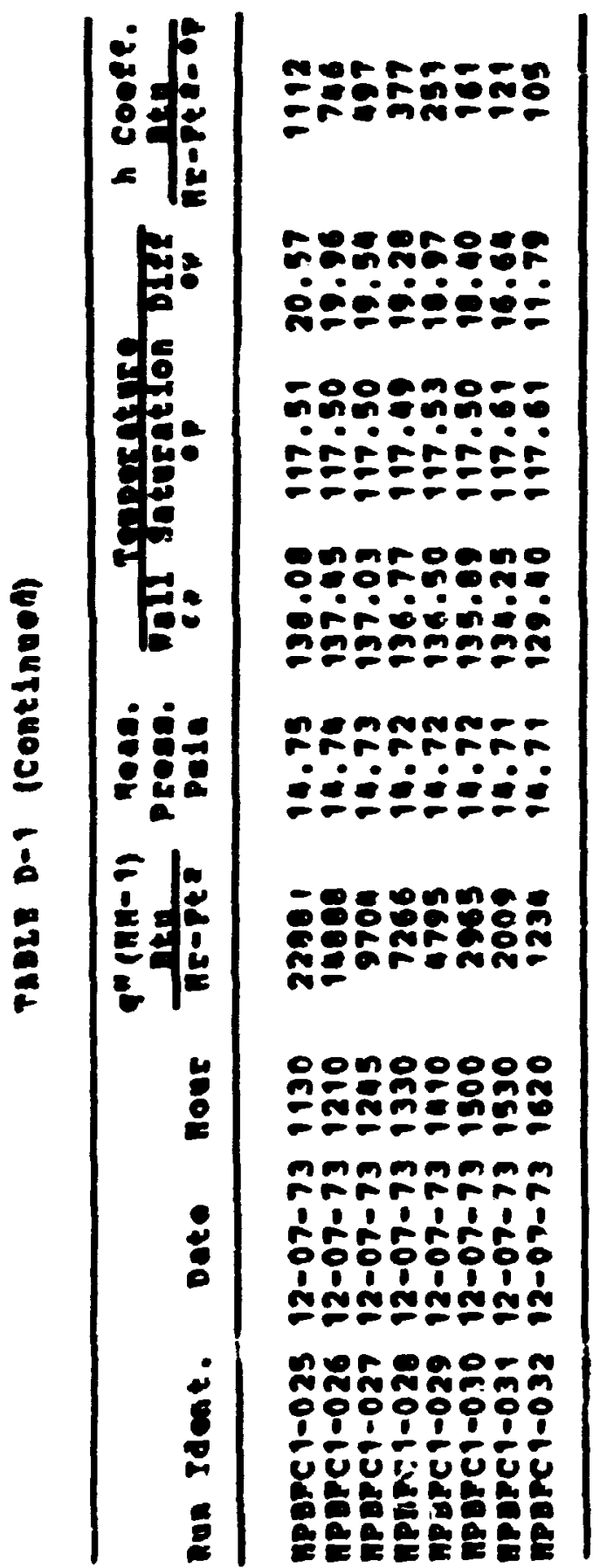




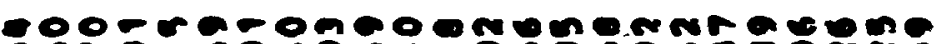

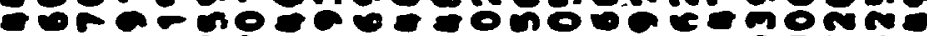
$\rightarrow$ a

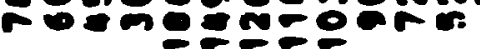

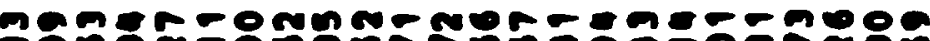

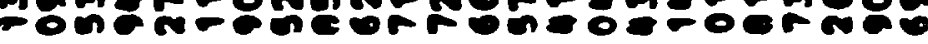

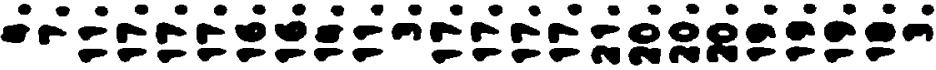

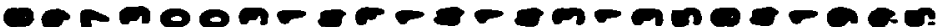

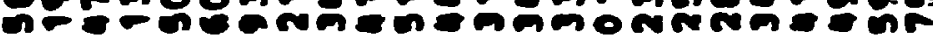

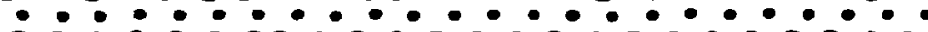

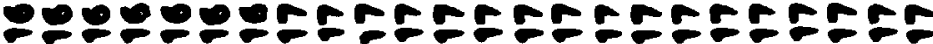

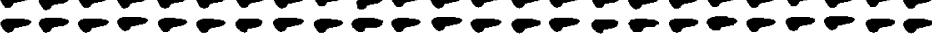

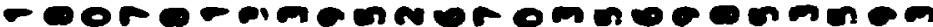

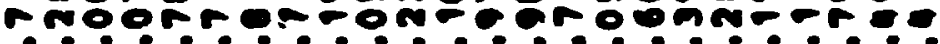

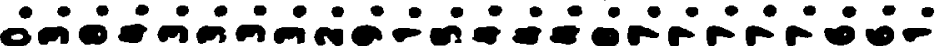

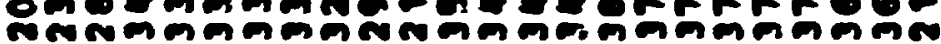

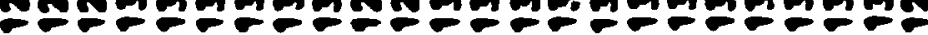

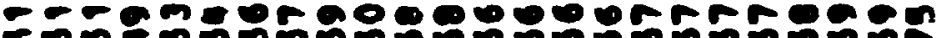
10

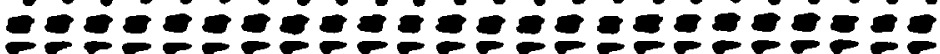

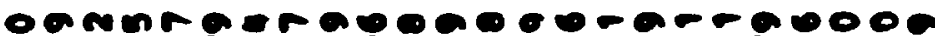

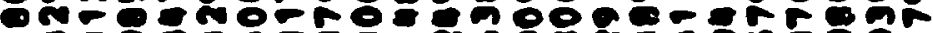
- 0 -

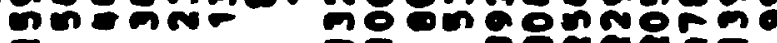

n

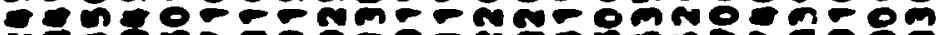

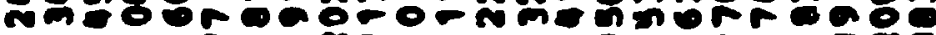

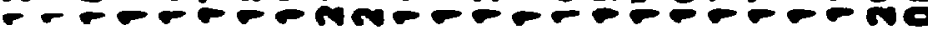

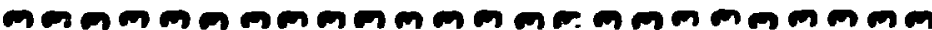

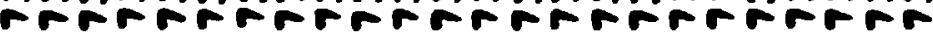

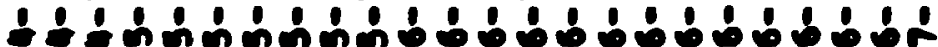

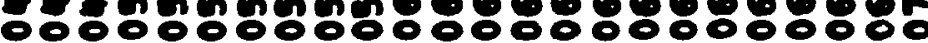

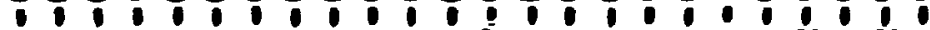

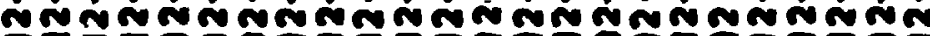
- nmangrogoramenorego-nme

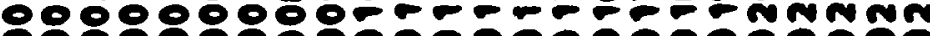
898989898999999998999899

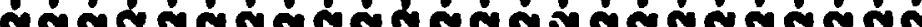

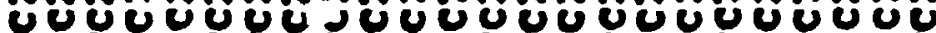

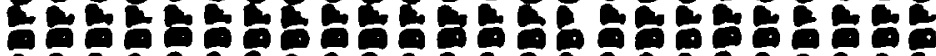

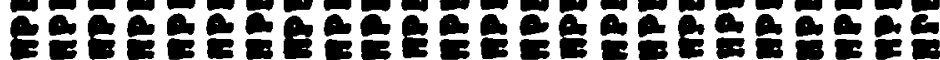


ragre n-2 (Conelnued)

\begin{tabular}{|c|c|c|c|c|c|c|c|c|}
\hline Run Racat. & Dato & Mont & $\frac{\left.q^{n} \operatorname{lin}_{n+n}-2\right)}{n x-p+8}$ & $\begin{array}{l}\text { noan. } \\
\text { proes. } \\
\text { pola }\end{array}$ & $\frac{1}{\operatorname{lag}^{\prime}}$ & peret & UI: & $\begin{array}{c}\text { n cooge. } \\
\text { neth } \\
\text { nz-peu-op }\end{array}$ \\
\hline 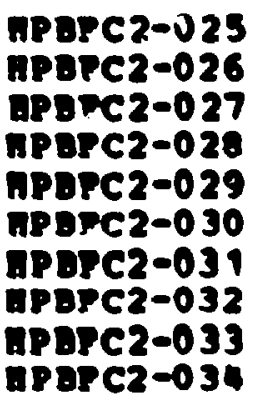 & $\begin{array}{l}12-07-73 \\
12-07-73 \\
12-07-73 \\
12-07-73 \\
12-07-73 \\
12-07-73 \\
12-07-73 \\
12-07-73 \\
12-07-73 \\
12-07-73\end{array}$ & $\begin{array}{l}1015 \\
1050 \\
1130 \\
1210 \\
1245 \\
1330 \\
1410 \\
1300 \\
1330 \\
1820\end{array}$ & $\begin{array}{l}39139 \\
31083 \\
22877 \\
19574 \\
10749 \\
7995 \\
3383 \\
3309 \\
2162 \\
1265\end{array}$ & $\begin{array}{l}14.78 \\
14.78 \\
14.75 \\
14.74 \\
14.73 \\
14.72 \\
14.72 \\
14.72 \\
14.71 \\
14.71\end{array}$ & $\begin{array}{l}138.99 \\
138.72 \\
138.24 \\
137.73 \\
137.15 \\
136.97 \\
136.60 \\
136.18 \\
135.93 \\
132.00\end{array}$ & $\begin{array}{l}117.55 \\
117.49 \\
117.59 \\
117.53 \\
117.59 \\
117.51 \\
117.64 \\
117.58 \\
117.58 \\
117.75\end{array}$ & $\begin{array}{l}21.44 \\
21.24 \\
20.85 \\
20.09 \\
19.56 \\
19.38 \\
10.98 \\
10.39 \\
19.37 \\
15.05\end{array}$ & $\begin{array}{l}1925 \\
1464 \\
1108 \\
775 \\
550 \\
413 \\
284 \\
170 \\
118 \\
04\end{array}$ \\
\hline
\end{tabular}


TABLE D-3

REDUCSD DATA POR POOL COILINO OF PRBOH-113 ON A PERTICAL COPPEA SORPACE ostro mEAT GETRR MH-1

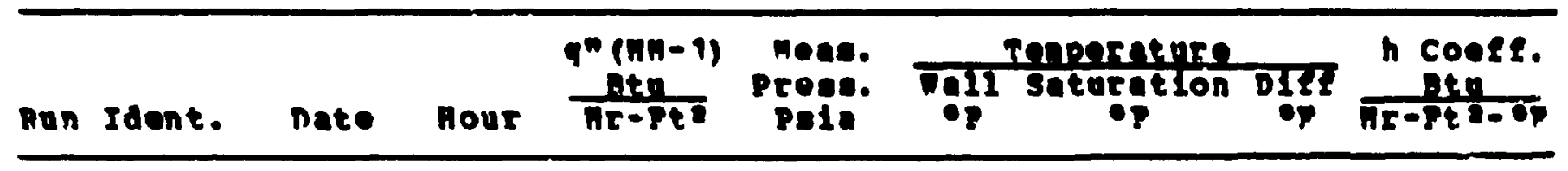

For Varving mH-l Plox

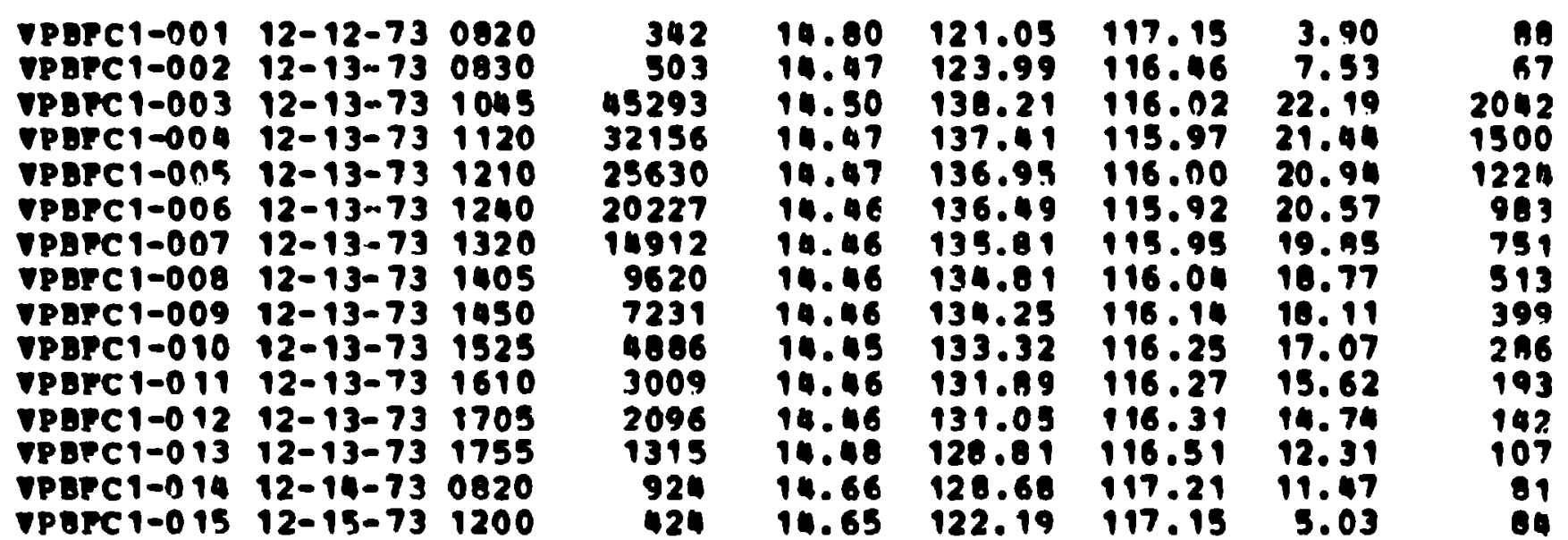

Por constant nh-1 plaz

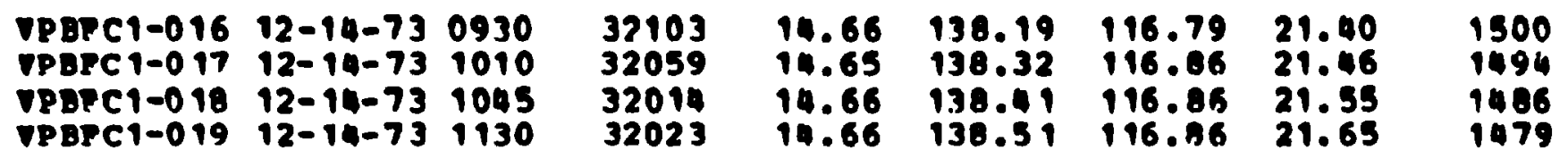


TABLE D-3 (Continuea)

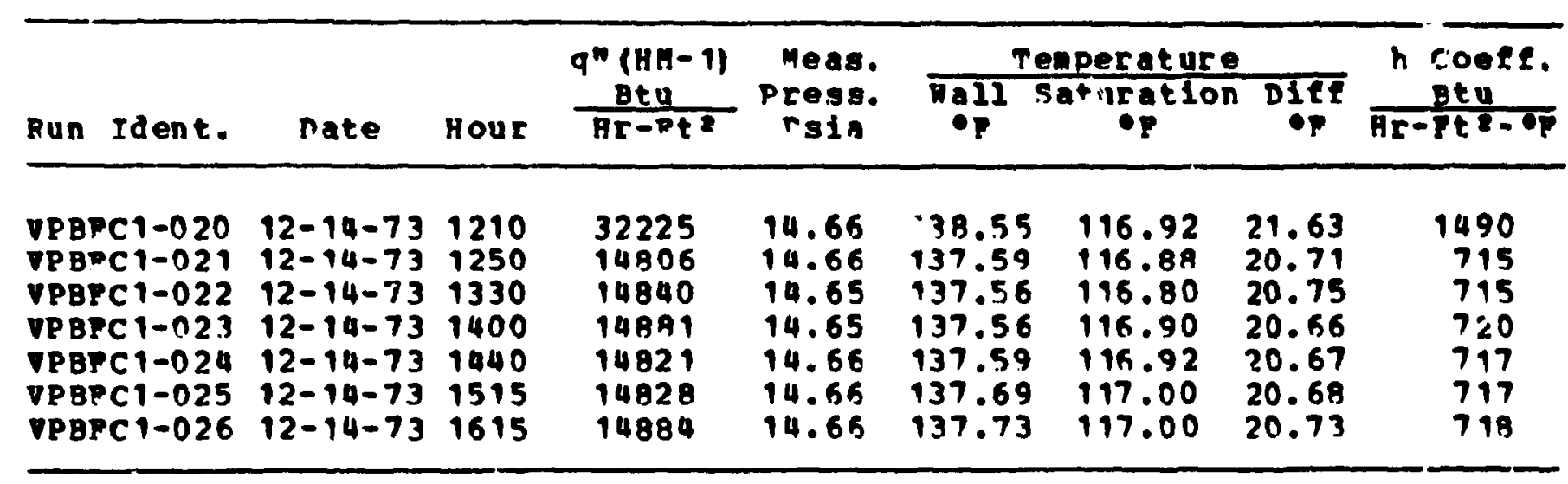


TABS, D $\mathbf{D}$

REDAFBR DATA FOR POOL BOILING OP PREON-113 ON A VERTICAL COPPER STRFACF USING HEAT METER HM-2

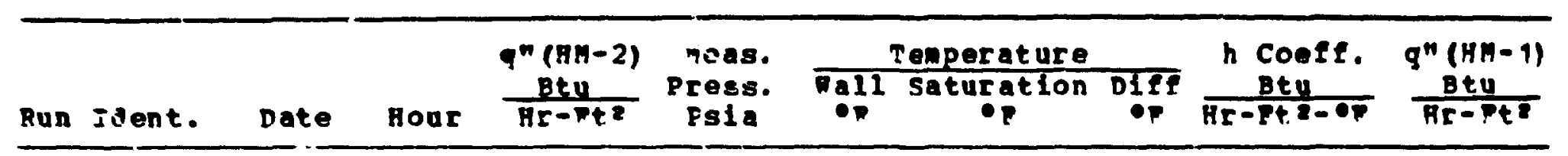

For Varying $\bar{n} \div-2$ plux

\begin{tabular}{|c|c|c|}
\hline 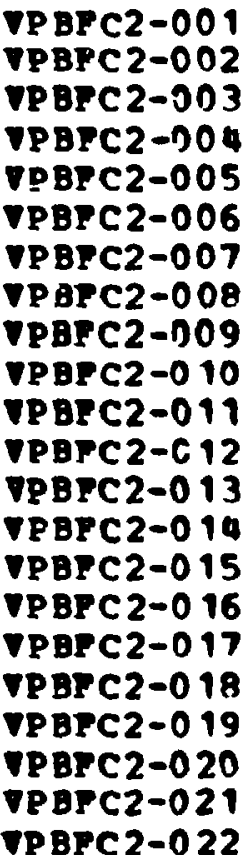 & $\begin{array}{l}12-12-73 \\
12-12-73 \\
12-12-73 \\
12-12-73 \\
12-12-73 \\
12-12-73 \\
12-12-73 \\
12-12-73 \\
12-12-73 \\
12-12-73 \\
12-12-73 \\
12-12-73 \\
12-12-73 \\
12-12-73 \\
12-12-73 \\
12-12-73 \\
12-13-73 \\
12-13-73 \\
12-13-73 \\
12-14-73 \\
12-15-73 \\
12-15-73\end{array}$ & $\begin{array}{l}0940 \\
1030 \\
1120 \\
1200 \\
1515 \\
1430 \\
14 \div 5 \\
1620 \\
1700 \\
1740 \\
1820 \\
1855 \\
1940 \\
2020 \\
2055 \\
2135 \\
0830 \\
0920 \\
0955 \\
0820 \\
1200 \\
1900\end{array}$ \\
\hline
\end{tabular}

$\begin{array}{rrrr}39171 & 14.65 & 139.49 & 117.22 \\ 30119 & 14.64 & 138.97 & 117.14 \\ 20703 & 14.64 & 138.17 & 117.10 \\ 15602 & 14.63 & 137.70 & 117.02 \\ 10578 & 14.58 & 136.66 & 117.11 \\ 7916 & 14.54 & 136.11 & 117.19 \\ 39377 & 14.54 & 139.12 & 117.00 \\ 30246 & 14.52 & 139.03 & 117.03 \\ 20594 & 14.52 & 138.62 & 117.08 \\ 15627 & 14.51 & 138.10 & 117.02 \\ 10519 & 14.51 & 137.19 & 117.06 \\ 7932 & 14.51 & 136.59 & 117.09 \\ 5349 & 14.50 & 135.69 & 117.08 \\ 3183 & 14.50 & 134.85 & 117.07 \\ 2359 & 14.49 & 134.31 & 116.99 \\ 1238 & 14.49 & 132.59 & 117.02 \\ 336 & 14.31 & 122.62 & 116.30 \\ 39328 & 14.32 & 138.84 & 116.14 \\ 25260 & 14.32 & 138.57 & 116.22 \\ 668 & 14.50 & 128.36 & 117.11 \\ 254 & 14.49 & 121.45 & 117.16 \\ 448 & 14.48 & 125.68 & 117.16\end{array}$

22.27
21.82
21.08
20.68
19.44
18.92
27.12
21.99
21.55
21.09
20.13
19.50
18.61
17.78
17.31
15.57
6.32
22.70
22.35
11.25
4.29
8.52

1759
1380
942
755
544
418
1780
1375
956
741
523
407
287
179
136
80
53
1733
1130
59
59
53


TABLE D-Q (Continued)

\begin{tabular}{|c|c|c|c|c|c|c|c|c|c|c|}
\hline Run & Ident. & Date & Hour & $\begin{array}{c}q^{n}(B n-2) \\
\frac{B+y^{2}}{\text { Br-pt? }}\end{array}$ & $\begin{array}{l}\text { neas. } \\
\text { Preas. } \\
\text { Psia }\end{array}$ & $\frac{1}{\operatorname{ma11}}$ & 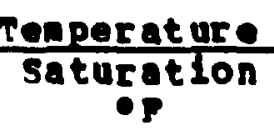 & $\overline{D I E P}$ & $\begin{array}{c}\text { h cuete. } \\
\frac{\text { Bty }}{\text { HI-Pt }}\end{array}$ & $\begin{array}{l}q^{n}(n m-1) \\
\frac{R+n}{h r-p t^{2}}\end{array}$ \\
\hline
\end{tabular}

For Constant HH- 2 Mux with Varping FH-1 plux

$\begin{array}{lll}\text { VPBFC2-023 } & 12-13-73 & 1045 \\ \text { VPBPC2-124 } & 12-13-73 & 1120 \\ \text { VPBFC2-025 } & 12-13-73 & 1210 \\ \text { VPBPC2-026 } & 12-13-73 & 1240 \\ \text { VPBPC2-027 } & 12-13-73 & 1320 \\ \text { VPBFC2-028 } & 12-13-73 & 1405 \\ \text { VPBPC2-029 } & 12-13-73 & 1450 \\ \text { VPEFC2-030 } & 12-13-73 & 1525 \\ \text { VPBPC2-03 } & 12-13-73 & 1610 \\ \text { PPSC2-032 } & 12-13-73 & 1705 \\ \text { VPBFC2-033 } & 12-13-73 & 1755\end{array}$

25367
25264
25386
25473
15639
15493
15580
15559
15614
15555
15551

14.34

14.31

14.31

14.30

14.30

14.30

14.30

14.30

14.30

14.31

14.33

139.67
138.67
138.69
138.68
138.18
138.22
138.22
138.20
138.20
138.27
138.35

116.02

115.96

115.99

115.95

115.95

116.06

116.12

116.25

116.23

116.31

116.41

22.65
22.72
22.71
22.73
22.22
22.15
22.09
21.95
21.97
21.96
21.94

For Varying hr-2

$\begin{array}{lll}\text { VPBFC2-034 } & 12-14-73 & 0930 \\ \text { VPBFC2-035 } & 12-14-73 & 1010 \\ \text { VPBFC2-036 } & 12-14-73 & 1045 \\ \text { VPBFC2-037 } & 12-14-73 & 130 \\ \text { VPBFC2-038 } & 12-14-73 & 1210 \\ \text { VPBPC2-039 } & 12-14-73 & 1250 \\ \text { VPBFC2-040 } & 12-14-73 & 1330 \\ \text { VPBPC2-041 } & 12-14-73 & 1400 \\ \text { VPBPC2-042 } & 12-14-73 & 1440 \\ \text { VPBFC2-043 } & 12-14-73 & 1515 \\ \text { VPBPC2-044 } & 12-14-73 & 1615\end{array}$

31982

22883

15518

10538

5443

18243

25418

10554

7824

5416

3526
$14.50 \quad 139.65$

14.50

14.50

14.50

14.50

14.50

14.49

14.49

14.50

14.50

14.51
139.44

139.16

138.26

133.98

139.30

139.48

138.32

137.49

135.27

130.26
116.80
116.84
116.84
116.86
116.90
116.84
116.79
116.89
116.89
117.00
117.00

22.85

22.60

22. 31

21.40

17.08

22.47

22.69

21.43

20. 59

18.27

13.26

$\begin{array}{ll}1120 & (45293) \\ 1112 & (32156) \\ 1118 & (25630) \\ 1121 & (20227) \\ 704 & (14912) \\ 699 & (9620) \\ 709 & (7231) \\ 709 & (4986) \\ 711 & (3009) \\ 708 & (2096) \\ 709 & (1315)\end{array}$

1400

1013

695

493

319

812

1120

493

380

296

266 
TADLE D-S

REDUCED DATA TOR POOL EOILIME OP MATA OP A MOAIEONTAL COPPRA SOAPACE OSING hBAT METPR nH-1

\begin{tabular}{|c|c|c|c|c|c|c|c|c|}
\hline Run Iaent. & nate & nour & 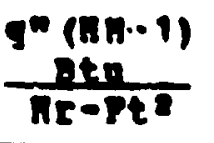 & $\begin{array}{l}\text { Yeas. } \\
\text { proge. } \\
\text { Pala }\end{array}$ & $\operatorname{Datr}_{\text {op }}$ & 4 & & $\begin{array}{c}\text { h coote. } \\
\text { neth }\end{array}$ \\
\hline 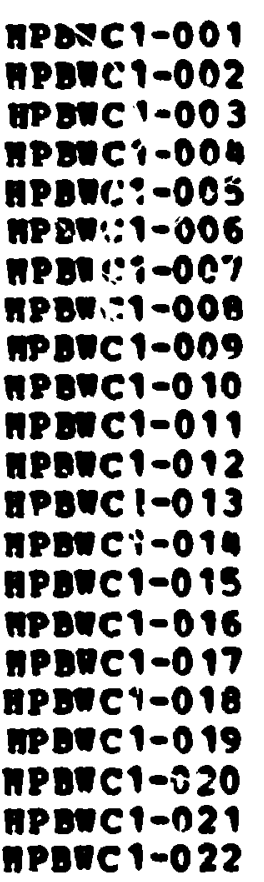 & $\begin{array}{l}12-21-73 \\
12-21-73 \\
12-21-73 \\
12-21-73 \\
12-21-73 \\
12-21-73 \\
12-21-73 \\
12-21-73 \\
12-21-73 \\
12-21-73 \\
12-21-73 \\
12-22-73 \\
12-22-73 \\
12-22-73 \\
12-22-73 \\
12-22-73 \\
12-22-13 \\
12-22-73 \\
12-22-73 \\
12-22-73 \\
12-22-73 \\
12-22-73\end{array}$ & $\begin{array}{l}1000 \\
1100 \\
1140 \\
1225 \\
1305 \\
1350 \\
1430 \\
1505 \\
1615 \\
1715 \\
1815 \\
0830 \\
1000 \\
1035 \\
1120 \\
1215 \\
1305 \\
1340 \\
1410 \\
1450 \\
1540 \\
1610\end{array}$ & $\begin{array}{l}1615 \\
66342 \\
56696 \\
46916 \\
36270 \\
26356 \\
17710 \\
12399 \\
7394 \\
5031 \\
3204 \\
2317 \\
71663 \\
61579 \\
51410 \\
11495 \\
31548 \\
21212 \\
16040 \\
11235 \\
1925 \\
2827\end{array}$ & 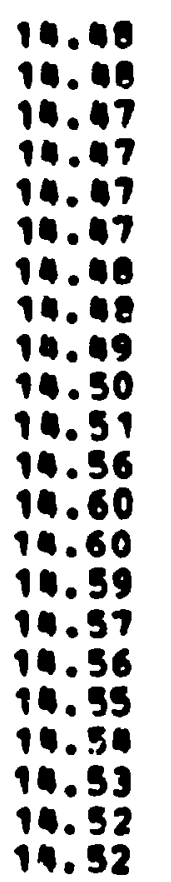 & $\begin{array}{l}213.69 \\
229.22 \\
225.05 \\
224.99 \\
224.73 \\
224.51 \\
224.18 \\
223.90 \\
223.25 \\
220.80 \\
217.11 \\
215.22 \\
226.52 \\
226.53 \\
226.61 \\
226.60 \\
226.38 \\
226.23 \\
225.89 \\
225.41 \\
222.04 \\
216.06\end{array}$ & $\begin{array}{l}211.01 \\
210.99 \\
210.93 \\
210.99 \\
210.96 \\
210.91 \\
210.99 \\
210.97 \\
211.00 \\
211.19 \\
211.10 \\
211.27 \\
211.29 \\
211.29 \\
211.29 \\
211.28 \\
211.25 \\
211.24 \\
211.18 \\
211.24 \\
211.14 \\
211.17\end{array}$ & $\begin{array}{r}2.67 \\
14.23 \\
14.13 \\
14.10 \\
13.127 \\
13.60 \\
13.21 \\
12.93 \\
12.25 \\
9.61 \\
6.03 \\
3.95 \\
15.23 \\
15.24 \\
13.31 \\
13.33 \\
15.13 \\
14.99 \\
14.72 \\
14.17 \\
10.90 \\
5.69\end{array}$ & $\begin{array}{r}606 \\
1662 \\
4013 \\
3327 \\
2614 \\
1938 \\
1340 \\
999 \\
601 \\
324 \\
531 \\
586 \\
4706 \\
1039 \\
3397 \\
2707 \\
2085 \\
1415 \\
1090 \\
793 \\
492 \\
497\end{array}$ \\
\hline
\end{tabular}


TABLE C-R

REDUCED DATA POR POOL bOTLTRG OP DATER ON A HORIzONTAL COPPRR SMRPACE OSING RMAT HETPR MM-2

\begin{tabular}{|c|c|c|c|c|c|c|c|c|}
\hline Pun Ident. & Date & Bont & $\begin{array}{c}g^{n}(B N-2) \\
\frac{B t u}{B r-\nabla t^{2}}\end{array}$ & $\begin{array}{l}\text { Meas. } \\
\text { Preas. } \\
\text { Psia }\end{array}$ & $\overline{\operatorname{la11}}_{0}$ & $\begin{array}{c}\text { mearatur } \\
\text { aturatir }\end{array}$ & $D_{\bullet P}$ & $\begin{array}{c}\text { h coose. } \\
\text { pen } \\
\text { hE-pet- }\end{array}$ \\
\hline 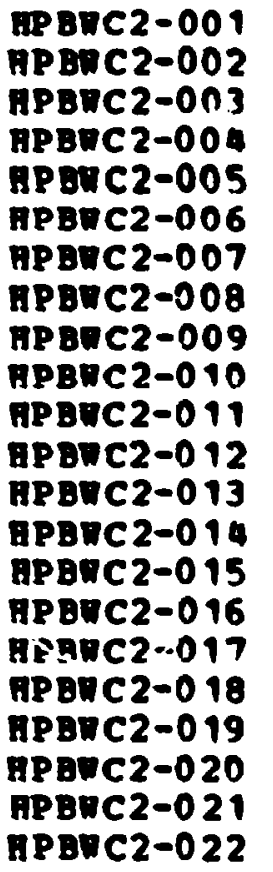 & $\begin{array}{l}12-21-73 \\
12-21-73 \\
12-21-73 \\
12-21-73 \\
12-21-73 \\
12-21-73 \\
12-21-73 \\
12-21-73 \\
12-21-73 \\
12-21-73 \\
12-21-73 \\
12-22-73 \\
12-22-73 \\
12-22-73 \\
12-22-73 \\
12-22-73 \\
12-22-73 \\
12-22-73 \\
12-22-73 \\
12-22-73 \\
12-22-73 \\
12-22-73\end{array}$ & $\begin{array}{l}1000 \\
1100 \\
1140 \\
1225 \\
1305 \\
1350 \\
1430 \\
1505 \\
1615 \\
1715 \\
1815 \\
0830 \\
1000 \\
1035 \\
1120 \\
1215 \\
1305 \\
1340 \\
1410 \\
1450 \\
1540 \\
1640\end{array}$ & $\begin{array}{l}1347 \\
66330 \\
57507 \\
46764 \\
36310 \\
26641 \\
18272 \\
13117 \\
7985 \\
5303 \\
3630 \\
1992 \\
72403 \\
62296 \\
51764 \\
41883 \\
31354 \\
21459 \\
16315 \\
11203 \\
5568 \\
2879\end{array}$ & $\begin{array}{l}14.48 \\
14.48 \\
14.47 \\
14.47 \\
14.47 \\
14.47 \\
14.48 \\
14.48 \\
14.49 \\
14.50 \\
14.51 \\
14.56 \\
14.60 \\
14.50 \\
14.59 \\
14.57 \\
14.56 \\
14.55 \\
14.54 \\
14.53 \\
14.52 \\
14.52\end{array}$ & $\begin{array}{l}213.85 \\
225.92 \\
225.65 \\
225.50 \\
225.21 \\
224.89 \\
224.51 \\
224.20 \\
223.46 \\
222.43 \\
218.57 \\
215.54 \\
227.34 \\
227.35 \\
227.23 \\
227.22 \\
227.02 \\
226.68 \\
226.42 \\
225.97 \\
221.86\end{array}$ & $\begin{array}{l}211.02 \\
211.00 \\
210.94 \\
210.99 \\
210.94 \\
210.98 \\
210.99 \\
211.00 \\
211.09 \\
211.25 \\
211.20 \\
211.29 \\
211.29 \\
211.33 \\
211.31 \\
211.29 \\
211.25 \\
211.26 \\
211.30 \\
211.23 \\
211.26 \\
211.21\end{array}$ & $\begin{array}{r}2.82 \\
14.92 \\
14.71 \\
14.52 \\
18.27 \\
13.91 \\
13.32 \\
13.20 \\
12.37 \\
11.18 \\
7.32 \\
16.30 \\
16.05 \\
16.02 \\
15.93 \\
15.94 \\
15.77 \\
15.42 \\
15.11 \\
14.73 \\
10.60\end{array}$ & $\begin{array}{r}477 \\
4445 \\
3910 \\
3220 \\
2545 \\
1915 \\
1352 \\
994 \\
646 \\
474 \\
496 \\
464 \\
4510 \\
3889 \\
3250 \\
2628 \\
1989 \\
1392 \\
1080 \\
760 \\
525 \\
488\end{array}$ \\
\hline
\end{tabular}


TABLP D-T

REDECED DATA FOR POOL BOILIHG OF MATEP ON A VERTICAL COPPER SARFACE DSTHE FRAT METFR AH-1

\begin{tabular}{|c|c|c|c|c|c|c|c|c|}
\hline Run Taent. & Date & Hour & $\begin{array}{c}q^{N}(A H-1) \\
\frac{A+y}{A x-F C^{2}}\end{array}$ & $\begin{array}{l}\text { Meas. } \\
\text { Press. } \\
\text { ogia }\end{array}$ & $\frac{T !}{\operatorname{Tat1}:}$ & $\frac{\text { peracus }}{\text { eurate }}$ & DIII & $\begin{array}{c}\text { h coote. } \\
\text { hety }\end{array}$ \\
\hline 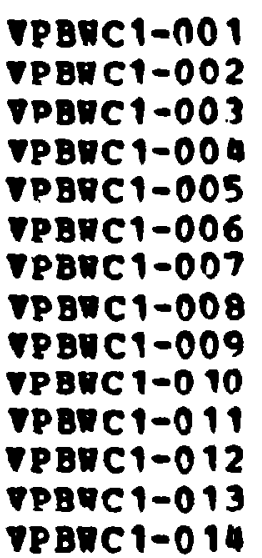 & $\begin{array}{l}12-18-73 \\
12-19-73 \\
12-19-73 \\
12-19-73 \\
12-19-73 \\
12-19-73 \\
12-19-73 \\
12-19-73 \\
12-19-73 \\
12-19-73 \\
12-19-73 \\
12-19-73 \\
12-19-73 \\
12-20-73\end{array}$ & $\begin{array}{l}0820 \\
0330 \\
1130 \\
1215 \\
1240 \\
1329 \\
1350 \\
1430 \\
1540 \\
1615 \\
1655 \\
1730 \\
1800 \\
0840\end{array}$ & $\begin{array}{l}1513 \\
2917 \\
71631 \\
61385 \\
51517 \\
41394 \\
31510 \\
21325 \\
36367 \\
26602 \\
10090 \\
11063 \\
5277 \\
3268\end{array}$ & $\begin{array}{l}14.63 \\
11.67 \\
14.65 \\
14.64 \\
14.63 \\
14.62 \\
14.60 \\
14.60 \\
14.59 \\
14.58 \\
14.58 \\
14.57 \\
14.57 \\
14.46\end{array}$ & $\begin{array}{l}213.97 \\
216.93 \\
227.03 \\
22.5 .30 \\
225.25 \\
229.62 \\
223.63 \\
222.32 \\
224.03 \\
222.89 \\
221.37 \\
220.65 \\
219.39 \\
218.21\end{array}$ & $\begin{array}{l}211.44 \\
211.46 \\
211.44 \\
211.37 \\
211.32 \\
211.37 \\
211.29 \\
211.26 \\
211.32 \\
211.29 \\
211.21 \\
211.22 \\
211.18 \\
210.82\end{array}$ & $\begin{array}{r}2.53 \\
9.48 \\
15.59 \\
14.93 \\
13.93 \\
13.24 \\
12.34 \\
11.05 \\
12.71 \\
11.59 \\
10.16 \\
9.43 \\
8.20 \\
7.40\end{array}$ & $\begin{array}{r}599 \\
533 \\
4594 \\
4111 \\
3699 \\
3126 \\
2554 \\
1930 \\
2862 \\
2295 \\
1583 \\
1173 \\
647 \\
442\end{array}$ \\
\hline
\end{tabular}


TABLE D-8

REDUCED DATA FOR POOL BOIIIYG OP RATER ON A PRTICAL COPPER SORFACE OSING HEAT METRR HH-2

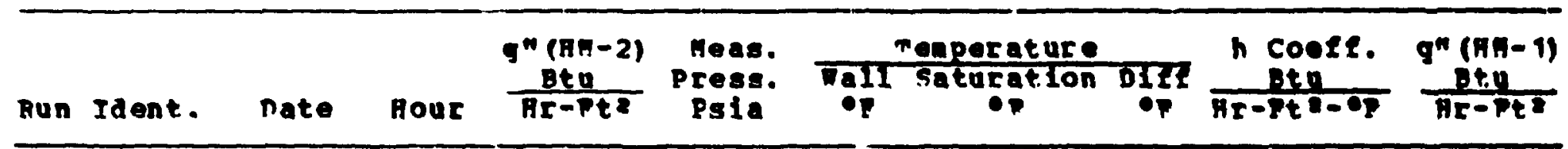

For Varying คH-2 Plux

\begin{tabular}{|c|c|c|}
\hline 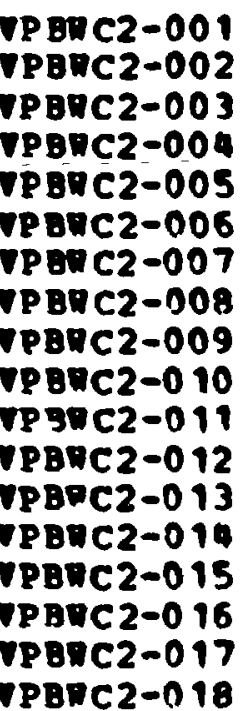 & $\begin{array}{l}12- \\
12- \\
12- \\
12- \\
12- \\
12- \\
12- \\
12- \\
12- \\
12- \\
12- \\
12- \\
12- \\
11\end{array}$ & $\begin{array}{ll}3 & 10 \\
11 \\
11 \\
11 \\
11\end{array}$ \\
\hline
\end{tabular}

1095
66446
57699
47002
36379
26187
21273
16695
13226
11345
7997
5411
4451
1839
66330
52088
26336
3555

$\begin{array}{lll}14.53 & 212.91 & 211.32 \\ 14.58 & 225.28 & 211.43 \\ 14.58 & 225.06 & 211.40 \\ 14.57 & 224.56 & 211.42 \\ 14.57 & 223.99 & 211.38 \\ 14.57 & 223.33 & 211.39 \\ 14.56 & 222.96 & 211.37 \\ 14.55 & 222.59 & 211.39 \\ 14.55 & 222.26 & 211.37 \\ 14.55 & 222.13 & 211.42 \\ 14.55 & 221.69 & 211.44 \\ 14.55 & 219.51 & 211.41 \\ 14.55 & 217.90 & 211.44 \\ 14.57 & 214.35 & 211.41 \\ 14.57 & 225.88 & 211.42 \\ 14.57 & 225.06 & 211.44 \\ 14.49 & 223.28 & 211.20 \\ 14.36 & 215.73 & 210.78\end{array}$

1.59

689

$13.86 \quad 4796$

$13.67 \quad \square 222$

13.14 3577

12.612885

11.942194

$11.58 \quad 1836$

$11.20 \quad 1491$

$10.88 \quad 1215$

$10.71 \quad 1060$

10.257 7.

$8.09 \quad 669$

$6.46 \quad 689$

2.96

14.46

13.62

622

4587

$12.08 \quad 2180$

$4.95 \quad 719$ 


\section{TABLE D-8 (Continued)}

\begin{tabular}{|c|c|c|c|c|c|c|c|c|c|}
\hline Run Ident. & Date & Hour & $\frac{q^{n}(n n-2)}{n+n-p e^{2}}$ & $\begin{array}{c}\text { Meas. } \\
\text { Prese. } \\
\text { Pola }\end{array}$ & $\frac{T a}{\operatorname{lal}^{2} \mathrm{~s}}$ & $\begin{array}{c}\text { mperature } \\
\text { saturation } \\
\text { op }\end{array}$ & $\frac{}{D I E E}$ & 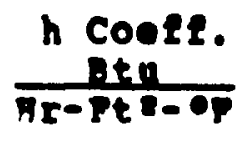 & $\frac{q^{n}(n n-1)}{n+n}$ \\
\hline \multicolumn{10}{|c|}{ Dor Constant $n$ m. 2 Plux } \\
\hline $\begin{array}{l}\text { VPBWC2-0 } 19 \\
\text { VPBWC2-020 } \\
\text { VPBWC2-021 } \\
\text { VPBWC2-022 } \\
\text { VPBWC2-023 } \\
\text { VPBIC2-024 } \\
\text { VPBWC2-025 } \\
\text { VPBWC2-026 } \\
\text { VPBDC2-027 } \\
\text { VPBWC2-028 }\end{array}$ & $\begin{array}{l}12-19-73 \\
12-19-73 \\
12-19-73 \\
12-19-77 \\
12-19-73 \\
12-19-73 \\
12-19-73 \\
12-19-73 \\
12-19-73 \\
12-19-73\end{array}$ & $\begin{array}{l}1130 \\
1215 \\
1320 \\
1355 \\
1430 \\
1540 \\
1615 \\
1655 \\
1730 \\
1800\end{array}$ & $\begin{array}{l}52246 \\
52257 \\
52276 \\
52188 \\
52345 \\
26439 \\
26266 \\
26294 \\
26321 \\
26246\end{array}$ & $\begin{array}{l}14.55 \\
14.54 \\
14.52 \\
14.51 \\
14.50 \\
14.49 \\
14.48 \\
14.48 \\
14.47 \\
14.47\end{array}$ & $\begin{array}{l}225.65 \\
225.53 \\
225.50 \\
225.47 \\
225.23 \\
223.47 \\
223.46 \\
223.43 \\
223.40 \\
223.37\end{array}$ & $\begin{array}{l}211.41 \\
211.36 \\
211.30 \\
211.28 \\
211.28 \\
211.31 \\
211.22 \\
211.20 \\
211.21 \\
211.15\end{array}$ & $\begin{array}{l}14.23 \\
14.16 \\
14.21 \\
14.20 \\
17.95 \\
12.17 \\
12.24 \\
12.23 \\
12.18 \\
12.22\end{array}$ & $\begin{array}{l}3671 \\
3689 \\
3680 \\
3676 \\
3752 \\
2173 \\
2146 \\
2150 \\
2160 \\
2147\end{array}$ & 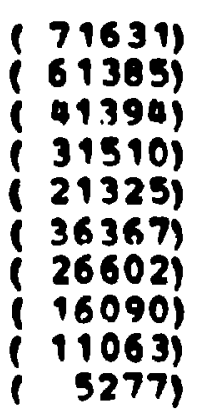 \\
\hline
\end{tabular}


ROASTMOE AMD ZOBER CORRFLATION PARAMETERS POR FULLY DEVELOPED, NOCLEATP, POOL DOILIMG OP PREOH-113 ON A RORTZONTAL COPEER SORPACE DSTMG YRAT METPR GH-1

\begin{tabular}{|c|c|c|c|c|c|c|c|c|}
\hline Run Ident. & $\frac{\text { Rohseno }}{\text { Cp-TdIEI }}$ & $\frac{0 \text { Corre }}{\text { Pr }}$ & $\frac{\text { elation Pars }}{\frac{\text { Cpotalff }}{\text { Hfg.Priot }}}$ & $\frac{\text { peterg }}{\text { Bubbie }}$ & $\frac{\text { quber ce }}{\text { Bubbla RaA. }}$ & 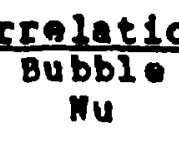 & $\begin{array}{l}\text { Parnees } \\
\text { Bubbie } \\
\text { Nu/Pris }\end{array}$ & $\frac{\text { ere }}{\text { Bubhio }}$ \\
\hline 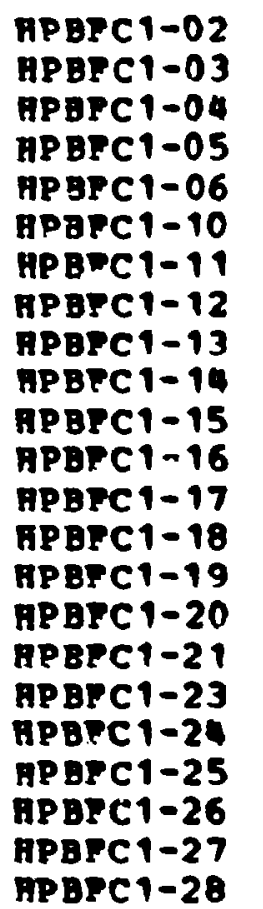 & $\begin{array}{l}0.06421 \\
0.06289 \\
0.06231 \\
0.06128 \\
0.05976 \\
0.06457 \\
0.06435 \\
0.06421 \\
0.06340 \\
0.07750 \\
0.07521 \\
0.07381 \\
0.07281 \\
0.07223 \\
0.07182 \\
0.07086 \\
0.05030 \\
0.08033 \\
0.07832 \\
0.07632 \\
0.07404 \\
0.07247 \\
0.07154\end{array}$ & $\begin{array}{l}7.105 \\
7.094 \\
7.090 \\
7.080 \\
7.075 \\
7.069 \\
7.072 \\
7.071 \\
7.070 \\
7.079 \\
7.074 \\
7.072 \\
7.069 \\
7.069 \\
7.068 \\
7.067 \\
7.064 \\
7.066 \\
7.063 \\
7.063 \\
7.063 \\
7.063 \\
7.063\end{array}$ & $\begin{array}{l}2.291 \cdot 10-3 \\
2.249 \cdot 10-3 \\
2.231 \cdot 10-3 \\
2.199 \cdot 10-3 \\
2.147 \cdot 10-3 \\
2.324 \cdot 10-3 \\
2.314 \cdot 10-3 \\
2.309 \cdot 10-3 \\
2.281 \cdot 10-3 \\
2.783 \cdot 10-3 \\
2.703 \cdot 10-3 \\
2.654 \cdot 10-3 \\
2.620 \cdot 10-3 \\
2.599 \cdot 10-3 \\
2.585 \cdot 10-3 \\
2.551 \cdot 10-3 \\
2.497 \cdot 10-3 \\
2.893 \cdot 10-3 \\
2.822 \cdot 10-3 \\
2.750 \cdot 10-3 \\
2.668 \cdot 10-3 \\
2.611 \cdot 10-3 \\
2.578 \cdot 10-3\end{array}$ & $\begin{array}{l}0.6247 \\
0.2042 \\
0.1796 \\
0.1263 \\
0.0896 \\
0.5253 \\
0.4178 \\
0.3111 \\
0.2097 \\
1.9220 \\
1.3620 \\
1.0870 \\
0.9729 \\
0.8567 \\
0.7377 \\
0.5779 \\
0.3539 \\
1.9150 \\
1.3680 \\
0.9714 \\
0.6320 \\
0.4119 \\
0.3084\end{array}$ & $\begin{array}{l}C .7005 \cdot 10-8 \\
0.6911 \cdot 10-8 \\
0.6871 \cdot 10-8 \\
0.6779 \cdot 10-8 \\
0.6722 \cdot 10-8 \\
0.6756 \cdot 10-8 \\
0.6776 \cdot 10-8 \\
0.6768 \cdot 10-8 \\
0.6749 \cdot 10-8 \\
0.7010 \cdot 10-8 \\
0.6949 \cdot 10-8 \\
0.6923 \cdot 10-8 \\
0.6886 \cdot 10-8 \\
0.6977 \cdot 10-8 \\
0.6864 \cdot 10-8 \\
0.6946 \cdot 10-8 \\
C .6798 \cdot 10-8 \\
0.6956 \cdot 10-8 \\
0.6916 \cdot 10-8 \\
0.6886 \bullet 10-8 \\
0.6860 \cdot 10-8 \\
0.6839 \cdot 10-8 \\
0.6827 \cdot 10-8\end{array}$ & $\begin{array}{l}0.1510 \\
0.0483 \\
0.0426 \\
0.0300 \\
0.0214 \\
0.1179 \\
0.0944 \\
0.0704 \\
0.0479 \\
0.3733 \\
0.2703 \\
0.2189 \\
0.1975 \\
0.1750 \\
0.1513 \\
0.1198 \\
0.0744 \\
0.3557 \\
0.2591 \\
0.1880 \\
0.1256 \\
0.0834 \\
0.0631\end{array}$ & $\begin{array}{l}0.07853 \\
0.02512 \\
0.02217 \\
0.01563 \\
0.01115 \\
0.06146 \\
0.04920 \\
0.03668 \\
0.02496 \\
0.19450 \\
0.14080 \\
0.119400 \\
0.10290 \\
0.09121 \\
0.07894 \\
0.06244 \\
0.03880 \\
0.18540 \\
0.13500 \\
0.09800 \\
0.06547 \\
0.04346 \\
0.03291\end{array}$ & $\begin{array}{r}80.4 \\
76.9 \\
74.6 \\
71.3 \\
67.4 \\
78.1 \\
79.9 \\
77.9 \\
75.5 \\
113.9 \\
106.6 \\
102.6 \\
99.5 \\
97.9 \\
96.6 \\
94.0 \\
89.5 \\
120.6 \\
114.3 \\
108.5 \\
102.1 \\
97.9 \\
95.4\end{array}$ \\
\hline
\end{tabular}


TABIE D-9 (Conetnuar)

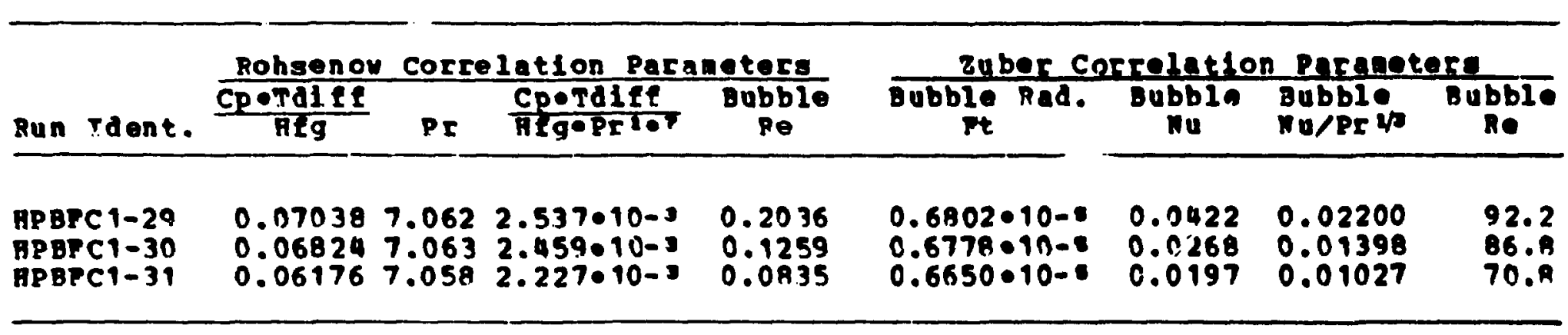


SOASEMOD AND ZDBFR CORRELTION PARAHETERS FOR POLIT DETELOPRD, MOCLEATE, POOL BOILING OP PREON-113 ON A HORIZONTAL COPPER SORPACE OSIMO HRAT HETER BH-2

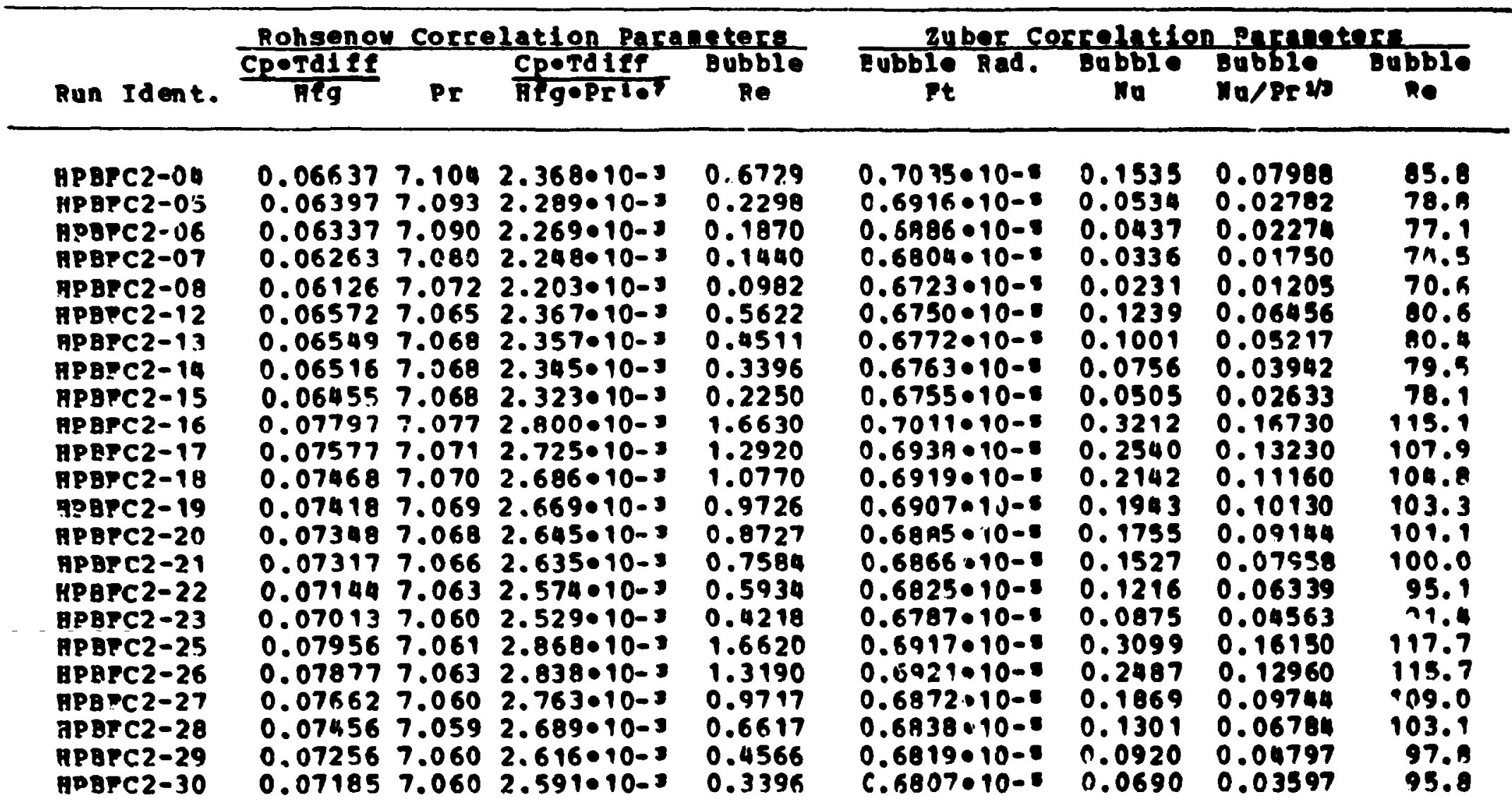


TABLE D-10 (Continued)

\begin{tabular}{|c|c|c|c|c|c|c|c|c|}
\hline Ron Ident. & $\frac{\frac{\text { Rohsenoy }}{\text { Cpotalfi }}}{\text { hig }}$ & $\begin{array}{l}\text { Corre } \\
\text { Pr }\end{array}$ & 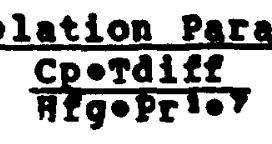 & $\frac{\text { Detere }}{\text { Bubbie }}$ & 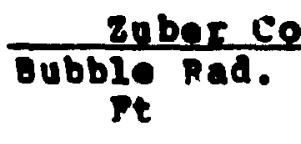 & $\frac{c r a 10+10}{\text { Dabbia }}$ & $\begin{array}{l}\text { Peranes } \\
\text { Dubbia } \\
\text { no/Pris }\end{array}$ & $\frac{21}{\text { Dabble }}$ \\
\hline $\begin{array}{l}\text { APBFC2-31 } \\
\text { FPBPC2-32 } \\
\text { FPBFC2-33 }\end{array}$ & $\begin{array}{l}0.07036 \\
0.06896 \\
0.06815\end{array}$ & $\begin{array}{l}7.059 \\
7.061 \\
7.061\end{array}$ & $\begin{array}{l}2.538 \cdot 10-3 \\
2.486 \cdot 10-3 \\
2.457 \cdot 10-3\end{array}$ & $\begin{array}{l}0.2287 \\
0.1905 \\
0.0918\end{array}$ & $\begin{array}{l}0.6780 \cdot 10-8 \\
0.6772 \cdot 10-8 \\
0.6763 \cdot 10-8\end{array}$ & $\begin{array}{l}0.0472 \\
0.0296 \\
0.0195\end{array}$ & $\begin{array}{l}0.02463 \\
0.01543 \\
0.01019\end{array}$ & $\begin{array}{l}91.8 \\
88.4 \\
86.4\end{array}$ \\
\hline
\end{tabular}


ROASEMON AND ZOBRR COERTLATION PARAMETERS TOR FOILY DEVELOPED, NUCLEATE, POOL, BUILIMG OP PREON-113-ON A VERTICAL COPEER SORFACE HSTMG REAT METER HH-1

\begin{tabular}{|c|c|c|c|c|c|c|c|c|}
\hline Run Ident. & $\frac{\frac{\text { Rohsenov }}{\text { Cpetafff }}}{\text { hfg }}$ & Corre & $\frac{\text { elation Parz }}{\frac{\text { CpoTdilf }}{\text { Hrgopriot }}}$ & 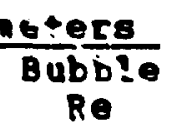 & $\frac{\text { muber } c}{\text { Bubble R:? }}$ & $\frac{\text { crelat } 10}{\mathrm{Bu}}$ & 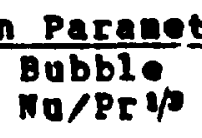 & $\frac{\text { re }}{\text { Bubble }}$ \\
\hline 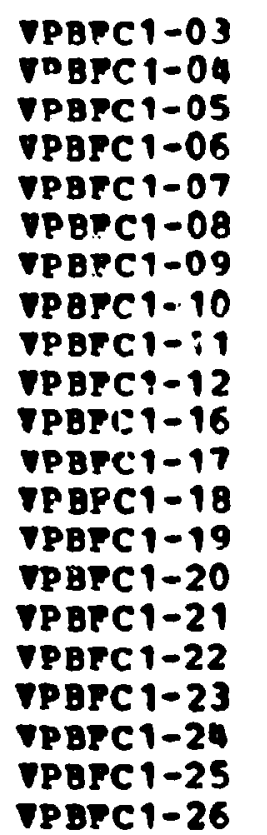 & $\begin{array}{l}0.08208 \\
0.07931 \\
0.07749 \\
0.07608 \\
0.07344 \\
0.06944 \\
0.06700 \\
0.06318 \\
0.05782 \\
0.05457 \\
0.07930 \\
0.07951 \\
0.07983 \\
0.08023 \\
0.08014 \\
0.07675 \\
0.07689 \\
0.07655 \\
0.07660 \\
0.07666 \\
0.07683\end{array}$ & $\begin{array}{l}7.107 \\
7.108 \\
7.107 \\
7.110 \\
7.109 \\
7.106 \\
7.103 \\
7.100 \\
7.099 \\
7.098 \\
7.084 \\
7.082 \\
7.082 \\
7.082 \\
7.080 \\
7.081 \\
7.084 \\
7.081 \\
7.080 \\
7.078 \\
7.078\end{array}$ & $\begin{array}{l}2.927 \cdot 10-3 \\
2.827 \cdot 10-3 \\
2.763 \cdot 10-3 \\
2.711 \cdot 10-3 \\
2.617 \cdot 10-3 \\
2.476 \cdot 10-3 \\
2.391 \cdot 10-3 \\
2.256 \cdot 10-3 \\
2.065 \cdot 10-3 \\
1.950 \cdot 10-3 \\
2.843 \cdot 10-3 \\
2.852 \cdot 10-3 \\
2.864 \cdot 10-3 \\
2.878 \cdot 10-3 \\
2.876 \cdot 10-3 \\
2.753 \cdot 10-3 \\
2.757 \cdot 10-3 \\
2.747 \cdot 10-3 \\
2.749 \cdot 10-3 \\
2.753 \cdot 10-3 \\
2.759 \cdot 10-3\end{array}$ & $\begin{array}{l}1.9050 \\
1.3520 \\
1.0780 \\
0.8504 \\
0.6270 \\
0.4047 \\
0.3044 \\
0.2058 \\
0.1268 \\
0.0883 \\
1.3570 \\
1.3560 \\
1.3540 \\
1.3540 \\
1.3630 \\
0.6261 \\
0.6273 \\
0.6294 \\
0.6269 \\
0.6275 \\
0.6299\end{array}$ & $\begin{array}{l}0.7274 \cdot 10-8 \\
0.7251 \cdot 10-8 \\
0.7222 \cdot 10-8 \\
0.7222 \cdot 10-8 \\
0.7179 \cdot 10-8 \\
0.7101 \cdot 10-8 \\
0.7042 \cdot 10-8 \\
0.6955 \cdot 10-8 \\
0.6851 \cdot 10-8 \\
0.6777 \cdot 10-8 \\
0.7075 \cdot 10-8 \\
0.7062 \cdot 10-8 \\
0.7065 \cdot 10-8 \\
0.7071 \cdot 10-8 \\
0.7056 \cdot 10-8 \\
0.7024 \cdot 10-8 \\
0.7042 \cdot 10-8 \\
0.7017 \cdot 10-8 \\
0.7014 \cdot 10-8 \\
0.6997 \cdot 10-8 \\
0.5999 \cdot 10-8\end{array}$ & $\begin{array}{l}0.3636 \\
0.2663 \\
0.2164 \\
0.1739 \\
0.1320 \\
0.0891 \\
0.0689 \\
0.0498 \\
0.0323 \\
0.0236 \\
0.2602 \\
0.2587 \\
0.2574 \\
0.2564 \\
0.2578 \\
0.1231 \\
0.1235 \\
0.1240 \\
0.1233 \\
0.1230 \\
0.1233\end{array}$ & $\begin{array}{l}0.18910 \\
0.13850 \\
0.11260 \\
0.09044 \\
0.06867 \\
0.04636 \\
0.03583 \\
0.02538 \\
0.01682 \\
0.01228 \\
0.13550 \\
0.13470 \\
0.13410 \\
0.13350 \\
0.13430 \\
0.06412 \\
0.06429 \\
0.06456 \\
0.06422 \\
0.06408 \\
0.06420\end{array}$ & $\begin{array}{r}138.1 \\
123.2 \\
117.5 \\
113.6 \\
105.7 \\
94.2 \\
87.4 \\
77.5 \\
64.8 \\
57.7 \\
119.9 \\
120.3 \\
121.2 \\
122.5 \\
121.9 \\
112.0 \\
112.7 \\
111.3 \\
111.8 \\
111.3 \\
111.8\end{array}$ \\
\hline
\end{tabular}


ROHSENON AND ZOBER CORRELATTON PARAHWTERS FOR FOLLY OEVELOPED, MOCLEATE. POOL BOILING OP PREON-113 ON A TSRTICAL COPPER SORPACE USIMG REAT METPR GH-2

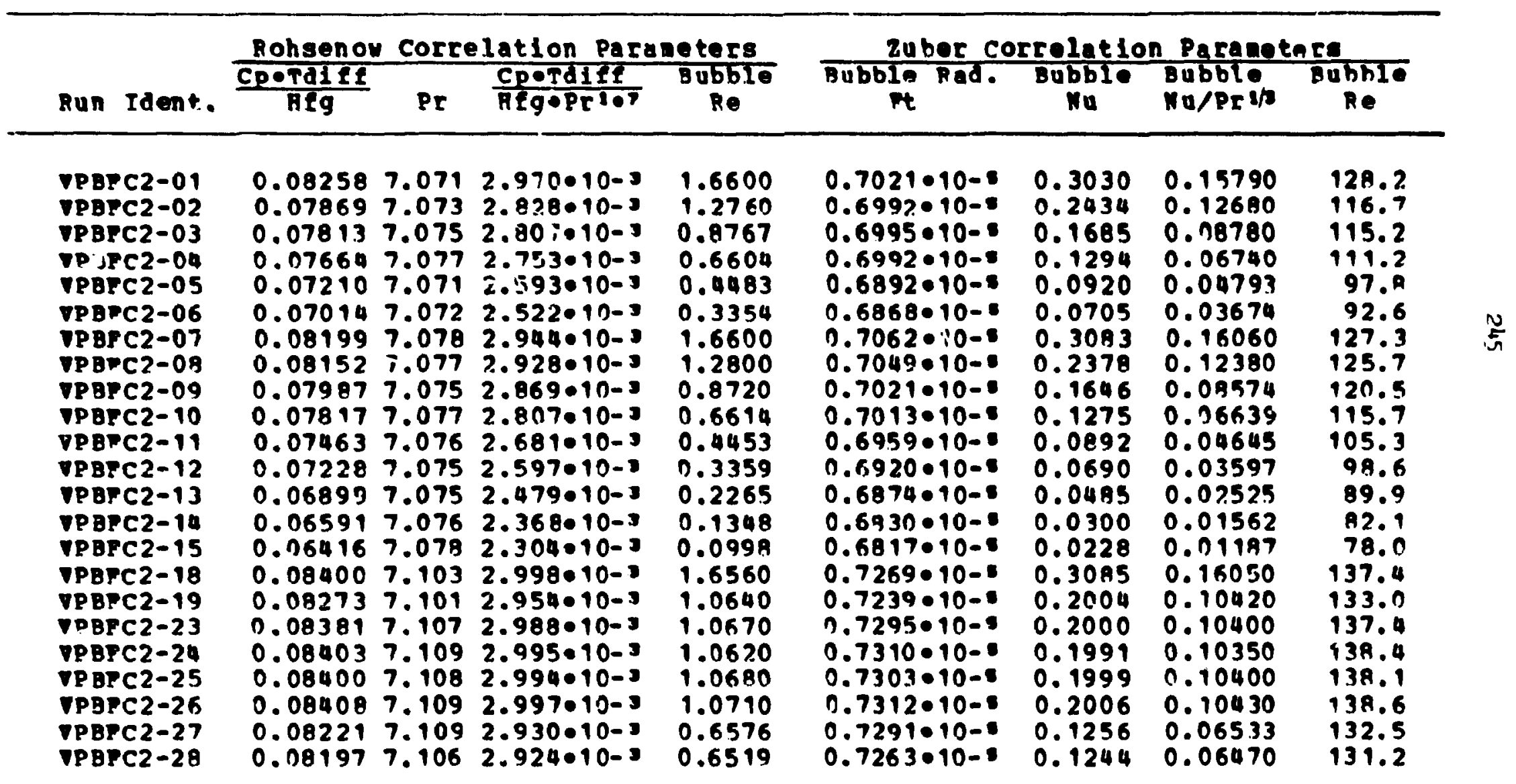


TABLE D-12 (Continued)

\begin{tabular}{|c|c|c|c|c|c|c|c|c|}
\hline Rus Ident. & $\frac{\text { Pshang }}{\text { Cperaies }}$ & $\because$ Corre & $\frac{\text { elation par }}{\frac{\text { Cporditf }}{\text { htgopriot }}}$ & $\frac{\text { eters }}{\text { Bubble }}$ & 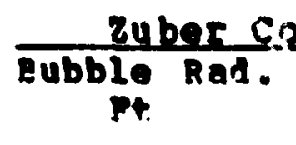 & $\begin{array}{c}\text { Crelat } 10 \\
\text { Bubble } \\
\text { Mu }\end{array}$ & $\begin{array}{l}n \text { Paranet } \\
\text { Bubble } \\
\text { Mu/Pr is }\end{array}$ & $\frac{\underbrace{}_{\text {Re }}}{\text { Bubble }}$ \\
\hline 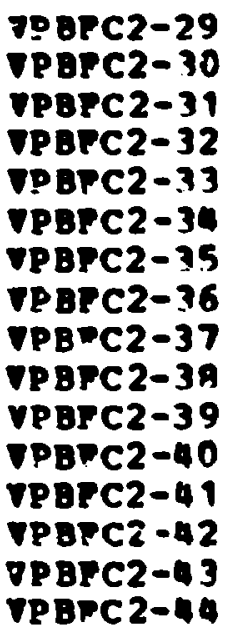 & $\begin{array}{l}0.08176 \\
0.08124 \\
0.08130 \\
0.08127 \\
0.08123 \\
0.08465 \\
0.08373 \\
0.08268 \\
0.07928 \\
0.06329 \\
0.08324 \\
0.08406 \\
0.07940 \\
0.07630 \\
0.06773 \\
0.04913\end{array}$ & $\begin{array}{l}7.104 \\
7.100 \\
7.101 \\
7.098 \\
7.095 \\
7.084 \\
7.082 \\
7.082 \\
7.082 \\
7.081 \\
7.083 \\
7.084 \\
7.081 \\
7.081 \\
7.078 \\
7.078\end{array}$ & $\begin{array}{l}2.917 \cdot 10-3 \\
2.901 \cdot 10-3 \\
2.903 \cdot 10-3 \\
2.904 \cdot 10-3 \\
2.904 \cdot 10-3 \\
3.035 \cdot 10-3 \\
3.003 \cdot 10-3 \\
2.965 \cdot 10-3 \\
2.844 \cdot 10-3 \\
2.271 \cdot 10-3 \\
2.986 \cdot 10-3 \\
3.014 \cdot 10-3 \\
2.849 \cdot 10-3 \\
2.738 \cdot 10-3 \\
2.432 \cdot 10-3 \\
1.764 \cdot 10-3\end{array}$ & $\begin{array}{l}0.6558 \\
0.6555 \\
0.6577 \\
0.6555 \\
0.6558 \\
1.3520 \\
0.9675 \\
0.6561 \\
0.4456 \\
0.2302 \\
0.7713 \\
1.0740 \\
0.4464 \\
0.3309 \\
0.2292 \\
0.1492\end{array}$ & $\begin{array}{l}0.7248 \cdot 10-8 \\
0.7213 \cdot 10-8 \\
0.7219 \cdot 10-8 \\
0.72 n 0 \cdot 10-8 \\
0.7179 \cdot 10-8 \\
0.7132 \cdot 10-8 \\
0.7114 \cdot 10-8 \\
0.7103 \cdot 10-8 \\
0.7059 \cdot 10-8 \\
0.6721 \cdot 10-8 \\
0.7110 \cdot 10-8 \\
0.7123 \cdot 10-8 \\
0.7054 \cdot 10-8 \\
0.7015 \cdot 10-8 \\
0.6873 \cdot 10-8 \\
0.6516 \cdot 10-8\end{array}$ & $\begin{array}{l}0.1252 \\
0.1253 \\
0.1257 \\
0.1250 \\
0.1247 \\
0.2448 \\
0.1766 \\
0.1211 \\
0.0852 \\
0.0533 \\
0.1416 \\
0.1954 \\
0.0852 \\
0.0654 \\
0.0500 \\
0.0425\end{array}$ & $\begin{array}{l}0.06511 \\
0.06517 \\
0.06540 \\
0.06503 \\
0.06499 \\
0.12750 \\
0.09199 \\
0.06307 \\
0.04440 \\
0.02776 \\
0.07372 \\
0.10200 \\
0.04437 \\
0.03474 \\
0.02602 \\
0.02214\end{array}$ & $\begin{array}{l}130.3 \\
128.1 \\
128.4 \\
127.9 \\
127.4 \\
136.6 \\
133.4 \\
130.1 \\
119.6 \\
76.1 \\
131.9 \\
134.7 \\
119.8 \\
110.6 \\
86.9 \\
45.7\end{array}$ \\
\hline
\end{tabular}




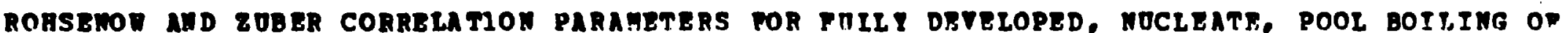
Datra ON a hORIZONTAL COPPER SORFACE OSTMG GEAT METER RM-1

\begin{tabular}{|c|c|c|c|c|c|c|c|c|}
\hline Run Ident. & $\frac{\frac{\text { Rohsenov }}{\text { CperdifI }}}{\text { irg }}$ & $\begin{array}{l}\text { Corre } \\
\text { Pr }\end{array}$ & $\frac{\text { elation Parg }}{\frac{\text { CpoTd ILI }}{\text { HIg・Pr }}}$ & $\frac{\text { deters }}{\text { Bubble }}$ & 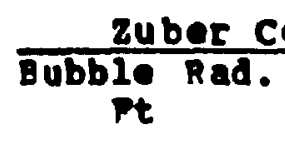 & 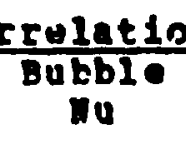 & $\begin{array}{l}\frac{\text { P Paranet }}{\text { Bubble }} \\
\text { Nu/Pr \& }\end{array}$ & $\begin{array}{c}\text { Buhb1e } \\
\text { Re }\end{array}$ \\
\hline 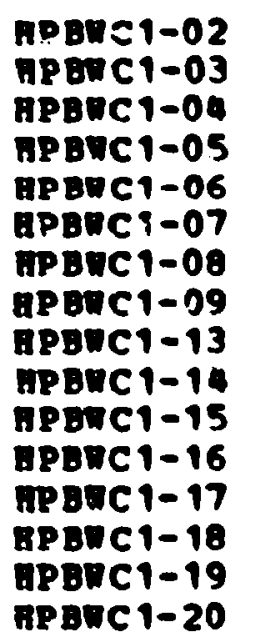 & $\begin{array}{l}0.01476 \\
0.01465 \\
0.01463 \\
0.01439 \\
0.01411 \\
0.01371 \\
0.01341 \\
0.01270 \\
0.01580 \\
0.01582 \\
0.01589 \\
0.01590 \\
0.01570 \\
0.01556 \\
0.01527 \\
0.01470\end{array}$ & $\begin{array}{l}1.740 \\
1.741 \\
1.741 \\
1.741 \\
1.741 \\
1.740 \\
1.740 \\
1.740 \\
1.737 \\
1.737 \\
1.737 \\
1.737 \\
1.737 \\
1.737 \\
1.738 \\
1.737\end{array}$ & $\begin{array}{l}8.484 \cdot 10-3 \\
8.419 \cdot 10-3 \\
8.402 \cdot 10-3 \\
8.264 \cdot 10-3 \\
8.106 \cdot 10-3 \\
7.878 \cdot 10-3 \\
7.708 \cdot 10-3 \\
7.302 \cdot 10-3 \\
9.098 \cdot 10-3 \\
9.108 \cdot 10-3 \\
9.150 \cdot 10-3 \\
9.156 \cdot 10-3 \\
9.038 \cdot 10-3 \\
8.954 \cdot 10-3 \\
8.784 \cdot 10-3 \\
8.463 \cdot 10-3\end{array}$ & $\begin{array}{l}0.9647 \\
0.8241 \\
0.6818 \\
0.5269 \\
0.3830 \\
0.2575 \\
0.1803 \\
0.1075 \\
1.0440 \\
0.8972 \\
0.7491 \\
0.6046 \\
0.4595 \\
0.3090 \\
0.2335 \\
0.1637\end{array}$ & $\begin{array}{l}5.4080 \cdot 10-8 \\
5.4120 \cdot 10-8 \\
5.4150 \cdot 10-8 \\
5.4070 \cdot 10-8 \\
5.3810 \cdot 10-8 \\
5.3460 \cdot 10-8 \\
5.3250 \cdot 10-8 \\
5.2710 \cdot 11)-8 \\
5.4180 \cdot 10-8 \\
5.4190 \cdot 10-8 \\
5.4210 \cdot 10-8 \\
5.4250 \cdot 10-8 \\
5.4190 \cdot 10-8 \\
5.4130 \cdot 10-8 \\
5.4090 \cdot 10-8 \\
5.3630 \cdot 10-8\end{array}$ & $\begin{array}{l}0.6413 \\
0.5524 \\
0.4583 \\
0.3596 \\
0.2652 \\
0.1822 \\
0.1299 \\
0.0809 \\
0.6484 \\
0.5567 \\
0.4628 \\
0.3735 \\
0.2873 \\
0.1948 \\
0.1499 \\
0.1081\end{array}$ & $\begin{array}{l}0.53320 \\
0.45920 \\
0.38100 \\
0.29890 \\
0.22040 \\
0.15150 \\
0.10800 \\
0.06730 \\
0.53940 \\
0.46310 \\
0.38510 \\
0.31070 \\
0.23900 \\
0.16200 \\
0.12470 \\
0.08996\end{array}$ & $\begin{array}{r}1051.0 \\
1037.0 \\
1035.0 \\
1002.0 \\
962.3 \\
906.6 \\
867.7 \\
777.9 \\
1192.0 \\
1995.0 \\
1205.0 \\
1208.0 \\
1179.0 \\
1158.0 \\
1118.0 \\
1034.0\end{array}$ \\
\hline
\end{tabular}


ROASPMND AND ZOBEY CORRELATION PARAMETRRS POR FIILP DEVELOPED, NOCLEATF, POOL BOILING OF QATEP ON $A$ HORIZONTAL COPPEA SORPACE OSTMG HEAT HETER HH-2

\begin{tabular}{|c|c|c|c|c|c|c|c|c|}
\hline Pun Ident. & $\frac{\frac{\text { Pohsenor }}{\text { CpotalfI }}}{\text { PIg }}$ & $\frac{\text { Cores }}{\text { Pr }}$ & $\frac{\text { elation Par }}{\frac{\text { Cp०TdIIf }}{\text { HgPr }}}$ & $\frac{\text { meters }}{\text { Bubbie }}$ & 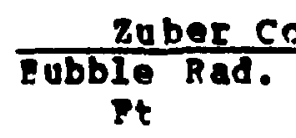 & $\frac{\text { relat } 10}{\text { Bublo }}$ & $\begin{array}{l}\frac{\text { Parana }}{\text { Bubble }} \\
\text { Nu/Pr is }\end{array}$ & $\frac{c 8}{\text { Bubble }}$ \\
\hline 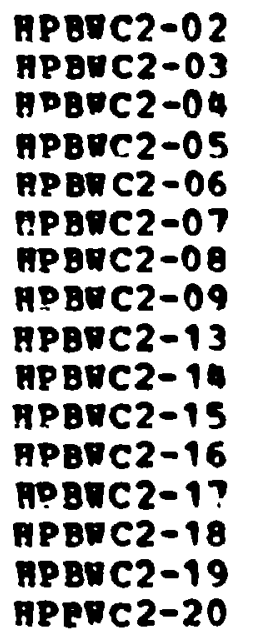 & $\begin{array}{l}0.01548 \\
0.01526 \\
0.01507 \\
0.01480 \\
1.01443 \\
0.01402 \\
0.011369 \\
0.01283 \\
0.01666 \\
0.01662 \\
0.01653 \\
0.01653 \\
0.01636 \\
0.01600 \\
0.01568 \\
0.01528\end{array}$ & $\begin{array}{l}1.740 \\
1.740 \\
1.740 \\
1.740 \\
1.740 \\
1.740 \\
1.740 \\
1.739 \\
1.737 \\
1.736 \\
1.736 \\
1.737 \\
1.737 \\
1.737 \\
1.736 \\
1.737\end{array}$ & $\begin{array}{l}8.898 \cdot 10-3 \\
8.765 \cdot 10-3 \\
8.659 \cdot 10-3 \\
8.504 \cdot 10-3 \\
8.295 \cdot 10-3 \\
9.060 \cdot 10-3 \\
7.871 \cdot 10-3 \\
7.378 \cdot 10-3 \\
9.591 \cdot 10-3 \\
9.572 \cdot 10-3 \\
9.517 \cdot 10-3 \\
9.521 \cdot 10-3 \\
9.419 \cdot 10-3 \\
9.211 \cdot 10-3 \\
9.030 \cdot 10-3 \\
8.798 \cdot 10-3\end{array}$ & $\begin{array}{l}0.8272 \\
0.7169 \\
0.5832 \\
0.4527 \\
0.3322 \\
0.2279 \\
0.1636 \\
0.0996 \\
0.9045 \\
0.7784 \\
0.6467 \\
0.5232 \\
0.3916 \\
0.2680 \\
0.2038 \\
0.1399\end{array}$ & $\begin{array}{l}4.6710 \cdot 10-8 \\
4.6690 \cdot 10-8 \\
4.6550 \cdot 10-8 \\
4.6460 \cdot 10-8 \\
4.6220 \cdot 10-8 \\
4.5990 \cdot 10-8 \\
4.5790 \cdot 10-8 \\
4.5150 \cdot 10-8 \\
4.6820 \cdot 10-8 \\
4.6750 \cdot 10-8 \\
4.6740 \cdot 10-8 \\
4.6780 \cdot 10-8 \\
4.6760 \cdot 10-8 \\
4.657 n \cdot 10-8 \\
4.6370 \cdot 10-8 \\
4.6280 \cdot 10-8\end{array}$ & $\begin{array}{l}0.5281 \\
0.4644 \\
0.3812 \\
0.3008 \\
0.2251 \\
0.1581 \\
0.1157 \\
0.0741 \\
0.5371 \\
0.4624 \\
0.3863 \\
0.3127 \\
0.2364 \\
0.1648 \\
0.1273 \\
0.0895\end{array}$ & $\begin{array}{l}0.43910 \\
0.38610 \\
0.31700 \\
0.25000 \\
0.18720 \\
0.13150 \\
0.09622 \\
0.06166 \\
0.44680 \\
0.38480 \\
0.32140 \\
0.26010 \\
0.19670 \\
0.13710 \\
0.10590 \\
0.07446\end{array}$ & $\begin{array}{l}1155.0 \\
1124.0 \\
1095.0 \\
1057.0 \\
1005.0 \\
948.3 \\
903.8 \\
790.9 \\
1325.0 \\
1317.0 \\
1303.0 \\
1306.0 \\
1290.0 \\
1223.0 \\
1174.0 \\
1118.0\end{array}$ \\
\hline
\end{tabular}


TABLE D-15

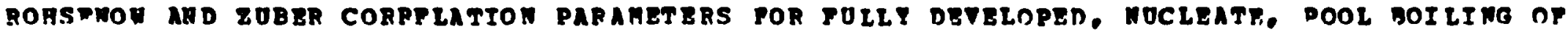
MATER ON A VERTTCAL COPPER SURPACF DSIME HEAT METER HH-1

\begin{tabular}{|c|c|c|c|c|c|c|c|c|}
\hline Run Ident. & $\frac{\frac{\text { Rohaenor }}{\text { Cpotalif }}}{\text { hIg }}$ & $\begin{array}{l}\text { Corre } \\
\text { Pr }\end{array}$ & $\frac{\frac{\text { lation Par }}{\text { Cporalfr }}}{\text { Hrgor }}$ & $\frac{\text { etere }}{\text { Boble }}$ & $\begin{array}{c}\text { Tuher co } \\
\text { obble Rad. } \\
\text { Pt }\end{array}$ & $\begin{array}{c}\text { arelatio } \\
\text { Bubbie } \\
\text { Nu }\end{array}$ & $\begin{array}{l}\frac{\text { Paranes }}{\text { Dobble }} \\
\text { No/Pr \& }\end{array}$ & 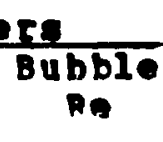 \\
\hline 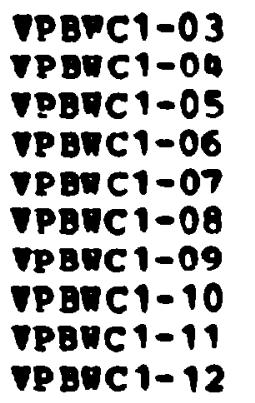 & $\begin{array}{l}0.01618 \\
0.01549 \\
0.01445 \\
0.01374 \\
0.01280 \\
0.01147 \\
0.01319 \\
0.01203 \\
0.01054 \\
0.00979\end{array}$ & $\begin{array}{l}1.735 \\
1.736 \\
1.736 \\
1.736 \\
1.737 \\
1.737 \\
1.736 \\
1.737 \\
1.738 \\
1.737\end{array}$ & $\begin{array}{l}9.326 \cdot 10-3 \\
8.926 \cdot 10-3 \\
8.324 \cdot 10-3 \\
7.917 \cdot 10-3 \\
7.370 \cdot 10-3 \\
6.601 \cdot 10-3 \\
7.594 \cdot 10-3 \\
6.025 \cdot 10-3 \\
6.068 \cdot 10-3 \\
5.632 \cdot 10-3\end{array}$ & $\begin{array}{l}1.0450 \\
0.8949 \\
0.7509 \\
0.6035 \\
0.4591 \\
0.3107 \\
0.5300 \\
0.3876 \\
0.2343 \\
0.1611\end{array}$ & $\begin{array}{l}5.1130 \cdot 10-8 \\
5.3980 \cdot 10-8 \\
5.3360 \cdot 10-8 \\
5.2330 \cdot 10-8 \\
5.2310 \cdot 10-8 \\
5.135 n \cdot 10-8 \\
5.2540 \cdot 10-8 \\
5.1750 \cdot 10-8 \\
5.13650 \cdot 10-8 \\
4.13910 \cdot 10-8\end{array}$ & $\begin{array}{l}0.6324 \\
0.3633 \\
0.3019 \\
0.4199 \\
0.3399 \\
0.2520 \\
0.3824 \\
0.3021 \\
0.2040 \\
0.1489\end{array}$ & $\begin{array}{l}0.32630 \\
0.46870 \\
0.41760 \\
0.34940 \\
0.75770 \\
0.20960 \\
0.31820 \\
0.25130 \\
0.16970 \\
0.12390\end{array}$ & $\begin{array}{l}1244.0 \\
1144.0 \\
996.8 \\
899.4 \\
782.1 \\
628.2 \\
929.4 \\
690.7 \\
532 . ? \\
458.3\end{array}$ \\
\hline
\end{tabular}




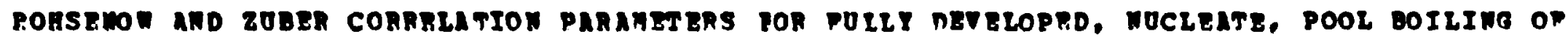
DATBR ON A VERTTCAL COPPEA SORPACE OSIMG HERT MTTER MH-2

\begin{tabular}{|c|c|c|c|c|c|c|c|c|}
\hline Run Ident. & $\frac{\text { Rohernow }}{\text { Coorntef }}$ & $\frac{\text { Corre }}{\text { Pr }}$ & $\frac{\text { elation Pars }}{\frac{\text { CpeTdIfI }}{\text { HIgePI }}}$ & $\frac{\text { aters }}{\text { Bubbio }}$ & $\frac{\text { guber ce }}{\text { gobbie Rad. }}$ & $\frac{\text { eralatio }}{\text { Dubbio }}$ & $\begin{array}{l}\text { n parent } \\
\text { Dubbia } \\
\text { wu/8ris }\end{array}$ & $\frac{2 c}{\text { Bubble }}$ \\
\hline 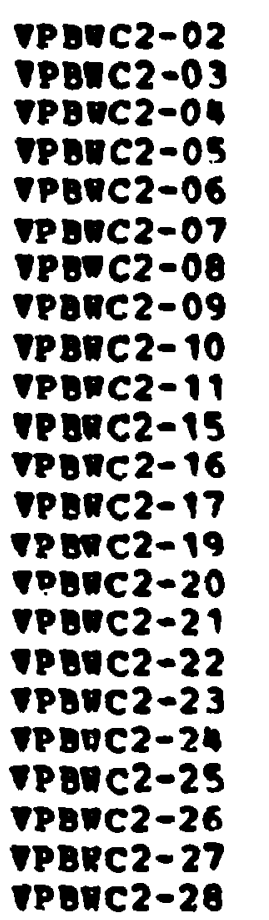 & $\begin{array}{l}0.01438 \\
0.01418 \\
0.01364 \\
0.01309 \\
0.01239 \\
0.01202 \\
0.01162 \\
0.01129 \\
0.01111 \\
0.01064 \\
0.01501 \\
0.01414 \\
0.01254 \\
0.01477 \\
0.01470 \\
0.01474 \\
0.01473 \\
0.01447 \\
0.01262 \\
0.01270 \\
0.01269 \\
0.01264 \\
0.01268\end{array}$ & $\begin{array}{l}1.735 \\
1.735 \\
1.735 \\
1.736 \\
1.736 \\
1.736 \\
1.736 \\
1.736 \\
1.735 \\
1.735 \\
1.735 \\
1.735 \\
1.738 \\
1.735 \\
1.736 \\
1.737 \\
1.737 \\
1.737 \\
1.736 \\
1.737 \\
1.738 \\
1.737 \\
1.738\end{array}$ & $\begin{array}{l}8.286 \cdot 10-3 \\
8.177 \cdot 10-3 \\
7.858 \cdot 10-3 \\
7.540 \cdot 10-3 \\
7.137 \cdot 10-3 \\
6.925 \cdot 10-3 \\
6.694 \cdot 10-3 \\
6.506 \cdot 10-3 \\
6.402 \cdot 10-3 \\
6.132 \cdot 10-3 \\
1.648 \cdot 10-3 \\
8.147 \cdot 10-3 \\
7.214 \cdot 10-3 \\
8.511 \cdot 10-3 \\
8.467 \cdot 10-3 \\
8.488 \cdot 10-3 \\
8.480 \cdot 10-3 \\
8.334 \cdot 10-3 \\
7.270 \cdot 10-3 \\
7.309 \cdot 10-3 \\
7.301 \cdot 10-3 \\
7.275 \cdot 10-3 \\
7.296 \cdot 10-3\end{array}$ & $\begin{array}{l}0.8307 \\
0.7212 \\
0.5876 \\
0.4547 \\
0.3273 \\
0.2659 \\
0.2087 \\
0.1653 \\
0.1418 \\
0.1000 \\
0.8293 \\
0.6513 \\
0.3288 \\
0.6531 \\
0.6531 \\
0.6531 \\
0.6519 \\
0.6539 \\
0.3303 \\
0.3280 \\
0.3283 \\
0.3287 \\
0.32 \% 6\end{array}$ & $\begin{array}{l}4.5550 \cdot 10-8 \\
4.5491 \cdot 10-8 \\
4.5160 \cdot 10-8 \\
4.4910 \cdot 10-8 \\
4.4460 \cdot 10-8 \\
4.475 n \cdot 10-8 \\
4.3950 \cdot 10-8 \\
4.3760 \cdot 10-8 \\
4.3550 \cdot 10-8 \\
4.3190 \cdot 10-8 \\
4.5990 \cdot 10-8 \\
4.5410 \cdot 10-8 \\
4.4820 \cdot 10-8 \\
4.5770 \cdot 10-8 \\
4.5810 \cdot 10-8 \\
4.5920 \cdot 10-8 \\
4.5950 \cdot 10-8 \\
4.5820 \cdot 10-8 \\
4.4730 \cdot 10-8 \\
4.4990 \cdot 10-8 \\
4.4190 \cdot 10-8 \\
4.4971 \cdot 10-8 \\
4.4980 \cdot 10-8\end{array}$ & $\begin{array}{l}0.5536 \\
0.4885 \\
0.4108 \\
0.3294 \\
0.2480 \\
0.2067 \\
0.1667 \\
0.1352 \\
0.1174 \\
0.0857 \\
0.3352 \\
0.4416 \\
0.2465 \\
0.4273 \\
0.4298 \\
0.4298 \\
0.4296 \\
0.4372 \\
0.2472 \\
0.2450 \\
0.2456 \\
0.2465 \\
0.2436\end{array}$ & $\begin{array}{l}0.46230 \\
0.17650 \\
0.34190 \\
0.27410 \\
0.20640 \\
0.177200 \\
0.13870 \\
0.11250 \\
0.09768 \\
0.07129 \\
0.44530 \\
0.36750 \\
0.20670 \\
0.35560 \\
0.35760 \\
0.35760 \\
0.35740 \\
0.36370 \\
0.20560 \\
0.20380 \\
0.20430 \\
0.20510 \\
0.20430\end{array}$ & $\begin{array}{r}982.7 \\
957.0 \\
884.0 \\
815.4 \\
730.4 \\
689.2 \\
642.3 \\
607.4 \\
586.8 \\
534.1 \\
1071.0 \\
949.8 \\
752.4 \\
1037.0 \\
10 \% 9.0 \\
1037.0 \\
1036.0 \\
1001.0 \\
760.6 \\
791.7 \\
770.5 \\
764.8 \\
771.5\end{array}$ \\
\hline
\end{tabular}


TABL8 $0-17$

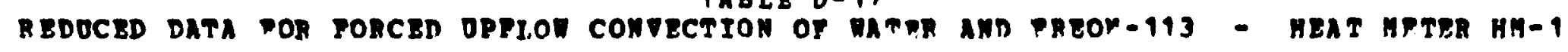

\begin{tabular}{|c|c|c|c|c|c|c|c|c|c|c|}
\hline Run & Ident. & $\begin{array}{l}q^{n}(\operatorname{Rn}-1) \\
\frac{\operatorname{ctu}}{\operatorname{Ar}-P{ }^{2}}\end{array}$ & 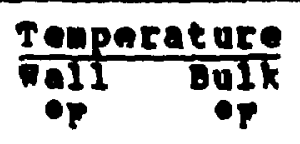 & 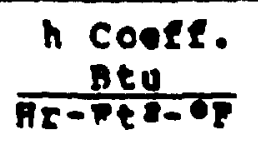 & $\begin{array}{l}\text { Vol. } \\
\frac{\text { Pec }}{\text { Soc }}\end{array}$ & $\begin{array}{l}6 \text { Plux } \\
\text { potrhn } \\
\text { he-tis }\end{array}$ & ne & $P r$ & Nu & $\begin{array}{l}\text { Plac. } \\
\text { Rat10 }\end{array}$ \\
\hline
\end{tabular}

Por nater on Nickel

\begin{abstract}
SPCAN1-001 SPCDN1-002 SPCHN1-003 SPCHR1-004 SPCDM1-005 SPCWH 1-006 SPENM1-007 SPCWM1-008 SPCWN1-009 SPCEN1-0 10 SPCQN1-011 SPCQN1-012 SPCWM1-0 13 SPCNN1-014 SPCWM1-015 SPCEN1-016 SPCPN1-0 17
\end{abstract}

SPCWC1-001 SPCIC1-002

$\begin{array}{llll}24628 & 279.97214 .75 & 1618 \\ 38575 & 238.79214 .86 & 1612 \\ 49415 & 245.73214 .76 & 1596 \\ 21097 & 227.50 & 215.19 & 1714 \\ 20060 & 227.16 & 215.15 & 1685 \\ 34554 & 252.39214 .98 & 931 \\ 29859 & 247.20215 .00 & 927 \\ 19958 & 236.40 & 215.03 & 934 \\ 24687 & 253.45 & 214.94 & 649 \\ 19851 & 246.02 & 214.92 & 638 \\ 14665 & 237.94214 .92 & 637 \\ 40189 & 236.52 & 215.12 & 1879 \\ 30278 & 231.22 & 215.06 & 1873 \\ 20323 & 225.64214 .98 & 1907 \\ 14950 & 222.80 & 214.98 & 1913 \\ 25096 & 241.96214 .95 & 929 \\ 14850 & 230.87214 .92 & 931\end{array}$

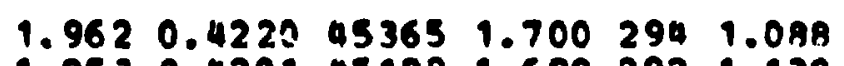
1.953
0.4201 $451891.699292 \quad 1.139$ $1.9440 .4182449641 .700290 \quad 1.181$ 2.0090 .4343464811 .6963911 .079 $1.9910 .4282 \quad 461351.696306 \quad 1.069$ $0.9870 .2122 \quad 22845 \quad 1.698 \quad 1691.217$ $0.9920 .2135229791 .698 \quad 168 \quad 1.18$ A $0.9920 .213522984 \quad 1.697 \quad 169 \quad 1.124$ $0.4940 .106311443 \quad 1.6981161 .225$ 0.4940 .1063114421 .6981161 .181 $0.4910 .1057 \quad 113761.6981161 .174$ $2.987 \quad 0.6425692191 .6963411 .124$ $3.0020 .6456 \quad 69529 \quad 1.697 \quad 340 \quad 1.094$ $3.002 \quad 0.6456 \quad 69498 \quad 1.698 \quad 346 \quad 1.062$ 3.01 e.6487 698.3n 1.6983471 .045 $0.9920 .2135229721 .698 \quad 1691.157$ $0.9970 .2122228 .36 \quad 1.698 \quad 169 \quad 1.092$

For water en copper

$\begin{array}{llll}25102 & 228.75 & 215.00 \quad 1826\end{array}$ $20178225.97215 .04 \quad 1847$
2.9870 .6425691711 .6983311 .079 $2.9870 .6425 \quad 69189 \quad 1.6973351 .067$ 
TABLE D-17 (Continued)

\begin{tabular}{|c|c|c|c|c|c|c|c|c|c|c|}
\hline Run Ident. & $\begin{array}{c}q^{\prime \prime}(\text { BH-1) } \\
\text { Btu } \\
\text { Ar-Pt' }\end{array}$ & $\frac{\text { reaper }}{\text { Dall }}$ & $\frac{\text { cature }}{\text { buik }}$ & $\begin{array}{c}\text { h coete. } \\
\frac{\text { Bet }}{\text { hr-Ptz-OI }}\end{array}$ & 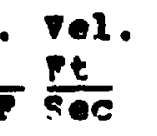 & $\begin{array}{l}\text { Plux } \\
\text { poptbn } \\
\text { HE-PtE }\end{array}$ & Re & Pr & Mu & $\begin{array}{l}\text { Tiac. } \\
\text { Ratio }\end{array}$ \\
\hline \multicolumn{11}{|c|}{ Por Preon on Copper } \\
\hline $\begin{array}{l}\text { SPCPC1-001 } \\
\text { SPCFC1-002 }\end{array}$ & $\begin{array}{l}3817 \\
1273\end{array}$ & $\begin{array}{l}136.82 \\
127.36\end{array}$ & $\begin{array}{l}122.15 \\
122.11\end{array}$ & $\begin{array}{l}260 \\
243\end{array}$ & $\begin{array}{l}1.958 \\
1.957\end{array}$ & $\begin{array}{l}0.6617 \\
0.6617\end{array}$ & $\begin{array}{l}40302 \\
40292\end{array}$ & $\begin{array}{l}6.928 \\
6.929\end{array}$ & $\begin{array}{l}467 \\
436\end{array}$ & $\begin{array}{l}1.094 \\
1.033\end{array}$ \\
\hline
\end{tabular}


TADLE $n-18$

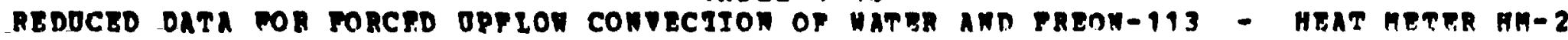

\begin{tabular}{|c|c|c|c|c|c|c|c|c|c|c|}
\hline un Id & $\begin{array}{l}q^{n}(n n-2) \\
\frac{p t y}{n r-p t^{2}}\end{array}$ & 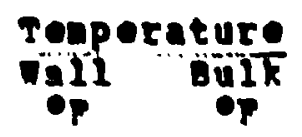 & $\begin{array}{l}h \text { Conef. } \\
\frac{\text { Btu }}{\text { Br-Ded-uT }}\end{array}$ & $\begin{array}{l}\text { Pel. } \\
p_{t}\end{array}$ & $\begin{array}{l}6 \operatorname{lux} \\
\frac{10 \cdot z b n}{H \tau-P t}\end{array}$ & Re & $\mathbf{P r}$ & Mu & $\begin{array}{l}\text { Viec. } \\
\text { nat } 10\end{array}$ & $\begin{array}{l}q^{n}(A n-1) \\
\frac{B+y}{\text { Br-per }}\end{array}$ \\
\hline
\end{tabular}

For mater on Mlekel - Convection moral with Hoat meter HM-

\begin{abstract}
SPCWN2-On 1 SPCWN2-002 SPCWN2-003 SPCDN2-004 SPCWn2-005 SPCrn2-006 SPCWN2-007 SPCWN2-008 SPCWN2-009 SPCIN2-0 10 SPCRn2-011 SPCWN2-012 SPCWN2-013 SPCWN2-0 14 SPCWN2-015 SPCEN2-0 16 SPCWN2-017 SPCNN2-0 Is SPCWM2-019 SPCNN2-020 SPCN $2-021$ SPCDI2-022 SPCW $12-023$ SPCNN2-024
\end{abstract}

$\begin{array}{llll}24124 & 230.12 & 213.31 & 1434 \\ 41999 & 243.77 & 213.75 & 1399 \\ 32370 & 235.94213 .75 & 1459 \\ 26566 & 231.75213 .75 & 1476 \\ 40289 & 239.73 & 213.64 & 1544 \\ 44708 & 242.62 & 213.61 & 1541 \\ 51297 & 246.31 & 213.51 & 1564 \\ 43921 & 243.25 & 214.96 & 1553 \\ 46819 & 245.01 & 214.99 & 1560 \\ 46560 & 244.73 & 213.07 & 1568 \\ 42477 & 242.11 & 215.07 & 1571 \\ 30121 & 234.34 & 214.94 & 1553 \\ 18191 & 226.92 & 215.16 & 1547 \\ 38279 & 239.63215 .11 & 1561 \\ 42697 & 243.94215 .18 & 1485 \\ 38248 & 240.61 & 214.96 & 1491 \\ 25269 & 231.86 & 214.97 & 1496 \\ 43873 & 245.54 & 214.83 & 1429 \\ 43545 & 245.49 & 215.04 & 1430 \\ 38104 & 241.65 & 215.05 & 1433 \\ 40353 & 244.35 & 215.05 & 1377 \\ 30196 & 237.20 & 215.08 & 1365 \\ 20074 & 229.94215 .04 & 1349 \\ 9752 & 222.83 & 215.09 & 1259\end{array}$

$2.0070 .4322 \quad 43982 \quad 1.7192601 .100$ $1.9900 .4284 \quad 456951.7142541 .178$ $1.9990 .4302458951 .714255 \quad i .132$ 1.9990 .4302458951 .7942581 .107 $\begin{array}{lllllll}1.981 & 0.4278 & 5604 & 1.715 & 280 & 1.153\end{array}$ $\begin{array}{lllllll}1.987 & 0.4278 & 45394 & 1.715 & 280 & 1.172\end{array}$ $1.9760 .425345304 \quad 1.717294 \quad 1.195$ $2.0190 .4744 \quad 466691.701282 \quad 1.167$ 2.0190 .4344466771 .7012831 .177

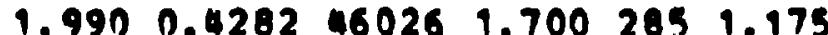

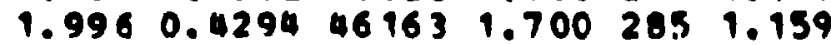
$2.0020 .430746262 \quad 1.702 \quad 282 \quad 1.115$ 2.0050 .4313463871 .6992811 .070 $2.0110 .4325 \quad 46306 \quad 1.700 \quad 283 \quad 1.145$ 1.98 1.9.4275 45988 1.6992691 .169 1.9990 .4301462001 .7012711 .131 2.0080 .4319464031 .7012711 .100 $1.9990 .430146167 \quad .7032591 .181$ $2.0020 .4307462881 .700260 \quad 1.179$ $1.096 \quad 0.4294 \quad 46156 \quad 1.700 \quad 260 \quad 1.157$ $1.9990 .4300462211 .700 \quad 250 \quad 1.173$ $1.999 \quad 0.4300 \quad 46228 \quad 1.700 \quad 248 \quad 9.130$ $1.9990 .4300 \quad 46220 \quad 1.700 \quad 245 \quad 1.098$ $1.9960 .4294461641 .700229 \quad 1.047$

ก

0

0

0

0 8 


\begin{tabular}{|c|c|c|c|c|c|c|c|c|c|c|c|}
\hline an Id & $\frac{g^{n}(n n-2)}{\text { Qte }}$ & $\frac{\text { Toper }}{\text { apd }}$ & $\frac{\text { rature }}{\text { Dupk }}$ & 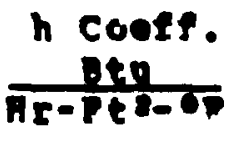 & $\frac{7 e 1}{\text { Pec }}$ & $\begin{array}{l}\text { o vlux } \\
\text { 10erpr } \\
\text { Hr-pet }\end{array}$ & ho & Pr & $\mathbf{n u}$ & $\begin{array}{l}\text { Viec. } \\
\text { Ratio }\end{array}$ & $\begin{array}{l}q^{n}(n n-1) \\
\text { Ptr } \\
\text { nr-her }\end{array}$ \\
\hline 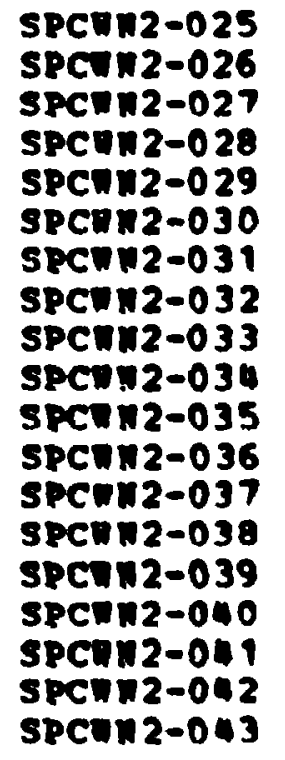 & $\begin{array}{l}35209 \\
15237 \\
64915 \\
56620 \\
79836 \\
9859 \\
19591 \\
29812 \\
33995 \\
9891 \\
19521 \\
24159 \\
29479 \\
14799 \\
20126 \\
30117 \\
40152 \\
39303 \\
29789\end{array}$ & $\begin{array}{l}240.52 \\
226.12 \\
261.13 \\
255.62 \\
251.45 \\
226.48 \\
237.58 \\
248.65 \\
253.82 \\
231.94 \\
247.57 \\
254.99 \\
262.85 \\
223.60 \\
226.67 \\
232.27 \\
237.59 \\
258.66 \\
248.10\end{array}$ & $\begin{array}{l}214.92 \\
214.83 \\
214.98 \\
215.03 \\
215.02 \\
219.02 \\
215.08 \\
215.06 \\
215.04 \\
215.39 \\
215.04 \\
215.02 \\
215.03 \\
211.98 \\
215.09 \\
215.12 \\
215.07 \\
215.06 \\
214.96 \\
215.03\end{array}$ & $\begin{array}{l}1376 \\
1350 \\
1387 \\
1380 \\
1368 \\
865 \\
170 \\
887 \\
884 \\
585 \\
600 \\
605 \\
616 \\
1736 \\
1743 \\
1751 \\
1783 \\
899 \\
901\end{array}$ & $\begin{array}{l}1 . \\
1 . \\
2 \\
1 . \\
2 . \\
0 \\
0 \\
0 \\
0\end{array}$ & $\begin{array}{l}0.4301 \\
0.4 .301 \\
0.4307 \\
0.4 .300 \\
0.4313 \\
0.2147 \\
0.2147 \\
0.2149 \\
0.2140 \\
0.1069 \\
0.1063 \\
0.1063 \\
0.1063 \\
0.6425 \\
0.0425 \\
0.6456 \\
0.6425 \\
0.21497 \\
0.2147\end{array}$ & $\begin{array}{l}46190 \\
46166 \\
46271 \\
46217 \\
46349 \\
23078 \\
23075 \\
23008 \\
23051 \\
11493 \\
11426 \\
11428 \\
11424 \\
69073 \\
69090 \\
69401 \\
69067 \\
23063 \\
23072\end{array}$ & $\begin{array}{l}1.702 \\
1.703 \\
1.701 \\
1.701 \\
1.701 \\
1.700 \\
1.700 \\
1.700 \\
1.697 \\
1.700 \\
1.701 \\
1.701 \\
1.701 \\
1.700 \\
1.700 \\
1.700 \\
1.700 \\
1.701 \\
1.701\end{array}$ & $\begin{array}{l}250 \\
245 \\
252 \\
250 \\
248 \\
157 \\
158 \\
161 \\
160 \\
106 \\
109 \\
110 \\
112 \\
115 \\
316 \\
318 \\
323 \\
163 \\
163\end{array}$ & $\begin{array}{l}1.151 \\
1.067 \\
1.277 \\
1.239 \\
1.215 \\
1.068 \\
1.133 \\
1.198 \\
1.226 \\
1.100 \\
1.192 \\
1.236 \\
1.283 \\
1.051 \\
1.069 \\
1.102 \\
1.133 \\
1.258\end{array}$ & $\begin{array}{l}0 \\
0 \\
0 \\
0 \\
0 \\
n \\
0 \\
0 \\
0 \\
0 \\
0 \\
0 \\
0 \\
0 \\
0 \\
0 \\
0 \\
0 \\
0\end{array}$ \\
\hline $\begin{array}{l}\text { SPCNN2-044 } \\
\text { SPCWN2-045 } \\
\text { SPCWN2-046 } \\
\text { SPCWN2-047 } \\
\text { SPCWN2-048 }\end{array}$ & $\begin{array}{l}34097 \\
24552 \\
14916 \\
29108 \\
19285\end{array}$ & $\begin{array}{l}254.64 \\
244.11 \\
232.89 \\
265.44 \\
249.31\end{array}$ & $\begin{array}{l}214.99 \\
215.00 \\
215.03 \\
214.94 \\
214.92\end{array}$ & $\begin{array}{l}860 \\
843 \\
935 \\
576 \\
561\end{array}$ & 0 & $\begin{array}{l}0.2122 \\
0.2135 \\
0.2135 \\
0.1063 \\
0.1063\end{array}$ & $\begin{array}{l}22902 \\
22936 \\
22941 \\
19421 \\
11420\end{array}$ & $\begin{array}{l}1.701 \\
1.701 \\
1.701 \\
1.702 \\
1.702\end{array}$ & $\begin{array}{l}156 \\
153 \\
152 \\
105 \\
102\end{array}$ & $\begin{array}{l}1.234 \\
1.172 \\
1.106 \\
1.299 \\
1.203\end{array}$ & $\begin{array}{l}34554 \\
29859 \\
19958 \\
24687 \\
19851\end{array}$ \\
\hline
\end{tabular}


TABLE E-18 (Continged)

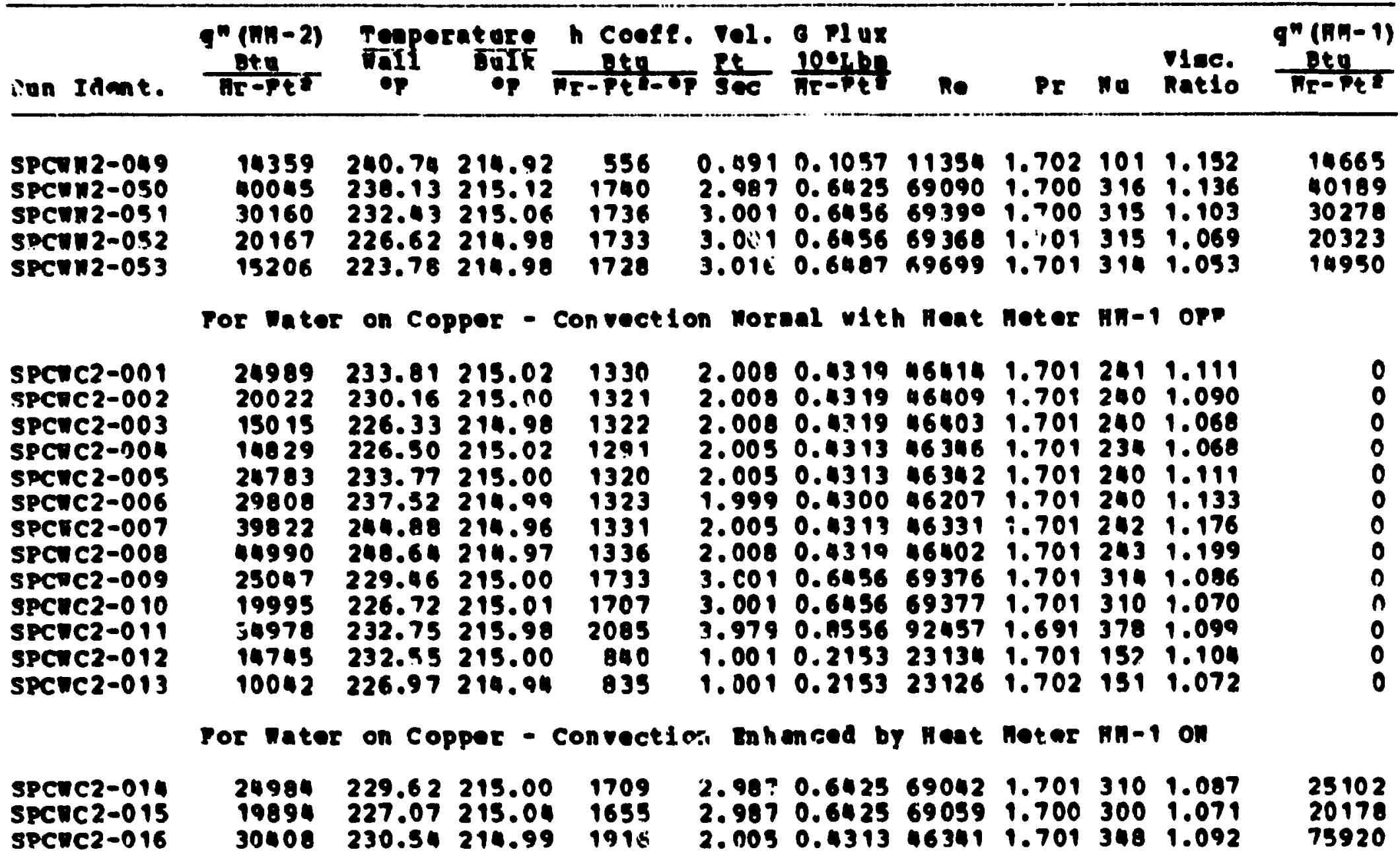


TABL n-1A (Continued)

\begin{tabular}{|c|c|c|c|c|c|c|c|c|c|c|c|}
\hline Pun Ident. & $\begin{array}{c}g^{n}(n n-2) \\
\frac{\text { Btu }}{B x-P t^{2}}\end{array}$ & $\frac{\text { Toep }}{\text { Mall }}$ & $\frac{\text { rature }}{\text { Durk }}$ & 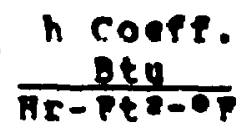 & $=\frac{v_{t}}{\text { sec }}$ & 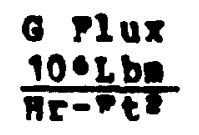 & Re & PI & Nu & $\begin{array}{l}\text { Ninc. } \\
\text { natio }\end{array}$ & $\begin{array}{c}\sigma^{n}(n n-1) \\
\text { Btu } \\
\text { Hr-pht }\end{array}$ \\
\hline $\begin{array}{l}\text { SPCDC2-017 } \\
\text { SPCDC2-018 } \\
\text { SPCEC2-019 } \\
\text { SPCWC2-020 } \\
\text { SPCDC2- } 21 \\
\text { SPCVC2-022 } \\
\text { SPCVC2-023 } \\
\text { SPCVC2-024 }\end{array}$ & $\begin{array}{l}30351 \\
22379 \\
20094 \\
15033 \\
14989 \\
14911 \\
19804 \\
24867\end{array}$ & $\begin{array}{l}231.35 \\
226.71 \\
225.59 \\
223.20 \\
223.45 \\
223.58 \\
226.04 \\
228.76\end{array}$ & $\begin{array}{l}214.93 \\
219.83 \\
215.00 \\
214.03 \\
215.11 \\
215.11 \\
215.02 \\
215.05\end{array}$ & $\begin{array}{l}1813 \\
1873 \\
1840 \\
1729 \\
1730 \\
1696 \\
1746 \\
1772\end{array}$ & $\begin{array}{l}2.002 \\
2.005 \\
1.999 \\
1.999 \\
2.005 \\
2.009 \\
2.005 \\
2.005\end{array}$ & $\begin{array}{l}0.4307 \\
0.4313 \\
0.4300 \\
0.4300 \\
0.4313 \\
0.4319 \\
0.4313 \\
0.4313\end{array}$ & $\begin{array}{l}46260 \\
46300 \\
46208 \\
46164 \\
46371 \\
46437 \\
46348 \\
46355\end{array}$ & $\begin{array}{l}1.702 \\
1.703 \\
1.701 \\
1.703 \\
1.700 \\
1.700 \\
1.701 \\
1.700\end{array}$ & $\begin{array}{l}329 \\
3.33 \\
3.14 \\
3114 \\
314 \\
302 \\
317 \\
322\end{array}$ & $\begin{array}{l}1.097 \\
1.071 \\
1.053 \\
1.050 \\
1.050 \\
1.051 \\
1.066 \\
1.081\end{array}$ & $\begin{array}{l}50548 \\
75976 \\
76013 \\
76167 \\
75533 \\
49385 \\
49377 \\
49308\end{array}$ \\
\hline & or Preor & a on $\mathrm{CO}$ & pper - & Convactio & on No & al vith & h heat & tor & Hก-1 & OPP & \\
\hline $\begin{array}{l}\text { SPCFC2-001 } \\
\text { SI ZFC2-002 } \\
\text { SPCFC2-003 } \\
\text { SPCPC2-004 } \\
\text { SPCPC2-005 } \\
\text { SPCPC2-006 } \\
\text { SPCFC2-007 } \\
\text { SPCPC2-009 }\end{array}$ & $\begin{array}{r}981 \\
628 \\
4800 \\
2437 \\
1017 \\
1098 \\
3084 \\
2053\end{array}$ & $\begin{array}{l}126.64 \\
125.07 \\
142.20 \\
132.92 \\
128.47 \\
127.75 \\
132.59 \\
130.14\end{array}$ & $\begin{array}{l}121.90 \\
121.87 \\
122.08 \\
121.98 \\
121.90 \\
123.84 \\
124.38 \\
124.31\end{array}$ & $\begin{array}{l}207 \\
196 \\
239 \\
223 \\
155 \\
281 \\
375 \\
352\end{array}$ & $\begin{array}{l}1.956 \\
1.959 \\
1.991 \\
1.953 \\
0.969 \\
2.946 \\
3.928 \\
3.900\end{array}$ & $\begin{array}{l}0.6619 \\
0.6609 \\
0.6598 \\
0.6607 \\
0.3279 \\
0.9948 \\
1.3258 \\
1.3164\end{array}$ & $\begin{array}{l}40108 \\
40042 \\
40028 \\
40059 \\
19867 \\
61038 \\
81625 \\
81012\end{array}$ & $\begin{array}{l}6.951 \\
6.952 \\
6.946 \\
6.949 \\
6.951 \\
6.895 \\
6.880 \\
6.882\end{array}$ & $\begin{array}{l}371 \\
352 \\
428 \\
400 \\
278 \\
506 \\
677 \\
634\end{array}$ & $\begin{array}{l}1.034 \\
1.024 \\
1.134 \\
1.074 \\
1.045 \\
1.028 \\
1.055 \\
1.040\end{array}$ & $\begin{array}{l}0 \\
0\end{array}$ \\
\hline & For Prec & on & 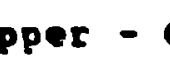 & 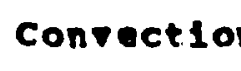 & on $F$ & 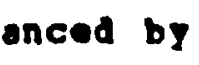 & Heat & & Hก- 1 & on & \\
\hline $\begin{array}{l}\text { SPCFC2-009 } \\
\text { SPCFC2-0 } 10 \\
\text { SPCFC2-011 } \\
\text { SPCPC2-0 } 12 \\
\text { SPCFC2-0 } 13\end{array}$ & $\begin{array}{l}4932 \\
2597 \\
2552 \\
2522 \\
1221\end{array}$ & $\begin{array}{l}142.48 \\
132.80 \\
129.25 \\
129.57 \\
125.37\end{array}$ & $\begin{array}{l}122.15 \\
122.11 \\
121.94 \\
121.90 \\
121.97\end{array}$ & $\begin{array}{l}243 \\
243 \\
324 \\
307 \\
309\end{array}$ & $\begin{array}{l}1.957 \\
1.956 \\
1.953 \\
1.956 \\
1.953\end{array}$ & $\begin{array}{l}0.6617 \\
0.6617 \\
0.6608 \\
0.6618 \\
0.6607\end{array}$ & $\begin{array}{l}40163 \\
40153 \\
40054 \\
40102 \\
40056\end{array}$ & $\begin{array}{l}6.944 \\
6.945 \\
6.950 \\
6.951 \\
6.949\end{array}$ & $\begin{array}{l}435 \\
436 \\
592 \\
550 \\
553\end{array}$ & $\begin{array}{l}1.136 \\
1.072 \\
1.050 \\
1.053 \\
1.025\end{array}$ & $\begin{array}{r}3817 \\
1273 \\
24842 \\
13815 \\
24356\end{array}$ \\
\hline
\end{tabular}


TABLE D-18 (Continuea)

\begin{tabular}{|c|c|c|c|c|c|c|c|c|c|c|c|}
\hline Run Ident. & 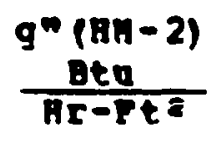 & $\frac{\text { Teaper }}{\text { Tall }}$ & $\frac{\text { rature }}{\text { ourk }}$ & $\begin{array}{l}\text { h Coeff. } \\
\frac{\text { Btu }}{\text { Br-Pts-oT }}\end{array}$ & $\begin{array}{l}\text { Vel. } \\
\frac{\text { Pet }}{\sec }\end{array}$ & $\begin{array}{l}\text { G Plux } \\
\frac{10 \operatorname{lob}}{\text { Hr-Ptz }}\end{array}$ & Re & $\mathbf{P r}$ & $\mathbf{M a}$ & $\begin{array}{l}\text { V18c. } \\
\text { Rat10 }\end{array}$ & $\begin{array}{c}g^{n}(\text { (Am-1) } \\
\frac{B t u}{B r-P t^{2}}\end{array}$ \\
\hline $\begin{array}{l}\text { SPCFC2-0 } 14 \\
\text { SPCFC2-0 } 15 \\
\text { SPCFC2-0 } 16 \\
\text { SPCF } 2-011\end{array}$ & $\begin{array}{l}1125 \\
1121 \\
2107 \\
1083\end{array}$ & $\begin{array}{l}125.31 \\
125.56 \\
128.77 \\
125.88\end{array}$ & $\begin{array}{l}122.05 \\
122.00 \\
121.92 \\
121.92\end{array}$ & $\begin{array}{l}292 \\
272 \\
285 \\
240\end{array}$ & $\begin{array}{l}1.957 \\
1.959 \\
0.969 \\
0.969\end{array}$ & $\begin{array}{l}0.6618 \\
0.6628 \\
0.3278 \\
0.3279\end{array}$ & $\begin{array}{l}40140 \\
40187 \\
19869 \\
19870\end{array}$ & $\begin{array}{l}6.947 \\
6.948 \\
6.950 \\
6.950\end{array}$ & $\begin{array}{l}525 \\
489 \\
511 \\
430\end{array}$ & $\begin{array}{l}1.024 \\
1.026 \\
1.047 \\
1.029\end{array}$ & $\begin{array}{l}24316 \\
14540 \\
14471 \\
14434\end{array}$ \\
\hline
\end{tabular}




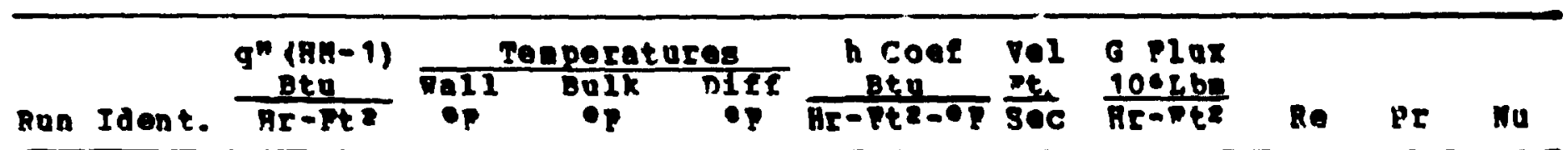

Freon-113 wth Essentially Tero Thermodyanic yoality

\begin{tabular}{|c|c|c|c|c|c|c|c|c|c|c|c|}
\hline 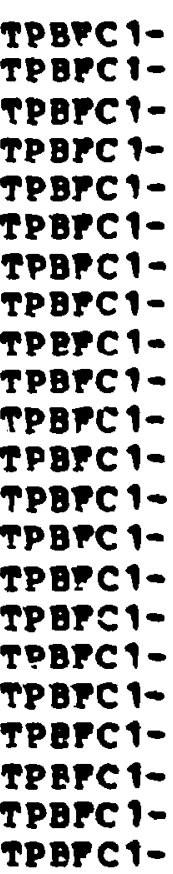 & $\begin{array}{l}2 \\
3 \\
4 \\
5 \\
6 \\
7 \\
8 \\
9 \\
10 \\
11 \\
12 \\
13 \\
11 \\
15 \\
16 \\
17 \\
18 \\
19 \\
20 \\
21 \\
22\end{array}$ & $\begin{array}{l}14517 \\
11543 \\
14383 \\
14515 \\
14471 \\
14434 \\
25271 \\
14571 \\
22720 \\
14673 \\
25356 \\
14623 \\
24857 \\
14516 \\
14384 \\
25016 \\
24842 \\
13815 \\
24356 \\
24316 \\
14540 \\
25251\end{array}$ & $\begin{array}{l}138.85 \\
138.77 \\
138.13 \\
138.64 \\
138.61 \\
138.64 \\
140.06 \\
138.26 \\
139.70 \\
138.21 \\
140.00 \\
138.24 \\
140.39 \\
138.45 \\
138.47 \\
140.15 \\
140.18 \\
138.37 \\
140.11 \\
140.42 \\
138.68 \\
142.38\end{array}$ & $\begin{array}{l}122.06 \\
122.06 \\
121.92 \\
121.89 \\
121.92 \\
121.92 \\
122.04 \\
122.02 \\
122.00 \\
122.02 \\
121.95 \\
122.01 \\
122.01 \\
121.98 \\
121.98 \\
121.97 \\
121.94 \\
121.90 \\
121.97 \\
122.05 \\
122.00 \\
124.05\end{array}$ & $\begin{array}{l}16.78 \\
16.70 \\
16.81 \\
16.76 \\
16.69 \\
16.72 \\
18.02 \\
16.24 \\
17.70 \\
16.19 \\
18.05 \\
16.22 \\
18.38 \\
16.47 \\
16.50 \\
18.28 \\
18.24 \\
16.47 \\
18.14 \\
18.38 \\
16.68\end{array}$ & $\begin{array}{r}865 \\
879 \\
856 \\
866 \\
867 \\
863 \\
1402 \\
899 \\
1284 \\
906 \\
1405 \\
901 \\
1352 \\
881 \\
872 \\
1369 \\
1362 \\
839 \\
1342 \\
1323 \\
872 \\
1377\end{array}$ & $\begin{array}{l}0.972 \\
0.970 \\
0.970 \\
0.970 \\
0.970 \\
0.970 \\
1.960 \\
1.957 \\
1.960 \\
1.960 \\
1.966 \\
1.966 \\
1.963 \\
1.960 \\
1.960 \\
1.957 \\
1.954 \\
1.957 \\
1.954 \\
1.958\end{array}$ & $\begin{array}{l}0.329 \\
0.328 \\
0.328 \\
0.328 \\
0.326 \\
0.328 \\
0.663 \\
0.662 \\
0.663 \\
0.663\end{array}$ & $\begin{array}{l}20012 \\
19954 \\
19938 \\
19935 \\
19939 \\
19939 \\
40335 \\
40273 \\
40327 \\
40330 \\
40430\end{array}$ & $\begin{array}{l}6 \\
6 \\
6 \\
6 \\
6 \\
6\end{array}$ & $\begin{array}{l}15 \\
15 \\
15 \\
15\end{array}$ \\
\hline
\end{tabular}


TABLE D-19 (Continued)

\begin{tabular}{|c|c|c|c|c|c|c|c|c|c|c|}
\hline an Ident. & 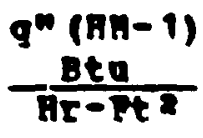 & $\operatorname{ma11}_{0 p}$ & $\frac{\text { eperat }}{\text { Duik }}$ & $\sum_{0 p}^{\operatorname{nir}}$ & $\begin{array}{c}\text { h coos } \\
\frac{\text { Dtu }}{\text { Me-ptz-0 }}\end{array}$ & $=\frac{P e 1}{\text { Pec }}$ & $\begin{array}{l}3 \text { Flux } \\
\frac{10 \text { LbD }}{\text { Hr-PtE }}\end{array}$ & no & PE & Mo \\
\hline $\begin{array}{l}\text { PBFC1- } 23 \\
\text { PBPC1- } 24\end{array}$ & $\begin{array}{l}25275 \\
39990\end{array}$ & $\begin{array}{l}142.41 \\
143.01\end{array}$ & $\begin{array}{l}124.09 \\
123.83\end{array}$ & $\begin{array}{l}18.32 \\
19.18\end{array}$ & $\begin{array}{l}1380 \\
1668\end{array}$ & $\begin{array}{l}2.947 \\
2.947\end{array}$ & & $\begin{array}{l}61316 \\
61233\end{array}$ & $\begin{array}{l}87 \\
88\end{array}$ & $\begin{array}{l}2487 \\
3005\end{array}$ \\
\hline & & & & 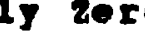 & & & & & & \\
\hline 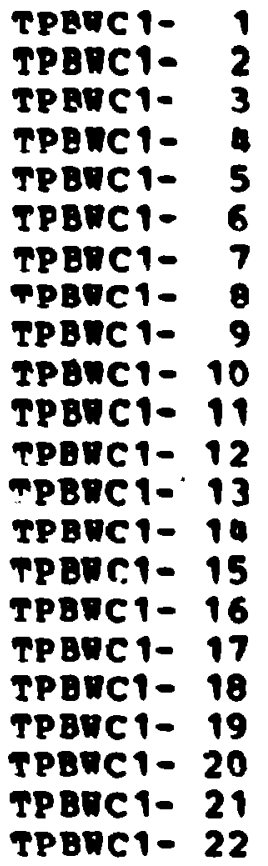 & $\begin{array}{l}50209 \\
34984 \\
65228 \\
75764 \\
50362 \\
75900 \\
49879 \\
75732 \\
49785 \\
75859 \\
50298 \\
75920 \\
50548 \\
75976 \\
76013 \\
76167 \\
75533 \\
49385 \\
49377 \\
49308 \\
75861 \\
50388\end{array}$ & $\begin{array}{l}231.17 \\
230.98 \\
232.23 \\
234.45 \\
233.35 \\
234.86 \\
234.10 \\
235.37 \\
234.41 \\
235.21 \\
234.70 \\
235.11 \\
234.57 \\
235.24 \\
235.28 \\
235.25 \\
239.12 \\
237.64 \\
237.47 \\
237.61 \\
228.32 \\
228.20\end{array}$ & $\begin{array}{l}215.00 \\
214.97 \\
214.97 \\
215.15 \\
215.15 \\
214.94 \\
214.99 \\
214.87 \\
215.00 \\
214.98 \\
214.94 \\
214.99 \\
214.93 \\
214.83 \\
215.00 \\
214.83 \\
215.11 \\
215.11 \\
215.02 \\
215.05 \\
215.00 \\
214.96\end{array}$ & $\begin{array}{l}16.17 \\
16.01 \\
17.26 \\
19.30 \\
18.20 \\
19.92 \\
19.11 \\
20.50 \\
19.41 \\
20.23 \\
19.76 \\
20.11 \\
19.63 \\
20.42 \\
20.28 \\
20.02 \\
24.00 \\
22.53 \\
22.45 \\
22.56 \\
13.32 \\
13.24\end{array}$ & $\begin{array}{l}3105 \\
2185 \\
3778 \\
3926 \\
2767 \\
3810 \\
2610 \\
3694 \\
2564 \\
3749 \\
2546 \\
3774 \\
2579 \\
3721 \\
3748 \\
3730 \\
3147 \\
2192 \\
2200 \\
2186 \\
5695 \\
3805\end{array}$ & $\begin{array}{l}0.491 \\
0.489 \\
0.499 \\
2.005 \\
2.005 \\
2.008 \\
2.008 \\
2.009 \\
2.002 \\
2.009 \\
2.017 \\
2.005 \\
2.002 \\
2.005 \\
1.999 \\
1.999 \\
2.005 \\
2.008 \\
2.005 \\
2.005\end{array}$ & $\begin{array}{l}0.1 \\
0.1 \\
0.1 \\
0.14 \\
0.4 \\
0.4 \\
0.4 \\
0.4 \\
0.4 \\
0.4 \\
0.4 \\
0.4 \\
0.4 \\
0.4 \\
0.4 \\
0.4 \\
0.4 \\
0.4 \\
0.4 \\
0.4 \\
0.4 \\
0.4\end{array}$ & $\begin{array}{l}11380 \\
11312 \\
11312 \\
46466 \\
46466 \\
46480 \\
46494 \\
46464 \\
46363 \\
46492 \\
46684 \\
46428 \\
46347 \\
46387 \\
46295 \\
46251 \\
46457 \\
46524 \\
46435 \\
46441 \\
46296 \\
46285\end{array}$ & $\begin{array}{l}1 \\
1 \\
1 \\
1 \\
1\end{array}$ & $\begin{array}{r}563 \\
396 \\
686 \\
712 \\
502 \\
691 \\
474 \\
670 \\
465 \\
680 \\
462 \\
685 \\
467 \\
675 \\
680 \\
677 \\
571 \\
399 \\
399 \\
397 \\
1033 \\
690\end{array}$ \\
\hline
\end{tabular}


TABLE $n-20$

REDOCBD DATA POR FLOA BOILIMG

OH GEAT MPTFR HA-2

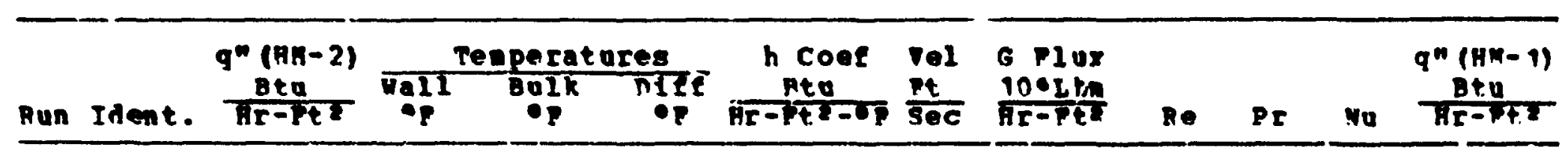

Preon-113 with Bssentially zero Thersodpnanic nuality

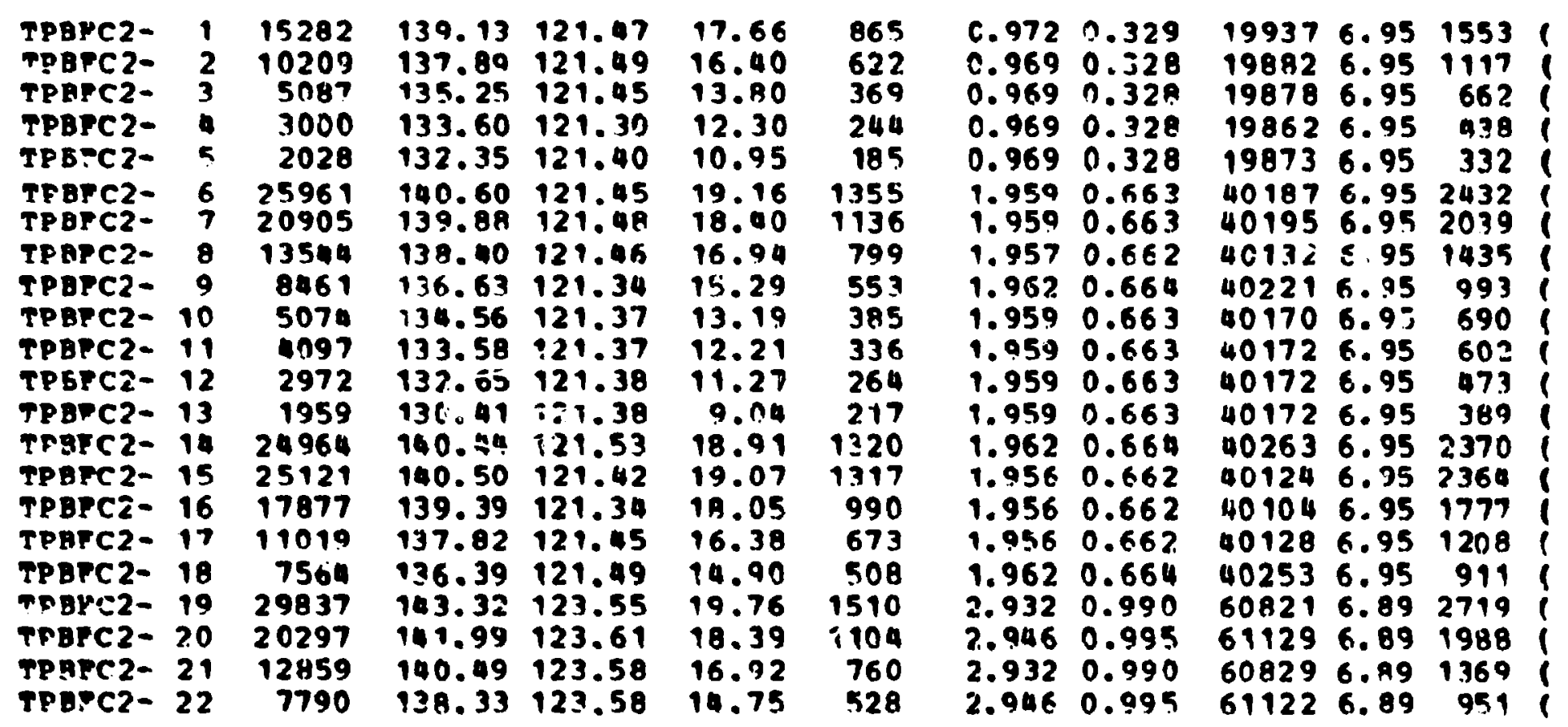


TABLE D-20 (Continuod)

\begin{tabular}{|c|c|c|c|c|c|c|c|c|c|c|c|}
\hline an & $\begin{array}{c}q^{n}(A n-2) \\
\frac{D t u}{n-F t^{2}}\end{array}$ & $\operatorname{Tan}^{2}$ & $\frac{\text { eneeraf }}{\text { Buxk }}$ & $\frac{\text { ces }}{\text { DIRI }}$ & $\begin{array}{c}\text { h coes } \\
\text { 8tu } \\
\text { HE-pts-op }\end{array}$ & $\begin{array}{l}\text { Vel } \\
\frac{P t}{\text { Sac }}\end{array}$ & $\begin{array}{l}G= \\
106 \\
15=\end{array}$ & Re & Pr & Nu & $\begin{array}{c}q^{N}(A H-1) \\
\text { Btu } \\
\text { HE-AEY }\end{array}$ \\
\hline 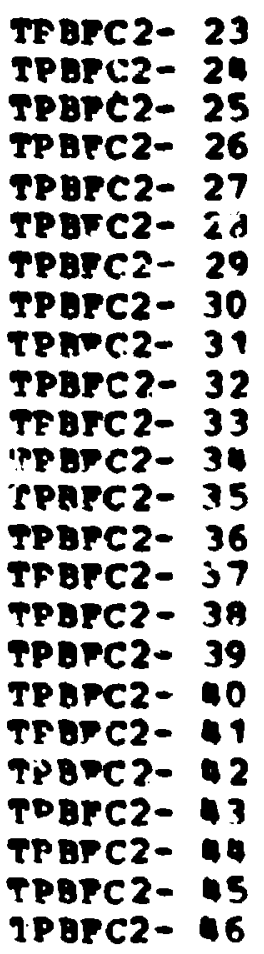 & $\begin{array}{r}5066 \\
3074 \\
34764 \\
20355 \\
12831 \\
6347 \\
9048 \\
15291 \\
10246 \\
5065 \\
3134 \\
25111 \\
25250 \\
17801 \\
17889 \\
12750 \\
12756 \\
7690 \\
7692 \\
5076 \\
5092 \\
30077 \\
20275 \\
30260\end{array}$ & $\begin{array}{l}136.47 \\
133.75 \\
149.43 \\
142.46 \\
140.90 \\
137.35 \\
136.85 \\
139.26 \\
137.80 \\
134.44 \\
131.59 \\
140.5 ! 5 \\
140.56 \\
139.60 \\
139.46 \\
139.39 \\
138.49 \\
135.98 \\
136.18 \\
133.97 \\
133.71 \\
143.32 \\
142.05 \\
143.67\end{array}$ & $\begin{array}{l}123.53 \\
129.51 \\
124.01 \\
123.93 \\
123.93 \\
123.65 \\
123.83 \\
121.51 \\
121.51 \\
121.37 \\
121.33 \\
121.49 \\
121.47 \\
121.45 \\
121.47 \\
121.39 \\
121.46 \\
121.46 \\
121.43 \\
121.42 \\
121.31 \\
123.53 \\
123.58 \\
123.31\end{array}$ & $\begin{array}{l}12.94 \\
10.24 \\
20.43 \\
18.54 \\
16.97 \\
13.70 \\
11.02 \\
17.75 \\
16.28 \\
13.07 \\
10.20 \\
19.07 \\
19.09 \\
18.15 \\
17.99 \\
16.99 \\
17.03 \\
14.52 \\
14.75 \\
12.55 \\
12.40 \\
19.78 \\
18.48\end{array}$ & $\begin{array}{l}391 \\
300 \\
1707 \\
1098 \\
756 \\
463 \\
367 \\
862 \\
629 \\
387 \\
307 \\
1317 \\
1323 \\
981 \\
994 \\
750 \\
749 \\
530 \\
522 \\
404 \\
411 \\
1520 \\
1097 \\
1486\end{array}$ & $\begin{array}{l}2.946 \\
2.946 \\
3.900 \\
3.914 \\
3.900 \\
3.914 \\
3.928 \\
0.972 \\
0.969 \\
0.969 \\
0.969 \\
1.959 \\
1.956 \\
1.959 \\
1.959 \\
1.965 \\
1.965 \\
1.962 \\
1.959 \\
1.959 \\
1.956 \\
2.946 \\
1.996\end{array}$ & $\begin{array}{l}0.995 \\
0.995 \\
1.316 \\
1.321 \\
1.316 \\
1.321 \\
1.326 \\
0.329 \\
0.328 \\
0.328 \\
0.328 \\
0.663 \\
0.662\end{array}$ & $\begin{array}{l}61105 \\
61100 \\
81095 \\
81356 \\
81068 \\
81224 \\
91605 \\
19942 \\
19885 \\
19869 \\
19866 \\
40195 \\
40133 \\
40187 \\
40190 \\
40289 \\
40305 \\
40247 \\
40181 \\
40182 \\
40098 \\
61105 \\
61119 \\
61035\end{array}$ & $\begin{array}{l}6.89 \\
6.89 \\
6.88 \\
6.88 \\
6.88 \\
6.89 \\
6.88 \\
6.95\end{array}$ & $\begin{array}{r}7 n 4 \\
540 \\
3067 \\
1979 \\
1362 \\
874 \\
662 \\
1546 \\
1129 \\
695 \\
551 \\
23164 \\
2374 \\
1760 \\
1785 \\
1346 \\
1344 \\
951 \\
936 \\
726 \\
737 \\
2738 \\
1976 \\
2676\end{array}$ & 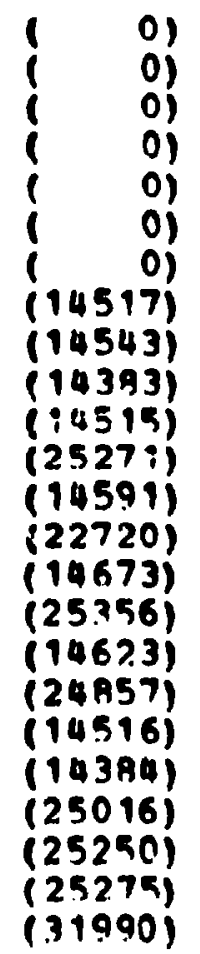 \\
\hline
\end{tabular}


TABLE $n-20$ (Continuon)

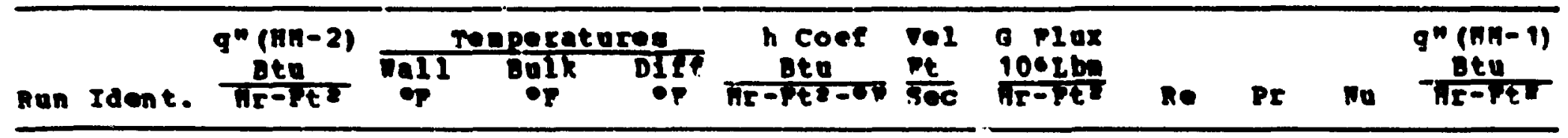

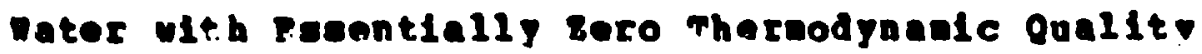

\begin{tabular}{|c|c|c|c|c|c|c|}
\hline $\begin{array}{l}\text { P. } \\
\text { PI } \\
\text { PI } \\
\text { PI }\end{array}$ & $\begin{array}{l}10 \\
12 \\
13\end{array}$ & $\begin{array}{l}34905 \\
61153 \\
51027 \\
11135 \\
30934 \\
25871 \\
18306 \\
71577 \\
61211 \\
51434 \\
40531 \\
30486 \\
70619 \\
70694 \\
61113 \\
50451 \\
40470 \\
30422 \\
70486 \\
64945 \\
35240 \\
94806\end{array}$ & $\begin{array}{l}232.99 \\
232.12 \\
231.94 \\
231.79 \\
231 \cdot 38 \\
230.97 \\
229.92 \\
237.57 \\
237.11 \\
236.43 \\
236.23 \\
235.20 \\
235.69 \\
236.54 \\
236.22 \\
236.18 \\
235.53 \\
234.65\end{array}$ & $\begin{array}{l}7 \\
72 \\
7\end{array}$ & $\begin{array}{l}1 \\
1\end{array}$ & $\begin{array}{l}4 \\
6 \\
1 \\
\\
3 \\
3 \\
6 \\
5 \\
6 \\
3\end{array}$ \\
\hline
\end{tabular}

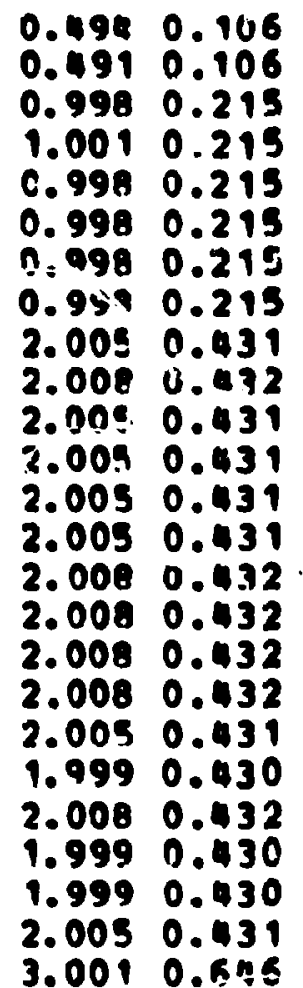

114291.70 113561.70 230751.70 231431.70 230771.70 230771.70 230761.70 230751.70 463601.70 464241.70 463551.70 463491.70 463431.70 463631.70 $\begin{array}{r}44501.70 \\ \hline\end{array}$ 464551.70 463591.70 464291.70 463591.70 $\$ 62.751 .70$ 464091.70 462131.70 461871.70 463671.70 693641.70

$480 !$
345
638
538
$437 !$
$337 !$
289
218
569
$496 !$
422
342
270
612
591
519
422
354
277
460
673
307
364
$505 !$
639

0)

$0)$

o)

o)

o)

o) 
Thele $n-20$ (Conelauen)

\begin{tabular}{|c|c|c|c|c|c|c|c|c|c|c|c|}
\hline in racat. & $\frac{q^{n}(n n-2)}{n+2+2}$ & $\frac{\pi}{\operatorname{man}}$ & $\frac{\text { gese }}{9 \mathrm{~g}}$ & $\frac{\operatorname{meg}}{D T^{\prime}}$ & $\begin{array}{l}h \text { coet } \\
\text { Reth } \\
=-\frac{1}{2}=0 T\end{array}$ & $\begin{array}{l}\frac{7 e 2}{306} \\
\frac{7 t}{306}\end{array}$ & $\begin{array}{l}\text { o plax } \\
\text { 10erph } \\
\text { ir-pty }\end{array}$ & Ro & Pr & ma & $\begin{array}{l}g^{n}(\mu m-1) \\
\frac{B t u}{W E-W T}\end{array}$ \\
\hline 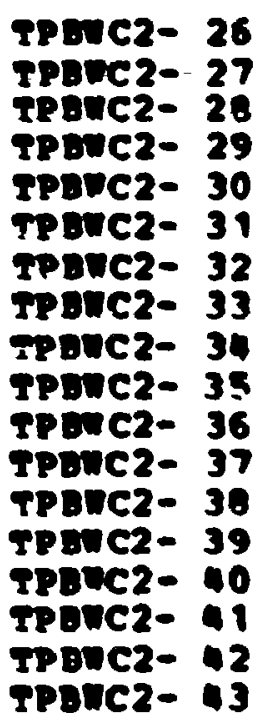 & $\begin{array}{l}56135 \\
35106 \\
45536 \\
30663 \\
84500 \\
34767 \\
34800 \\
34832 \\
70004 \\
70774 \\
60768 \\
60047 \\
50967 \\
50073 \\
40347 \\
40367 \\
34903 \\
34973\end{array}$ & $\begin{array}{l}233.23 \\
231.99 \\
232.78 \\
231.31 \\
239.25 \\
233.33 \\
233.49 \\
233.30 \\
236.77 \\
236.83 \\
236.58 \\
236.76 \\
236.78 \\
236.47 \\
234.80 \\
234.99 \\
231.40 \\
231.69\end{array}$ & $\begin{array}{l}214.68 \\
214.68 \\
214.70 \\
214.68 \\
215.73 \\
214.68 \\
214.64 \\
2114.64 \\
114.83 \\
214.83 \\
214.61 \\
214.67 \\
214.55 \\
214.68 \\
214.65 \\
214.62 \\
214.68 \\
214.63\end{array}$ & $\begin{array}{l}18.55 \\
17.32 \\
18.08 \\
16.64 \\
23.52 \\
18.65 \\
10.80 \\
18.66 \\
21.94 \\
22.00 \\
21.97 \\
22.09 \\
22.23 \\
21.79 \\
20.23 \\
20.37 \\
16.73 \\
17.05\end{array}$ & $\begin{array}{l}3026 \\
2027 \\
2519 \\
1813 \\
2745 \\
1864 \\
1856 \\
1867 \\
3227 \\
3216 \\
2766 \\
2754 \\
2293 \\
2332 \\
1994 \\
1902 \\
2007 \\
3031\end{array}$ & $\begin{array}{l}3.001 \\
3.001 \\
3.001 \\
3.016 \\
3.965 \\
0.491 \\
0.489 \\
0.489 \\
2.003 \\
2.005 \\
2.008 \\
2.008 \\
2.008 \\
2.002 \\
2.008 \\
2.016 \\
1.999 \\
1.999\end{array}$ & $\begin{array}{l}0.646 \\
0.646 \\
0.646 \\
0.649 \\
0.852 \\
0.106 \\
0.105 \\
0.105 \\
0.431 \\
0.431 \\
0.432 \\
0.432 \\
0.432 \\
0.431 \\
0.432 \\
0.434 \\
0.430 \\
0.430\end{array}$ & $\begin{array}{l}69376 \\
69376 \\
69385 \\
69709 \\
92161 \\
11359 \\
11291 \\
11291 \\
46380 \\
46379 \\
46392 \\
46407 \\
46377 \\
46276 \\
46405 \\
46597 \\
46209 \\
46198\end{array}$ & $\begin{array}{l}1.70 \\
1.10 \\
1.70 \\
1.70 \\
1.69 \\
1.70 \\
1.70 \\
1.70 \\
1.70 \\
1.70 \\
1.70 \\
1.70 \\
1.70 \\
1.70 \\
1.70 \\
1.70 \\
1.70 \\
1.70\end{array}$ & $\begin{array}{l}549 \\
368 \\
457 \\
334 \\
498 \\
338 \\
337 \\
339 \\
585 \\
384 \\
502 \\
500 \\
416 \\
423 \\
362 \\
360 \\
379 \\
372\end{array}$ & 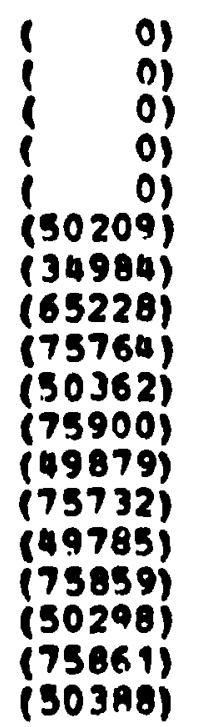 \\
\hline
\end{tabular}


PABs. $n-21$

REDUCED DATA FOR ANMOLAR FLOR BOTLIMG OF PRFON-113 OR GEAT METER HM-2

\begin{tabular}{|c|c|c|c|c|c|c|c|c|c|c|}
\hline Run Ident. & $\begin{array}{l}q^{n}(n n-2) \\
\frac{\text { Btu }}{n-p e^{2}}\end{array}$ & $\operatorname{TaII}_{\bullet}$ & $\frac{\text { eperat }}{\text { butk }}$ & Des & $\begin{array}{c}\text { h coes } \\
\text { beu }\end{array}$ & 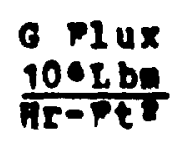 & Be & Pr & $\pi \mathbf{u}$ & $\begin{array}{l}\text { Therno. } \\
\text { ouality }\end{array}$ \\
\hline 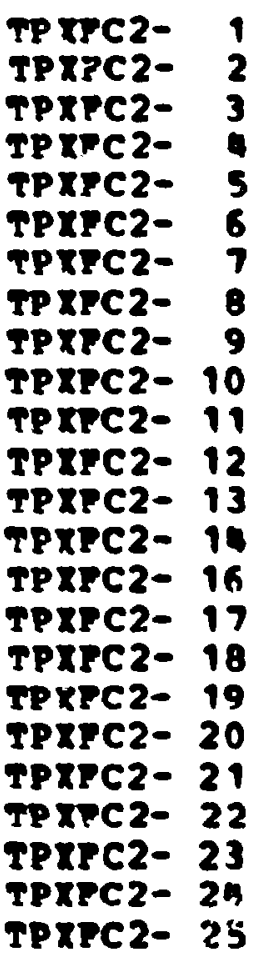 & $\begin{array}{r}25058 \\
17862 \\
10219 \\
5194 \\
25266 \\
20254 \\
15334 \\
7796 \\
22760 \\
12922 \\
7790 \\
22751 \\
15470 \\
7742 \\
25225 \\
20245 \\
15363 \\
10265 \\
5177 \\
2148 \\
25089 \\
17904 \\
10379 \\
29908\end{array}$ & $\begin{array}{l}141.32 \\
140.19 \\
138.15 \\
134.07 \\
141.38 \\
140.58 \\
139.53 \\
136.18 \\
140.72 \\
138.39 \\
135.77 \\
140.91 \\
139.40 \\
135.45 \\
141.60 \\
140.68 \\
139.46 \\
137.35 \\
132.07 \\
126.35 \\
142.65 \\
141.13 \\
137.93 \\
144.03\end{array}$ & $\begin{array}{l}122.33 \\
122.32 \\
122.25 \\
122.26 \\
122.33 \\
122.27 \\
122.24 \\
122.13 \\
121.98 \\
121.96 \\
122.30 \\
122.21 \\
122.27 \\
122.22 \\
121.75 \\
121.75 \\
121.70 \\
121.57 \\
121.70 \\
121.56 \\
122.11 \\
122.06 \\
122.13 \\
124.33\end{array}$ & $\begin{array}{l}18.99 \\
17.86 \\
15.90 \\
11.81 \\
19.05 \\
18.32 \\
17.30 \\
14.06 \\
19.74 \\
16.43 \\
13.47 \\
18.69 \\
17.13 \\
13.23 \\
19.85 \\
18.88 \\
17.76 \\
15.78 \\
10.32 \\
9.79 \\
20.54 \\
19.06 \\
15.80 \\
19.69\end{array}$ & $\begin{array}{r}1319 \\
1000 \\
643 \\
440 \\
1327 \\
1106 \\
886 \\
555 \\
1215 \\
787 \\
579 \\
1217 \\
903 \\
585 \\
1271 \\
1072 \\
465 \\
650 \\
502 \\
448 \\
1221 \\
939 \\
657 \\
1519\end{array}$ & $\begin{array}{l}0.326 \\
0.326 \\
0.326 \\
0.326 \\
0.325 \\
0.325 \\
0.325 \\
0.325 \\
0.323 \\
0.325 \\
0.325 \\
0.321 \\
0.321 \\
0.322 \\
0.656 \\
0.656 \\
0.656 \\
0.657 \\
0.660 \\
0.650 \\
0.655 \\
0.656 \\
0.655 \\
0.990\end{array}$ & $\begin{array}{l}19890 \\
19889 \\
19880 \\
19882 \\
19799 \\
19793 \\
19789 \\
19780 \\
19655 \\
19767 \\
19815 \\
19582 \\
19588 \\
19637 \\
39872 \\
39884 \\
39861 \\
39891 \\
40093 \\
40060 \\
39868 \\
39916 \\
39874 \\
61145\end{array}$ & $\begin{array}{l}6.92 \\
6.92 \\
6.92 \\
6.92 \\
6.92 \\
6.92 \\
6.93 \\
6.93 \\
6.93 \\
6.93 \\
6.92 \\
6.93 \\
6.92 \\
6.93 \\
6.94 \\
6.94 \\
6.94 \\
6.94 \\
6.94 \\
6.94 \\
6.93 \\
6.93 \\
6.93 \\
6.97\end{array}$ & $\begin{array}{r}2371 \\
1797 \\
1155 \\
790 \\
2384 \\
1987 \\
1593 \\
996 \\
2181 \\
1413 \\
1040 \\
2187 \\
1623 \\
1051 \\
2282 \\
1925 \\
1553 \\
1168 \\
901 \\
804 \\
2194 \\
1687 \\
1180 \\
2738\end{array}$ & $\begin{array}{l}1.99 \\
2.00 \\
2.02 \\
1.99 \\
3.91 \\
3.96 \\
3.89 \\
3.89 \\
6.09 \\
6.919 \\
5.84 \\
8.13 \\
8.12 \\
8.16 \\
1.86 \\
1.94 \\
1.98 \\
1.85 \\
1.95 \\
1.99 \\
4.00 \\
4.00 \\
3.99 \\
1.75\end{array}$ \\
\hline
\end{tabular}


TABIE D-21 (Contineed)

\begin{tabular}{|c|c|c|c|c|c|c|c|c|c|c|}
\hline Ron Ident. & $\begin{array}{c}g^{\prime \prime}(A n-2) \\
\frac{D t 0}{H r-F t^{g}}\end{array}$ & $-\frac{1}{911}$ & 2neridt & $\frac{29}{\text { DIII }}$ & $\begin{array}{c}\text { h Coes } \\
\text { Bto } \\
\text { Hr-pt. }\end{array}$ & 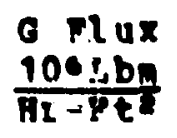 & Re & Pr & Mu & $\begin{array}{l}\text { Therno. } \\
\text { Quality }\end{array}$ \\
\hline $\begin{array}{l}\text { TPTFC2- } 26 \\
\text { TPXPC2- } 27 \\
\text { TPXPC2- } 28 \\
\text { TPXPC2- } 29 \\
\text { TPXPC2- } 30 \\
\text { TPXPC2- } 31 \\
\text { TPXPC2- } 32 \\
\text { TPXFC2- } 33 \\
\text { TPXPC2- } 34 \\
\text { TPXPC2- } 35 \\
\text { TPXPC2- } 36 \\
\text { TPXFC2- } 37 \\
\text { TPXPC2- } 38 \\
\text { TPXPC2- } 39\end{array}$ & $\begin{array}{l}22639 \\
15406 \\
10380 \\
4421 \\
27916 \\
20503 \\
12845 \\
6206 \\
34552 \\
25062 \\
17652 \\
10202 \\
7668 \\
5051\end{array}$ & $\begin{array}{l}142.94 \\
141.30 \\
139.09 \\
131.62 \\
145.95 \\
144.66 \\
142.85 \\
136.78 \\
147.96 \\
146.81 \\
145.59 \\
142.54 \\
140.76 \\
137.32\end{array}$ & $\begin{array}{l}124.12 \\
124.10 \\
124.03 \\
124.06 \\
126.34 \\
126.39 \\
126.41 \\
126.39 \\
128.24 \\
128.41 \\
128.33 \\
128.33 \\
128.55 \\
128.56\end{array}$ & $\begin{array}{r}18.82 \\
17.20 \\
15.06 \\
7.56 \\
19.61 \\
18.27 \\
16.45 \\
10.38 \\
19.72 \\
18.41 \\
17.26 \\
14.21 \\
12.21 \\
8.77\end{array}$ & $\begin{array}{r}1203 \\
696 \\
5 \\
689 \\
585 \\
1423 \\
1122 \\
781 \\
798 \\
598 \\
1752 \\
1362 \\
1023 \\
718 \\
628 \\
676\end{array}$ & $\begin{array}{l}0.990 \\
0.995 \\
0.990 \\
0.990 \\
0.987 \\
0.987 \\
0.987 \\
0.987 \\
1.141 \\
1.141 \\
1.141 \\
1.141 \\
1.141 \\
1.145\end{array}$ & $\begin{array}{l}61062 \\
61349 \\
61038 \\
61052 \\
61725 \\
61749 \\
61738 \\
61731 \\
72176 \\
72248 \\
72216 \\
72218 \\
72290 \\
72595\end{array}$ & $\begin{array}{l}6.87 \\
6.87 \\
6.88 \\
6.88 \\
6.81 \\
6.81 \\
6.81 \\
6.81 \\
6.76 \\
6.76 \\
6.76 \\
6.76 \\
6.75 \\
6.75\end{array}$ & $\begin{array}{l}2168 \\
1614 \\
1242 \\
1054 \\
2575 \\
2030 \\
1413 \\
1081 \\
3180 \\
2472 \\
1856 \\
1303 \\
1140 \\
1046\end{array}$ & $\begin{array}{l}1.83 \\
1.81 \\
1.80 \\
1.78 \\
2.29 \\
2.25 \\
2.36 \\
2.37 \\
2.10 \\
2.05 \\
2.06 \\
2.06 \\
2.11 \\
2.10\end{array}$ \\
\hline
\end{tabular}


TABLE $n-22$

ROASEMOR ADDITIVE CORPEIATION DATA FOR FOR BOTLIMG OR HEAT HETPR AH-1

\begin{tabular}{|c|c|c|c|c|c|c|}
\hline Rua Ident. & 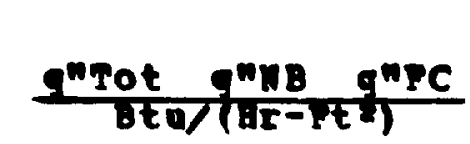 & $\begin{array}{c}\text { Temp. } \\
\text { nit2. } \\
\text { P }\end{array}$ & $\frac{h \text { Heas } h \text { NB } h \text { PC }}{B t u /(h r-1, t-U T)}$ & $\frac{h \text { Heas }}{h \text { IC }}$ & 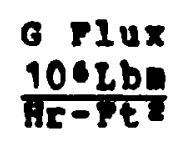 & $\begin{array}{l}\text { Recl procal } \\
\text { hart Inelil } \\
\text { parameter }\end{array}$ \\
\hline
\end{tabular}

Freon-113 with Esentially Rero Thernodynanic Qual1ty

\begin{tabular}{|c|c|c|c|c|c|c|c|c|c|c|c|}
\hline $\begin{array}{l}\text { TPBFC1- } \\
\text { TPBPC1- } \\
\text { TPBFC1- } \\
\text { TPBPC1- } \\
\text { TPBFC1- } \\
\text { TPBFC1- } \\
\text { TPBPC1- } \\
\text { TPBFC1- } \\
\text { TPBFC1- } \\
\text { TPBनC1- } \\
\text { TPBFC1- } \\
\text { TPEFC1- } \\
\text { TPBFC1- } \\
\text { TPBPC1- } \\
\text { TPBPC1- } \\
\text { TPBFC1- } \\
\text { TPBFC1- } \\
\text { TPBFC1- } \\
\text { TPBPC1- } \\
\text { TPBPC1- } \\
\text { TPBPC1- } \\
\text { TPBFC1- }\end{array}$ & $\begin{array}{l}1 \\
2 \\
3 \\
4 \\
5 \\
6 \\
7 \\
8 \\
9 \\
10 \\
11 \\
12 \\
13 \\
14 \\
15 \\
16 \\
17 \\
18 \\
19 \\
20 \\
21 \\
22\end{array}$ & $\begin{array}{l}14517 \\
14543 \\
14383 \\
14515 \\
14771 \\
14434 \\
25271 \\
14591 \\
22720 \\
14673 \\
25356 \\
14623 \\
24857 \\
14516 \\
14384 \\
25016 \\
24842 \\
13815 \\
24356 \\
24316 \\
1454 C \\
2525 \mathrm{C}\end{array}$ & $\begin{array}{l}12150 \\
12192 \\
12017 \\
12157 \\
12122 \\
12081 \\
21342 \\
11055 \\
18862 \\
11144 \\
21415 \\
11080 \\
20847 \\
10917 \\
10798 \\
21136 \\
20873 \\
11229 \\
20409 \\
20314 \\
10904 \\
11098\end{array}$ & $\begin{array}{l}2367 \\
2351 \\
2366 \\
2358 \\
2349 \\
2353 \\
3929 \\
3536 \\
3858 \\
3529 \\
3941 \\
3543 \\
4010 \\
3589 \\
3596 \\
3980 \\
3969 \\
3586 \\
3947 \\
4002 \\
3636 \\
5152\end{array}$ & $\begin{array}{l}16.78 \\
16.70 \\
11.81 \\
16.76 \\
16.69 \\
16.72 \\
18.02 \\
16.24 \\
17.70 \\
16.19 \\
18.05 \\
16.22 \\
18.38 \\
16.47 \\
16.50 \\
18.28 \\
18.24 \\
16.47 \\
18.14 \\
18.38 \\
16.68 \\
18.34\end{array}$ & $\begin{array}{r}865 \\
871 \\
856 \\
866 \\
867 \\
863 \\
1402 \\
899 \\
1284 \\
906 \\
1405 \\
901 \\
1352 \\
881 \\
872 \\
1369 \\
1362 \\
839 \\
1342 \\
1323 \\
872 \\
1377\end{array}$ & $\begin{array}{r}724 \\
730 \\
715 \\
726 \\
726 \\
723 \\
1184 \\
681 \\
1066 \\
688 \\
1186 \\
683 \\
1134 \\
664 \\
654 \\
1151 \\
1144 \\
621 \\
1125 \\
1105 \\
654 \\
1096\end{array}$ & $\begin{array}{l}141 \\
141 \\
141 \\
141 \\
141 \\
141 \\
218 \\
218 \\
218 \\
218 \\
219 \\
218 \\
218 \\
218 \\
218 \\
218 \\
218 \\
218 \\
218 \\
218 \\
218 \\
281\end{array}$ & $\begin{array}{l}6.1 \\
6.2 \\
6.1 \\
6.2 \\
6.2 \\
6.1 \\
6.4 \\
4.1 \\
5.9 \\
4.2 \\
6.4 \\
4.1 \\
6.2 \\
4.0 \\
4.0 \\
6.3 \\
6.3 \\
3.9 \\
6.2 \\
6.1 \\
4.0 \\
4.9\end{array}$ & $\begin{array}{l}0.329 \\
0.328 \\
0.328 \\
0.328 \\
0.328 \\
0.328 \\
0.663 \\
0.662 \\
0.663 \\
0.663 \\
0.665 \\
0.665 \\
0.664 \\
0.663 \\
0.663 \\
0.662 \\
0.661 \\
0.662 \\
0.669 \\
0.662 \\
0.663 \\
0.995\end{array}$ & $\begin{array}{l}0.000 \\
0.000 \\
0.000 \\
0.000 \\
0.000 \\
0.000 \\
0.000 \\
0.000 \\
0.000 \\
0.000 \\
0.000 \\
0.000 \\
0.00 n \\
0.000 \\
0.000 \\
0.000 \\
0.000 \\
0.000 \\
0.000 \\
0.000 \\
0.000 \\
0.000\end{array}$ \\
\hline
\end{tabular}


TABL. $n-22$ (Continued)

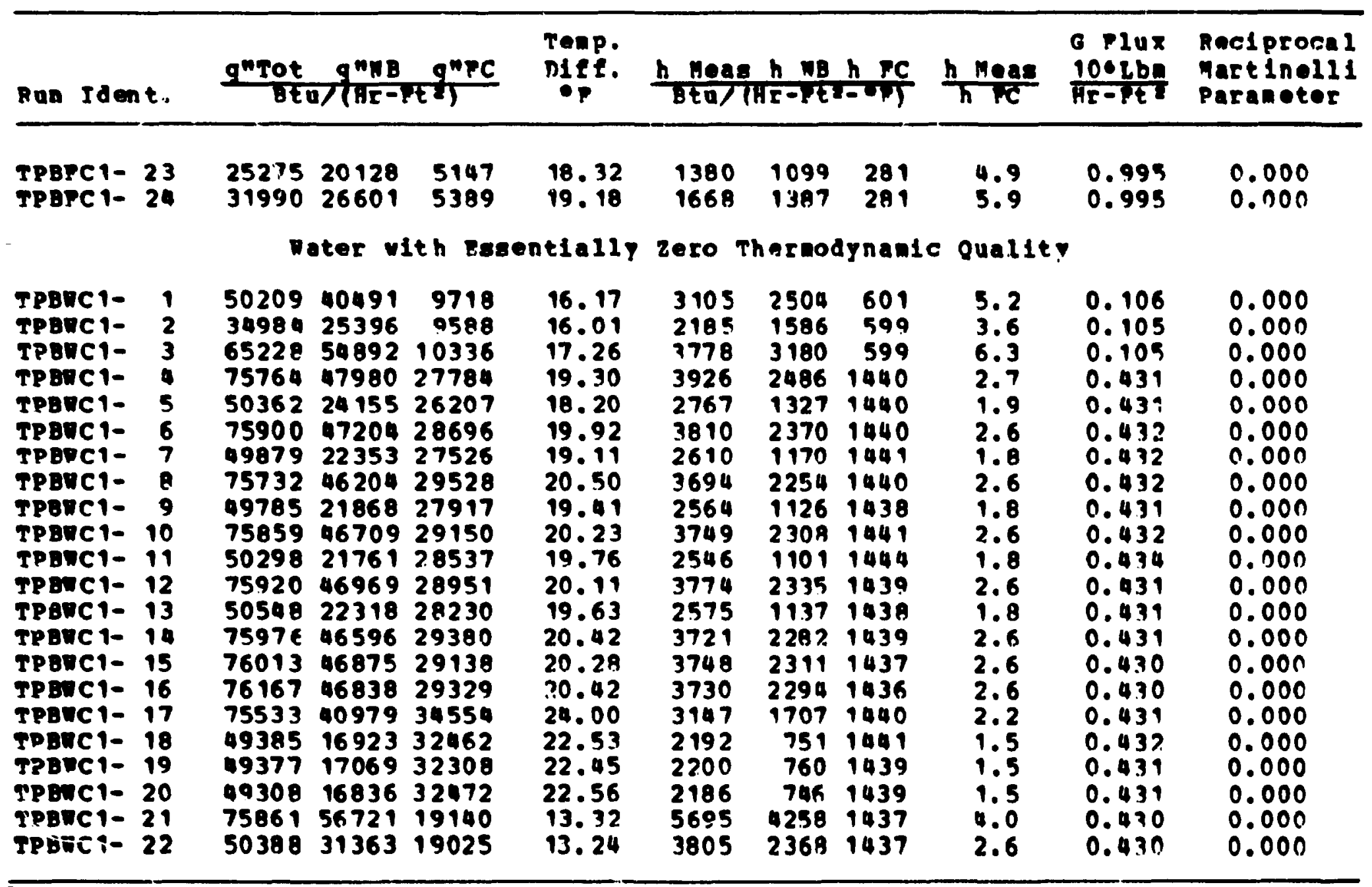


TABLE D-23

ROASE MOE ADDITIVE CORRELATION DATA FOR TLON BOILIRG ON FEAT HETER RH-2

\begin{tabular}{|c|c|c|c|c|c|c|c|c|c|c|}
\hline Run Ident. & $\frac{g^{\text {nrot }}}{\text { btt }}$ & $\mathrm{q}^{n \mathrm{n}}$ & $\frac{q^{n p c}}{\left.\right|^{2}}$ & $\begin{array}{l}\text { Tenp. } \\
\text { Dief. } \\
\text { op }\end{array}$ & $\frac{h \text { Heas }}{B t u /(h}$ & $\frac{h N B}{\mid x-P t^{2}}$ & $\frac{h+c}{-\Delta \nabla 1}$ & $\frac{h \text { Mags }}{h \sqrt{C}}$ & 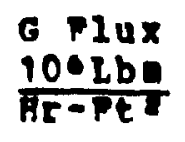 & $\begin{array}{l}\text { Reciproc } \\
\text { Wartinel } \\
\text { paranote }\end{array}$ \\
\hline \multicolumn{11}{|c|}{ Preon-113 vith } \\
\hline 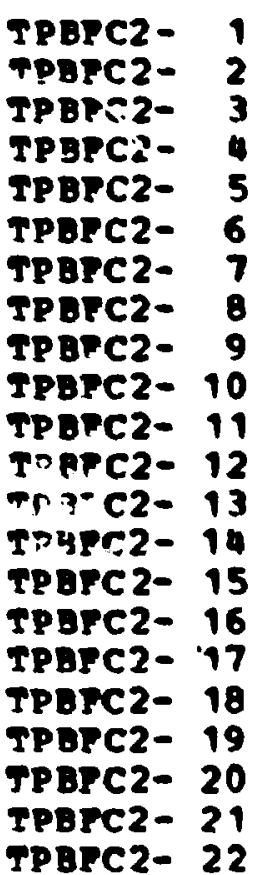 & $\begin{array}{r}15282 \\
10209 \\
5087 \\
3000 \\
2028 \\
25961 \\
20905 \\
13544 \\
9461 \\
5074 \\
4097 \\
2972 \\
1959 \\
24964 \\
25121 \\
17877 \\
11019 \\
7564 \\
29837 \\
20297 \\
12859 \\
7790\end{array}$ & $\begin{array}{r}12793 \\
7901 \\
3145 \\
1269 \\
488 \\
21787 \\
16897 \\
9856 \\
5126 \\
2201 \\
1437 \\
516 \\
90 \\
20841 \\
20970 \\
13948 \\
7455 \\
4319 \\
24303 \\
15133 \\
8122 \\
3647\end{array}$ & $\begin{array}{l}2489 \\
2308 \\
1942 \\
1731 \\
1540 \\
4174 \\
4008 \\
3688 \\
3335 \\
2873 \\
2660 \\
2456 \\
1968 \\
4123 \\
4151 \\
3929 \\
3564 \\
3249 \\
5534 \\
5164 \\
4737 \\
4143\end{array}$ & $\begin{array}{l}17.66 \\
16.40 \\
13.80 \\
12.30 \\
10.95 \\
19.16 \\
18.40 \\
16.94 \\
15.29 \\
13.19 \\
12.21 \\
11.27 \\
9.04 \\
18.91 \\
19.07 \\
18.05 \\
16.38 \\
14.90 \\
19.76 \\
18.39 \\
16.92 \\
14.75\end{array}$ & $\begin{array}{r}865 \\
622 \\
369 \\
244 \\
185 \\
1355 \\
1136 \\
799 \\
553 \\
385 \\
336 \\
264 \\
217 \\
1320 \\
1317 \\
990 \\
673 \\
508 \\
1510 \\
1104 \\
760 \\
528\end{array}$ & $\begin{array}{r}724 \\
482 \\
228 \\
103 \\
45 \\
1137 \\
918 \\
582 \\
335 \\
167 \\
118 \\
46 \\
10 \\
1102 \\
1099 \\
773 \\
455 \\
290 \\
1230 \\
823 \\
480 \\
247\end{array}$ & $\begin{array}{l}141 \\
141 \\
141 \\
141 \\
141 \\
218 \\
218 \\
218 \\
218 \\
218 \\
218 \\
218 \\
218 \\
218 \\
218 \\
218 \\
219 \\
218 \\
280 \\
281 \\
280 \\
281\end{array}$ & $\begin{array}{l}6.1 \\
4.4 \\
2.6 \\
1.7 \\
1.3 \\
6.2 \\
5.2 \\
3.7 \\
2.5 \\
1.8 \\
1.5 \\
1.2 \\
1.0 \\
6.1 \\
6.1 \\
4.6 \\
3.1 \\
2.3 \\
5.4 \\
3.9 \\
2.7 \\
1.9\end{array}$ & $\begin{array}{l}0.329 \\
0.328 \\
0.328 \\
0.328 \\
0.328 \\
0.663 \\
0.663 \\
0.667 \\
0.564 \\
0.667 \\
0.663 \\
0.663 \\
0.663 \\
0.664 \\
0.662 \\
0.662 \\
0.662 \\
0.664 \\
0.990 \\
0.995 \\
0.990 \\
0.995\end{array}$ & $\begin{array}{l}0.000 \\
0.000 \\
0.000 \\
0.000 \\
0.000 \\
0.000 \\
0.000 \\
0.000 \\
0.000 \\
0.000 \\
0.000 \\
0.000 \\
0.000 \\
n .000 \\
0.000 \\
0.000 \\
0.000 \\
0.000 \\
0.000 \\
0.001 \\
0.001 \\
0.00 n\end{array}$ \\
\hline
\end{tabular}


TABL: D-23 (Continued)

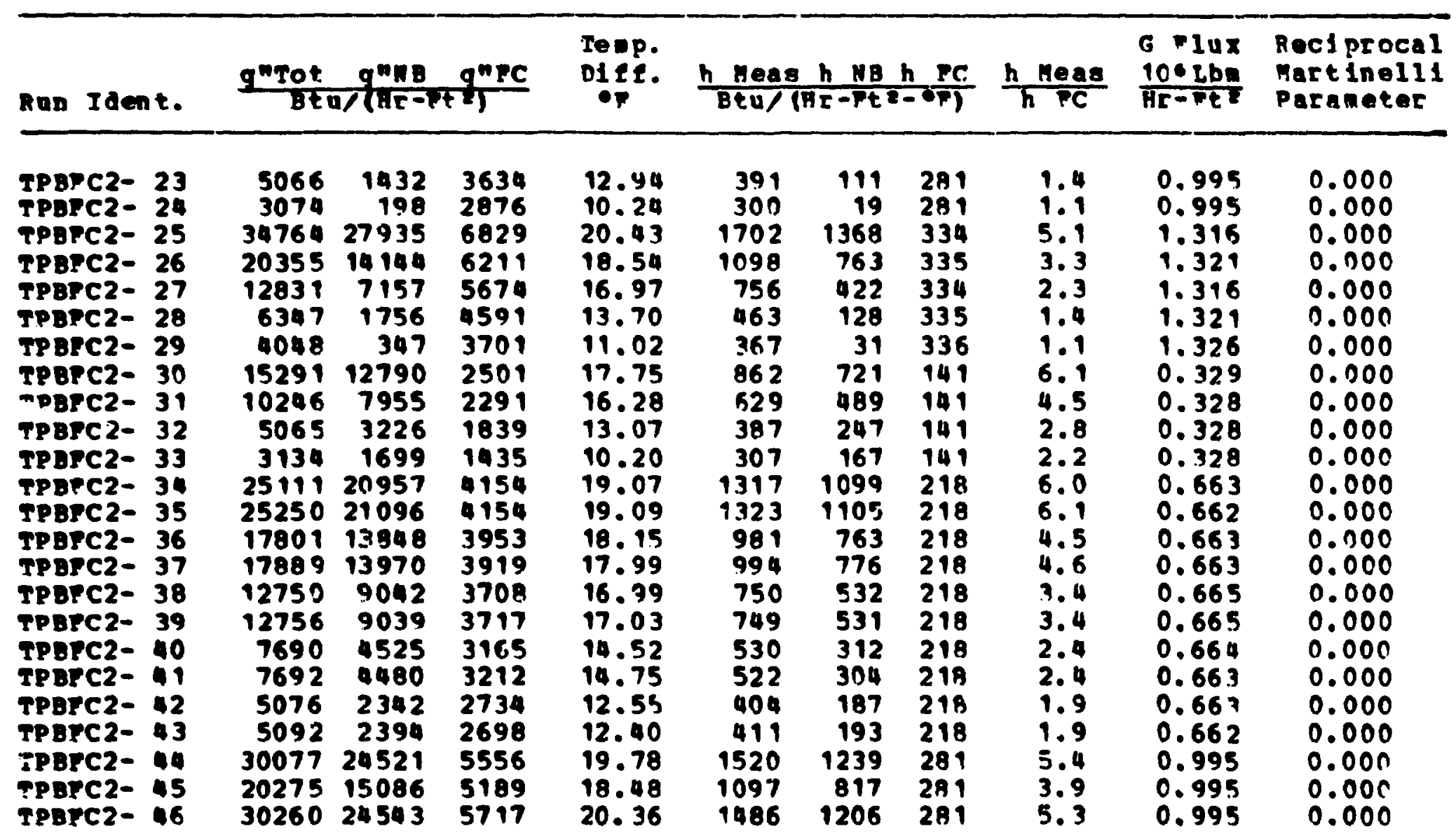


TABLE D-23 (Continued)

\begin{tabular}{|c|c|c|c|c|c|c|c|}
\hline Run & Ident. & $\frac{g^{n} \text { Tot } g^{n N B} g^{n F C}}{\text { Bture }}$ & $\begin{array}{l}\text { Tenp. } \\
\text { Diff. } \\
\text { P }\end{array}$ & $\frac{h \operatorname{rens} h \text { ng } h \text { FC }}{B t u /\left(h r-t^{2}-U F\right)}$ & $\frac{h \text { Meas }}{h \text { FC }}$ & $\begin{array}{l}\text { G Plux } \\
\text { 10olbn } \\
\text { Br- It }\end{array}$ & $\begin{array}{l}\text { Reciprocal } \\
\text { Mart inelil } \\
\text { Parameter }\end{array}$ \\
\hline
\end{tabular}

\section{Dater wth Pssentlally zero Thermodynanic Quality}

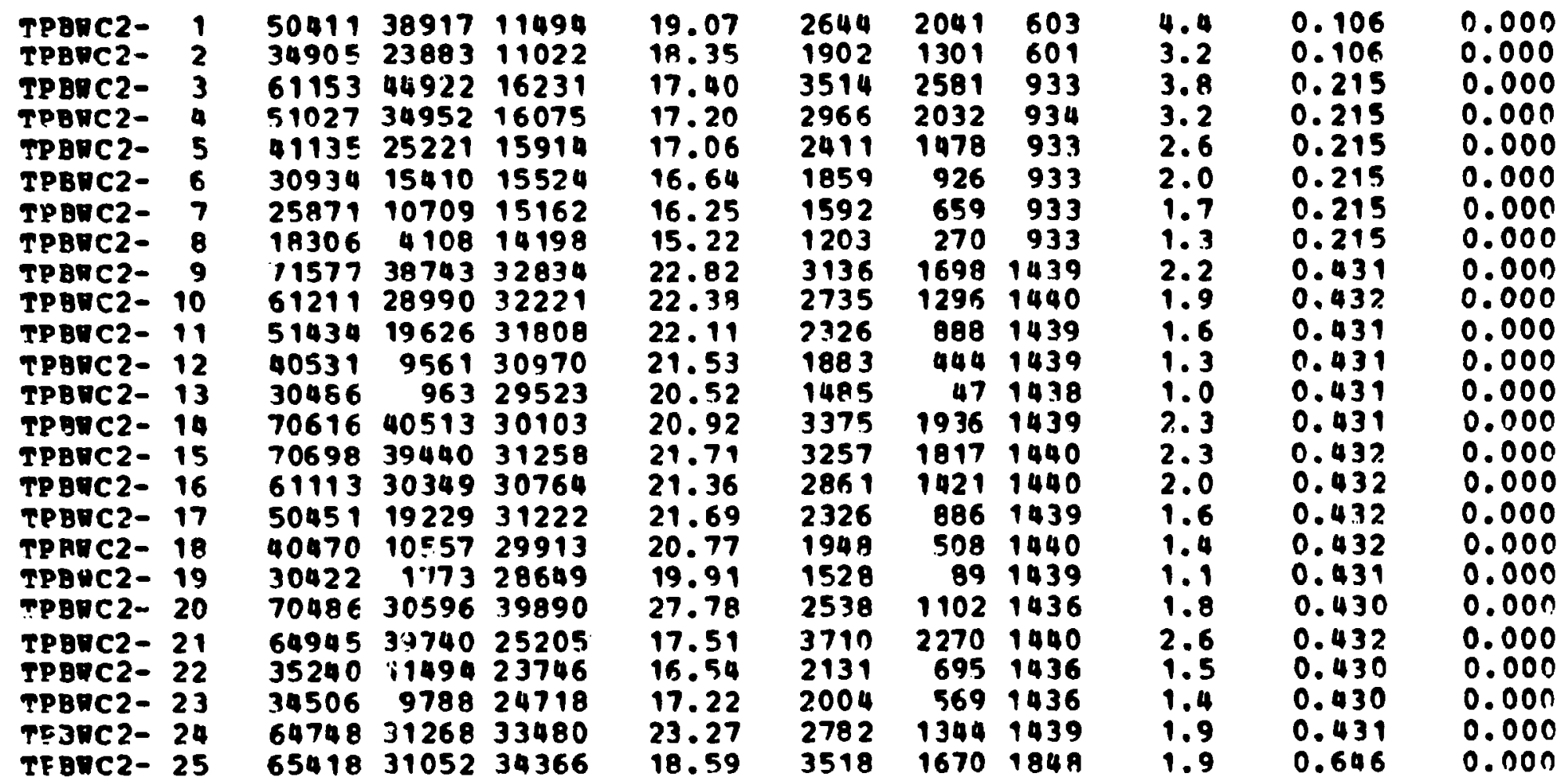


TABLF D-23 (Continued)

\begin{tabular}{|c|c|c|c|c|c|c|c|c|c|c|}
\hline un Iaent. & $\frac{g^{n T o t}}{\text { Btt }}$ & $\frac{g^{n n B}}{a / 1: \tau-F}$ & $E^{g^{n}+C}$ & $\begin{array}{l}\text { Temp. } \\
\text { Diff. } \\
\text { op }\end{array}$ & $\frac{h \text { Heas }}{\text { Btu/ }}$ & $\frac{h N B}{A r-P t^{2}}$ & $\frac{h P C}{(-O P I}$ & $\frac{h \text { Heas }}{h \text { PC }}$ & $\begin{array}{l}\text { G Iux } \\
\frac{10 \cdot I b x}{\text { Hx-Pt }}\end{array}$ & $\begin{array}{l}\text { Reclprocal } \\
\text { Mart inelil } \\
\text { Parameter }\end{array}$ \\
\hline 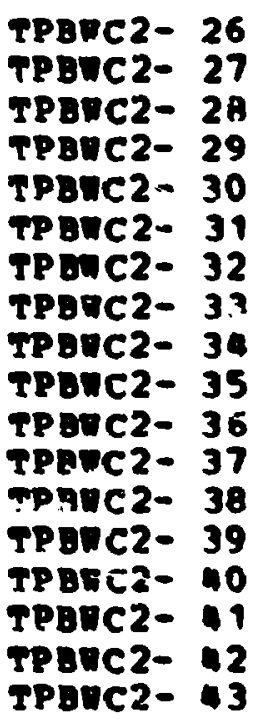 & $\begin{array}{l}56135 \\
35106 \\
45536 \\
30663 \\
64540 \\
34767 \\
34880 \\
34832 \\
70804 \\
70774 \\
60768 \\
60847 \\
50967 \\
50829 \\
40347 \\
40367 \\
34903 \\
34973\end{array}$ & $\begin{array}{r}21851 \\
3102 \\
12118 \\
166 \\
12791 \\
23565 \\
23632 \\
23669 \\
39232 \\
39115 \\
29142 \\
29040 \\
18967 \\
19509 \\
11222 \\
10963 \\
10885 \\
10486\end{array}$ & $\begin{array}{l}34284 \\
32004 \\
33418 \\
30842 \\
51749 \\
11202 \\
11248 \\
11163 \\
31572 \\
31659 \\
31626 \\
31807 \\
32000 \\
31320 \\
29125 \\
29404 \\
28018 \\
24487\end{array}$ & $\begin{array}{l}18.55 \\
17.32 \\
18.08 \\
16.64 \\
23.52 \\
18.65 \\
18.80 \\
18.66 \\
21.94 \\
22.00 \\
21.97 \\
22.09 \\
22.23 \\
21.79 \\
20.23 \\
20.37 \\
16.73 \\
17.05\end{array}$ & $\begin{array}{l}3026 \\
2027 \\
2579 \\
1843 \\
2745 \\
1864 \\
1856 \\
1867 \\
3227 \\
3216 \\
2766 \\
2754 \\
2293 \\
2332 \\
1994 \\
1982 \\
2087 \\
2051\end{array}$ & $\begin{array}{l}1178 \\
179 \\
670 \\
10 \\
544 \\
1263 \\
1257 \\
1269 \\
1788 \\
1778 \\
1327 \\
1315 \\
653 \\
895 \\
555 \\
538 \\
551 \\
615\end{array}$ & $\begin{array}{l}1848 \\
1848 \\
1948 \\
1854 \\
2201 \\
601 \\
598 \\
598 \\
1439 \\
1439 \\
1440 \\
1440 \\
1439 \\
1437 \\
1440 \\
1444 \\
1436 \\
1436\end{array}$ & $\begin{array}{l}1.6 \\
1.1 \\
1.4 \\
1.0 \\
1.2 \\
3.1 \\
3.1 \\
3.1 \\
2.2 \\
2.2 \\
1.9 \\
1.9 \\
1.6 \\
1.6 \\
1.4 \\
1.4 \\
1.5 \\
1.4\end{array}$ & $\begin{array}{l}0.646 \\
0.646 \\
0.646 \\
0.649 \\
0.852 \\
0.106 \\
0.105 \\
0.105 \\
0.431 \\
0.431 \\
0.432 \\
0.432 \\
0.432 \\
0.431 \\
0.432 \\
0.434 \\
0.430 \\
0.430\end{array}$ & $\begin{array}{l}0.000 \\
0.000 \\
0.000 \\
0.000 \\
0.000 \\
0.000 \\
0.000 \\
0.000 \\
0.000 \\
0.000 \\
0.000 \\
0.000 \\
0.000 \\
0.000 \\
0.000 \\
0.000 \\
0.000 \\
0.000\end{array}$ \\
\hline
\end{tabular}


TABLE $n-? 4$

MOASEMON ADDITIVE CORRELATION DATA POR ANMULAR FLON BOILIMG OP PREON-113 OH HEA? METER HH-2

\begin{tabular}{|c|c|c|c|c|c|c|c|c|c|c|}
\hline Run Ident. & $\frac{\text { mot }}{\text { Bt }}$ & $\frac{g^{n n B}}{(1 / r-1}$ & $\frac{g^{n} F C}{E(T)}$ & $\begin{array}{l}\text { Temp. } \\
\text { oles. } \\
\text { op }\end{array}$ & $\frac{h \text { Hea }}{\text { Btu/ }}$ & $\frac{h N B}{A r-\sqrt{t^{2}}}$ & $\frac{h F C}{-O P I}$ & $\frac{h \text { Heas }}{h \text { PC }}$ & $\begin{array}{l}\text { G Flux } \\
106 \mathrm{LbD} \\
\text { Hr-Ft' }\end{array}$ & $\begin{array}{l}\text { Reciprocal } \\
\text { Mart inelil } \\
\text { Paranoter }\end{array}$ \\
\hline 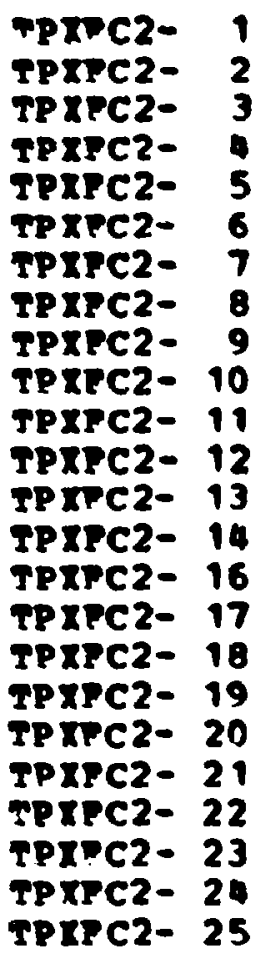 & $\begin{array}{r}25058 \\
17862 \\
10219 \\
5194 \\
25266 \\
20254 \\
15331 \\
7796 \\
22760 \\
12922 \\
7790 \\
22751 \\
15470 \\
7742 \\
25225 \\
20245 \\
15363 \\
10265 \\
5177 \\
2148 \\
25089 \\
17904 \\
10379 \\
29908\end{array}$ & $\begin{array}{r}22392 \\
15355 \\
7987 \\
3536 \\
22600 \\
17691 \\
12913 \\
5828 \\
20146 \\
10622 \\
5904 \\
20152 \\
13088 \\
5899 \\
20926 \\
16155 \\
11517 \\
6844 \\
2934 \\
1106 \\
20645 \\
13776 \\
6961 \\
24389\end{array}$ & $\begin{array}{l}2666 \\
2507 \\
2232 \\
1658 \\
2666 \\
2563 \\
2421 \\
1968 \\
2614 \\
2300 \\
1886 \\
2595 \\
2382 \\
1843 \\
4299 \\
4090 \\
3846 \\
3421 \\
2243 \\
1042 \\
4444 \\
4128 \\
3418 \\
5519\end{array}$ & $\begin{array}{l}19.99 \\
17.96 \\
15.90 \\
11.81 \\
19.05 \\
18.32 \\
17.30 \\
14.06 \\
18.74 \\
16.43 \\
13.47 \\
18.69 \\
17.13 \\
13.23 \\
19.85 \\
18.89 \\
17.76 \\
15.78 \\
10.32 \\
4.79 \\
20.54 \\
19.06 \\
15.80 \\
19.69\end{array}$ & $\begin{array}{r}1319 \\
1000 \\
643 \\
440 \\
1327 \\
1106 \\
886 \\
555 \\
1215 \\
787 \\
579 \\
1217 \\
903 \\
585 \\
1271 \\
1072 \\
865 \\
650 \\
502 \\
448 \\
1221 \\
939 \\
657 \\
1519\end{array}$ & $\begin{array}{r}1179 \\
860 \\
502 \\
299 \\
1187 \\
966 \\
746 \\
415 \\
1075 \\
647 \\
4.38 \\
1078 \\
764 \\
446 \\
1054 \\
855 \\
649 \\
434 \\
284 \\
231 \\
1005 \\
723 \\
441 \\
1239\end{array}$ & $\begin{array}{l}140 \\
140 \\
140 \\
140 \\
140 \\
140 \\
140 \\
140 \\
139 \\
140 \\
140 \\
139 \\
139 \\
139 \\
217 \\
217 \\
217 \\
217 \\
217 \\
217 \\
216 \\
217 \\
216 \\
280\end{array}$ & $\begin{array}{l}9.4 \\
7.1 \\
4.6 \\
3.1 \\
9.5 \\
7.9 \\
6.3 \\
4.0 \\
2.7 \\
5.6 \\
4.1 \\
8.8 \\
6.5 \\
4.2 \\
5.9 \\
4.9 \\
4.0 \\
3.0 \\
2.3 \\
2.1 \\
5.6 \\
4.3 \\
3.0 \\
5.4\end{array}$ & $\begin{array}{l}0.326 \\
0.326 \\
0.326 \\
0.326 \\
0.325 \\
0.325 \\
0.325 \\
0.325 \\
0.323 \\
0.325 \\
0.325 \\
0.321 \\
0.321 \\
0.322 \\
0.656 \\
0.656 \\
0.655 \\
0.657 \\
0.660 \\
0.660 \\
0.655 \\
0.656 \\
0.655 \\
0.990\end{array}$ & $\begin{array}{l}0.280 \\
0.280 \\
0.28 .1 \\
0.290 \\
0.522 \\
0.517 \\
0.520 \\
0.514 \\
0.798 \\
0.798 \\
0.755 \\
1.054 \\
1.051 \\
1.057 \\
0.264 \\
0.262 \\
0.267 \\
0.264 \\
0.263 \\
0.267 \\
0.535 \\
0.536 \\
0.533 \\
0.244\end{array}$ \\
\hline
\end{tabular}


TABLE D-24 (Cont inuej)

\begin{tabular}{|c|c|c|c|c|c|c|c|c|c|c|}
\hline Ron Ident. & $\frac{n_{\text {Tot }}}{\text { bto }}$ & $g^{n n B}$ & $\frac{g^{n p}}{21}$ & $\begin{array}{l}\text { Teng. } \\
\text { DIIP. } \\
\text { OP }\end{array}$ & $\frac{\text { h Heas }}{\text { btu/ }}$ & $h N B$ & $\frac{\mathrm{h} F \mathrm{C}}{-W H}$ & $\frac{h \text { meas }}{h / C}$ & $\begin{array}{l}\text { G Plux } \\
\frac{10 \operatorname{lob}}{\text { Hr-Pts }}\end{array}$ & $\begin{array}{l}\text { Reciprocal } \\
\text { Hartinelil } \\
\text { Paraneter }\end{array}$ \\
\hline $\begin{array}{l}\text { TPXPC2- } 26 \\
\text { TPXPC2- } 27 \\
\text { PPXPC2- } 28 \\
\text { TPXPC2- } 29 \\
\text { TPXPC2- } 30 \\
\text { PPXPC2- } 31 \\
\text { TPXPC2- } 32 \\
\text { TPXPC2- } 33 \\
\text { TPXFC2- } 34 \\
\text { PPXPC2- } 35 \\
\text { TPXPC2- } 36 \\
\text { TPXPC2- } 37 \\
\text { TPXPC2- } 38 \\
\text { TPXPC2- } 39\end{array}$ & $\begin{array}{r}22639 \\
15406 \\
10380 \\
4421 \\
27916 \\
20503 \\
12845 \\
6206 \\
34552 \\
25062 \\
17652 \\
10202 \\
7668 \\
5051\end{array}$ & $\begin{array}{r}17364 \\
10572 \\
6161 \\
2303 \\
22421 \\
15383 \\
8237 \\
3297 \\
20499 \\
19410 \\
12353 \\
5839 \\
3918 \\
2353\end{array}$ & $\begin{array}{l}5275 \\
4834 \\
4219 \\
2118 \\
5495 \\
5120 \\
4608 \\
2909 \\
6053 \\
5652 \\
5299 \\
4363 \\
3750 \\
2698\end{array}$ & $\begin{array}{l}18.82 \\
17.20 \\
15.06 \\
1.056 \\
13.61 \\
11.27 \\
16.45 \\
10.39 \\
19.72 \\
18.41 \\
17.26 \\
14.21 \\
12.21 \\
8.77\end{array}$ & $\begin{array}{r}1203 \\
896 \\
689 \\
585 \\
1423 \\
1122 \\
781 \\
598 \\
1752 \\
1362 \\
1023 \\
718 \\
628 \\
576\end{array}$ & $\begin{array}{r}922 \\
615 \\
409 \\
305 \\
1143 \\
842 \\
501 \\
318 \\
1445 \\
1055 \\
716 \\
411 \\
321 \\
268\end{array}$ & $\begin{array}{l}280 \\
281 \\
280 \\
280 \\
280 \\
280 \\
280 \\
280 \\
307 \\
307 \\
307 \\
307 \\
307 \\
308\end{array}$ & $\begin{array}{l}4.3 \\
3.2 \\
2.5 \\
2.1 \\
5.1 \\
4.0 \\
2.8 \\
2.1 \\
5.7 \\
4.4 \\
3.3 \\
2.3 \\
2.0 \\
1.9\end{array}$ & $\begin{array}{l}0.990 \\
0.995 \\
0.990 \\
0.990 \\
0.987 \\
0.987 \\
0.987 \\
0.987 \\
1.141 \\
1.141 \\
1.141 \\
1.141 \\
1.141 \\
1.145\end{array}$ & $\begin{array}{l}0.256 \\
0.253 \\
0.252 \\
0.248 \\
0.308 \\
0.303 \\
0.316 \\
0.318 \\
0.280 \\
0.274 \\
0.275 \\
0.274 \\
0.281 \\
0.279\end{array}$ \\
\hline
\end{tabular}


TABLE D-25

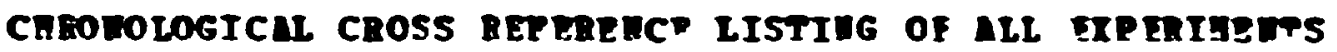

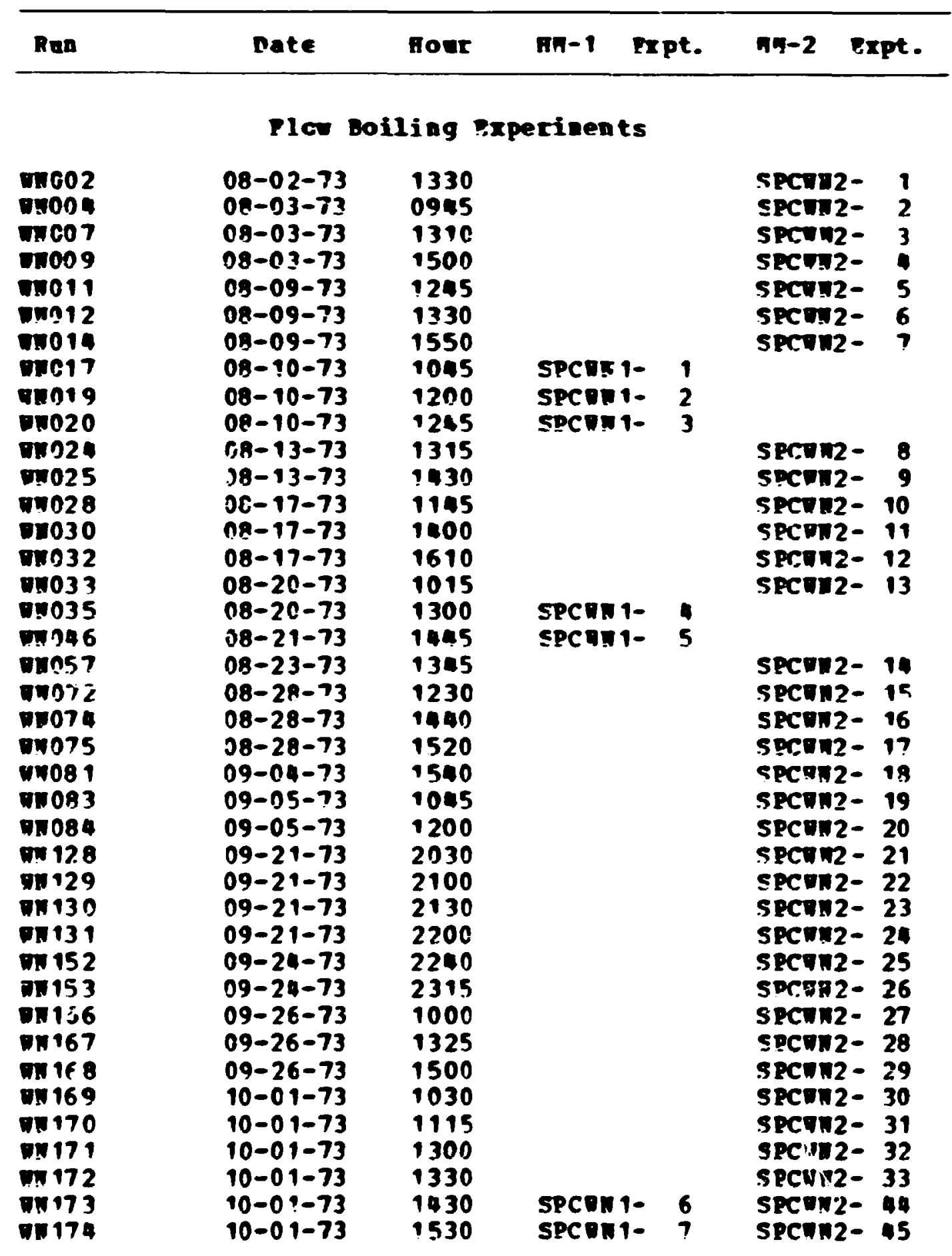




\begin{tabular}{|c|c|c|c|c|c|c|}
\hline $\begin{array}{l}02 \\
61 \\
81 \\
16 \\
91 \\
61 \\
16 \\
08 \\
81 \\
6 E \\
8 E \\
11 \\
2 E \\
96 \\
91 \\
51 \\
5 E \\
16 \\
01 \\
6 \\
2 \\
1 \\
E 1 \\
21 \\
11 \\
41 \\
6\end{array}$ & 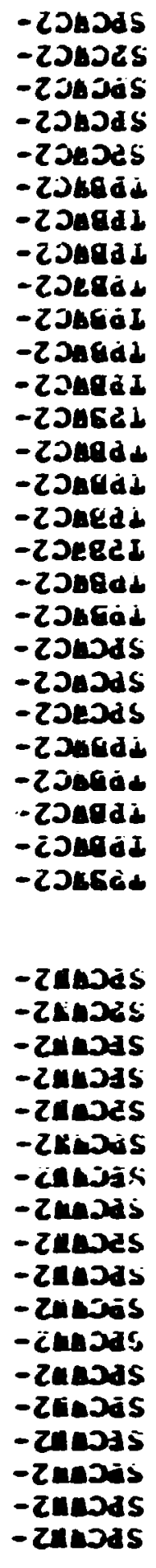 & $\begin{array}{l}91 \\
51 \\
11 \\
E 1 \\
21 \\
11 \\
01 \\
6 \\
8 \\
1 \\
9\end{array}$ & 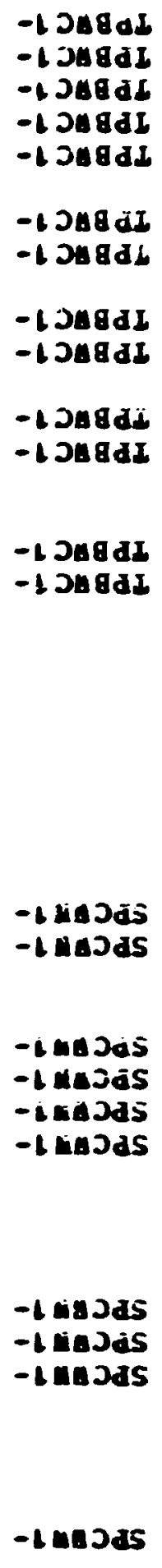 & 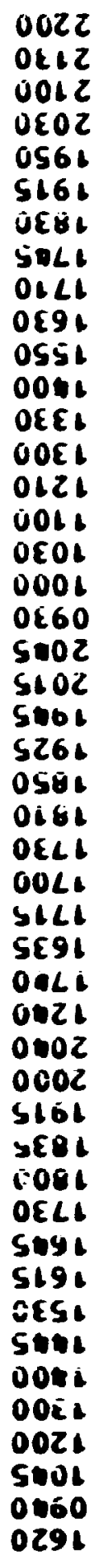 & 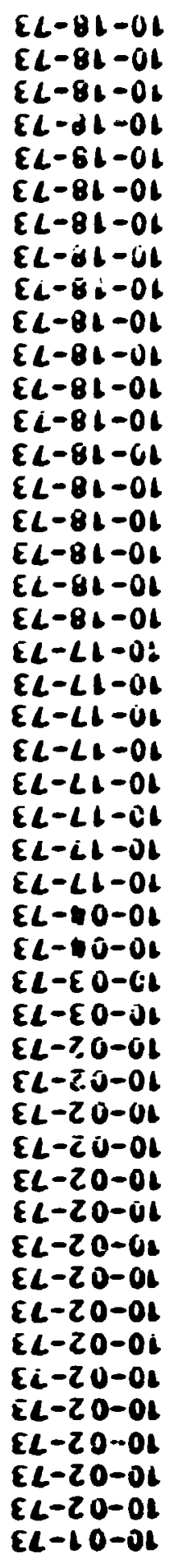 & 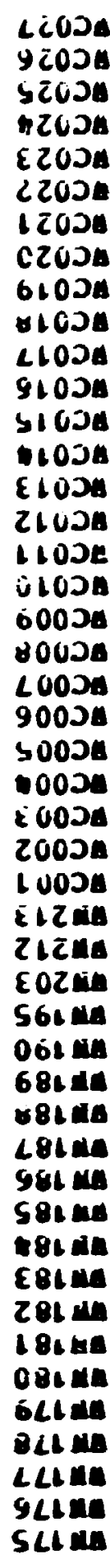 \\
\hline & & & t-4u & 3008 & 3220 & and \\
\hline
\end{tabular}

(panu!̣uoj) si-0 3า8ง1 
TABLE D-25 (Continued)

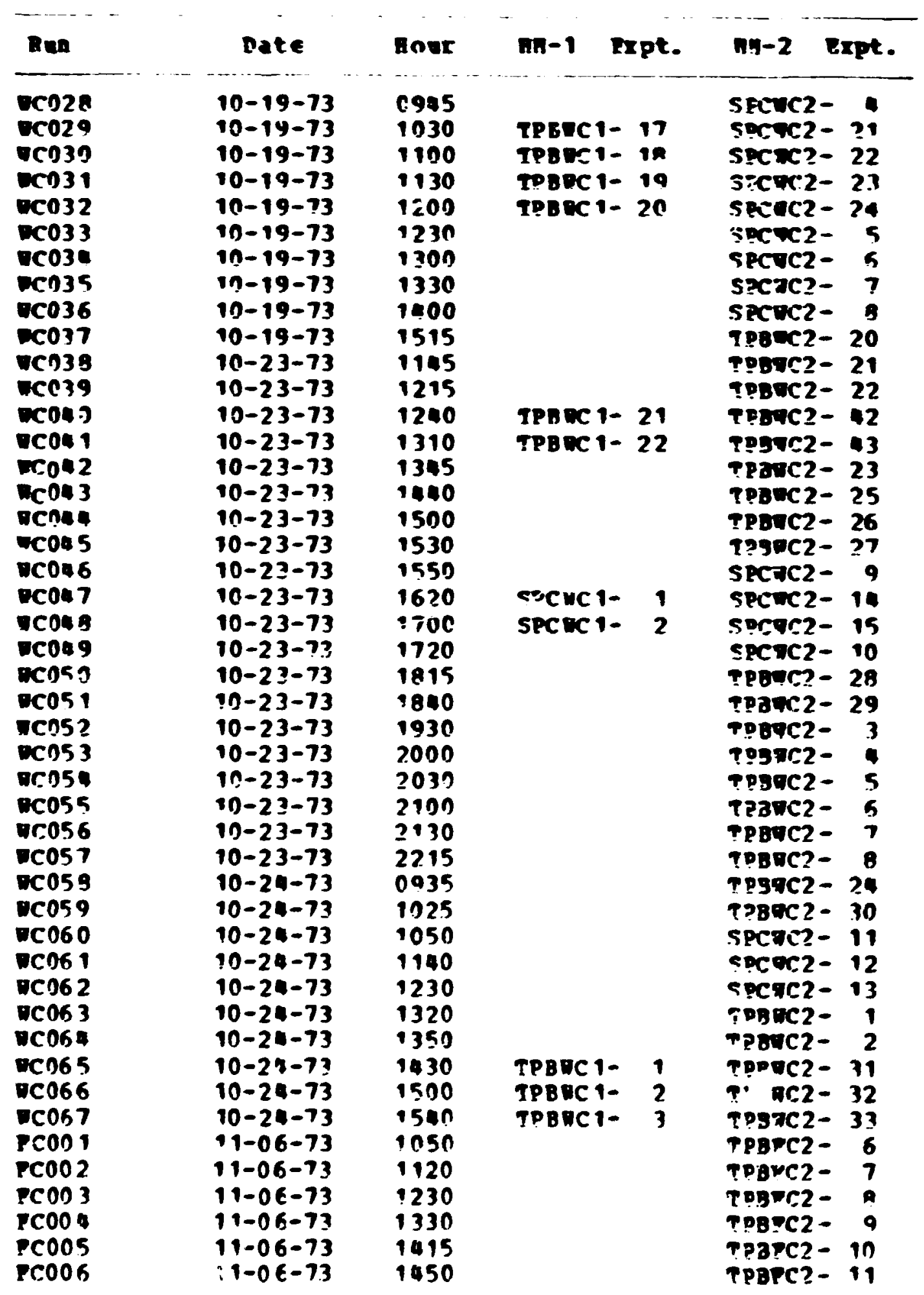


TARLE 0-25 (Continued)

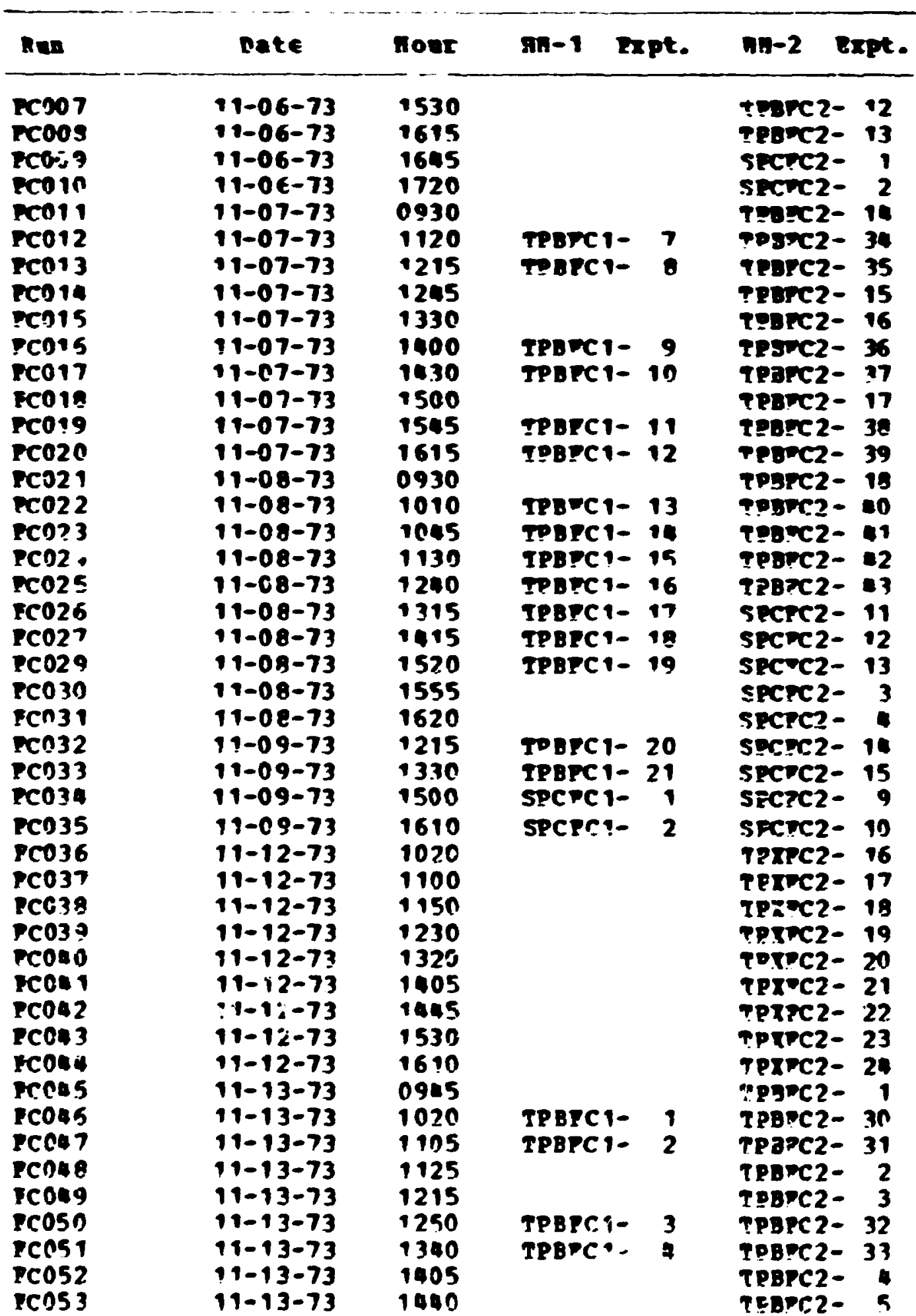


TABLE D-23 (Continued)

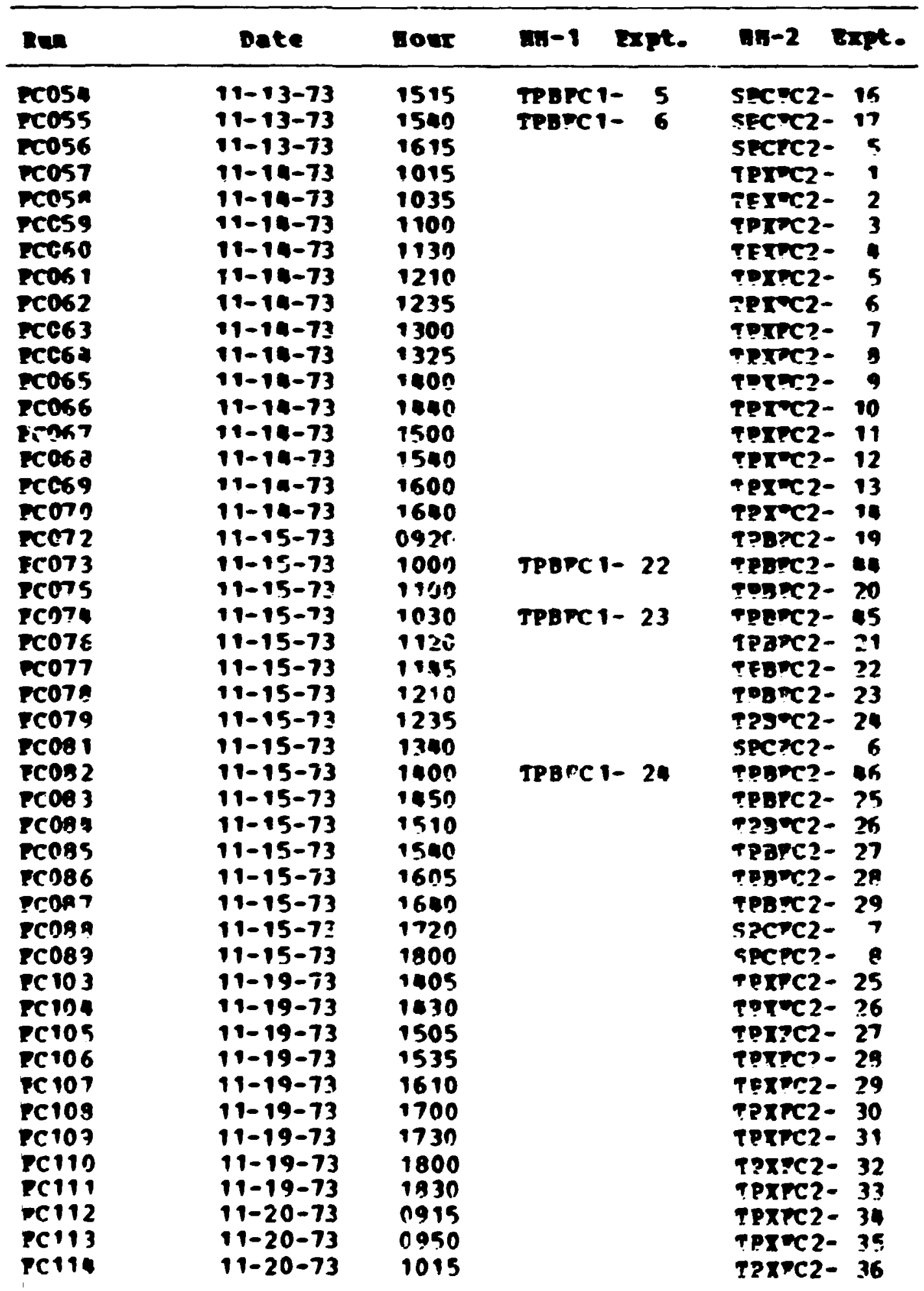


TABLE 0-25 (Continied)

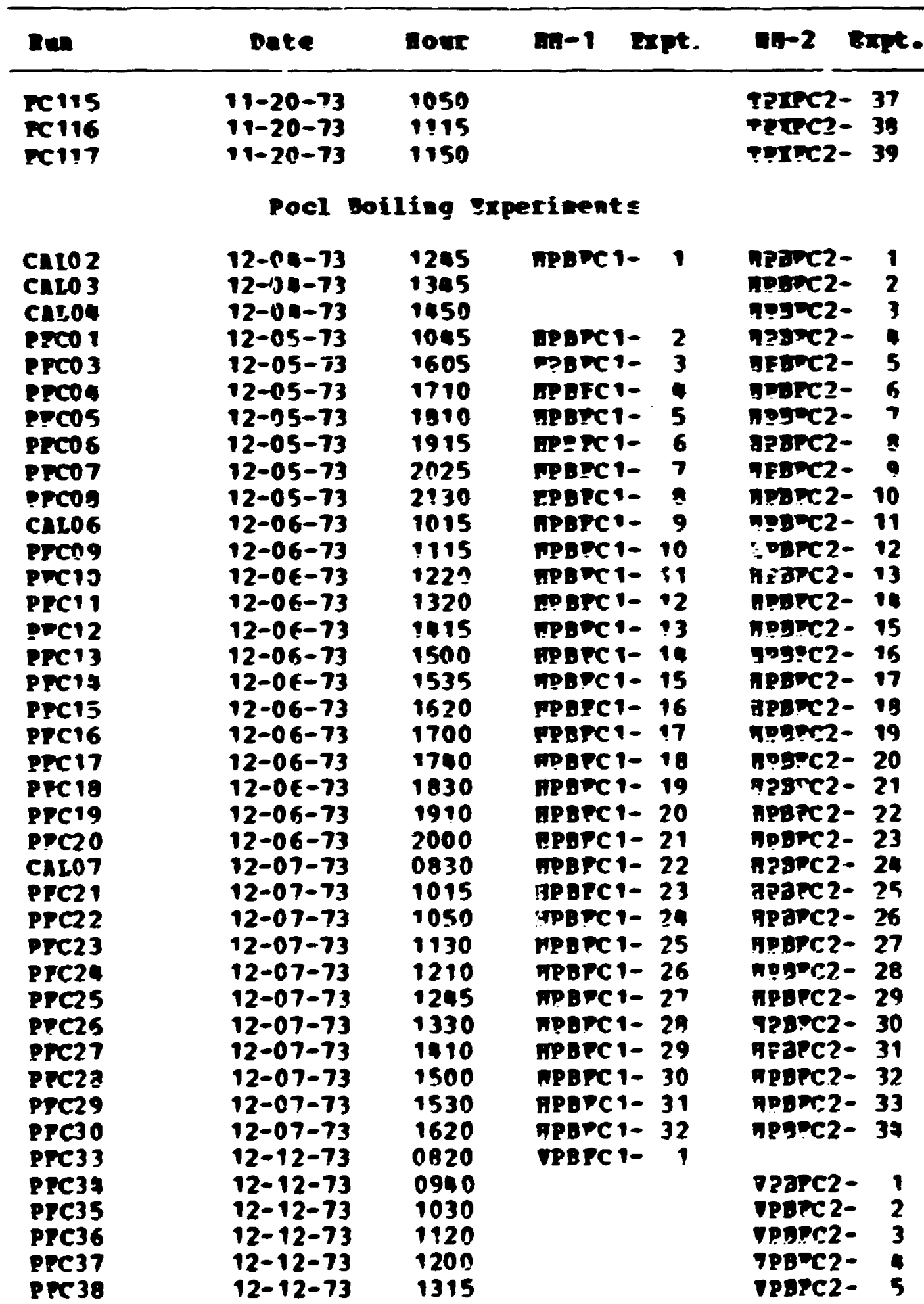


TABLE 0-25 (Continued)

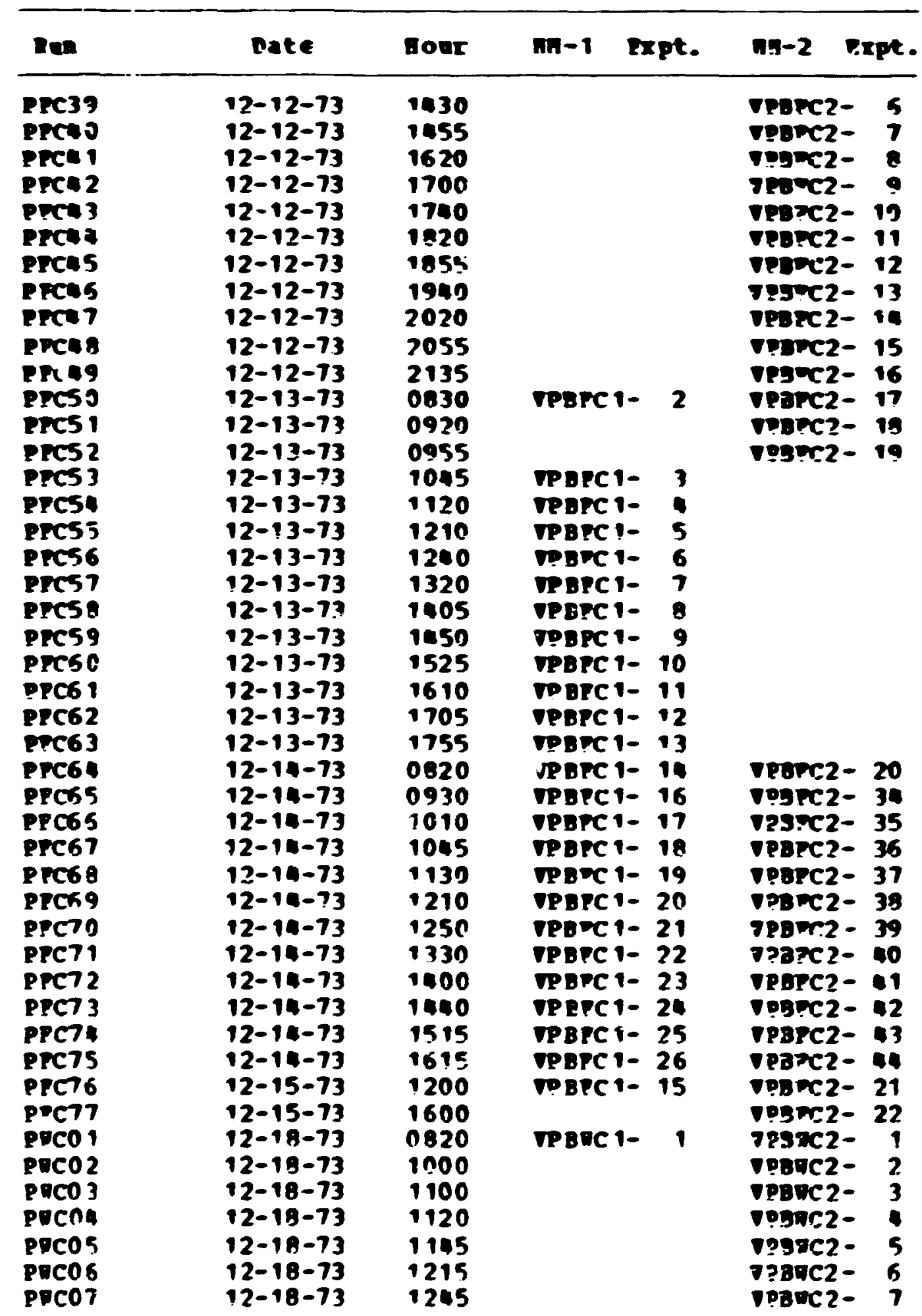


TABLE 0-25 (Continued)

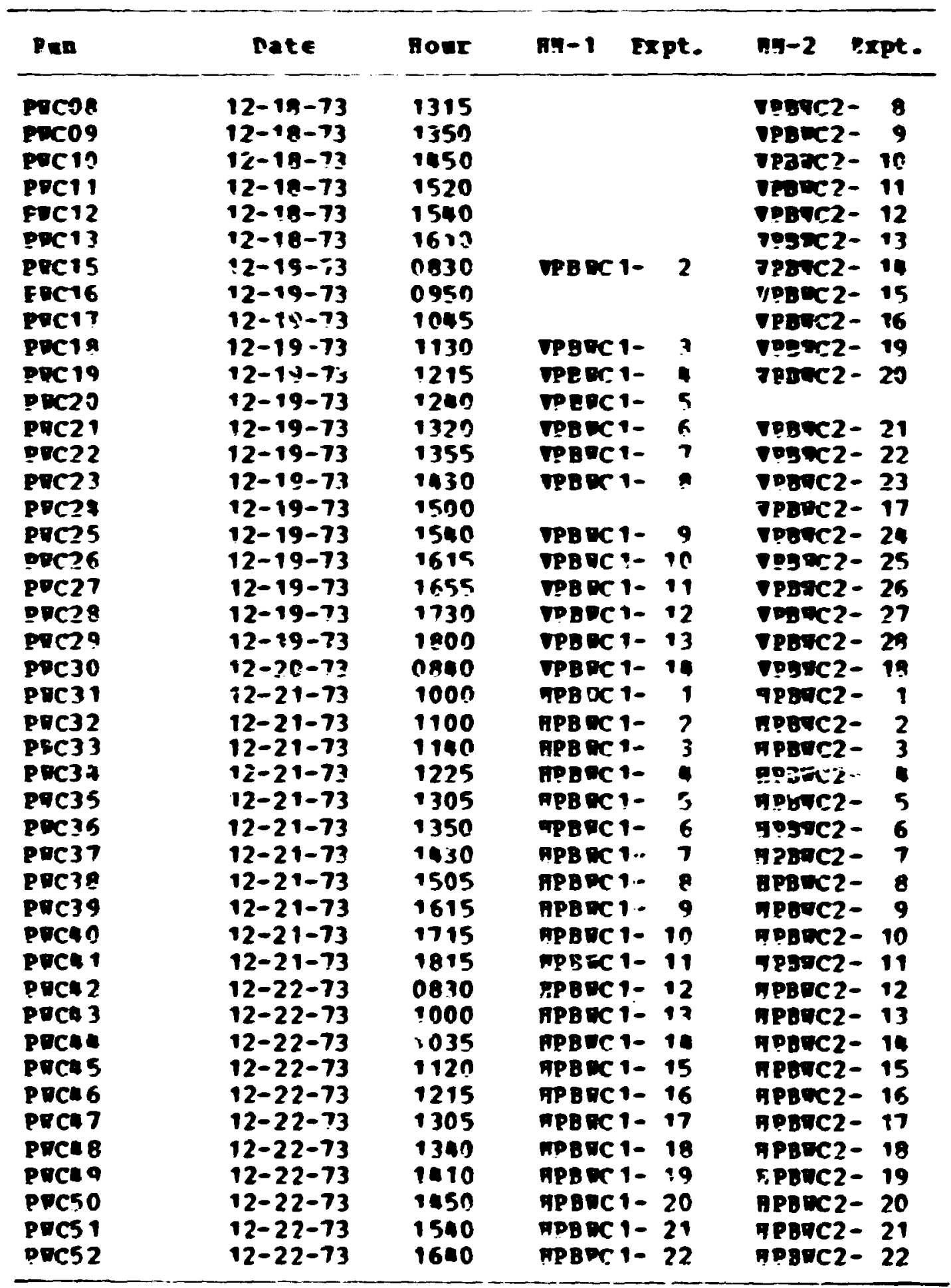


AFE:TD

\section{تSTDAE OF PPROE}

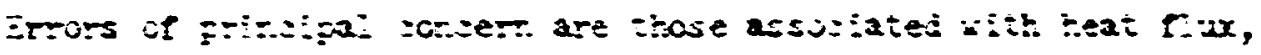

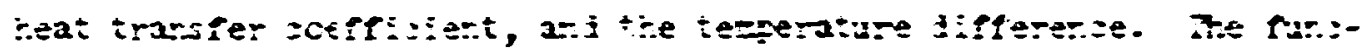

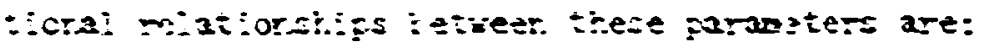

$$
\begin{aligned}
& \vec{P}_{\text {sat }}=\vec{I}_{:-\vec{I}_{5 a t},} \\
& \xi=+\operatorname{tgat} I
\end{aligned}
$$

ar.j

$$
\dot{r}=\dot{i} \boldsymbol{r}_{\text {eat }},
$$

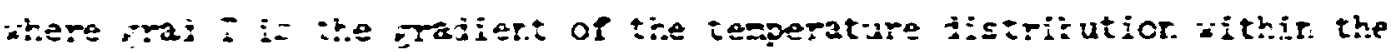

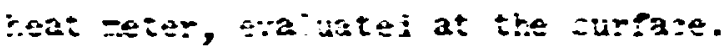

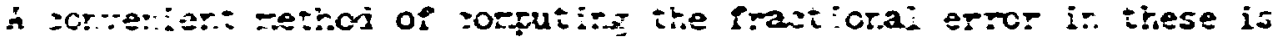
:c isre ito :oraritim of Eoth zijes of the e suatiors ard ther. differerDise to ci iaj::

$$
\begin{aligned}
& \frac{i\left(\therefore I_{\text {sat }}\right)}{\therefore I_{\text {sat }}}=\frac{d\left(T_{-j}-T_{j a t}\right)}{\therefore I_{\text {at }}} \text {, } \\
& \frac{i}{i}=-\left(\frac{1 k}{k}+\frac{d(\operatorname{grad} T)}{\operatorname{srad} r}\right),
\end{aligned}
$$

ard

$$
\frac{i t}{h}=\frac{d i^{\circ}}{i}-\frac{d\left(\hat{i}_{i j}-\Gamma_{\text {sat }}\right)}{I I_{\text {sat }}} \text {. }
$$

Peplaning, the differentials with finite raiues and considering or.ly the sum of aisoluie raiues for the indigilual error scmporents to oftain a maximum ercor, the frastional error relations tecome: 


\section{BLANK PAGE}




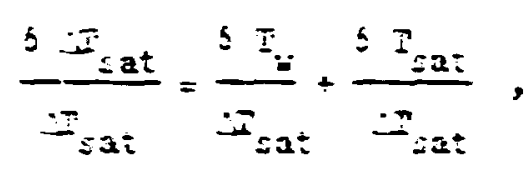

$$
\begin{aligned}
& \frac{E}{i}=\frac{5 j}{x}+\frac{s \sin I}{\sin I} \text {, }
\end{aligned}
$$

$2 \cdot \dot{s}$

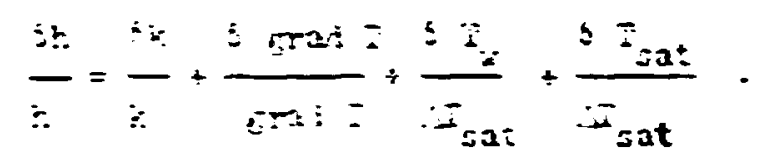

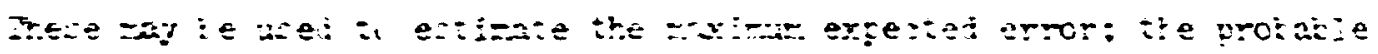

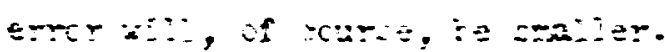

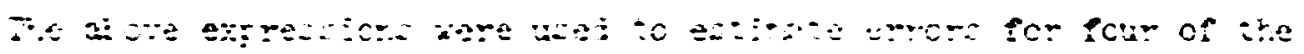

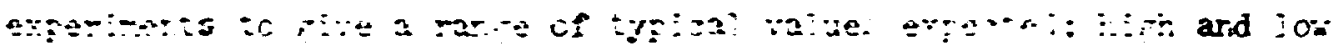

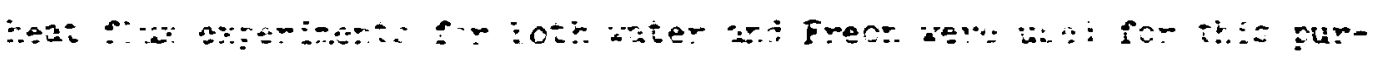
sc: $:-$

$\therefore$ a

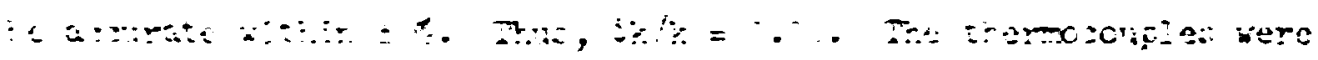

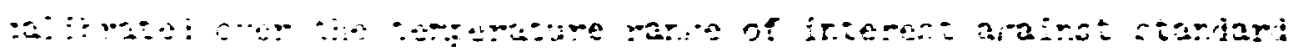

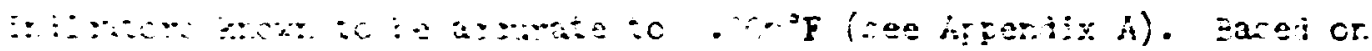

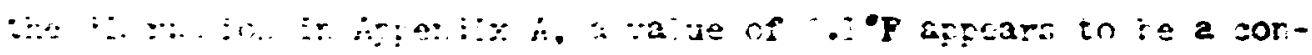

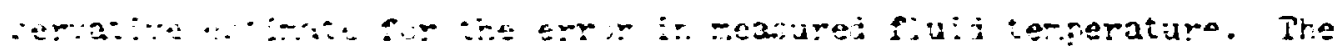

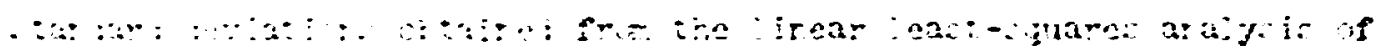

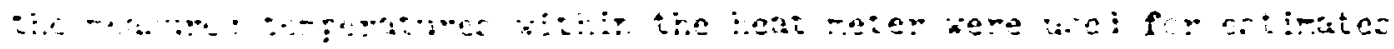

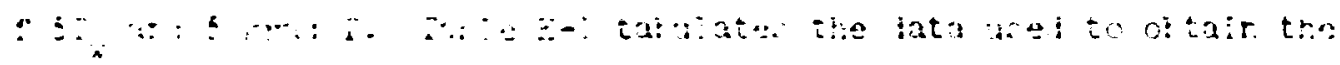

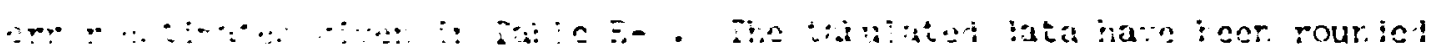

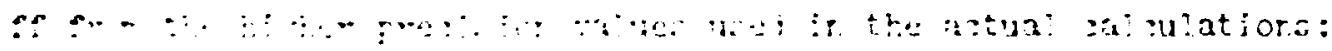

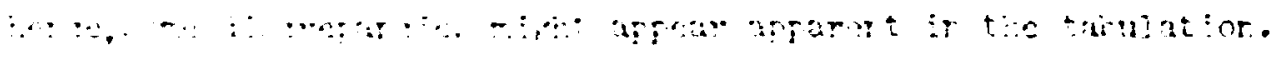


IAELE 三-

IATA FCE ESTEEALE: CF BRRORE

\begin{tabular}{|c|c|c|c|c|}
\hline & \multicolumn{2}{|c|}{ Frecr: Testa } & \multicolumn{2}{|c|}{ Hiter $\vec{i} \in \approx s$} \\
\hline & Lo: FI: & II: Flax & Lo: Fliv & X \\
\hline Experirert :̈o. & :PEFS - $:=$ & IFEF- 25 & VPENC-III & $\because$ PENC - \\
\hline$g\left(\Xi t u / h r-f^{2}\right)$ & $\vdots 12$ & $\because \because, 1=\hat{y}$ & 205 & $\therefore \therefore, \therefore-$ \\
\hline i. $\left(B t u / h r \cdot \rho t^{2} \cdot{ }^{3} F\right)$ & $\cdots$ & $1,2=2$ & $6 \approx$ &..,$\vdots=-$ \\
\hline $\mathbb{T}_{\approx \text { at }}\left({ }^{\circ} \mathrm{F}\right)$ & 11.53 & $=1.26$ & 2.5 & $1 \ldots .06$ \\
\hline $\mathrm{I}_{\text {sat }}\left({ }^{\circ} \mathrm{F}\right)$ & IIÉ: & $31^{\cdots}$ & 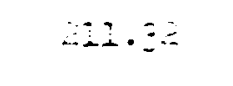 & $2=1.22$ \\
\hline $\mathrm{ST}_{\text {sat }}\left({ }^{\circ} \mathrm{F}\right)$ & $C . i c$ & $\therefore . i c$ & S.12 & 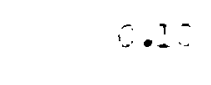 \\
\hline$\Gamma_{W}\left({ }^{\circ} \mathrm{F}\right)$ & $1 \geq 8 \times C$ & $1-8 .$. & $22 \therefore \cdot 1$ & $\therefore 5.25$ \\
\hline$S_{W}\left({ }^{\circ} F\right)$ & 0.05 & o.s. & $0.0=$ & 2.3 \\
\hline $\operatorname{Grad} \mathrm{P}\left({ }^{\circ} \mathrm{F} / \mathrm{in}.\right)$ & 0.20 & $14.2=$ & $\therefore \ldots$ & $\therefore \ldots$ \\
\hline$\delta_{\text {grid }} \mathrm{T}\left({ }^{\circ} \mathrm{F} /\right.$ in. $)$ & 0.04 & 2.27 & 0.03 & $\because \cdot z$ \\
\hline
\end{tabular}


DABI, L : :-:

RANGE OF LSTIMATSIN ERROR:;

\begin{tabular}{|c|c|c|c|c|c|c|c|c|c|}
\hline \multirow[b]{2}{*}{$\begin{array}{c}\text { Expe:iment } \\
\text { No. }\end{array}$} & \multirow[b]{2}{*}{$\left(B t u / h r \cdot \mathrm{ft}^{2}\right)$} & \multirow[b]{2}{*}{$\begin{array}{r}\Delta T_{\text {sat }} \\
\left({ }^{\circ} \mathrm{F}\right) \\
\end{array}$} & \multirow[b]{2}{*}{$\begin{array}{c}h \\
\left(B t u / h r \cdot f t^{2} \cdot{ }^{\circ} F\right)\end{array}$} & \multicolumn{3}{|c|}{ Fract :unal Eryor } & \multicolumn{3}{|c|}{ Error } \\
\hline & & & & $\frac{5.7}{97}$ & $\frac{\delta T_{\text {sat }}}{N_{\text {sat }}}$ & $5 h$ & $\left(B t u / h r \cdot f t^{a}\right)$ & $\begin{array}{l}\Delta I_{\text {sut }}^{\prime} \\
\left({ }^{\circ} \mathrm{F}\right)\end{array}$ & $\begin{array}{c}h \\
\left(B t u / h r \cdot f t^{a} \cdot{ }^{\circ} \mathrm{F}\right)\end{array}$ \\
\hline HPBFC $2-003$ & 812 & 11.53 & TO & $0.1 \div 2$ & 0.013 & 0.164 & Li? & 0.25 & 11 \\
\hline HPBFC $2-025$ & 39,138 & $21.4:$ & $18: 5$ & $0.0 \cdot 0$ & 0.013 & $0.10 ?$ & 3515 & $0 . x y$ & 188 \\
\hline VPBWC $2-001$ & $=, 095$ & $i .59$ & 68 & 0.083 & 0.084 & 0.173 & 97 & 0.13 & $1: 9$ \\
\hline VPBWC & 66,330 & 24.46 & 4587 & 0.033 & 0.034 & $0.06 i$ & 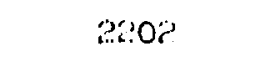 & 0.149 & $30 \%$ \\
\hline
\end{tabular}




\section{APPEMDIX 5}

\section{ALTEPRYATIVE ROHSTYON CORRELATIOA OF BOIIITS IATA}

The Rohsencw pool boiling correlating equation was given ea:-lier as Eq. $(2-23)$; it is repeated here for converience as:

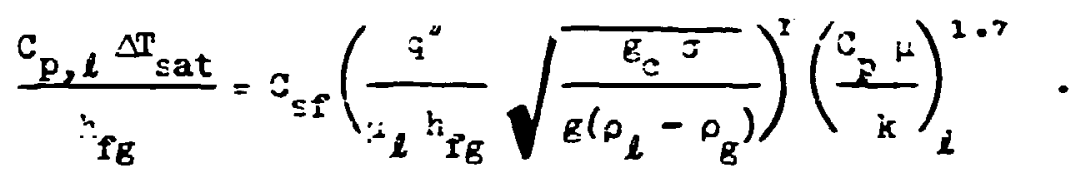

Altho gh it vas originally suggested ${ }^{32}$ that the kubble Reyrolds modulus exporent, $r$, should have a value of $1 / \equiv$ for most fluias to agree with

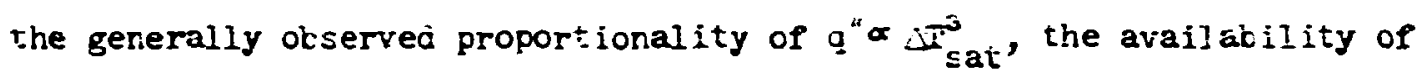

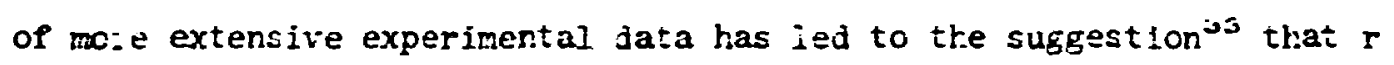
should be permitted tc take cn different values (consistent with the surface-fluid factor, $C_{r}$ ) to obtain better agreement with experimental observations. [Like'sise, the Prandt I moduius exponent, 1. in the above equation, assumes the value of 1.0 for water ${ }^{33}$ and remains 1.7 for other flus is.]

Equation (F-1) is usually written for correlating purposes in the form:

$$
\frac{C_{D_{2},} \Delta r_{\text {sat }}}{h_{f g} N_{P r}^{1} \cdot 7}=C_{s f} N_{R e, b}^{r}
$$

If the left side of the equation is called $x$ and $N_{R e, b}$ is called $y$, taking the logarithm of both sides results in:

$$
\ln x=r \ln y+\ln c_{s f} \text {. }
$$

Equation ( $7-3)$ plots ar a linear function on log-log coordinates. Thus, if the experimental data ure cast in the form represented by $x$ and $y, a$ 
linear regression analys is can be used to determine values for the slupe (r) and the constant $\left(\ln C_{s f}\right)$ in Eq. $(F-3)$ that minimize the deviations in $x$. This is the method used by most boiling researchers to determine values reported $f_{0}:=$ and $C_{s f}$; similarly, the values reporied in Chapter $\mathrm{V}$ were determined as above. This ignores a fundamental premise of least-squares aralysis; namely, that the parameter with ihe smalier experinental error (in real $i^{4} . y$ assumed to be insigrificant compared to the error $i y_{i}$ the other parameter) is taken to be the independert parameter and the deviatiors of the parameter jith tne larger experimertal error are mirimized ir: the least-squares sense.

Comparicon of the maximur: exper'mental errors in: $q^{4}$ ard $i$ sat (expressed as fracticnal trors) given in Table E-2 reveals that $\Delta x_{\text {sat }}$ in Gereral has smalle frational experimental errcrs than $q^{\prime \prime}$. Thus, regrezion analysis applied to $\mathrm{Eq} \cdot(\mathrm{F}-\bar{\xi})$ viclates the above mentioned premise. Formally, analysis of variance requires under these circumstarice: that $\bar{B}:$. $(F-$.$) be written in the form:$

$$
y=\left(x / C_{s f}\right)^{1 / x}
$$

Tairing the logarithm of both sides results in another linear eyluation:

$$
\text { kr } y=\frac{1}{r} \operatorname{lr} x-\frac{1}{r} \text { er c } C_{s f} \text {, }
$$

which should te used wher the $x$ parameter has a smaller experimental error than that associated ith $\mathrm{y}$.

The experimental data presented in Fige. $V-15, v-16, v-23$, and $\mathrm{V}-\mathrm{8}$ of Chapter $\mathrm{V}$ were analyzed, using $\mathrm{E} q(\boldsymbol{P}-5)$, to determine a.ternative best fit :alues for $C_{\approx f}$ and $r$ under these rules. Table $F-1$. gives the results and a comparison with the values determinei in Chapter V; Fire.F-l through F-lb show the data plotted with the best fit 
TABLE F-I

SUMMAFY OF CORREIATTING PARANETERS AND STANDATID DEVIATIONS LETERMINED BY ANALYSIS OF VARIANCE OF EQS. $(F-3)$ AND $(F-5)$

\begin{tabular}{|c|c|c|c|c|c|c|}
\hline \multirow{2}{*}{ Data Set } & \multicolumn{3}{|c|}{$\mathrm{Eq} \cdot(F-3)$} & \multicolumn{3}{|c|}{ Eq. $(F-5)$} \\
\hline & $c_{s i}$ & $r$ & $\begin{array}{l}\text { Std. iev. } \\
\text { of } \ln x\end{array}$ & $c_{s f}$ & $r$ & $\begin{array}{l}\text { Std. nev. } \\
\text { of } \ln y\end{array}$ \\
\hline \multicolumn{7}{|l|}{ Freon Pool Boiling } \\
\hline $\begin{array}{l}\text { EM-1 Vertical } \\
\text { HM-1 Horizonta] } \\
\text { HM-2 Vertica] } \\
\text { HM-.- Horizontal } \\
\text { Combined Data }\end{array}$ & $\begin{array}{l}0.00: 15 \\
0.00: 265 \\
0.00 .285 \\
0.00267 \\
0.00: 2\end{array}$ & $\begin{array}{l}0.13 \% \\
0.0 \% 8 \\
0.093 \\
0.076 \\
0.0 \%\end{array}$ & $\begin{array}{l}0.017 \\
0.049 \\
0.017 \\
0.046 \\
0.049\end{array}$ & $\begin{array}{l}0.002: 15 \\
0.002: 3 \\
0.00: 86 \\
0.00276 \\
0.00279\end{array}$ & $\begin{array}{l}0.133 \\
0.113 \\
0.096 \\
0.112 \\
0.11 .5\end{array}$ & $\begin{array}{l}0.126 \\
0.524 \\
0.1 .76 \\
0.525 \\
0.1469\end{array}$ \\
\hline \multicolumn{7}{|l|}{ Water Pool Boiling } \\
\hline $\begin{array}{l}\text { HM-l Vertical } \\
\text { HM-l Horizontal } \\
\text { HM-C. Vertical } \\
\text { HM-:- Hori:ontal } \\
\text { Comb, ined Data } \\
\text { Reference } 33\end{array}$ & $\begin{array}{l}0.00910 \\
0.00807 \\
0.00801 \\
0.001947 \\
0.008 \times 9 \\
0.0097\end{array}$ & $\begin{array}{l}0.073 \\
0.063 \\
0.155 \\
0.074 \\
0.114 \\
0.10\end{array}$ & $\begin{array}{l}0.01: ? \\
0.05 ? \\
0.015 \\
0.061 \\
0.106 \\
-\end{array}$ & $\begin{array}{c}0.00911 \\
0.00964 \\
0.00863 \\
0.01035 \\
0.01089 \\
-\end{array}$ & $\begin{array}{l}0.27 ! \\
0.148 \\
0.148 \\
0.165 \\
0.324 \\
-\end{array}$ & $\begin{array}{l}0.0113 \\
0.553 \\
0.093 \\
0.524 \\
0.545 \\
-\end{array}$ \\
\hline \multicolumn{7}{|l|}{ Freon Flow Boiling } \\
\hline $\begin{array}{l}\text { Low Quality ( } 2 \%) \text { Tests } \\
\text { Annular Flow Tests }\end{array}$ & $\begin{array}{l}0.0026 ? \\
0.00: 76\end{array}$ & $\begin{array}{l}0.144 \\
0.10 \%\end{array}$ & $\begin{array}{l}0.050 \\
0.030\end{array}$ & $\begin{array}{l}0.00: 166 \\
0.002 \% 99\end{array}$ & $\begin{array}{l}0.156 \\
0.013\end{array}$ & $\begin{array}{l}0.336 \\
0.14 \%\end{array}$ \\
\hline
\end{tabular}


OANL-DNG 74-2183

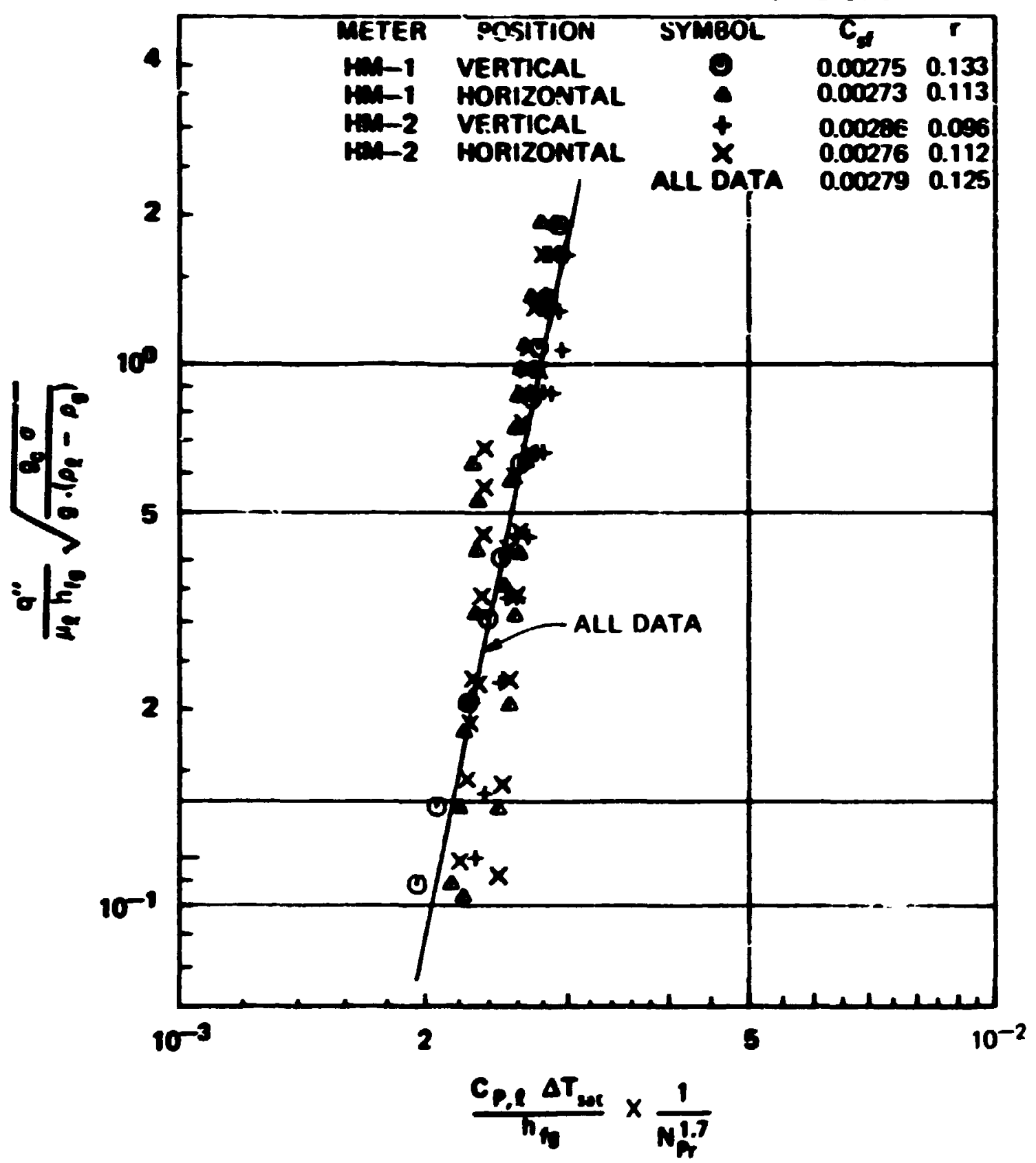

Fig. F-1. Alternative Rohsenow pool bolling correlation for Freon-113. 


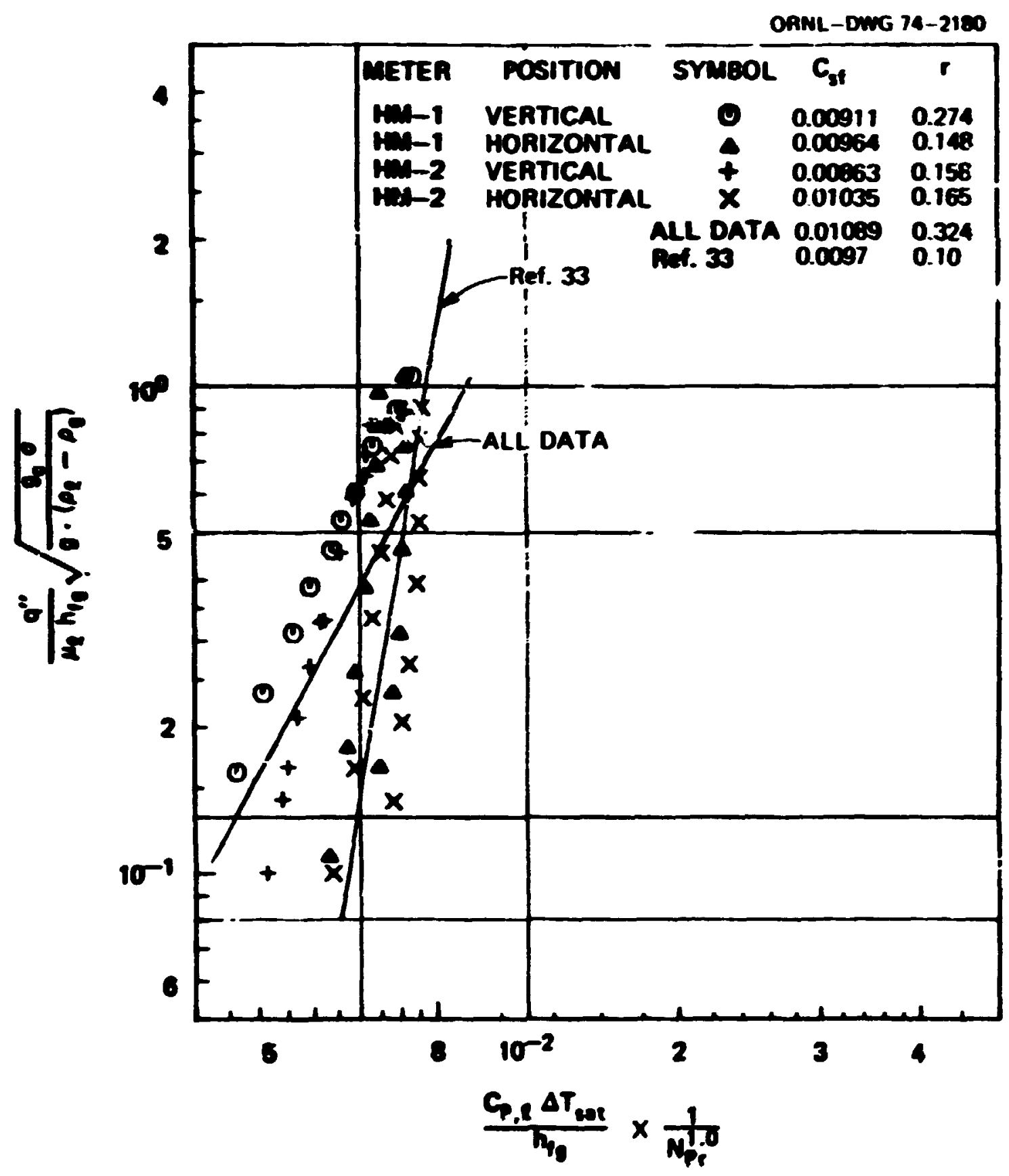

Fig. I-2. Alternative Rohsenow pool boiling ccrrelation for water. 


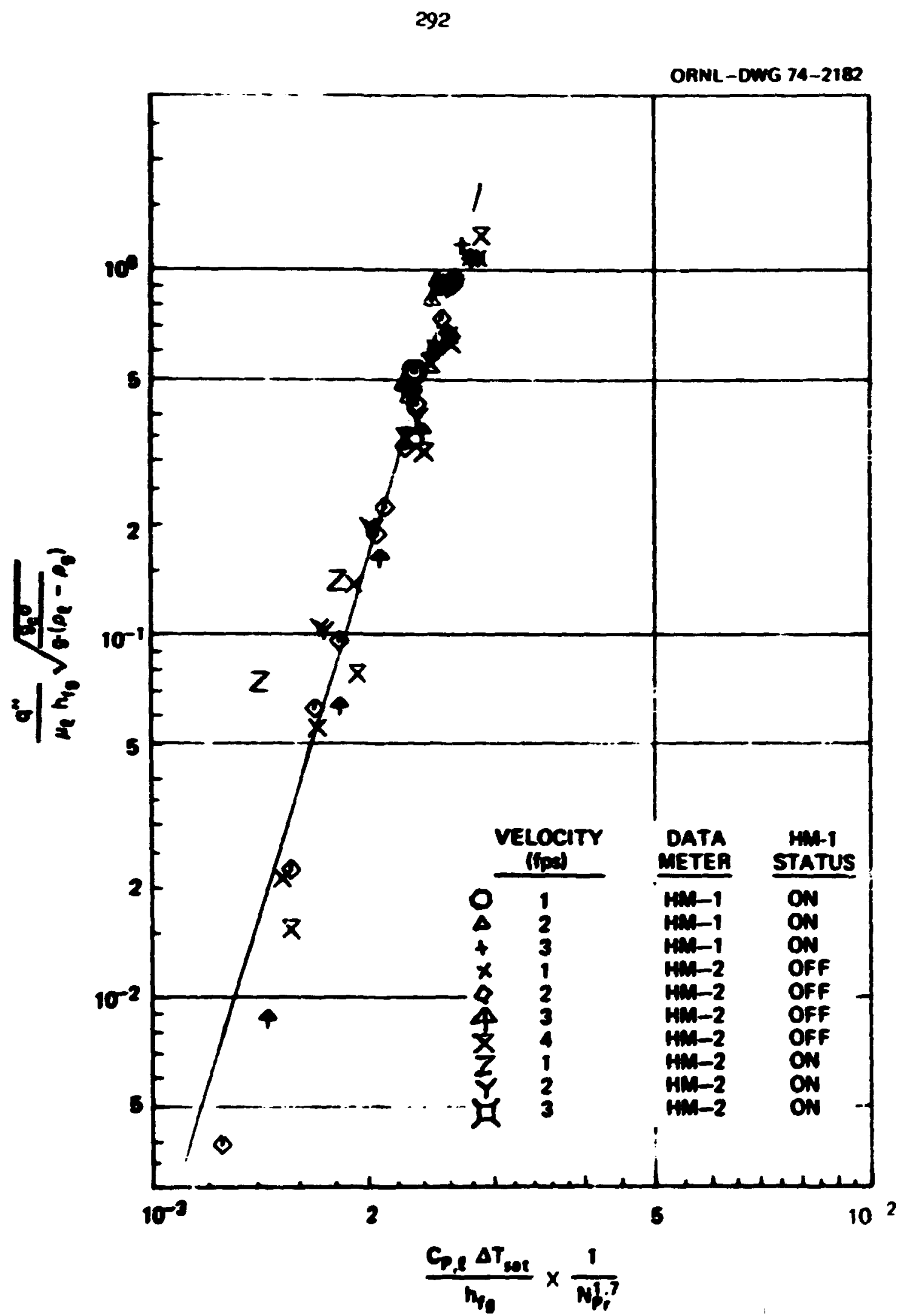

$\bullet$

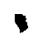

Fir. F- . Al iernative Rorcenow correlatior of froon fiow boiline reaultz. 
4

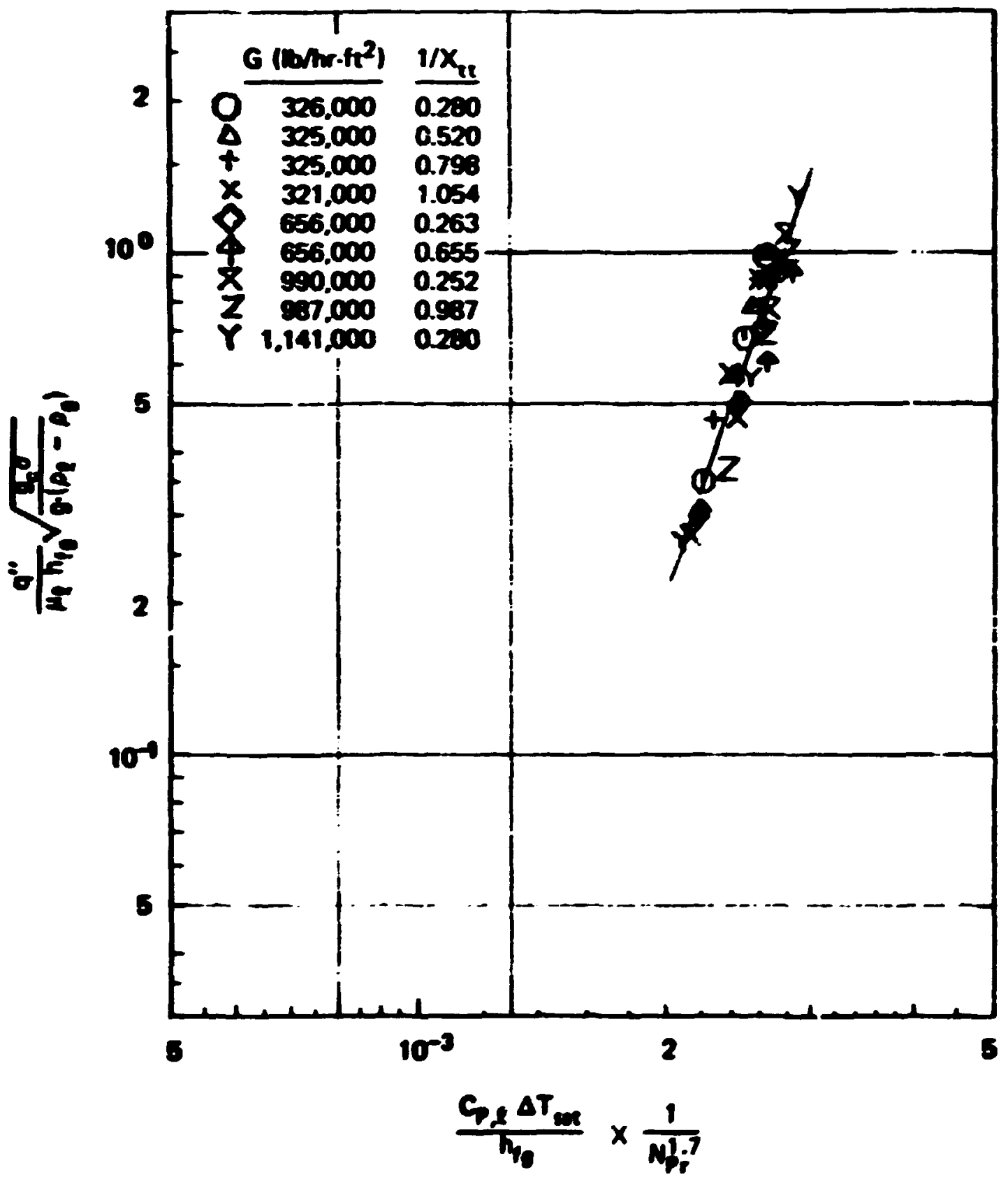

Fie. F i. Altemative Rohsenow correlation of Preon annular flow tolling.

OANL-DWG 74-2181 
correlating ine. These figures are to te coapared with Figs. V-15, $v-16, v-23$, and $v-28$, respectivelis of Chapter $v$ to shou the difference in the correlating methods.

Table F-2 gives the distribution of the deviations from the best fit line as deterained by the proper analys is of variance of the data; i.e., Eq. (F-5).

It is noted that Ifttle difference peils in the values of $\mathrm{C}_{\text {sf }}$ as determined by the two analyses; the most noticeable erfect is in the values of $r$ for pool bolling of water. This is a result or the wide scatter in the data. The now bolling date showed closer agreement than did the "true" pool kn'ling aata. Considering the fact that the now kolling data were obtained indirectly (by differences), the narrow data kand (indiceted by the Pable P-2) gives additional support for the suftabliity of the Rohsenow additive technique for correlating Freon flow boll ing data. 
TABLE $\mathbf{F - 2}$

TABULATION OF PERCENT DEVIATION OF DATA FROM CORRELATION

\begin{tabular}{|c|c|c|c|c|}
\hline $\begin{array}{l}\text { Percent Deviation } \\
\text { of Data from } \\
\text { Correlation }\end{array}$ & $\begin{array}{l}\text { Percent of Freon } \\
\text { Pool Boiline Data } \\
\text { witlin Deviation } \\
\text { Percentage }\end{array}$ & $\begin{array}{l}\text { Percent of Water } \\
\text { Pool Boiling Data } \\
\text { within Deviation } \\
\text { Percentage }\end{array}$ & $\begin{array}{l}\text { Percent of Freon } \\
\text { Flow Bolling Data } \\
\text { within Deviation } \\
\text { Percentage }\end{array}$ & $\begin{array}{c}\text { Percent of Freon } \\
\text { Annular Flow Bolling } \\
\text { Data within Deviation } \\
\text { Percentage }\end{array}$ \\
\hline 10 & 17.7 & 10.9 & 28.6 & 46.4 \\
\hline 20 & 38.0 & 21.8 & 58.6 & 89.3 \\
\hline 30 & 51.9 & 36.4 & 17.2 & 96.4 \\
\hline 40 & 67.1 & 60.0 & 84.3 & 100.0 \\
\hline 50 & 75.9 & 74.5 & $90.1)$ & 100.0 \\
\hline$>50$ & 24.1 & 25.5 & 10.0 & 0 \\
\hline
\end{tabular}

